\title{
Advanced Coal-Fueled Gas Turbine Program
}

Final Report

\author{
M.W. Horner \\ E.E. Ekstedt \\ E. Gal \\ M.R. Jackson \\ S.G. Kimura \\ R.G. Lavigne \\ C. Lucas
}

\author{
J.R. Rairden \\ P.E. Sabla \\ J.F. Savelli \\ D.M. Slaughter \\ C.L. Spiro \\ F.W. Staub
}

February 1989

Work Performed Under Contract No.: DE-AC21-86MC23168

For

U.S. Department of Energy

Office of Fossil Energy

Morgantown Energy Technology Center

Morgantown, West Virginia

By

General Electric Company

Schenectady, New York 


\section{DISCLAIMER}

This report was prepared as an account of work sponsored by an agency of the United States Government. Neither the United States Government nor any agency thereof, nor any of their employees makes any warranty, express or implied, or assumes any legal liability or responsibility for the accuracy, completeness or usefulness of any information, apparatus, product, or process disclosed, or represents that its use would not infringe privately owned rights. Reference herein to any specific commercial product, process, or service by trade name, trademark, manufacturer, or otherwise, does not necessarily constitute or imply its endorsement, recommendation, or favoring by the United States Government or any agency thereof. The views and opinions of authors expressed herein do not necessarily state or reflect those of the United States Government or any agency thereof.

This report has been reproduced directly from the best available copy.

Available to DOE and DOE contractors from the Office of Scientific and Technical Information, P.O. Box 62, Oak Ridge, TN 37831; prices available from (615)576-8401, FTS 626-8401.

Available to the public from the National Technical Information Service, U.S. Department of Commerce, 5285 Port Royal Rd., Springfield, VA 22161. 


\title{
Advanced Coal-Fueled Gas Turbine Program
}

\author{
Final Report
}

M.W. Horner

E.E. Ekstedt

E. Gal

M.R. Jackson

S.G. Kimura

R.G. Lavigne

C. Lucas
J.R. Rairden

P.E. Sabla

J.F. Savelli

D.M. Slaughter

C.L. Spiro

F.W. Staub

Work Performed Under Contract No.: DE-AC21-86MC23168

For

U.S. Department of Energy Office of Fossil Energy

Morgantown Energy Technology Center

P.O. Box 880

Morgantown, West Virginia 26507-0880

\author{
By \\ General Electric Company \\ P.O. Box 8 \\ Schenectady, New York 12301
}

February 1989 


\title{
FOREWORD
}

This final report is submitted in accordance with the requirements of DOE/METC Contract No. DE-AC21-86ML23168, specifically for the Advanced Coal-Fueled Gas Turbine Program.

\author{
Program Manager: \\ Michael W. Horner \\ GE Aircraft Engines \\ Marine \& Industrial Engines \& Service Division \\ One Neumann Way \\ P.O. Box 156301 \\ Cincinnati, Ohio 45215
}

(513) 552-5417 


\section{TABLE OF CONTENTS}

Section

EXECUTIVE SUMMARY

1 PROGRAM OVERVIEW

1.1 Original Intent of the Request for Proposal

1.2 DOE Performance Standards

1.3 Technical Barriers Identified and Solved .......................................................... 1-2

1.4 Technical Problems Remaining .......................................................................... $\quad 1-3$

2 GAS TURBINE SYSTEM SUMMMARY

$2.1 \quad$ Annular-Combustor System .................................................................................. 2-1

2.1.1 System Summary ................................................................................ 2-1

2.1.2 Combustor Development Aproach ..................................................... 2-17

2.1.3 Annular Combustor Technical Assessment ............................................. 2-64

2.1.4 Exhaust Gas Cleanup System ............................................................. 2-65

2.2 Off-Board Combustor/Integrated Cleanup System .......................................... $\quad 2-70$

2.2.1 System Description ................................................................................ $\quad 2-70$

2.2.2 Developmental Approach .................................................................. 2-72

2.2.3 System Assessment ................................................................................. 2-89

3 SUPPORTING TECHNICAL RESULTS …........................................................

3.1 Deposition Amelioration .......................................................................................... 3-1

3.1.1 Introduction: Deposition ................................................................................ $3-1$

3.1.2 Chemistry of Deposition and Cementation .............................................. 3-9

3.1.3 The Effects of Kaolin Additives on Deposition ...................................... 3-24

3.1.4 The Effect of Boehmite Addition on Deposit Formation in Coal-Fired Gas Turbines

3.1.5 Taggart Coal Study ............................................................................... $\quad 3-75$

3.1.6 Taggart Coal with Kaolin ....................................................................... 3-91

3.1.7 Elk Creek High Ash Coal .......................................................................... 3-98

3.1.8 Summary of Deposit Remediation Strategies and Results .................... 3 3-109 Environmental Summary ...................................................................... 3-111

3.2 Emissions Control ................................................................................................. 3-112

3.2.1 Program Definition .................................................................................. $\quad 3-112$

3.2.2 Sulfur Emissions Control ........................................................................ 3-113

3.2.3 NO Control ................................................................................... 3-146

3.2.4 Particulate Control ....................................................................................... 3-149

3.2.5 Economic Evaluation of Exhaust Gas Cleanup ........................................ 3-162

3.2.6 Summary and Conclusions ................................................................ 3-174

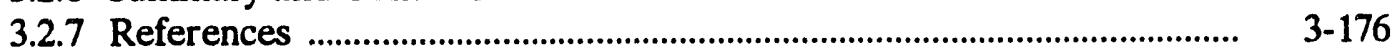

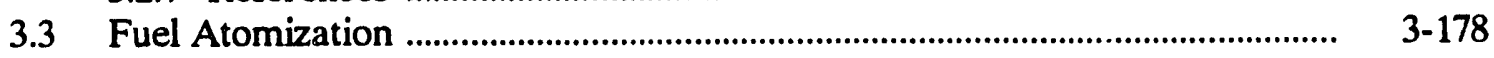

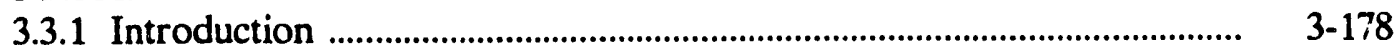

3.3.2 Fuel Nozzle Characterization ..................................................................... 3-178 
TABLE OF CONTENTS (Cont'd)

Section

Page

3.3.3 Predictive Combustor Performance Criteria

3.3.4 Conclusions

3-214

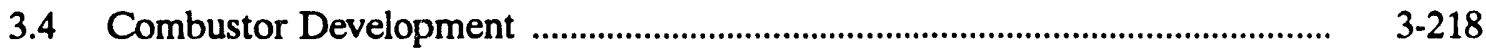

3.4.1 Introduction ............................................................................................. 3-218

3.4.2 LM500 Turbine Simulator Test Facility ................................................. 3-. 3-219

3.4.3 Coal-Water Mixture Fuel …................................................................... 3-219

3.4.4 Fuel Nozzle ..................................................................................... $\quad 3-219$

3.4.5 Main Air Swirler ................................................................................ $\quad 3.224$

3.4.6 Test Procedure ….................................................................................. $\quad 3-228$

3.4.7 Test Results ................................................................................................ $\quad 3-229$

3.4.8 Conclusions ........................................................................................... $\quad 3-230$

3.5 Materials Research for the GE Coal-Fired Turbine ........................................ 3.232

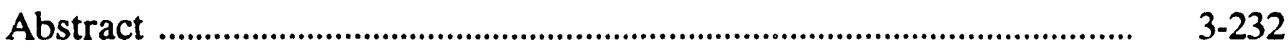

3.5.1 Introduction .................................................................................. $\quad 3-232$

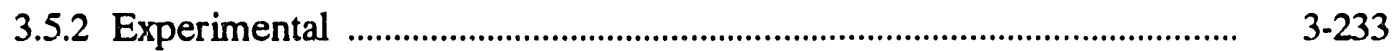

3.5.3 Results and Discussion ........................................................................ $\quad 3-233$

3.5.4 Conclusions ...................................................................................... $\quad 3-245$

3.6 LM500 Turbine Simulator Test Facility ......................................................... 3-246

3.6.1 Combustion Section .......................................................................... 3-246

3.6.2 Test Section .................................................................................... $\quad 3-250$

3.6.3 Instrumentation Section .................................................................... $\quad 3-252$

3.6.4 Auxilliary Systems ......................................................................... 3-252 APPENDICES

A-1.1 Test Summary, LM500 Turbine Simulator

A-1.2 Test Summary, Single-Cup Can Combustor

A-2.0 MIT Combustion of CWM Summary

A-3.0 Grain Model Description for Sulfur Sorption 


\section{LIST OF ILLUSTRATIONS}

\section{Figure}

2.1.1 Annular combustor system schematic.

2.1.1.1 LM500 engine assembly.

2.1.1.2 LM500 engine.

2.1.1.3 Concept annular combustor design.

2.1.1.4 Annular coal combustor assembly.

2.1.1.5 Gearbox bracket design.

2.1.1.6 LM500 accessory location.

2.1.1.7 Annular combustor.

2.1.1.8 Combustor liner cooling concepts.

2.1.2.1 Annular sector combustor dome.

2.1.2.2a Sector combustor liner assembly inlet side.

2.1.2.2h Sector combustor liner.

2.1.2.2c Sector combustor liner.

2.1.2.2 J Sector impingement sinield.

2.1.2.2e Sector combustor liner.

2.1.2.3 Seven-nozzle sector combustor test rig.

2.1.2.4 Test rig casing.

2.1.2.5 Test rig aft bulkhead and combustor mount.

2.1.2.6 Test rig exit shroud and instrumentation mount.

2.1.2.7 Test rig instrumentation and quench water access ring.

2.1.2.8 Test rig exhaust section.

2.1.2.9 One-nozzle segment combustor test rig.

2.1.2.10 One-nozzle segment combustor test rig setup.

2.1.2.11 One-Nozzle segment combustor.

2.1.2.12 One-Nozzle segment combustor liner.

2.1.2.13 One-Nozzle segment combustor assembly.

2.1.2.14 One-Nozzle segment combustor dome.

2.1.2.15 Parker-Haniffin CWM fuel nozzle.

2.1.2.16 GE-CRD CWM fuel nozzle.

2.1.2.17 One-nozzle segment combustor fired test.

2.1.2.18 One-nozzle segment combustor test, $10 \mathrm{hr}$ zero-oil. 


\section{LIST OF ILLUSTRATIONS (Cont'd)}

\section{Figure}

2.1.2.20 One-nozzle segment combustor emissions.

2.1.2.21 One-nozzle segment combustor velocity effectson carbon monoxide emissions.

2.1.2.22 One-nozzle segment combustor fuel-air-ratio effect on carbon burnout

2.1.2.23 One-nozzle segment combustor test, $10 \mathrm{hr}$ zero-oil.

2.1.2.24 One-Nozzle segment combustor post test $(10-1 / 2 \mathrm{hr})$ condition.

2.1.2.25 Combustor dome components.

2.1.2.26 Spray test of dome and fuel nozzle.

2.1.2.27 Multi-tube patternator.

2.1.2.28 Patternation results for Parker-Hannifin CWM fuel nozzle with dome

2.1.4.1 Dry flue gas desulfurization for utility pulverized coal-fired boiler applications.

2.1.4.2 Simplified process flow diagram.

2.1.4.3 Preliminary drawing of exhaust gas cleanup system

2.2.2.1 Schematic of the GE fixed/moving granular bed filter.

2.2.2.2 Cold flow model, initial configuration

2.2.2.3 Cold flow model, final configuration

2.2.2.4 Pressure drop vs flow rate in GBF

2.2.2.5 Pressure drop vs time in GBF.

2.2.2.6 Dust emission from the FMGBM. Inlet concentration is $2 \mathrm{gr} / \mathrm{acf}$.

2.2.2.7 Granular bed filter vessel for bench scale high-pressure high-temperature experiments at GE-CRD.

2.2.2.8 Granular bed filter system layout for bench scale experiments at GE-CRD.

2.2.2.9 Process flow diagram for full scale (LM500) granular bed filter system.

2.2.2.10 Layout for full scale (LM500) granular bed filter system

2.2.2.11 Preliminary design of the full scale FMGBF vessel

3.1.1.1. Quench probe sample from CWM combustion.

3.1.1.2. Unfused leading edge deposits.

3.1.1.3. Unfused leading edge deposits.

3.1.1.4. Fused pressure-side deposits.

3.1.1.5 NAIN plot compares deposition rate with- and without on-line abrasive cleaning. 


\section{LIST OF ILLUSTRATIONS (Cont'd)}

\section{Figure}

3.1.2.1. Photograph of deposits on LM500 airfoil.

3.1.2.2 Micrograph illustrates that slag and powder coexist. ............................................ 3-13

3.1.2.3. Diffractograms of powder 1 , slag 1 and 2. .........................................................

3.1.2.4. Lattice parameters of standard and deposited spinels. ......................................... $\quad 3-17$

3.1.2.5. Simulated plagioclase XRPD patterns. .................................................................... $3-18$

3.1.2.6. Diffractograms of heat treated powder. .............................................................. $3-21$

3.1.2.7. Summary of relevant powder/slag chemistry in the coal-fired gas turbine ........ $\quad 3-22$

3.1.3.1. Normalized NAIN plot of kaolin-added test, 12/8-9/87. ..................................... 3-29

3.1.3.2. Normalized NAIN plot of kaolin-added test, 2/2/88. ......................................... $\quad 3-30$

3.1.3.3. Normalized NAIN plot of kaolin-added test, 11/17-18,/87. ................................ 3-31

3.1.3.4. LM500 turbine simulator pressure-side and leading edges. ................................. $3-32$

3.1.3.5. Close-up of leading edge deposits at the end of $11 / 18 / 87$ test. ............................. 3-34

3.1.3.6. Suction side deposits at the end of $11 / 19 / 87$ test. ................................................. $3-35$

3.1.3.7. Transmission electron micrograph of quenched hot gas stream. ......................... $\quad 3-36$

3.1.3.8. Energy dispersive X-ray analysis of a solid sphere of ash. ....................................

3.1.3.9. Aerosol condensate from quenched hot gas stream. ............................................ 3-39

3.1.3.10. Liner deposits were minimal at the outer rings, and only
occurred near the fuel nozzle to any degree. ......................................................

3.1.3.11. This shows that the morphology of the transition section deposits, and those lodged in the throats of the airfoils, is twofold. ................... $3-43$

3.1.3.12. Scanning electron micrograph of unfused deposit in transition section .............. $3-44$

3.1.3.13. Scanning electron micrograph of fused slag in transition section. ....................... $3-45$

3.1.3.14. Scanning electron micrograph of platy leading edge underlayer deposit ............. $\quad 3-46$

3.1.3.15. Typical untreated coal pressure-side deposit. ........................................................... $\quad 3-47$

3.1.3.16. Pressure-side deposits from kaolin-added test ..................................................... $\quad 3-48$

3.1.3.17. Calcia-alumina-silica equilibrium phase diagram. ............................................. $\quad 3-50$

3.1.3.18. Scanning electron micrograph of kaolin-doped ash slag morphology. ................ $\quad 3-54$

3.1.3.19. Scanning electron micrograph of untreated coal ash slag. .................................... 3-55

3.1.3.20. Scanning electron micrograph of kaolin-treated coal ash interface. ..................... $\quad 3-56$

3.1.4.1. Structure of boehmite. .......................................................................................... 3-61

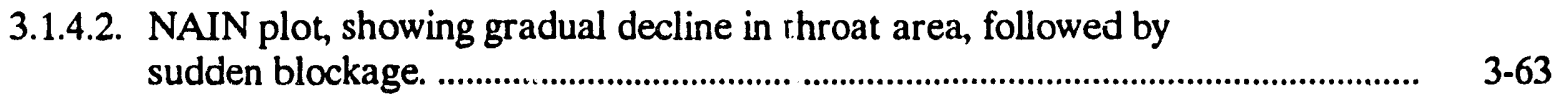




\section{LIST OF ILLUSTRATIONS (Cont'd)}

\section{Figure}

3.1.4.3. Leading edge and pressure side deposits at the end of the boehmite test.

3.1.4.4. Combustion liner deposits.

3.1.4.5. Transition section deposits.

3.1.4.6. Suction side deposits.

3.1.4.7. Transmission electron micrograph of quench probe sample.

3.1.4.8. Unfused primary leading edge deposits.

3.1.4.9. Porous fused deposits from leading edge.

3.1.4.10. Corundum crystals and anorthite needles.

3.1.4.11. Suction side deposite showing near-complete fusion

3.1.5.1. Flow chart, Otisca-T Process.

3.1.5.2. LM500 turbine simulator cascade after 4 -hr operation on Taggart CWM fuel.

3.1.5.3. LM500 turbine simulator suction side deposit after 4-hr operation on Taggart CWM fuel.

3.1.5.4. LM500 turbine simulator transition section deposit after 4-hr operation on Taggart CWM fuel

3.1.5.5. LM500 turbine simulator combustion liner after 4-hr operation on Taggart CWM fuel.

3.1.5.6. Calculated slag viscosities based on ash composition

3.1.5.7. NAIN plot, Taggart CWM study.

3.1.6.1. NAIN plots-untreated vs kaolin-treated Taggart CWM.

3.1.6.2. NAIN plot, kaolin treated Taggart CWM.

3.1.6.3. LM500 turbine simulator showing deposits.

3.1.6.4. LM500 turbine simulator showing close-up of leading edge deposits.

3.1.6.5. Transition section and liner regions of LM500 turbine simulator.

3.1.7.1. NAIN plot for Elk Creek high-ash CWM test.

3.1.7.2. Liner surfaces are generally clean from the Elk Creek high-ash CWM test.

3.1.7.3. Suction surfaces are generally clean from the Elk Creek high-ash CWM test.

3.1.7.4. Large chunks which had spalled from the dome region of the fuel nozzle.

3.1.7.5. Close-up of the dome region where deposits form. 


\section{LIST OF ILLUSTRATIONS (Cont'd)}

Figure

Page

3.1.7.6. Pressure and leading-edge surfaces are generally clean from the Elk Creek high-ash CWM test.

3.1.7.7. Quench probe samples from the Elk Creek high-ash study.

3.1.8 1. Summary-methods of deposit remediation.

3.2.2.1. Schematic of LM500 turbine simulator.

3.2.2.2. Schematic of fuel delivery systems.

3.2.2.3. Sulfur capture

3.2.2.4. Photograph of nozzle cascade after oil/ $\mathrm{CaO}$ test.

3.2.2.5. Sulfur capture for $\mathrm{CaO}$ sorbent-doped $\mathrm{CWM}$.

3-122

3.2.2.6. Deposition rate for $\mathrm{C}: \mathrm{O}$ sorbent-doped CWM.

3.2.2.7. Photograph of nozzle cascade after CWM-calcium hydrate test.

3.2.2.8. Photomicrographs of pressure side deposit from CWM-calcium hydrate test.

3.2.2.9. Sulfur capture for dolomitic hydrate-doped CWM.

3.2.2.10. SEM micrographs of cascade deposit extracted from the pressure side: dolomitic deposit.

3.2.2.11. Deposition rate for kaolin-doped $\mathrm{CaO} / \mathrm{CWM}$.

3.2.2.12. Photograph of nozzle cascade after kaolin-doped $\mathrm{CaO} / \mathrm{CWM}$ test.

3.2.2.13. Schematic diagram of PSIT drop tube furnace.

3.2.2.14. Schematic diagram of venturi modified drop tube furnace.

3.2.2.15. Diagram of phase discrimination probe.

3.2.2.16. Effect of residence time on sulfur capture.

3.2.2.17. Effect of temperature on sulfur capture for dolomitic and calcitic sorbent.

3.2.2.18. Effect of $\mathrm{SO}_{2}$ concentration on sulfur capture-dolomitic sorbent.

3.2.2.19. Effect of $\mathrm{SO}_{2}$ concentration on sulfur capture-calcidic sobent

3.2.2.20. Comparison of grain model prediction and experimental data for sulfur capture.

3.2.3.1. The effect of water on the $\mathrm{NO}_{\mathrm{x}}$ formation from distillate oil combustion

3.2.4.1. SEM photographs of ash samples from the turbine-simulator.

3.2.4.2. TGA of turbine simulator ash sample.

3.2.4.3. Mass spectrograph of ash constituents.

3.2.4.4. Cold flow model of the granular bed filter. 


\section{LIST OF ILLUSTRATIONS (Cont'd)}

\section{Figure}

3.2.4.5. GBF pressure drop - cold flow model.

3.2.4.6. GBF pressure drop with time - cold flow model

3-158

3.2.4.7. Dust emission from the FMGBM-Inlet concentration is $2 \mathrm{gr} / \mathrm{acf}$.

3-159

3.2.5.1. Dry-flue gas desulfurization process for coal-fired boilers.

3-163

3.2.5.2. Simplified process flow diagram.

3-165

3.2.5.3 Preliminary arrangement of the exhaust gas clean-up system.

3.3.1. CRD spray tunnel schematic.

3.3.2. Schematic of LT nozzle geometry.

3.3.3. Effect of solids loading on high shear rate viscosity of Otisca $\mathrm{CWF}$ at room temperature $\left(25^{\circ} \mathrm{C}\right)$.

3.3.4. Effect of fuel temperature on high shear rate viscosity of Otisca CWF at solids loading of $48.5 \%$.

3.3.5. Average RR mean drop diameters.

3.3.6. Radial distribution of Rosin Rammler drop size.

3.3.7. Temporal distribution of drop size larger than $20 \mu \mathrm{m}$ in in flowing fuel.

3.3.8. Temporal drop size distributions.

3.3.9. Chordal average Sauter mean diameter of Otisca CWM sprays at various radial locations.

3.3.10. Effect of fuel temperature on Sauter mean diameters of Otisca CWF and water sprays

3.3.11. Comparison of calculated and measured axial air velocity profiles ..................... 3-192

3.3.12. The morphology of the transition section deposits. ............................................... 3-194

3.3.13. Schematic of LM500 combustor.

3.3.14. Calculated $30 \mu \mathrm{m}$ drop residence time $5 \mathrm{~cm}$ downstream of primary holes

3.3.15. Calculated mean $30 \mu \mathrm{m}$ drop tracks for $30^{\circ}$ swirler with LT nozzle (a) and HS nozzle (b).

3.3.16. Comparison of calculated gas backflow with minimum auxiliary fuel combustor operation.

3.3.17. Calculated gas backflow velocity contours in primary zone of M500 combustor.

3.3.18. Schematic of sector can combustor.

3.3.19. Comparison of measured and calculated axial velocity component in simulated s $x$ tor can.

3.3.20. Comparison of measured and calculated swirl velocity component. 


\section{LIST OF ILLUSTRATIONS (Cont'd)}

\section{Figure}

3.3.21. Measured velocity components in simulated sector can.

3.3.22. Measured axial velocities on each side of centerline in simuiated sector can.

3.4.1. Schematic diagram of LM500 turbine simulator. .................................................. $\quad 3-220$

3.4.2. Flow rate through fuel nozzle measured at atmospheric pressure. ...................... 3-222

3.4.3. Schematic of fuel nozzie spray angle. ................................................................... $3-223$

3.4.4. Photograph of original air swirler. .................................................................... $\quad 3-225$

3.4.5. New air swirler. .................................................................................................... 3-226

3.4.6. Flow rate through air swirler measured at atmospheric pressure. ....................... $\quad 3-227$

3.5.1. Coated X-40 pins mounted on a rod holder for the first simulator test ................ 3-235

3.5.2. Pins and holder after first simulator test ............................................................. $\quad 3-236$

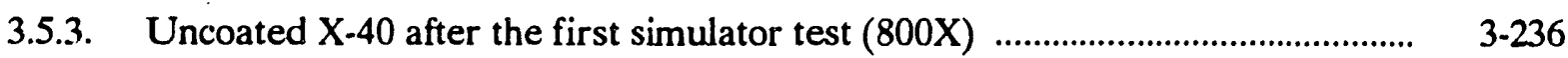

3.5.4. MCrAlY coating on X-40 after the first simulator test (400X). ........................... 3-237

3.5.5. Aluminized coating on $\mathrm{X}-40$ after the first simulator test $(400 \mathrm{X})$........................ $3-238$

3.5.6. Photograph of the 16 pins mounted.$n$ the holder after the second ...................... 3-241

3.5.7. Coated blades assembled into a vane cascade reacly for test on the CRD turbine simulator rig.

3.6.1. GE-LT fuel nozzle schematic …....................................................................... 3-249

3.6.2. CWM fuel delivery system schematic. .............................................................. 3-249

3.6.3. LM500 turbine simulator cascade. ........................................................................ 3-251

3.6.4. Air-quenched particulate sampling probe. ........................................................... $\quad 3-253$ 


\section{LIST OF TABLES}

Table

2.1.1.1 Combustor Design/Operating Requirements ...................................................... 2-11

2.1.1.2 Combustor Configuration .............................................................................. $2-11$

2.1.1.3 Combustor Design Parameters ......................................................................... 2-13

2.1.1.4 Preliminary Liner Flow Distribution .............................................................. 2-13

2.1.1.5 Impingement/Film Cooling Design Features ................................................... 2-16

2.1.2.1 GEAE Advanced Combustion Laboratories ...................................................... 2-32

2.1.2.2 $140^{\circ}$ Sector Combustor Test Conditions .............................................................. 2-32

2.1.2.3 DOE-METC Mid-Program Assessment ................................................................. 2-43

2.1.2.4 One-Nozzle Segment Combustor Flow Distribution \& Pressure Drop .............. 2-46

2.1.2.5 One-Nozzle Segment Combustor Test Results .................................................. 2-48

2.1.2.6 Exhaust Particulate Analysis ......................................................................... 2-54

2.1.2.7 Patternation Test Results ............................................................................ 2-62

2.1.4.1 System Conditions and Performance Requirements ........................................ 2-68

2.1.4.2 Pulse Jet Baghouse Design \& Operating Conditions ........................................... 2-68

3.1.2.1 Otisca Blue Gem Coal-Water Mixture Fuel Specification .................................. 3-10

3.1.2.2 Lattice Parameters of Standard \& Experimental Spinel Phases ......................... 3-15

3.1.2.3 Plagioclase Lattice Parameters ............................................................................. 3-19

3.1.3.1 Properties of Otisca Coal-Water Mixture .............................................................. 3-27

3.1.3.2 Table 2 - X-ray Fluorescence Data ......................................................................... 3-28

3.1.3.3 X-ray Fluorescence Data ............................................................................... $\quad 3-41$

3.1.5.1 Properties of Otisca Coal-Water Mixture …......................................................... 3-78

3.1.5.2 X-ray Fluorescence Data, Taggart Steam Coal Ash ........................................... 3-79

3.1.7.1 Properties of OXCE Elk Creek Coal-Water Mixture .......................................... 3-99

3.1.7.2 Ash Composition Data - Elk Creek Coal ............................................................. 3-100

3.2.2.1 Nominal Turbine Simulator Operating Conditions .............................................. 3-118

3.2.2.2 Otisca Coal-Water Mixture Properties ............................................................... 3-118

3.2.2.3 Sorbent Properties ..................................................................................................... $\quad 3-118$

3.2.2.4 Meaured BET Surface Area ….............................................................................. $\quad$ 3-135

3.2.2.5 System Conditions \& Performance ......................................................................... 3-137

3.2.3.1 $\mathrm{NO}_{\mathrm{x}}$ Production from CWM Fuels ........................................................................ 3-148

3.2.5.1 System Conditions \& Performance .......................................................................... 3-166

3.2.5.2 Pulse Jet Baghouse Design \& Operating Conditions .......................................... 3-166 


\section{LIST OF TABLES(Cont'd)}

Table

Page

3.2.5.3 Economic Parameter Used Consistent with 1986 EPRI TAG ............................ 3-168

3.2.5.4 Economic Parameters Used Based on Best Estimates ........................................ 3-169

3.2.5.5 Base-Case Economic \& Performance Parameters .............................................. 3-169

3.2.5.6 Capital Cost Estimates ................................................................................. 3-170

3.2.5.7 Exhaust Gas Cleanup Cost Assumptions .............................................................. 3-171

3.2.5.8 Exhaust Gas Cleanup Direct Cost Estimate ....................................................... 3-172

3.2.5.9 Effect of Gas Turbine Maintenance Costs ............................................................. 3-173

3.2.6.1 Candidate Emissions Control Technologies …...................................................... 3-175

3.3.1 Effect of LT Nozzle Size on CWS Drop Size ........................................................ 3-188

3.3.2 Operating Conditions for Combustion Tests ........................................................... 3-196

3.3.3 Summary of Combustion Tests ................................................................................. 3-198

3.3.4 Design Point Combustor Flow Rates …….............................................................. 3-198

3.3.5 Calculated Coal-Water Flow Slurry .................................................................. 3-199

3.3.6 Operating Condition for Sector Can .................................................................. 3-207

3.3.7 Design Point Sector Can ....................................................................................... 3-207

3.3.8 Calculated Design Point Performance of Sector Can .......................................... 3-215

3.4.1 Operating Conditions for LM500 Combustion Tests ............................................. 3-221

3.4.2 Properties of Otisca Coal-Water Mixture ................................................................ 3-221

3.4.3 Air Swirler Design Parameters ........................................................................... 3-228

3.4.4 Percentage of Total Combustor Air Flor .......................................................... 3-230

3.4.5 LM500 Combustor Test Results …....................................................................... 3-231

3.5.1 Environmental Attack Observations ................................................................. 3-241

3.6.1 LM500 Air Flow Split ............................................................................. 3-247

3.6.2 LM500 Typical Operating Conditions …........................................................... 3-247 


\section{EXECUTIVE SUMMARY}

The GE program to explore the technical and commercial feasibility of a direct coalfueled gas turbine system has addressed the areas of fuel handling, combustion, emissions controls, and turbine durability for aeroderivative turbines. The GE program has been highly successful in surmounting major technical issues associated with these areas, although technical challenges currently remain. In addition, system economics have been considered, and economic projections indicate that acceptable rates of return can be attained with a coalfueled gas turbine system. Technical accomplishments include:

- Coai-combustion efficiencies of over $99.9 \%$ have been achieved with Coal Water Mixture (CWM) fuels in metal-wall, short-residence-time (30 ms) combustors.

- An approach for reducing ash deposition through the use of additives has been dernonstratej to be effective. This enabled consideration of down-stream gas cleanup approaches for emissions control. The role of ash chemistry on deposition was determined, and an approach for the assessment of deposition character for coal, based on its ash composition was formulated.

- Effective capture of sulfur within the combustor, by mixing a calcium-based sorbent with the fuel, was demonstrated. Over $60 \%$ sulfur capture was achieved at $\mathrm{Ca} / \mathrm{S}=1.5$. However, this resulted in excessive deposition on turbine components. Combining $60 \%$ in situ sulfur capture with nearly quantitative pyritic sulfur removal through selective agglomeration will meet the New Source Performance Standard's goals for a broad range of domestic high- and low-sulfur coals.

- Conceptual designs and assessments were performed for two configurations: 1) annular combustor with post-expansion cleanup, and 2) off-board combustor with integrated cleanup using a granular bed filter upstream of the turbine. Due to successes achieved in deposit control and high commercial risk associated with the granular bed filter, it was recommended that the annular combustor approach be selected for further development.

- $\mathrm{NO}_{\mathrm{x}}$ levels were measured, and it was determined that approximately a $50 \% \mathrm{NO}_{\mathrm{x}}$ reduction would be required in the combustor through staging. However $\mathrm{No}_{\mathbf{x}}$ suppression did not constitute a goal of this program.

- Routine operation with CWM fuels was demonstrated, showing that fuel handling is not a barrier problem. 
While excellent technical progress has been achieved, GE believes that the commercial viability of a small scale-direct coal-fueled gas turbine is unlikely in the forseeable future, due to the current abundance of inexpensive natural gas and petroleum fuels. For this business reason, further development of the GE direct coal-fueled gas turbine system has been deferred.

GE reaffirms its support of the DOE/METC mission to develop technologies for the clean and efficient use of coal. This development work is a valuable contribution to the power generation future of the U.S. In addition, the coal system options developed under DOE sponsorship, has been an assistance in maintaining the cost of foreign oil at reasonable price levels. We also remain enthusiastic about aeroderivative engines and technologies in providing a basis for efficient coal-burning plants.

The results and breakthroughs from the GE Coal-Fueled Gas Turbine Systems program provide a substantial body of technical knowledge, which can be used in support of DOE's ongoing coal-fueled heat engines programs. This report details the results obtained in the first two years of the program. 


\section{Section 1}

\section{PROGRAM OVERVIEW}

\subsection{Original Intent of the Request for Proposal}

The objective of the original Request for Proposal was to establish the technological bases necessary for the subsequent commercial development and deployment of advanced coalfueled gas turbine power systems by the private sector. The offeror was to identify the specific application or applications, toward which his development efforts would be directed: define and substantiate the technical, economic, and environmental criteria for the selected application; and conduct such component design, development, integration, and tests as deemed necessary to fulfill this objective.

Specifically, the offeror was to choose a system through which ingenious methods of grouping subcomponents into integrated systems accomplishes the following:

- Preserve the inherent power density and performance advantages of gas turbine systems.

- System must be capable of meeting or exceeding existing and expected environmental regulations for the proposed application.

- System must offer a considerable improvement over coal-fueled systems which are commercial, have been demonstrated, or are being demonstrated.

- System proposed must be an integrated gas turbine concept, i.e., all fuel conditioning, all expansion gas conditioning, or post-expansion gas cleaning, must be integrated into the gas turbine system.

The GE program addressed these objectives as stated in PRDA DE-RA21-85MC22028 (page 1 - PRDA Objectives). An integrated systems approach has been taken to accomplish the complete tasks of introducing a coal-water slurry fuel into a gas-turbine system while preserving the inherent high and expected environmental emission levels. Several alternatives for integration of the gas cleanup devices and technology have been studied ( vide infra.).

The selected coal-fueled gas-turbine systems for this program which would introduce a partially cleaned coal-water-mixture (CWM) fuel into a gas-turbine combustor represent considerable simplification over conventional coal-fired systems. In general, existing systems include extensive coal-handling and coal-preparation systems at the power-plant facility. This is the case for coal-fired boilers. The application of a liquid form fuel to a gas turbine simplecycle or combined-cycle power plant would offer significant improvement in thermal efficiency over the coal-fired boiler options. Capital costs of these systems are also projected to be lower than for existing coal-fired boiler configurations at the same power output scale. 
Component and system design have been conducted to accomodate the specific requirements for the CWM fuel and its associated products of combustion. Laboratory and subsystems development testing has been performed to verify design predictions and to provide technical data for evaluations of engine/system performance and tolerance to corrosion, erosion and ash deposition. Significant progress has been made in these areas which has added confidence in the capabililties of the aeroderivative gas turbine to burn the CWM fuel.

\subsection{DOE Performance Standards}

GE believes that the work performed has met DOE performance standards and that significant technical progress has been demonstrated. The fundamental data and assessments provided by the GE program should be useful to DOE and others in their further research and development of gas turbines burning coal-water mixtures. Summaries of the work have been documented and presented at DOE/METC Heat Engines Gas Steam Cleanup Conference, ASME Gas Turbine Conference, and other technical conferences and symposia for public information and scrutiny.

\subsection{Technical Barriers Identified and Solved}

The GE program has demonstrated that a suitably prepared CWM can be burned in an aeroderivative gas-turbine combustor without the use of a pilot fuel. This achievement required extensive fuel nozzle and combustor development. Modifications to the combustor hardware were consistent with engine ready features. These features were incorporated into the sector combustor and design of the full annular combustor for the LM500 gas turbine.

Ash deposition has been identified as a significant barrier in earlier programs aimed at burning coal in gas turbines. Increased turbine components cooling to achieve lower metal surface temperatures and both on-line abrasive and shut-down/water-wash cleaning methods were found to increase the time to a given level of aerodynamic passage plugging. The rate of plugging and the character of the deposits were, however, found to still be unacceptable from the standpoints of engine operations and system economics.

The most significant resolution of the ash deposition problem was found to be the addition of ash-modifying materials such as kaolin clay. This breakthrough achieved both reduced rates of deposition and a softer, more easily removed, deposit. The insights provided by the overall study of the ash deposits and the associated physical-chemistry of formation has also given a technique for improved understanding of the indigent coal-ash propensity to form undesirable ash products. As a test of this projection two coals which possessed more favorable ash constituency were tested and found to have low- and very low-rates of ash-deposition as measured on a turbine nozzle downstream of a small scale gas turbine combustor.

Erosion of turbine airfoils by coal ash and/or additive materials has been found to depend on particle sizes and hardness. In the duration of testing in the turbine simulator facility with CWM fuels, the only evidence of erosion of the turbine airfoils has been when a high- hard- 
ness additive, alumina, $v$ is used. As long as high-combustion efficiencies and appropriate allowances are made for coal-particle sizes and combustor residence times, erosion of downstream turbine components is not believed to be a problem.

No evidence of hot corrosion of combustor or turbine components has been observed in the duration of testing in the turbine simulator. Earlier work on the combustion of CWM fuels has indicated that the level of alkali metals which are free to reait with the turbine components after combustion, are relatively low. Additional work toward further evaluation of long term effects and selection of materials and coatings for application is recommended.

Injection of sorbent material into the combustor has been effective achieving up to about $60 \%$ sulfur capture. This result is significantly higher than would have been predicted for a relatively short residence time combustor. The result of sorbent injection, however, on downstream ash deposition was severe ( 10 times the deposit rate). Efforts to solve the deposition of spent sorbent by introducing additives to inhibit the build up of ash were not successful.

\subsection{Technical Problems Remaining}

As indicated above, no solution was found for the control of downstream ash deposition when sulfur sorbent material was injected into the combustor. The only selected alternative for the GE system was to employ a downstream desulfurization device such as dry flue gas desulfurization (DFGD). The DFGD technology is proven but adds to both capital and operating costs of the plant system.

Long term effects of ash deposition and cleaning, and erosion of downstrean turbine components have not been established. Such testing is outside the scope of this program. Any subsequent efforts should take these potentially harmful consequences into consideration.

Since the annular sector combustor testing has not been performed, no evaluation of further $\mathrm{NO}_{x}$ reduction potential by fuel/air tailoring was possible to date, in the GE program. Earlier work and specific features of the CWM combustor indicate favorable conditions for additional $\mathrm{NO}_{x}$ reduction. Any continued efforts should provide for development of the combustor to assess $\mathrm{NO}_{x}$ reduction. 
Section 2

\section{GAS TURBINE SYSTEM SUMMMARY}

\subsection{Annular-Combustor System}

\subsubsection{System Summary}

The system concept features an areoderivative gas turbine using an annular combustor modified for coal-water-mixture (CWM) fuels. This concept is shown schematically in Figure 2.1.1. The gas turbine is directly fired with CWM fuel, resulting in a compact and efficient engine which can be scaled to other aeroderivative engines and can take full advantage of advances in aircraft-engine technology. The annular-combustor system incorporates deposit amelioration strategies developed under this program, rather than hot gas cleanup devices for turbine-component protection. This system concept requires technology efforts to be foculed on the gas-turbine and fuel- ash interactions.

The fuel would be a relatively clean CWM with ash levels between 0.2 and $0.8 \mathrm{wt} \%$, dry basis. Tests have shown that with additives as kaolin, deposition in the hot gas path of the turbine can be controlled to acceptable levels. The coal-fuel and the deposition- test results are described in Section 3. $\mathrm{NO}_{x}$ emissions will be controlled by axial air staging in the combustor while particulates and sulfur emissions will be removed from the exhaust gas. The gas cleanup system is described in Section 3.2.

The proof-of-concept integrated test would be performed with an LM500 gas generator and modified CWM annular combustor (as in our original proposal). Since DFGD is commercially available, this system would not be included in the integrated test system.

\subsubsection{Introduction}

The LM500 marine and industrial engine is derived from the TF34- and CF34-aircraft gas turbine engine family. The TF34 is a military application and the CF34 is a civil aviation application. Therefore, the LM500 is an aeroderivative engine from a proven design based on extensive service in two fields of application. The LM500 engine uses the same combustor design as the TF34; a short, compact annular configuration. The multiple-fuel-injection stations around the circumference provide uniform fuel and air distribution for easy starting and controlled exit temperature distribution. The machined ring liner construction provides lowmetal temperatures and structural integrity. A photograph of the engine and a cross-sectional drawing are shown in Figures 2.1.1.1 and 2.1.1.2.

All GE aeroderivative gas turbines use annular combustors, and the annular-combustor design selected for CWM-application uses state-of-the-art technology evolved from the latest aircraft gas turbine and industrial applications. The technology used includes a similar cool- 


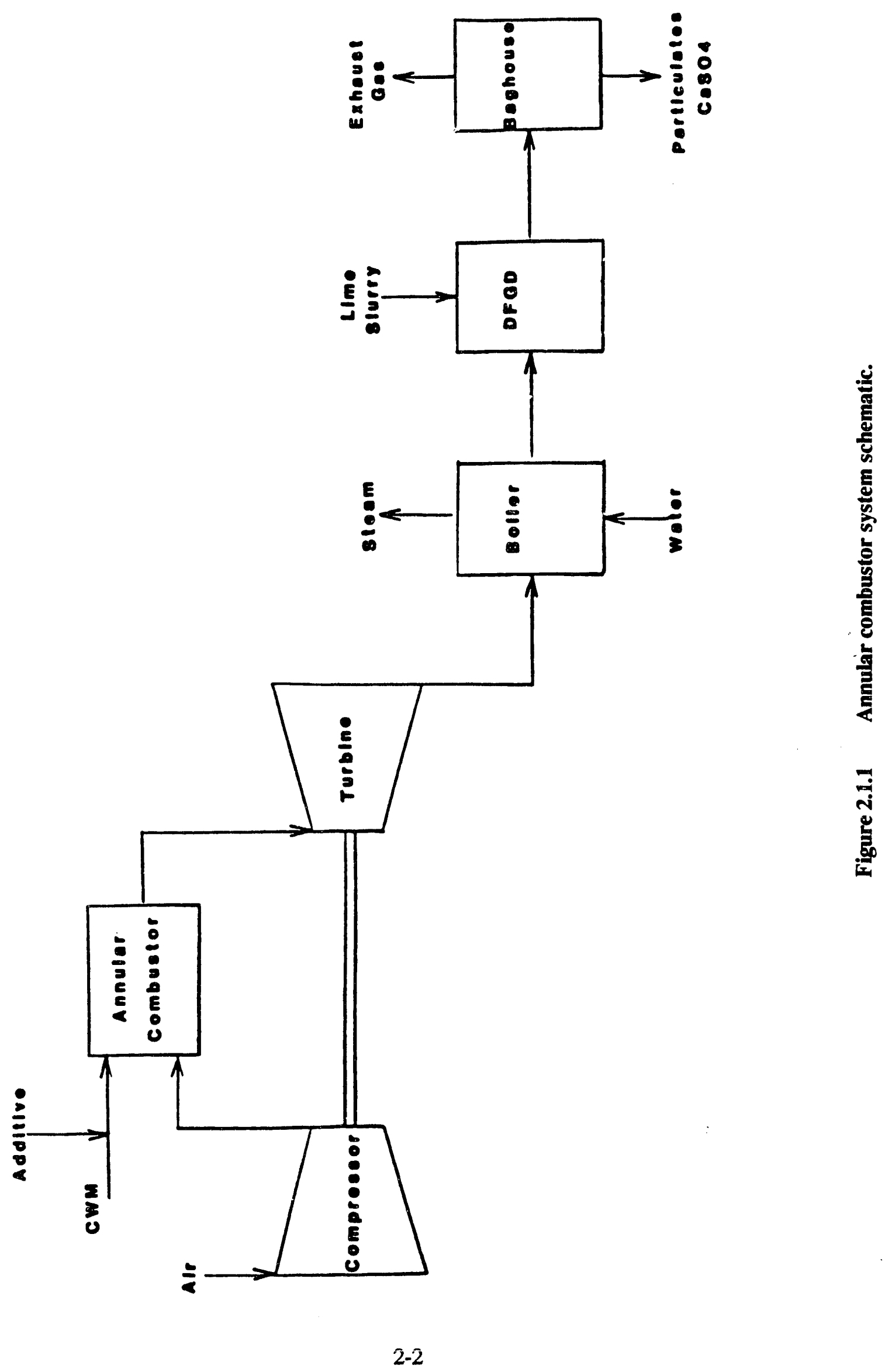




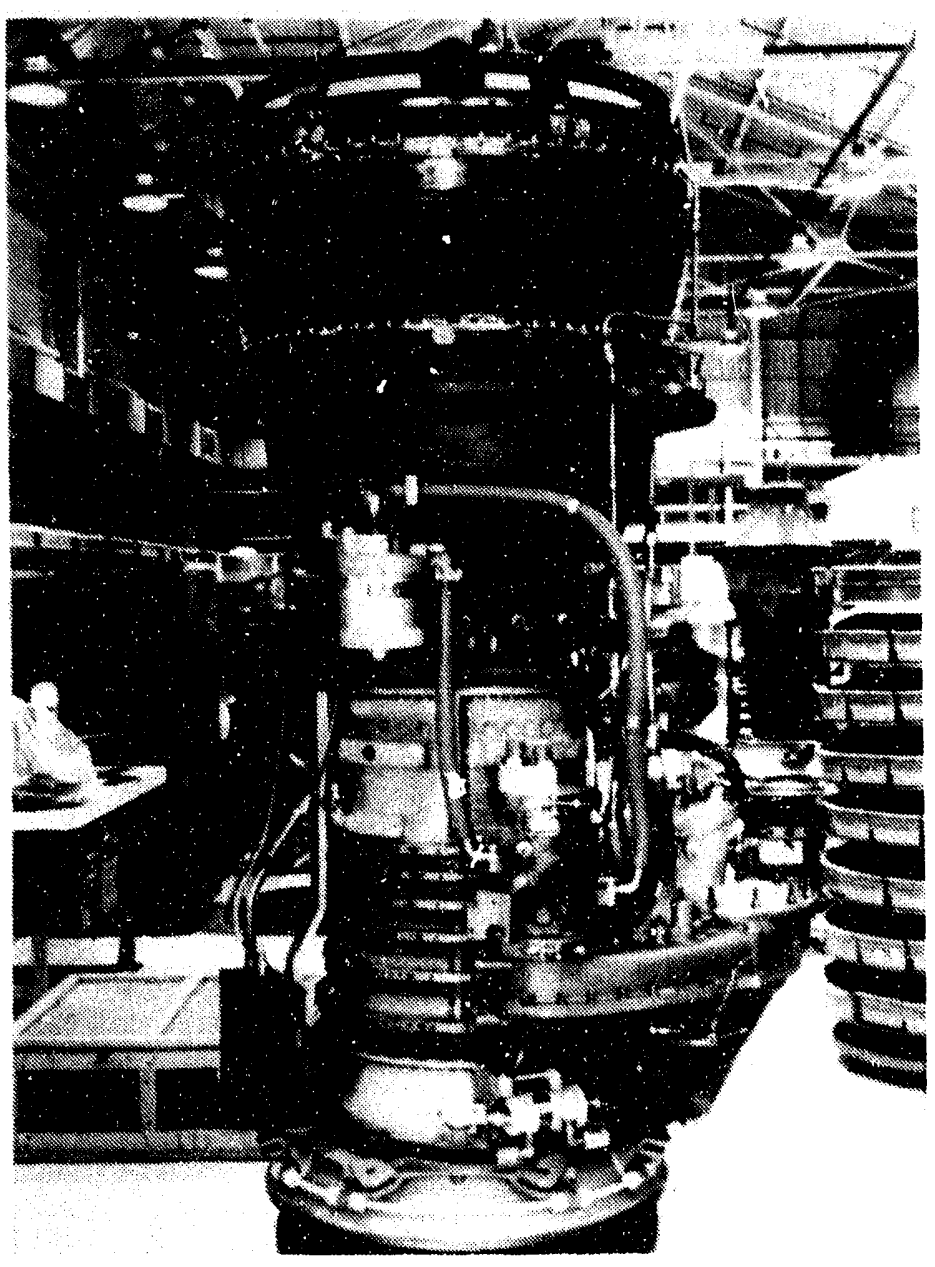

Figure 2.1.1.1 LM500 engine assembly. 


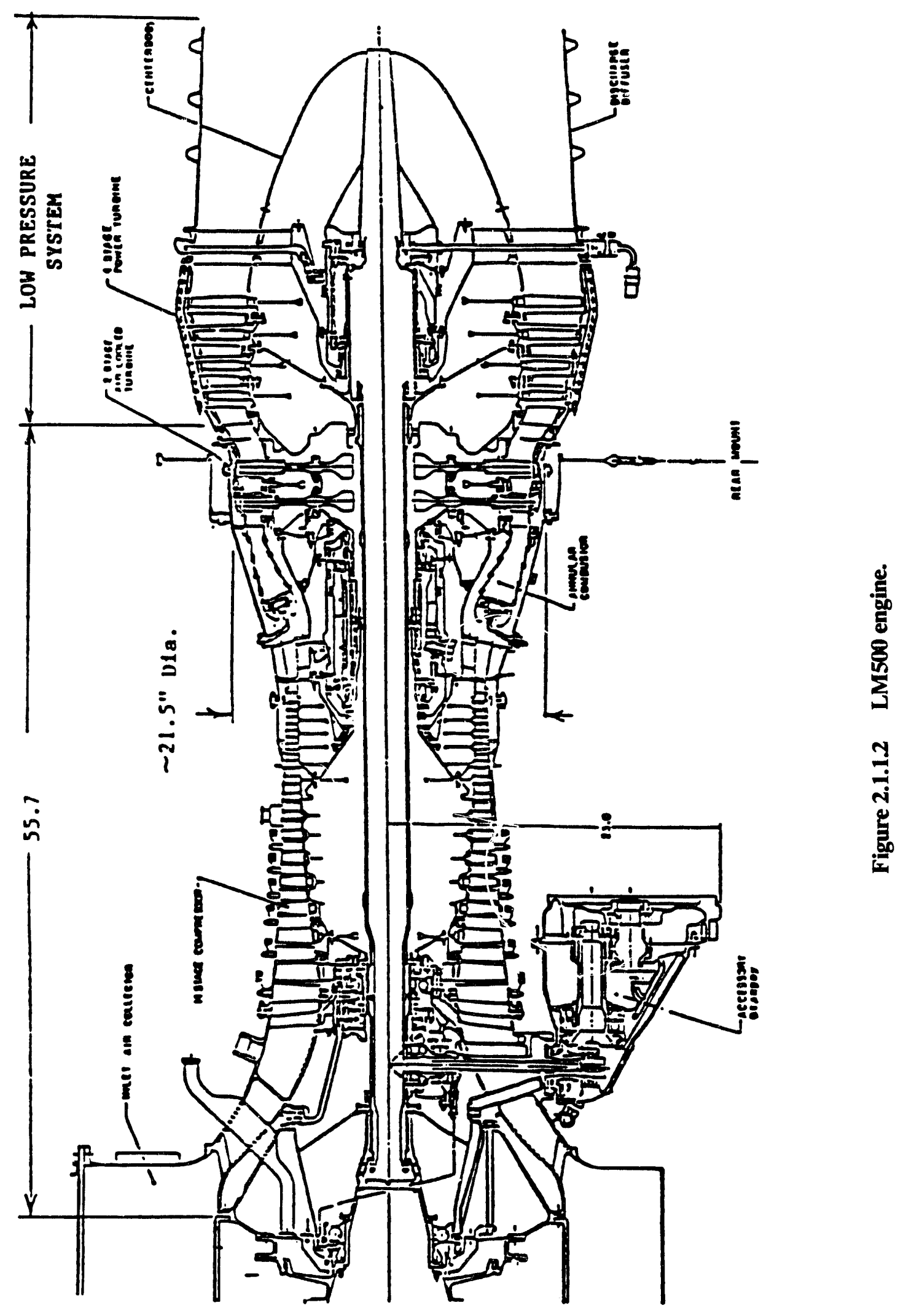


ing technique, liner wall construction and dome arrangement. However, the combustor volume and reference velocity have been sized based upon coal-combustion requirements.

The coal-water-mixture (CWM) annular combu tor in a gas-turbine engine offers advantages for direct coal firing in a very compact and efficient combustion system. In this system, clean micronized coal mixed with water is directly injected into an annular combustor. The annular combustor forms a natural match with the annular flow paths of the compressor and turbine. The flow path is annular in its entirety and results in uniform airflow to the combustor for low pressure drop and excellent pattern factor and profile control.

The annular combustor evolved during this program is illustrated, mounted in the engine, in Figures 2.1.1.3 and 2.1.1.4. As illustrated by these charts, considerably more space is occupied by the combustion system. For this reason, combustor casing support brackets will be required to transfer loads to the inlet frame. To allow for the spatial requirements of the combustor support brackets, the gearbox will be lowered. A gearbox support bracket will also be added to prevent axial and radial movement of the gearbox. No modifications are required for the engine gearbox mounts. The lowered gearbox and support bracket arrangement are illustrated in Figure 2.1.1.5. Other accessories will also be affected by the larger combustor. Figure 2.1.1.6 shows the other components that will be moved.

\subsubsection{Annular Combustor Design Approach}

The annular combustor configuration evolved in this program is illustrated in Figure 2.1.1.7. Because of the increased volume and residence time required for combustion of coal, the combustor has been enlarged relative to the standard LM500 combustor. The combustor extends outboard and forward of the compressor rear stages. A portion of the compressor-discharge air flows forward and then around the dome to supply the outer liner. Reverse-flow combustors have been employed successfully at GE in other engine applications. The combustor liner uses an advanced cooling technique with impingement film cooled walls. The dome has eighteen swirlers for spray control and atomization, and also uses impingement cooled walls. The multiple fuel injection sources not only provide uniform distribution of the fuel, but also provide the capability for fuel staging for high turndown ratio.

The combustor design point operating parameters are presented in Table 2.1.1.1. These conditions are quite similar to the base-load operating conditions for the standard LM500 except for the fuel-air ratio of 0.0724 which is required to reach a turbine inlet temperature of $2212^{\circ} \mathrm{F}$. The fuel-air ratio is much higher due to the lower heating value resulting from the added water.

Key dimensional features are shown in Table 2.1.1.2. Eighteen fuel nozzles are used as in the standard LM500. This results in a spacing of $4.3 \mathrm{in}$. between fuel nozzle tips. This spacing is roughly the same as the dome height, so that each fuel nozzle supplies fuel to a symmetrical segment of the combustor. The combustion length to dome height ratio, a parameter often 


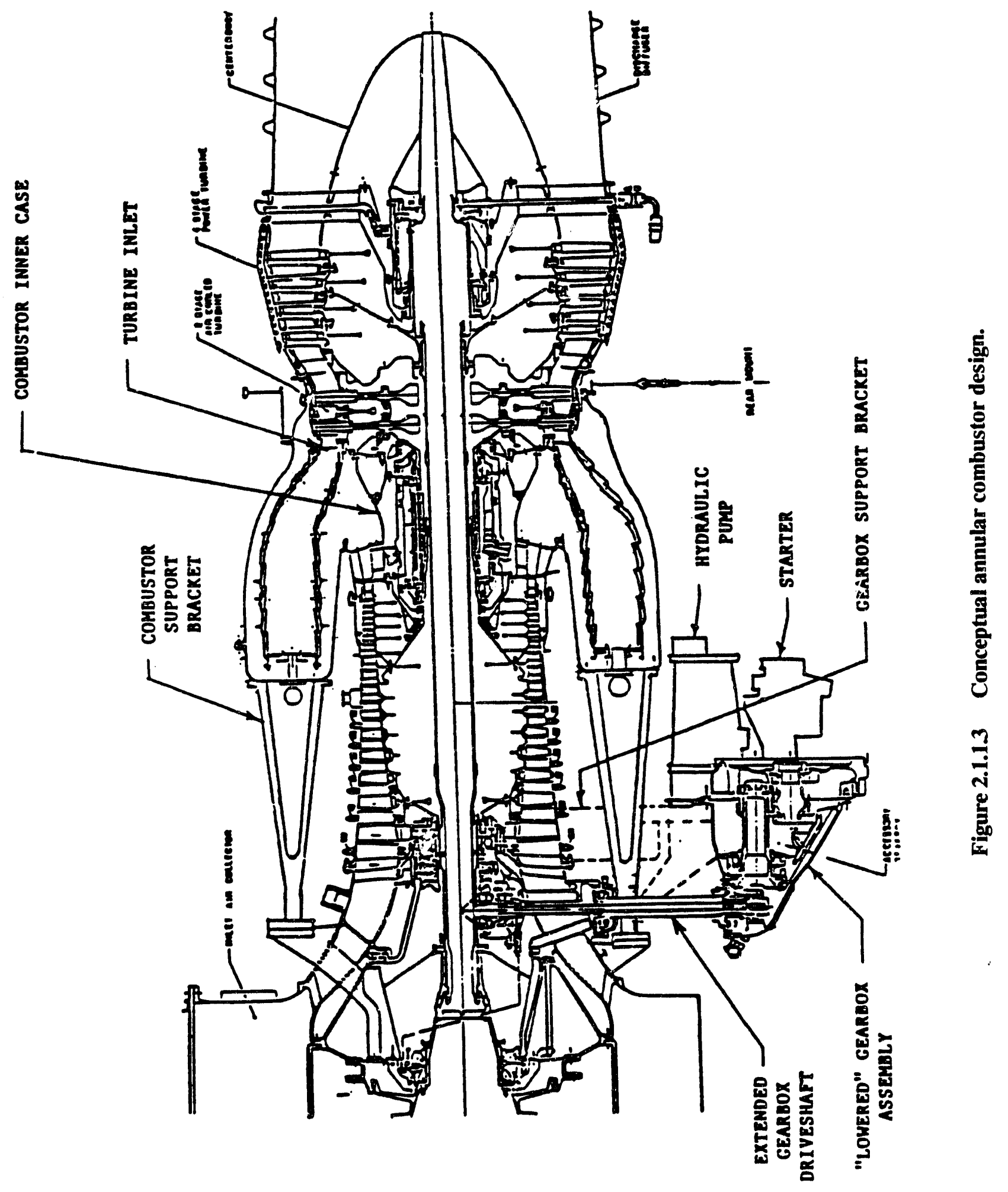




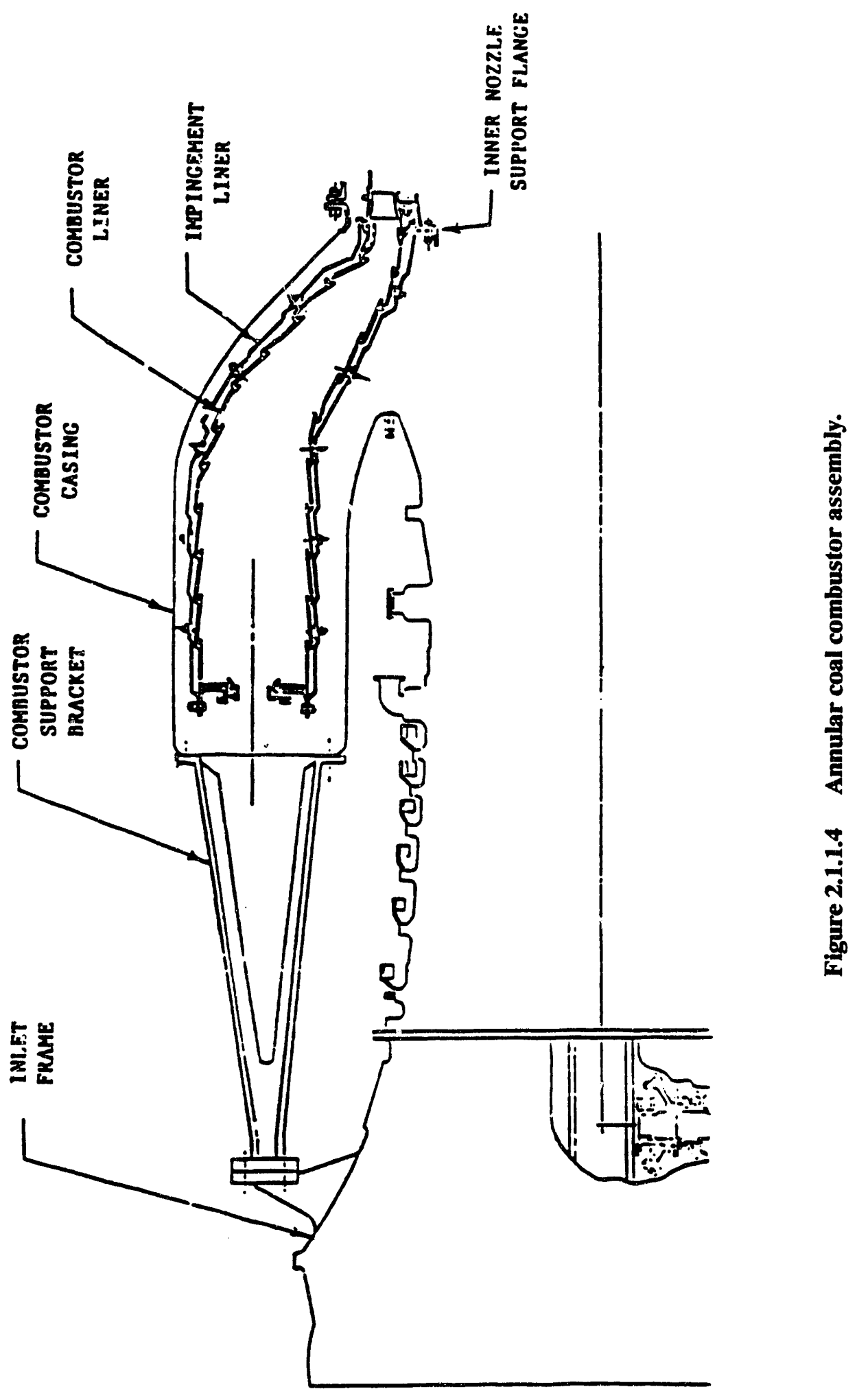




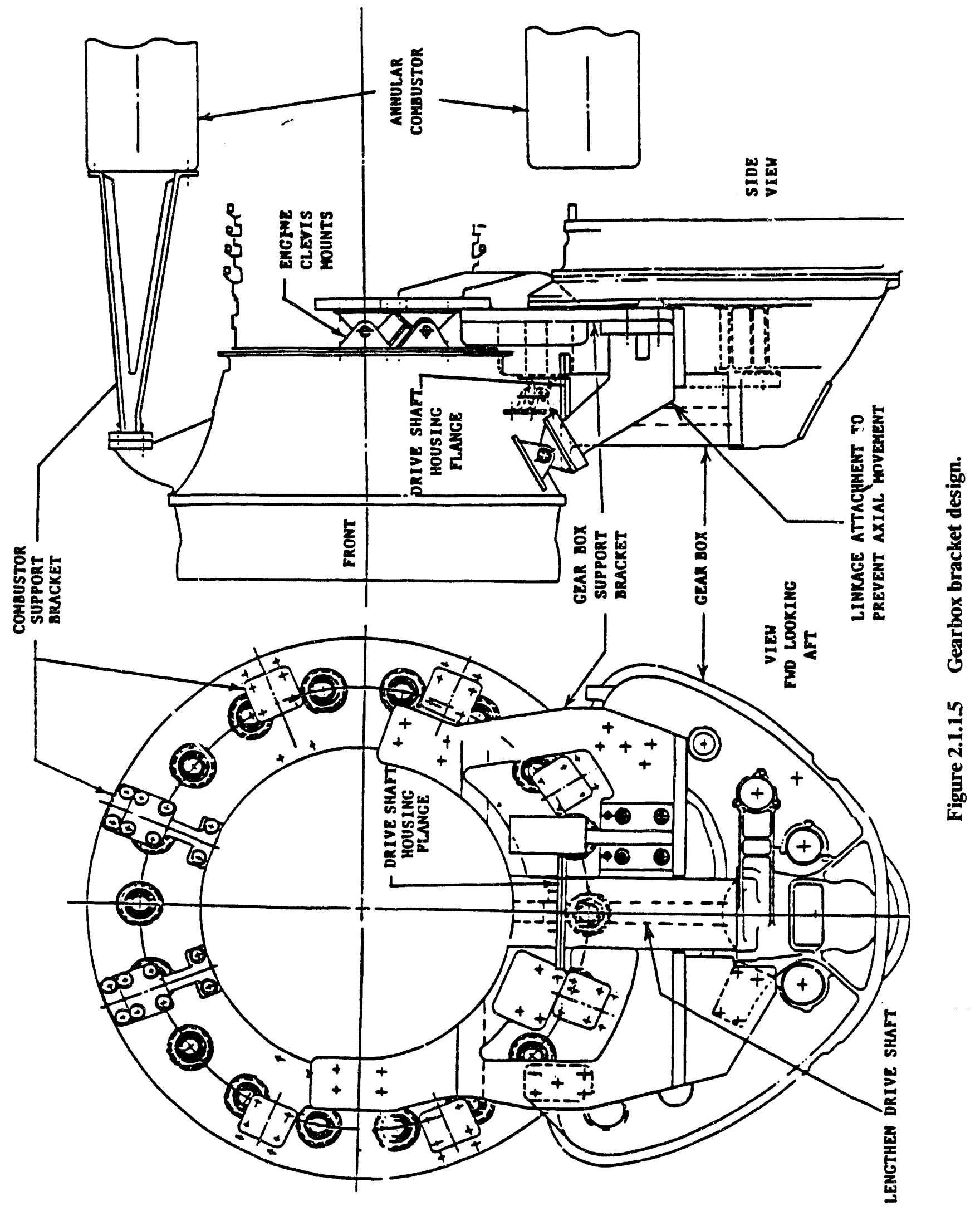



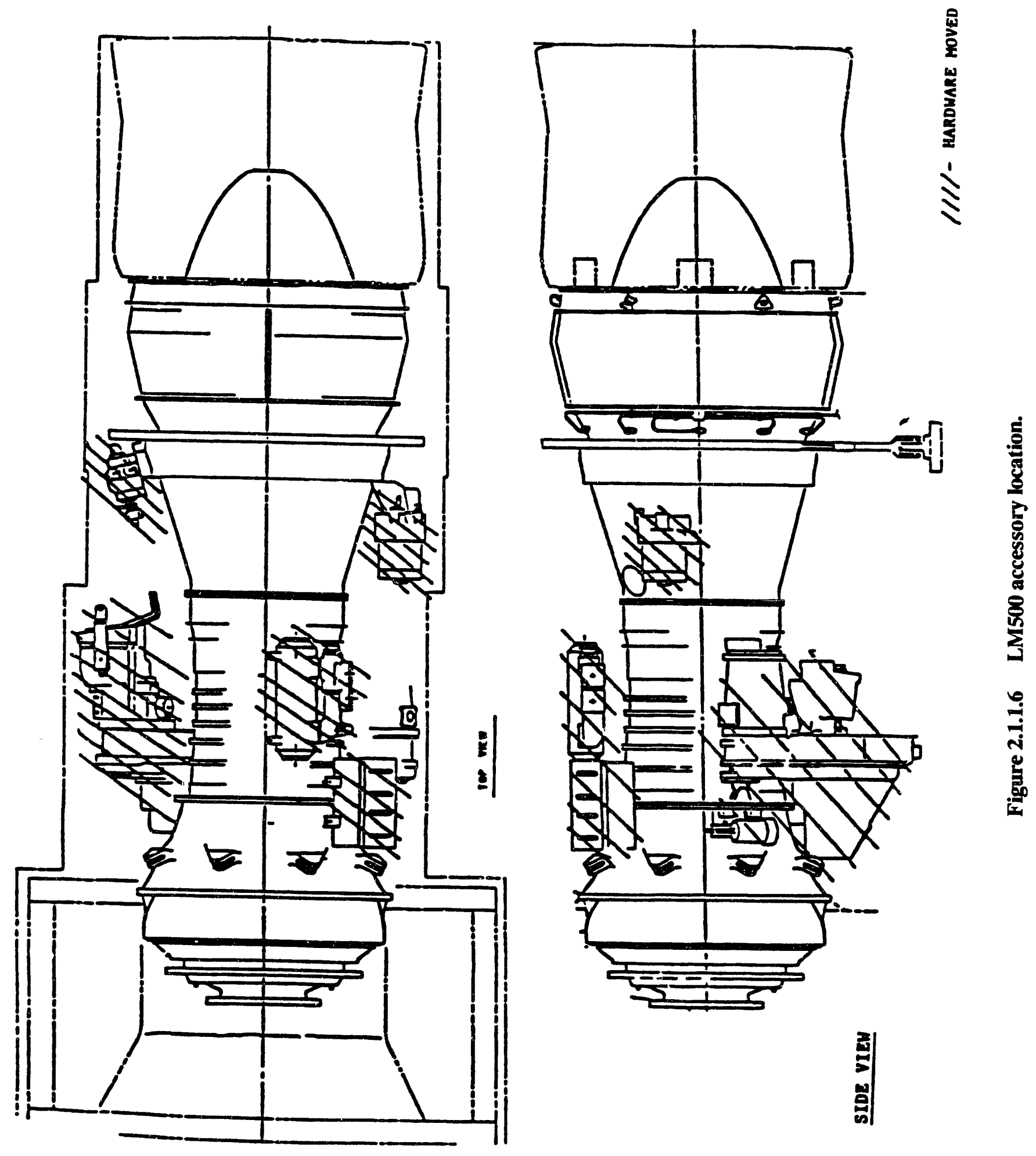

밈 


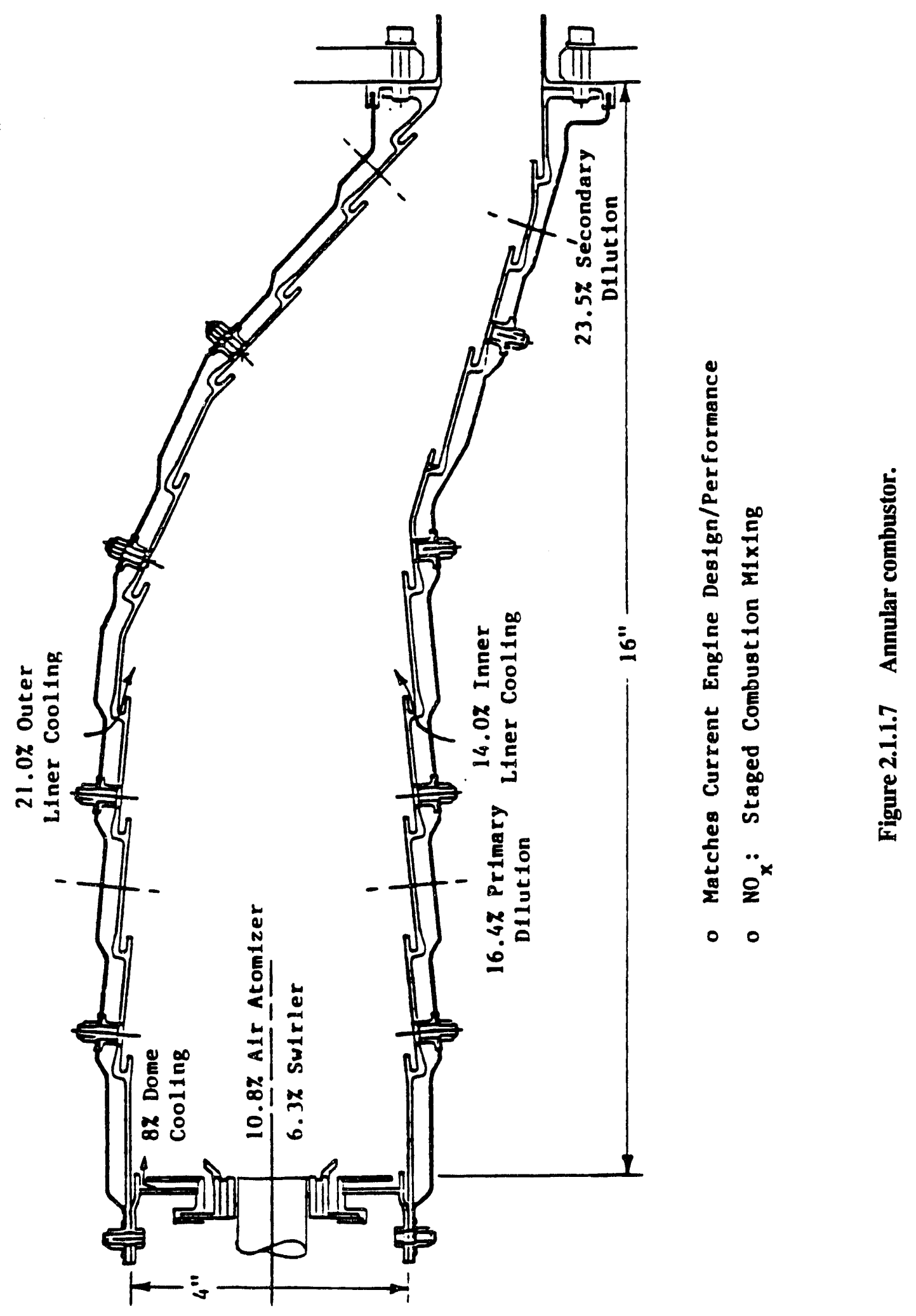


Table 2.1.1.1

Combustor Design/Operating

Requirements

\begin{tabular}{lc}
\hline $\mathrm{W}_{3}$ (pps) & 34.55 \\
$\mathrm{~W}_{\text {comb }}$ (pps) & 27.2 \\
$\mathrm{P}_{3}$ (psia) & 208 \\
$\mathrm{~T}_{3}\left({ }^{\circ} \mathrm{R}\right)$ & $1219\left(759^{\circ} \mathrm{F}\right)$ \\
$\mathrm{T}_{4}\left({ }^{\circ} \mathrm{R}\right)$ & $2672\left(2212^{\circ} \mathrm{F}\right)$ \\
$\Delta \mathrm{T}\left({ }^{\circ} \mathrm{R}\right)$ & 1453 \\
$\mathrm{f} / \mathrm{a}$ & 0.0724
\end{tabular}

Table 2.1.1.2

Combustor Configuration

Combustor Type

Combustor Length, $\mathrm{L}_{\boldsymbol{c}}$ (in.)

Dome Height, $\mathrm{H}$ (in.)

Combustor Nominal O.D. (in.)

Number of Nozzles

Nozzle Spacing, B(in.)

$\mathrm{I}_{\boldsymbol{c}} / \mathrm{H}$

$\mathrm{L}_{\boldsymbol{c}} / \mathrm{B}$

$\mathrm{B} / \mathrm{H}$
Annular Reverse Flow

16.0

4.0

29.0

18

4.3

4.0

3.7

1.1 
used to compare combustion systems, is 4.0 . This is considerably longer than many advanced combustors but is required for ample mixing time to obtain high-combustion efficiency and low-pattern factors.

Key combustor operating parameters are presented in Table 2.1.1.3. The overall combustor presisure drop is $6 \%$. Approximately $1 \%$ of this is diffuser loss making the combustor pressure drop about $5 \%$. The combustor pressure drop across the liner walls is divided evenly beiween the impingement shield and the liner.

The dome reference velocity is $30 \mathrm{fps}$. This velocity is based on the dome flow area and all of the combustion airflow at the compressor discharge. This velocity is approximately onethird that of the standard LM500 combustor, which is considerably smaller, to provide sufficient combustor residence time. At the design point when operating on CWM, the residence time in the combustor is $28 \mathrm{~ms}$. This residence time was based upon estimates of the time required for the completion of the key processes involved, such as droplet evaporation, devolatilization and char burnout. This velocity will also result in excellent starting capability and low-speed performance on liquid hydrocarbon.

At the design point, the overall equivalence ratio of the combustor is 0.4 . In the dome region, the equivalence ratio is 1.2 . This value was intentionally made richer than stoichiometric, for two reasons. First, as the engine power level is reduced, the fuel-air ratio decreases. This will result in increased flame zone temperature rise as stoichiometric fuel-air ratio is approached in the dome. The increased temperature rise will offset reductions in inlet temperatures and pressures and will provide a wider operating range with CWM. The second and most important reason for use of an over stoichiometric fuel-air ratio in the combustion zone is for reduced $\mathrm{NO}_{x}$ emissions. Two stage, (rich/lean) combustors have been used as a means to control $\mathrm{NO}_{x}$ emissions. A rich/lean combustor contains a rich stage followed by a lean stage to complete the combustion process. In the rich stage, fuel bound nitrogen is liberated in the form of $\mathrm{N}_{2}$ without forming $\mathrm{NO}_{x}$ due to the reduced availability of oxygen. In the lean stage, the fuel-air ratio is reduced rapidly to below stoichiometric where excess oxygen is available to complete the combustion process. At the design point, the equivalence ratio is approximately 0.8 just aft of the primary dilution holes in the combustor. A third stage is also employed where additional dilution air is introduced and the hot gases are cooled to the desired turbine inlet temperature and profile shape. At the end of the dilu. tion stage, the equivalence ratio is 0.4 . The equivalence ratio in the various stages of the combustors are a function of the combustor airflow distribution. The airflow distributiun is controlled by the hole patterns in the combustor flow path. The annular design lends itself to easy modification and location of the air introduction stations.

The preliminary airflow distribution for the annular combustor is presented in Table 2.1.1.4. As indicated above, the airflow distribution is easily adjusted during development, and 
Table 2.1.1.3

Combustor Design Parameters

Combustor $\triangle \mathrm{P} / \mathbf{P}_{\mathbf{3}}$

Dome Reference Velocity (fps)

Residence Time (ms)

Primary Zome Equivalence Ratio

Overall Equivalent Ratio

Atomizing Air/Fuel Flow
6.0 (including $1 \%$

Diffuser Loss)

30

28

1.2

0.4

1.5

Table 2.1.1.4

Preliminary Liner Flow Distribution

\begin{tabular}{lc}
\hline & $\frac{\% \mathrm{~W}_{c}^{*}}{}$ \\
\cline { 2 - 2 } Swirl Cup & 6.3 \\
Atomizing Air & 10.8 \\
Dome Cooling & 8.0 \\
Primary Dilution & 16.4 \\
Secondary Dilution & 23.5 \\
Liner Cooling & 35.0 \\
\hline
\end{tabular}


all of these values may change in order to achieve an optimum balance between the various performance requirements; such as life, emissions, exit temperature profile, efficiency, etc. The total dome flow is approximately $25 \%$ of the total combustor airflow. The liner cooling air is $35 \%$. The primary and secondary dilution airflow rates are $16.4 \%$ and $23.5 \%$, respectively.

Several types of liner cooling construction were considered for the annular combustor. These cooling concepts are illustrated in Figure 2.1.1.8. The standard film-cooled type wall has been used successfully on many modern combustion systems and is employed in the current LM500 combustor. This concept introduces a uniform film of air to the liner wall at selected points along the combustor length. The cooling air is metered by an array of cooling holes in each cooling slot. A plenum region in the slot allows for spreading and mixing of the individual air jets so that the film flow is even around the liner.

The more advanced multihole concept utilizes many small holes throughout the liner wall. These holes are at a shallow angle to the liner wall so that the air jets turn and form a film on the liner. This concept provides convective cooling of the wall as well as film cooling on the hot side.

The impingement/film-cooled liner uses an impingement shield along with the standard film cooled liner. The impingement shield contains bands of holes to impinge jets of air on the warmest portions of the liner. The warmest portion of the liner usually occurs just forward of the cooling slot. The combustor pressure drop is divided evenly between the impingement shield and the liner wall. The velocity of these impingement jets is greater than $300 \mathrm{fps}$ which results in excellent convective cooling of the liner. The impingement hole position can be adjusted to provide convective cooling where required.

A fourth design is the shingled liner wall. This concept also uses an impingement shield plus film cooling. An additional feature is that individual panels or shingles can be removed and have been designed so as to reduce stress due to thermal differential growth between cool and hot parts.

The impingement/film-cooled concept has been selected for the annular combustor. The many features of this design are tabulated in Table 2.1.1.5. It was selected over the standard film cooled concept because of the improved cooling with the impingement jets. Also, the metering holes with the impingement/film cooled design are shielded by the ccoling slot overhang. The multihole concept was not selected because the cooling holes are exposed directly to the inner surface of the liner wall and the hot gas region. These holes may be subject to plugging with CWM fuel which may produce some liner deposits. The shingle concept was not selected because it is heavier, costly and more complex than the impingement/filmcooled design. 


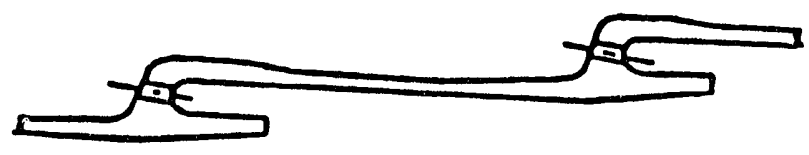

FILM COOLED

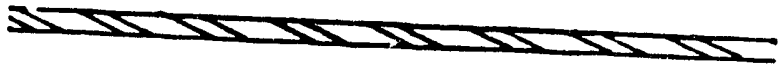

MULTI, HOLE

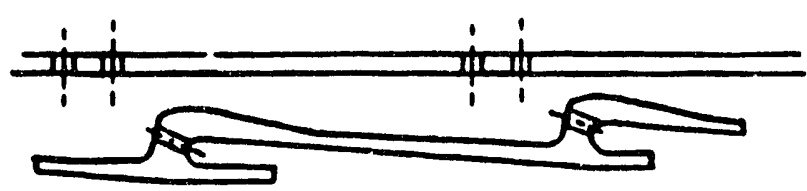

INPINGEMENT/FILM COOLED

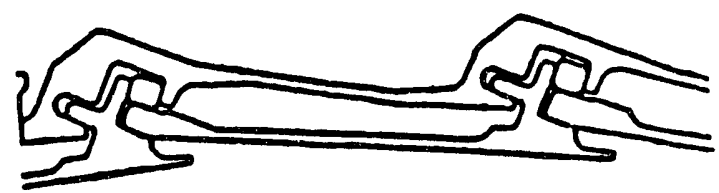

SHINGLE

Figure 2.1.1.8 Combustor liner cooling concepts. 
Dual fuel, air-atomizing fuel nozzles are used for the annular combustor. At starting and low power, liquid fuel will be used. The liquid fuel circuit is on the centerline of the fuel nozzle. The CWM fuel circuit is concentric with the liquid-fuel tube. A third circuit supplies the atomizing air. Two fuel-nozzle designs with variations in the atomization air introduction and liquid fuel atomization technique were evaluated in this program. The ratio of atomization air-to-fuel flow rate is 1.5 and the atomization air pressure ratio is approximately 2.0. These levels provide excellent atomization even with CWM fuel.

Table 2.1.1.5

Impingement/Film Cooling Design Features

- Good Results on Turbine Simulation Program

- Can Concentrate Back Side Cooling on Hot Spots

- Can Use Preferential Film Cooling

- Insensitive to Plugging of Holes

- Cooling Holes Larger. 50\% $\Delta \mathrm{P}$ Each Across Liner and Impingement Shield

- Cooling Hole Exit Shielded by Cooling Slot Overhang

- Reduced Complexity Relative to Shingled Liner

- Amenable to Use of Thermal Barrier Coatings (TBC) 


\subsubsection{Combustor Development Aproach}

In developing the annular combustor, a variety of testing activities would be required to characterize the design concept and hardware. Such component evaluation will be performed on all assemblies which would include airflow and pressure drop testing of the liners, impingement shields and dome assemblies. Patternation and spray visualization studies would be conducted on all fuel-nozzle candidates.

A one nozzle segment combustor has been developed to facilitate rapid screening of subcomponents, such as swirler/dome assemblies and fuel nozzles, as well as combustion airflow distribution. Finally, a $140^{\circ}$ sector combustor would be assembled incorporating concepts developed in the aforementioned evaluation to assess the CWM combustion performance of an annular configuration.

\subsubsection{Annular Sector Combustor}

A $140^{\circ}$ sector combustor has been designed and is being constructed for testing and assessment of combustion system performance. Two important factors were considered in the choice of the sector combustor sizing. The larger the sector combustor, the more representative the test will be of a full annular combustor. However, it is advantageous economically to limit the sector combustor size to accommodate facility constraints on airflow and pressure capabilities. The $140^{\circ}$ sector combustor was chosen because a seven-cup configuration would provide good representation of an annular combustor yet be within the limits of the current facility.

The seven-cup arrangement provides five unperturbed cups with the two outer cups acting as a buffer to mitigate side wall effects. Data analysis would concentrate on the center five cups. Because the $140^{\circ}$ sector was being constructed from a full annular assembly, a $140^{\circ}$ sector would allow construction of a complete test assembly including side walls plus spare hardware for possible use during the component development testing. This flexibility would greatly facilitate the modification of the combustor if early testing dictates changes. The $140^{\circ}$ sector combustor incorporates all the design features of the full annular combustor design including dome/splashplate and swirler configuration, fuel-nozzle design, dilution hole placement and impingement/film cooled liner walls.

Two fuel-nozzle configurations have been considered. The first is a design developed at GE during the LM500 simulator deposition testing. This nozzle is capable of dual fuel operation; that is fuel oil and coal/water mixture. Both oil and CWM fuels are air-atomized.

The second nozzle is a Parker-Hannefin designed and manufactured component modified specifically for this application. It is also capable of dual-fuel operation and also uses air atomization, primarily for the CWM fuel. Fuel oil is pressure-atomized using a conventional engine type simplex nozzle tip. The major differences between the Parker-Hannefin- and the GE-nozzles are the internal passages and the method of distribution of the CWM fuel. Both 
nozzles have the same physical configuration and are interchangeable in the test rig.

The sector combustor hardware manufacture has been completed. The combustor dome is shown in Figure 2.1.2.1. The aft view shows the sliding fuel nozzle ferrules. The view looking forward shows the swirler exits and the splashplates. The splashplates are impingement cooled from the forward side. The cooling air exits around the edges of the splashplate.

The liners and impingement shields are shown in Figures 2.1.2.2a through e.

\subsubsection{Annular Sector Combustor Test Rig Design}

The test rig to house the sector combustor was designed and fabricated to provide sufficient flexibility in the event geometric changes are required during testing. These changes could include increased combustor length and possibly increases in combustor dome height. The test rig is shown in Figure 2.1.2.3.

The rig is designed to operate at or above four atmospheres pressure and full operating temperatures. Maximum capability of the rig has been set at $14 \mathrm{~atm}$, design point for the LM500 engine. The structure would allow easy installation and removal of the combustor and fuel nozzles. Both combustion-liner and fuel-nozzle installation are representative of the engine mounting arrangements. In particular, the fuel nozzles are removable from the test rig and the fuel and air connections are external to the rig.

The rig itself is comprised of two-pressure shells. The forward section which houses the combustor is a stainless steel pipe flanged at both ends. The forward end has an end cover where the fuel nozzles mount and the inlet air enters the rig. The aft end attaches to a bulkhead where the combustor is mounted. The combustor exit plane closely resembles the nozzle inlet of the LM500 engine. The exhaust gases pass into an instrumentation/ exhaust quenching section. This section contains the gaseous emissions, particulate probe and temperature rakes as well as the cooling-water spray bars. Exhaust gases exit this section through a system backpressure valve. A backpressure valve is used in lieu of an actual first-stage nozzle cascade. This arrangement allows better control of combustor pressure and provides capabilities to investigate pressure and residence time effects on combustion.

Combustion liner thermocouples as well as static pressure taps, would exit the test rig through access ports in the forward section. This would allow quick disconnection with combustor removal. Exhaust instrumentation including thermocouple rakes and gaseous emissions rakes will be oriented in-line and in between the five center cups of the sector combustor. Location of these rakes can be interchanged between tests. The particulate probe location will be fixed at the center cup.

The CWM fuel-delivery system required for testing would use a 100-gallon storage tank that would provide a positive head to a high- capacity Moyno ${ }^{\circ}$ progressive cavity pump. A ten-to-one bypass ratio can be maintained to continually agitate the storage tank and also pro- 

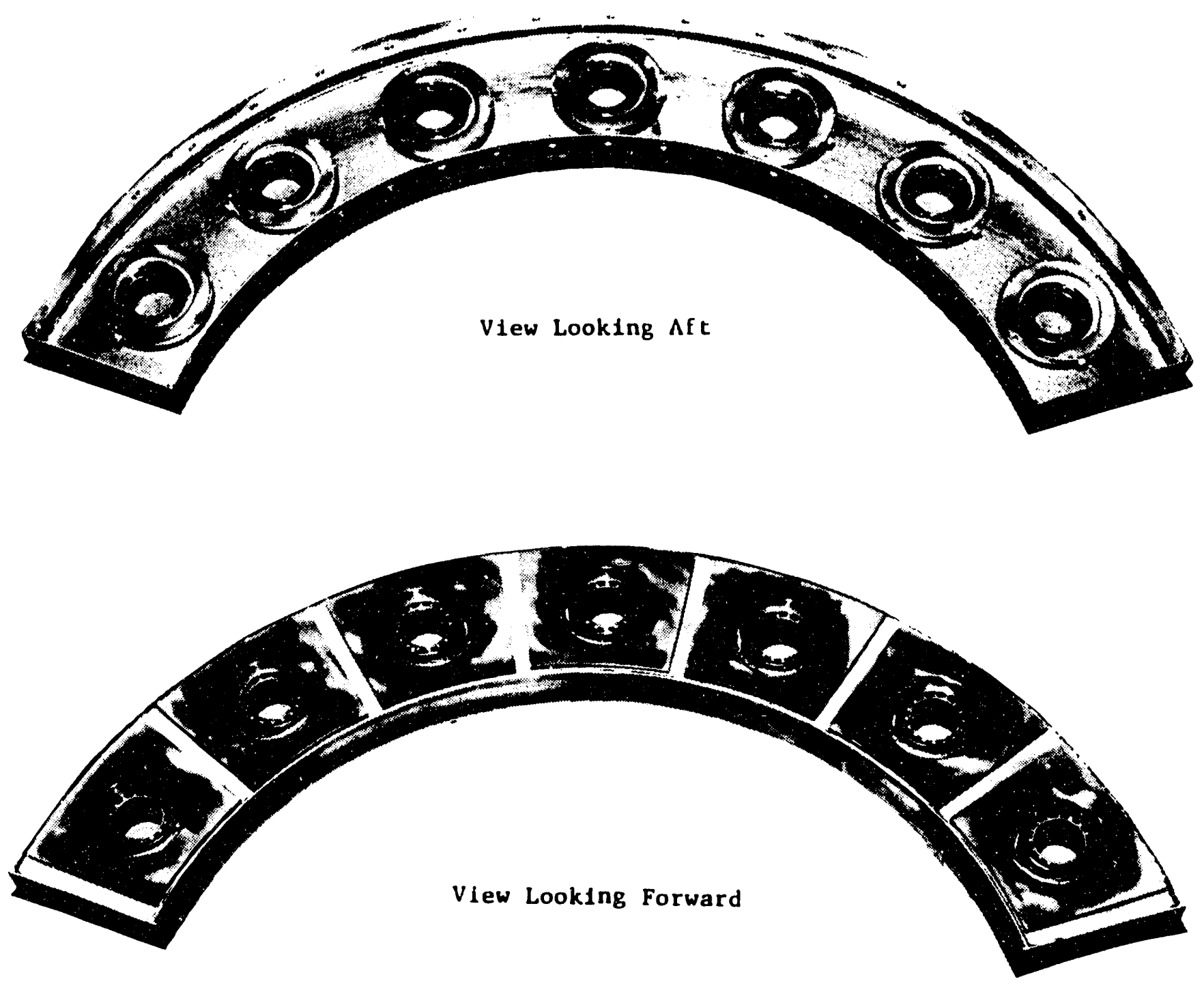

Figure 2.12.1 Annular sector combustor dome. 

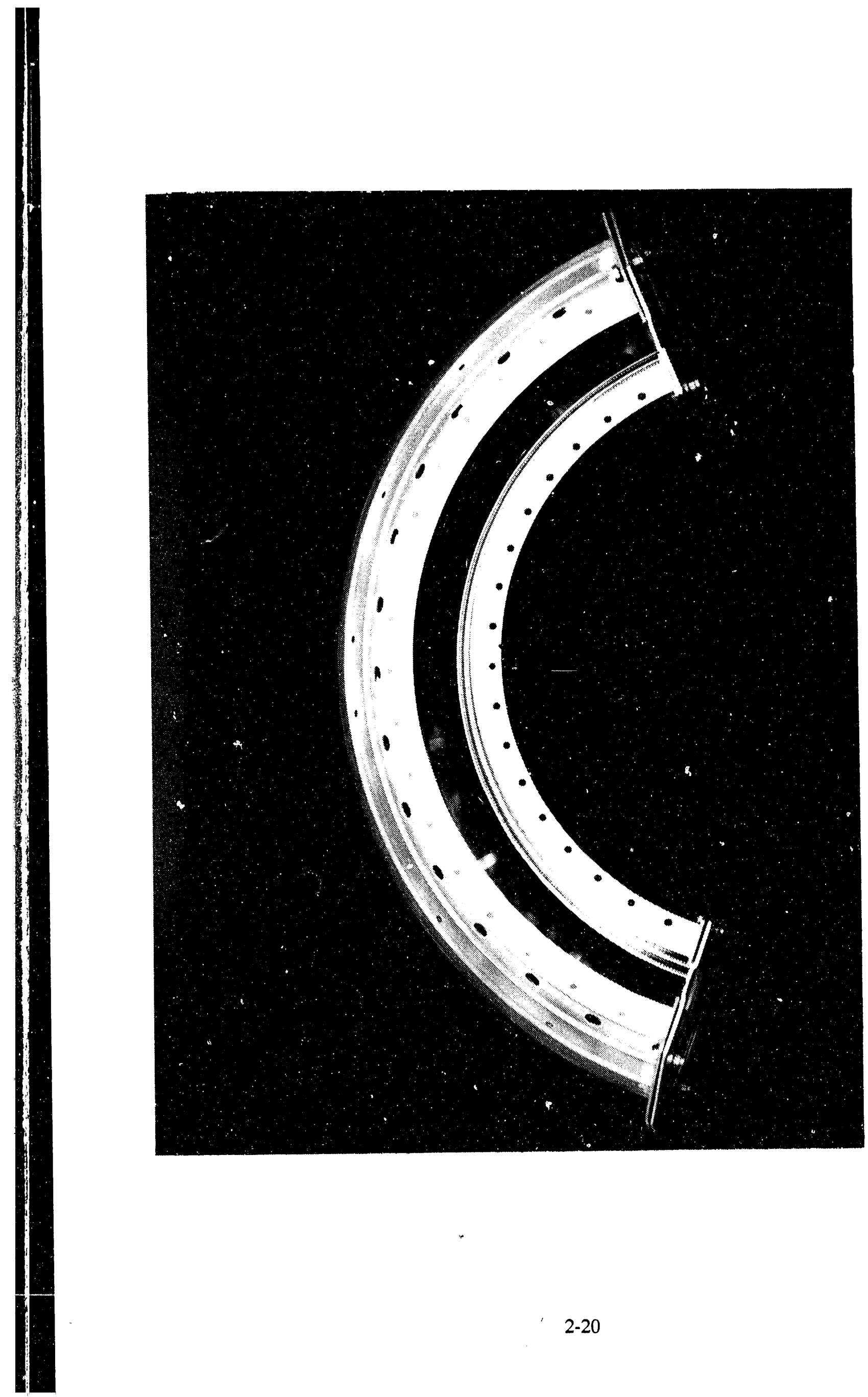

ह. 


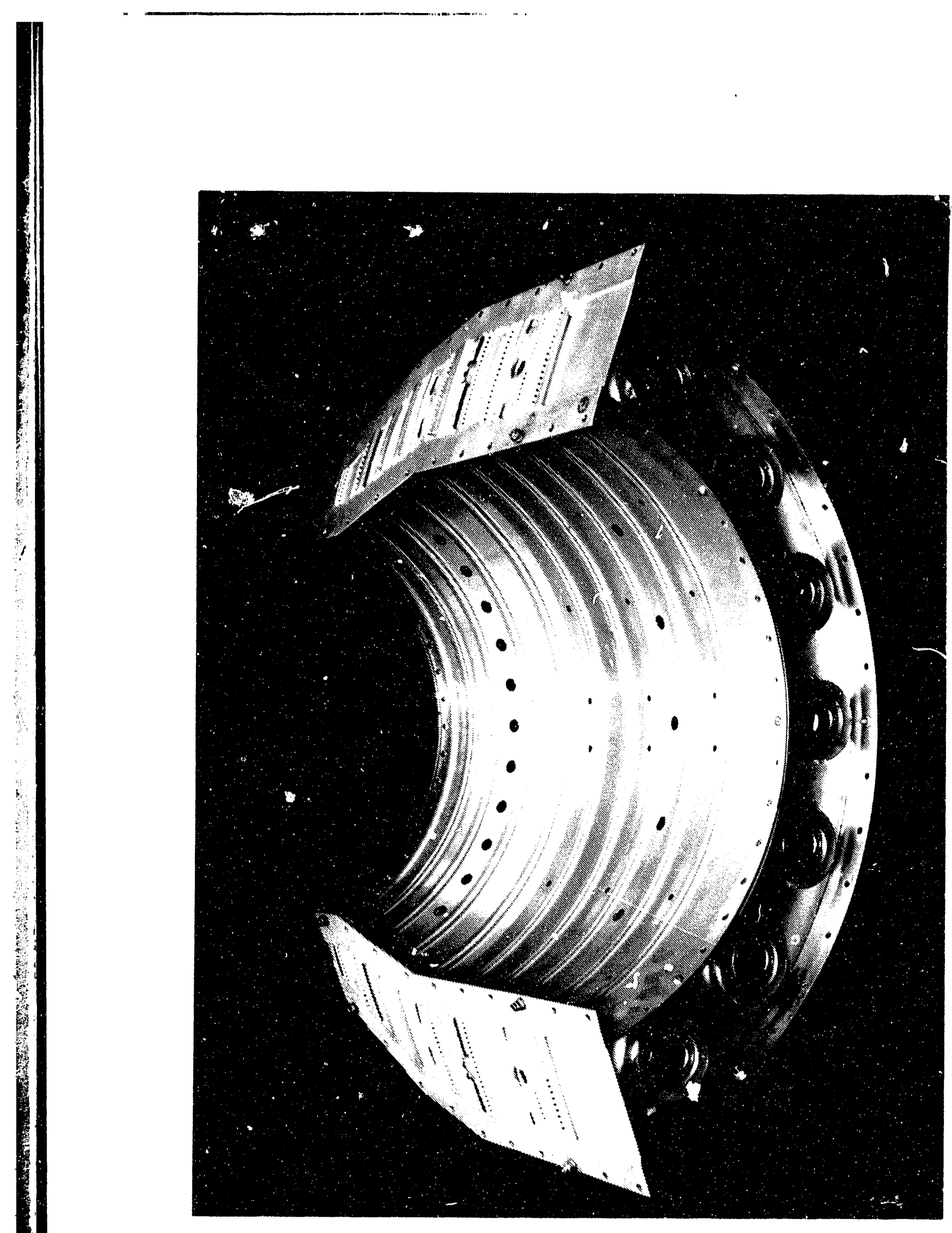

苛 


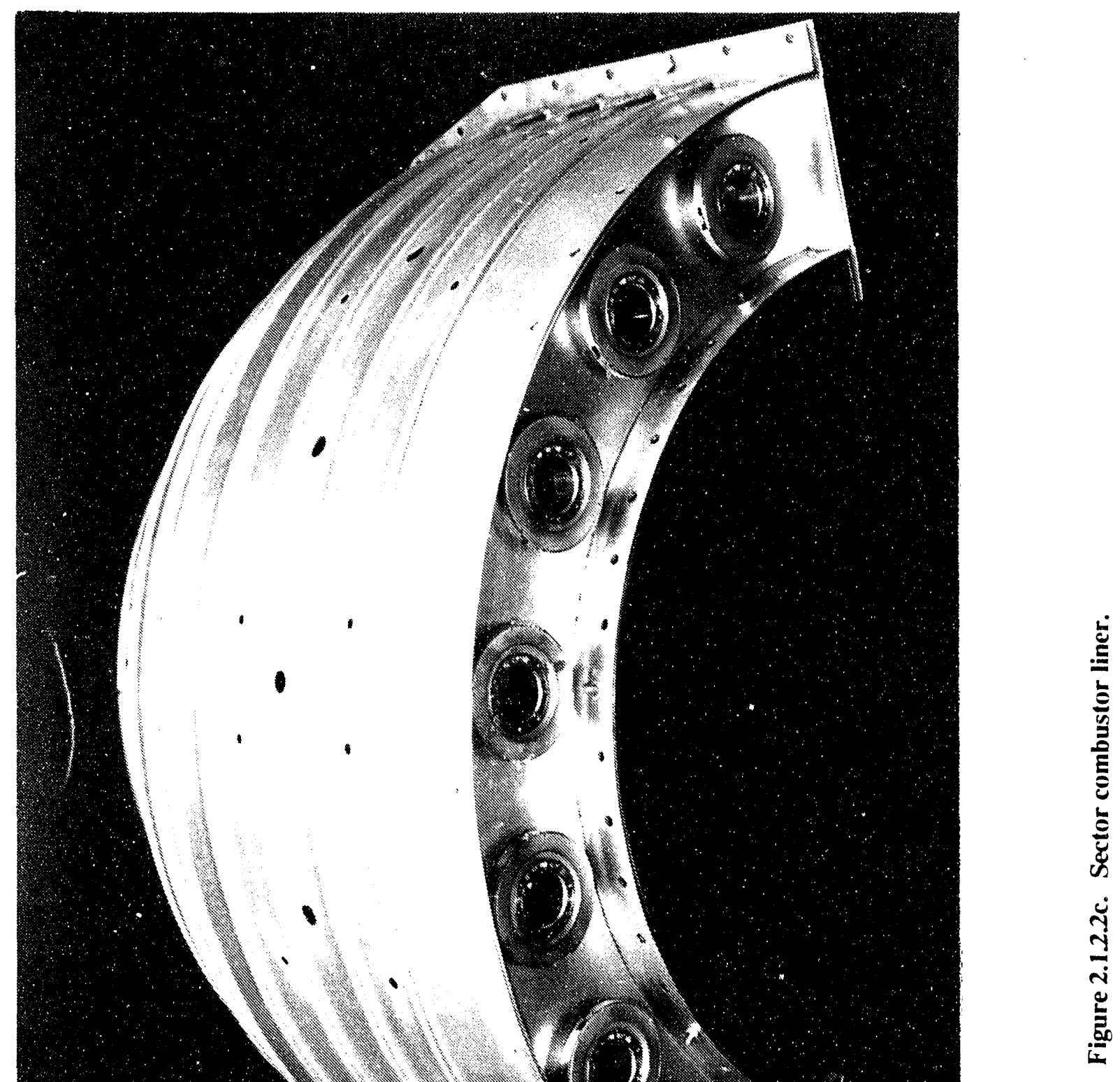




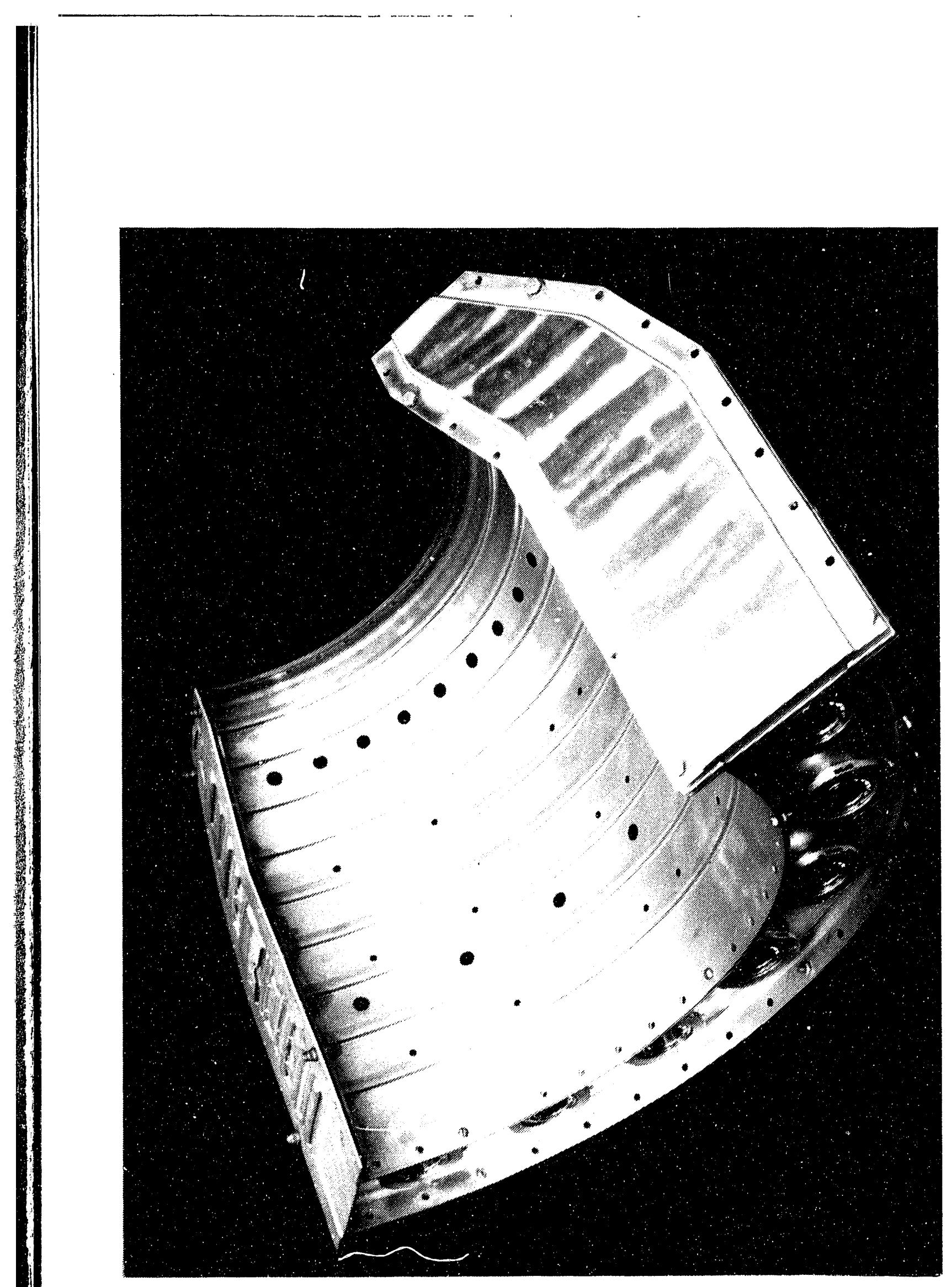

है 


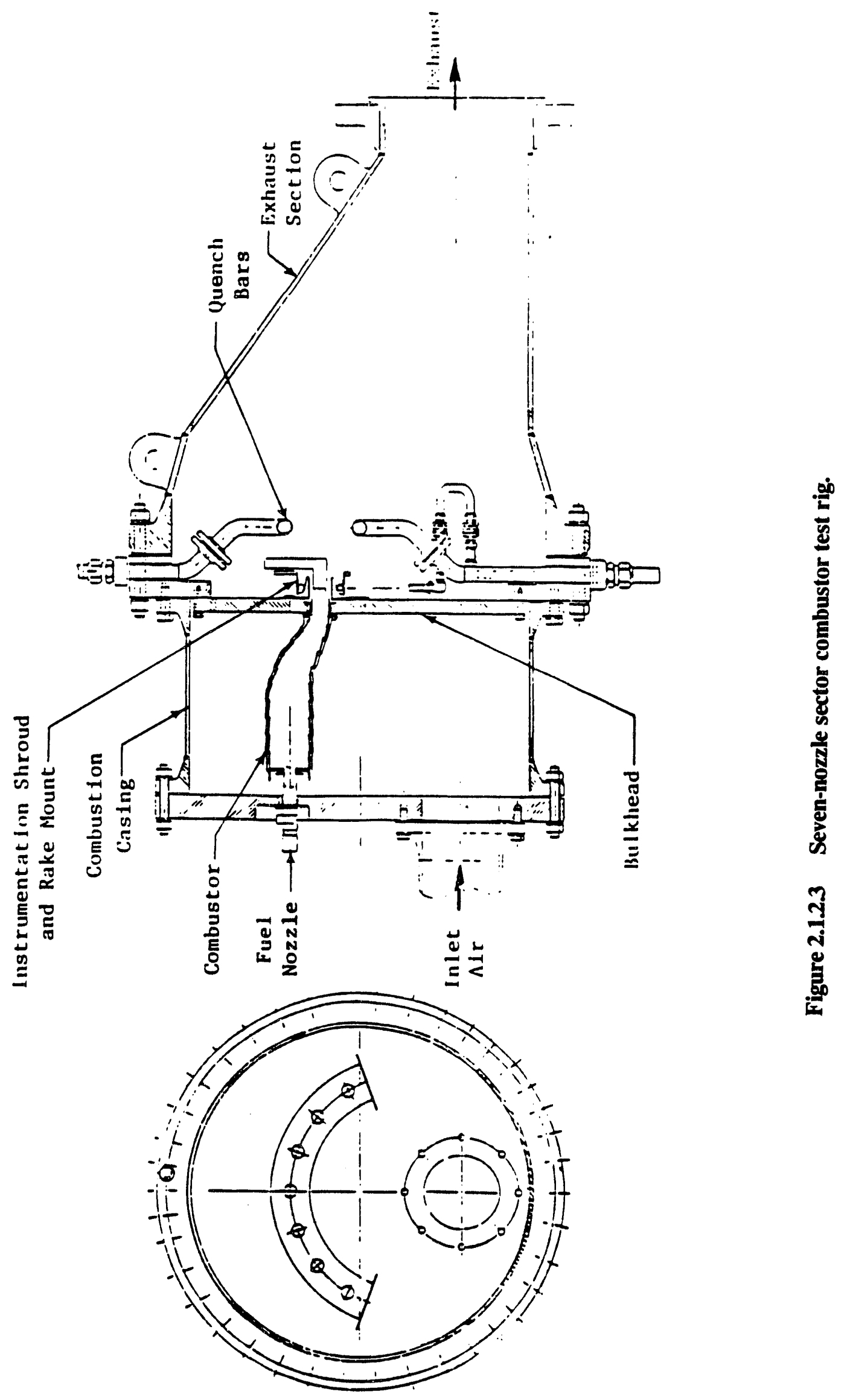


vide a precise level of fuel control to the test rig. CWM flow will be measured using a MicroMotion flow sensor. Parameters such as delivery pressure and temperature can also be measured.

CWM fuel distribution to the seven fuel nozzles would be accomplished by an axial flow distributor. This design uses axially mounted, concentric tubes. This arrangement, along with the slow moving, highly viscous CWM fuel, would allow uniform fuel flow to all seven nozzles.

All of the sector combustor test rig hardware has been manufactured. Figure 2.1.2.4 shows the combustor casing. The casing has numerous fittings for instrumentation lead-out and has two large ports for hand access to the inside. Figure 2.1.2.5 shows the test rig aft bulkhead. The combustor bolts to this bulkhead. Figure 2.1.2.6 shows the combustor exit shroud and instrumentation rake mount. The exit shroud has the same dimensions as the LM500 turbine inlet section and shields the instrumentation from quench water and recirculating combustion gases. Figure 2.1.2.7 is the access ring which is used to lead out the exit instrumentation lines and quench water lines. Figure 2.1.2.8 is the exhaust section with the back-pressure valve and valve-actuation system.

\subsubsection{Test Facilities}

Testing would be conducted in the GEAE Advanced Combustion Laboratory located in Evendale, Ohio. This facility has the capability of running a sector combustor at various inlet pressures and temperatures as well as a range of combustor firing temperatures. The laboratory has associated with it, considerable instrumentation and automated data acquisition systems that enable real time data analysis and storage.

Combustion air is brought to test pressure by multi-stage compressors. The air is then preheated to the desired air-inlet temperatures by an indirect fired heater. Flows, temperatures and pressures would be monitored continuously. Gaseous emissions instrumentation located permanently on-site to provide $\mathrm{NO} / \mathrm{NO}_{2}, \mathrm{CO}, \mathrm{O}_{2}$ and $\mathrm{CO}_{2}$ data. Particulate material is collected over a prescribed period of time and analyzed later for carbon content. Table 2.1.2.1 outlines the nominal capacities of the laboratories.

\subsubsection{Combustor Test Results}

2.1.2.4.1 Test Overview. All combustor and fuel nozzle hardware undergoes flow testing to ensure proper manufacture prior to combustion tests.

Initially, sector combustion testing would be conducted at $4.0 \mathrm{~atm}$ pressure and full engine temperature conditions. The procedure for reduced pressure testing is to maintain the same flow function $W \sqrt{T / P}$ as for $14.0 \mathrm{~atm}$ testing. Table 2.1.2.2 presents a comparison of test conditions between the 4.0 and 14.0 atm operation. 


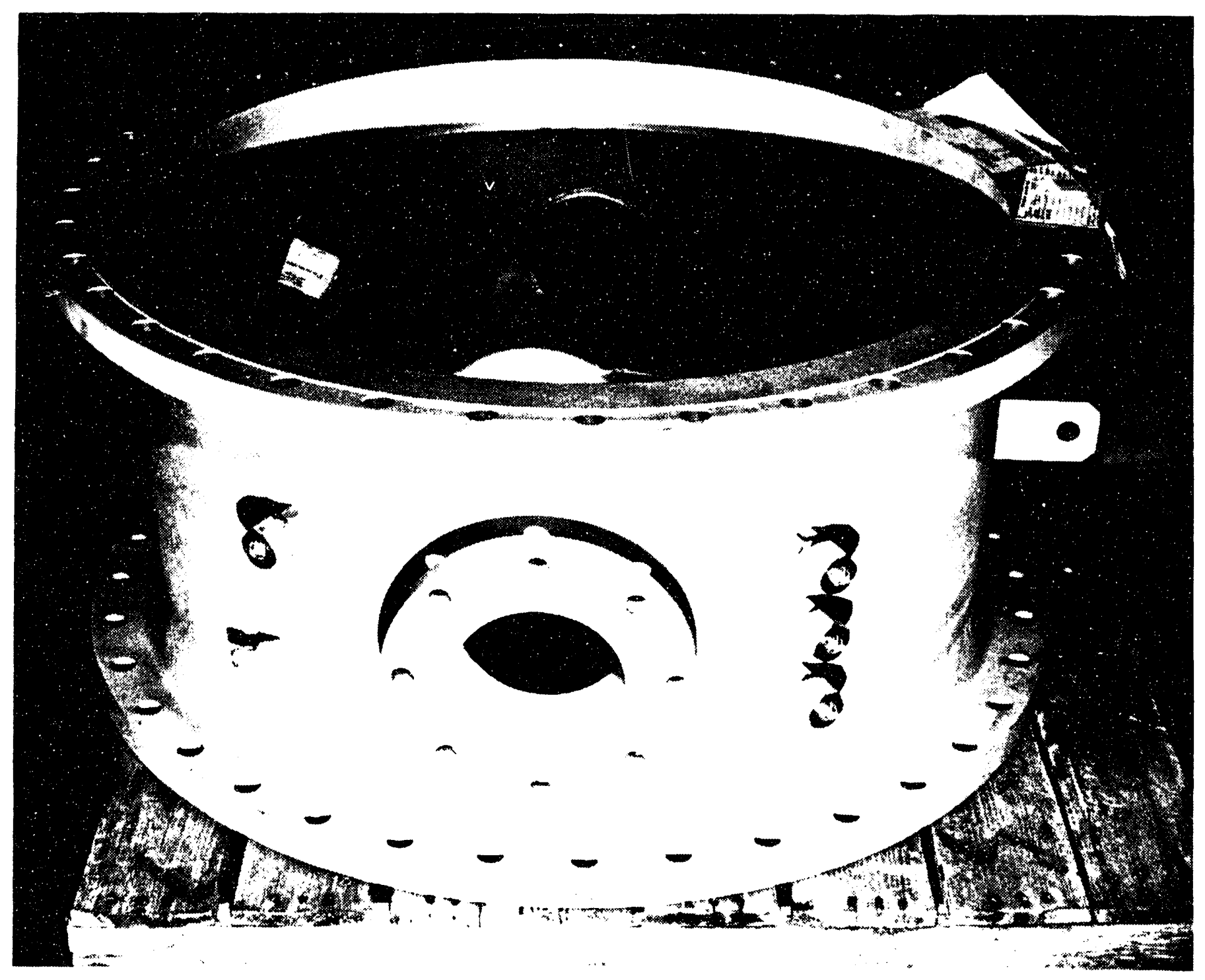

Figure 2.1.2.4 Test rig casing. 


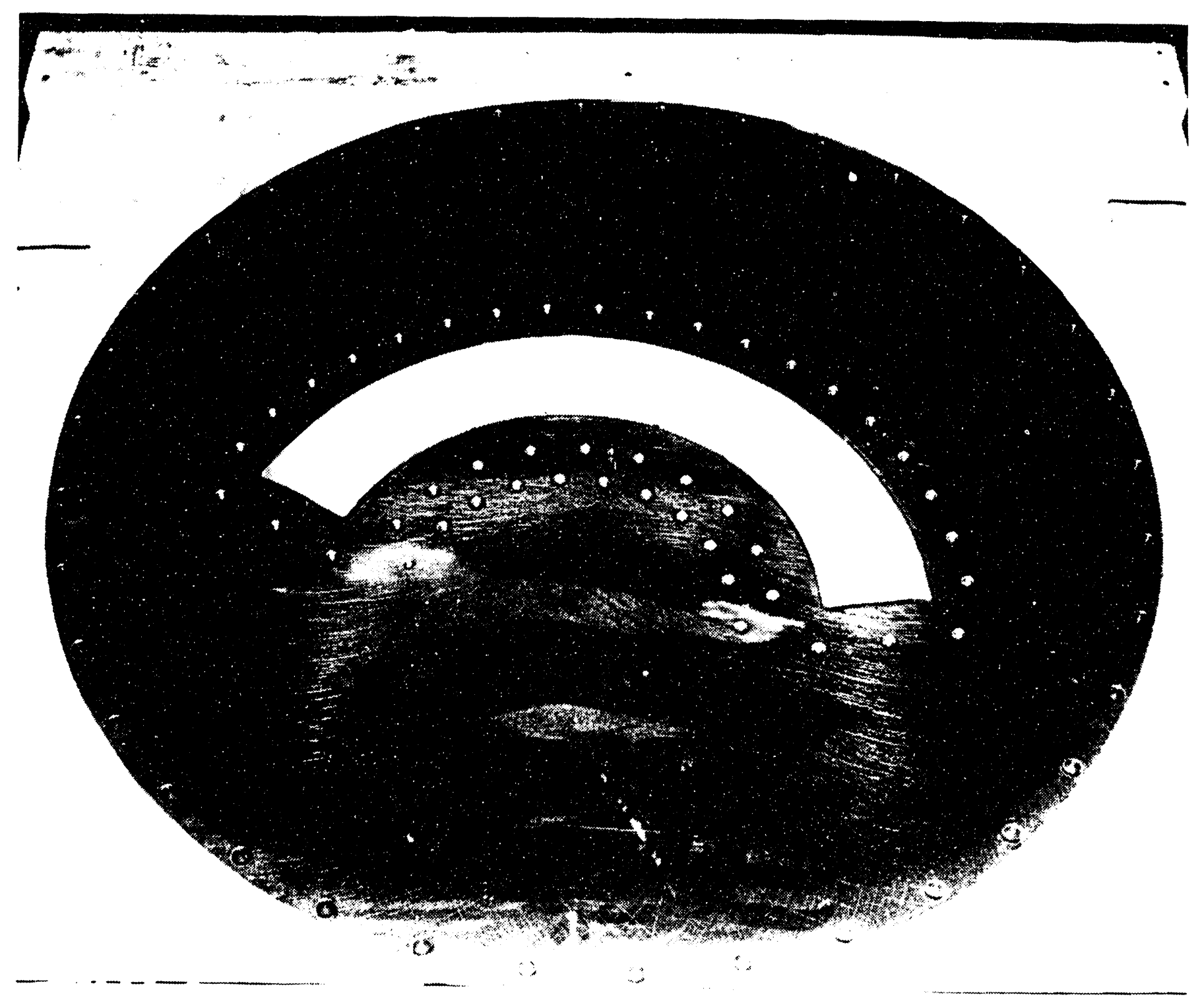

Figure 2.1.2.5 Test rig aft bulkhead and combustor mount. 

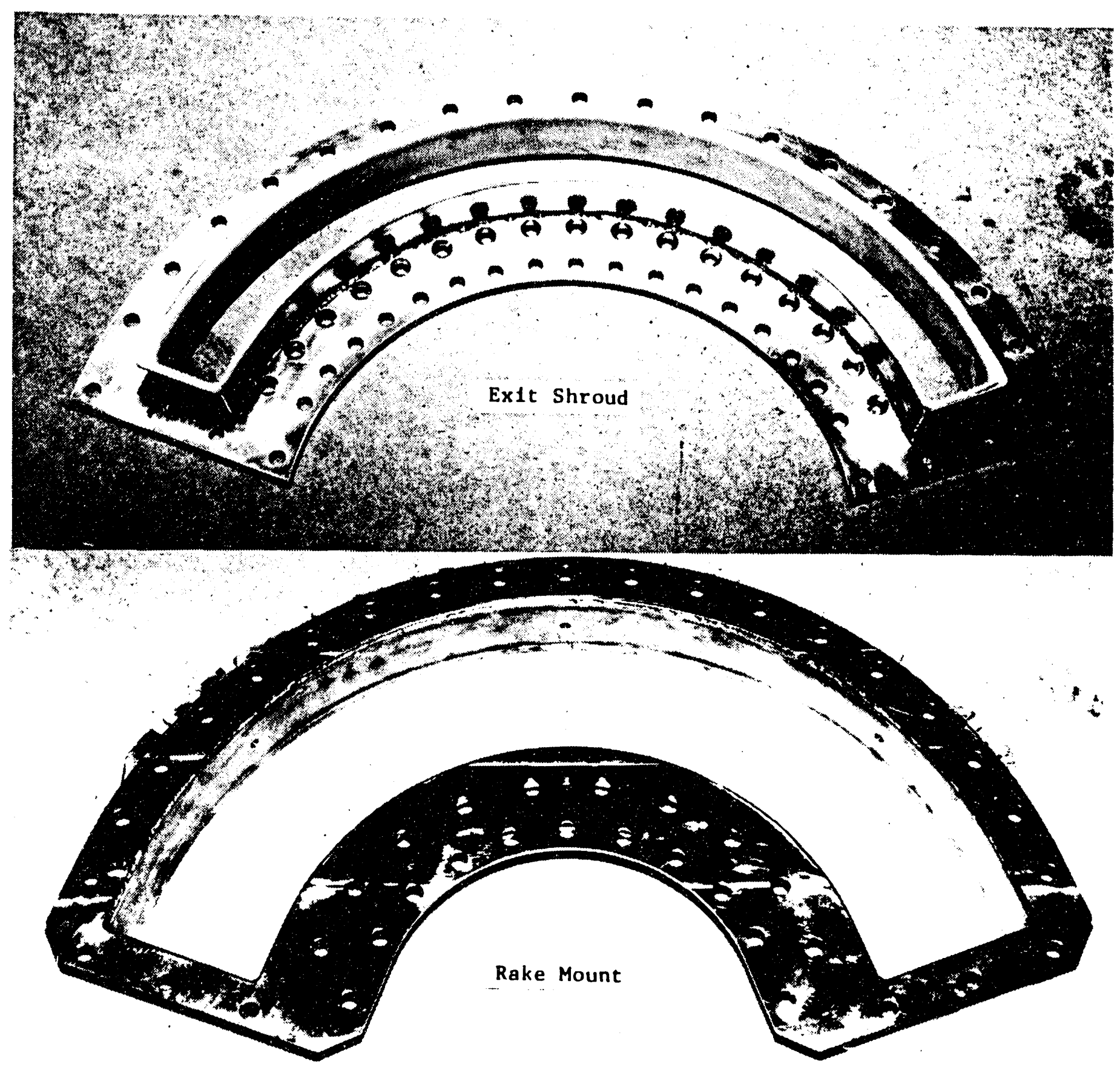

Figure 2.1.2.6 Test rig exit shroud and instrumentation mount. 


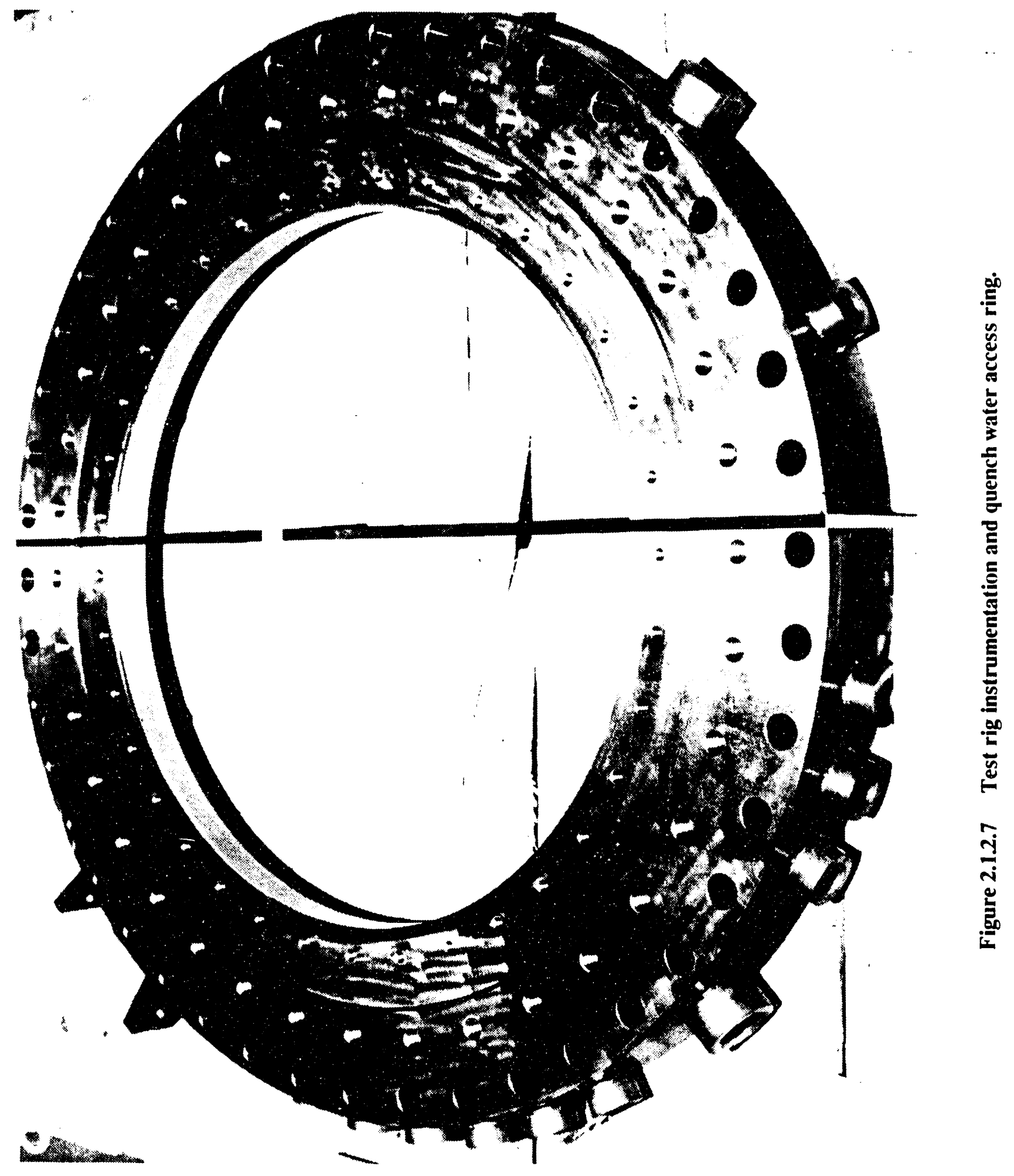




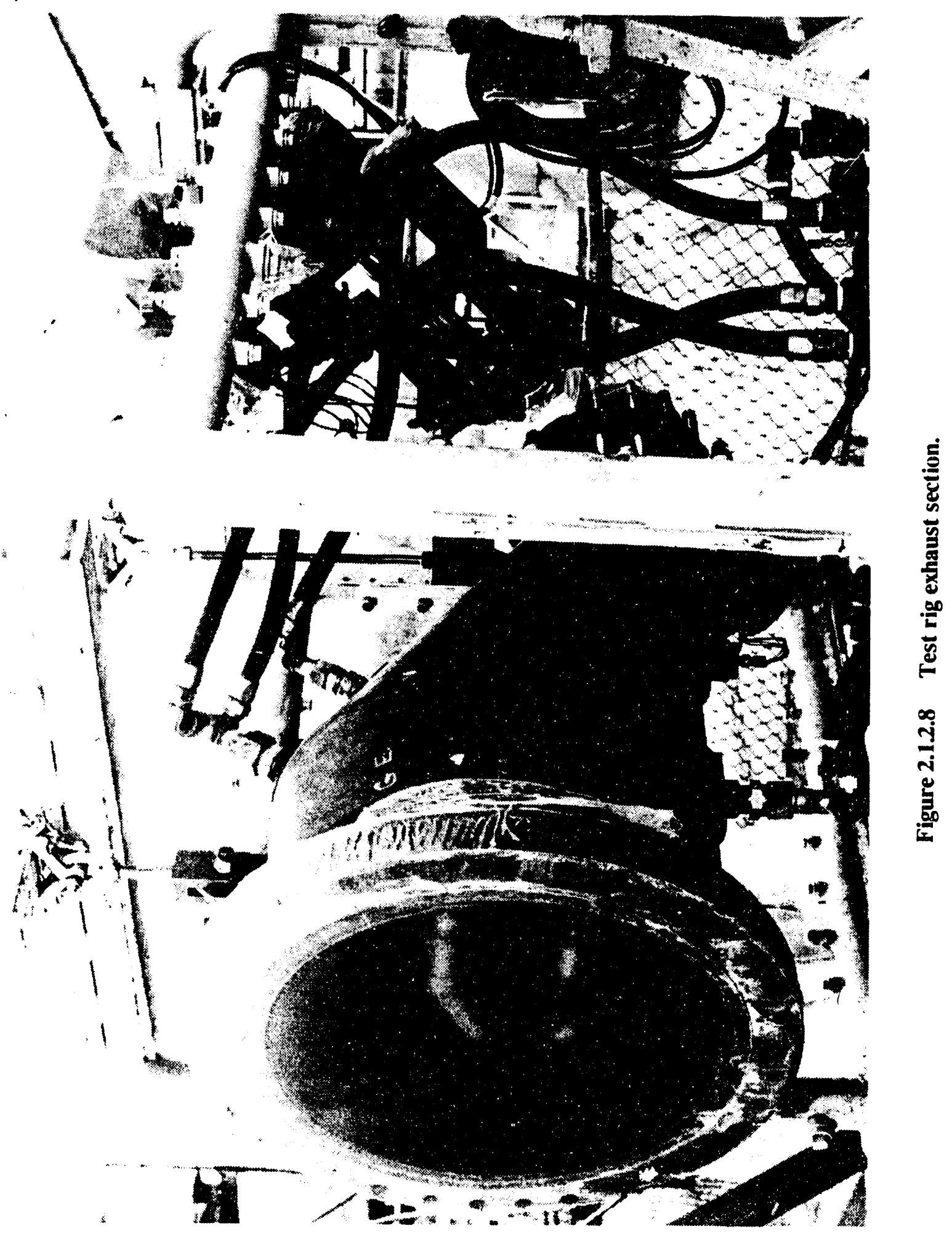


Table 2.12.1

GEAE Advanced Combustion Laboratories Nominal Capabilities

Max Air Flow

Max Air Flow

Max Inlet Air Temperature

Air Inlet Temperature

Exit Temperature
$5 \mathrm{lb} / \mathrm{s} @ 100$ psig

3 lb/s@300 psig

1000\% @ 100 psig

Ambient to $1000^{\circ} \mathrm{F}$

Ambient to $300^{\circ} \mathrm{F}$

Table 2.1.2.2

$140^{\circ}$ Sector Combustor Test Conditions

LM500 Engine Sector Combustor

$\mathrm{P}_{3}$ (psia)

$\mathrm{T}_{3}\left({ }^{\circ} \mathrm{F}\right)$

$\mathrm{W}_{\text {comb }}$ (pps)

$\mathrm{W}_{\text {arm air }}$ (pps)

Fuel Flow (pps)

$\mathrm{T}_{4}\left({ }^{\circ} \mathrm{F}\right)$
206.0

760.0

10.7

1.1

0.78

2200
58.8

760.0

3.1

0.3

0.22

2200 
Baseline testing would be first conducted to verify the combustion liner cooling flows and overall pressure drop and airflow distribution. This would be conducted first on fuel oil and then at a minimum oil/CWM Btu ratio. Once effective cooling air distribution has been established, $100 \% \mathrm{CWM}$ operation would begin with the subsequent evaluation of combustion parameters such as efficiency, gaseous emissions and stability. Depending on the results of these tests, various modifications will be implemented to optimize performance.

21.2.4.2 One-Nozzle Segment Combustor. During the procurement of the annular sector combustor, preliminary studies were conducted in a one-cup segment combustor. These tests were conducted at the laboratory facilities located at GE-CRD in Schenectady, NY. This one-nozzle sector combustor was used for preliminary screening tests to evaluate the aerodynamic characteristics and operating limits of the annular sector combustor design.

For the one-nozzle segment combustor, a circular constant cross-section combustor was designed. Although circular, the combustor design uses the basic mechanical features of the annular combustor. The dome incorporates an impingement cooled splashplate with an axial flow swirler. The swirler is identical to that of the annular sector combustor. Dome airflow is fed by total system pressure drop. The liner walls are comprised of slot cooled segments with an outer impingement shield. Both are designed to take one-half the system pressure drop. As with the annular combustor, primary and secondary dilution are designed to be supplied by either full or one-half system pressure drop.

Because the surface area of this circular combustor is approximately $40 \%$ greater than one eighteenth of the annular design, more cooling air would be required to maintain the same design metal temperature as the annular combustor design. However, in order to maintain the same combustor stoichiometry, the cooling airflow was maintained at the same level as the annular combustor design at the expense of metal temperature increase. The calculated increase in liner temperature relative to the annular combustor is $75^{\circ} \mathrm{F}$.

One other change relative to the annular combustor is that four holes were used for primary dilution in the one nozzle segment combustor. This was to maintain flow symmetry. In the annular combustor, two holes per swirl cup are used.

The one nozzle segment combustor test rig is shown in Figures 2.1.2.9 and 2.1.2.10. The combustor is concentrically mounted in a section of $10 \mathrm{in}$. diameter pipe. Combustion air enters through an annular passage around the pipe. The fuel nozzle, identical to the annular sector combustor nozzle, mounts through a flange on the forward end of the rig.

Combustor exit gases are ducted through a closed circuit cooled instrumentation section. Mounted in this, approximately 8 in. downstream of the combustor exit, are platinum/rhodium thermocouples. A highly quenched probe is installed farther downstream to collect solid particles of combustion. Gaseous emissions sampling probes are also located 


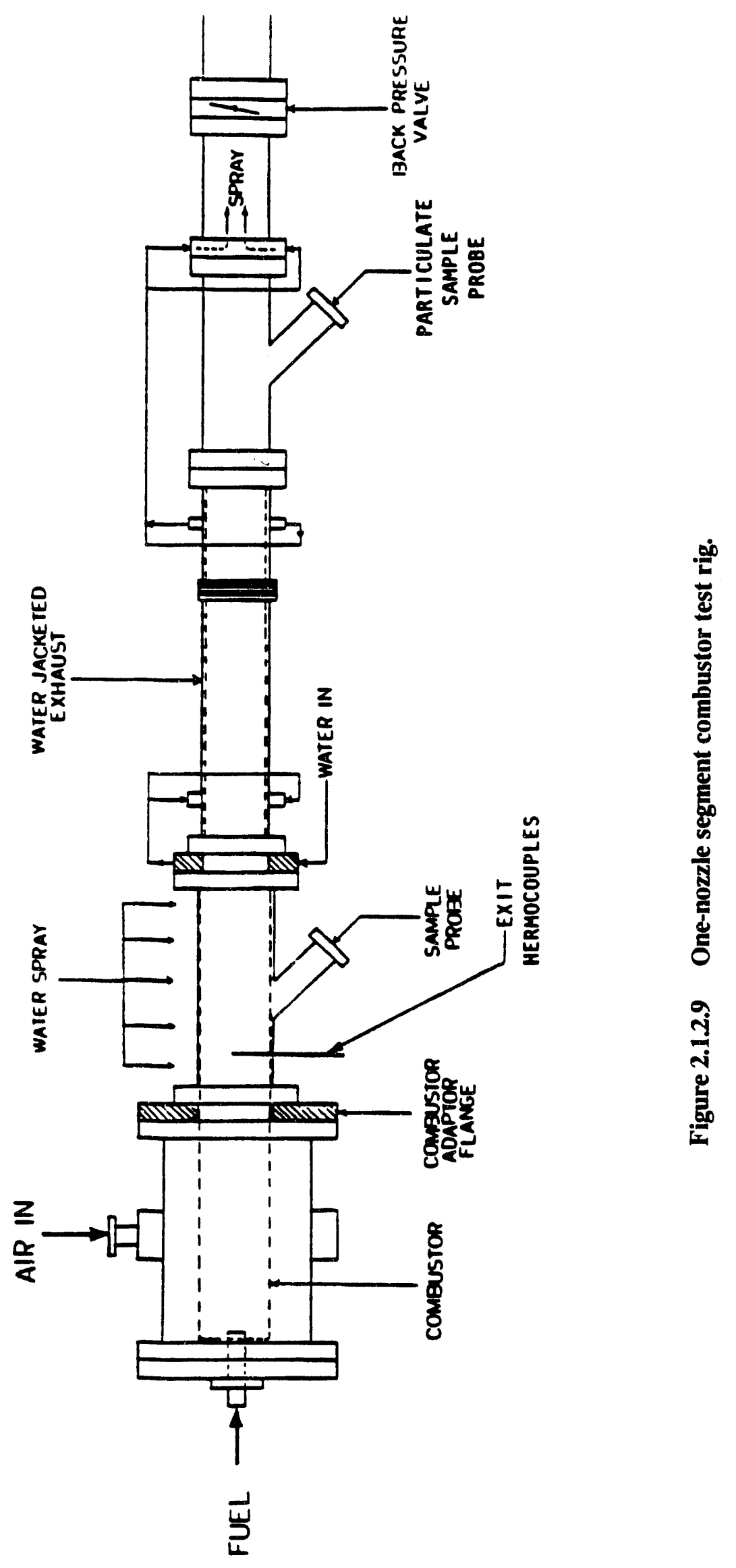




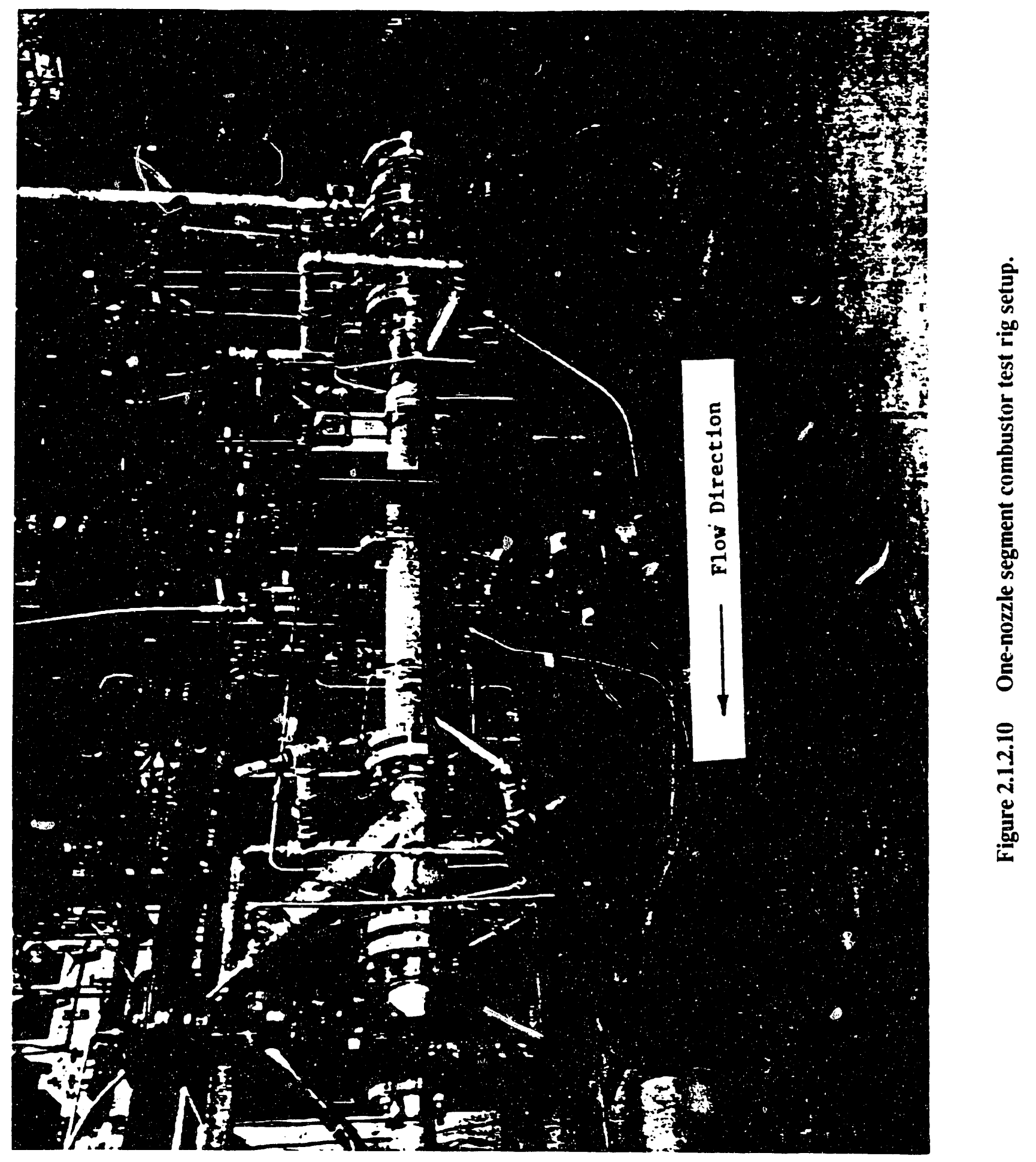


at this position. Following this instrumentation section is a water quench zone just upstream of a back-pressure valve.

The advantage in using a backpressure valve is that combustor airflow (velocity) can be varied independently of combustor pressure. This allows parametric evaluation of combustor residence times and system pressure drop.

Real time data analysis of combustor aero properties including pressures, temperatures and flows are accomplished using a computerized data acquisition system. Gaseous emissions including $\mathrm{NO} / \mathrm{NO}_{2}, \mathrm{CO}, \mathrm{UHC}$ and $\mathrm{O}_{2}$ are monitored continuously and recorded by the same data acquisition system. Solid products of combustion are collected over a prescribed time period at steady state test conditions and analyzed later.

The fuel delivery system consists of an agitated storage tank, MicroMotion flow meter and high bypass progressive cavity pump.

The one nozzle segment combustor schematic and hardware photos are shown in Figures 2.1.2.11 through 2.1.2.16. Figure 2.1.2.11 shows the schematic of the combustor that uses a liner and an impingement shield for improved/controlled backside liner cooling. This is the same as for the annular combustor. Figure 2.1.2.12 shows the combustor liner. Figure 2.1.2.13 shows the assembly. The impingement cooling holes can be seen in this photo. Figure 2.1.2.14 shows the assembly viewed from the dome end. The swirler vanes can be seen in this photo. Figures 2.1.2.15 and 2.1.2.16 show the Parker-Hannefin and GE CWM fuel nozzles. Functionally, these are identical to the designs planned for the annular sector combustor.

\subsection{One-Nozzle Segment Combustor Test Results. The one nozzle segment} combustor test program demonstrated that the design concept incorporated into the annular combustor could meet the performance goals set forth by DOE-METC. These goals included operation of the combustor on $100 \%$ CWM fuel for $10 \mathrm{hr}$ with carbon burnout greater than $90 \%$ and $\mathrm{NO}_{x}$ emission less than 230 ppmvd.

All these criteria were exceeded. The one-nozzle segment combustor was operated for over $18 \mathrm{hr}, 10$ of which were continuous at over $99 \%$ carbon burnout with $\mathrm{NO}_{x}$ levels below 100 ppmvd.

Overall program assessment parameters are included in Table 2.1.2.3. The combustor performance items have been addressed in the one nozzle segment combustor testing. The remainder would be accomplished during the annular sector combustor effort and the technology support work discussed separately.

The primary objective of the one-nozzle segment combustor baseline testing was to assess the aerodynamic performance of the annular combustor and locate where cooling air concen- 


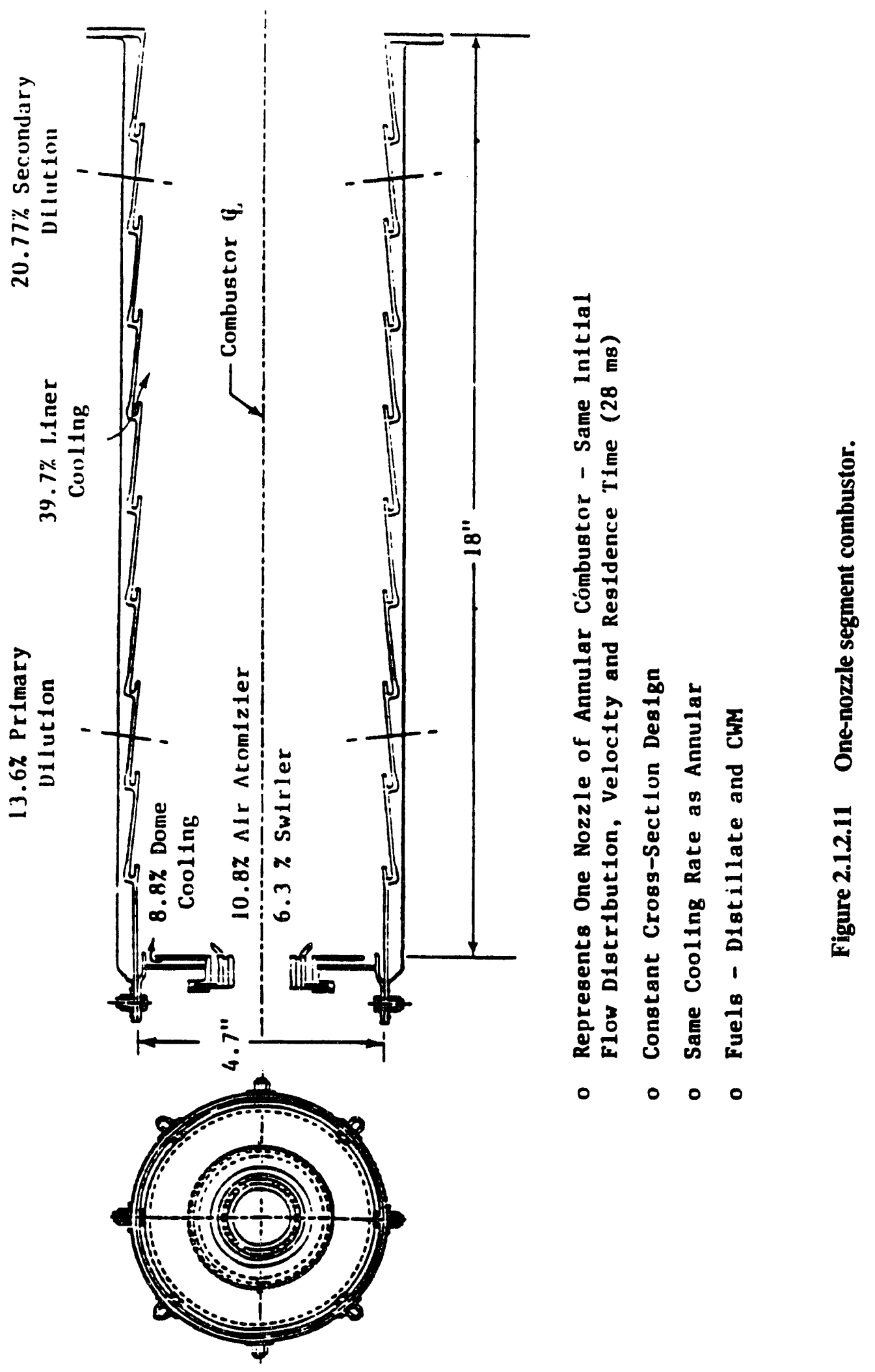




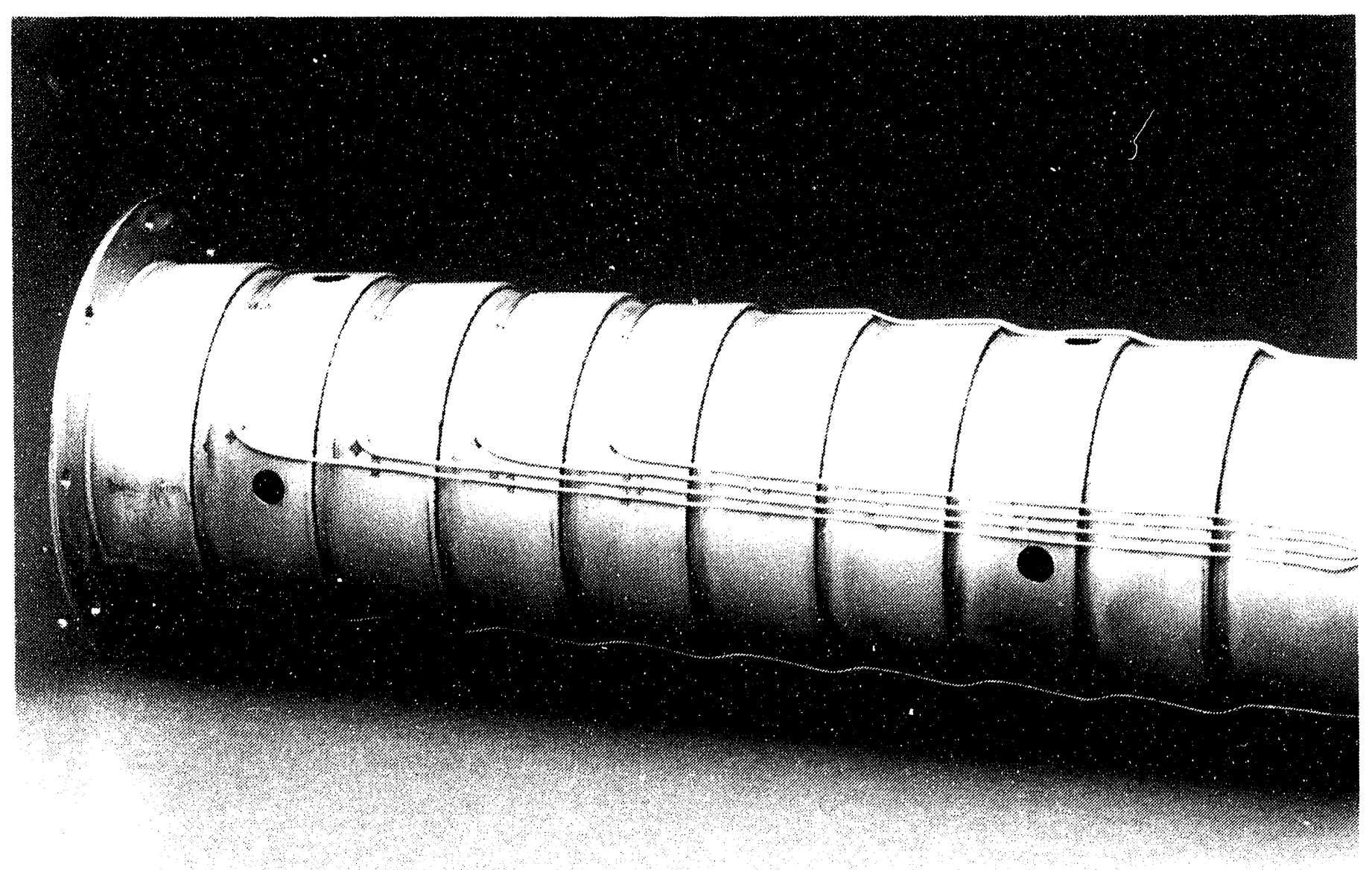

Figure 2.1.2.12 One-nozzle segment combustor liner. 


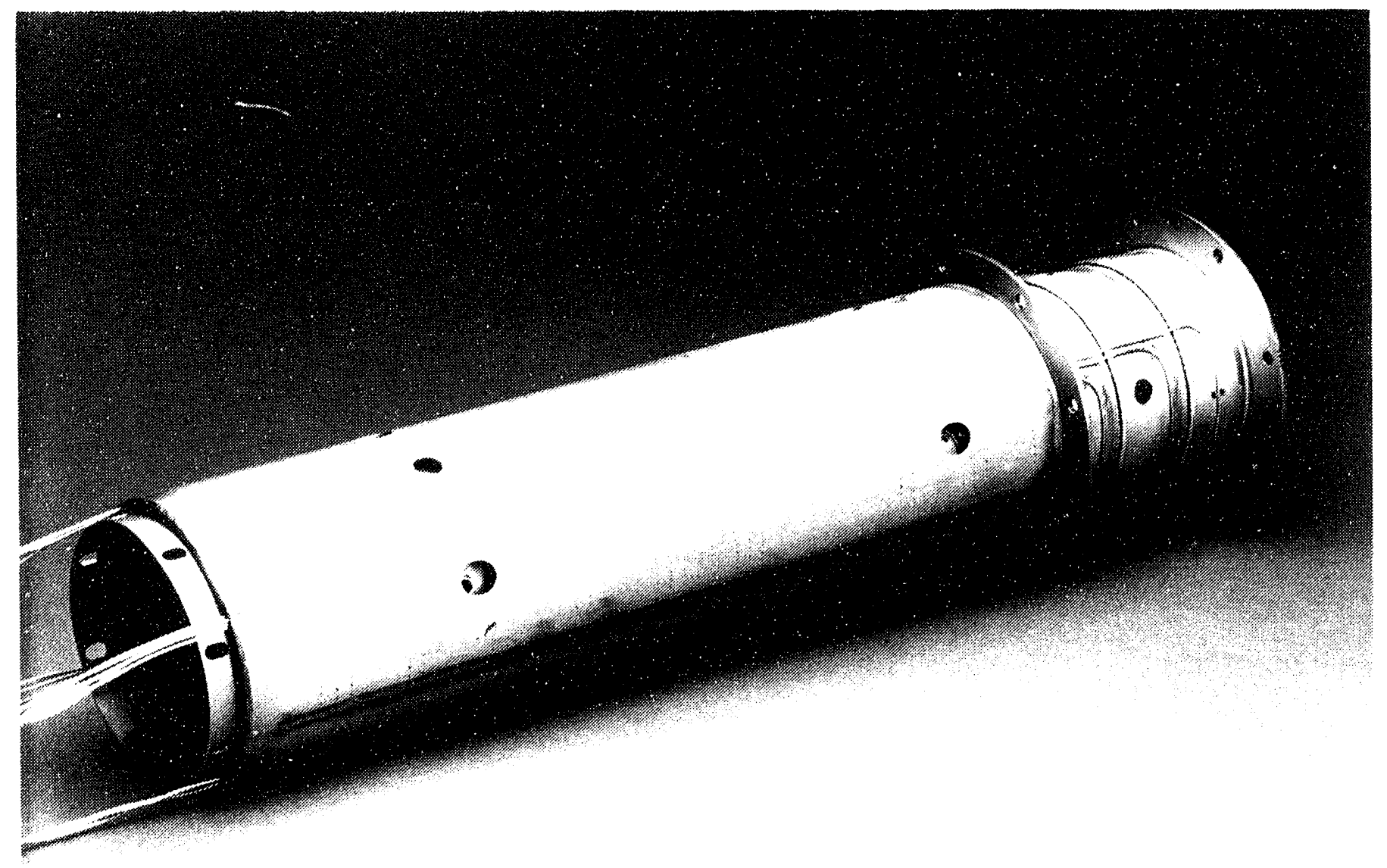

Figure 2.1.2.13 One-nozzle segment combustor assembly. 


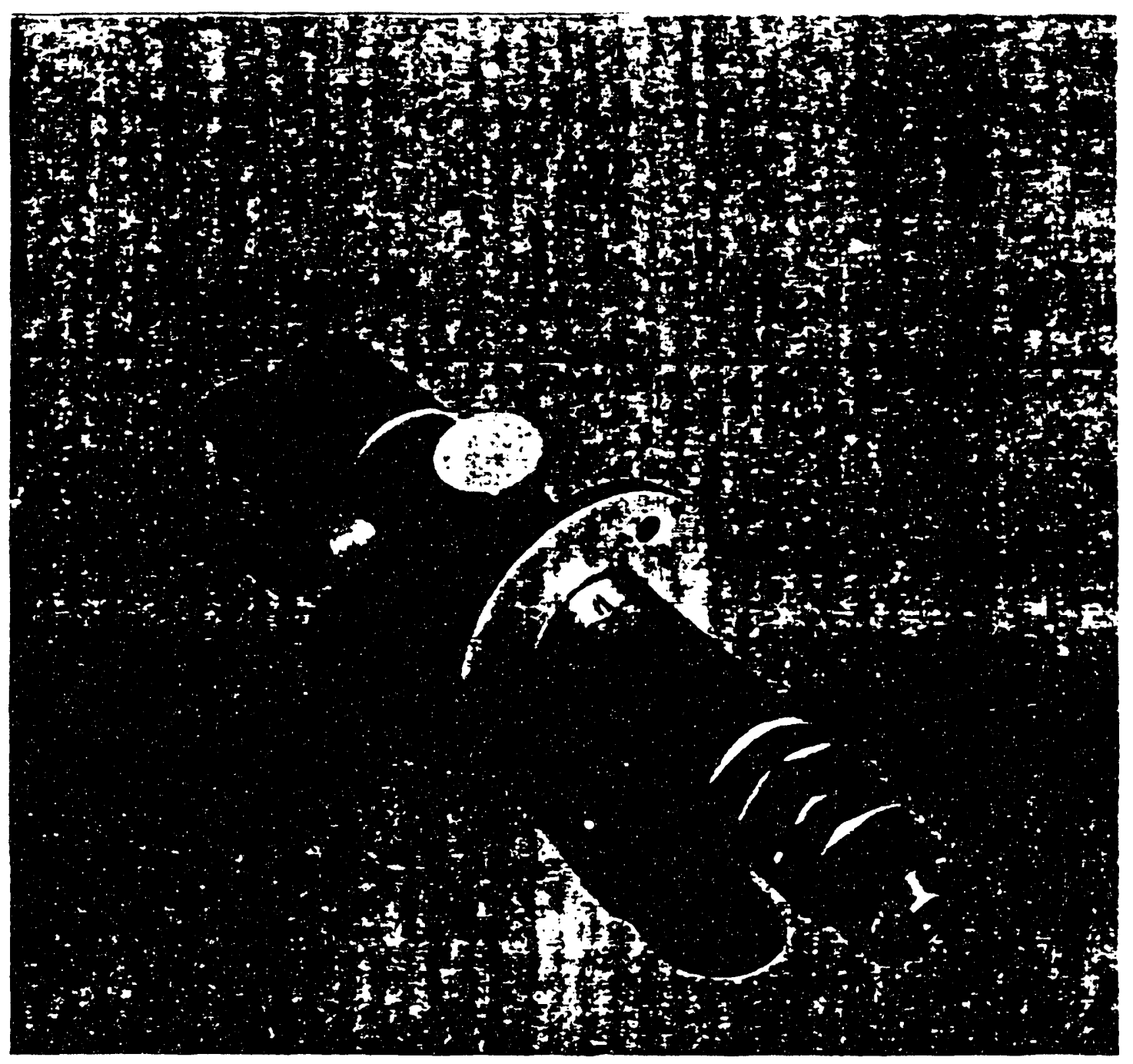

Figure 2.1.2.15 Parker-Haniffin CWM Fuel Nozzle. 


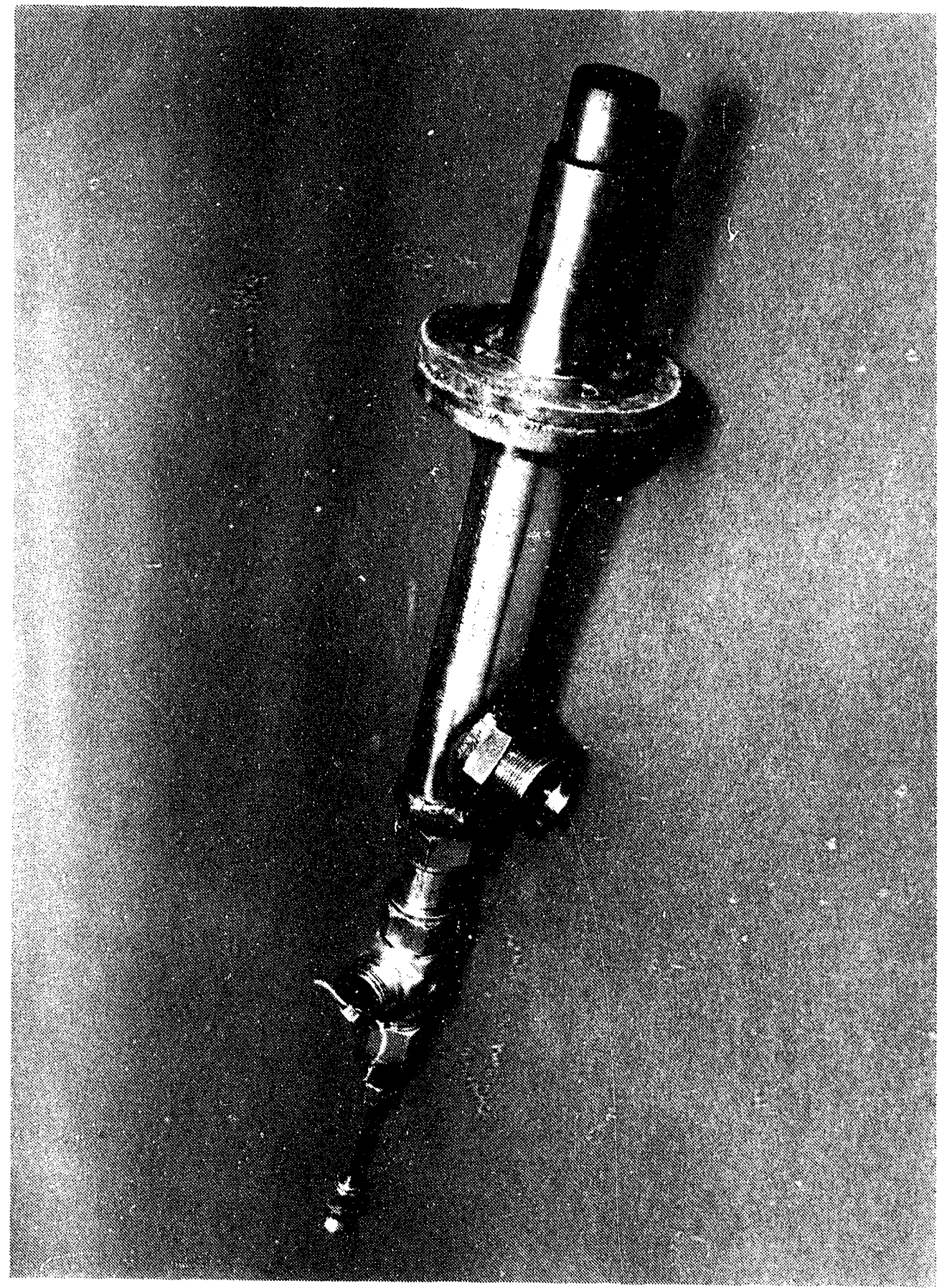

ปัป

בั: 


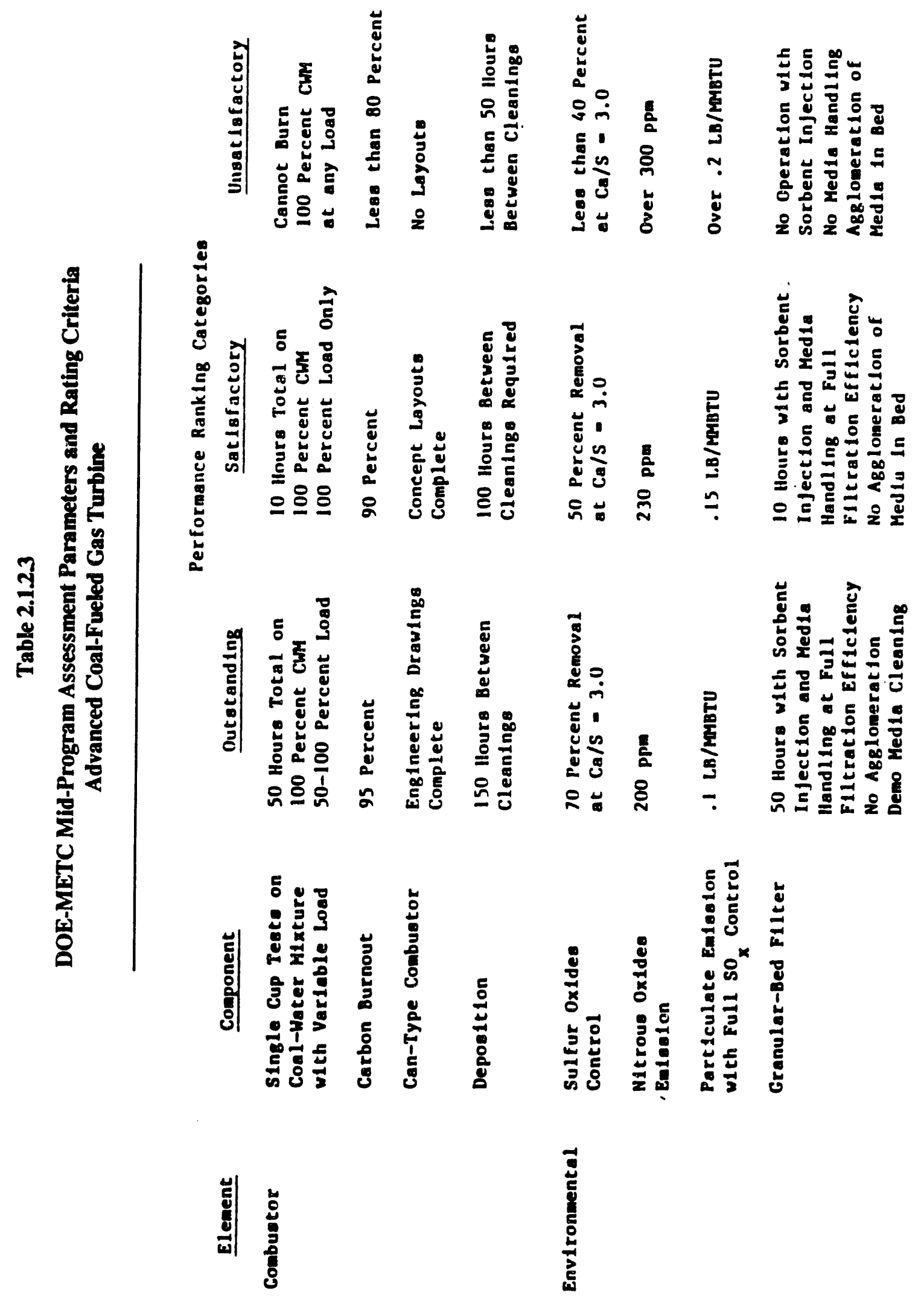


tration was required. Baseline testing was conducted with both the primary and secondary dilution holes fed with total system pressure drop and using the GE-designed fuel nozzle. This nozzle configuration had an included CWM spray angle of approximately $45^{\circ}$. The combustor was first run up to ten atmospheres pressure on oil fuel only. Combustor pressure drop and metal temperature were monitored. At an average combustor exit temperature of $1700^{\circ} \mathrm{F}$, maximum liner metal temperatures reached $1670^{\circ} \mathrm{F}$. Total combustor pressure drop $(\Delta P / P)$ was $2.15 \%$. The combustor was transferred over to approximately $50 \% \mathrm{CWM}$ at a combustor exit of $1707^{\circ} \mathrm{F}$. Maximum liner metal temperatures were $1698^{\circ} \mathrm{F}$ with the same low-pressure drop. These high-metal temperatures precluded any further testing above a combustor exit of $1700^{\circ} \mathrm{F}$.

The combustor was removed from the test rig and modifications made to increase liner pressure drop and improve cooling. Mod I, as this configuration has been designated, was altered by plugging one-third of the downstream impingement shield cooling holes, feeding primary dilution by one-half the system pressure drop, that is, placing dilution holes underneath the impingement shield, and reducing combustion liner slot cooling by ten percent in the aft end.

Testing was resumed using the GE-nozzle with a significant improvement in liner metal temperatures resulting from the changes. Combustor exit temperatures were raised to $2047^{\circ} \mathrm{F}$ on $100 \%$ oil where maximum liner metal temperatures were $1466^{\circ} \mathrm{F}$. However, combustion system pressure drop $(2.77 \%)$ was still below the design level of $5.0 \%$.

The Parker-Hannefin fuel nozzle with the $70^{\circ}$ included spray angle was tested with MOD I at $10 \mathrm{~atm}$. The system was operated down to $30 \%$ oil/CWM Btu ratio at a combustor exit temperature of $1600^{\circ} \mathrm{F}$. Liner metal temperatures were within $1650^{\circ} \mathrm{F}$, but still considered high. The wide Parker-Hannefin spray angle was suspected as being the cause along with the low-system pressure drop. Parker-Hannefin was contacted and agreed to modify this nozzle to reduce the included spray angle to $45^{\circ}$.

Following these sets of testing, the combustion system was disassembled and the impingement shield and liner were cold flow tested. Data from these tests indicated that the coefficient of discharge for the liner and impingement shield cooling holes was 0.92 as opposed to 0.65 used in the design calculations. The high $C_{D}$ of these holes accounts for the low pressure-drop and is attributed to rounding of the hole entrance during machining.

Computer flow models were run with the cold-flow data to determine the actual flow splits of the total combustion system, dome, impingement shield and liner together. Results of the modeling indicated that the flow distribution deviated from the original design. To avoid fabricating a new liner and impingement shield, a decision was made to redirect airflow commensurate with the original design and allow the system to operate at a lower-pressure drop. Table 2.1.2.4 compares the baseline and MOD I configurations with the final MOD II revi- 
sion.

MOD II was installed in the test rig and tested with the GE-nozzle and oil fuel. Metal temperatures were well within limits at a combustor exit of $1950^{\circ} \mathrm{F}$ at $9.2 \mathrm{~atm}$. Coal/water mixture testing was attempted and the oil/CWM Btu ratio lowered to about $10 \%$. The combustor operated satisfactorily; however, facilities problems such as poor oil flow control prevented extended operation and no significant data was collected.

In an attempt to assess the effect of lengthening the primary zone, MOD III was initiated. Primary dilution holes were moved 1.8 in. downstream and resized to accommodate the same flow, but fed through six holes instead of four holes. MOD III was tested again using the GE-nozzle on $100 \%$ oil and at an oil/CWM Btu ratio of $20 \%$. Combustion performance was marginal with no improvement over MOD II. The Parker- Hannefin nozzle with the $70^{\circ}$ included spray angle was tried with this configuration as well. Performance of the Parker-Hannefin- nozzle with oil was on a par with the GE-nozzle, but with CWM fuel, performance was not as good as with the GE-nozzle. The cause for this phenomena is thought to be the wide spray angle of the Parker- Hannefin nozzle interacting insufficiently with the liner primary dilution holes.

The preferred MOD II was again tested with the GE-nozzle with facilities modifications to improve fuel oil and CWM fuel flow control. At $13.0 \mathrm{~atm}$, the combustor was brought to a combustor exit temperature of $2137^{\circ} \mathrm{F}$ on oil and gradually transferred to $100 \% \mathrm{CWM}$. Combustion was stable with maximum liner metal temperatures of $1444^{\circ} \mathrm{F}$. The system was operated approximately $90 \mathrm{~min}$ continuously on $100 \% \mathrm{CWM}$. The rig was shut down only because the supply of CWM was exhausted. Over the $90 \mathrm{~min}$ period, fuel-air ratio was lowered approximately $25 \%$; again, with no loss in combustion stability or system distress.

Upon completion of the $90 \mathrm{~min}$ run on $100 \%$ CWM, the test rig was disassembled for inspection. To this point, the combustor had operated almost continuously for about $5 \mathrm{hr}$ on at least $90 \%$ or more CWM with $90 \mathrm{~min}$ at $100 \% \mathrm{CWM}$. On removal, the liner interior showed no signs of deposition or distress. Surfaces were darkened by a light coating of soot.

To assess the effect of a ceramic lined combustor, thermal barrier coating (TBC) was applied to the combustor prior to the $100 \%$ CWM 10-hr run. The TBC material applied was a nickel-chromium-aluminum ytrium composite approximately $0.015^{n}$ thick with a surface roughness of 350 to 400 micro inches. The interior walls of the liner were coated as well as the dome splashplate.

This test rig was reassembled with the GE-nozzle and the 10-hr test conducted. During a 10-1/2 hr period, the combustor was operated continuously on $100 \% \mathrm{CWM}$. A number of parametric test points were run over this period to assess combustor performance and map operability. Parameters investigated include fuel-air ratio, combustor residence times and 
Table 2.12.4

One Nozzle Segment Combustor Flow Distribution And Pressure Drop

\begin{tabular}{lrrr}
\hline & Baseline & Mod I & Mod II \\
\hline Pressure Drop (\%) & 2.15 & 2.77 & 4.91 \\
Dome Flow (\%) & 23.45 & 26.59 & 25.89 \\
Primary Dilution Flow (\%) & 13.21 & 13.71 & 13.61 \\
Secondary DilutionFlow(\%) & 18.29 & 20.75 & 20.77 \\
Cooling Flow (\%) & 45.05 & 38.95 & 39.73
\end{tabular}


chamber pressure effects. Fuel-air ratios were varied; adjusting fuel flows holding air flow constant. Combustor residence times were changed approximately $+20 \%$ by varying airflow holding chamber pressure constant. Chamber pressure effects were achieved by holding system flow function $(W \sqrt{T / P})$ constant.

Table 2.1.2.5 outlines the significant test points run and a summary of the basic operating conditions. Figures 2.1.2.17 and 2.1.2.18 show the continuous time log of both $100 \% \mathrm{CWM}$ test runs.

Figure 2.1.2.19 presents the effect of the various combustor modifications on liner metal temperatures. Clearly, MOD II was very effective in redistributing liner cooling air to the hot sections of the liner and making the liner metal temperatures more uniform. TBC had a significant effect on reducing liner-metal temperatures. Liner interior TBC surface temperatures are estimated to be approximately $100^{\circ} \mathrm{F}$ hotter than the indicated metal temperatures.

Figure 2.1.2.20 illustrates the impact of combustor residence times on carbon monoxide oxidation. As expected, with increasing combustor velocities (and the attendant decrease in residence times), carbon monoxide levels increase although absolute levels are within acceptable limits. Carbon monoxide data shown in Figure 2.1.2.21 is about one-half the values shown in Figure 2.1.2.20 at the same fuel-air ratio. These data were taken approximately $4 \mathrm{hr}$ apart with an instrument recalibration in between. Instrument drift is suspected to be the cause of the difference; however, the overall levels are very low and believed to be representative.

Table 2.1.2.6 lists the particulate sample analysis collected during the 90-min and 10-1/2hr test runs. Figure 2.1.2.22 shows the effect of fuel-air ratio on combustion burnout. As anticipated from the "CO" results shown in Figure 2.1.2.20, carbon burnout is relatively constant over this same range.

Upon completion of the 10-1/2-hr run, the combustor was removed from the test rig and inspected. The interior of the liner was found to have a significant amount of deposition. Deposits in general were about 0.10 in. thick throughout, but showed no signs of plugging cooling or dilution holes. Deposition material upstream of the primary dilution holes was black and shiny in nature, while further downstream, the deposits were brown and somewhat coarse.

The only difference between the hardware configurations during the 90 -min $100 \% \mathrm{CWM}$ test (when no deposition was observed) and the 10-1/2-hr test is the application of thermal barrier coating on the latter. Figures 2.1.2.18 and 2.1.2.23 present the temperature history of the 10-1/2-hr test run. These curves show that during the first $5 \mathrm{hr}$ of operation with nearly constant combustor exit temperature (Type B thermocouple avg.), combustor average metal temperature was steadily dropping, which indicates steady liner deposition. At about $5 \mathrm{hr}$ into 


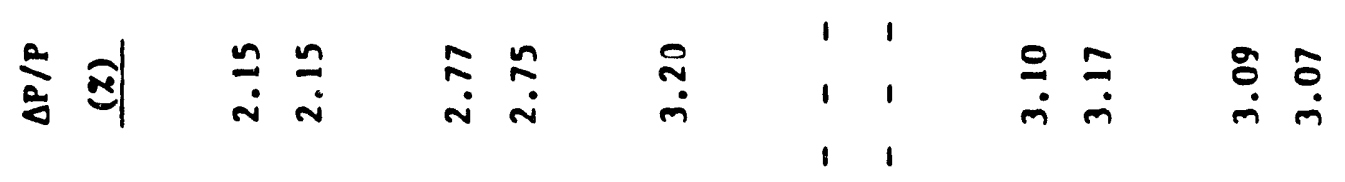

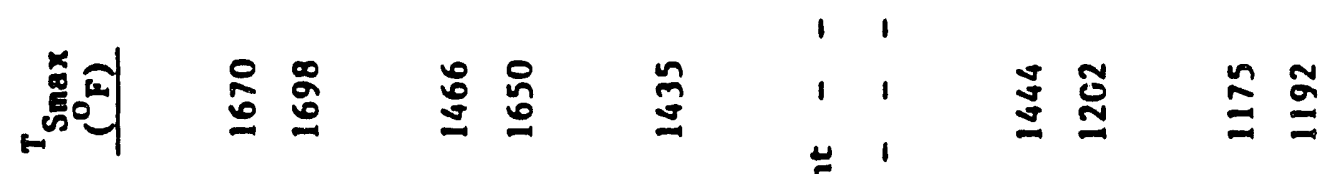

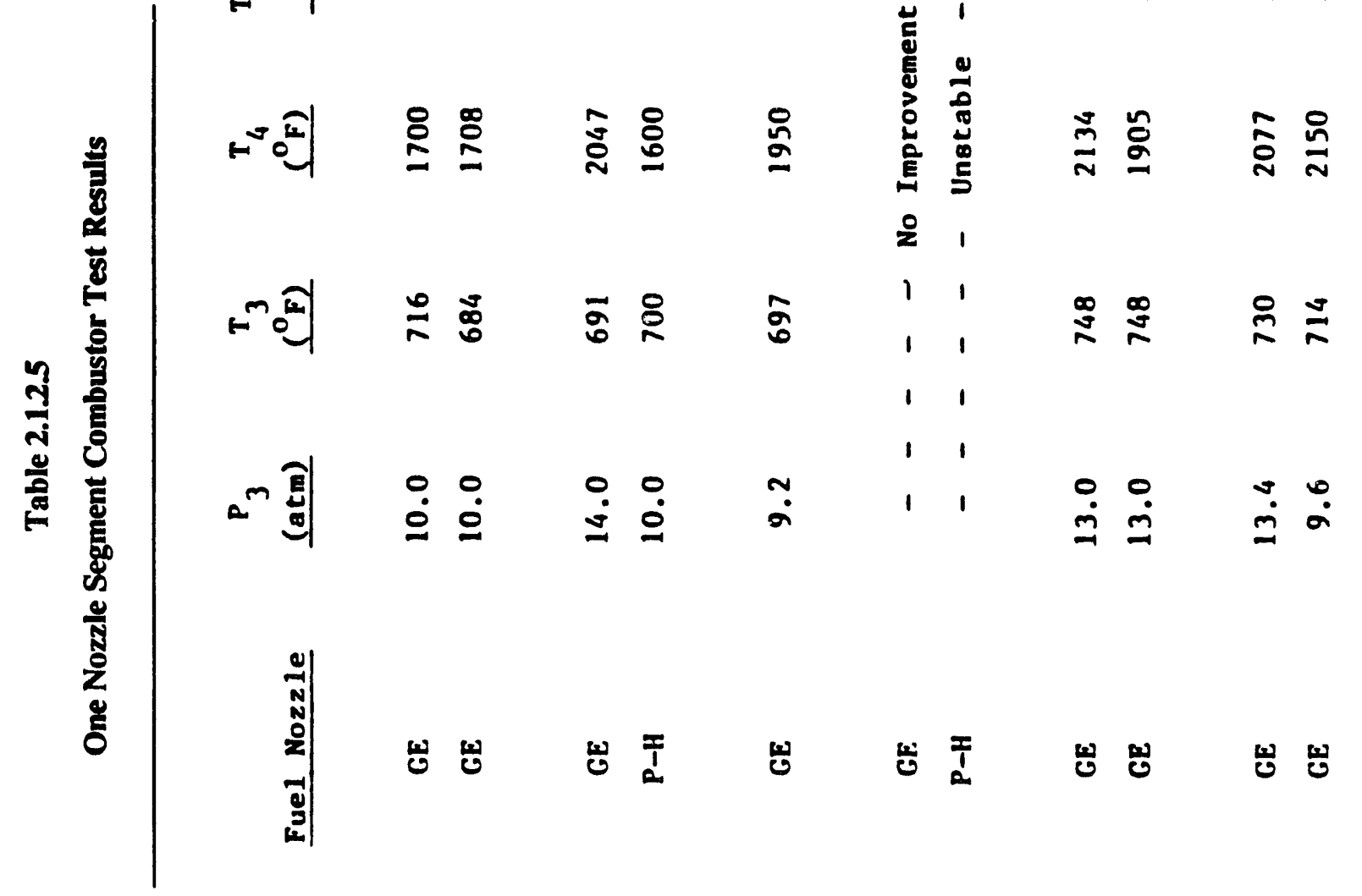

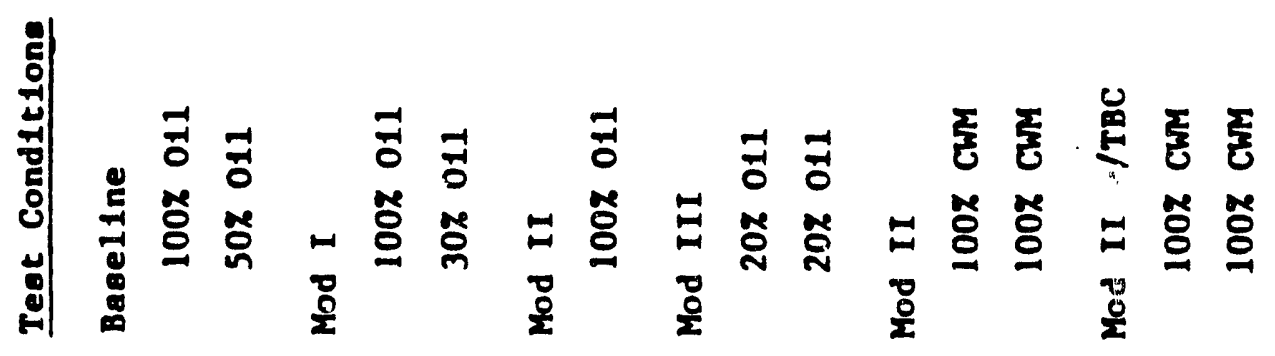




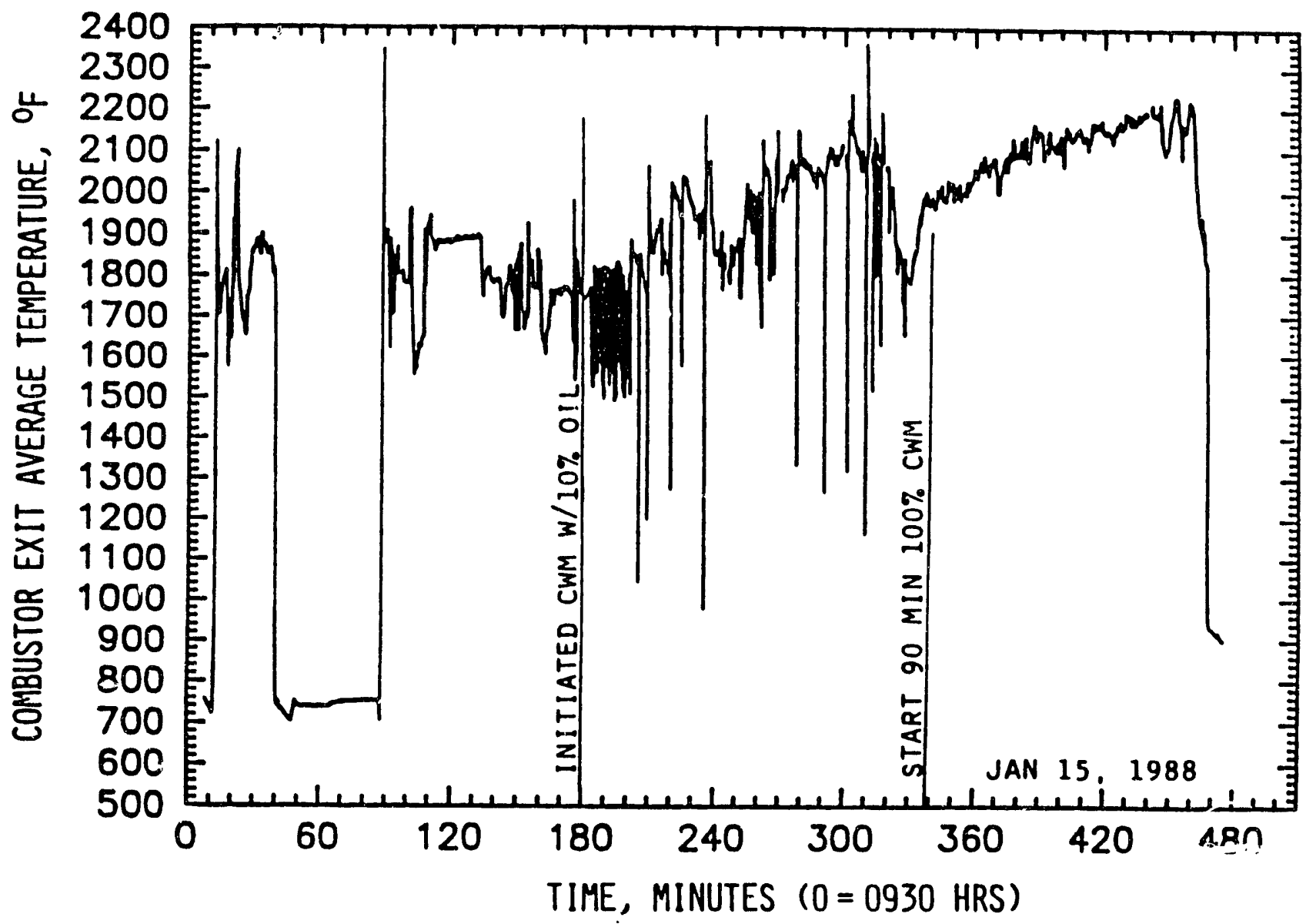

Figure 2.1.2.17 One-nozzle segment combustor fired test. 


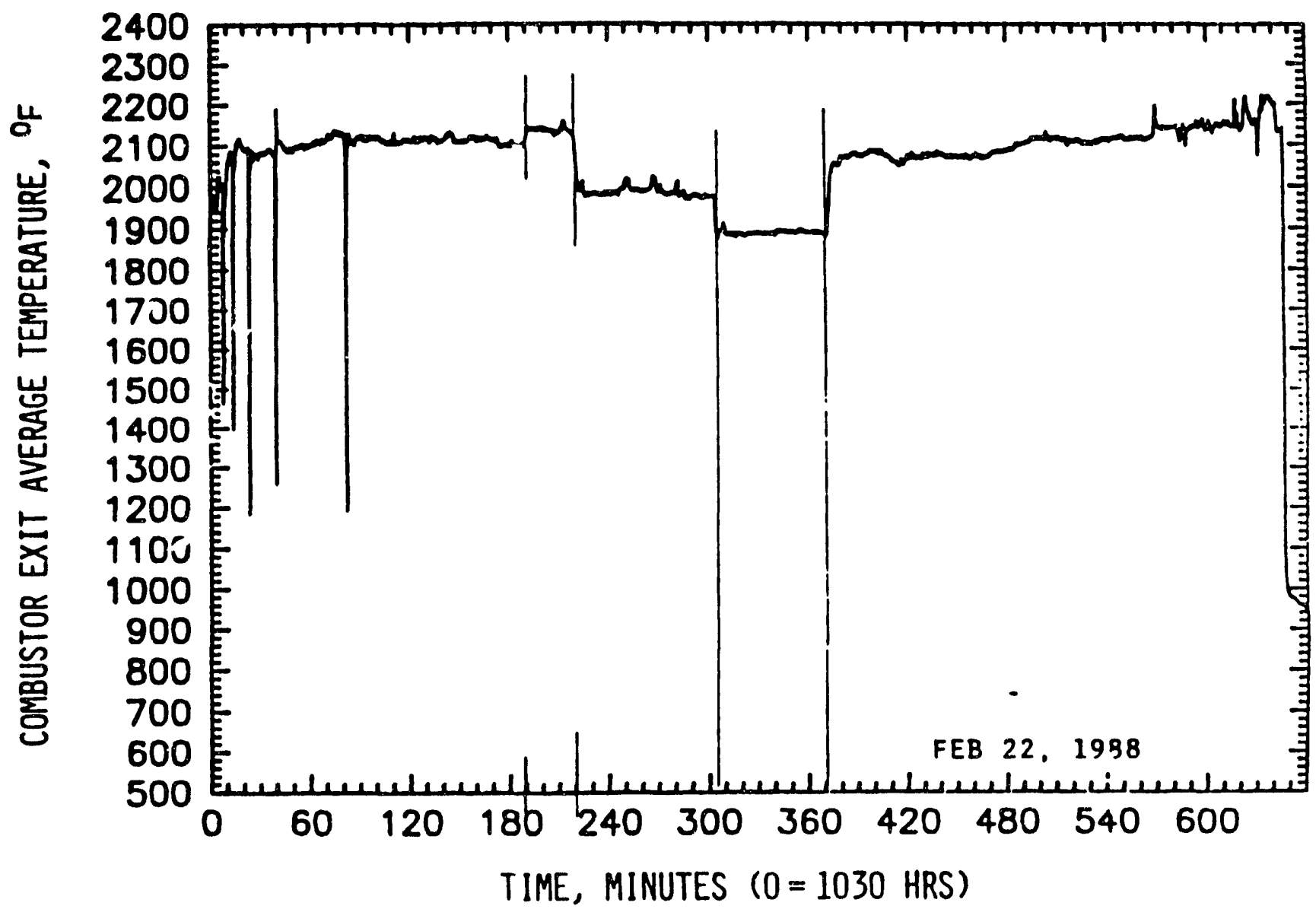

Figure 2.1.2.18 One-nozzle segment combustor test, $10 \mathrm{hr}$ zero-oil. 


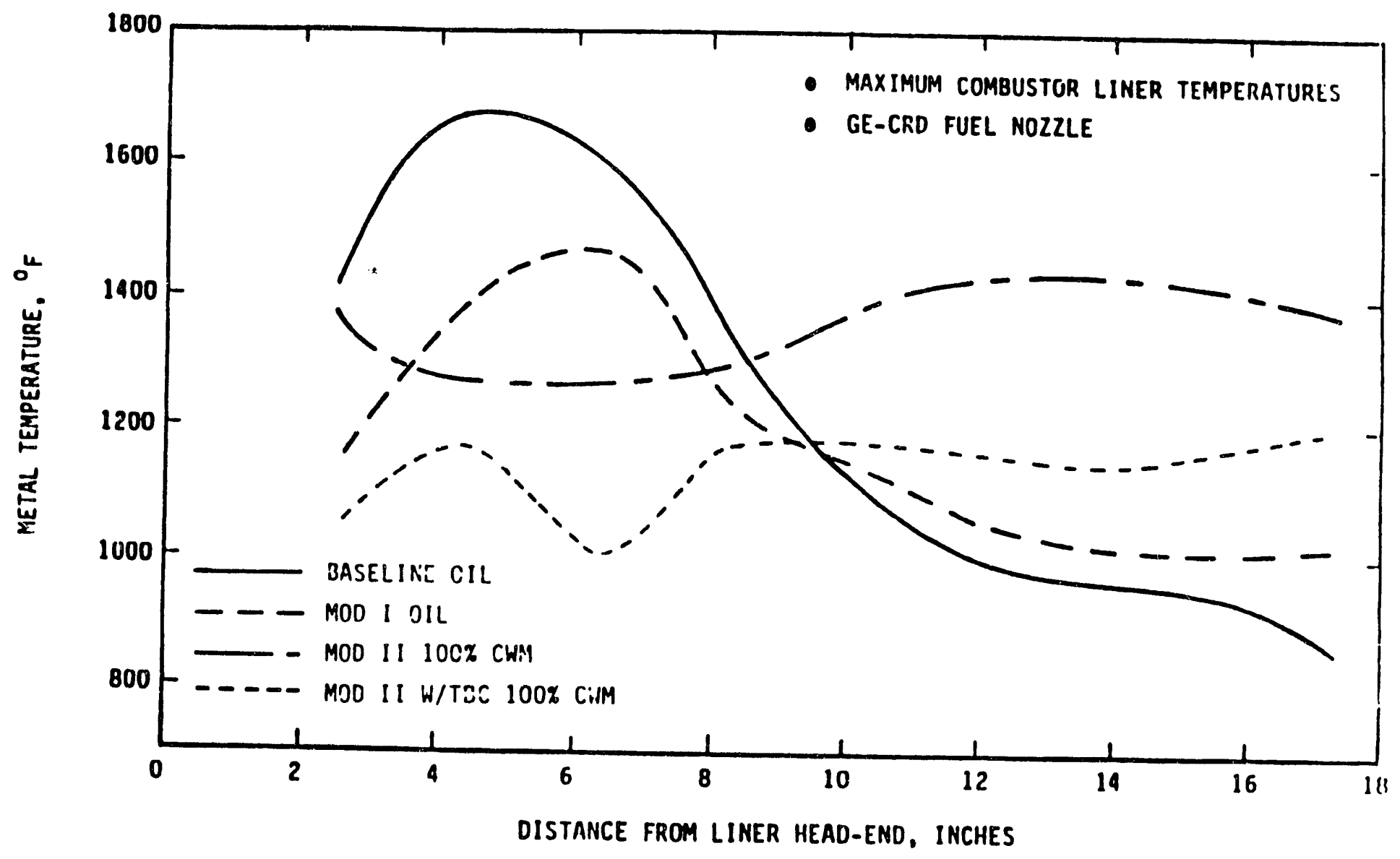

Figure 2.12.19 One-nozzle segment combustor liner temperatures. 


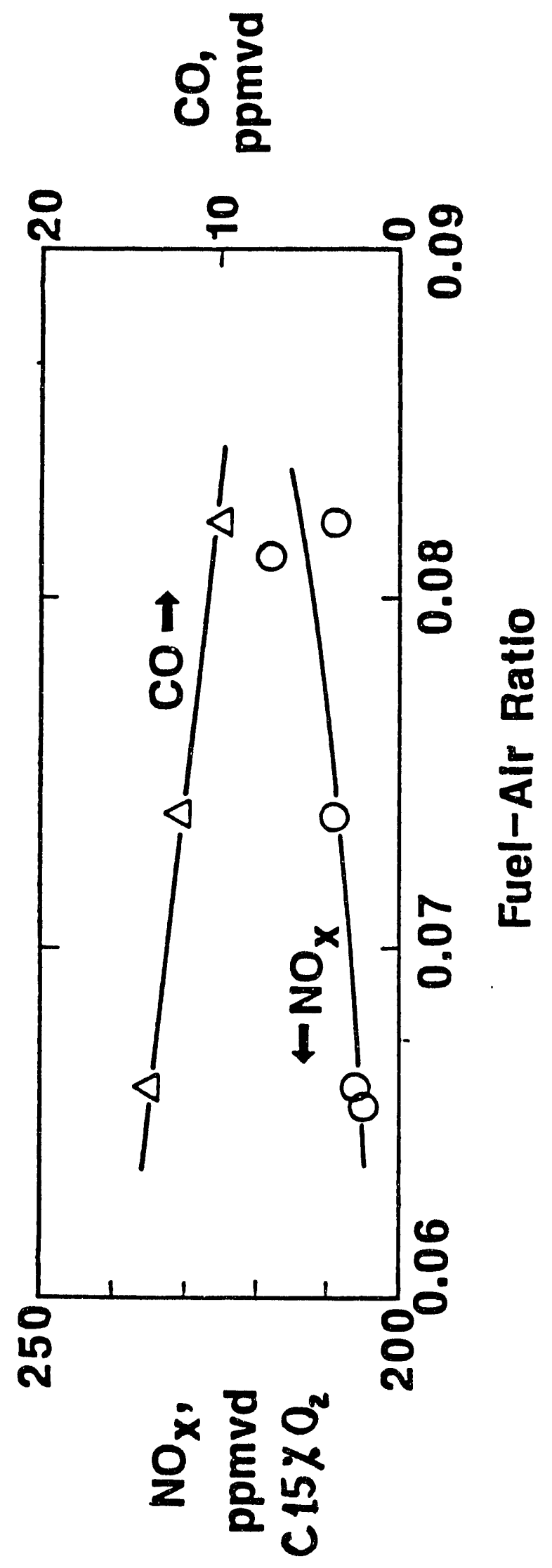

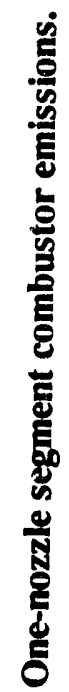

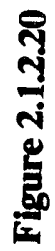




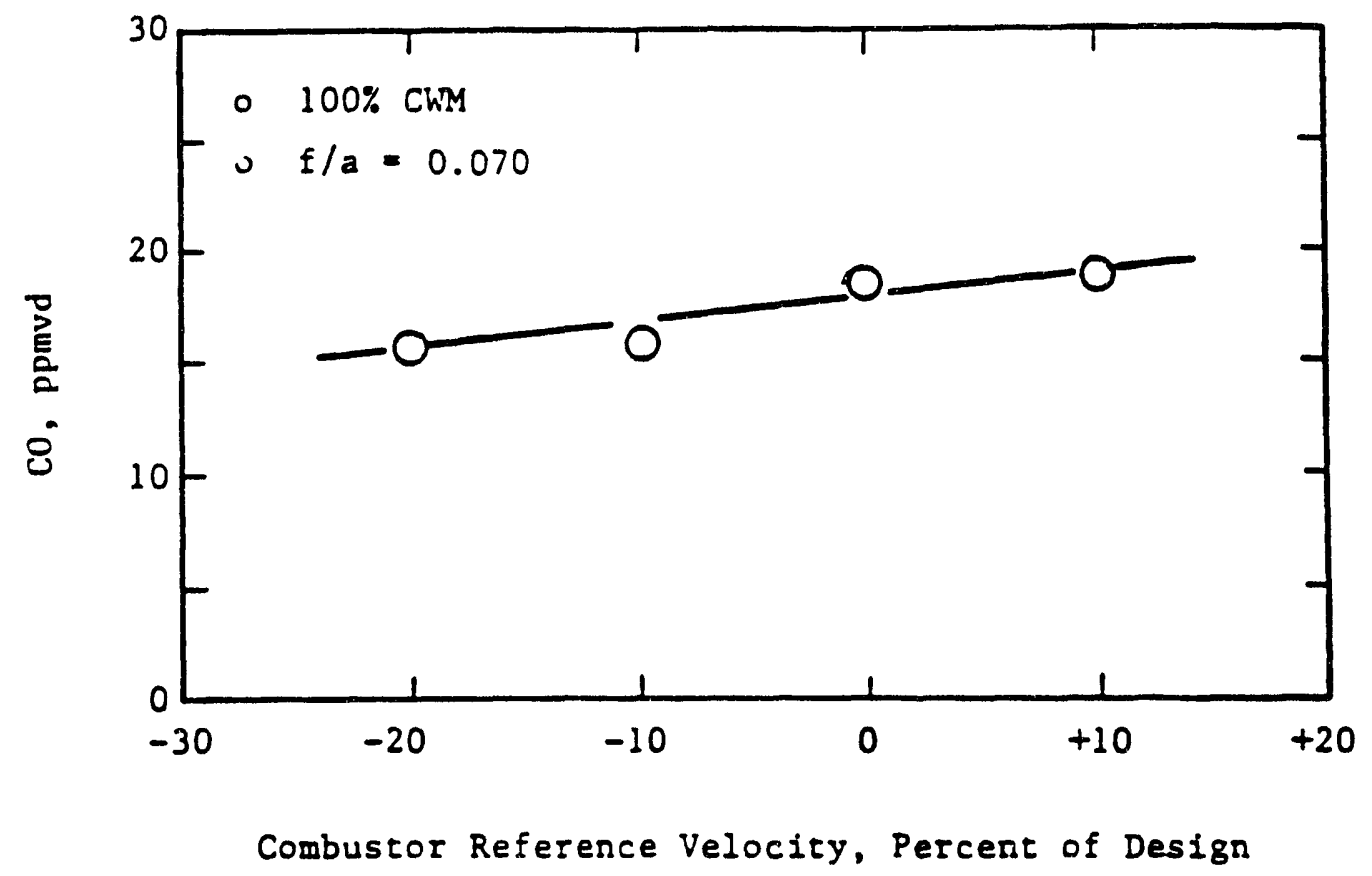

Figure 2.1.2.21 One-nozzle segment combustor velocity effects on carbon monoxide emissions.

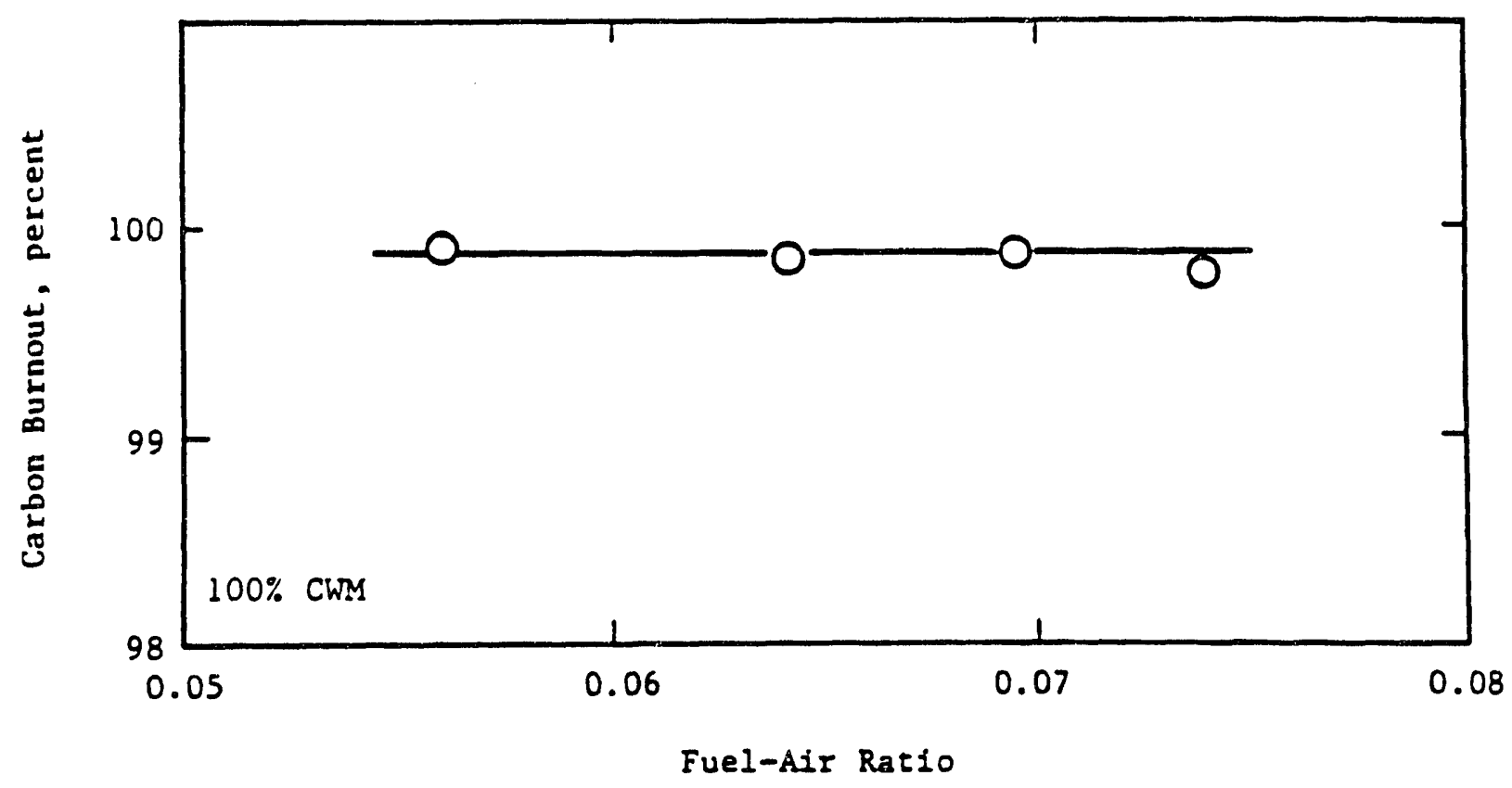

Figure 2.1.2.22 One-nozzle segment combustor fuel-air-ratio effect on carbon burnout. 
Table 2.12.6

Exhaust Particulate Analysis - 100\% CWM

\begin{tabular}{cccccc}
\hline $\begin{array}{c}\text { Combustor } \\
\text { Exit } \\
\left({ }^{\circ} \mathrm{F}\right)\end{array}$ & $\begin{array}{c}\text { Fuel-Air } \\
\text { Ratio }\end{array}$ & $\begin{array}{c}\text { Carbon } \\
(\%)\end{array}$ & $\begin{array}{c}\text { Nitrogen } \\
(\%)\end{array}$ & $\begin{array}{c}\text { Ash } \\
(\%)\end{array}$ & $\begin{array}{c}\text { Carbon } \\
\text { Burnout } \\
(\%)\end{array}$ \\
\hline & & & & & \\
2140 & 0.0746 & 18.23 & 0.35 & 80.40 & 99.78 \\
1998 & 0.0639 & 11.26 & 0.13 & 88.33 & 99.88 \\
1984 & 0.0564 & 9.47 & 0.10 & 90.08 & 99.90 \\
2077 & 0.0692 & 10.99 & 0.16 & 88.33 & 99.88
\end{tabular}

Note: CWM Ash Content $=0.9 \%$ 


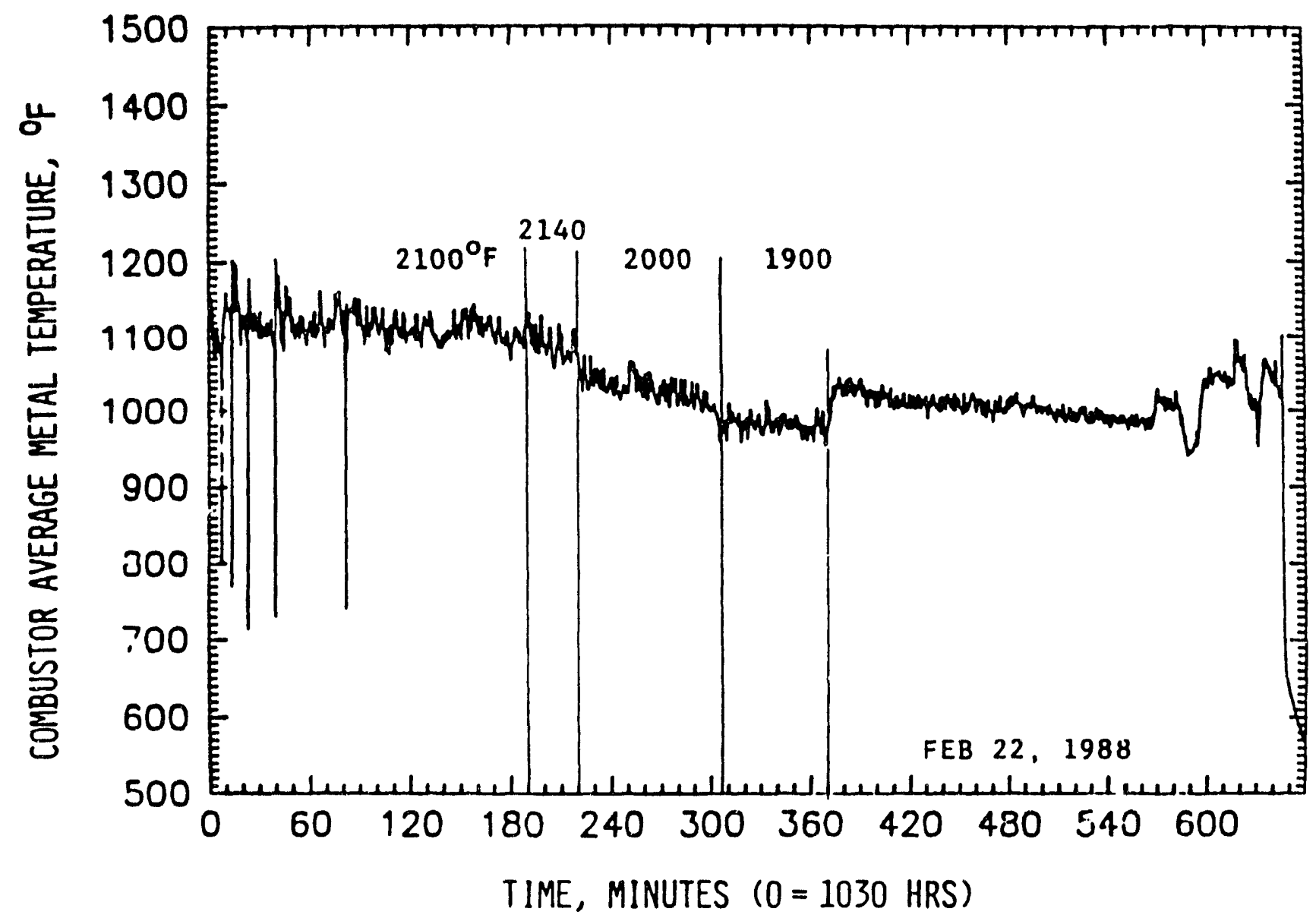

Figure 2.1.2.23 One-nozzle segment combustor test, $10 \mathrm{hr}$ zero-oil. 
the test ( $300 \mathrm{~min}$ on Figure2.1.2.23, metal temperatures began to level out at a relatively constant value, indicating deposition may have reached equilibrium. Figure 2.1.2.17 presents combustor exit temperatures (Type B avg.) for January 15, 1988, when 100\% CWM was tested with the uncoated liner. The plot shows combustor operation for $5 \mathrm{hr}$ on CWM fuel with 90 min at $100 \%$ CWM. As mentioned earlier, this combustor with smooth interior metal surfaces had no deposition at the conclusion of this testing.

Studies have shown a strong correlation between surface roughness and a particles ability to stick to a surface ${ }^{1}$. When particle sizes are smaller than the liner surface disruptions, particles are more likely to adhere to the surface. Surface roughness with the TBC is approximately 350 to $450 \mu$ in. while bare Hastalloy $X$ is about 80 to $90 \mu$ in.. Particles during combustion can be as small as $200 \mu$ in. As more and more particles accumulated on the surface, an insulating layer develops. This insulation effect causes the liner metal temperature to decrease and the deposition surface temperature to increase. This increase in temperature results in increased adhesion between the particles and the ash coated liner wall thus aggravating deposition. Figure 2.1.2.24 is a photograph of the liner interior following the 10-1/2-hr run.

Follow-up testing initiated with the objective to evaluate ash deposition on a clean, smooth (no TBC) combustor liner operating on 100\% CWM. Conditions of the original 10-1/2-hr test run were duplicated and the system p[erated pm 100\% CWM at $14.0 \mathrm{~atm}$ for approximately $5-1 / 2 \mathrm{hr}$. Post-test desassembly and inspection revealed no slag-like deposition and only a slight dusting of brown on the liner interior.

During this test series, $\mathrm{NO}_{x}$ emissions were carefully evaluated using the updated $\mathrm{CRD}$ gaseous emission console. Nitrogen oxide results obtained during the 10-hr test were lower than expected and instrumentation problems were suspected. Data obtained during the most recent run are shown in Figure 2.1.2.20. Carbon monoxide emissions were consistent with earllier estimates and representative of FBN yields reported by other GE studies using hydrocarbon fuels and water injection.

Four atmosphere testing was tried during this period to characterize combustor performance in support of the $140^{\circ}$ sector combustor. Results here were disappointing. Stable combustion was achieved at less than $5 \%$ supplementary oil fuel; however, $0 \%$ oil was achieved for only a few minutes at a time. In earlier testing, the one-nozzle segment combustor was operated at $100 \% \mathrm{CWM}$ at $7.0 \mathrm{~atm}$. If $100 \% \mathrm{CWM}$ operation could not be accom-

* J. Fernandez de la Mora and S.K. Friedlander, "Aerosol and Gas Deposition to Fully Rough Surfaces: Filtration Model for Blade-Shaped Elements", Int. Journal of Heat Mass Transfer vol. 25, No. 11, pp.1725-1735, 1982. 


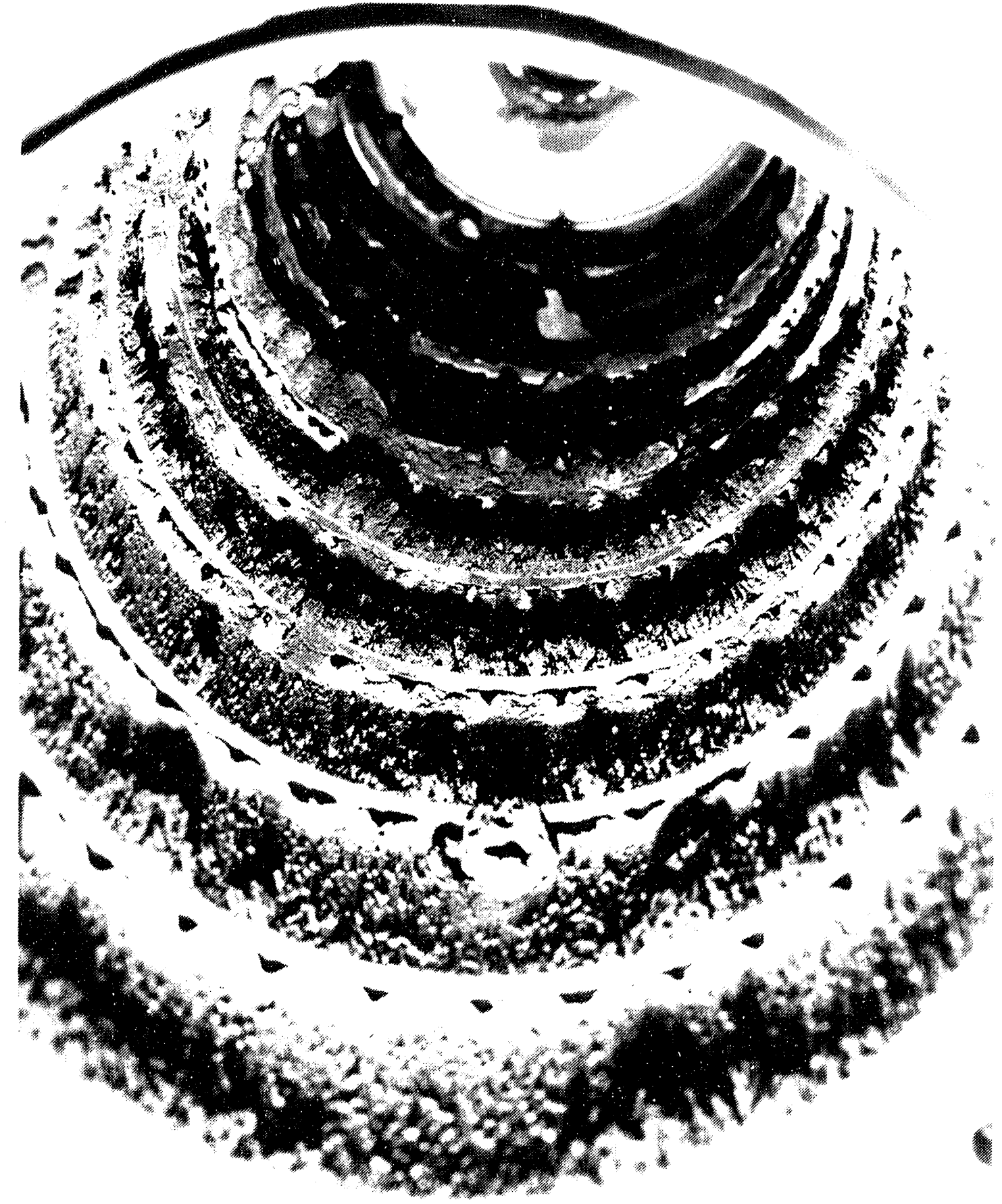

Figure 2.1.2.24 One-nozzle segment combustor post test (10-1/2 hr) condition. 
plished at $4.0 \mathrm{~atm}$ in $140^{\circ}$ sector combustion, $7.0 \mathrm{~atm}$ operation would be a viable alternative.

A comprehensive evaluation of the Parker-Hannifin reduced spray angle CWM fuel nozzle was also conducted during this test session. This evaluation included fired combustion tests, Malvern drop size and fluent-flow modeling.

Fired testing was conducted using the PH nozzle with a counter swirler dome configuration (GE-CRD nozzle tested in the past always used a co-swirler dome configuration). Atmospheric tests conducted earlier indicated the counter and co-swirl arrangements had little effect on fuel nozzle spray patterns. The fired testing revealed that the reduced spray angle $\mathrm{PH}$ nozzle performed much better than the earlier design. Combustion liner metal temperatures were well within design limits; however, these data indicated that the flame front had moved downstream of the primary dilution holes. Testing with the GE-CRD nozzle held the flame front just upstream of these holes. Combustion performance with $\mathrm{PH}$ nozzles was good, but not stable enough to allow 100\% CWM fuel separation.

Following this test, GE-CRD evaluated the PH nozzle in their Malvern facility and with these results, conducted fluent flow modeling studies. This work revealed that the revised PH design had drop sizes and included spray angle similar to the GE-CRD design, but the counter flow swirler configuration was having a deleterious effect on combustion. The model predicted, as witnessed during the fire testing, that counter swirl diminishes the primary zome recirculation and allows the flame to stabilize downstream of the primary dilution holes. This phenomenon reduces primary zone residence time and reduces combustion performance. To remedy this situation, co-swirl dome swirlers were fabricated to use the $\mathrm{PH}$ nozzles in the $140^{\circ}$ sector combustor.

2.1.2.4.4 Subcomponent Tests. Dome assembly hardware was received and screened early in the CWM program. A design swirler $\left(45^{\circ}\right)$ and deflector $\left(45^{\circ}\right)$ and several alternates were tested. All components of the dome assembly met expected flow rates. A photo of the hardware is shown in Figure 2.1.2.25.

A series of spray tests was conducted with one CWM nozzle and one standard oil nozzle. Twelve swirler/deflector configurations were used. The swirler angles were $30^{\circ}, 37.5^{\circ}, 45^{\circ}$, and $60^{\circ}$. The deflector angles were $30^{\circ}, 37.5^{\circ}$ and $45^{\circ}$. The nominal design angle is $45^{\circ}$ for both components. Water was sprayed as the fuel. Spray test results were within the expected range for all configurations. A spray test photo is shown in Figure 2.1.2.26.

Patternation testing was conducted in the multi-tube patternator shown in Figure 2.1.2.27. The height of fluid in each of 40 tubes was measured at the end of each test. Two "peak" tube heights (one on each side of centerline) were recorded for each of six positions. The distortion index is defined as the maximum peak tube height/average peak tube height. A distortion index of less than or equal to 2.0 is considered acceptable. Figure 2.1.2.28 and Table 2.1.2.7 

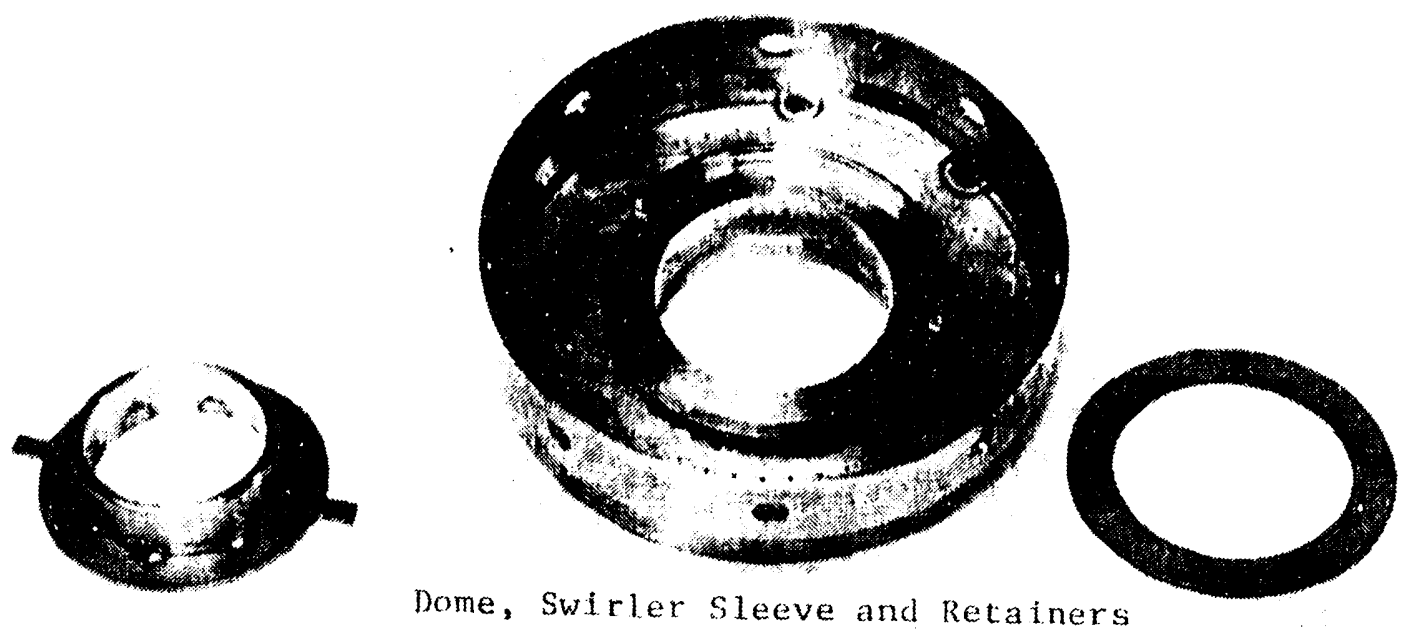

Dome, Swirler sleeve and Retainers
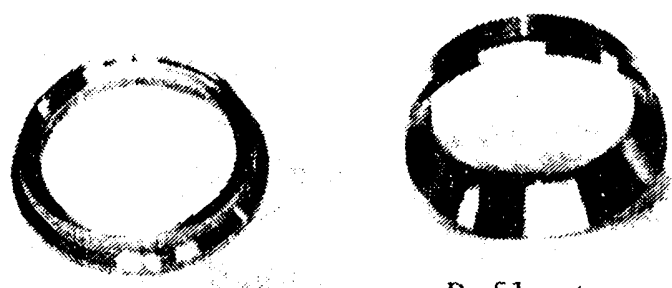

Deflectors
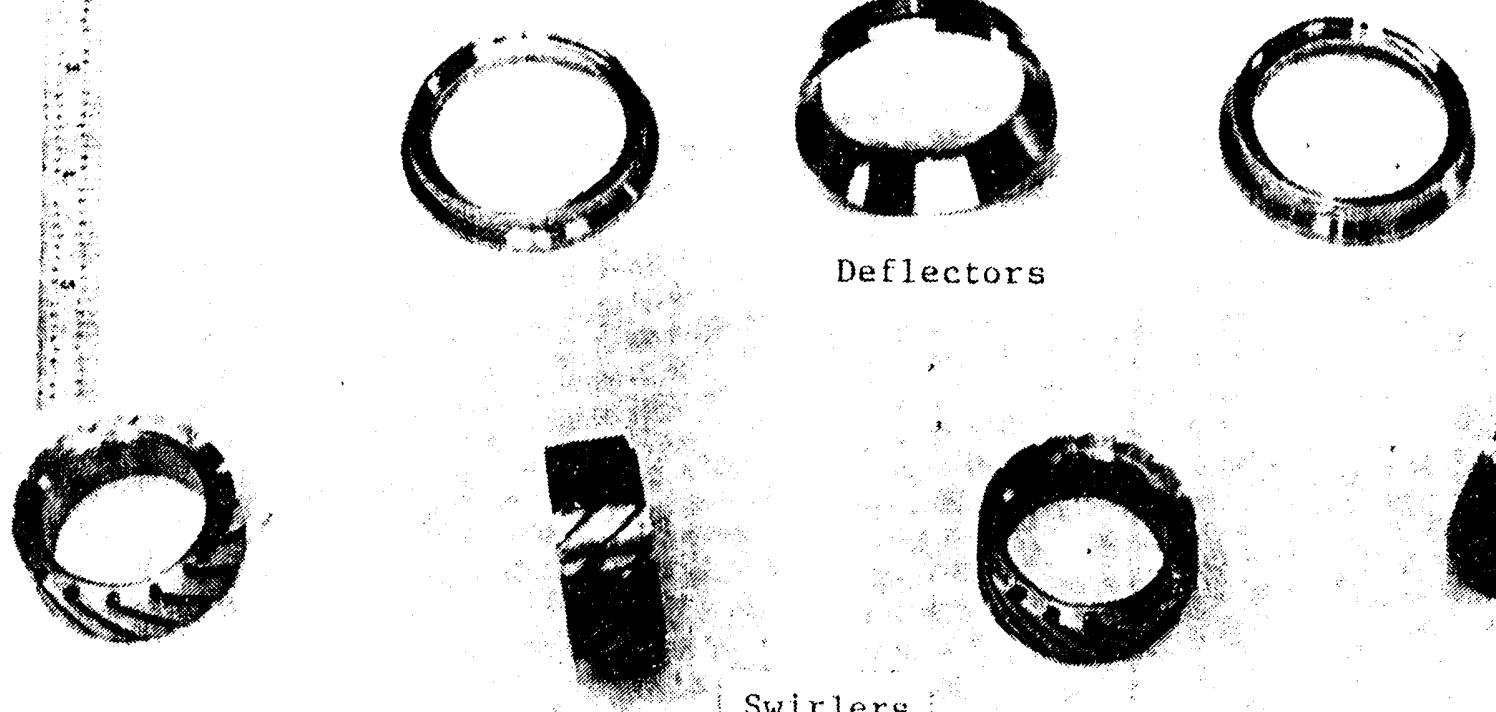

Swirlers

Figure 2.12.25 Combustor dome components. 


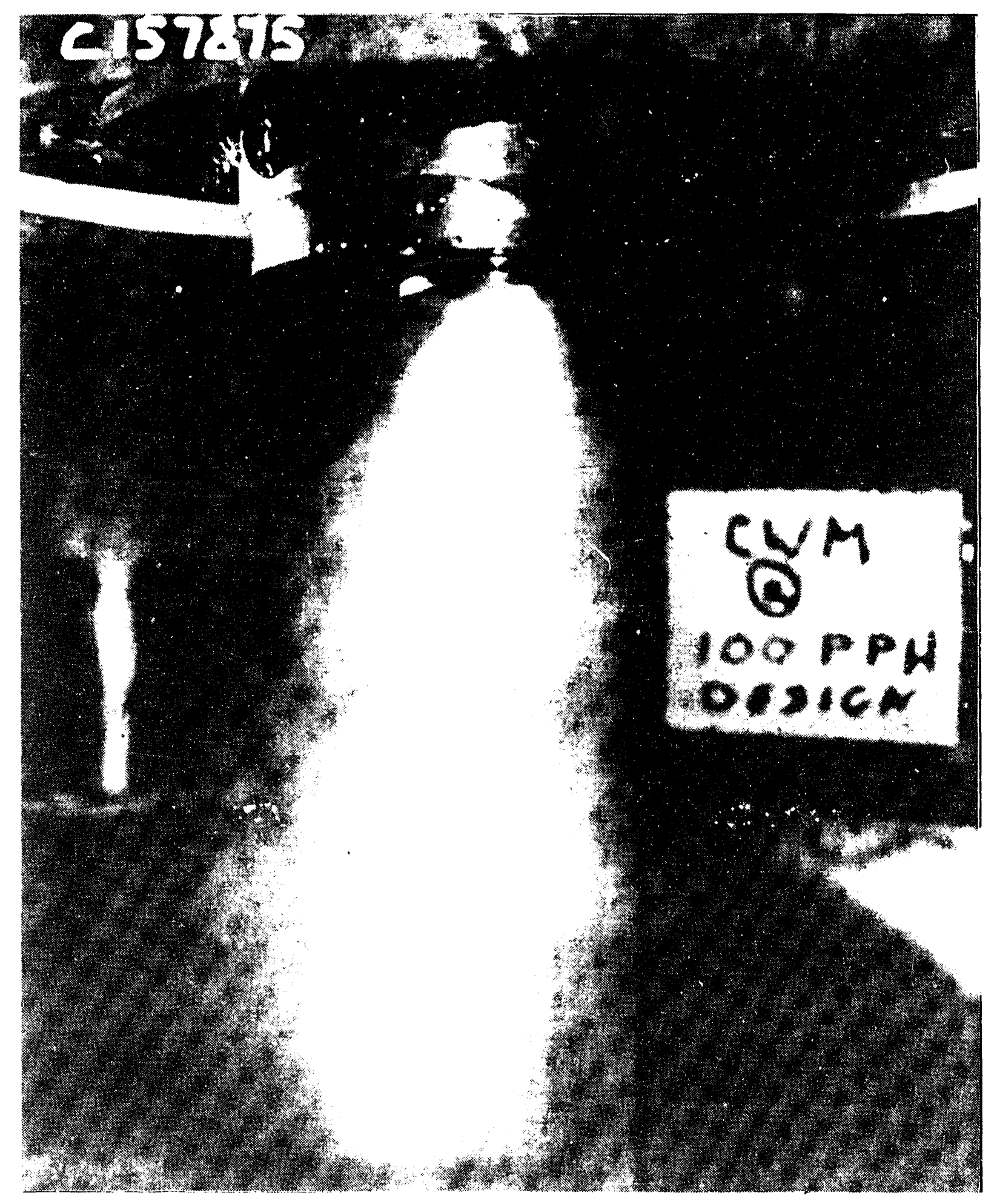

Figure 2.1.2.26 Spray test of dome and fuel nozzle. 


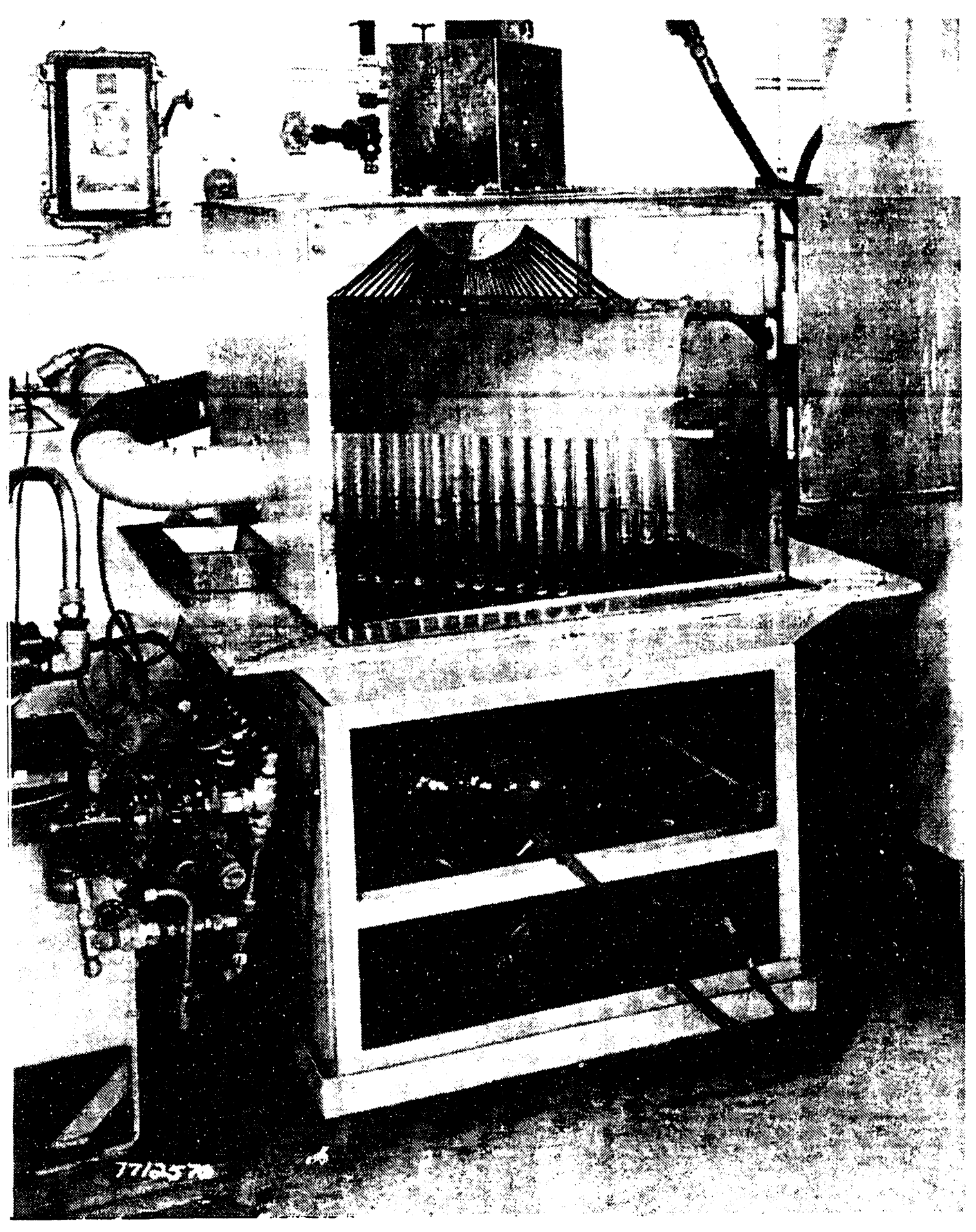

Figure 2.1.2.27 Multi-tube patternator. 
show patternation results which were acceptable with the CWM fuel nozzle and were comparable to that of the standard nozzle.

Dome assembly hardware and the CWM fuel nozzle were accepted and released for use in the one nozzle segment combustor tests.

Table 2.1.2.7

Patternation Test Results

\begin{tabular}{ccc} 
Nozzle & Fuel & Distortion Index \\
\hline Standard & Water & 1.49 \\
CWM & Water & 1.43 \\
CWM & Oil & 1.46
\end{tabular}




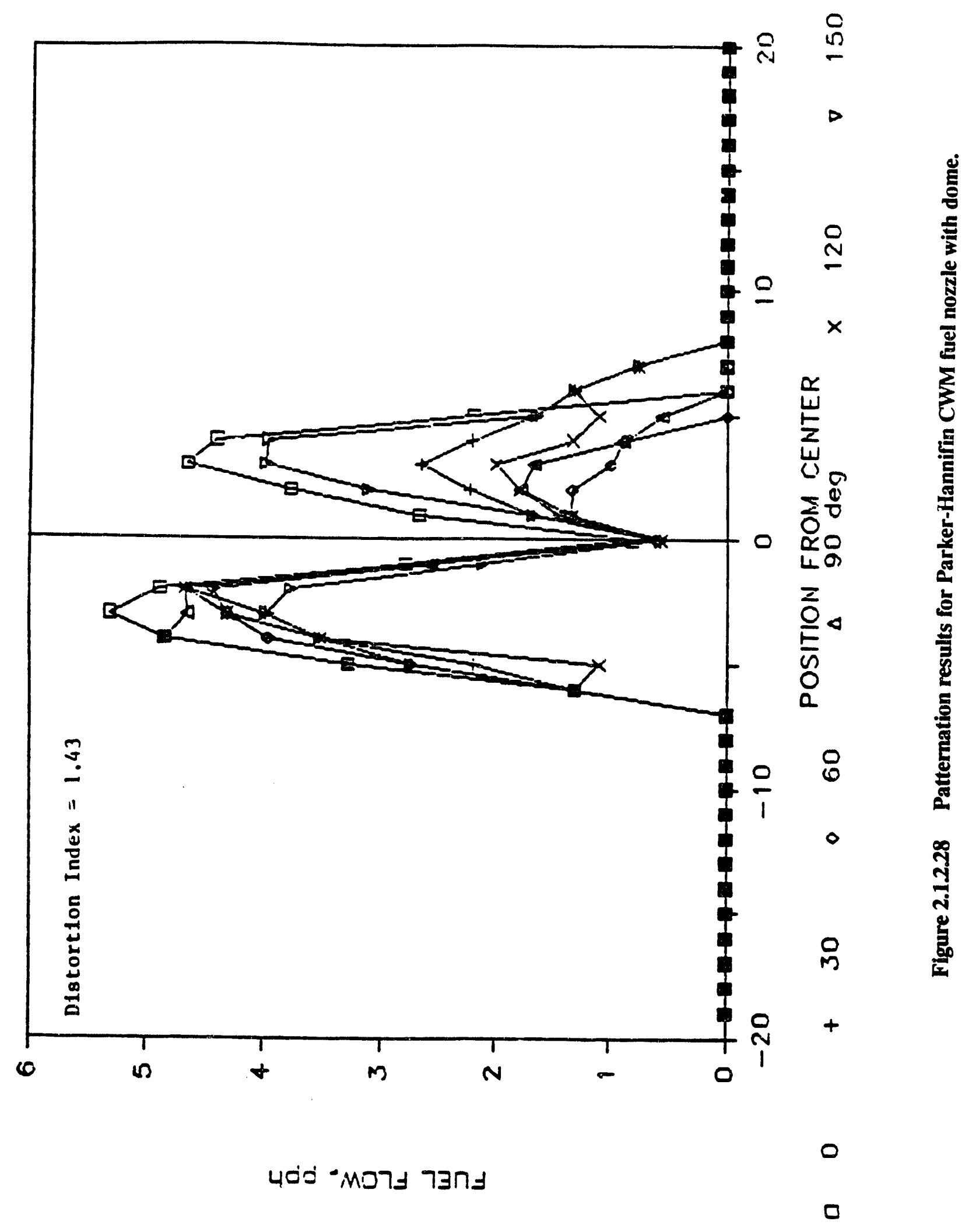




\subsubsection{Annular Combustor Technical Assessment}

\subsubsection{Merits}

The annular combustor design proposed for this project represents state-of-the-art technology used in all GE modern-day aircraft, marine and industrial engine applications. The annular design offers low surface to volume ratio, minimizing the amount of air required for structural cooling. Therefore, more air is available for controlling the combustion process. The multiple fuel-injection locations of the annular design provide more uniform mixing of the fuel and air, thus providing circunferential control of the exit conditions. The annularcorrbustor configuration transitions naturally into the annular-turbine nozzle thus eliminating any steps, discontinuities or transition devices between the combustor exit and the turbine inlet. The close coupling of the combustor exit and turbine inlet lends itself to optimizing the temperature profile at the turbine inlet for performance and durability and reduces external heat losses.

The impingement and film cooled liners represent the latest in cooling technology for efficient control of metal temperature, utilizing the least amount of air. Strategic placement of the jet-impingement holes can provide very uniform metal temperatures circumferentially and axially along the liner. The multiple concentric shells provide a structurally sound flowpath able to easily withstand the pressure loads imposed during operation. The inner surface of the liners can be coated with ceramic thermal barrier coating (TBC) to provide additional thermal protection to the metal liners providing that the TBC surface roughness is controlled so as not to adversely impact deposition.

The fuel nozzle is capable of operation on several types of fuel. Air assist is used to provide very fine atomization required for efficient burning of CWM. The fuel nozzle is simple in design, and easy to install.

\subsubsection{Technical Progress}

The detailed aero and mechanical design of the annular-combustor design are complete. A full scaie $140^{\circ}$ segment of the annular comoustor has been manufactured and is awaiting test. Two different fuel-nozzle designs have, been manufactured and are ready for evaluation as part of the sector combustor test program. The sector combustor test rig, which is complete, is capable of operation at true engine conditions and is equipped with sampling rakes for measuring gaseous and particulate emissions as well as other performance parameters.

A one-nozzle segment which simulates the aero- design of the annular combustor has been fabricated. The dome hardware, including the fuel nozzle, is identical to the annular design. Operation on $100 \%$ CWM for over $12 \mathrm{hr}$ has been demonstrated with no major problems. Combustor performance of over $99 \%$ efficicncy with greater than $99.7 \%$ carbon burnout was r. :easured. Liner metal temperatures remained below $1200^{\circ} \mathrm{F}$ and pressure drop was maintained throughout the test. Some ash deposits occurred during one test, but is believed 
to be associated with TBC surface roughness used during that test. During another test with bare metal walls, no deposition was observed. Key variables affecting operation on CWM were identified during this test. Operating pressure, fuel-to-air ratio, pressure drop and residence time (air mass flow) were all evaluated for their impact upon CWM combustion performance.

Based on these findings, the operating procedures for successful operation of the sector combustor have been defined.

\subsubsection{Shortcomings}

The main shortcomings of the annular combustor are the multiplicity of fuel injectors and engine modifications for on-board installation. The multiple-fuel injectors add cost and some increased probability of injector failure. However, the consequence of failure is not as severe as with a single injector since the flow is diverted to the other operable injectors. The onboard combustion system does require partial teardown of the engine for removal of the combustor. These shortcomings are not considered significant with respect to developing this system for commercial deployment.

\subsubsection{Risks}

The risk for the annular-combustor system is low. The key concern for the annular design would be ash buildup on the hot side flow path. However, the multiple-film buildup should protect the liner from ash buildup by blanketing the surface with cold air. The other area of risk centers around meeting the emissions of $\mathrm{NO}_{x}$. The thermal $\mathrm{NO}_{x}$ produced with $\mathrm{CWM}$ is low due to the reduced flame temperatures. However, the $\mathrm{NO}_{x}$ produced from nitrogen chemically bound up in the fuel could be unacceptable. To prevent formation of these emissions, a rich-fuel mixture is maintained at the front end of the combustor. Unless the fuel and air are uniformly mixed, hot spots can result and reduce combustor-liner life. Therefore, a well mixed combustion zone is mandatory if long liner life and low $\mathrm{NO}_{x}$ emissions are to be achieved. The actual risk regarding $\mathrm{NO}_{x}$ reduction was to be assessed in the next six months in one nozzle segment combustor tests; and if needed, mitigating strategies were to be defined.

\subsubsection{Exhaust Gas Cleanup System}

\subsubsection{Introduction}

A conventional particulate and $\mathrm{SO}_{2}$ removal system, such as a spray absorber and a pulse jet baghouse, can be installed downstream of a coal-fueled gas turbine to meet NSPS. This section presents the description and the performance estimates for a commercial system, and a general arrangement is shown. Performance, size and cost of this system have been included in the economic evaluations of a coal-fired gas turbine system presented in Section 3.2.5. The advantage of this system is that it is proven technology for NSPS compliance. 


\subsubsection{System Description}

The commercial system planned for exhaust gas cleanup downstream of a coal-fired gas turbine is comprised of a spray absorber for $\mathrm{SO}_{2}$ removal and a fabric filter for particulate removal. This system is a direct transfer of proven technology from existing dry flue gas desulfurization installations for utility pulverized coal-fired boiler applications as illustrated in Figure 2.1.4.1. As shown in this Figure, $\mathrm{SO}_{2}$ and flyash-laden gas from the boiler enters the top of the spray absorber. There it is contacted by a lime slurry atomized into fine droplets by a single rotary atomizer. Cyclonic gas flow within the absorber provides sufficient residence time for the gas inside the unit to evaporate the slurry water and to allow the lime to react with, and remove the $\mathrm{SO}_{2}$ from the gas stream. Additional $\mathrm{SO}_{2}$ removal occurs in the dust cake on the filter bags.

Deviating from the conventional dry flue gas desulfurization system for utility power generation, hydrated lime, rather than lower cost lime, can be specified in an effort to reduce the overall capital cost of this small system by the elimination of lime slaker. A waste heat recovery boiler is however required ahead of the spray absorber to reduce the flue gas temperature to the appropriate value for the absorber and the baghouse. A simplified process flow diagram is shown in Figure 2.1.4.2. Table 2.1.4.1 summarizes system conditions and performance. Table 2.1.4.2 describes the design and operating conditions of the pulse jet baghouse. The spray absorber and the baghouse are sized to operate at and up to about $50 \%$ in excess of the expected gas flow rate. A preliminary general arrangement of this exhaust gas cleanup system is presented in Figure 2.1.4.3.

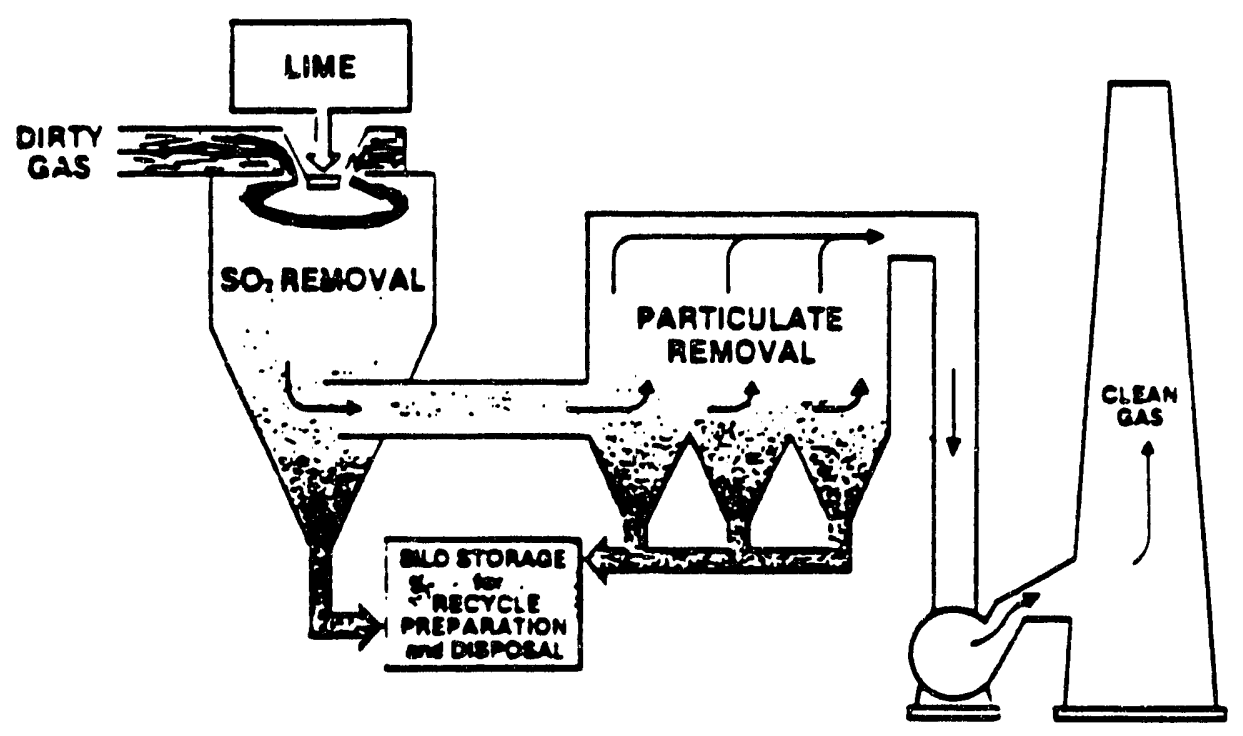

Figure 2.1.4.1 Dry fue gas desulfurization for utility pulverized cos! fired boiler applications. 


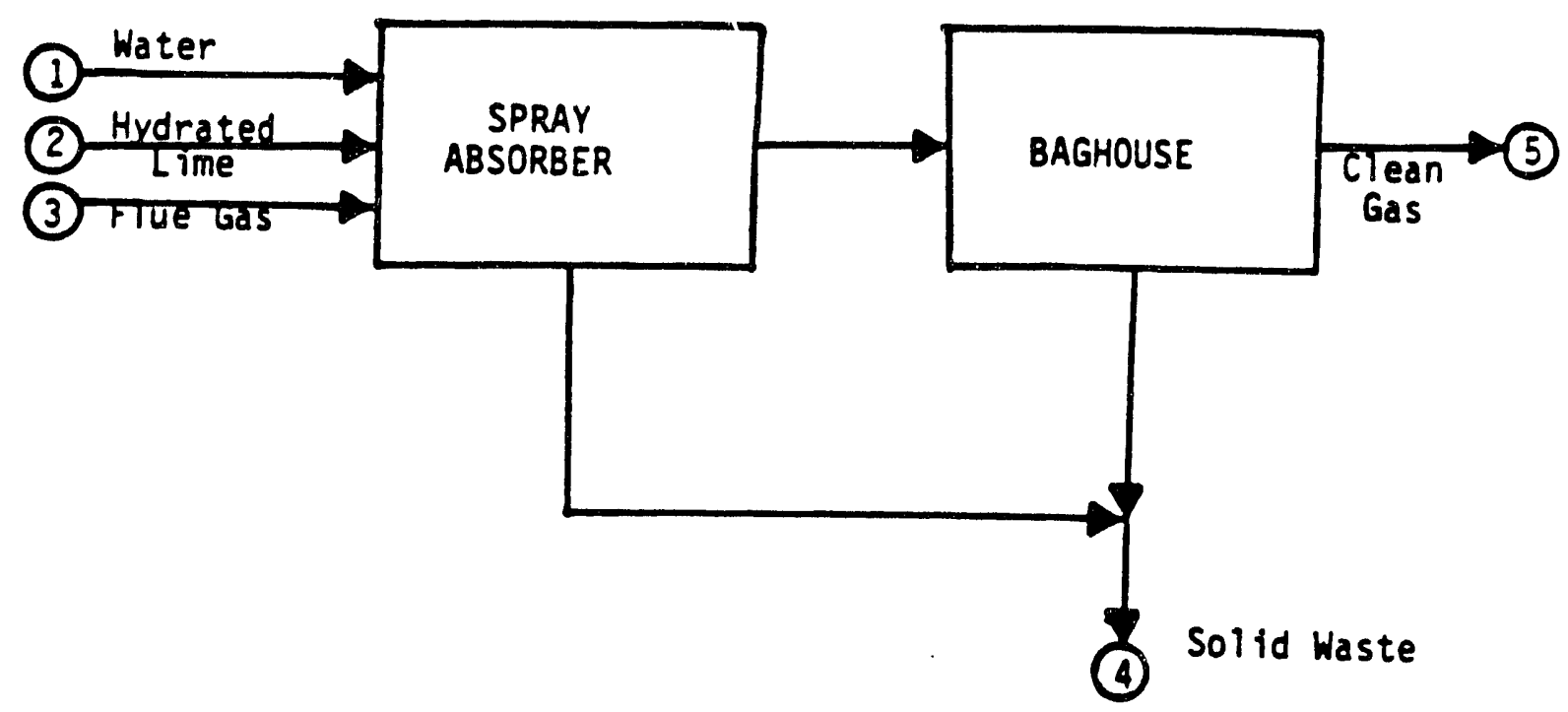

(1) Water $5340 \mathrm{lbs} / \mathrm{hr}$

(2) Hydrated Line $80 \mathrm{lbs} / \mathrm{hr}$
(3) Flue Gas $97,000 \mathrm{lbs} / \mathrm{hr}$
Particulate $40 \mathrm{lbs} / \mathrm{hr}$
$\mathrm{SO}_{2} \quad 40 \mathrm{ibs} / \mathrm{hr}$
(4) Solid Waste $150 \mathrm{lbs} / \mathrm{hr}$
(5) Clean Gas $102.302 \mathrm{lbs} / \mathrm{hr}$
Particulate $0.7 \mathrm{lbs} / \mathrm{hr}$
$\mathrm{SO}_{2} \quad 8 \mathrm{ibs} / \mathrm{hr}$

Figure 2.1.4.2 Simplified process flow diagram. 
Table 2.1.4.1

System Conditions and Performance Requirements

Inlet Conditions to Dry FGD

Flow Rate

Pressure

Temperature

Particulate Loading (with kaolin)

Sulfur Dioxide

35,000 ACFM

$14.7 \mathrm{psi}$

$370^{\circ} \mathrm{F}$

$40 \mathrm{lb} / \mathrm{hr}$

$40 \mathrm{lb} / \mathrm{hr}$

187 PPMV

Outlet Conditions from Fabric Filter

Flow Rate

Pressure

Temperature

Particulate Loading

Sulfur Dioxide

$27,000 \mathrm{ACFM}$
$14.7 \mathrm{psi}$
$165^{\circ} \mathrm{F}$
$0.7 \mathrm{lb} / \mathrm{hr}$
$8 \mathrm{lb} / \mathrm{hr}$
$35 \mathrm{PPMV}$

Table 2.1.4.2

Pulse Jet Baghouse Design and Operating Conditions

Design Conditions

Maximum Volume

Temperature

44,000ACFM

$175^{\circ} \mathrm{F}$

Dust Loading

$1.0 \mathrm{GR} / \mathrm{ACF}$

Assumed Part. Size Dist.

$6 \mu \mathrm{m} \mathrm{MMD}$

Expected Pulse Jet Offering

Pulse Jet Model No.

4-154-6-14

Air-to-cloth Ratios

Gross

3.26:1

Net-1

4.35:1

Expected Pressure Drop

6.0 in W.C.

Expected Outlet Emission Level $\quad 0.02-0.03 \mathrm{lb} / \mathrm{mm}$ Btus 


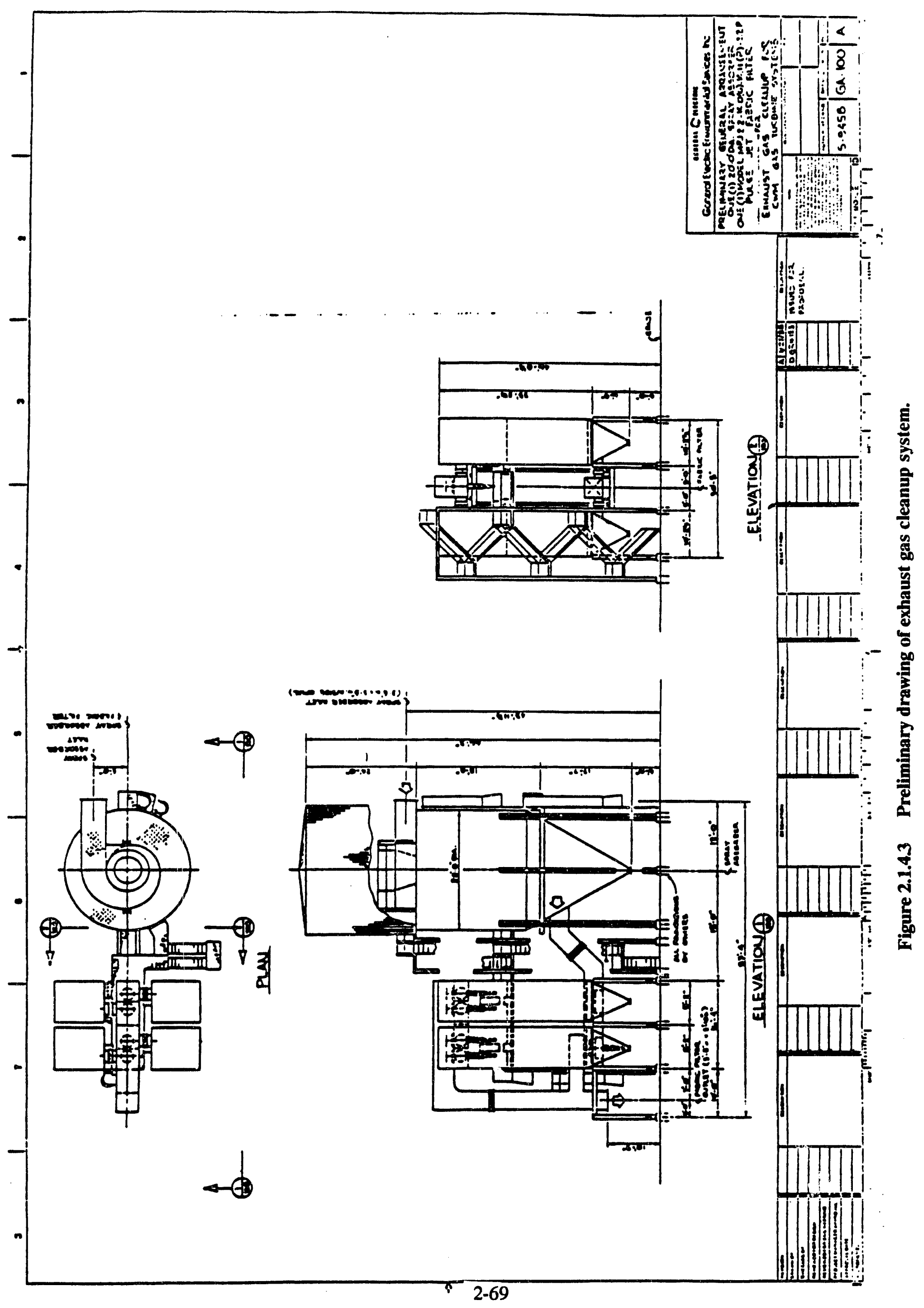




\subsection{Off-Board Combustor/Integrated Cleanup System}

\subsubsection{System Description}

\subsubsection{System}

The can combustor represents relatively old technology, but is a very simple geometry and generally inexpensive. Can combustors were used in early vintage aircraft jet-engine applications and are presently used in large gas turbine applications where size is a critical issue. Can combustors are structurally sound due to their cylindrical shape and generally have a single-fuel nozzle to supply fuel. On-board multiple-can systems usually require a shape transition from cylindrical to annular to interface with the high-pressure turbine inlet annulus. Off-board can designs require scroll ducting to route the combustor airflow off engine and then back to the turbine. Off-board designs - without considerations to the GFB size and structure - offer the advantage that it is accessible and easy to maintain.

\subsubsection{Technical Progress}

An off-board can combustor system has been designed for the LM500 engine system which is coupled with a granular bed filter (GBF). The LM500 was selected as the design basis since it is the engine to be used in the integrated proof-of-concept system test. The design uses nested scrolls to minimize the heat losses by sheltering the hot gas return within the compressor air supply. Several design alternatives were considered (see Appendix A), but found to have unacceptable system heat and pressure losses. The nested scroll arrangement represents an innovative design concept to avoid these losses by close coupling the off-board system in a recuperative manner.

The GFB technology is currently under development for fluidized bed coal combustors. GFB is not a commercial technology and has never been tested at temperatures or pressures representative of aero-derivative gas turbines. Cold flow modeling with a dry dust has been performed with good success; however, the major challenge will be in the removal of sticky ash/slag particles present in the hot combustor exhaust gases.

The combustor is of conventional design using an impingement film cooled liner and airblast swirler dome.

The combustor exhausts into moving granules of the GBF where the particulate and sulfur are captured. The exhaust gases percolate up through the bed and return to the turbine. A viable concept has been evolved for this off-board combustor system, but formidable challenges exist to transition the design to a practical commercial system.

\subsubsection{Shortcomings}

The key disadvantages of can combustors are the high surface area to volume ratio associated with this geometry - four times greater than an annular configuration. This high surface-to-volume ratio implies that for the same heat release, much larger cooling airflows 
will be needed to control metal temperature. This air generally will be eliminated from the combustion process and results in poor performance and difficulty in controlling the exit temperature quality. Additionally, the larger surface area provides a heat sink that can deteriorate the combustion performance due to radiant heat losses to the walls.

On-board can combustor concepts require a transition into the high-pressure turbine, thus requiring multiple interfaces between the combustor exit and turbine inlet. Leakage can occur, as well as misassembly, impacting performance and mechanical integrity. An off-board combustor represents an even more challenging interface problem with all of the associated ducting and cooling requirements. The heat and pressures losses associated with this approach make this concept very difficult to implement successfully.

Ash deposition on the various interface joints would certainly present a problem. The large size and exposed surface area of the off-board system make the heat losses very difficult to control. Any heat lost to the surroundings must be made up by increasing gas temperatures and increased fuel flow, thus penalizing operating efficiency. The tortuous gas path also introduces additional pressure losses in the system which severely impacts turbine performance and overall gas turbine power output.

Many of the shortcomings associated with the off-board system are operational. Startup of the system will be difficult and time consuming due to the large mass of material that will soak up heat before the gases reach the turbine. Sealing the many interfaces to prevent leakage while still tolerating the large thermal gradients that will exist between the hot thin parts and cold large masses during transients will require very special joint designs. Operation of the granular bed filter will be a challenge in itself. Maintaining fluidity of the moving bed portion will be important; therefore, its temperatures must be carefully maintained to prevent solidification of any liquids in the exhaust, but prevent ash and other particulate from becoming sticky.

Another significant shortcoming is the GFB system size. The GFB vessel is very large (9 $1 / 2 \mathrm{ft}$ OD) for the $3.7 \mathrm{MW}$-power system. It will not be practical to fabricate a GFB vessel which could be used with the next size GE aero-derivative gas turbine that requires roughly three times the mass flow volume. The system also requires that the engine be mounted on the filter vessel at an elevation of 30 to 40 feet - this makes installation and maintenance of the gas turbine, generator, inlet filters, and HRSG very difficult. This will increase both capital and operational costs.

\subsubsection{Risks}

In addition to the shortcomings delineated above, two major risks in the off-board combustor system concept are the GBF operation and the availability of high-temperature materials to withstand the very high turbine inlet temperatures of an aero-derivative gas turbine. The use of ceramics is highly unlikely due to the large thermal gradients, and metals capable of sustained exposure to $2200+{ }^{\circ} \mathrm{F}$ gas temperatures at very high pressures do not exist today. 


\subsubsection{Developmental Approach}

\subsubsection{Introduction}

This section describes an investigation on the feasibility of operating a Fixed/Moving Granular Bed Filter (FMGBF) system under the harsh conditions that exist in the exhaust of a gas-turbine combustor. To be successful, the filter must reduce particulate matter to a level which meets New Source Performance Standard (NSPS) for coal-fired power plants. The particulate matter removed by the filter contains ash, unburned coal and calcium sorbents. Sulfur capture may be performed by injection of calcium based sorbents into the combustor or by introduction with the recycled media. The ash particles are estimated to be mainly in the range of 1 to $10 \mu \mathrm{m}$ in diameter; a size range which could be collected efficiently in a granular bed filter.

The design conditions for the combustion gas coming out of the combustor in the CWM fired LM500 turbine are $200 \mathrm{psi}$ and $2000^{\circ} \mathrm{F}$. The total flow rate of the gas is $97000 \mathrm{lb} / \mathrm{hr}$ and it contains $26.6 \mathrm{lb} / \mathrm{hr}$ of ash and $26.6 \mathrm{lb} / \mathrm{hr}$ of sulfur, mainly in the form of sulfur dioxide. The high temperature of the gas limits the filtration options to devices constructed of ceramic materials such as ceramic bag filters, or to granular bed filters in refractory lined vessels. Continuously operating filter systems at $2200^{\circ} \mathrm{F}$ are not commercially available. GEES was assigned, under its current work scope, to develop an existing GEES concept of a Fixed/Moving Granular Bed Filter (FMGBF) to be used as a particulate removal device located between the combustor and the gas turbine.

\subsubsection{The Granular Bed Filter System}

\subsubsection{Granular Bed Filtration Mechanism}

In granular bed filtration processes, particle-laden gas flows through a bed of granules. The particles, traveling in the void space of the bed, collide with the much larger bed granules. If they adhere to the surface of the granules, filtration is achieved. The particles remain in the bed while the clean gas discharges from the system. Collision between the bed material and the dust particles is due to a combination of inertial impaction, diffusion, gravitational settling and electrostatic forces. At high temperature and high gas velocity, the main collision mechanism is inertial impaction which is caused by the fact that particles have higher inertial momentum, compared with the gas in which they are traveling. As a result, the trajectories of the particles may bring them to collide with granules in the bed due to the extremely small void spaces. The inertia parameter is the Stokes number which is defined as

$S t=(2 \mathrm{Dp} \operatorname{rp} 2 \mathrm{~V} / 9 \mathrm{u} a) * f(\operatorname{Re}, E)$ 
where:

$$
\begin{aligned}
& \text { Dp - Particle density } \\
& \text { rp - Particle radius } \\
& \text { V - Gas velocity } \\
& \text { u - Gas viscosity } \\
& \text { a - Granule diameter } \\
& \text { Re - Reynolds number } \\
& \text { E - Bed porosity }
\end{aligned}
$$

The filtration efficiency is a function of the Stokes number and is generally higher for larger values of the Stokes number (the above statement being accurate for cases where particles bouncing from granules surface is not significant). Higher efficiency is obtained in granular bed filters for large, high-density particles. High-filtration efficiency can also be achieved for micron and submicron dust particles when high velocity gas, in the range of 1 to $10 \mathrm{ft} / \mathrm{sec}$, flows through a granular bed filter comprised of small size bed material in the range of 0.5 to $2.0 \mathrm{~mm}$. The effectiveness of the system in handling partially molten ash has not been investigated.

\subsubsection{Granular Bed Filter Concept}

The main objectives of developing the FMGBF for direct CWM firing of gas turbine are to provide an alternate approdch for turbine protection and to meet NSPS requirements. In order to reduce cost and minimize heat losses, the filter must be small, well insulated and it should operate continuously without plugging.

Currently, DOE is supporting the development of screenless moving bed granular bed filter designed by Combustion Power Corp. (CPC) for high pressure high temperature applications. High-filtration efficiency has been demonstrated by the CPC filter over many hours of operation. The main disadvantage of the CPC filter is the fact that there is no bed support and as a result the gas velocity is limited to substantially below the fluidization velocity of the bed material. In order to achieve high-filtration efficiency, small granules $(2 \mathrm{~mm}$ alumina spheres) are used, and the gas velocity is limited to about $2 \mathrm{ft} / \mathrm{sec}$. Upset conditions in the CPC system may cause a higher than design gas flow rate which may result in bed material carryover downstream of the filter and into the turbine.

The GEES Fixed/Moving Granular Bed Filter, shown in Figure 2.2.2.1, is a combination of a moving bed of 1 to $2 \mathrm{~mm}$ spherical alumina granules supported by a fixed bed of larger size granular alumina bed media. The supporting fixed bed is comprised of few layers of increasingly larger granules in the outflow direction. The size of the channels in each layer is smaller than the size of the granules which it is supporting so that penetration of the small size granules through the channels is avoided. The outermost layer may be comprised of very 


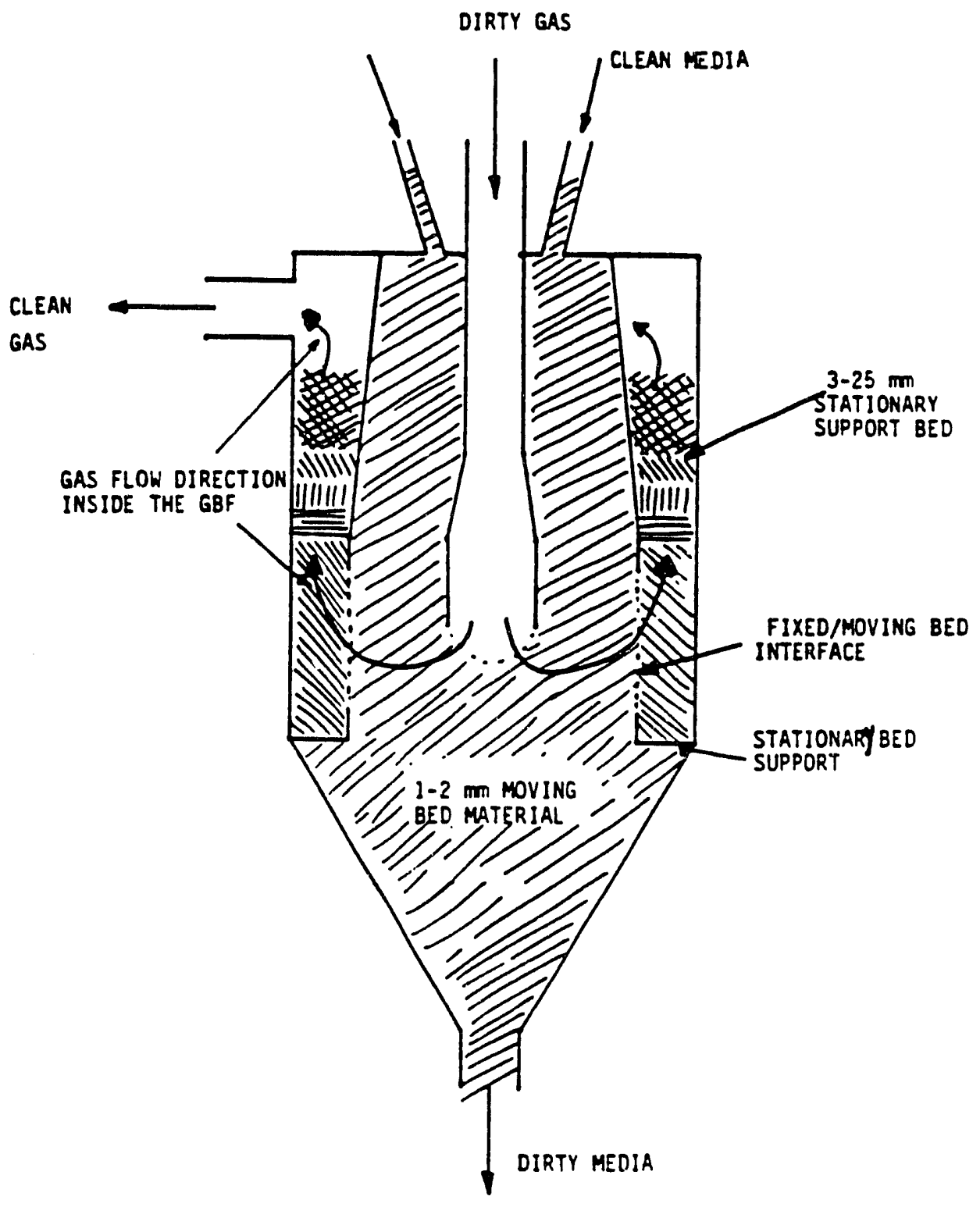

Figure 2.2.2.1 Schematic of the GE fixed/moving granular bed filter. 
large granules (as large as $1 \mathrm{in}$. in diameter) so that even at a very high velocity, entrainment of the bed will not occur. The use of small size bed material in the moving bed zone, results in a high filtration efficiency. At the same time, high gas velocity, below the minimum fluidization velocity of the large size upper support layer, but well above the fluidization velocity of the moving bed, can be used.

The Stokes number is the maximum in the moving bed zone where filtration occurs. The value of the Stokes number is lower in the fixed-bed zone and as a result very fine dust particles that penetrate through the moving zone penetrate the fixed bed as well, and plugging will not occur.

The filter vessel contains two concentric internal pipes open at the bottom, as shown in Figure 2.2.2.1. The length and diameter of these pipes determine the boundaries of the moving bed, the velocity of the particle laden gas and its injection location into the moving bed. The inner most pipe is an extension of the combustor (in the CWM-firing system). The gas flows inside the pipe at a velocity comparable to the gas velocity in the combustor. The clean small size alumina spheres, are fed to the annular space between the two internal pipes and move downward by gravity into the bottom of the conical hopper. The stationary support bed, comprised of few layers of increasingly larger size granules in the gas outer flow direction, is located in the annular space between the vessel refractory wall and the outer of the two internal pipes. The stationary bed is supported from the bottom, as shown in Figure 2.2.2.1. The Fixed/Moving bed interface is determined by both the size of the stationary bed support and the diameter of the internal pipe.

Particle filtration is accomplished in the cross-flow zone of the moving bed where the bed moves down by gravity and the gas flows radially outward. As a result, the drag force on the moving bed material is mainly in the horizontal direction and it has a rather small impact on the moving bed gravitational flow.

\subsubsection{Cold Flow Modeling and Filtration Experiments}

A cold flow model was constructed in the GEES Engineering Laboratory to investigate the performance of the FMGBF. The filter system initial and final configuration is shown in Figures 2.2.2.2 and 2.2.2.3, respectively. The filter is a cylindrical vessel with a conical hopper. Both vessel and hopper are split along the axis of symmetry as shown in Figure 2.2.2.3. The plan wall (front view in Figures 2.2.2.2 and 2.2.2.3) is constructed of transparent plexiglass to allow observation of bed material, gas and dust flows. The two inner pipes form an annular space in which the moving bed material, comprised of 1 to $2 \mathrm{~mm}$ alumina spheres, flows downward by gravity and discharges at the bottom of the hopper. A stationary bed of coarser material fills the annular space between the external inner pipe and the vessel wall and is used as a support for the moving bed. The stationary bed is layered, as shown in Figures 2.2.2.1 and 2.2.2.2, with large granules layered in the outer flow direction. Dusty gas flows through 


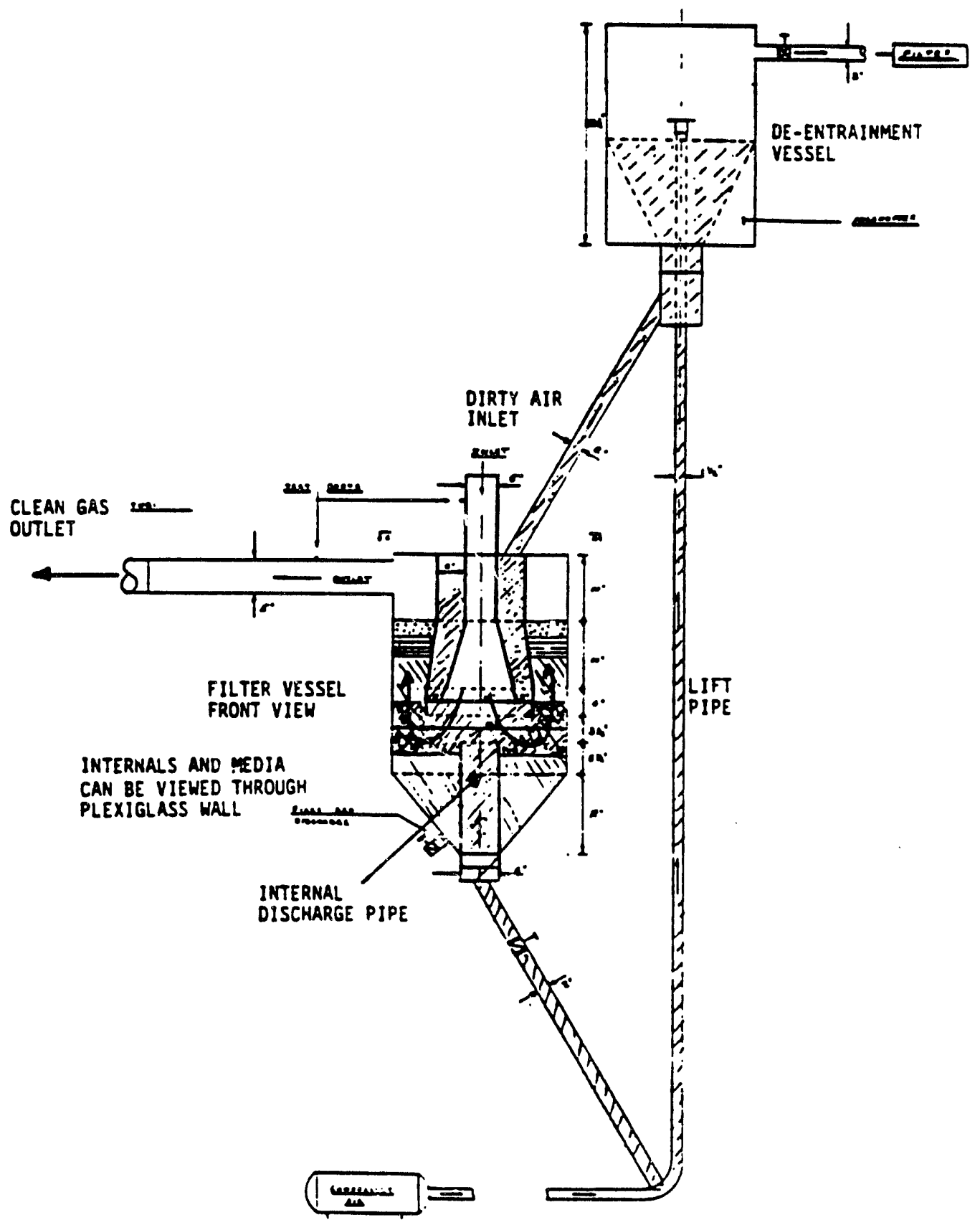

Figure 2.2.2.2 Cold Flow model, initial configuration. 


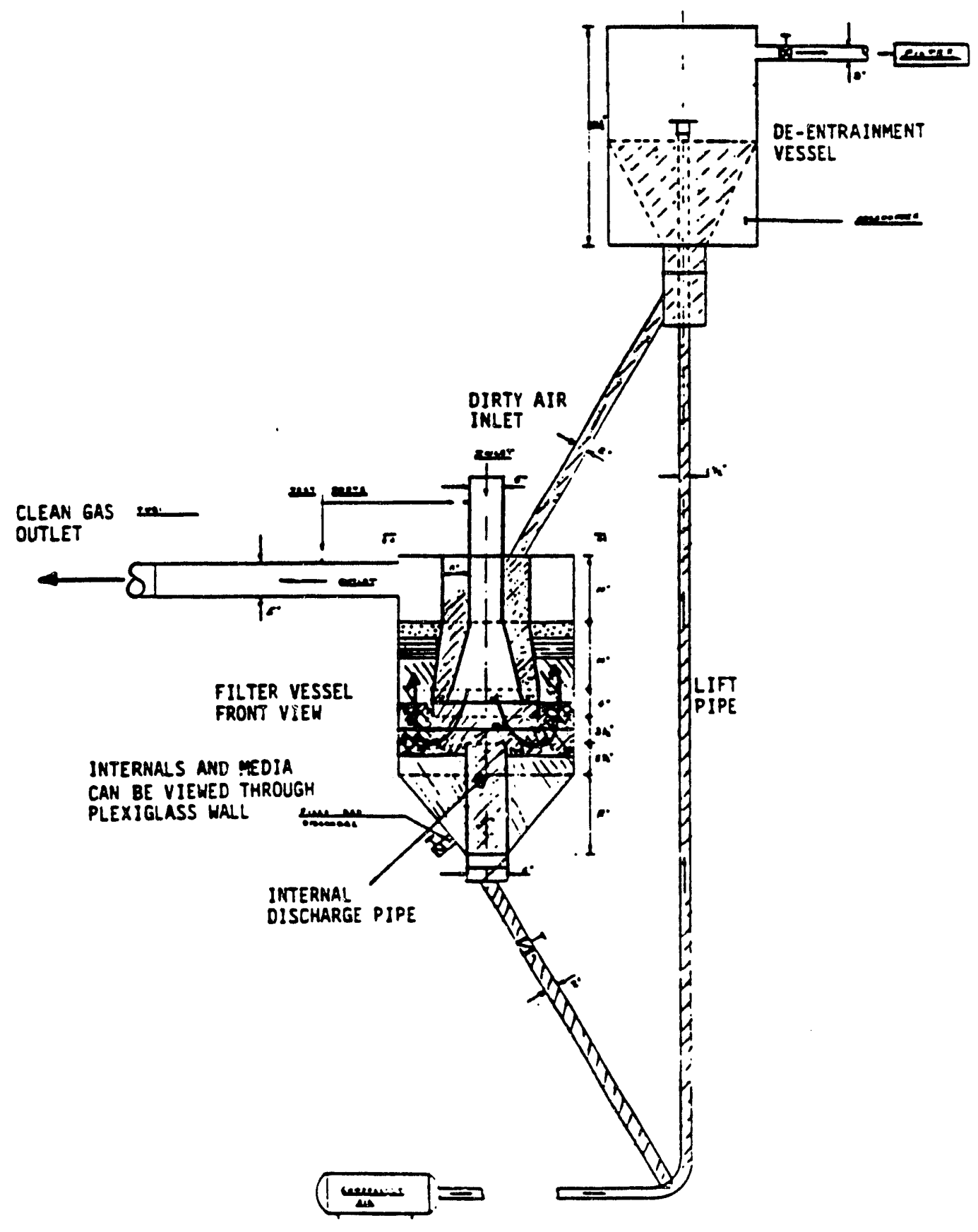

Figure 2.2.2.2 Cold Flow model, initial configuration. 


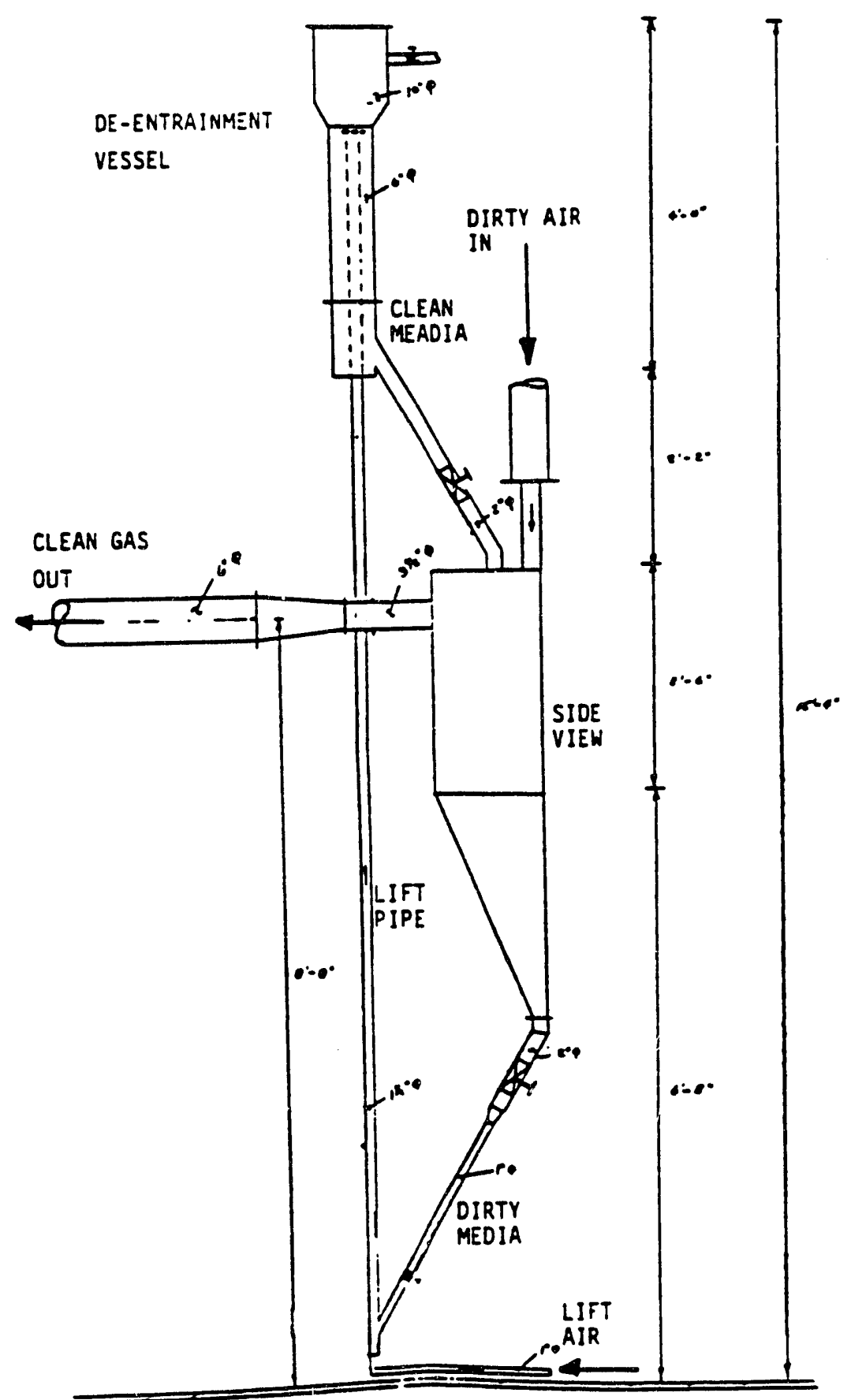

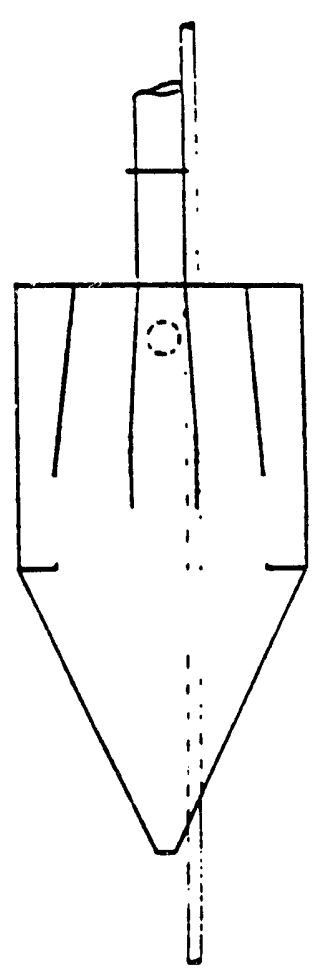

FRONT VIEW

Figure 2.2.2.3 Cold flow model, final configuration. 
the internal pipe and penetrates through the moving bed at high velocity. The gas then further penetrates into the stationary bed and discharges from the bed in an upward flow direction. The dust is collected in the moving bed and discharges with the moving bed material. A separate, small stream of lift air, pneumatically transports the granules and the dust up to the de-entrainment vessel where the granules settle and flow back into the filter, and the dust entrains in the air stream. The dusty gas stream is cleaned in a small baghouse (not shown in Figures 2.2.2.2 and 2.2.2.3).

The filter was sized to accommodate gas-flow rates in excess of the flow rates expected in the one-nozzle segment combustor.

All the designs that were tested showed a high removal efficiency. However, in the early design (Figure 2.2.2.2), the Fixed/Moving bed interface between the stationary and the moving bed tended to plug after few hours of operation due to accumulation of ash in that layer. Modifications to the design, which included enlarging of the moving bed depth from 5 in. to 7.5 in. and improvement of the bed material discharge arrangement (see the difference in arrangements between the initial design, Figure 2.2.2.2, and the final design, Figure 2.2.2.3) solved the plugging problem.

The test results to date have been very encouraging. Pressure drop through the bed is as expected from theoretical calculations and it is small overall due to the fact that most of the bed is comprised of a large material. The difference in pressure drop through a clean bed and a coniaminated bed is rather small and bed plugging does not occur. Pressure drop through a clean bed is shown as a function of gas-flow rate in Figure 2.2.2.4. The pressure drop as a function of time during $5 \mathrm{hr}$ of filtration at an inlet dust concentration of $2 \mathrm{gr} / \mathrm{acf}$ is shown in Figure 2.2.2.5. A gas-flow rate of $100 \mathrm{acfm}$ represents an overall average gas velocity of 0.68 $\mathrm{ft} / \mathrm{sec}$. Overall average gas velocity is defined as gas-flow rate divided by the overall cross sectional area of the vessel. The $600 \mathrm{cfm}$ represents an overall average gas velocity of $4.08 \mathrm{ft} / \mathrm{sec}$, far higher than the velocities in the screenless filter. Significantly higher gas-flow rates can be achieved in the current filter. The main limitation has been the capability of the fans available in GEES engineering laboratory.

Filtration efficiency of the granular bed filter using a 7.5 in.-thick bed is shown in Figure 2.2.2.6. From an inlet concentration of $2 \mathrm{gr} / \mathrm{acf}$, emission was reduced from 0.006 to $0.007 \mathrm{gr} /$ acf representing filtration efficiency in excess of $99.6 \%$. Penetration of dust occurs along the plexiglass wall and the actual filtration efficiency, through the bed, is believed to be even higher. It is expected that the commercial size filter with a 12 in.-thick bed will be extremely efficient. 


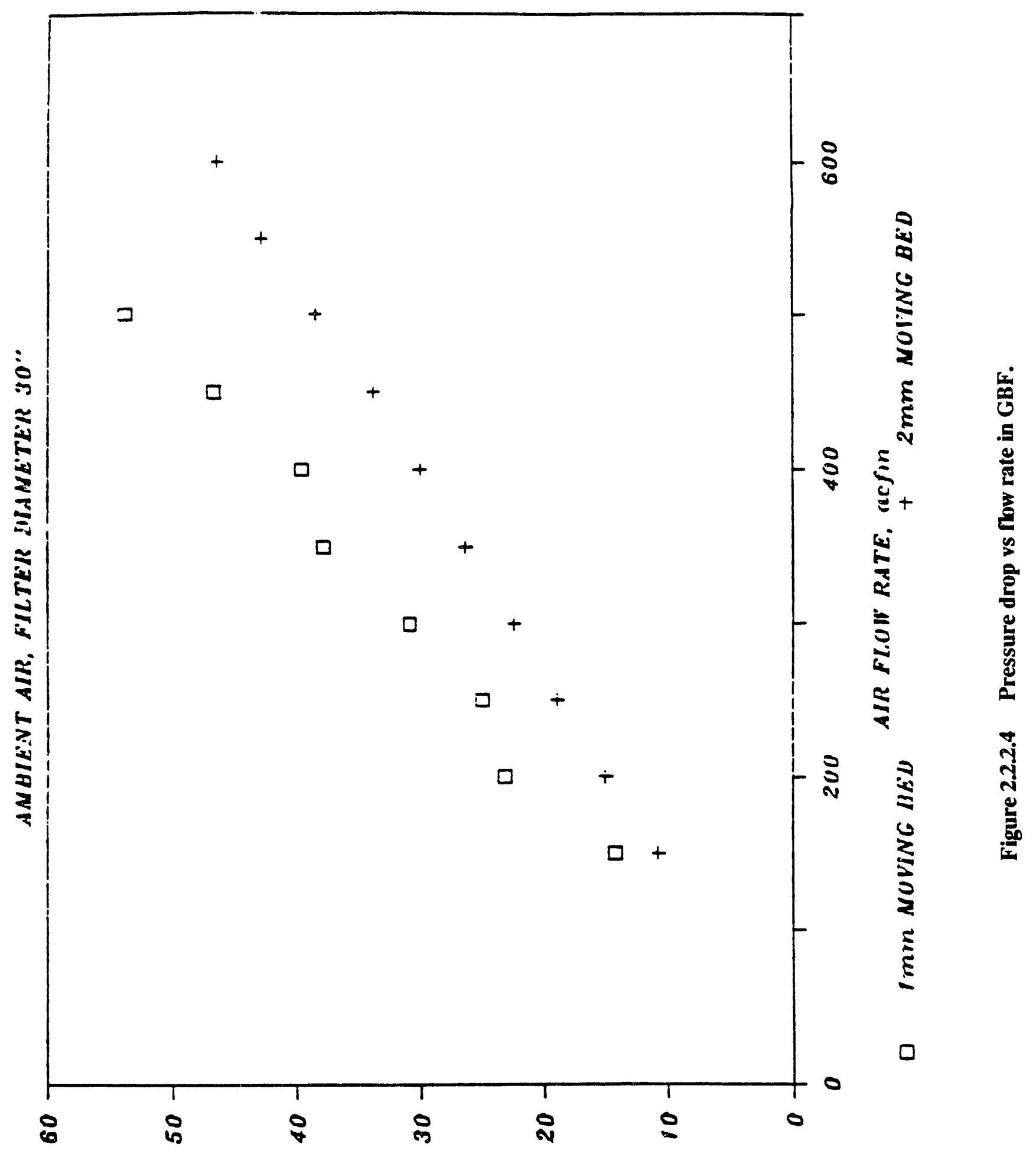

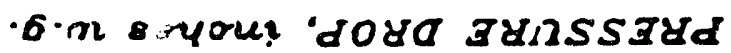




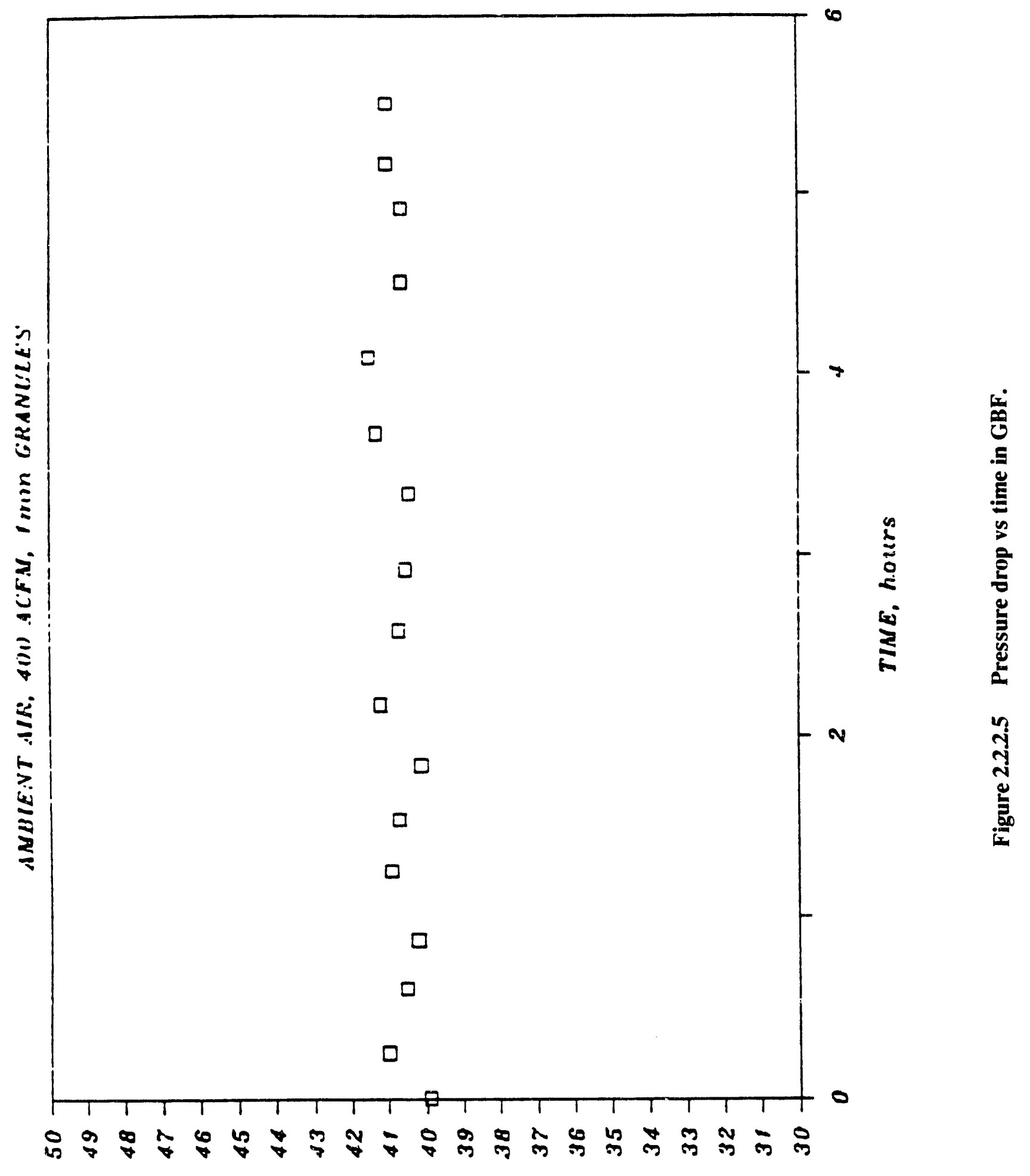

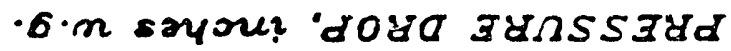




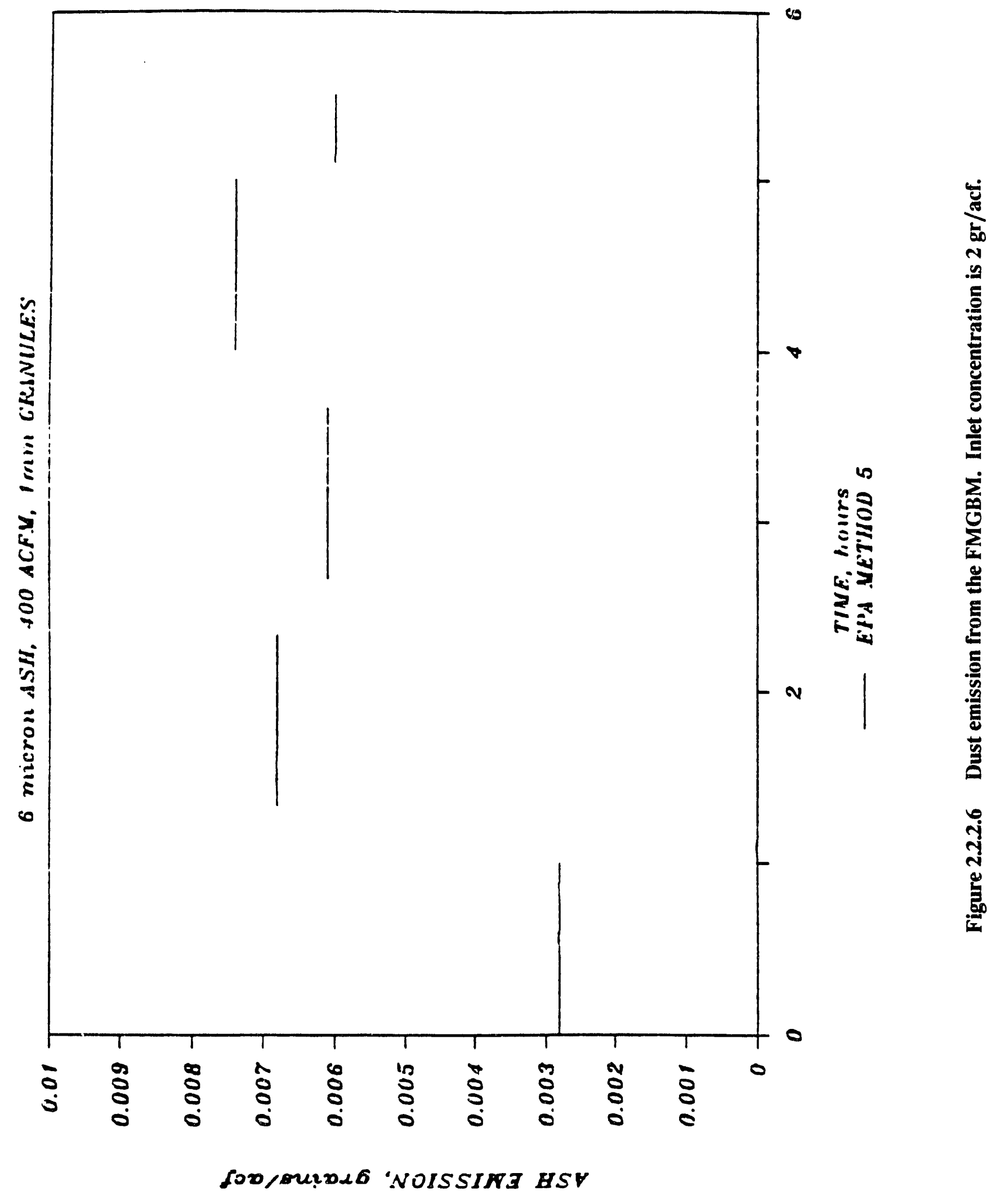




\subsubsection{Bench Scale High Pressure High-Temperature Granular Bed Filter Design for One-Nozzle Segment Combustor}

The bench scale system for the one-nozzle segment combustor test rig at GE-CRD is similar in size to the cold-flow model described above. It is designed to operate at $2200^{\circ} \mathrm{F}$ and 200 psi and to filter combustion gas particulate matter that includes cral ash, unreacted lime and calcium sulfate. The vessel is shown in Figure 2.2.2.7. The vessel is refractory lined and shell temperature is reduced to below $200^{\circ} \mathrm{F}$. The combustor is installed on tcp of the vessel and the hot gases are fired downward through a ceramic pipe into the filter media. The outer internal pipe that forms the aniular void for moving bed flow will either be made of ceramic or fabricated of high-alloy metal such as Hastelloy with a thermal boundary coating (TBC). If a metal is used, a cool stream of high-pressure steam or air will be injected in the annular space between the internal pipes to maintain low-metal temperature. No recycle of granules is designed for the small bench system. Instead, the bed material will move down from a pressurized inlet lockhopper to an outlet lockhopper at the bottom until the top lockhopper is empty and the bottom one is full. There will be enough bed material in the bed for $8 \mathrm{hr}$ of continuous operation.

The bench scale high temperature high-pressure granular bed filter has been designed for installation at the GE-CRD facility. A lot of effort was given to sizing and general arrangement to fit the system to the available space, as shown in Figure 2.2.2.8. The structure's total height is about $18 \mathrm{ft}$ leaving enough space between the structure and the ceiling to allow free access to the combustor.

\subsubsection{Conceptual Design of a Full Scale Granular Bed Filter Interfacing with LM500 Gas Turbine}

A conceptual design of a closely coupled CWM-fired gas turbine with a GE granular bed filter was performed. A process flow diagram including all the main streams of the granular bed filter system is shown in Figure 2.2.2.9. The fuel feed to the combustor, stream 1 in Figure 2.2.2.9, is a CWM containing $26.6 \mathrm{lb} / \mathrm{hr}$ ash, $26.6 \mathrm{lb} / \mathrm{hr}$ sulfur and $92.4 \mathrm{lb} / \mathrm{hr}$ hydrated lime representing $1.5 \mathrm{Ca} / \mathrm{S}$ ratio. Stream 3 is the hot, clean, combustion gas containing $50 \%$ of the inlet sulfur and less than $1 \%$ of the total solids input. The captured sulfur in calcium sulfate form, as well as excess lime and coal ash are captured by the granular bed material and discharged from the filter vessel by means of a bottom discharge pipe, Stream 5 . The particle-laden bed material discharging from the filter vessel contains about $5 \%$ particulate matter by weight. It is elevated to the de-entrainment vessel by a stream of lift air, Stream 6 . In the de-entrainment vessel the bed granules settle and flow back into the filter vessel through a small media reservoir vessel. The particles are entrained in the lift air, Stream 8 , which is cooled in the heat exchanger, Stream 9, and filtered in a small low temperature highpressure baghouse. The particles discharge from the system through a lockhopper system, Stream 11, while the clean air, Stream 10, is compressed in a boost compressor and recycled 


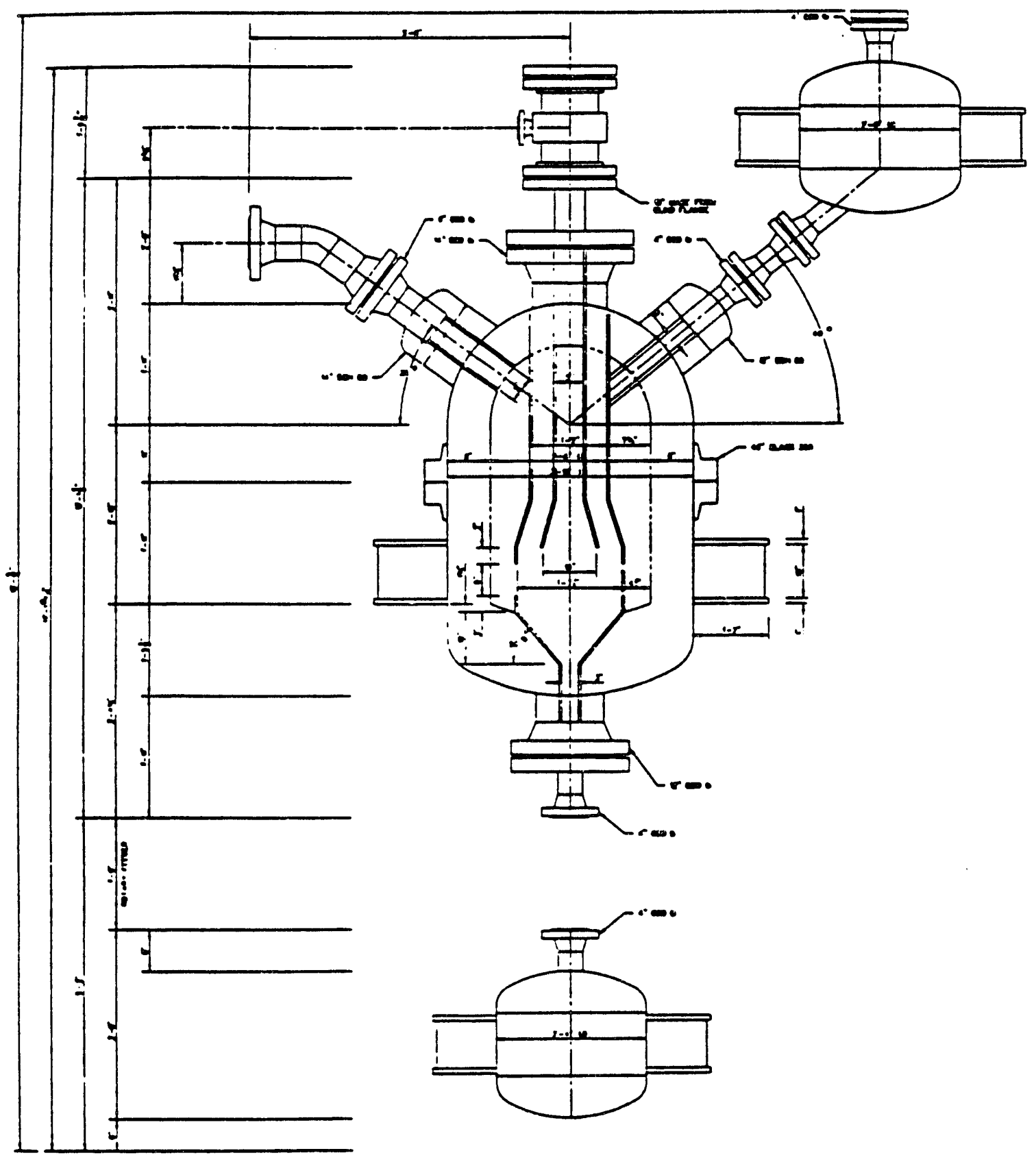

Figure 2.2.2.7 Granular bed filter vessel for bench scale high pressure high-temperature experiments at GE-CRD. 

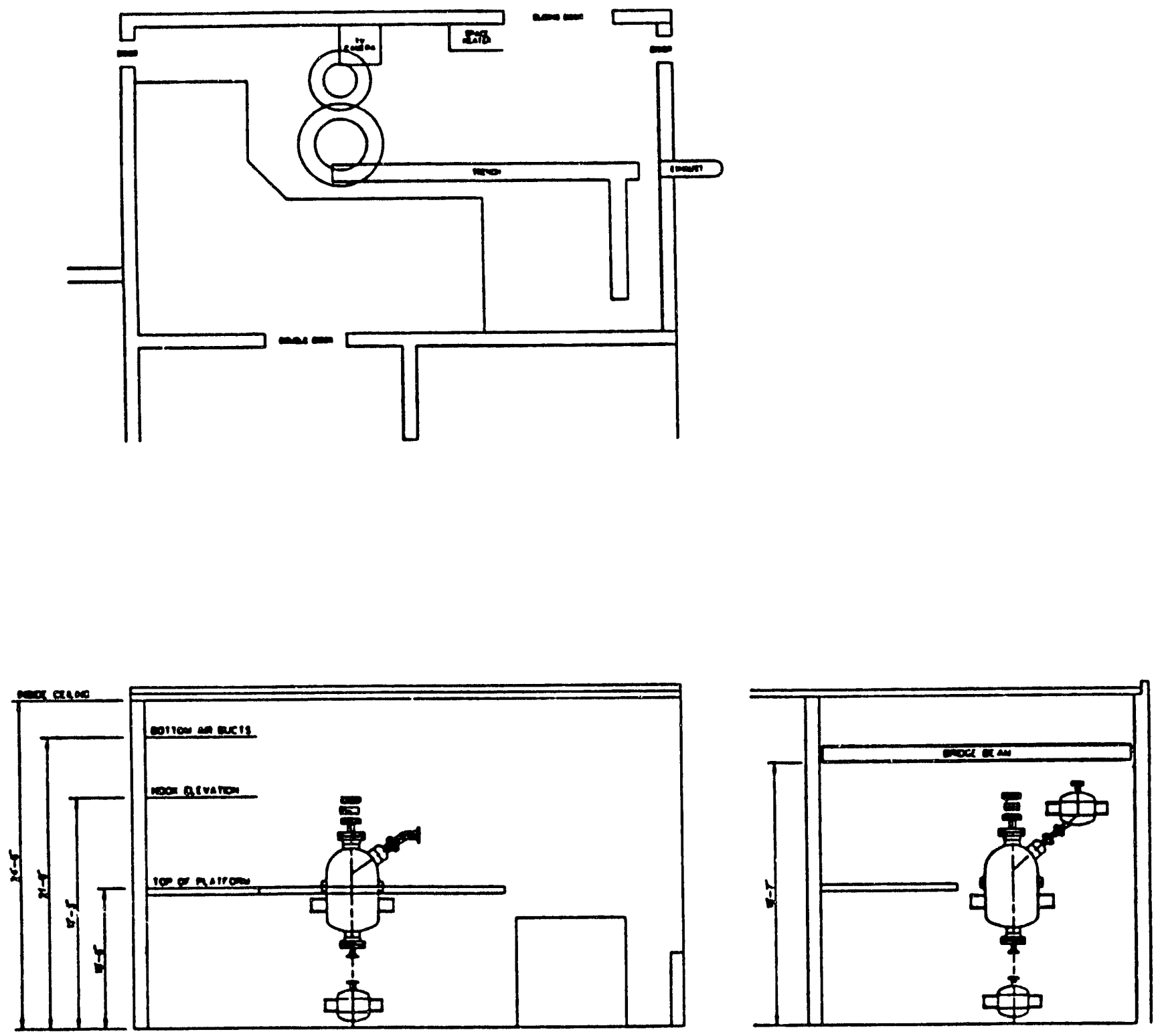

Figure 2.2.2.8 Granular bed filter system layout for bench scale experiments at GE-CRD. 


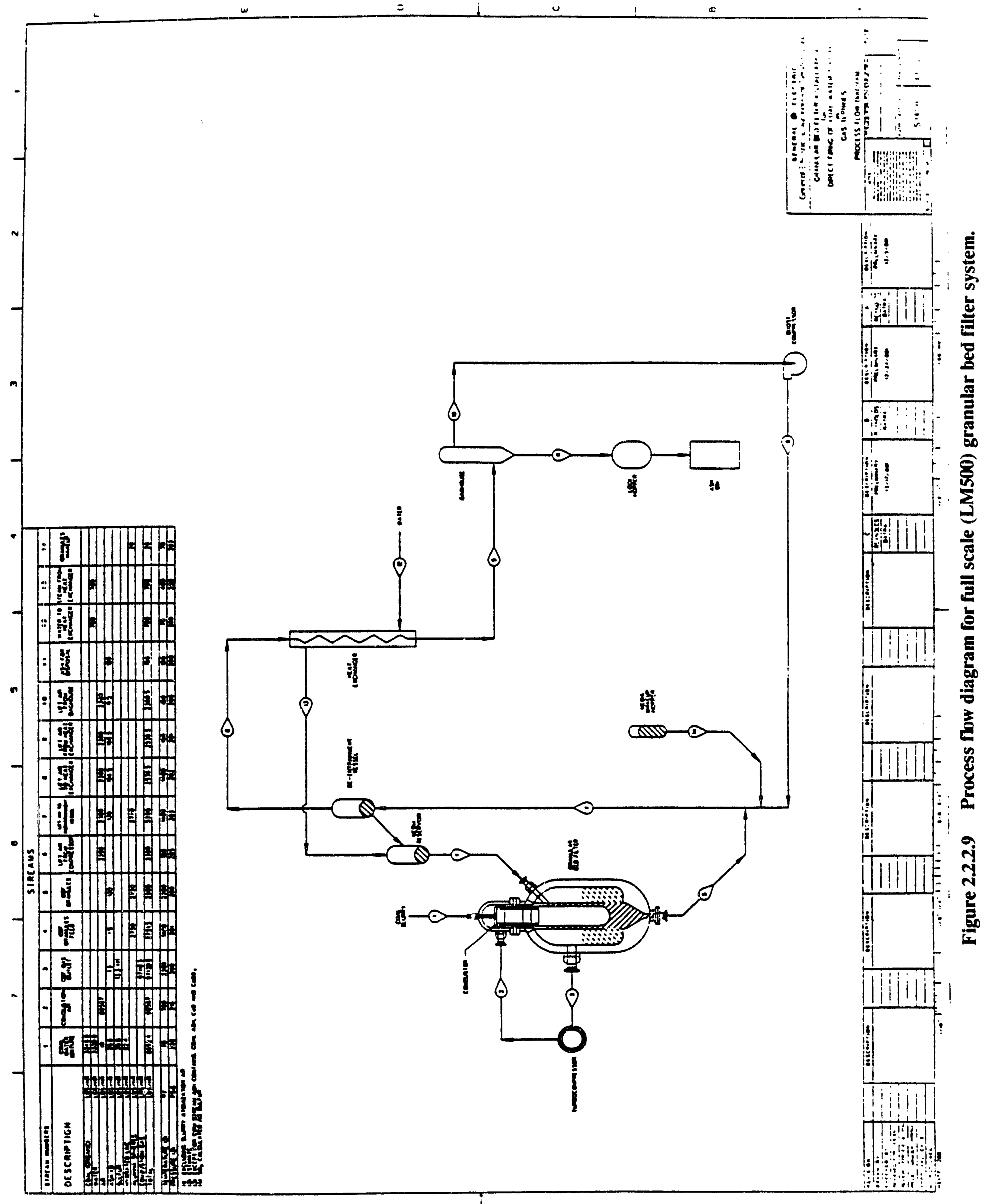


into the pneumatic lift system. The heat lost by the bed material during transportation is recovered by the heat exchanger and generates $700 \mathrm{lb} / \mathrm{hr}$ of high-pressure steam. The $400^{\circ} \mathrm{F}$ 250 psi steam is being used to cool the internal pipes. The steam, Stream 13, can be injected through the media reservoir or directly into the top of the annular space between the internal pipes. Steam injection increases the mass flow through the filter and the turbine by less than $1 \%$.

A schematic of the system layout, drawn to scale, is shown in Figure 2.2.2.10. The total height of the structure is about $70 \mathrm{ft}$. The height is driven by the need to allow access to the combustor and room for removing the top of the vessel.

The $9.5 \mathrm{ft}$ diameter granular bed filter shown in Figure 2.2.2.11 is a carbon steel vessel with $1 \mathrm{ft}$-thick refractory lining which reduces the internal diameter of the vessel to $7.5 \mathrm{ft}$. A manhole on top of the vessel provides access to the vessel for stationary bed loading and for maintenance. The vessel is conservatively designed for an overall average; velocity of about $3 \mathrm{ft} / \mathrm{sec}$. Based on projection from current cold-flow modeling it is believed that the overall average velocity can be doubled. As a result the vessel size can be significantly reduced or the flow can be significantly increased.

The can combustor is located inside the vessel suspendid from the top of the small dome shown in Figure 2.2.2.11. The combustor and engine arrangement were described earlier in Section 2 . There is an inner and outer pipe arrangement similar to that in the cold-flow model for introduction of gases and media in the bed. The inner pipe ( $2 \mathrm{ft}$ diameter) penetrates deep into the granular bed vessel and directs the hot-combustion gas into the bed. A moving bed of 1 to $2 \mathrm{~mm}$ alumina spheres is formed in the void between this inner pipe and the $4 \mathrm{ft}$ diameter outer pipe. The bed is 12 in. thick. It flows by gravity downward to the conical hopper at the bottom of the vessel and discharges through a 6 in.-discharge pipe. The outer boundary of the moving bed is formed by the $4 \mathrm{ft}$ in diameter alloy pipe hanging from the top of the vessel. The fixed bed is located in the annular void between the $4 \mathrm{ft}$ internal pipe and the vessel refractory lined wall. The stationary bed comprises of layers of increasingly larger (in the outer and upper direction) alumina spheres. Without considerations to sticky or partially molten particles, the efficiency of the moving bed is expected to exceed $99 \%$.

Moving bed material is fed to the vessel from the top through three feeding pipes. The bed material then flow by gravity downward as described above. Steam at $400^{\circ} \mathrm{F}$ and $250 \mathrm{psi}$ is injected to the moving bed and is a sink for the heat conducteu from the hot combustion gases. Heat transfer calculations shows that it takes about $500 \mathrm{lb} / \mathrm{hr}$ of $400^{\circ} \mathrm{F}$ steam to reduce the metal temperature to below $1800^{\circ} \mathrm{F}$ when the combustor gas is at $2200^{\circ} \mathrm{F}$. Higher flow rate of steam results in an even lower temperature.

The small dome on top of the vessel is maintained at a temperature level of 500 to $800^{\circ} \mathrm{F}$ by the flow of compressor-discharge air at about $750^{\circ} \mathrm{F}$, the flow of steam at about $400^{\circ} \mathrm{F}$ and 


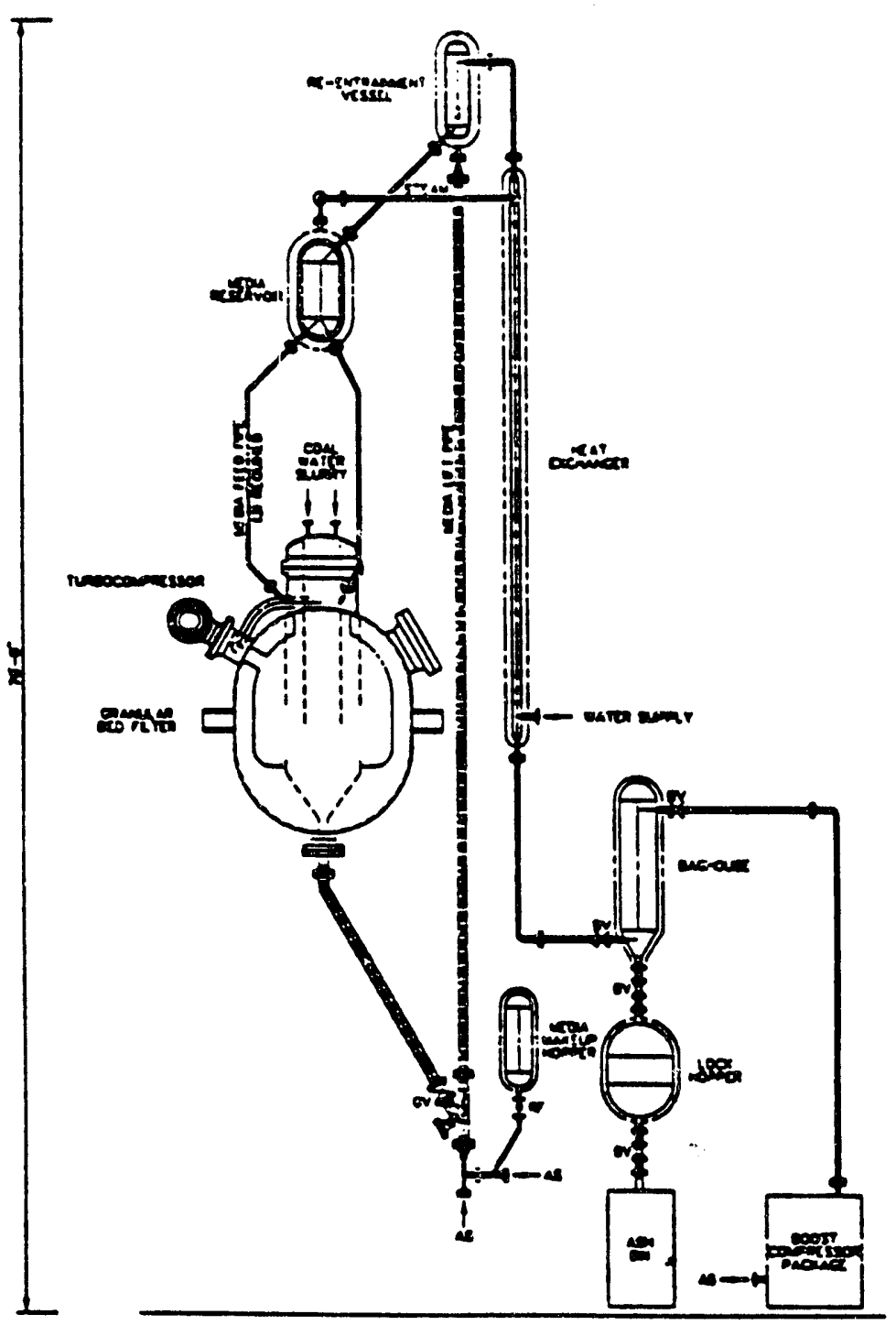

Figure 2.2.2.10 Layout for full scale (LM500) granular bed filter system. 

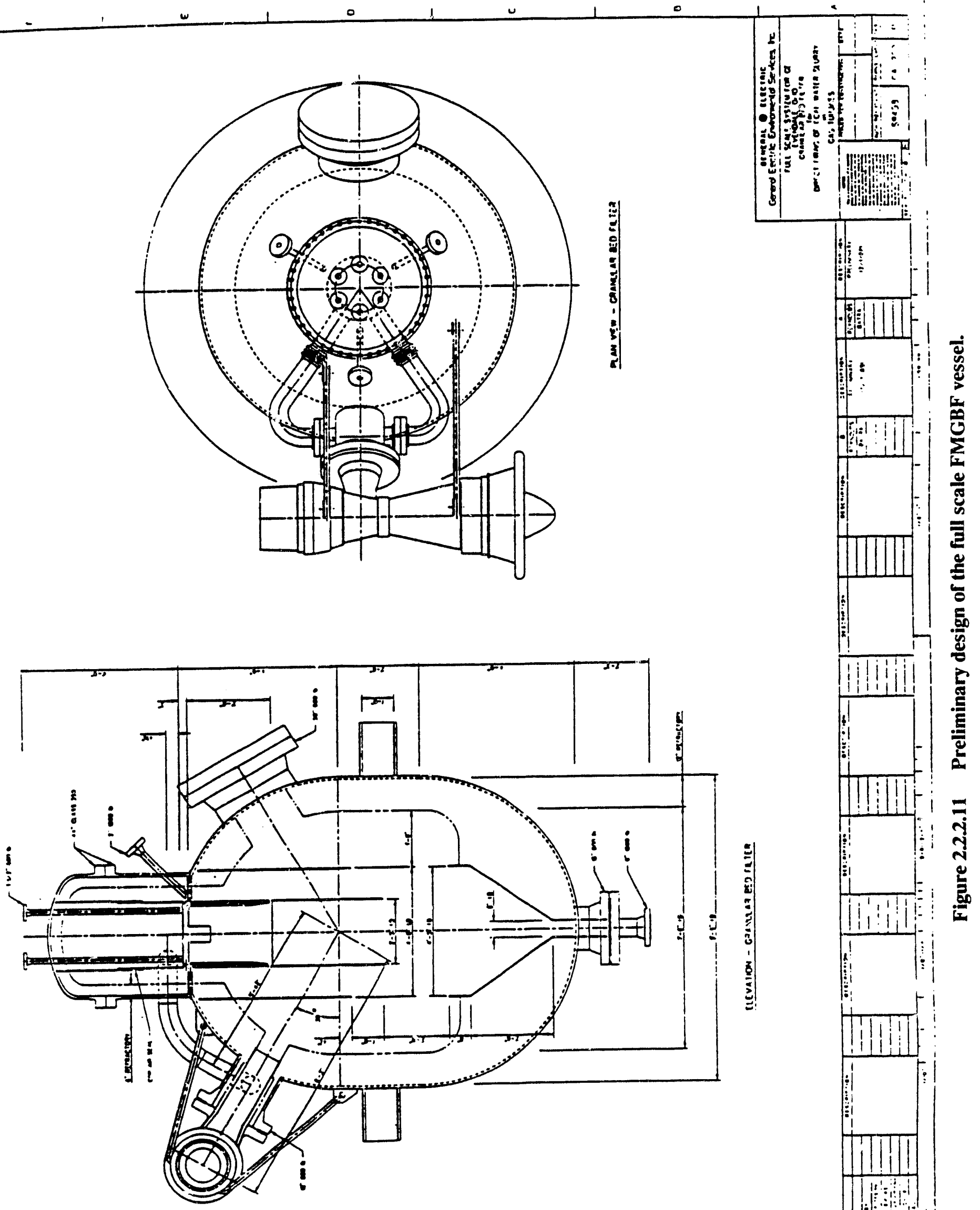
the flow of granular material at $1400^{\circ} \mathrm{F}$. All the flows are in the downward direction and hot gases from the combustor are not expected to penetrate into the dome space.

The conceptual interface between the granular bed filter and the turbocompressor is described in Section 2. Additional work and detailed design of granular bed turbine interface as well as detailed design of the granular bed vessel are still required.

\subsubsection{System Assessment}

The GE granular bed filter has the advantage of using fine granules to achieve highfiltration efficiency, yet it operates at high gas throughputs per unit area which is typical of low-efficiency large bed material granular bed filters. Cold-flow modeling tests have shown that the concept is feasible, that filtration efficiency is high enough to meet NSPS requirements, that gas throughputs are high, that pressure drop is reasonable and acceptable for high gas-pressure applications and that the filter can operate continuously without plugging.

Yet the filter is still in early stages of development and more cold and hot tests are required before a commercial system can be built. Additional work should include investigation of the impact of various type of dusts on filtration efficiency and bed plugging. The impact of dust stickiness on filtration efficiency, bed plugging, and bed material cleaning are critical areas requiring further study. Optimization of internal pipes arrangement to achieve higher gas throughputs and erosion problems due to sorbent flow should also be investigated further before the filtration feasibility can be fully assessed. 


\section{Section 3}

\section{SUPPORTING TECHNICAL RESULTS}

\subsection{Deposition Amelioration}

\subsubsection{Introduction: Deposition}

\subsubsection{Background-Deposit Phenomenology}

In section 2.0 , we described our determination that the only potentially commercial technology for the GE advanced coal-fueled gas turbine would require in-line annular combustion and post-expansion particulate and suifur dioxide cleanup. This places the bulk of the technical challenge on ameliorating hot-gas path degradation. In particular, deposition, erosion, and corrosion (DEC) considerations become paramount in this proof-of-concept effort.

Products of combustion (POCs) which influence DEC include gaseous and particulate phases. Of the gases, sulfur dioxide and alkali halides are most likely to participate directly in DEC, especially corrosion. Carbon monoxide indirectly participates through the generation of locally reducing conditions which could enhance metal wastage through sulfidation and carburization. Still, the bulk of the concern in DEC must be from condensed phases.

Particulate emissions are threefold. Included are solid spheres of frozen slag ranging in size from $3 \mu \mathrm{m}$ down to less than $0.1 \mu \mathrm{m}$, resulting from individual mineral grains which have melted. Some ash vaporizes and condenses into fume, and is largely comprised of iron. The balance of particulate consists of unburned carbonaceous char shells and fragments. Even for combustion efficiencies of $99.9 \%$, char constitutes $10 \%$ of the particulate combustion products. For $99 \%$ burnout, over half of the particulate is carbon. The ratio of fume to slag is not precisely known, but is probably less than $1 \%$ wt based on microscopic analyses. The aerosol typically nucleates on larger particles. Examples of these particulate POCs can be seen in Figure 3.1.1.1.

In general, deposition can be considered as a sequence of events consisting of particle arrival, adherence, and finally, cementation. The bulk of the leading edge and pressure side deposition in the GE direct coal-fired gas turbine occurs through inertial impaction. Figures 3.1.1.2 and 3.1.1.3 show micrographs of deposits at varying degrees of magnification, indicating that spherical slag grains have frozen in the boundary regime of the highly air-cooled airfoils, and appear largely intact. Subsequent sintering and fusion, Figure 3.1.1.4 results in a viciously adherent mass. The chemistry of this tras sformation has been characterized and can be found in Section 3.1.2 of this Report. 


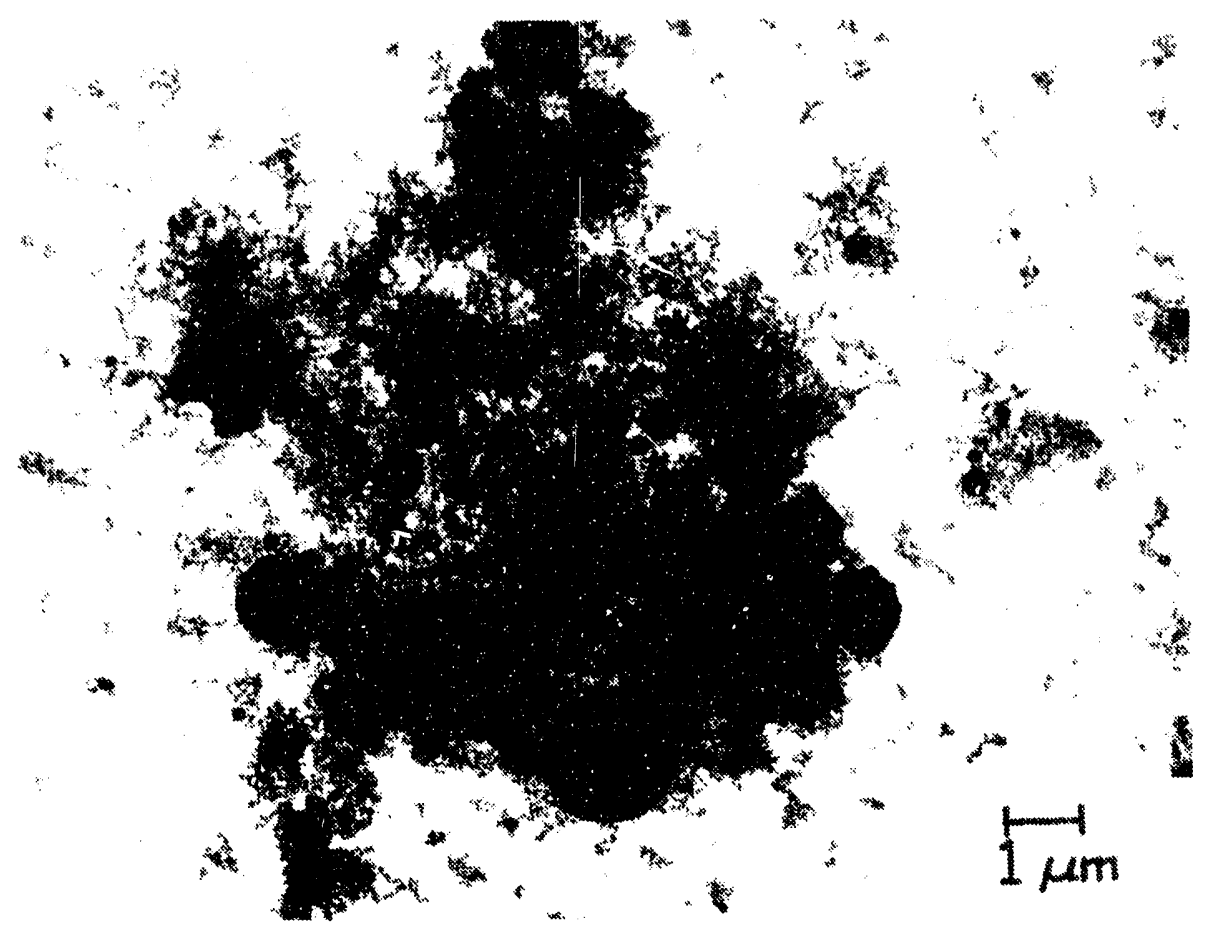

Figure 3.1.1.1 Quench probe sample from CWM combustion. 


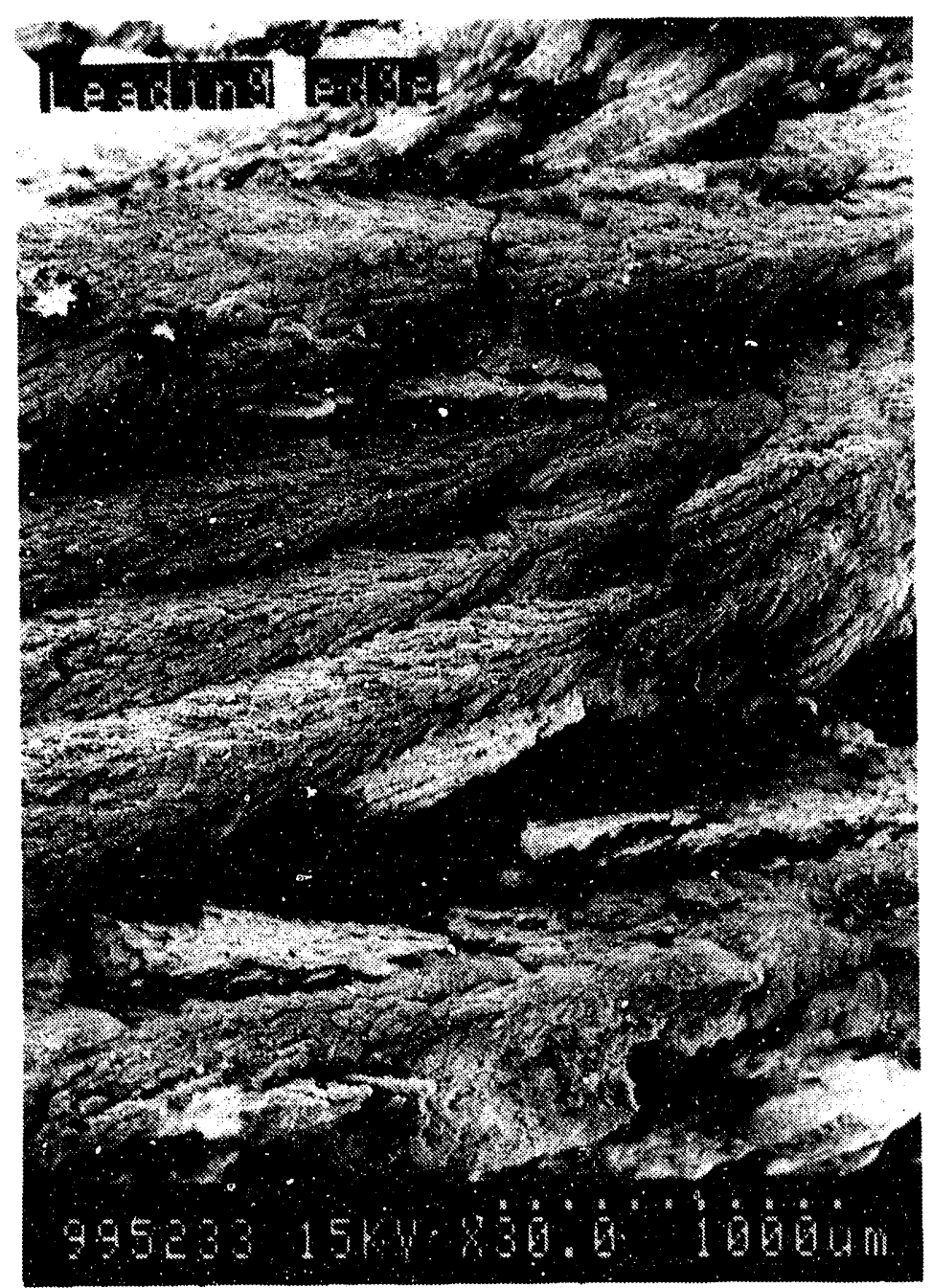

Figure 3.1.12 Unfused leading edge deposits. 


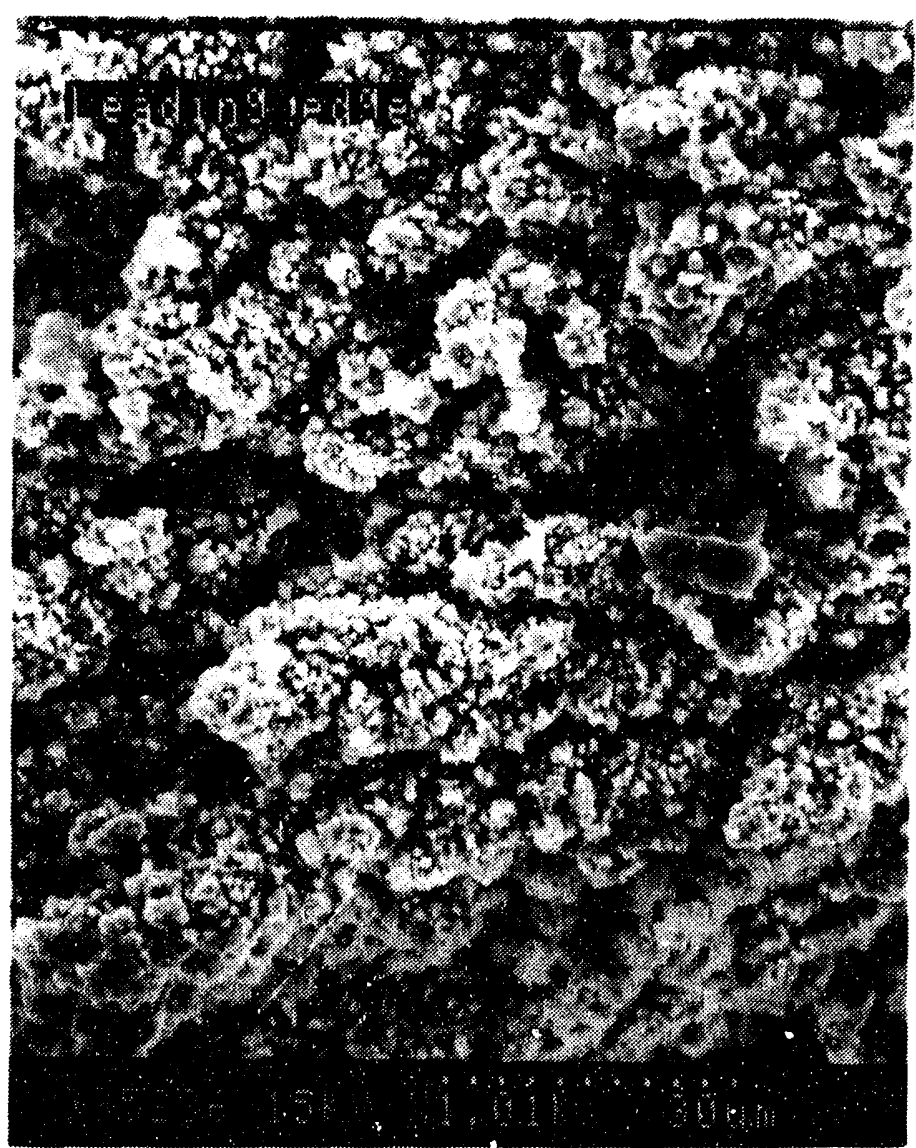

Figure 3.1.1.3 Unfused leading edge deposits.

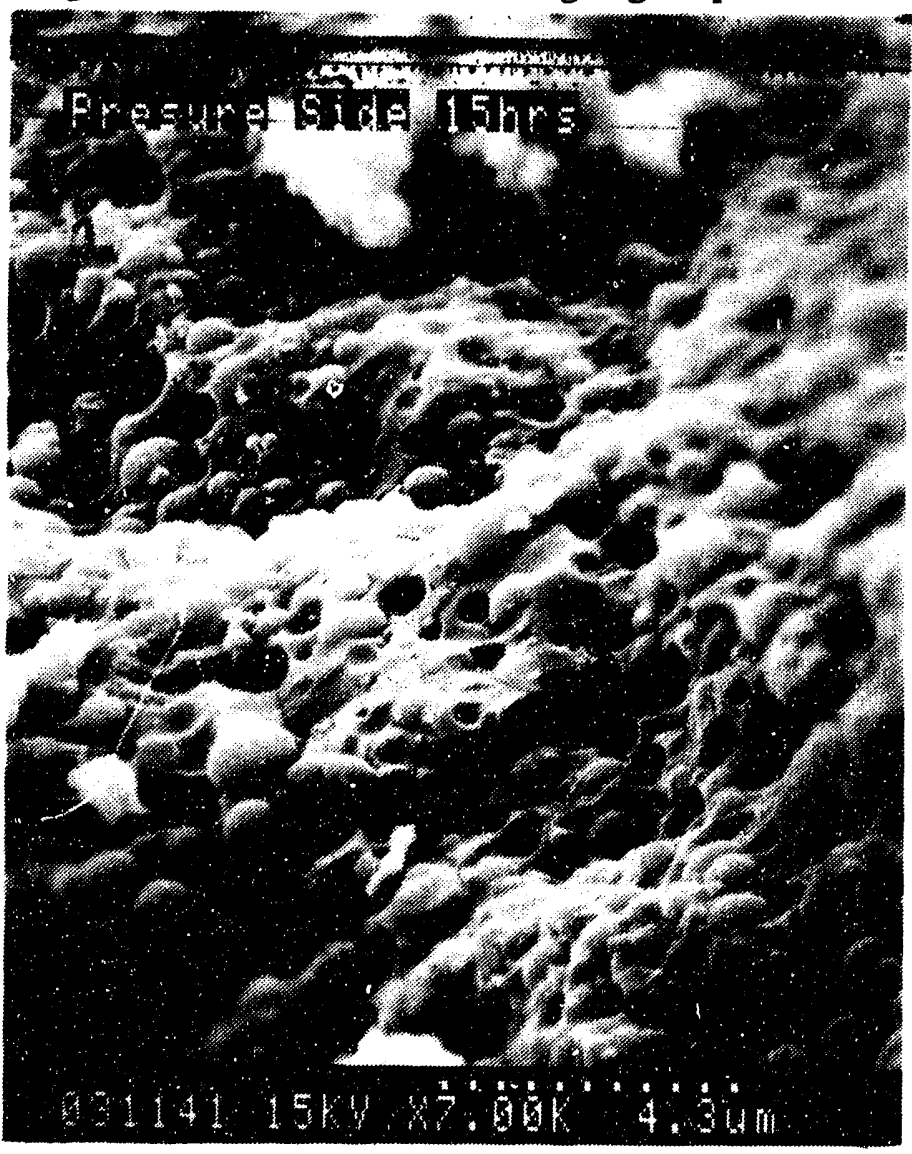

Figure 3.1.1.4 Fused pressure-side deposits. 
Suction side deposits probably occur through a combination of eddy impaction, Brownian diffusion, thermophoresis, and vapor condensation. In general deposits on the suction surface have a much finer grain structure and vapor based chemistry.

\subsubsection{Deposit Abatement}

Deposit abatement strategies consist of minimizing total particulate flux in the system, reduction of particle arrival at the airfoil surface, minimizing the fraction of arriving particles which stick, reducing the sintering and fusion rate of those particles which do stick so that they are weak and friable, removal of deposits on line through abrasive injection or inherent erosion, off-line cleaning through water washing or mechanical treatment, and finally, through a new process developed under the auspices of this program - in situ deposit modification which causes deposits to spontaneously spall... sort of a "self-cleaning" gas turbine.

In order to minimize total system particulate, the fuel has been beneficiated to reduce the overall quantity of ash present in the system. Mineral matter occurs in coal as finely disseminated grains that melt during combustion. Presumably, if there is less mineral matter in the coal, there is less to adhere. Complete de-ashing of the coal is not yet economically feasible. The second prong in particulate minimization is through the achievement of high combustion efficiency. As pointed out earlier, over half the particulate passing through the turbine is unburned carbonaceous char, even when combustion efficiencies are in excess of $99 \%$.

The next step in minimizing deposition is through reducing particle arrival rates. This is achieved through coal comminution and good slurry atomization. By micronizing the fuel, mineral and organic grains are comminuted. Finer particles are more likely to follow hot gas path streamlines and avoid impaction on the airfoils. For mineral matter, comminution yields finer ash; for organic matter, finer particles mean better burnout and reduced char yield. As described in Section 3.3, improved atomization plays an important role in char fragment size and burnout.

The next phase of deposit control is through airfoil cooling. Once the particles approach the airfoil surfaces, they can undergo elastic or inelastic collisional impact. To adhere, the particle kinetic energy must be discharged to the surface or it will not stick. By cooling the target, the molten slag which comprises the ash will freeze in the boundary layer, greatly reducing its stickiness and tendency for inelastic adhesion. A tradeoff from cooling is an increase in deposition through vapor condensation and thermophoresis. Another means to dissipate particle kinetic energy is through char shedding and fromentation. Thus poor combustion efficiency is once again indicted. Of course, if burnout is very poor, for example less than $90 \%$, deposition may actually be diminished in that only hard, non-adherent char surfaces are presented to the airfoils, an effect further enhanced by inherent erosion of large char species. Indeed we have anecdotal evidence of this; during one combustion trial which had especially poor combustion no deposits were found. Of course, poor burnout is economically untenable. 
The condition of the target surface will also influence deposition. If it is cold and clean, there will be a limited tendency for inelastic collisions by the ash. If it is covered with a porous and fluffy surface, collisions may collapse the suprastructure and increase deposition. A very weak deposit may be eroded by incoming combustion products. A viscous liquid on the surface will very efficiently capture particles. In the event of extreme viscosity, the capture may be reduced as the surface may appear to be solid to the products of combustion. The condition of the surface will also affect heat transfer, establishing thermal gradients with the outer surfaces eventually reaching the ambient temperature, sufficient to melt many of the ash components. Deposit buildup on the surface is never uniform, so that eddies and fluid flow instabilities can arise which further accelerate deposition..

Once deposited, the particles can be re-entrained by erosion, or may be sintered or even completely fused into a liquid. A weakly sintered deposit initially develops, which is subject to erosion or on-line abrasive cleaning. As seen in Figure 3.1.1.5, nutshelling would be required too frequently to be viable by itself as a deposition strategy.

Water-washing may help matters, though this requires several hours of down-time. The composition of deposits was analyzed and indicated that few components were water soluble. An exception was on the suction surfaces where soluble aphthidolite species were occasionally observed. Indeed water washing was found to be most effective on suction surfaces. On highly fused pressure side deposits, microcracking occurs during shut-down presumably from thermal stresses. Water may penetrate these cracks and, during relight, may cause deposits to spall by explosive boiling.

The last method for deposit remediation involves in situ deposit chemistry modification in which deposit chemistry is affected either by judicious coal selection, or more generally, through addition of small amounts of ash modifiers. These are typically inexpensive clays or ceramics that weaken the deposit internal and interfacial bond strength so that deposits spontaneously spall or erode. The first attempt to modify ash chemistry took place under the auspices of the Components Screening program. There we examined the use of alumina as a means to alter ash chemistry and sticking. This did successfully reduce deposition, though the alpha-alumina used in these tests introduced erosion along the trailing edges of the airfoils.

In the following sections, we report, first, a detailed analysis of the chemistry of deposition and fusion, Section 3.1.2, followed by discussions about our several attempts to vitiate deposition through ash modification. Key factors under consideration included deposition control without creating deleterious technical, environmental, or economic side effects. Thus ash modifiers that exacerbate corrosion or erosion or required extreme coal selectivity were to be avoided. The ash modification procedure should be general, easy to implement, and not interfere with fuel handling and rheology. Expensive ash modifiers, ones that pollute, or interfere with the downstream cleanup system were to be avoided. 


\section{DEPOSTMON RATE FOR CWM-FUELED LMSOO TURBINE SIMULATOR}

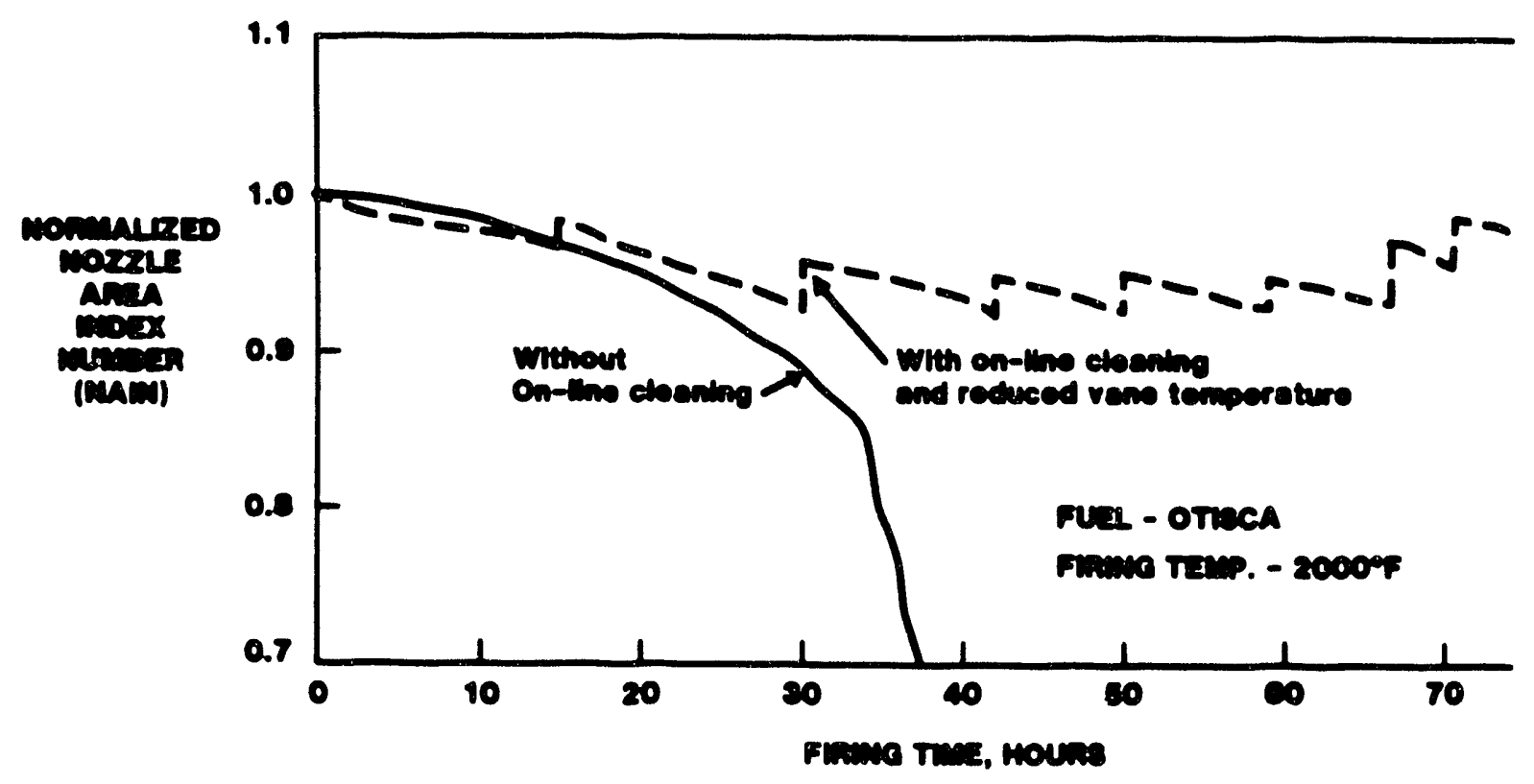

Figure 3.1.1.5 NAIN plot compares deposition rate with and without on-line abrasive cleaning. 
Several candidate additives were explored including a variety of kaolin aluminosilicate clays, hydrous aluminum oxide of the boehmite structure, and calcia based reagents for sulfur capture which also served to provide valuable insights into the deposition process. Adjusting the ash chemistry through judicious coal selection was also explored, culminating in the successful burn of a 5.5\% ash Elk Creek coal from OXCE Fuels.

Of more general value is the additive approach. Here kaolin clay was found to be the best additive for deposit remediation. Kaolin is inexpensive and abundant, and can be admixed directly with the slurry with no adverse rheological effects. Most significant is that kaolin clay quantitatively prevents airfoil deposition without introducing erosion. Where deposits did occur, i.e., upstream along the transition section between the combustion liner and the airfoils, they could be ascribed to stagnation points and hot spots not likely to be present in an actual annular combustor. Considerable effort was expended in eliminating these system artifacts by redirecting coolant to the dead zones, which proved to be effective.

We speculate that kaolin was effective by virtue of its ability to react in situ with airfoil dejosits so as to devitrify the melt, raise its viscosity, and reduce deposit volume so as to cause it to spontaneously spall. We reasoned that boehmite, a hydrous aluminum oxide, would outperform kaolin in these respects. In fact, this was observed, but an unanticipated side reaction caused the release of alkali metals which deposited as alkali sulfate glues. Thus kaolin seems to be the superior agent. 


\subsubsection{Chemistry of Deposition and Cementation}

\subsubsection{Introduction}

In order to minimize or eliminate deposition in coal-fired gas turbine engines, a detailed knowledge of deposit chemistry is required. This may provide the basis for interrupting the sequence of particle arrival, adhesion, and cementation/fusion on the surface.

As described in Section 3.1.1, the deposition process, as manifest in NAIN measurements, is a two step process. Initially deposition is moderately rapid, $\sim 1 \%$ NAIN drop every 6 to $8 \mathrm{hr}$. After an induction period of usually greater than $24 \mathrm{hr}$, the process becomes catasirophic. In this section, we will show that the two stages of deposition are also evident on a microscopic basis. Initially there is a porous and weakly adhered array of primary ash grains generally associated with a single (or few) mineral grains which have melted, frozen in the boundary layer, and stuck. As these build up, the outer layer gets hotter, and sinters, eventually fusing into a single molten slag which is extremely effective in capturing and fusing newly arrived particles.

The chemistry associated with these steps is described herein, and represents the basis for subsequent deposit remediation efforts.

\subsubsection{Experimental}

3.1.2.2.1 Engine and Fuel Description. Our understanding of deposit chemistry comes from previous studies including the Alkali Species Characterization and Components Screening contracts, as well as from samples and data obtained in this study. As usual, the LM500 turbine simulator and,(from the Alkali Species Contract), a "minirig" combustor were employed for sampling. Both the "minirig" and the LM500 combustion systems mimic the timetemperature-pressure profiles in actual gas turbine engines. The LM500 includes stationary airfoils from a GE LM500 aircraft-derivative engine, oriented to simulate a sector of the first stage nozzles where greatest deposition and wear is anticipated. The "minirig" includes a back pressure orifice and air-cooled pins for sampling. A detailed description of each combustion apparatus, experimental parameters and a summary of the deposit characterization is in References 1 and 2.

Coal water mixtures (CWM) were used as fuel and prepared by beneficiation of high volatile A Kentucky Blue Gem coal. Physical beneficiation was performed by Otisca Industries Ltd. An organic hydrophobe was added to an aqueous slurry of micronized coal to agglomerate the organic components and disperse the mineral matter [3]. Properties of the fuel are listed in Table 3.1.2.1. Low temperature oxygen plasma ashing experiments were performed on the raw and product Otisca coal [4]. The beneficiation reduced the ash content by about $97 \%$. Minerals were identified in the coal by first removing the organic matter using an oxygen plasma etch at $100^{\circ}$ or less. The Blue Gem coal minerals consist of quartz, kaolinite, il- 
Table 3.12.1

Otisca Blue Gem Coal-water Mixture Fuel Specifications

Coal content (wt.\%)

Particle size ( $\mu \mathrm{m})$

Viscosity (mPa s)

Proximate analysis (dry, wt.\%)

Fixed carbon $\quad 60.3$

Volatiles $\quad 38.8$

$\begin{array}{ll}\text { Ash } & 0.9\end{array}$

Ultimate analysis (dry, wt.\%)

83.0

$\mathrm{H} \quad 5.3$

$\mathrm{N} \quad 2.1$

S $\quad 0.9$

$\mathrm{Cl} \quad 0.2$

$\mathrm{O}$ (by difference) $\quad 7.6$

Ash composition (wt.\%)

$\mathrm{SiO}_{2}$

$\mathrm{Al}_{2} \mathrm{O}_{3}$

23.2

$\mathrm{Fe}_{2} \mathrm{O}_{3}$

28.2

$\mathrm{CaO}$

11.6

$\mathrm{MgO}$

2.9

$\mathrm{NaO}$

0.5

$\mathrm{K}_{2} \mathrm{O}$

0.5

$\mathrm{TiO}_{2}$

1.1

$\mathrm{SO}_{3}$

13.5

Others

0.3 
lite, calcite, dolomite, anhydrite and pyrite.

The collected deposits were characterized using X-ray powder diffraction (XRPD), energy dispersive fluorescence spectroscopy (EDS), scanning electron microscopy (SEM) and transmission electron microscopy (TEM). Results from $x$-ray absorption fine structure analysis of the deposits from AMAX CWM combustion can be found in Reference 6.

The instruments used for the analysis were a Siemens D500 diffractometer using Cu K alpha radiation ( $50 \mathrm{kV} / 40 \mathrm{~mA}$ ), EDAX 901 with TN4000 using Rh radiation (29 kV), Hitachi S520 LB SEM with PGT windowless detector and System IV EDS and a Hitachi H600 TEM with TN4000 EDS. The diffraction data were reduced using Specplot [7], and the plagioclase lattice parameters were calculated using the LSR program from Reference 8. Calibration of the diffraction data was done with $\mathrm{SPEX} \mathrm{Al}_{2} \mathrm{O}_{3}$ as an external standard.

\subsubsection{Results and Discussion}

The results described below are from the characterization of the airfoil deposits formed from combusting Otisca CWM in the LM500 simulator. Photographs of the deposits are shown in Figure 3.1.2.1. Figure 3.1.2.2 illustrates that slags and powder coexist. In general, the deposits were in the form of a partially sintered powder which often graded into a slag. For a detailed description of the deposit location and corresponding morphology see Reference 1. The powder and slag portions were separated for a comparative analysis.

The powders typically contained major amounts of hematite and varying amounts of anhydrite, $\mathrm{CaSO}_{4}$; the spinel structure, $\mathrm{AB}_{2} \mathrm{O}_{4}$; and the plagioclase structure, $(\mathrm{Na}, \mathrm{Ca})$ $\mathrm{Al}_{1-2} \mathrm{Si}_{3-2} \mathrm{O}_{8}$.

The slags typically contained spinel and plagioclase with lesser amounts of hematite and no anhydrite. The lattice parameters of the spinel and plagioclase, and the splitting of the plagioclase $\{220\}$ line was notably different between the powder and slag deposits. In Figure 3.1.2.3 overlayed diffractograms of a powder and two slags show the $\{220\}$ splitting and the spinel line shifts. The spinel line profiles indicated a compositional distribution was present; this was substantiated with TEM EDS of slag 2. The lattice parameters of the spinels based on the line position of the major and minor compositional distributions are given in Table 3.1.2.1.

In the deposits containing no $\mathrm{CaSO}_{4}, \mathrm{EDS}$ detected the following elements: $\mathrm{Mg}, \mathrm{Al}, \mathrm{Si}, \mathrm{Ca}$ and $\mathrm{Fe}$ in major to minor amounts. Trace amounts of $\mathrm{Na}, \mathrm{K}, \mathrm{Ti}, \mathrm{Cr}$ and $\mathrm{Sr}$ were also detected. The common spinel forming elements in this assemblage are $\mathrm{Mg}, \mathrm{Al}, \mathrm{Cr}, \mathrm{Ti}$ and $\mathrm{Fe}$. TEM EDS confirmed this association with $\mathrm{Cr}$ and $\mathrm{Ti}$ being minor components. The end member spinel phases containing these elements and their lattice parameters are given in Table 3.1.2.2. Since spinels can form solid solutions between the end members it is instructive to observe the variation of lattice parameter from Al-rich spinels to Al-poor spinels. The 


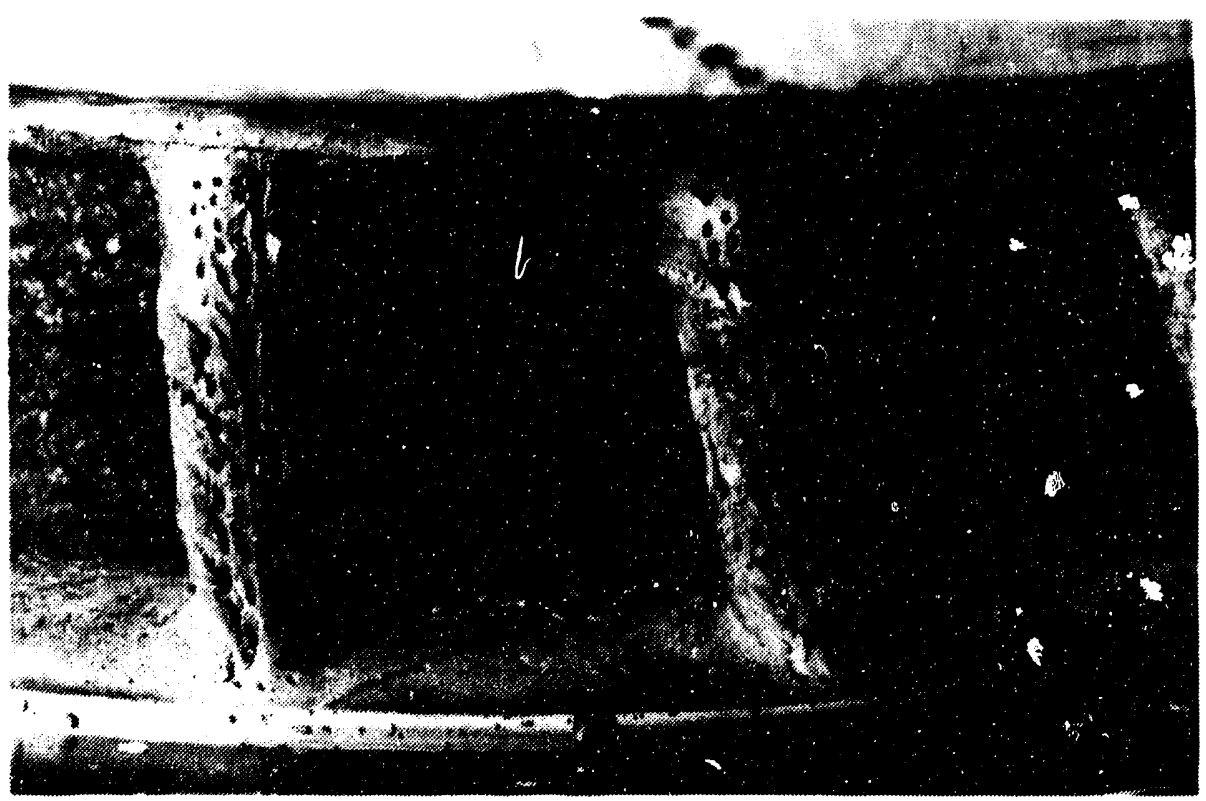

Figure 3.12.1 Photograph of deposits on LM500 airfoil. 


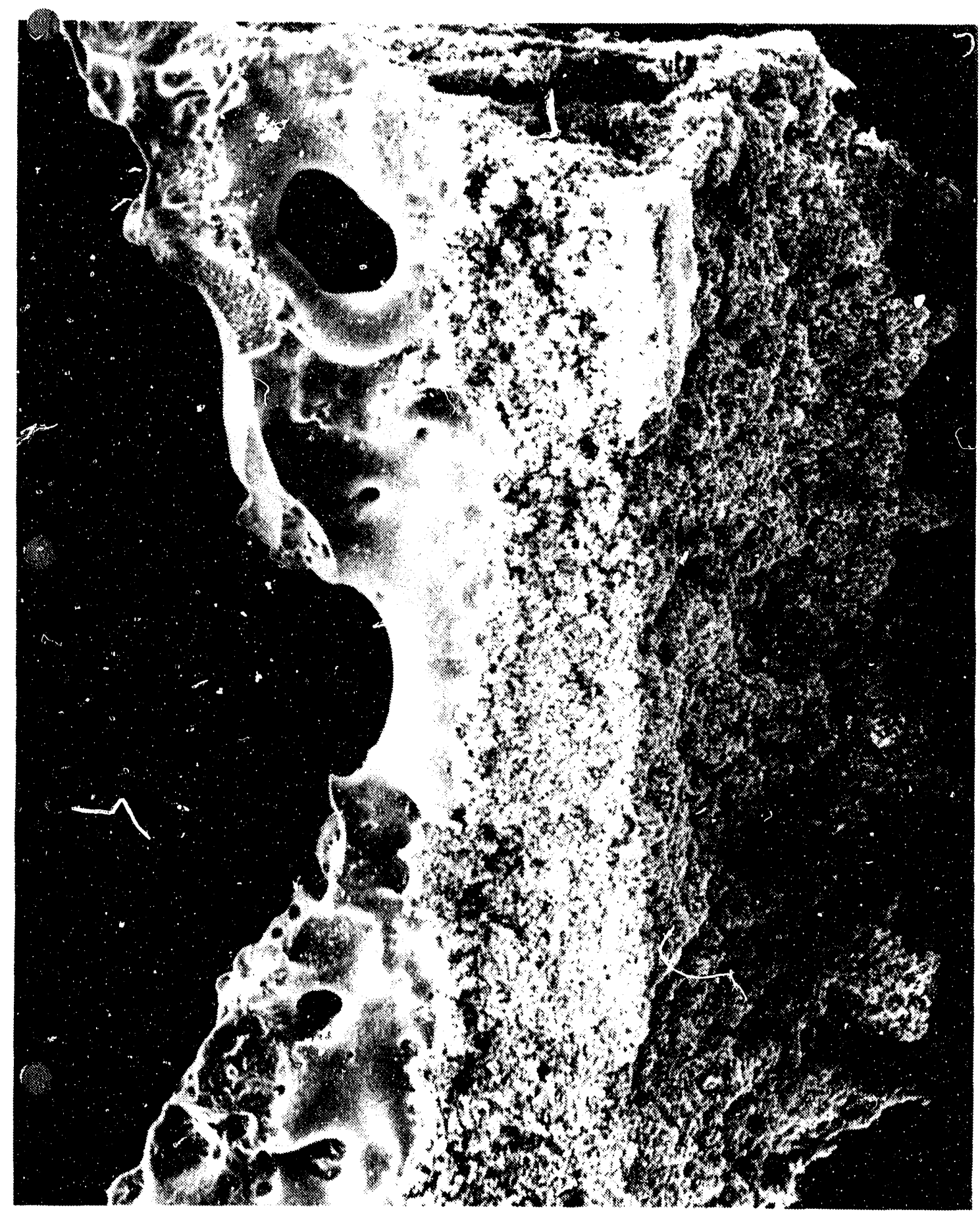

Figure 3.1.2.2 Micrograph illustrates that slag and powder coexist. 


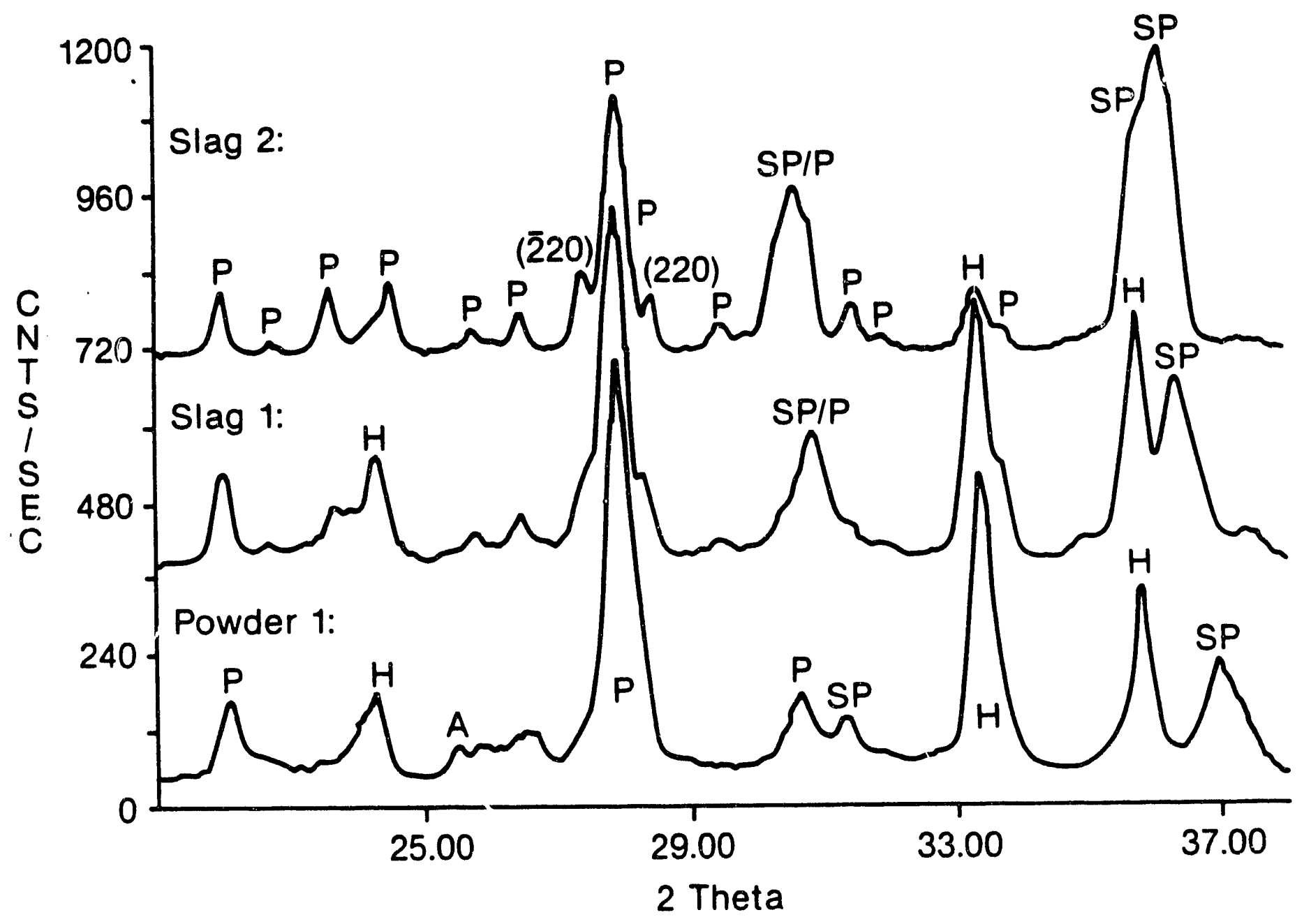

Figure 3.1.2.3 Diffractograms of powder 1, slag 1 and 2 showing the spinel line shifts and plagioclase $\{220\}$ line splitting. P-plagioclase, H-hematite, S-spinel, Aanhydrite. 
Table 3.1.2.2

Lattice Parameters of Standard and Experimental Spinel Phases

\begin{tabular}{|c|c|c|c|}
\hline \multicolumn{2}{|c|}{ Composition } & a & JCPDF \# \\
\hline \multicolumn{2}{|l|}{$\mathrm{MgAl}_{2} \mathrm{O}_{4}$} & 8.08 & $21-1152 *$ \\
\hline \multicolumn{2}{|l|}{$\mathrm{FeAl}_{2} \mathrm{O}_{4}$} & 8.15 & $34-192 *$ \\
\hline \multicolumn{2}{|c|}{$\mathrm{Mg}(\mathrm{Al} 0.65, \mathrm{Fe} 0.34) \mathrm{O}$} & 8.19 & $21-540 *$ \\
\hline \multicolumn{2}{|l|}{$\mathrm{MgCr}_{2} \mathrm{O}_{4}$} & 8.33 & $10-351$ * \\
\hline \multicolumn{2}{|l|}{$\mathrm{MgFe}_{2} \mathrm{O}_{4}$} & 8.38 & $17-464 \mathrm{i}$ \\
\hline \multicolumn{2}{|c|}{$\mathrm{Fe}_{2} \mathrm{O}_{3}$ (defect spinel) } & 8.38 & $24-81$ \\
\hline \multicolumn{2}{|c|}{$\mathrm{FeCr}_{2} \mathrm{O}_{4}$} & 8.38 & $34-140 *$ \\
\hline \multicolumn{2}{|l|}{$\mathrm{FeFe}_{2} \mathrm{O}_{4}$} & 8.40 & $19-629 *$ \\
\hline \multicolumn{2}{|l|}{$\mathrm{TiMg}_{2} \mathrm{O}_{4}$} & 8.44 & $25-1157 *$ \\
\hline \multicolumn{2}{|l|}{$\mathrm{MgTi}_{2} \mathrm{O}_{4}$} & 8.47 & $16-215 *$ \\
\hline \multicolumn{2}{|l|}{$\mathrm{TiFe}_{2} \mathrm{O}_{4}$} & 8.54 & $34-177$ * \\
\hline \multicolumn{2}{|l|}{ powder 1} & 8.07 & \\
\hline \multirow[t]{2}{*}{ slag 1} & major & 8.19 & \\
\hline & minor & 8.16 & \\
\hline \multirow[t]{2}{*}{ slag 2} & major & 8.37 & \\
\hline & minor & 8.24 & \\
\hline
\end{tabular}


smaller lattice parameters are associated with the Al-rich spinels and the larger parameters are associated with $\mathrm{Al}$-poor spinels. This trend is important for interpretting the lattice parameter shift observed between the powder and slag spinels, Figure 3.1.2.4.

The common plagioclase forming elements detected by EDS TEM and SEM were Na, Al, $\mathrm{Si}, \mathrm{K}, \mathrm{Ca}$ and $\mathrm{Sr}$. Plagioclase is a group of feldspar minerals which can form a complete solid solution between the Na-end member and the $\mathrm{Ca}$-end member. Characterization of the structural changes associated with compositional variation in this solid solution has been performed using XRD. Simulated XRPD patterns suggests a relation beween the $\{220\}$ splitting about the strongest line and the plagioclase composition, Figure 3.1.2.5. Recent investigations have indicated that the gamma angle of the plagioclase triclinic unit cell can be used to determine the structural state or the amount of $\mathrm{Ca}$ in solid solution [9], as long as it is carefully -afined. The lattice parameters of slag 1 and 2 were computed (Table 3.1.2.3). using an LSR [8] and plotted on the determinative diagram from Reference 6 The powder did not have enough unique lines for a lattice parameter refinement. The computed lattice parameters were identical (within $2 \sigma$ ) except for the gamma angle.

The compositions obtained using the disordered curve are An-58 for the powder and An-75 for the slag. Using the extreme possibility of the disorder curve for the slag and the order line for the powder, one obtains An-73 for the powder and An-75 for the slag. Since our specimens contain $\mathrm{Sr}$ they might not be comparable to the synthesized and natural specimens used for the determinative diagram; no unequivocal compositions can be obtained with our diffraction data alone.

TEM EDS analysis of a powder grading into a slag revealed a notable increase in the plagioclase Ca-to-Si ratio from the powder compared to the slag. Although only a small portion of the sample was analyzed in a couple of locations, this analysis suggests the same compositional trend observed from extrapolating the diffraction data. TEM EDS comparison of the spinel compositions in the powders and slag could not be done since the powder contained Fe in both hematite and spinel.

Heat treatments were performed on one powder sample. The powder contained major amounts of hematite, plagioclase and spinel and a trace amount of $\mathrm{CaSO}_{4}$. The plagioclase did not have the $\{220\}$ split and the spinel lattice parameter was 8.08 . The powder was heated for $3 \mathrm{hr}$ at $855^{\circ} \mathrm{C}$ in air. Sulfur was not detected by EDA after the treatment, the plagioclase $\{220\}$ became partially split, and the spinel lattice parameter increased to 8.09. The spinel and hematite line widths decreased, indicating more crystallinity and/or less compositional variation. The heat treated powder was subsequently spiked with about $20 \mathrm{wt} \% \mathrm{CaSO}_{4}$ and heated for $10 \mathrm{hr}$ at $825^{\circ} \mathrm{C}$ in air. The plagioclase $\{22 \mathrm{C}\}$ became distinctintly split from the strongest line and the spinel lattice parameter changed to 8.32 and 8.45 . The $\mathrm{Ca}$ added to the specimen remained, while the sulfur was not detected after the heat treatment. The structural 


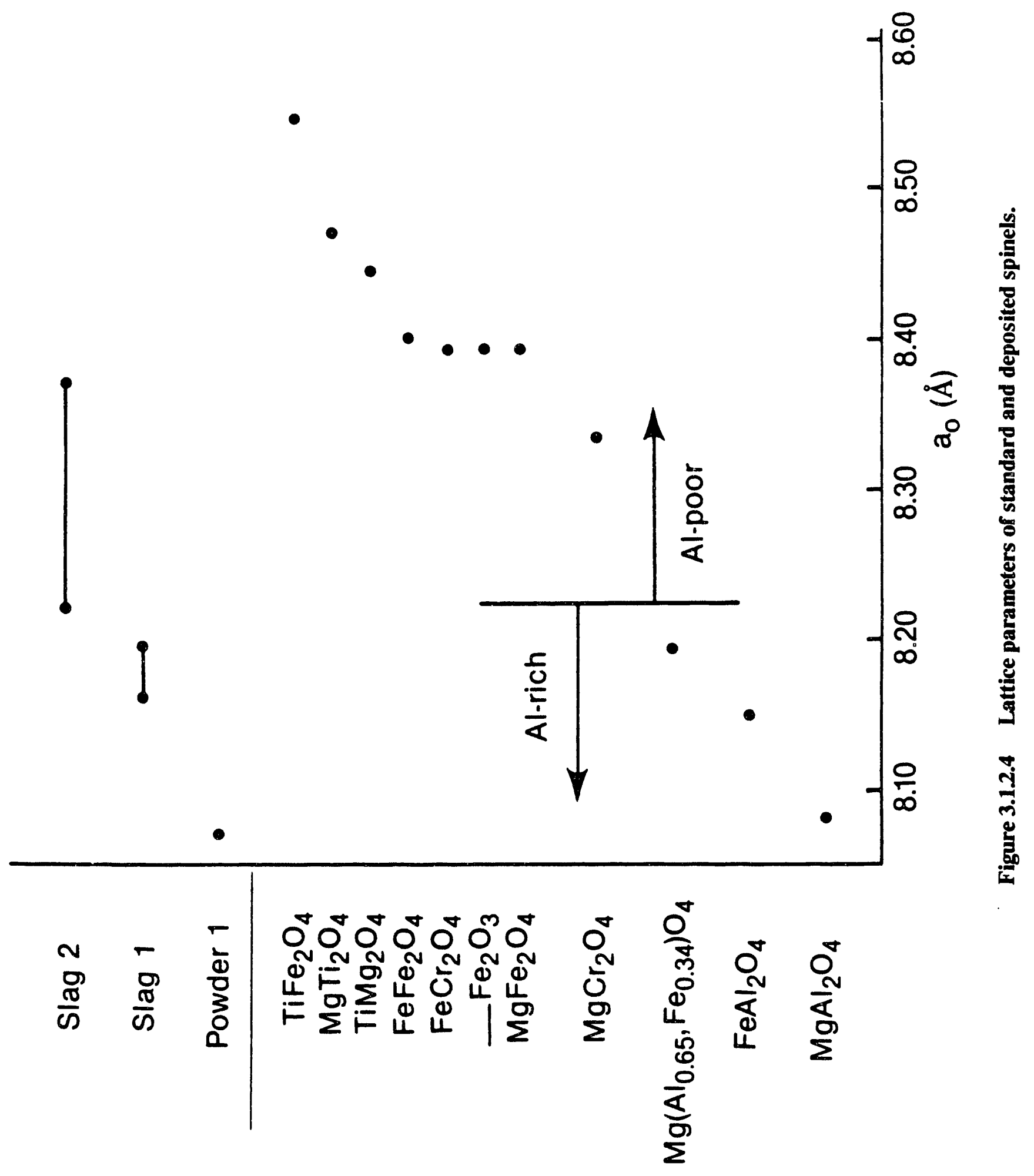




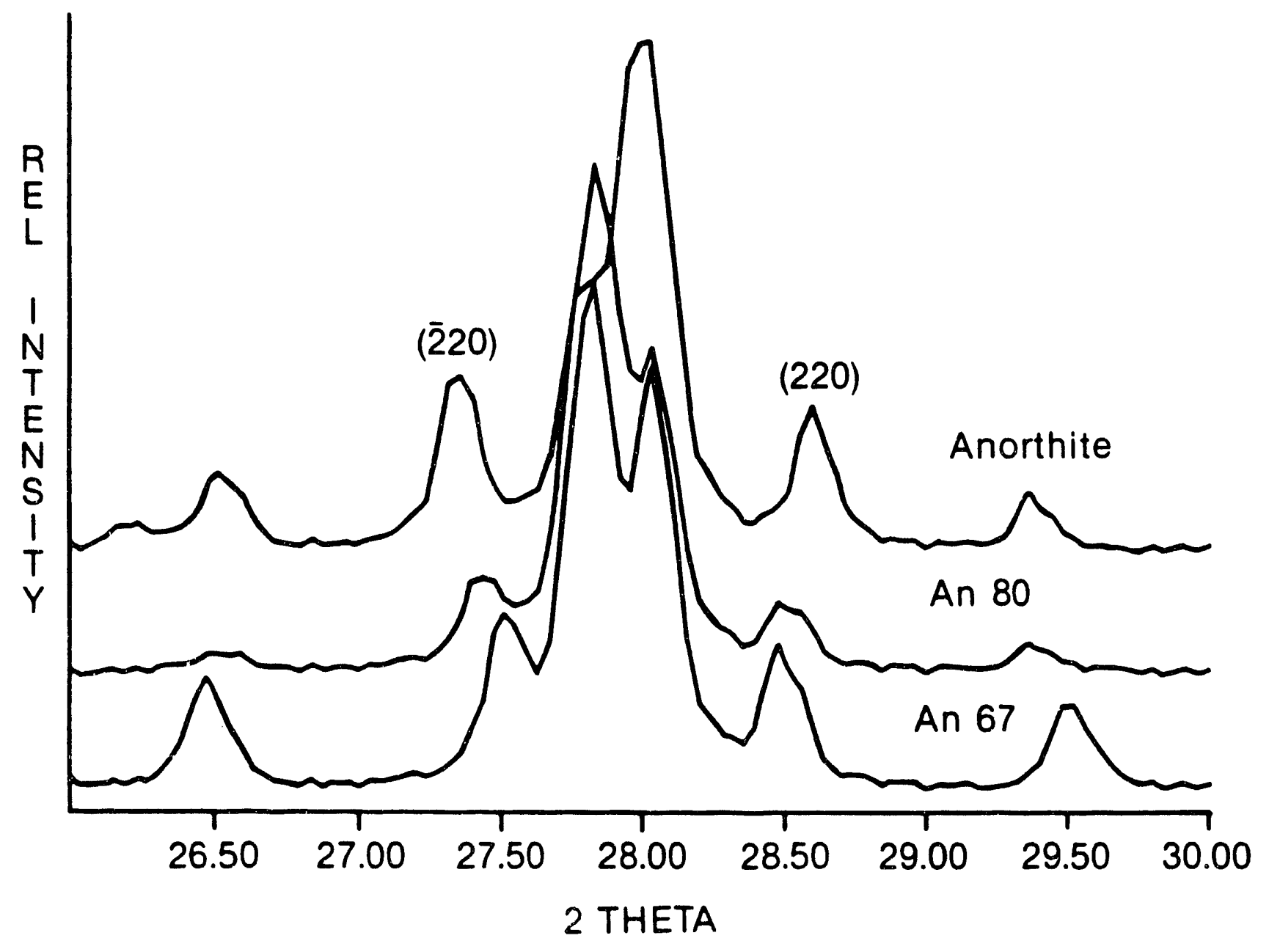

Figure 3.1.2.5 Simulated plagioclase XRPD patterns showing the splitting of the $\{220\}$ about the strongest lines. 
Table 3.1.23

Plagioclase Lattice Parameters, Indexing and LSR Output for Slag 1 and 2

\begin{tabular}{lcccccc}
\hline Sample & a & b & c & alpha & beta & gamma \\
\hline Slag 1 & $8.18(1)$ & $12.87(2)$ & $14.19(2)$ & $93.11(6)$ & $115.62(8)$ & $90.51(3)$ \\
Slag 2 & $8.18(1)$ & $12.85(2)$ & $14.19(2)$ & $93.19(4)$ & $115.74(8)$ & $90.73(3)$
\end{tabular}

\begin{tabular}{|c|c|c|}
\hline $\begin{array}{l}\text { Slag } 1,2 \\
\text { 2thet }\end{array}$ & HKL & 2T(exp.-cal.) \\
\hline $22.00,22.00$ & -202 & $-0.01,0.00$ \\
\hline $22.69,22.70$ & $1-12$ & $0.00,0.01$ \\
\hline $25.75,25.75$ & $-1-14$ & $0.03,0.03$ \\
\hline $26.48,26.50$ & -114 & $0.02,0.02$ \\
\hline $27.47,27.45$ & -220 & $0.01,0.01$ \\
\hline $28.35,28.45$ & 220 & $0.00,0.00$ \\
\hline $29.48,29.45$ & $1-32$ & $-0.01,-0.01$ \\
\hline * 31.50 & 132 & 0.00 \\
\hline $51.60,51.60$ & -208 & $-0.01,-0.01$ \\
\hline
\end{tabular}

The indexing was based on Ca rich triclinic plagioclases in the JCPDF. Indexing $L$ for $14 \mathrm{~A} \mathrm{c}$ axis was arbitrary.

* Overlap with hematite. 
changes displayed in the diffractogram mimic the changes observed going from the powder to slag 1 and 2, Figure 3.1.2.6. The heat-treated specimens remained powdery and did not fuse to form a slag. The treated powder was again spiked with about $25 \mathrm{wt} \% \mathrm{CaSO}_{4}$ and heated to $815^{\circ} \mathrm{C}$ for $6 \mathrm{hr}$ in air. The major phase that formed had the melilite structure type and the plagioclase was not detected. This experiment indicates that the plagioclase $\{220\}$ splitting can be used as an indicator for $\mathrm{Ca}$ enrichment.

One plausible interpretation of these analytical results is as follows. The initially deposited powder phases fuse to form the slag when the temperature is hot enough to decompose anhydrite. Anhydrite decomposes to form $\mathrm{SO}_{x}$ gas as has been shown to occur in the laboratory at temperatures as low as $600^{\circ} \mathrm{C}$. The intermediate "CaO" species reacts with the plagioclase and spinel phases. The $\mathrm{Ca}$ is incorporated into the plagioclase solid solution which concomitantly requires additional $\mathrm{Al}$ for charge balance. The spinel supplies the required $\mathrm{Al}$ and transforms to an Al poor composition. Hematite could contribute the Fe needed to replace the $\mathrm{Al}$ given to the plagioclase and a maghemite vacancy structure could result. Magnetite, $\mathrm{Fe}_{3} \mathrm{O}_{4}$ could also form if some of the $\mathrm{Fe}$ remained in a reduced state.

Figure 3.1.2.7 represents a summary of the phases and their associated changes in slagging and fusion.

\subsubsection{Conclusion}

A detailed picture of the deposition process from a chemical and microstructural standpoint has emerged. Initially the assemblage anhydrite- hematite-spinel-plagioclase is present in an unfused, weak and porous microstructure. About $20 \%$ of the aluminum partitions into the spinel phase, with the remainder found as aluminosilicate, i.e., plagioclase and glass.

After prolonged exposure to the turbine environment, anhydrite is found to decompose, evolving $\mathrm{SO}_{x}$, and generates a metastable and highly reactive " $\mathrm{CaO}$ " moiety. This in turn triggers a sequence of irreversive chemical transformations involving the wresting of alumina from the spinel, slagging, and eventual devitrification to yield anhydrite. The spinel accommodates the loss of alumina by either vacancy or substitution.

One unexpected consequence of this interpretation is that, with the minor perturbation due to alumina partitioning in the spinel, for the most part, the calcia-alumina-silica phase assemblage behaves reasonably from the iron and minor spinel-forming elements. Thus the well-known calcia-alumina-silica equilibrium phase diagram may approximate the slag properties. In subsequent sections, we will use this as the basis for identifying additives which may alter the phase assemblage to yield more refractory, dense, embrittled, and non-adherent deposits.

The assemblage anhydrite-hematite-spinel-plagioclase is not commonly found in conventional coal ash and slag deposits. It is a unique system for understanding the phenomenology of slag formation in a gas turbine fired on coal. Plagioclase has been reported as the major 


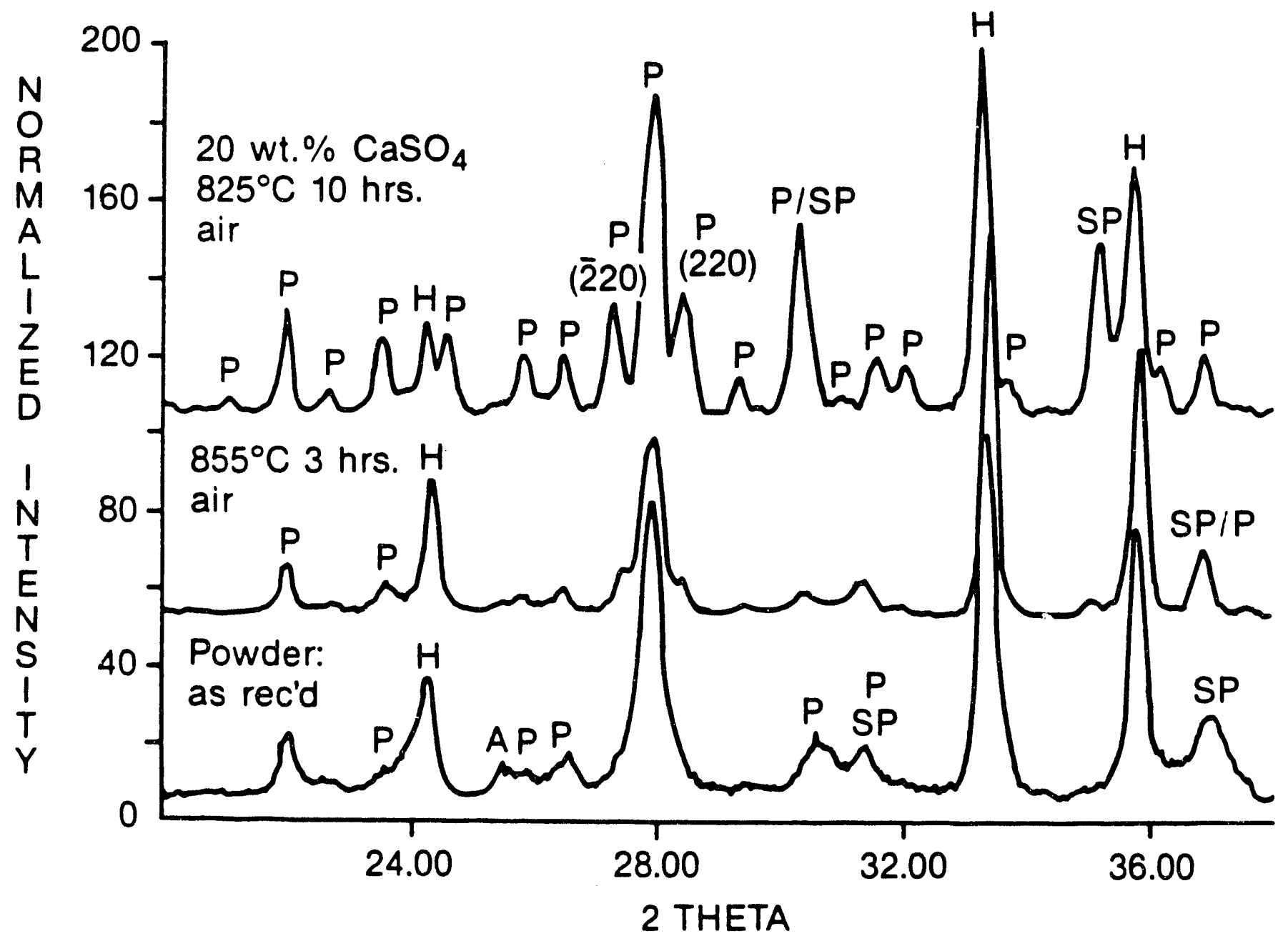

Figure 3.12.6 Diffractograms of heat treated powder showing spinel line shifts and plagioclase line splitting. 


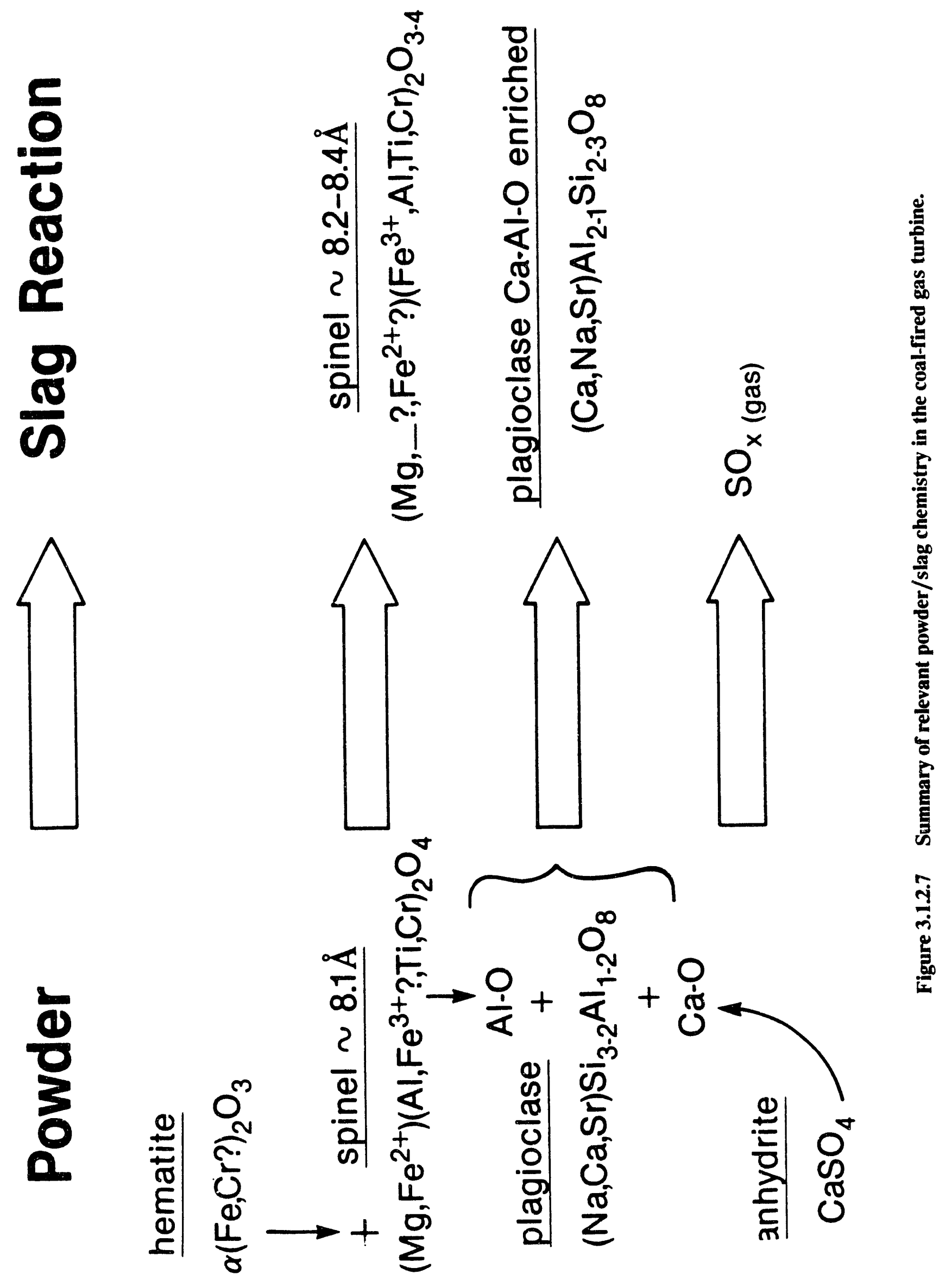


coal slag phase in a Southern Australian brown coal (Leigh Creek) [10], but no phenomenology was concluded. Plagioclase was also identified in British and South African bituminous coal ashes [11] from "laboratory tests." The plagioclase was proposed to be involved with fouling and slagging characteristics.

It is desirable to prevent slagging since the primary powdery deposits were readily removed by waterwashing and nutshelling, while the slag tenaciously adhered to the metal surfaces. Our results indicate that film cooling of the air foils reduces the slagging tendency of deposits, presumably by preventing anhydrite thermal decomposition. Deposit remediation through modification of operating conditions is currently being investigated.

\section{References}

[1] S.G. Kimura. and C.L. Spiro," Alkali Species Characterization for Coal- Fueled Gas Turbine”, GE CRD Final Report, DOE/MC/22164-2188, Dec., 1986.

[2] S.G. Kimura and C.L. Spiro, "Gas Turbine Components Screening Program", GE CRD Final Report, Vol. II, DOE/MC/21395-2298, March, 1987.

[3] D.V. Keller, Fifth Symp. on Coal Slurry for Combustion Tech., Tampa, FL, April 1983, DOE, Pittsburgh, PA, 269 (1983).

[4] R.C. Streeter, BCR National Laboratory, Quarterly Progress Report, $\mathrm{DOE} / \mathrm{MC} / 62690$.

[5] A.K. Bhasin et al., DOE Report, DOE/MC/2700-1635, Aug. 1984.

[6] C.L. Spiro, C.C. Chen, J. Wong, S.G. Kimura and R.B. Greegor, Fuel 66, 563 (1987).

[7] R. Goehner,Advances in X-ray Analysis 23, 305-311, 1980.

[8] L. Heaton, Argone Laboratory Report ANL-6176, 1961.

[9] H. Kroll and P.H. Ribbe, Am Min. 65, 449 (1980).

[10] H.J. Kisch, Am. Min., 50, 1015 (1965).

[11] W.H. Gibb, J. Inst. Enengy 59:441, 206, 1986. 


\subsubsection{The Efrects of Kaolin Additives on Deposition}

Abstract The addition of kaolin ( $0.4 \% \mathrm{wt}$ ) to a slurry of micronized coal (50\% wt containing $0.8 \%$ wt ash on a dry basis) was found to ameliorate deposition in a coal-fired gas turbine simulator. Pressure-side deposits were all but eliminated, while leading edge and suction side deposits were minimal. Where airfoil deposits did occur, they were ascribed to extraneous alkali impurities in the kaolin and surfactant. Additional deposits along the transition section between the combustion liner and airfoils were ascribed to stagnation points associated with thermocouples and walls which would not likely be present in an actual annular combustor.

The deposit chemistry, microstructure, and phase assemblage has been characterized in detail. In the absence of additive, the calcia-alumina-silica ternary equilibrium phase diagram adequately describes the deposits with the caveats that iron behaves as an independent oxide to a large degree, with only limited participation as a component of an aluminum, magnesium spinel. The addition of kaolin also results in an assemblage which is consistent with the same phase diagram, again with an independent iron oxide, but without spinel. Thus the full complement of alumina participates in the chemistry, yielding mullite, and an anorthitic glass, the combination of which spalls from the airfoils.

A possible mechanism for deposit remediation consists of primary deposits reacting in situ to form a melt which devitrifies to exsolve mullite before spalling. The change in molar volume due to exsolution of mullite creates voids which are preserved in the slag. Voids are created in the bulk and at the interface between deposit and melt which weaken the bulk deposit strenghth and especially reduce the deposit/metal contact area. The new deposit either spontaneously spalls or erodes.

During the tests, chunks of deposits formed in the transition piece. These deposit chunks spalled and lodged in the nozzle cascade causing premature shutdown. Transition piece deposits are an artifact of the test rig design due to the external cooling arrangement and to stagnation points associated with thermocouples and corners, and to high transition piece temperatures. These stagnation points would be present in an actual film-cooled annular combustor. To verify the cooling effect, short duration tests were run with improved cooling to eliminate hot spots on the transition piece exterior. No deposits were found in the transition section after a 4 to $5 \mathrm{hr}$ test run, except at the two sites (actuall small holes) where the thermocouples were previously located. This confirms that where deposition occurs, it is associated with stagnation points, and is not inherent to the process.

\subsubsection{Introduction}

Deposit formation represents a technological barrier to commercialization of a coalburning gas turbine engine. Deposits may limit engine efficiency, necessitate frequent maintenance, cause sudden flame-outs, induce corrosion, and may create turbulence which further exacerbates deposition. The spalling of large deposit fragments may damage the engine dur- 
ing downstream passage through expansion stages.

As reported in Section 3.2, deposit formation may also limit strategies for environmental control. For example, injection of sulfur sorbents prior to expansion of the gas is one option under study. Here sorbents create untenable deposition. To prevent excessive deposition of sorbents, particulate removal strategies involving slagging or pre-filtration of the hot gases may be required. This would result in significant departures from existing distillate-fired engine design and would undoubtedly delay, if not vitiate entirely, the commercial viability of the technology.

Deposits consist of mineral matter which has undergone thermal transformations along the hot gas path and which adhere to metal surfaces (especially airfoils) via a combination of several thermophysical mechanisms [1]. Once primary deposits have formed, they may further react in place through a combination of sintering, melting, and exsolution of new phases. It is unlikely that complete equilibration occurs on the airfoils, though localized pseudoequilibria have been identified, Section 3.1.2.

The specific chemistry which occurs on the airfoil will depend on both composition and conditions $[2,3]$. For example, using a Kentucky Blue Gem bituminous coal which had been beneficiated via selective agglomeration [4] by Otisca Industries Ltd., primary deposits were found to consist of hematite (iron oxide), anhydrite (calcium sulfate), plagioclase (alkali aluminosilicate), spinel (magnesium aluminum oxide), and traces of aluminosilicate glass. These deposits were reasonably benign- weakly adherent and readily removed by on-line nutshelling. As these deposits built up, film cooling efficiency dropped off and prolonged exposure to higher temperatures took place. As a result, calcium sulfate decomposed, yielding sulfur dioxide and highly reactive calcia which entered the plagioclase lattice [5]. It is suggested that this triggers a sequence of chemical events in which alumina also enters the feldspar, in turn creating spinel vacancies which are partly filled by iron. The net effect of this complex chemistry was a tenaciously adherent slag.

Through the identification of chemical intermediates and mechanisms, it has been possible to propose and test methods to interrupt the sequence in order to render the ash nonadherent. The results of one such strategy using kaolin clay are reported herein.

The use of kaolin clay for deposit remediation is counterintuitive; after all, this clay is widely used in the manufacture of china and pottery. Its chief feature is the formation of massive and tough refractory oxides at high temperatures, exactly the antithesis of the desirable deposit features in an engine. Why should it work? Did it work? How did it work?

In the following sections, we will address these questions by first describing the experimental procedures, followed by reporting the results, and finally presenting analysis and interpretation. 


\subsubsection{Experimental and Test Results}

Coal-water mixture was provided as a $50 \%$ slurry by Otisca Industries. A summary of the slurry properties appears in Table 3.1.3.1. Table 3.1.3.2 reports properties of the untreated coal ash. For the first four tests, an air classified kaolin was generously provided by Albion Kaolin of Hepzibah, GA as both a dry powder and a 70\% slurry. The dry powder was slurried with water and Colloid 211 sodium polyacrylate surfactant. Kaolin slurry was added slowly with stirring to pre-mixed coal slurry, and stirred for $1 \mathrm{hr}$. prior to combustion. The amount of kaolin was $0.8 \%$ by weight of dry coal. The kaolin contained mostly kaolinite with traces of anatase $\left(\mathrm{TiO}_{2}\right)$. Atomic absorption spectroscopy also revealed $1000 \mathrm{ppm}$ sodium on a slurry basis with comparable amounts of potassium anticipated.

Analytical data on deposits (vide infra) suggested that sodium was responsible for the more severe deposition. In order to limit its participation, a highly beneficiated kaolin, Satintone V ( Registered Trademark of the Englehard Corporation) was generously provided by Meyers Chemical Company of Buffalo NY. It has a mean particle diameter of $0.8 \mu \mathrm{m}$ and was mixed as a $46 \%$ slurry with Colloid 111 ammonium polyacrylate surfactant. Centrifugation of the slurry at $7000 \mathrm{rpm}$ for $2 \mathrm{hr}$ yielded a supernatant liquor with soluble sodium content of 2.8 ppm as determined by inductively coupled plasma emission spectroscopy. Thus the impact of alkali in such low concentrations could be minimized.

Slurry was burned as usual, Section 3.4 with no special measure taken to accommodate the presence of kaolin. Five combustion trials with kaolin-doped slurry were made over a period of several days, with a total accumulated $32 \mathrm{hr}$ at the designated test conditions which included $2000^{\circ} \mathrm{F}$ firing temperature, a chamber pressure of $130 \mathrm{psig}$ and the atomizing air pressure ratio maintained at $\sim 1.9$. Oil assist was set at $10 \%$ to minimize complications due to combustion instability. In actuality, combustion instability did occur in the initial testing due to excessive atomizing air temperature, but this was corrected at the latter stages of testing.

In all of the test sequences, deposition data revealed qualitatively the same series of events. First, (Figures 3.1.3.1 through 3.1.3.3), for several hours there was very little change in NAIN - i.e., nozzle area index number which is an indirect measure of deposition determined by measuring mass flow at pressure. As deposits build up, the throat area is diminished and pressure increases at constant mass. Unlike the undoped coal studies which show steady decline in NAIN, with kaolin, after an induction period which had no deposition, a sudden and catastrophic drop in NAIN occurred. After shutdown, examination of the airfoils, Figure 3.1.3.4, revealed that the sudden loss of NAIN was a result of a large plastic mass of deposit which originated upstream of the airfoils, and which had spalled and lodged in the airfoils. Indeed, the transition section leading up to the cascade had large deposits which appeared to have grown along stagnation points associated with a row of type-B thermocouples. These were removed in stages, and revealed considerable improvement in transition section deposition; stagnation points associated with the transition section walis still collected unacceptable 
Table 3.1.3.1

Properties of Otisca Coal-Water Mixture

Proximate Analysic (Dry Basis)

\begin{tabular}{|c|c|}
\hline Ash Content & $0.90 \%$ \\
\hline Total Sulfur & $0.80 \%$ \\
\hline Volatile & $37.92 \%$ \\
\hline Fixed Carbon & $61.18 \%$ \\
\hline Solids & $49.87 \%$ \\
\hline Viscosity $\mathrm{cp}$ & 270 \\
\hline
\end{tabular}

$(112 / \mathrm{sec})$

Particle Size Distribution

\begin{tabular}{cc}
\hline Diameter & Mass \% \\
\hline$>11.5$ & 7.0 \\
11.5 & 0.5 \\
10.5 & 0.0 \\
9.5 & 4.0 \\
8.5 & 4.4 \\
7.5 & 3.2 \\
6.5 & 6.2 \\
5.5 & 7.6 \\
4.5 & 10.8 \\
3.5 & 14.0 \\
2.5 & 18.4 \\
1.5 & 18.5 \\
0.5 & 5.4 \\
&
\end{tabular}


Table 3.13.2

Table 2-X-ray Fluorescence Data, Transition Section Deposit Untreated CWM

\begin{tabular}{lcc}
\multicolumn{3}{c}{ Commercial Testing and Engineering } \\
\hline $\mathrm{SiO}_{2}$ & $22.4 \%$ \\
$\mathrm{Al}_{2} \mathrm{O}_{3}$ & 29.15 \\
$\mathrm{TiO}_{2}$ & 1.80 \\
$\mathrm{Fe}_{2} \mathrm{O}_{3}$ & 28.54 \\
$\mathrm{CaO}$ & 9.86 \\
$\mathrm{MgO}$ & 3.00 \\
$\mathrm{~K}_{2} \mathrm{O}$ & 0.17 \\
$\mathrm{Na}_{2} \mathrm{O}$ & 0.54 \\
$\mathrm{SO}_{3}$ & 0.62 \\
$\mathrm{P}_{2} \mathrm{O}_{5}$ & 0.33 \\
$\mathrm{SrO}$ & 1.09 \\
$\mathrm{BaO}_{\mathrm{MnO}}$ & 0.67 \\
& 0.04 \\
& \\
& Ash & \\
Initial Defion Data & Reducing & Oxidizing \\
Softening & 2215 & 2470 \\
Hemispherical & 2415 & 2545 \\
Fluid & 2535 & 2605 \\
& 2655 & 2655
\end{tabular}




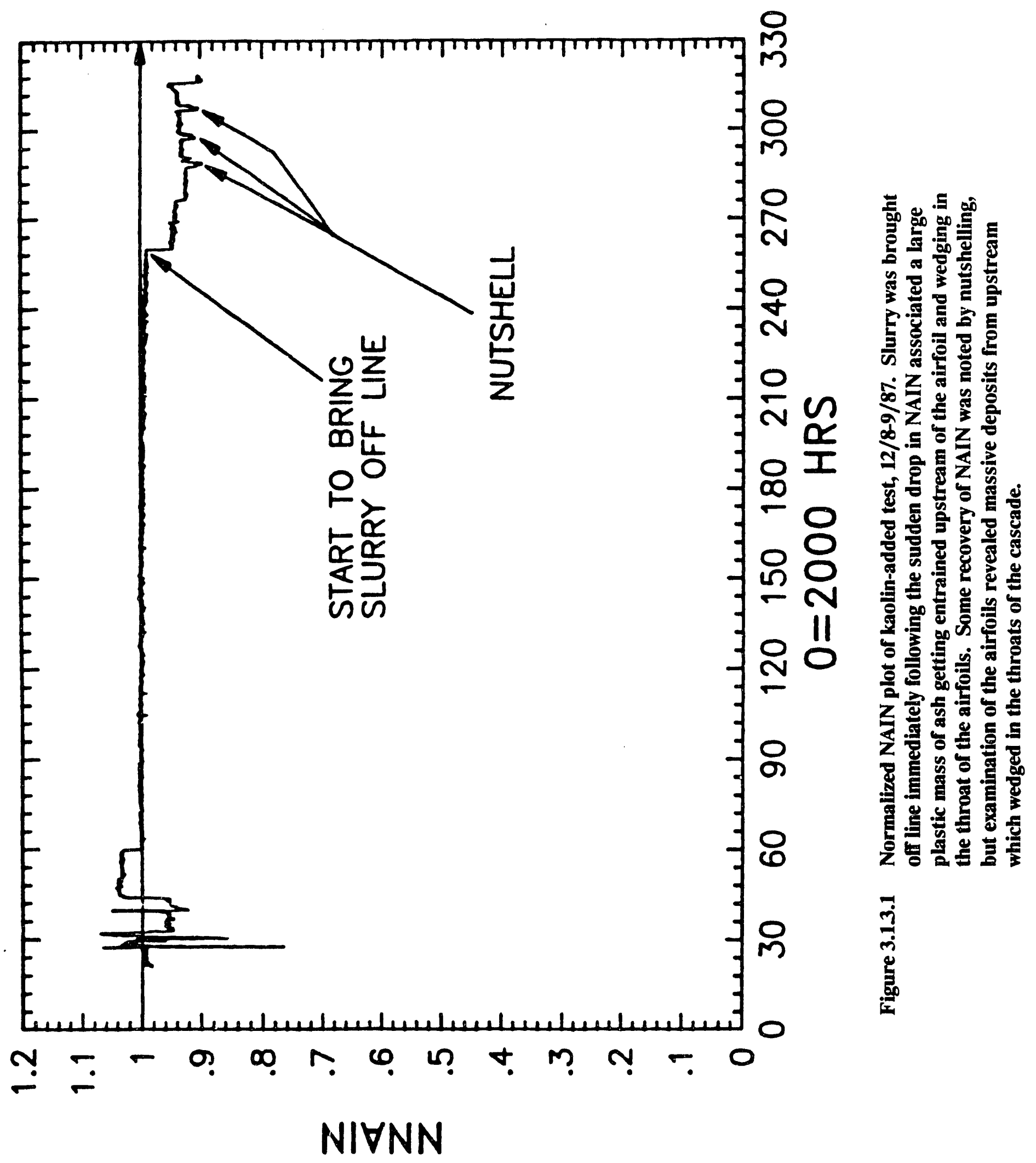




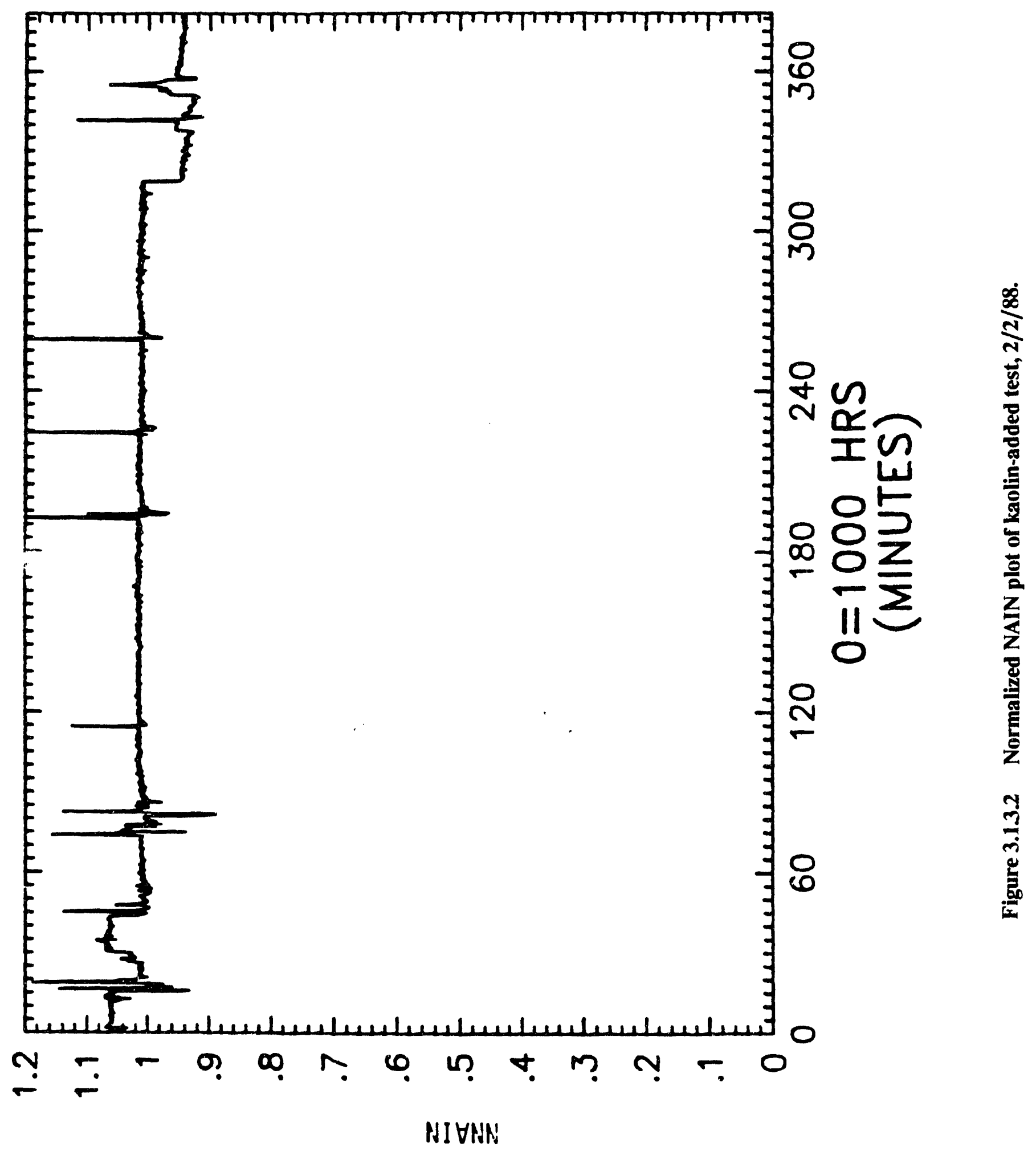




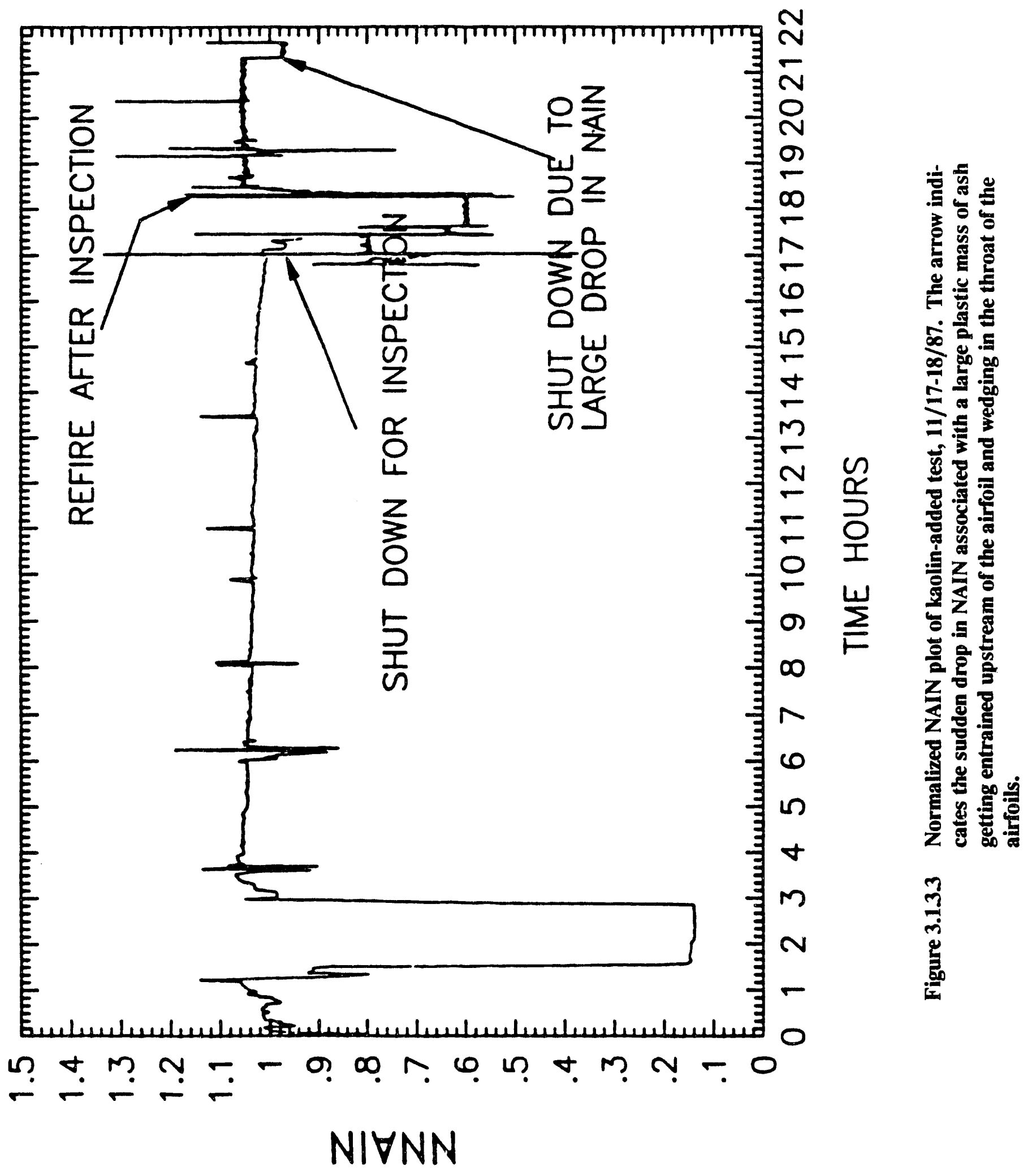




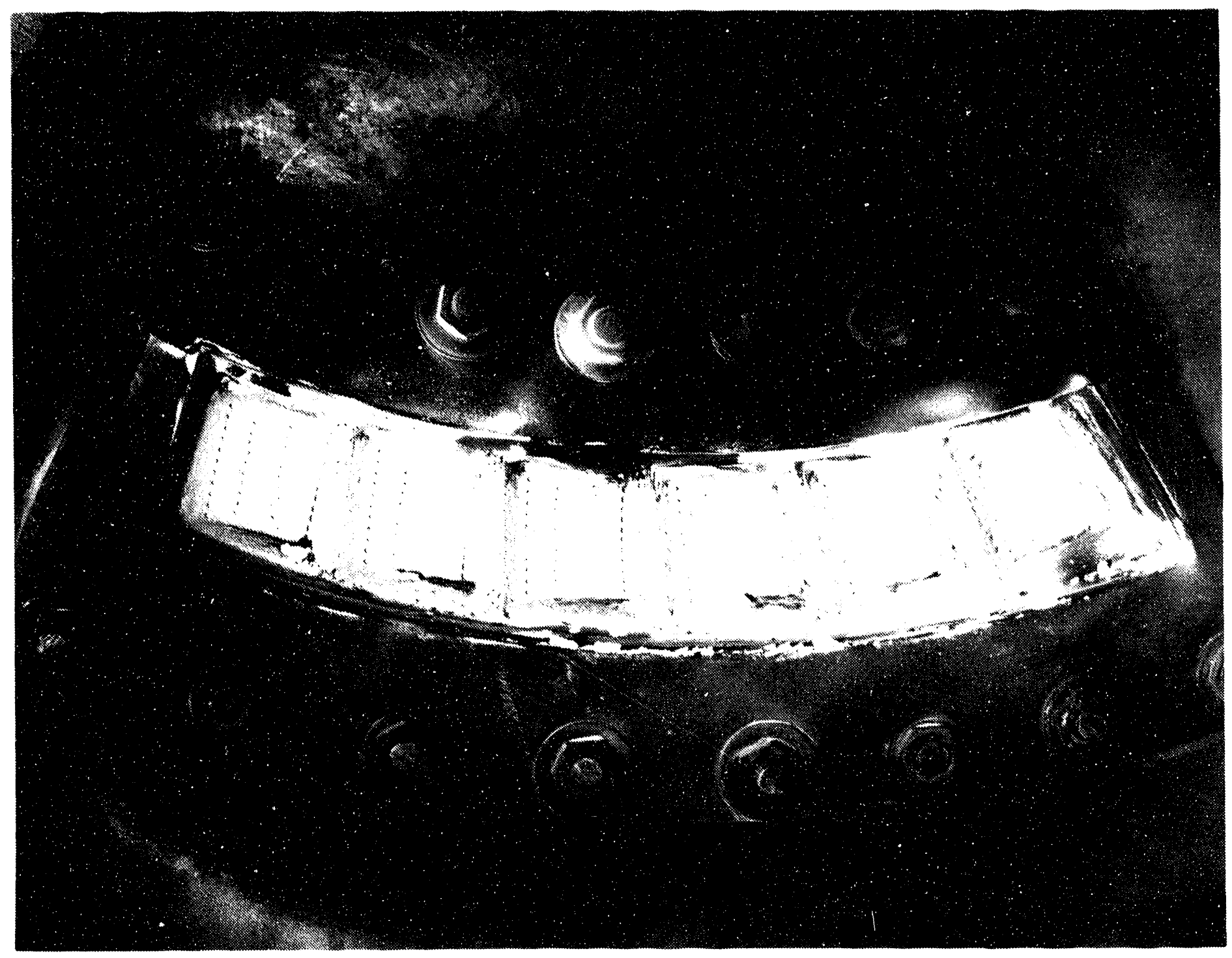

Figure 3.1.3.4 LM500 turbine simulator pressure-side and leading edges after using kaolin-added slurry. The large mass wedged in the throat was responsible for the sudden drop in NAIN. Noteworthy are the othwerwise clean airfoil surfaces. The black flecks along the base of the airfoils are unburned slurry associated with shutdown. 
deposits.

Aside from the large mass that spalled from the thermocouples, the airfoils were remarkably clean - especially along the pressure side where previous studies showed the most severe deposition. Some deposition was noted on both the leading edge and suction sides, Figures 3.1.3.5 and 3.1.3.6 respectively, but was not considered severe, and is probably due to alkali impurities in the unwashed kaolin. In fact, when the alkali-free kaolin was tested, there was no evidence of any airfoil deposit, thus confirming this notion.

\subsubsection{Analytical Data}

Several analyses were performed on products of combustion. These included elemental composition, scanning electron microscopy, scanning transmission electron microscopy, $x$-ray fluorescence, and $x$-ray diffraction.

\subsubsection{Quench Probe Samples}

Hot gases were rapidly quenched and collected on the Mott sintered stainless steel filter, and were analyzed by transmission electron microscopy, $x$-ray and electron diffraction. These samples provide a representation of the particulate constituents of the gas stream. Figure 3.1.3.7 is a transmission electron micrograph which reveals all the major morphologies obtained from the quenched gas stream. These include carbonaceous cenospheres (a), solid spheres of ash (b) which had been liquid, aerosol (c) which condensed from a vapor, and a flake of kaolinite (d) which passed through simulator unchanged.

Carbonaceous cenospheres (a) constitute on average $24.4 \%$ wt of the quenched gas stream, which corresponds to a combustion efficiency of $99.47 \%$ They are the result of gas evolution during he organic metaplast stage of coal pyrolysis which takes place between 350 and $500^{\circ} \mathrm{C}$. During this stage the coal forms a viscous plastic mass which balloons into the hollow carbon shells. Wall thicknesses are typically $0.1 \mu \mathrm{m}$ or less. Average particle sizes are $\sim 5 \mu \mathrm{m}$, with larger shells fragmenting, possibly due to centripetal acceleration, impact, thermal stress, or char burnout. X-ray fluorescence of the shells reveals only organic sulfur and carbon; $\mathrm{X}$-rays and electrons show no diffraction from the amorphous semicoke like structure.

Ash spheres (b) result from melting of indigenous coal mineral matter and kaolin. There is no evidence that kaolin reacts with mineral matter in the gas stream; ash and kaolin apparently act independently until deposition. Each sphere has unique composition associated with the localized mineral assemblages within a given grain of coal. X-ray fluorescence, Figure 3.1.3.8, reveals the presence of melted kaolin apparently unaffected by the coal ash. In addition, $x$-ray diffraction indicates the presence of hematite, anhydrite, and an iron spinel just as in the untreated coal, along with a large amorphous component which includes glass from melted kaolin, other aluminosilicates and char. 


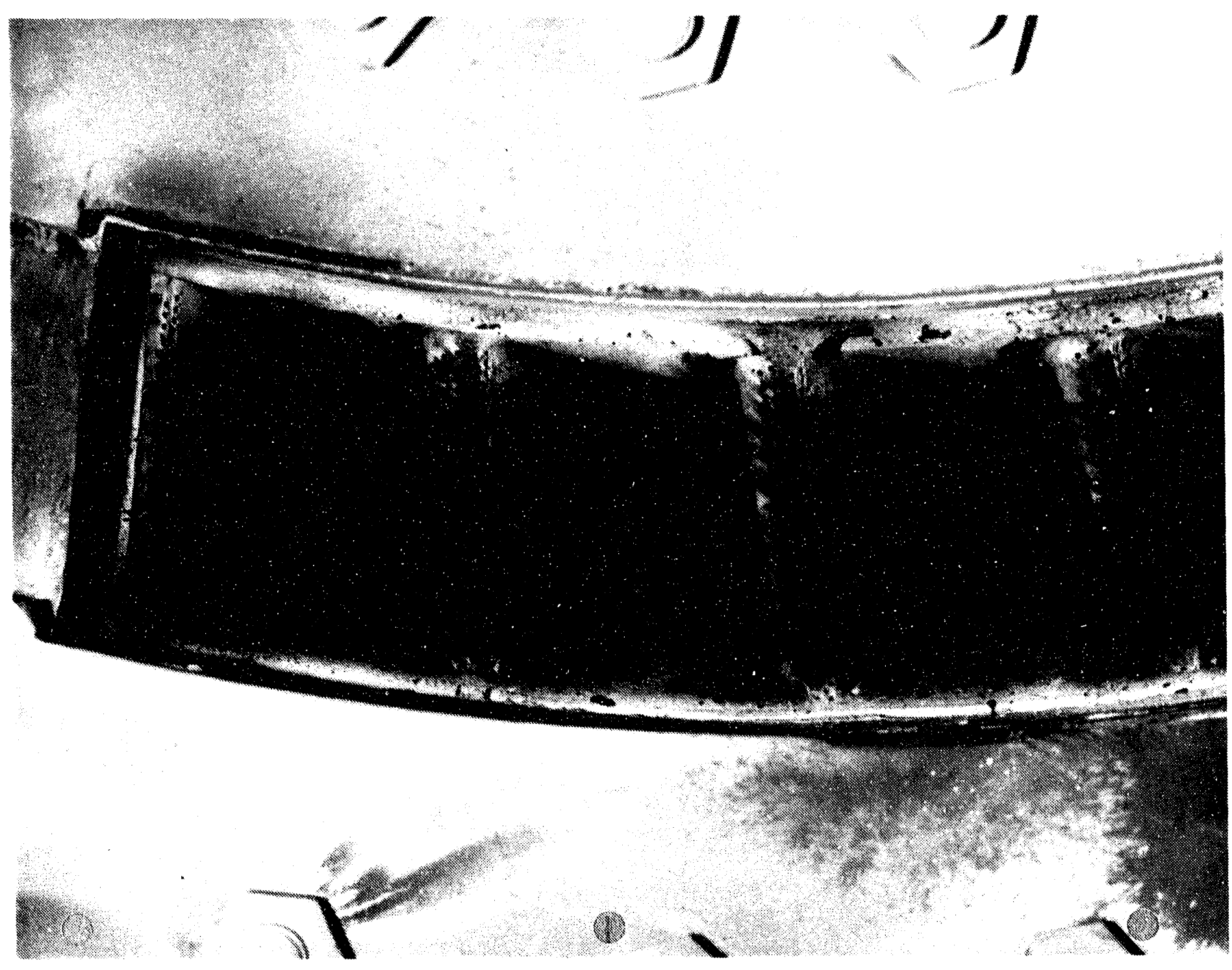

Figure 3.1.3.5 Close-up of leading edge deposits at the end of $11 / 18 / 87$ test. 


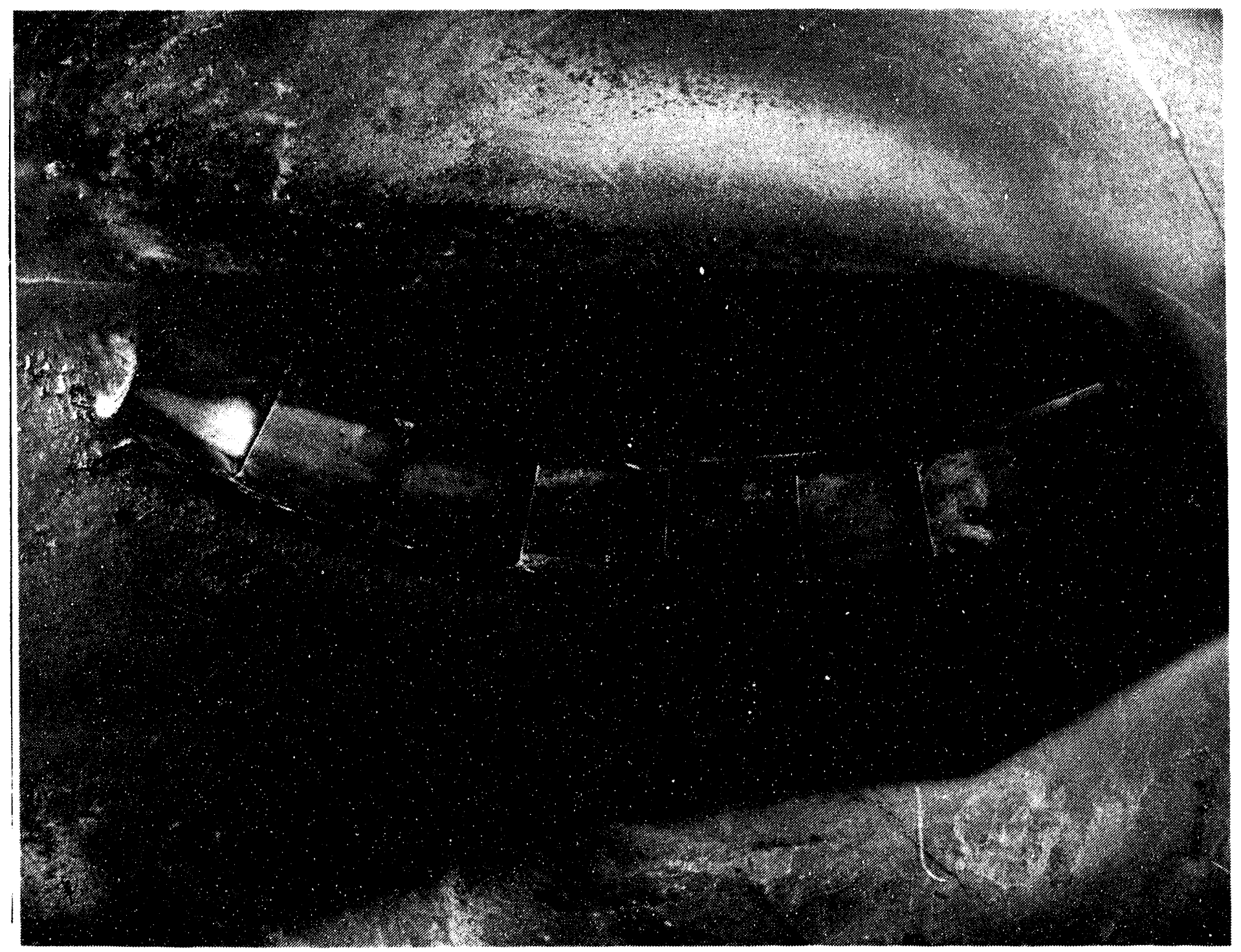

Figure 3.13.6 Suction side deposits at the end of 11/19/87 test showing highly clean surfaces, except for the large mass wedged in throat 3 . This is the same deposit as in Figure 3.1.3.4. 


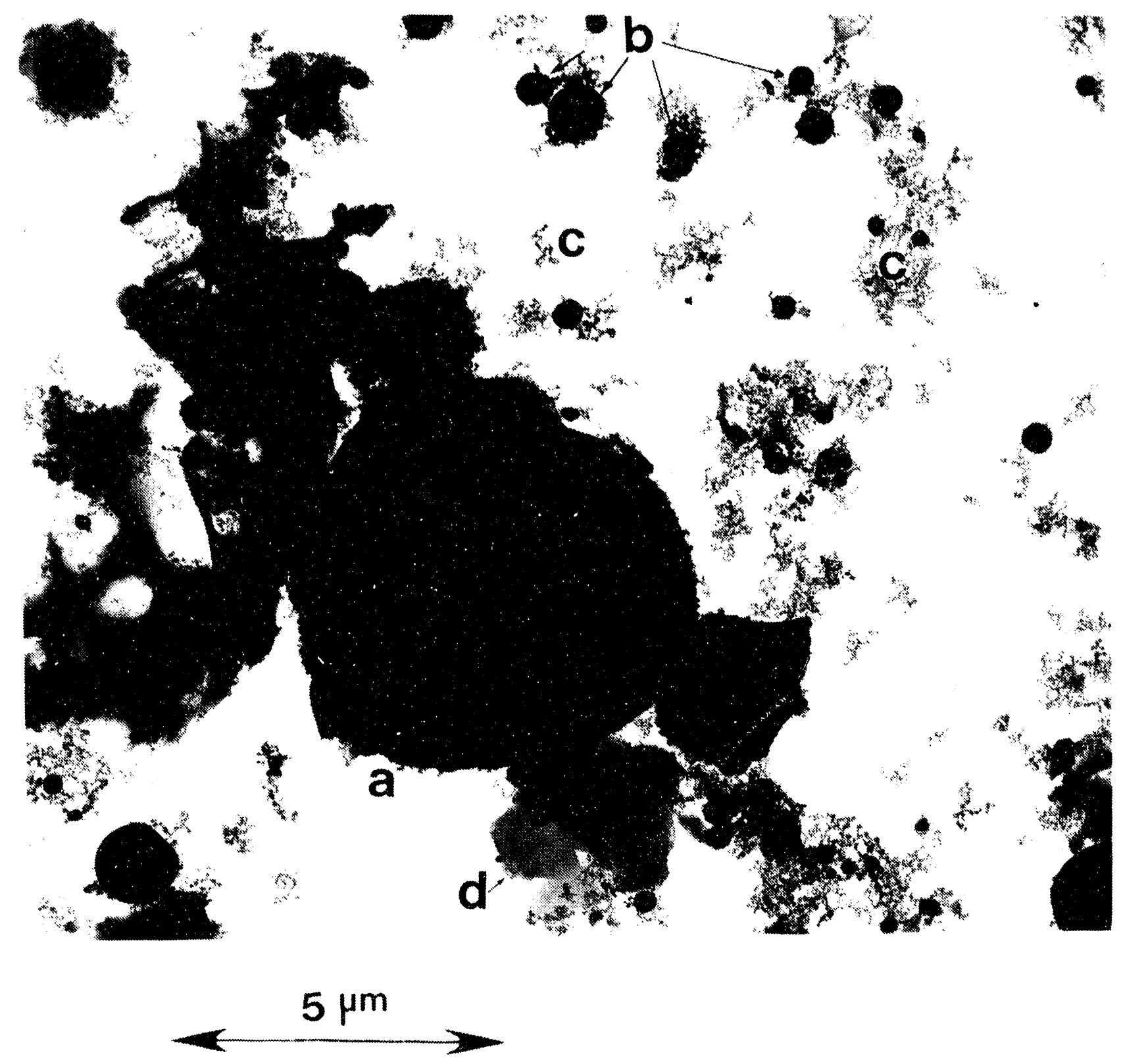

Figure 3.13.7 Transmission electron micrograph of quenched hot gas stream showing (a) unburned carbonaceous cenospheres, (b) solid sphere of quickly frozen ash droplets, (c) aerosol from metallic vapor condensate, and (d) a flake of kaolinite. Note scale. 
IST HALF: MOTT 348-414 1111818 LT= 55 SECS 0.82S KE'

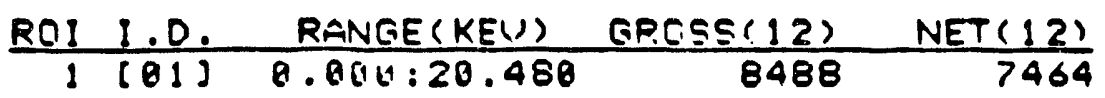

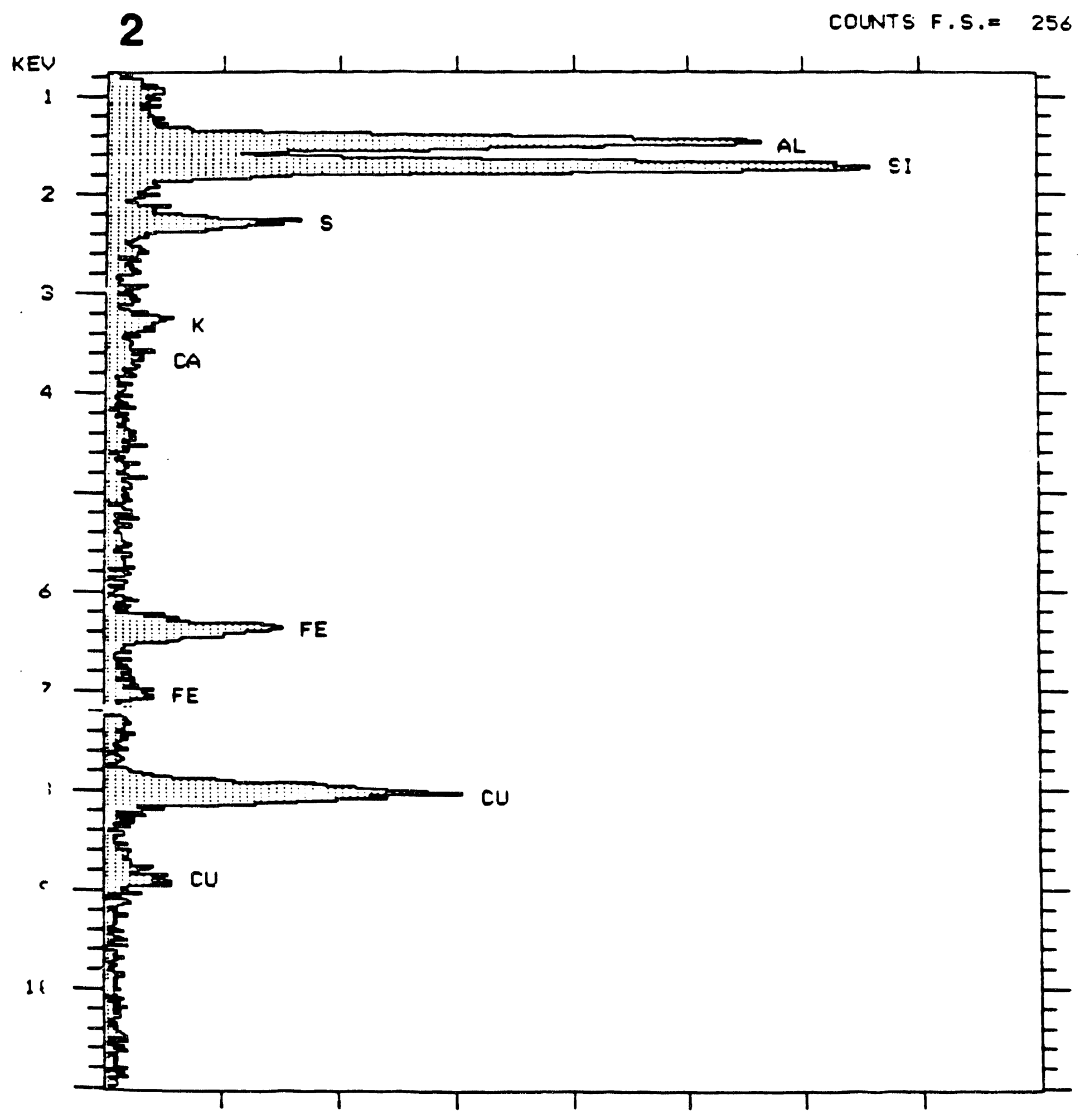

Figure 3.1.3.8 Energy dispersive X-ray analysis of a solid sphere of ash obtained from quenching the hot gas stream. The sample is primarily melted kaolin with a surface condensate of iron sulfate. 
The aerosol (c) results from a vapor intermediate which condenses and nucleates to a filigreed morphology, Figure 3.1.3.9. X-ray fluorescence of the fume reveals iron oxide and iron sulfate, but little to no alkali or aluminosilicate.

The last component of the quench is unreacted kaolin flakes. These flakes show electron diffraction patterns which are consistent with with kaolinite's [001] lattice plane spacing, and have the typical platy morphology of the phyllosilicates. The appearance of kaolinite is rare, and is probably associated with shutdown or flame-out, as it would not be expected to survive the hot gas stream during combustion. Sufficiently little kaolinite was present so as not to be $\mathrm{x}$-ray detectable by diffraction, and should be ignored as a constituent of the combustion stream. The micrograph is illustrative of the kaolin habit and particle size which averages less than a micron.

\subsubsection{Combustion Liner Deposits}

As can be seen in Figure 3.1.3.10, there were no liner deposits at the outer rings, and only a small amount of deposit close to the fuel nozzle. They were not analyzed.

\subsubsection{Transition Section Deposits}

Massive deposits occur in the transition section in most of the LM500 turbine simulator trials, irrespective of the fuel character. Typically these build up on a row of type-B thermocouples placed normal to the gas flow through the narrow passage between the transition section and the airfoils. Additional deposits build up in the corners of the transition section. We speculate that these are stagnation zones where a combination of eddies and poor cooling result in buildup and melting of the coal ash. Such zones hopefully will not be present in an actual gas turbine, though careful design must be made to ensure that dead spots cannot occur. Indeed, removal of the thermocouples resulted in significant reduction in transition section deposition, though the problem was not eliminated entirely.

Because transition section deposits were the only deposits present in greater than milligram quantities, these were destructively analyzed for composition and ash fusion temperatures. They are not representative of the leading edge or suction side deposits.

$\mathrm{X}$-ray fluorescence analysis of the untreated coal ash deposit taken from an earlier trial on the LM-500 turbine simulator appears in Table 3.1.3.2. Analyses were performed by Commercial Testing and Engineering, measuring $x$-ray fluorescence of a glass which was prepared by melting the ash into lithium borate, and comparing fluorescence with NBS standards. In general the precision is no better than $1 \%$ absolute.

Table 3.1.3.3 reports $x$-ray fluorescence data on a sample taken from the kaolin trial, again from the transition section. Along with the observed composition appears a calculated analysis assuming that the starting coal ash had composition from Table 3.1.3.1, and was mixed equally with pure kaolinite, $\mathrm{Al}_{2} \mathrm{Si}_{2} \mathrm{O}_{5}(\mathrm{OH})_{4}$. Noteworthy is the gencrally good agreement between 


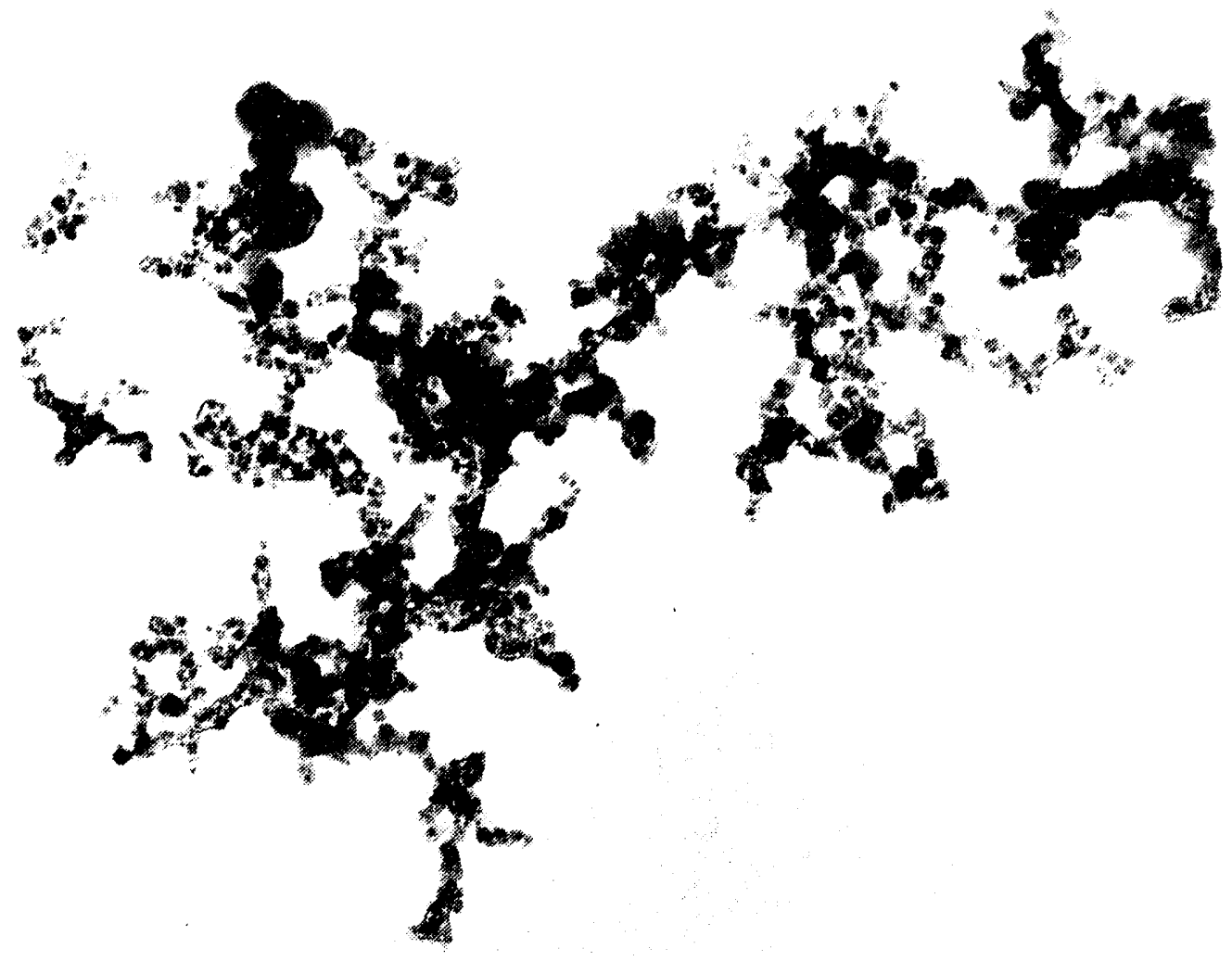

$30 \mathrm{~nm}$

Figure 3.1.3.9 Aerosol condensate from quenched hot gas stream. Composition is primarily iron oxide and iron sulfate. 


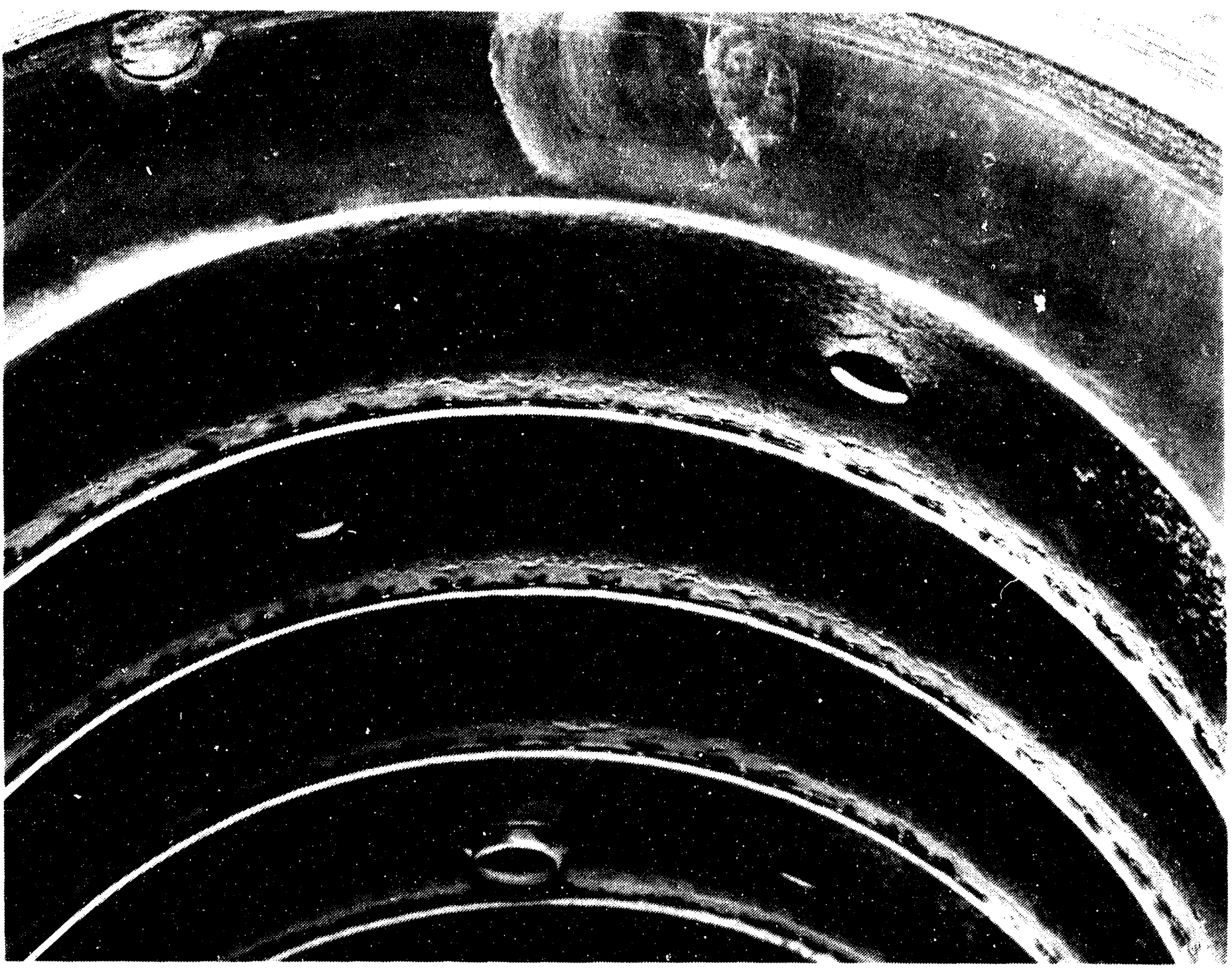

Figure 3.1.3.10 Liner deposits were minimal at the outer rings, and only occurred near the fuel nozzle to any degree. 
Table 3.13.3.

X-ray Fluorescence Data, Transition Section Deposit Kaolin Added

Commercial Testing and Engineering

\begin{tabular}{lcr}
\hline \multicolumn{3}{c}{ observed (calculated) } \\
\hline $\mathrm{SiO}_{2}$ & $37.5 \%$ & $(38.2)$ \\
$\mathrm{Al}_{2} \mathrm{O}_{3}$ & 34.99 & $(37.5)$ \\
$\mathrm{TiO}_{2}$ & 1.87 & $(0.9)$ \\
$\mathrm{Fe}_{2} \mathrm{O}_{3}$ & 13.9 & $(14.2)$ \\
$\mathrm{CaO}$ & 3.96 & $(4.4)$ \\
$\mathrm{MgO}$ & 1.12 & $(1.5)$ \\
$\mathrm{K}_{2} \mathrm{O}$ & 0.73 & $(0.1)$ \\
$\mathrm{Na}_{2} 0$ & 2.56 & $(0.3)$ \\
$\mathrm{SO}_{3}$ & 0.26 & $(0.3)$ \\
$\mathrm{P}_{2} \mathrm{O}_{5}$ & 0.36 & $(0.2)$ \\
$\mathrm{SrO}_{\mathrm{BaO}}$ & 0.60 & $(0.5)$ \\
$\mathrm{MnO}$ & 0.44 & $(0.0)$ \\
\hline \multicolumn{3}{c}{ Ash Fusion Data } \\
\hline Initial Def & Reducing & Oxidizing \\
\cline { 2 - 2 } Softening & 2280 & 2410 \\
Hemispherical & 2480 & 2520 \\
Fluid & 2580 & 2620 \\
& 2680 & $>2700$
\end{tabular}


the calculated and the observed results, with the primary exception of alkali. The observed alkali is nearly an order of magnitude greater than predicted. Alkali metals are common impurities in kaolin with additional sodium coming from the sodium polyacrylate surfactant. In light of the propensity for alkali to glue deposits as inorganic sulfates, the cleanliness of the airfoils is even more remarkable. In addition, by washing the kaolin to remove alkali, it is found that the transition section deposits were substantially reduced.

The kaolin did suppress ash fusion, though not to the degree anticipated. Again, much of this diminished effect can be ascribed to alkali contamination.

The morphology of the transition section deposits, and those lodged in the throats of the airfoils, is twofold, consisting of powder, location "a" in Figure 3.1.3.11, and slag, location " $b$ " in Figure 3.1.3.11. The microstructure of the powdery debris, Figure 3.1.3.12, reveals ash spheres typically under $1 \mu \mathrm{m}$ in diameter and reminiscent of the solid spheres collected from the quench probe Figure 3.1.3.7. Presumably these spheres collect in stagnation points along the hot gas path, and eventually fuse into the massive metallic slag with a smooth, but porous microstructure Figure 3.1.3.13.

The chemistry of the powdery unfused deposits includes mullite from kaolin decomposition, small amounts of hematite and anhydrite from the coal, and plagioclase which could arise from either kaolin or coal. Upon devitrification, the feldspar comprises the major phase.

\subsubsection{Leading Edge Deposits}

Lead g edge deposits consisted occasionally of powdery, unfused icicles which grew back from the airfoils toward the liner, and a thin, fused underlayer. Nutshelling quantitatively removed the unfused deposits. No leading edge deposits were noted using the alkali-free kaolin.

The unfused deposits consisted of mullite, the aluminum silicate which results from the thermal decomposition of kaolinite, as well as hematite and plagioclase feldspar which come from the coal. Salient by its absence is anhydrite, while a large glassy component made up the balance.

Underlayer deposits on the leading edge were up to 4-mils thick after $\sim 20 \mathrm{hr}$ of operation, and were fused, but brittle, Figure 3.1.3.14. They consisted of alkali iron sulfate eutectics, and probably resulted from alkali impurities in the kaolin. In tests using untreated coal, much more extensive, though unfused, deposits formed on the leading edge, a result of inertial impaction coupled with rapid freezing due to the high density of cooling holes along this surface.

\subsubsection{Pressure Side Deposits}

The pressure side has been the site where the most severe deposits occur when untreated coal is burned, Figure 3.1.3.15. As is evident in Figure 3.1.3.16, there were no pressure side deposits. 


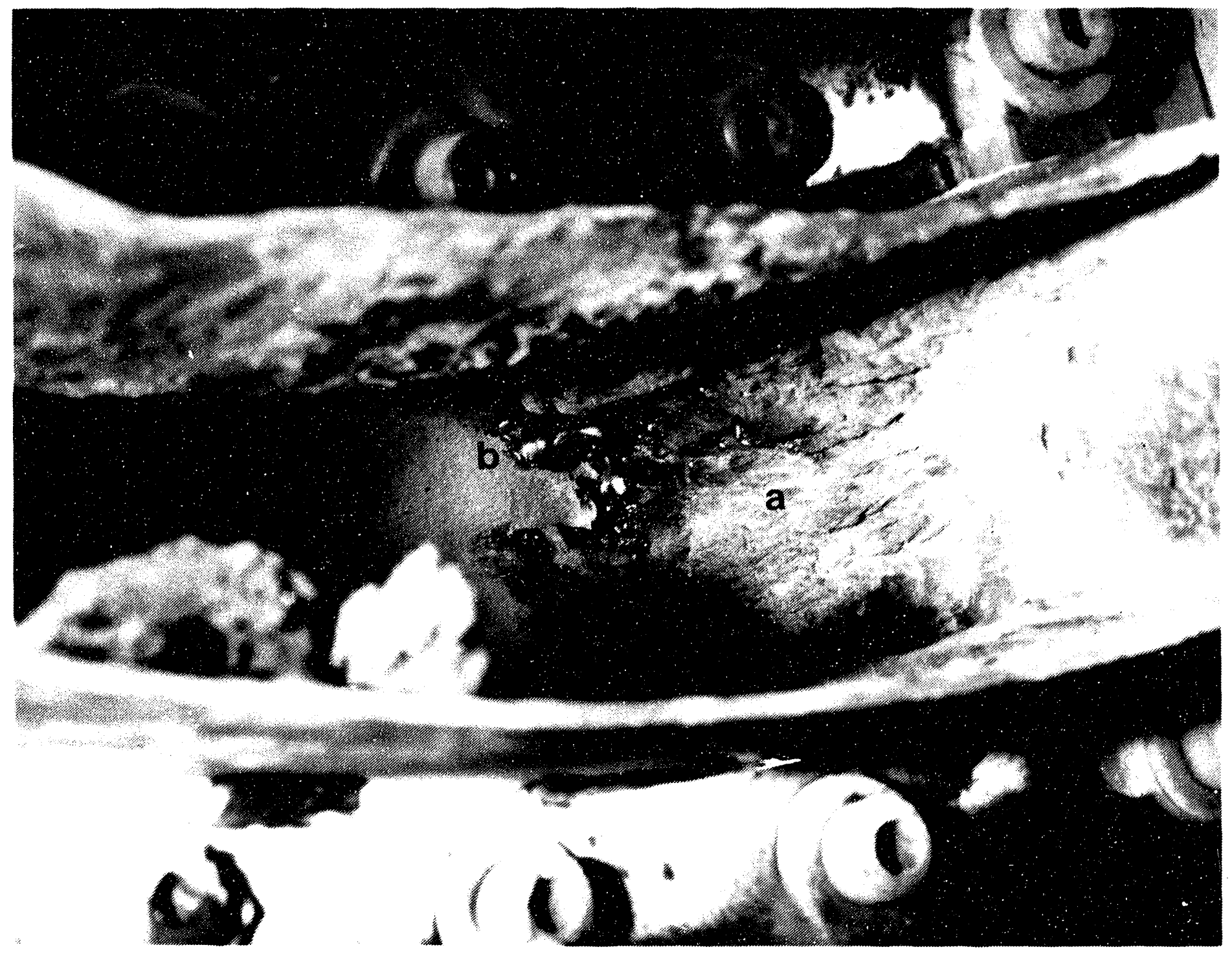

Figure 3.1.3.11 This shows that the morphology of the transition section deposits, and those lodged in the throats of the airfoils, is twofold, consisting of powder (a) and slag (b). 


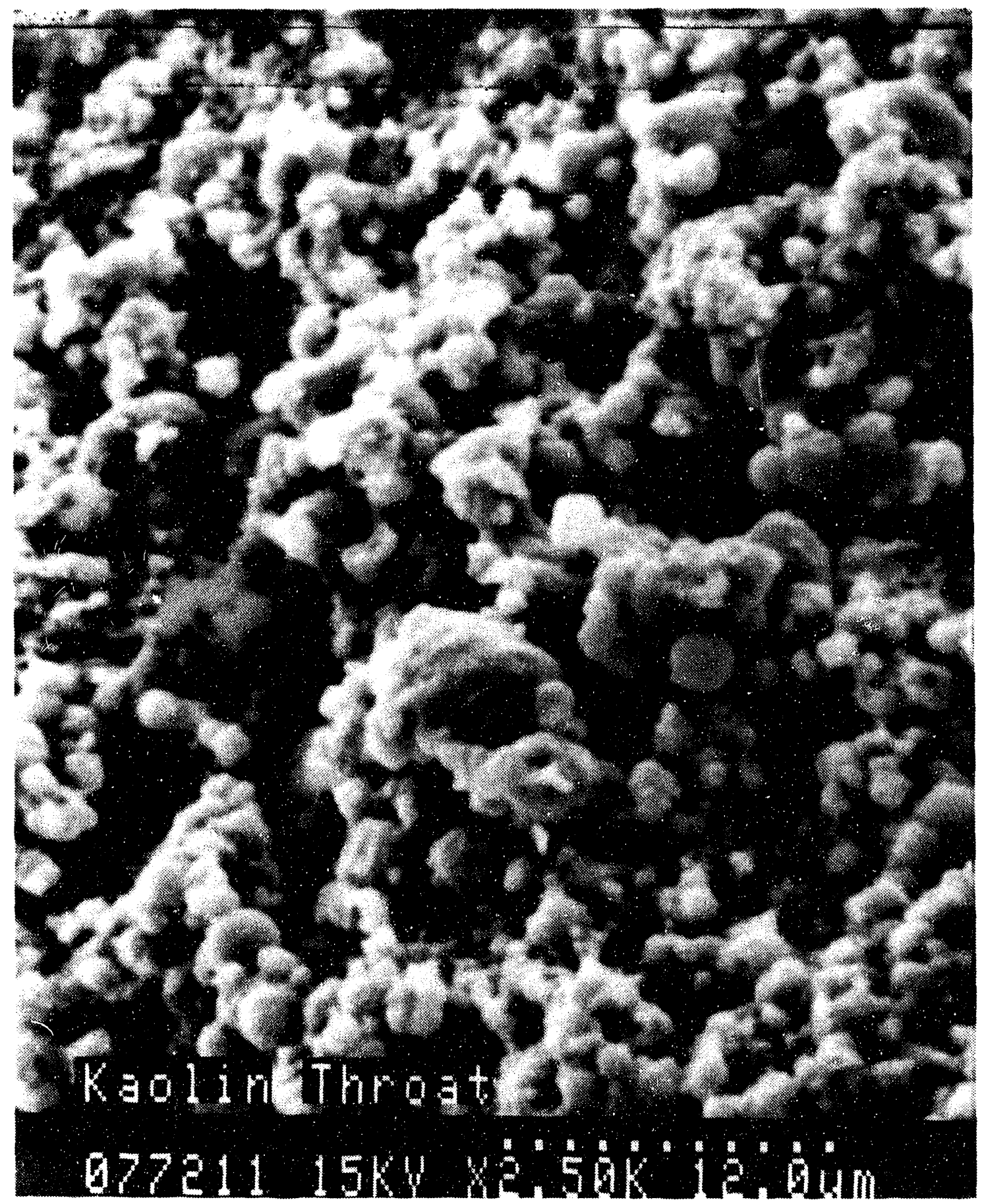

Figure 3.1.3.12 Scanning electron micrograph of unfused deposit in transition section. Note spherical ash morphology reminiscent of solid spheres from quenched gas stream (Figure 3.13.7b). 


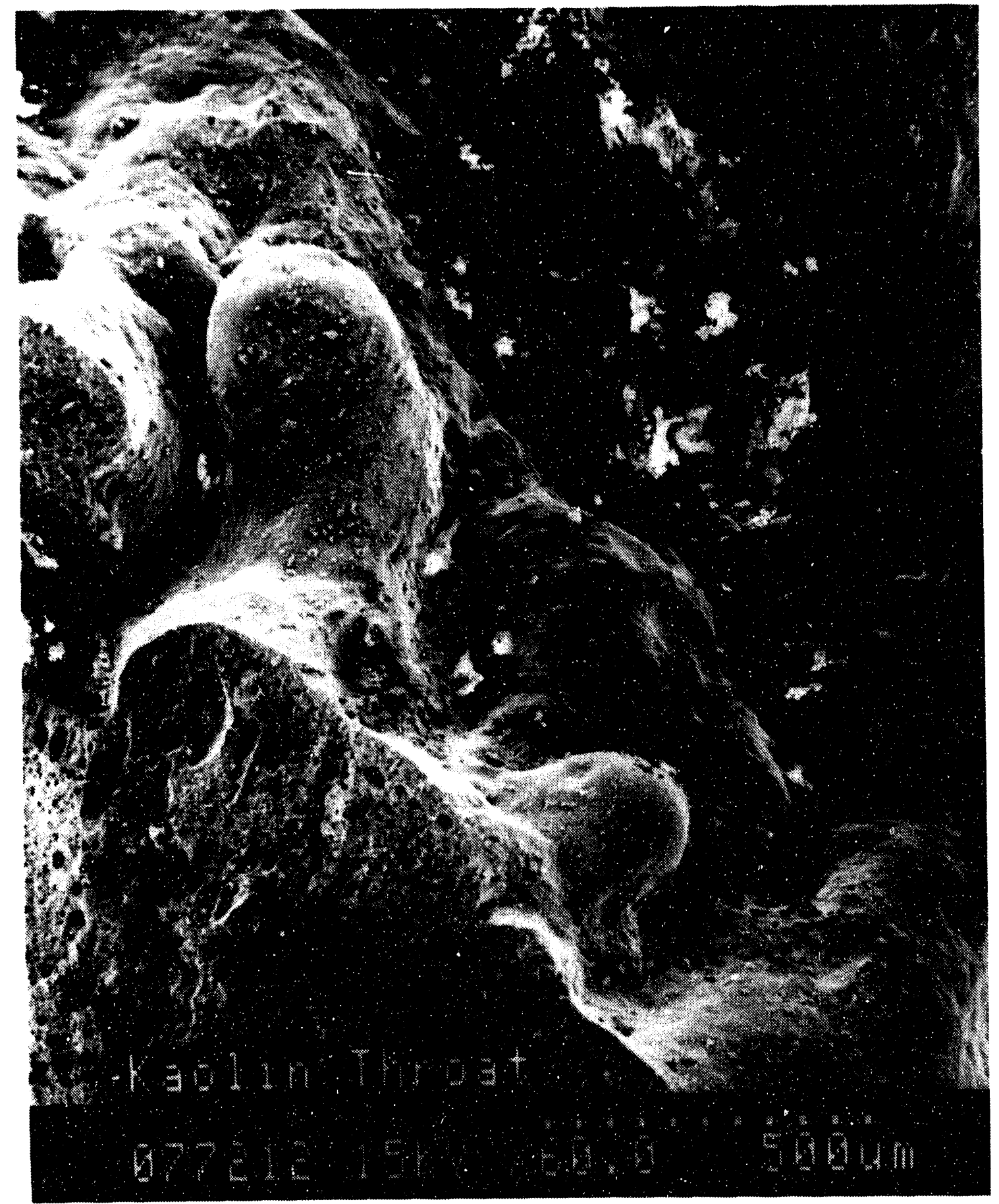

Figure 3.1.3.13 Scanning electron micrograph of fused slag in transition section showing smooth microstructure. Where fractured, note the extensive porosity. The elongated pores reveal a melt of high viscosity. 


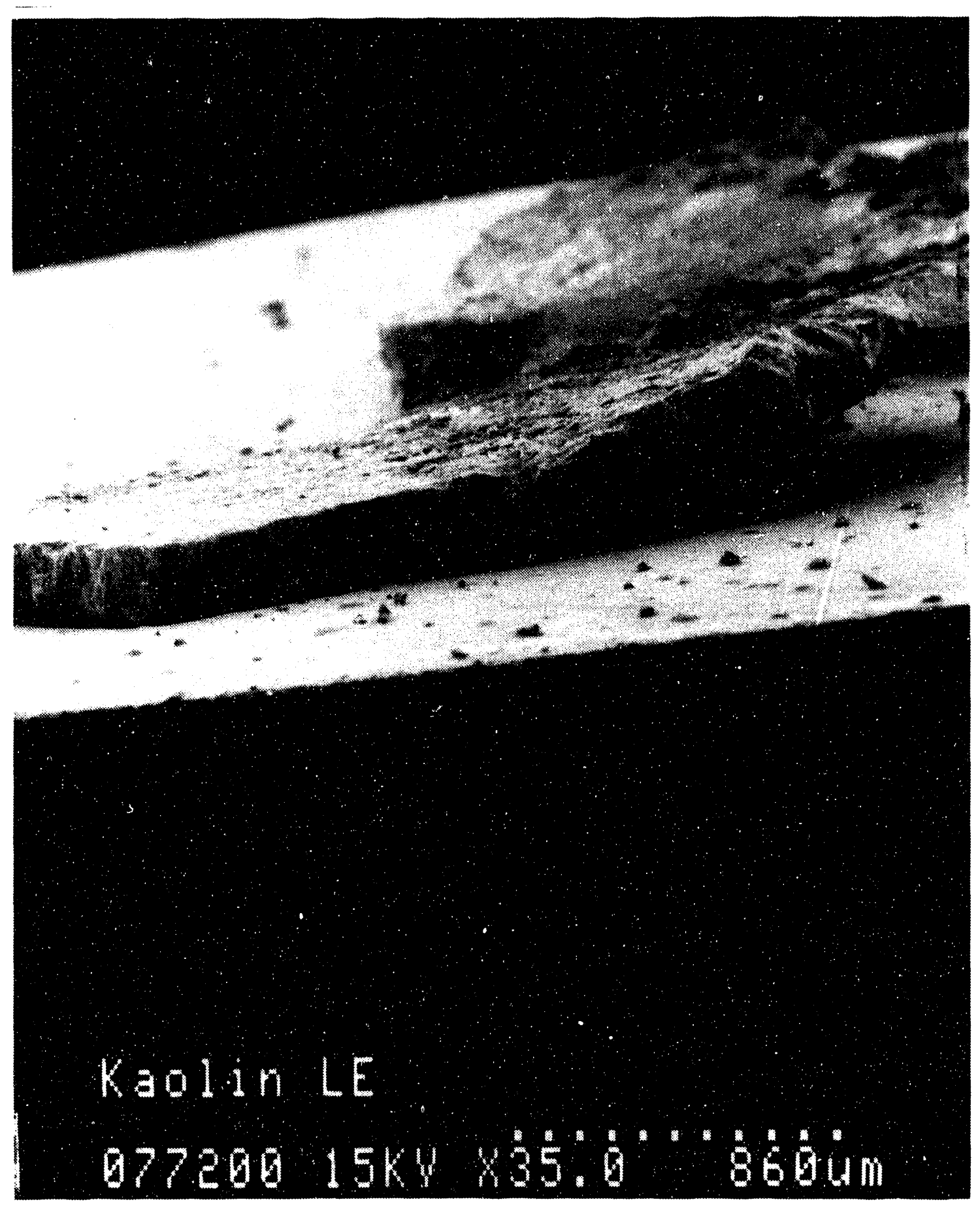

Figure 3.13.14 Scanning electron micrograph of platy leading edge underlayer deposit. 


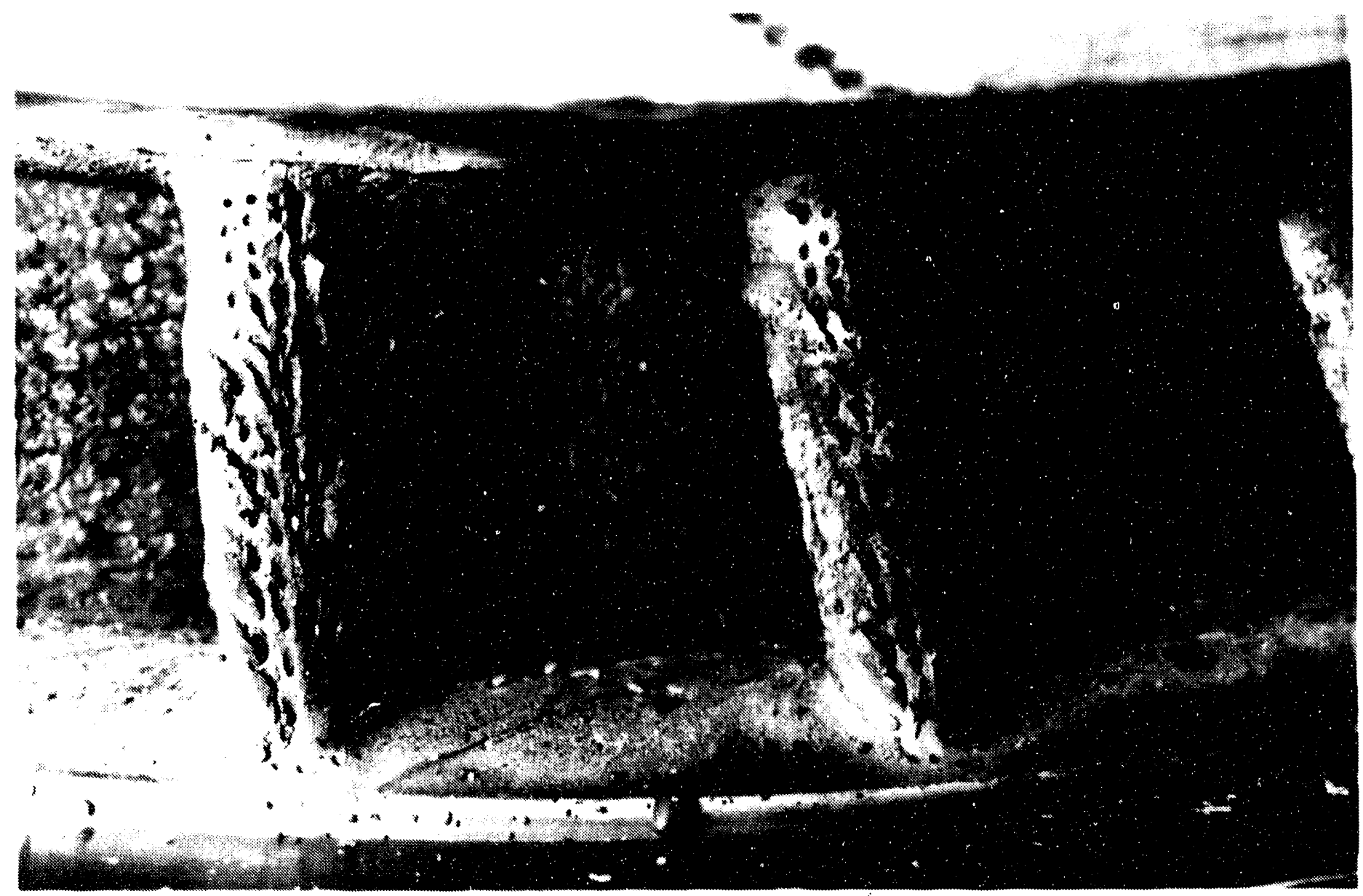

Figure 3.13.15 Typical untreated coal pressure-side deposit. Compared with Figure 3.1.3.16, it is evident that kaolin markedly remediates deposition. 


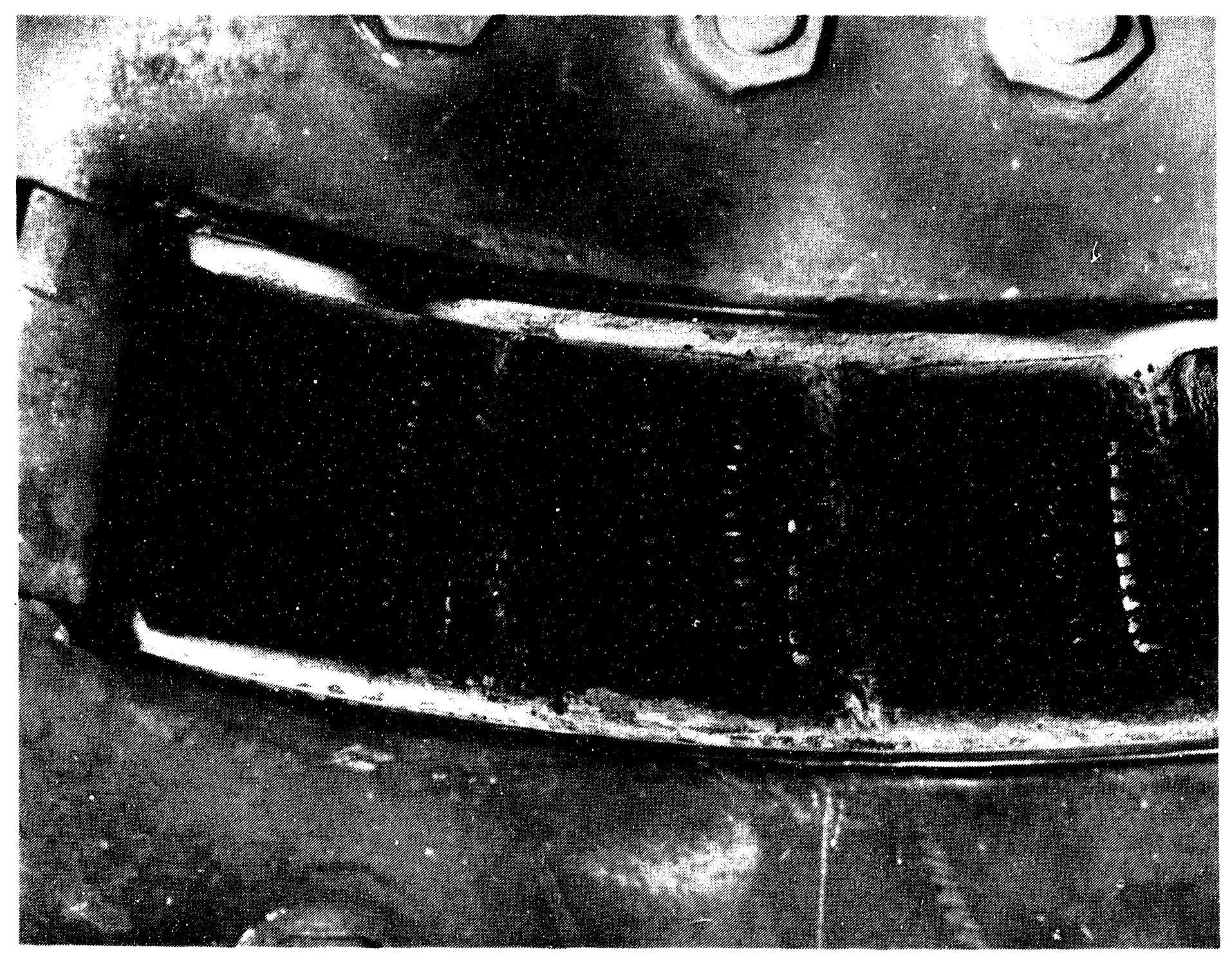

Figure 3.13.16 Pressure-side deposits from kaolin-added test. 


\subsubsection{Suction Side Deposits}

A fused, $30 \mu \mathrm{m}$ thick suction side deposit consisting of hematite, sodalite feldspathoid, and sodium sulfate were found. As before, the sodium impurities in the additive are implicated.

\subsubsection{Discussion}

As demonstrated first under the Gas Turbine Components Screening program, DEAC21-84MC21935, additives can alter the deposit characteristics, resulting in deposit embrittlement and spalling. Using alumina, deposition was reduced, though not eliminated. The deposits that formed with alumina were soft and friable. Considerable erosion due to alumina ( hardness $=9$ on Moh's scale ) took place, including both the friable deposits and the trailing edge of the airfoils. The degree of erosion tended to obscure reduced deposition due to chemical effects.

In order to further test the hypothesis that altering the deposit chemistry could reduce deposition, kaolin was added to the slurry. Kaolin is extremely soft ( hardness $=2$ on Moh's scale), and is also inexpensive. Bulk kaolin FOB Georgia costs $40 \$ /$ ton, which translates to $0.0129 \$ / \mathrm{MBtu}$ when $0.8 \%$ is added to the coal on a dry basis. Transportation costs from Georgia to New York would add an additional 0.014\$/MBtu, certainly less than prohibitive.

Kaolin slurry was obtained from Albion Kaolin Co, Hephzibah, Georgia. The slurry consisted of $70 \%$ Georgia kaolin in water containing Colloid 211 surfactant. The slurry was grade APX 850-SC. Addition of the slurry to Otisca coal-water mixture caused a slight reduction in viscosity. The addition of $0.8 \%$ wt was equivalent to the inherent coal ash content.

Combustion of the doped slurry proceeded without apparent complications due to the presence of kaolin; indeed as described earlier, the coal behaved independently of the kaolin prior to deposition; primary, unfused ash chemistry was a near superimposition of coal mineral and kaolin thermal decomposition products.

The key result was that kaolin additive virtually eliminated pressure-side deposition where previous trials experienced the most severe problems. Why did this work?

As a basis for understanding the relevant chemistry, consider the calcia-alumina-silica ternary phase diagram, Figure 3.1.3.17. In general each point on the map describes a unique composition. In addition, if the composition was artificially prepared in the laboratory, and heated to equilibrium, the chart indicates the temperature of incipient crystallization of the melt and the resulting phase which develops upon cooling. In order to determine the composition of a given point on the diagram, one simply draws lines from each corner of the triangle, through the point, and intersecting with the opposite side. The intersection with the line yields the ratio of two of the three species on the diagram.

The diagram shown has four points marked a,b,c, and $d$. Point a represents the composition of the undoped coal ash assuming that all the calcia, alumina, and silica are incorporated 


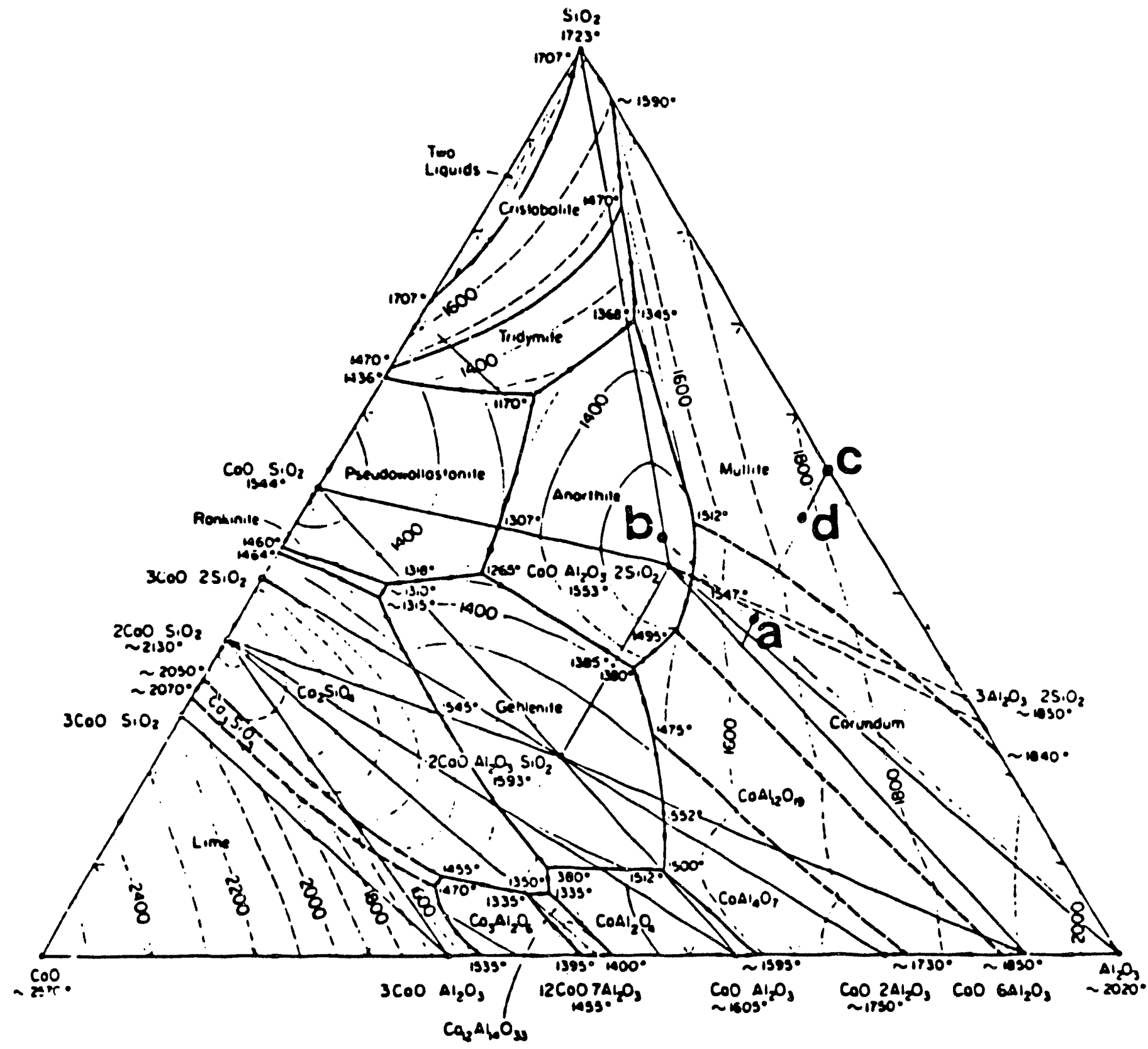

Figure 3.1.3.17 Calcia-alumina-silica equilibrium phase diagram, reprinted from Phase Diagrams for Ceramists, Volume 1, of the American Ceramic Society Press. Point (a) corresponds to the calculated equilibrium phase assemblage of untreated coal ash, assuming that iron and other ash components besides $\mathrm{Ca}, \mathrm{Al}$, and $\mathrm{Si}$ do not participate, and no other coexistent phases occur. Point (b) is the observed phase assemblage, indicating that the ash is depleted of alumina into a spinel. Point (c) corresponds to kaolin. Point (d) is the observed phase assemblage when kaolin is added, indication that alumina from the spinel now participates in the kaolin-ash reaction. 
into the deposit, and nothing else is incorporated. This assumption has two potentially mitigating factors. First, ferrous iron may react with the aluminosilicate, behaving much like calcia. Second, the calcia, alumina, or silica may partition into other phases. The first assumption is not apparently a bad one; iron seems to predominate as the simple oxide -hematite or $\mathrm{Fe}_{2} \mathrm{O}_{3}$. Where iron reacts with the aluminosilicates, it seems to result only in a spinel oxide (Fe,Mg,Al) $\mathrm{O}_{4}$. The second assumption is not as good as the first; as just noted, iron enters the spinel along with alumina, thus effectively slightly depleting the melt of alumina. According to the phase diagram, this causes the composition to alter, moving away from the alumina corner along the line to point $b$. Indeed the observed undoped deposit has hematite, spinel, and anorthite as predicted in the diagram.

Now consider what happens when kaolin is added. Kaolin has the composition described by point $c$ on the diagram. In principle, we should be able to draw a line between points $b$ and c which would describe the new deposit. A 50:50 kaolin/ash deposit should lie halfway along this line. This is not the observed result. What was observed was a deposit of composition d, which lies in between points a (the original coal ash) and point $c$ (the kaolin). The significance of this is that the addition of kaolin suppresses the formation of spinel, which makes available the full inherent alumina from the starting coal ash.

The second interesting feature of point d's location, which adds even more confidence that this phase diagram is applicable, is that even though equal amounts of ash and kaolin were combined, point $d$ lies about $2 / 3$ of the way along the line a-c, indicating that more kaolin was incorporated into the deposit than coal ash. But of course, this makes sense since a third of the coal ash is iron oxide which does not participate in this chemistry. Indeed equal combinations of kaolin and coal ash in actuality represents a two-fold excess of kaolin. Also, the predicted phases - mullite, hematite, and the absence of spinel were observed.

Thus we have a self-consistent picture of the kaolin-added test in which the two assumptions are justified, the phase diagram is applicable, and to an excellent degree of accuracy, we know where on the phase diagram the deposits lie. Noteworthy is that it is the Ca-Al-Si-phase diagram which applies, and that within these species, a pseudoequilibrium condition takes place, in which iron apparently does not participate. This is in contrast to boiler deposits where major exceptions to the phase diagram applicability were observed [6]. Probably the film cooling for the gas turbine froze the pseudoequilibria at the calcia-alumina-silica stage, and prevented further reaction with iron as in the boiler.

An understanding of the deposit chemistry does not, a priori, explain why deposit remediation occurred in the test, but does provide the basis for further discussion of the phenomenon. Consider the following hypotheses for deposit remediation:

- Kaolin may simply erode deposits at a rate comparable to their formation; 
- Kaolin and coal ash may simply form a composite in which coal ash fusion cannot take place except locally in pockets.

- Kaolin-based ash has a higher melting point than coal ash so that it may freeze more completely than coal ash in the boundary layer, thus making it less sticky;

- Kaolin ash may react in situ with coal deposits, forming mullite which changes the molar volume of the deposit and causing it to spall.

- Kaolin ash may react with coal ash to form a weakened and embrittled deposit which is readily eroded.

- Kaolin ash may react with coal ash to yield a new ash which does not wet or adhere to the metal surfaces.

Of the hypotheses listed above, some can be easily dismissed. For example, there was little evidence for erosion, with small scratches persisting in the metal at the start of the test. Also, in spite of its abrasive properties, the alumina additive from earlier testing did not reduce deposits as-thoroughly as did the much softer kaolin, suggests that chemistry, rather then erosion, is the dominant effect taking place.

The suggestion that the deposit consists of a composite of coal ash and kaolin ash which do not react with one another but are simply deposited to form a weakened matrix, is also not likely. Where deposits were obtained, they have clearly reacted with one another. Absent are calcium sulfate and spinel. Kaolinite has lost silica to yield mullite, and the released silica reacts with both calcium sulfate and spinel to form a calcium aluminosilicate glass which devitrifies to yield anorthite. Since the pressure side has higher temperatures than the leading edge, it is unreasonable to suggest that the coal ash would react with kaolinite on the leading edge but not on the hotter pressure side.

Another unlikely explanation is that the coal/kaolin ash has a higher melting point, and simply freezes more quickly in the boundary layer than normal coal ash. Evidence to the contrary is found in analysis of the quench probe sample in which coal ash has not apparently reacted with kaolin. Thus since untreated coal ash has been shown to be sticky, it should be equally sticky in this trial, and might even be expected to selectively deposit, even if the kaolin ash was frozen more completely in the boundary layer. This was not observed. Further, this effect would be more pronounced at the leading edge, rather than at the pressure side where cooling is less efficient. Thus if it was simply a matter of raising the ash fusion temperature in the gas stream, leading edge deposits should be the most affected, not the pressure side.

The last three hyputheses are less readily dismissed. The notion that the primary deposits react in situ, and as a result of the reactions are weakened is consistent with most of the data. One way the deposits might be weakened, especially with respect to the ash/airfoil interface, 
would be a consequence of molar volume changes. Consider the usual deposits of feldspar $(2.8 \mathrm{~g} / \mathrm{cc})$, anhydrite $(2.9 \mathrm{~g} / \propto c)$, and glass $(\sim 2.7 \mathrm{~g} / \propto)$. If these react to form mullite $(3.2 \mathrm{~g} / \mathrm{cc})$, and additional feldspar, there would necessarily be a contraction due to densification and devitrification of the melt. In principle, the contraction could be sufficient to reduce the metal/ash interfacial contact area, and cause the deposits to spontaneously spall.

The second possibility, that the primary deposits react in situ to form a weakened and embrittled deposit may also occur; indeed one way the deposit may be embrittled is through contraction due to devitrification of the glass as noted in the previous paragraph. The subtle difference between this explanation and the previous one is that, rather then causing the deposit to spall by shrinking at the deposit/metal interface, here it is suggested that the contraction causes void formation in the bulk which embrittles the deposit so that further impact causes fracture and erosion to take place. Indeed, examination of the slag microstructure, Figure 3.1.3.18, reveals a highly porous slag with uuggy mullite crystals lining the pores. Clearly the microstructure of this melt is quite different from the slags encountered in untreated slurries, Figure 3.1.3.19. The high density of pores, often with non-spherical shapes, suggests a melt of unusually high viscosity, which is consistent with an aluminosilicate-enriched liquidus. Close examination of transmission micrographs, i.e., Figure 3.1.3.7 reveals occasional nonspherical droplets of frozen ash, again suggesting regions of unusually high viscosity which a low calcia/aluminosilica ratio can cause [6]. Possibly as the frozen spheres of ash pack onto the metal surface, the resultant voids are preserved during fusion. This is unlike the untreated slags where the high fluidity of the melt causes the pores to collapse. In collapsing the pores, hypothetically this can mechanically strengthen the deposit and increase the metal/slag interfacial contact area. Thus one effect of the kaolin addition could be to weaken the deposit by preserving voids through increased melt viscosity. Thus a combination of void formation due to volumetric changes upon devitrification, coupled with void preservation due to increased melt viscosity and possibly poor diminished wetting of the ash/metal interface could cause spalling by reduced metal contact area. Indeed scanning electron microscopy, Figure 3.1.3.20 shows direct evidence for void formation at the metal/slag interface.

The last plausible explanation ( though there may be others ) is again related to the previous two, in which deposits react in situ to devitrify the liquidus and weaken the deposit so that subsequent erosion is effective. In this hypotheses, it is suggested that it is primarily the glass phase which cements the deposit along grain boundaries and especially at the deposit/metal interface, and simply the substitution of a crystalline phase for the glass is sufficient to cause the deposit to spall or erode. Indeed, comparison of slag microstructures in the treated (Figure 3.1.3.18) and untreated (Figure 3.1.3.19) slags reveals distinclty different grain structures which will surely affect mechanical properties. 


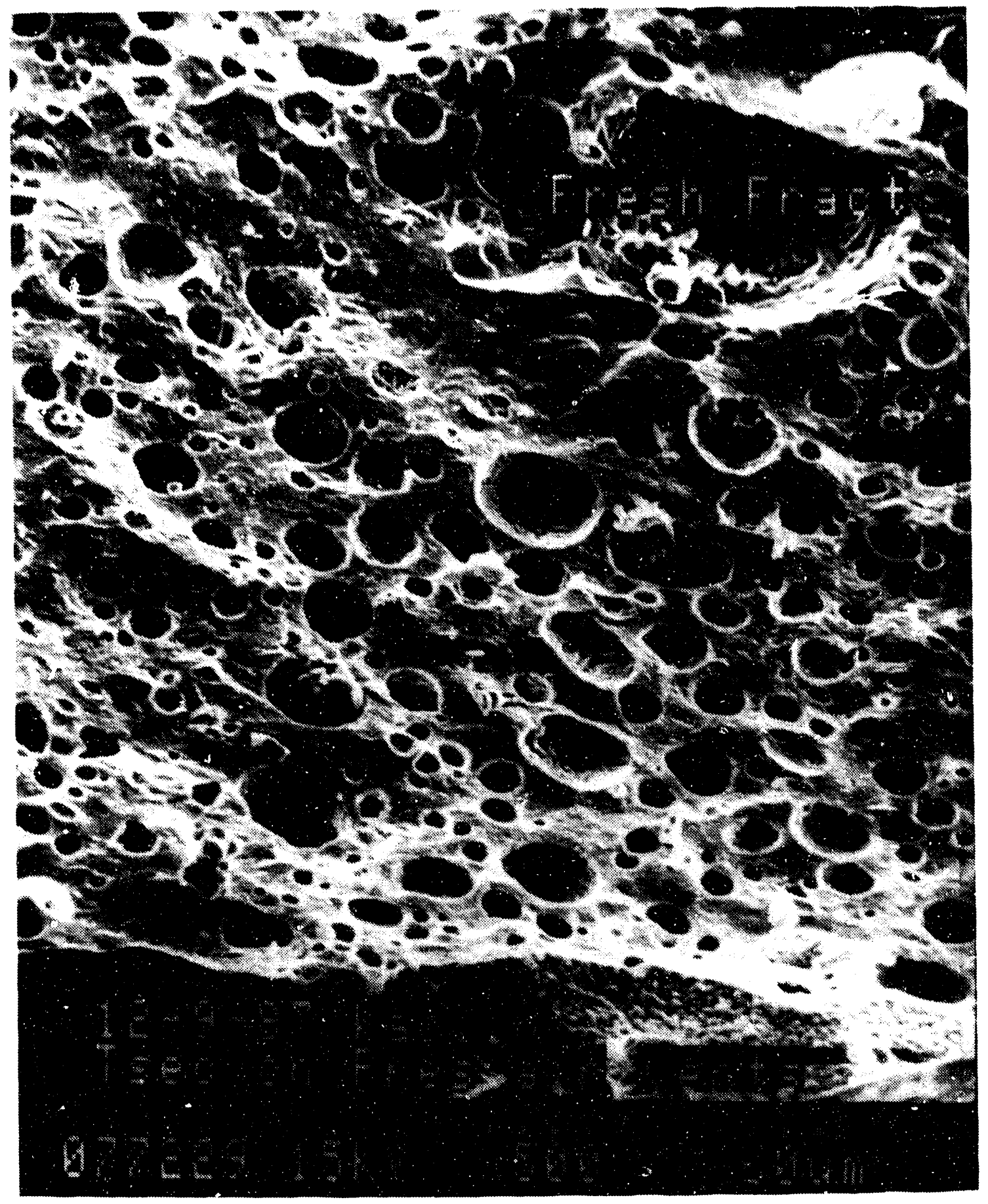

Figure 3.13.18 Scanning electron micrograph of kaolin-doped ash slag morphology reveals highly porous microstructure with vuggy mullite crystallites lining the cavities. 


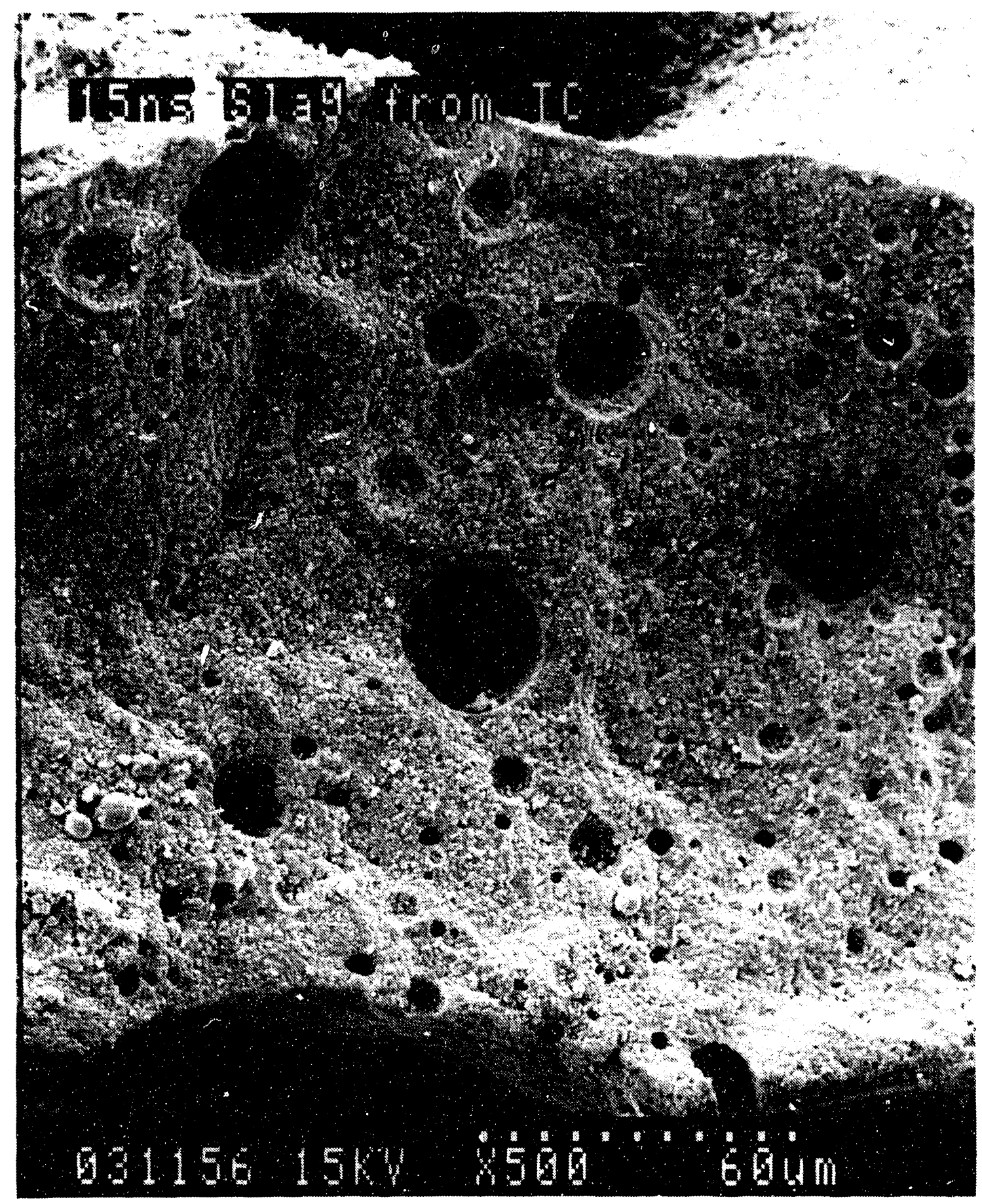

Figure 3.1.3.19 Scanring electron micrograph of untreated coal ash slag indicating few and large pores, with a granular microstructure. 


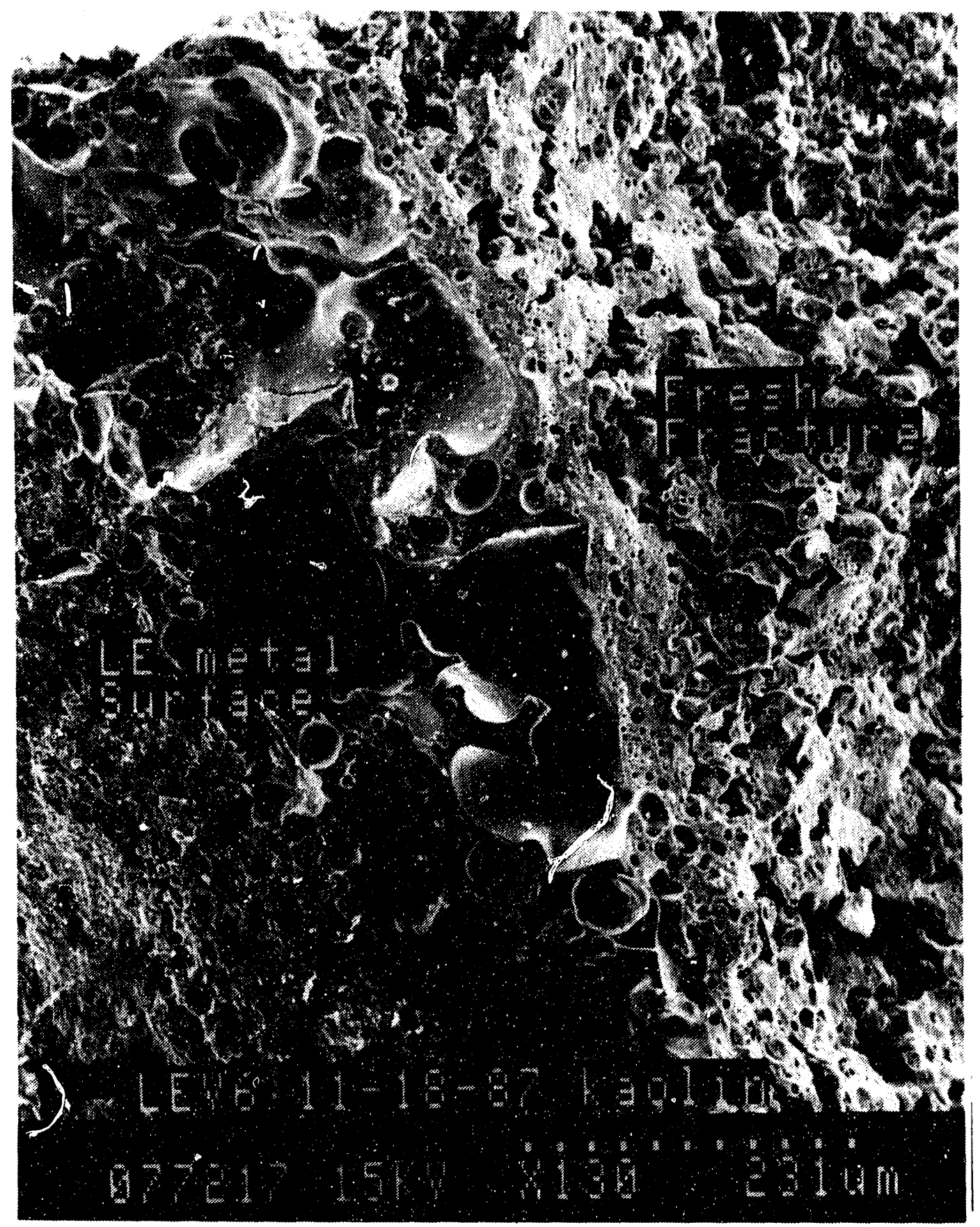

Figure 3.1.3.20 Scanning electron micrograph of kaolin-treated coal ash interface with airfoil surface. Note that at the metal interface, considerable growth of pores has occured, substantially reducing the deposit/metal contact area. It appears that the slag has pulled away from the surface, and did not collapse and contact. 


\subsubsection{Summary and Conclusions}

Kaolin can be added to coal-water mixture for the purpose of deposit abatement. Kaolin is inexpensive, and when added to coal-water mixture at the $0.8 \%$ level on a dry basis $(0.4 \%$ slurry basis), the net economic impact is 0.0129 / MBtu not including shipping. There is no apparent adverse impact on slurry rheology. Most important, deposition on the pressure side of the LM500 gas turbine simulator was virtually nonexistent. The pressure side of the simulator is most representative of the first row of stator blades in an actual engine where deposition is anticipated to be most severe.

Deposit formation was severe in stagnation points along the hot gas pathway (i.e., in the throat of the transition section between the combustion liner and the airfoils) which will probably not take place in an actual annular combustor. Indeed removal of thermocouples in the transition section caused considerable improvement in deposition. Very thin deposits on the leading edge and suction side surfaces was ascribed to sodium sulfate formation from impurities in the kaolin, which could be eliminated by washing or better kaolin and surfactant selection.

The chemistry of the deposits is well understood by examination of the calcia-aluminasilica ternary equilibrium phase diagram, with only limited caveats. First, iron does not directly participate with the calcia-alumina-silica pseudoequilibria, but rather deposits as the simple oxide hematite. Small amounts of iron will be incorporated in a spinel oxide which includes many of the remaining species such as magnesium, possibly titanium, and aluminum. The loss of alumina from the melt into the spinel represents the second caveat which restricts the use of the simple ternary phase diagram. The partitioning of alumina simply causes a shift in composition from that predicted by absolute compositions, to one somewhat depleted by alumina.

Addition of kaolin $(\mathrm{Al} / \mathrm{Si}$ ratio $=1)$ to the combustor causes decomposition of the kaolin into muilite $(\mathrm{Al} / \mathrm{Si}$ ratio $=2$ ) in which the excess silica combines with calcia from anhydrite and alumina from the spinel, to yield a glass which devitrifies to anorthite feldspar.

The reason that deposition is suppressed by kaolin is not fully understood, but is clearly due to consequences of chemical effects. The most plausible hypotheses involve kaolin induced devitrification of the liquidus at elevated temperatures, the net effect of which is to either cause spontaneous spalling due to changes in molar volume and porosity at the metal/deposit interface, weaken the deposit by creating voids, or to embrittle deposits by virtue of glass depletion due to devitrification along grain boundaries. In order to sort these or other hypothetical mechanisms, additional studies are planned including a so-called "rainbow" test of deposit/metal interfaces in which airfoils will be tested with a variety of coating compositions. 


\section{References.}

[1] R.J. Anderson, C.J. Romanowski, and J.E. France, DOE Report DOE/METC85/2007, October, 1984

[2] C.L. Spiro, C.C. Chen, J. Wong, S.G. Kimura, and R.B. Greegor, "Characterization of Products from a Direct Coal-Water Mixture Fired Gas Turbine Combustor", Fuel 66(4), 563-567, 1987.

[3] C.L.Spiro, S.G. Kimura, and C.C. Chen, "Ash Behavior During Combustion and Deposition in Coal Fueled Gas Turbines", ASME Joumal for Engineering and Power 109 (3), 325-330, 1987. Also presented as paper 87-GT-267 at the Gas Turbine Conference and Exhibition, 5/31/87, Anaheim, CA.

[4] D.V. Keller, Jr., in Fifth Symp. on Coal Slurry for Combustion Tech., Tampa, Fl, April 1983, U.S. DOE, Pittsburgh, PA, 269, 1983.

[5] P.J. Schields, C.L. Spiro, and E. Koch, "Phase Characterization of Coal-Fueled Engine Deposits," "Fly-Ash and Coal Conversion By-Products: Characterization, Utilization and Disposal, IV" edited by G.J. McCarthy. F.P. Glasel, and D.M. Roy; Materials Research Society Symposium series vol. 113, 133-142, 1988.

[6] Sanyal and Williamson, J. Inst. Energy 54 (420) 158-162, 1981. 


\subsubsection{The Effect of Boehmite Addition on Deposit Formation in Coal-Fired Gas Tur- bines}

\subsubsection{Introduction}

As part of this investigation of methods to alleviate deposition in coal-fired gas turbine engines, we have recently tested synthetic boehmite as a candidate fuel additive. Boehmite was selected for several reasons as described below.

Recently we reported [1] a detailed phenomenological model of coal ash thermochemistry, which is reviewed in Section 3.1.2. In the model, a portion of the deposition process is ascribed to a calcia-alumina-silica pseudoequilibrium. Based on this model, a series of coalfired simulator tcists were performed using kaolin clay additives to alleviate deposition, Section 3.1.3. As a result of the kaolin addition, deposition was nearly quantitatively eliminated on the airfoils, especially on the pressure side surfaces where deposition and deposit adhesion had been most severe. A mechanism for deposit amelioration by kaolin was suggested involving pore formation at the deposit/metal interface, which resulted from exsolution of high density mullite from a viscosity-enhanced melt. The net effect was to cause spontaneous or erosion-aided spalling of the deposits. Further, the relevant chemistry still seemed to be governed by the calcia-alumina-silica pseudoequilibrium, in which a phase field shift from anorthite to mullite resulted from kaolin addition as anticipated from the ternary equilibrium phase diagram.

While alleviating deposition on the film-cooled airfoils, kaolin addition did not completely eliminate upstream deposition which probably results from a combination of localized hot spots and flow instabilities on the transition section. In the current test configuration, this uncooled transition section directs the hot gas flow from the modified J-79 can combustor into the airfoils. After several hours of continuous combustion using kaolin-augmented coal water mixture, a sudden airfoil obstruction occurred as the upstream deposit spalled and lodged in the airfoil throats. Though these spurious deposits are ascribed to artifacts of the test design which would not likely be present in an actual engine, they do prevent prolonged testing of engine durability, an important objective of our test program.

In order to prevent upstream deposition as well as airfoil deposition, it was reasoned that the calcia-alumina-silica ternary equilibrium phase diagram should still be applicable, but rather than seeking the mullite phase field with kaolin, exsolution of corundum from the melt might be preferred. Corundum is denser and more refractory, having the potential to surpass kaolin's efficacy in thermal stability, viscosity enhancement, and void formation. It was anticipated that the voids would be larger from corundum which has $20 \%$ higher density than mullite, and the enhanced viscosity and thermal stability would persist even in uncooled hot spots upstream of the airfoils. 
In order to achieve the corundum phase field, boehmite was selected as an additive. Previous work with alumina [2] resulted in complications due to erosion. Alumina has a hardness of 8 on the Moh's scale, and is sharp and angular. Boehmite, $\mathrm{AlO}(\mathrm{OH})$ is softer (hardness 3 to 4 on Moh's scale) and occurs as fume. It is available for $\sim \$ 0.7 / \mathrm{lb}$, which is not considered prohibitive. Finally, it contains no detectable alkali, which had been implicated in the kaolin testing as a source of deposition.

\subsubsection{Experimental}

Boehmite has the formula $\mathrm{AlO}(\mathrm{OH})$, occurring in the gamma orthorhombic form illustrated in Figure 3.1.4.1 [3]. It has true density of $3 \mathrm{~g} / \mathrm{cc}$, and a hardness of 3.5 to 4 on Moh's scale, or roughly that of calcite. It is available in ultrapure form (no detectable alkali) as a byproduct of the Ziegler process for making alpha-olefins and fatty alcohols [3], under the tradename Catapal from Vista Chemicals in Houston, TX.

The actual boehmite used in the testing was Catapal A, a dry flowable powder which consists of 30 to $50 \AA$ boehmite crystals that had been spray-dried to 30 to $50 \mu \mathrm{m}$ granules. While complete dispersion of the crystals is possible under mildly acidic conditions, it was deemed undesirable since complete dispersions greater than $2 \%$ by weight will gel. On the other hand, the as-received grains were considered to be too coarse, representing a potential source of erosion in the event that sintering took place in the gas stream. However unlikely this might seem, precautionary comminution was performed in a mullite lined Abbe 7 gallon dry ball mill, using a charge of 50\% volume 1-in. cylindrical alumina media for not less than 24 hr. Sedimentation equivalent spherical diameter of the milled grains had a mean of $0.6 \mu \mathrm{m}$, considered to represent an acceptable risk of erosion, as was borne out in the test (vide infra).

Coal-water inixture was provided as a $50 \%$ slurry by Otisca Industries. Fuel properties appear in Tables 3.1.3.1 and 3.1.3.2.

Dry addition of the milled Catapal A was attempted with limited success. The dry powder showed a tendency to clump, though high-shear mixing for $\sim 12 \mathrm{hr}$ eliminated most of the lumps. Because of fuel flow rates of ca. 1 gallon $/ \mathrm{min}(4 \mathrm{l} / \mathrm{min})$, overnight mixing of such large quantities of slurry was not feasible. In a commercial facility, dry mixing may be accommodated. For this pilot-scale testing, the Catapal A was mixed with an equal weight of water, and rolled on a drum roller for 1 to $2 \mathrm{hr}$ before addition to the coal water mixture. The slurry was added at a rate of $3.8 \#$ / 55 gallon drum of coal slurry. This exactly doubles the ash content of the slurry, and according to the phase diagram should be sufficient to move the ash into the corundum phase field.

Combustion proceeded as described in Section 3.6. with no special measure taken to accommodate the presence of boehmite. A single trial was attempted with a total accumulated combustion time of $6 \mathrm{hr}$ at the designated test conditions, which included $2000^{\circ} \mathrm{F}$ firing temperature, a chamber pressure of $130 \mathrm{psig}$ and the atomizing air pressure ratio maintained at 


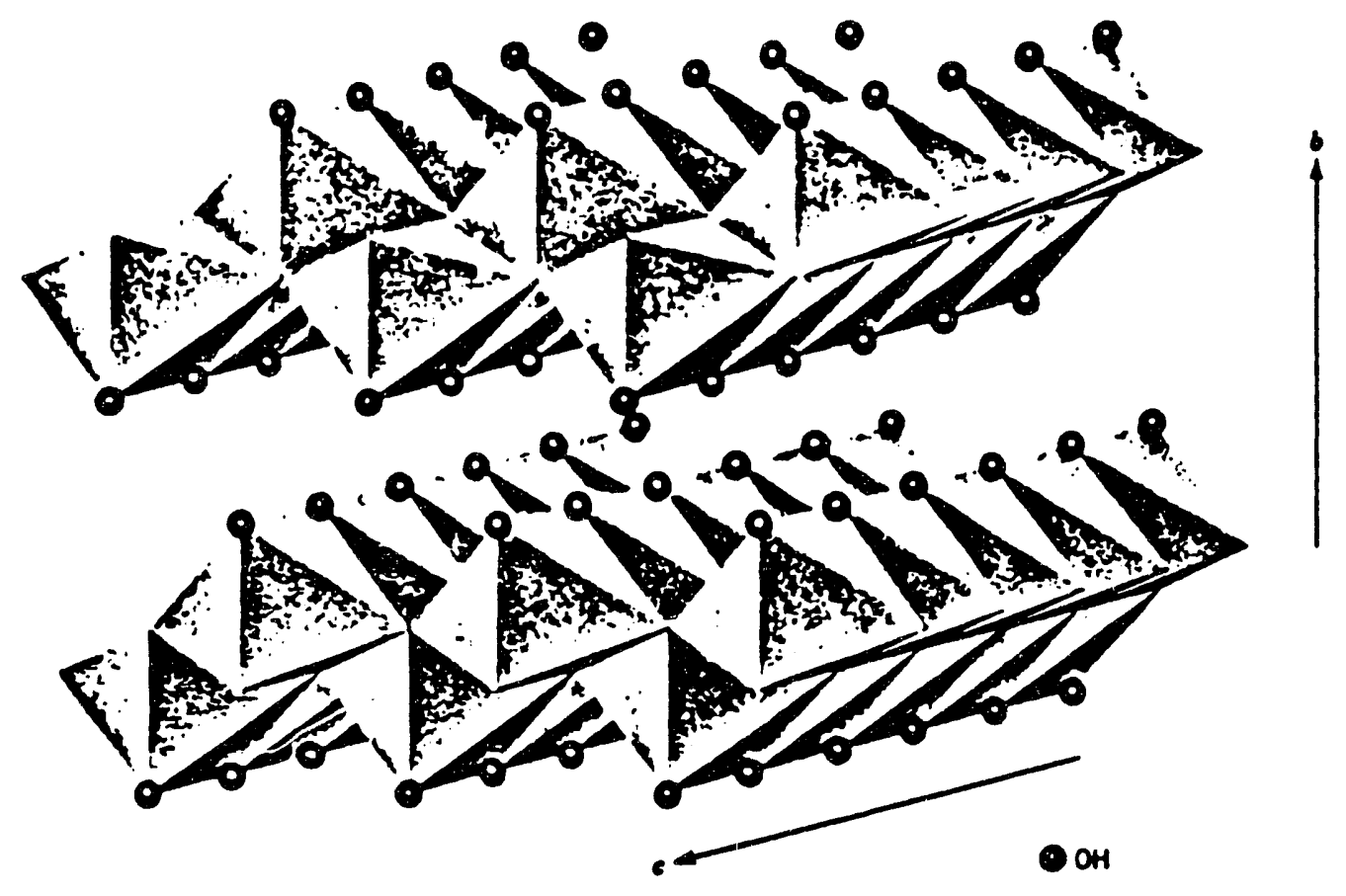

Figure 3.1.4.1 Structure of boehmite. 
$\sim 1.9$. Oil assist was set at $10 \%$ to minimize complications due to combustion instability.

\subsubsection{Results}

Results of deposition testing appear as a NAIN plot in Figure 3.1.4.2. NAIN is the normalized nozzle area index number, which is an indirect measure of deposition rate determined by measuring mass flow at pressure. As deposits build up, the throat area is diminished and pressure increases at constant mass. As is evident from the figure, NAIN was dropping at a rate of $1 \%$ per $5 \mathrm{hr}$, indicating that, unlike the kaolin-added trial, here deposition was taking place. At 500 minutes after start-up on oil, a sudden drop in NAIN from $98 \%$ to $91 \%$ occurred, indicating a catastrophic event. This was accompanied by flame-out. On close examination of the NAIN data, Figure 3.1.4.2, it appears that flame-out may have occurred just prior to deposition, though some caution must be exercised in interpreting the calculated pressure traces at this level of detail.

Visual examination of the airfoils confirmed that deposition had occurred in several distinct manners. Figure 3.1.4.3 shows that a massive deposit had been building up (point a) in the third throat, but which had little effect on the NAIN plot as it was open and attached to the leading edge of the airfoils. The sudden drop in NAIN was due to the deposits wedged in the second throat ( point $b$ ), which had spalled from upstream either from the liner, Figure 3.1.4.4, or the transition section, Figure 3.1.4.5. The steady decline in NAIN was, in fact, due to the most severe suction side deposition noted to date for coal-fired testing, Figure 3.1.4.6. This form of deposit builds up at the critical throat orifice and has the strongest influence on NAIN. It is more typical of a residual oil deposit.

\subsubsection{Discussion}

Hydrous alumina in the boehmite structure was added to coal-water mixture in order to prevent deposition both on the airfoils and upstream. The object was to generate an even more viscous and porous slag than the kaolin provided, which in turn would spontaneously spall not only from the airfoils, but upstream as well. As is evident from Figures 3.1.4.2 to 3.1.4.6, the test was not successful, though close examination of the pressure side of the airfoils, Figure 3.1.4.3, indicates that at least this troublesome region was clean.

In order to better understand the test results, detailed analyses of deposits and combustion products were performed using scanning electron microscopy, transmission electron microscopy, $\mathrm{x}$-ray diffraction, electron diffraction, energy dispersive $\mathrm{x}$-ray fluorescence spectroscopy, and carbon burnout by combustion gas sorption. Based on these data, a better picture of the coal ash chemistry has emerged.

In fact, just as predicted, the ash and the alumina passed through the hot gases with only minor interactions, Figure 3.1.4.7, and codeposited into an unfused, powdery deposit, Figure 3.1.4.8. This deposit subsequently fused into a viscous and porous mass, Figure 3.1.4.9, with larger cavities than observed with the kaolin test. Again as predicted, the pores were 


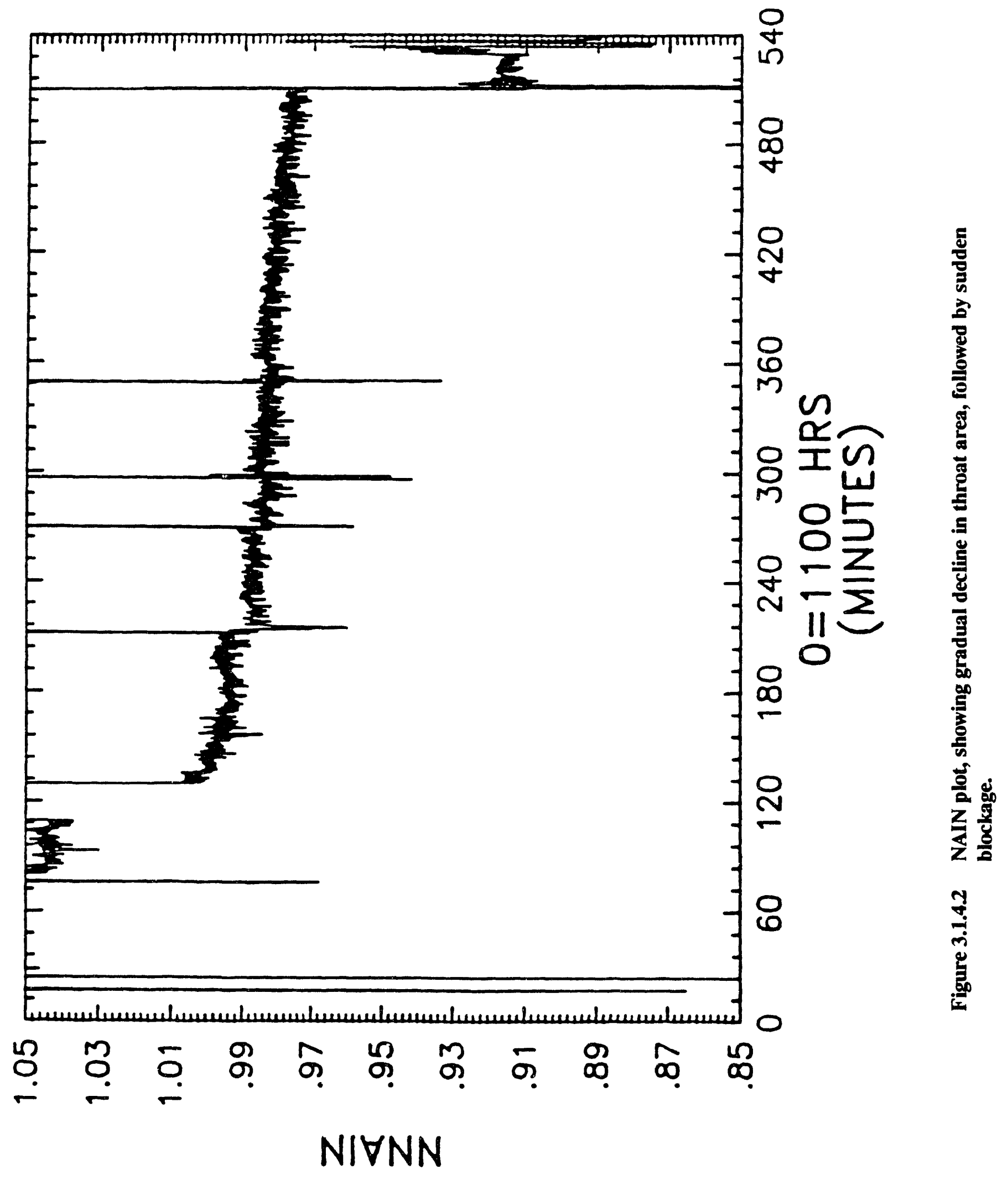




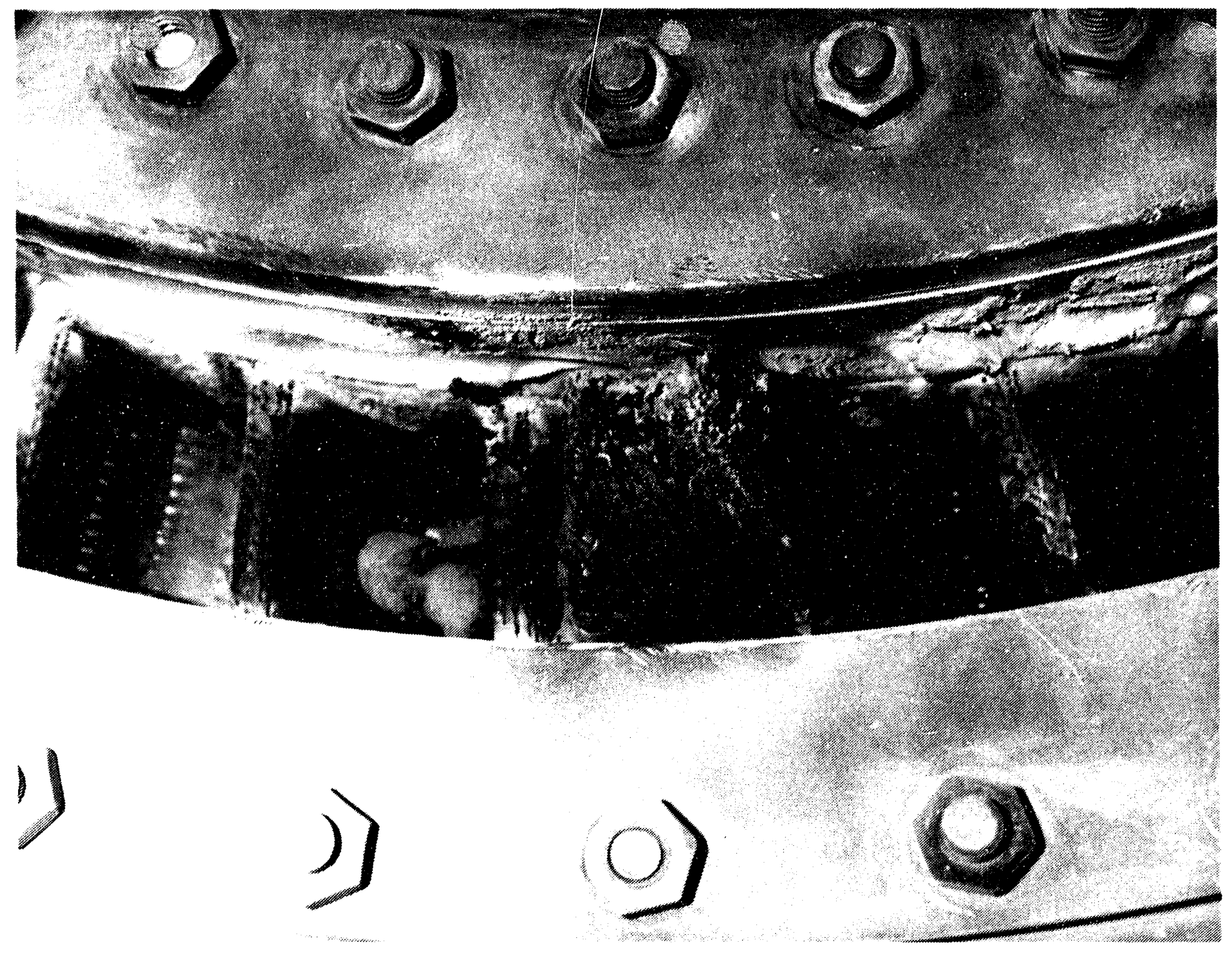

Figure 3.1.4.3 Leading edge and pressure side deposits at the end of the boehmite test. 


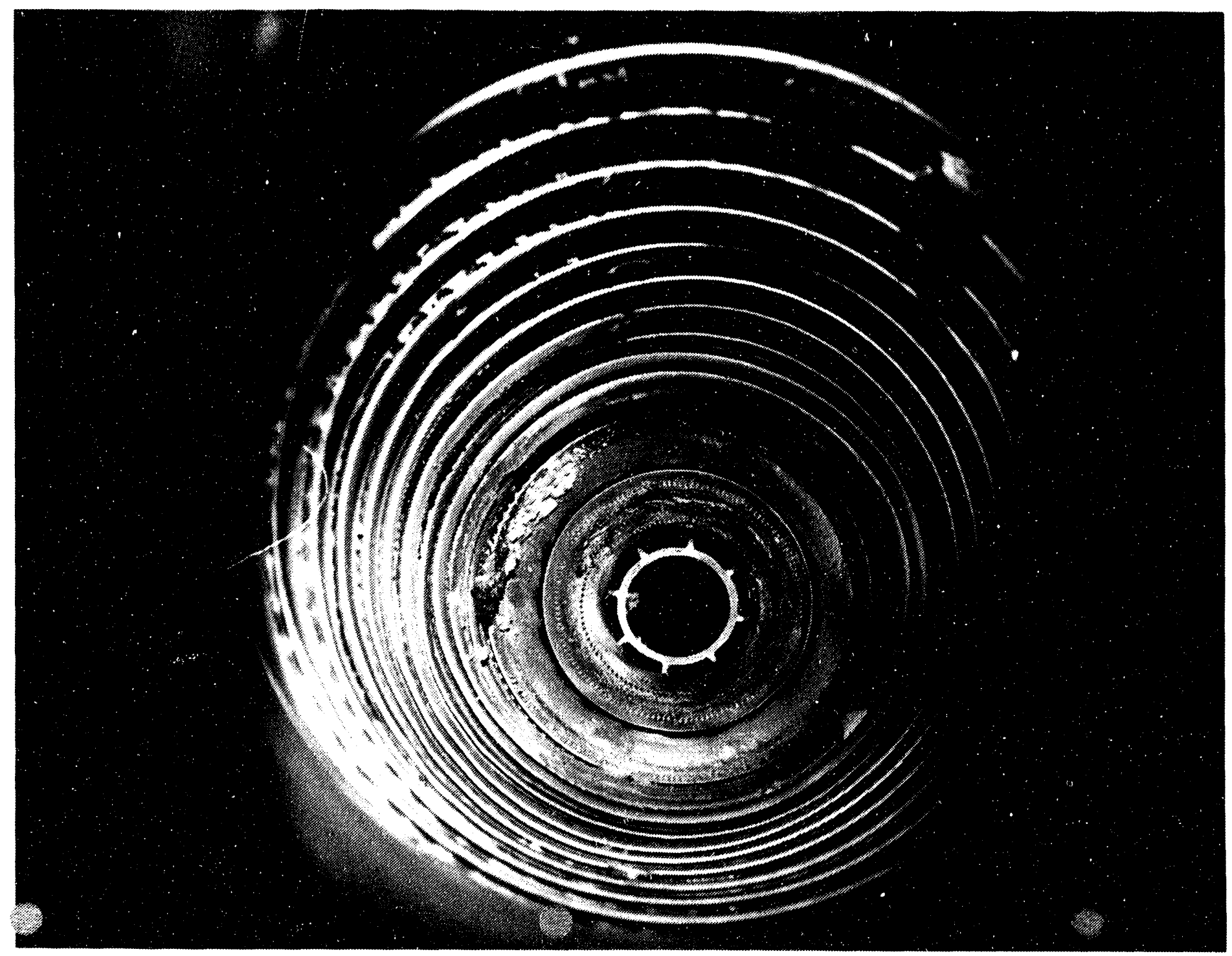

Figure 3.1.4.4 Combustion liner deposits. 


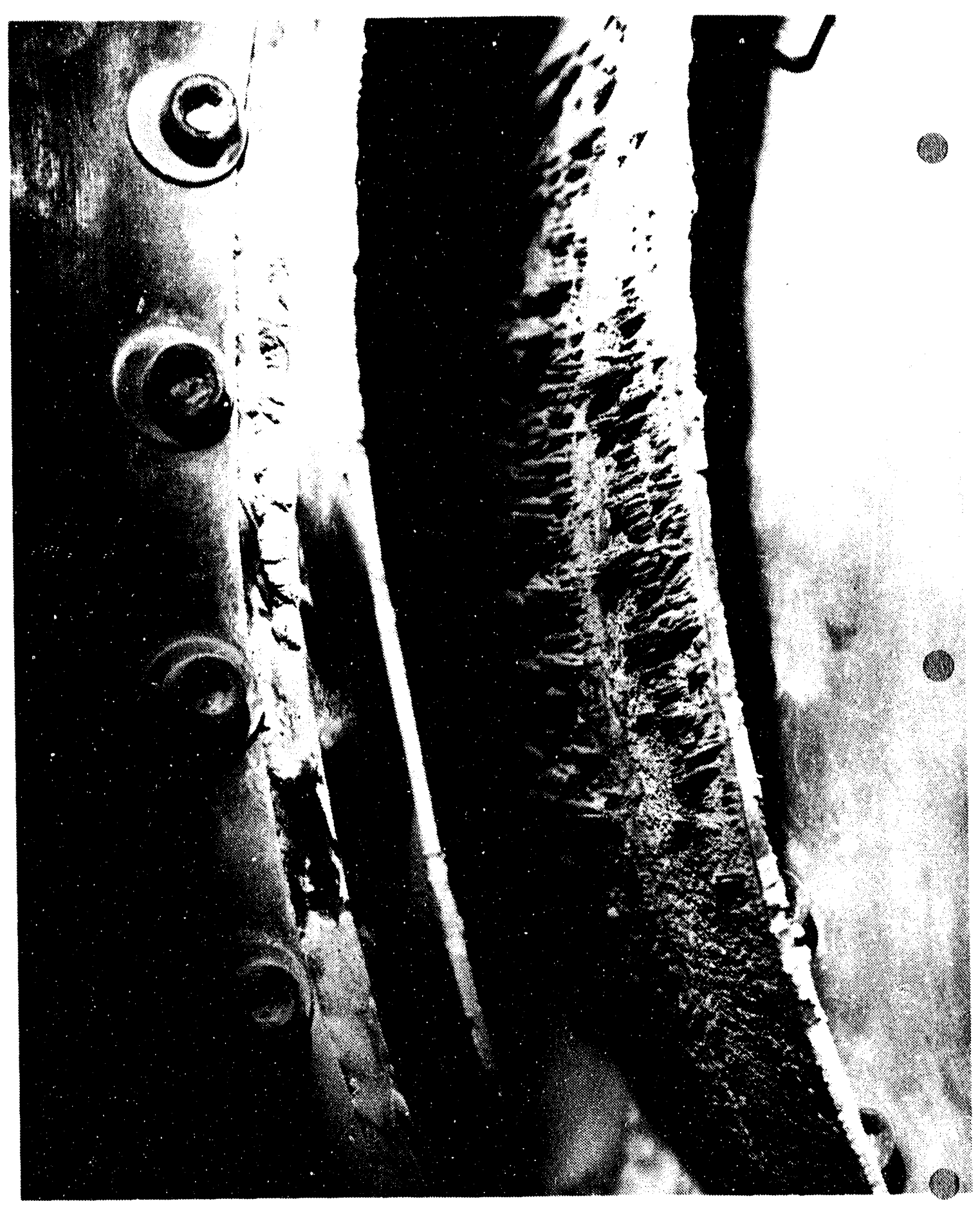

Figure 3.1.4.5 Transition section deposits. 


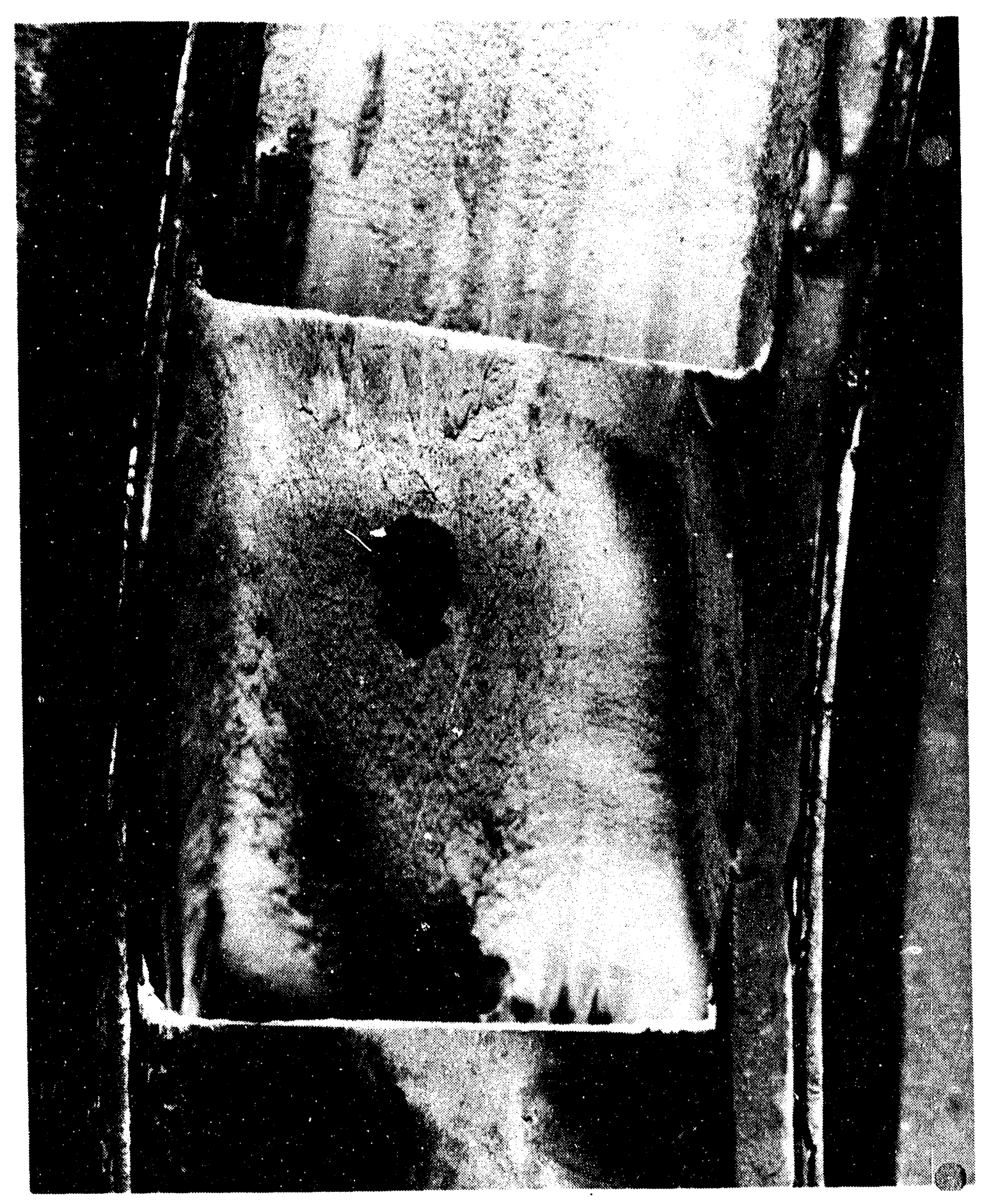

Figure 3.1.4.6 Suction side deposits. 


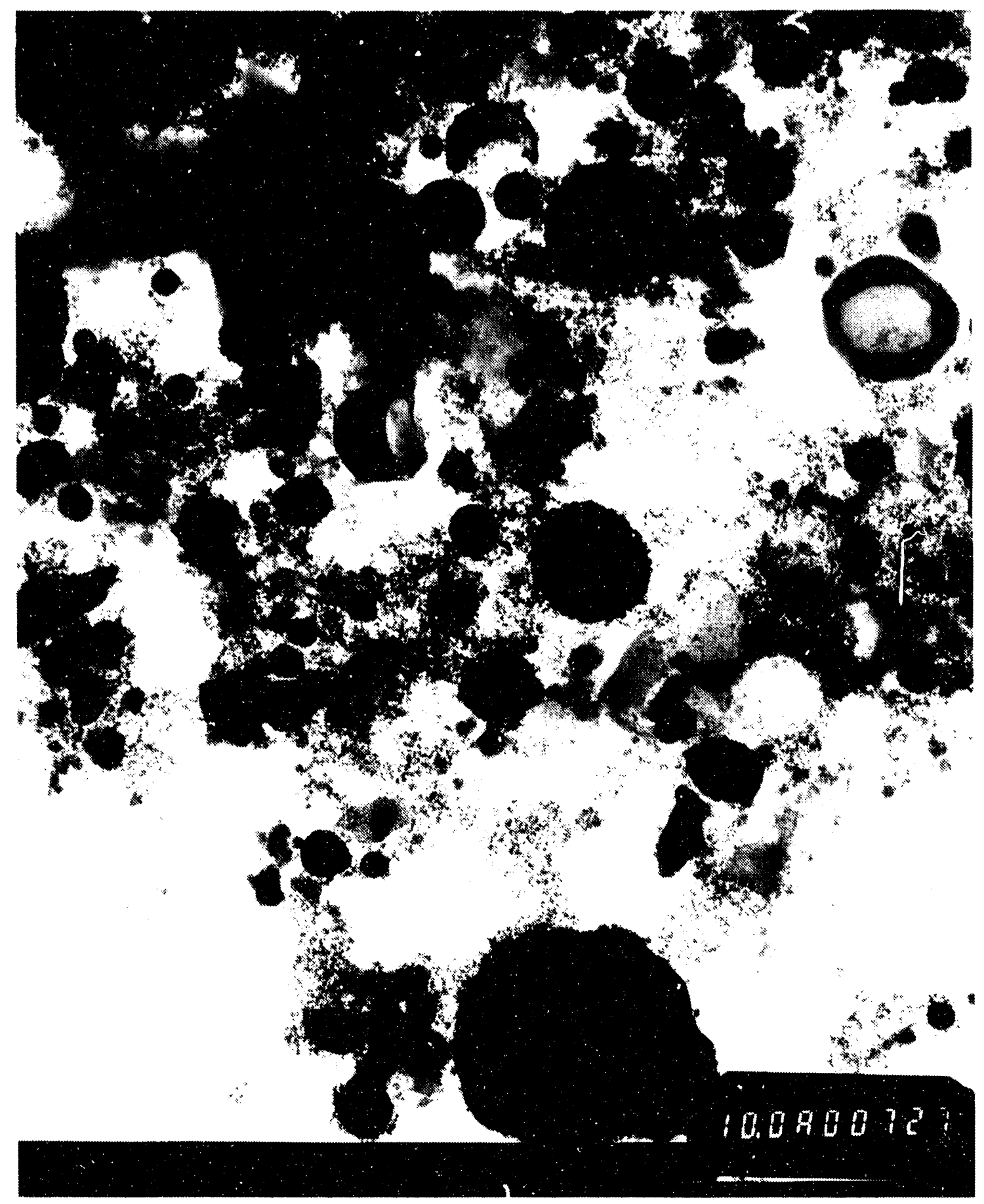

Figure 3.1.4.7 Transmission electron micrograph of quench probe sample. 


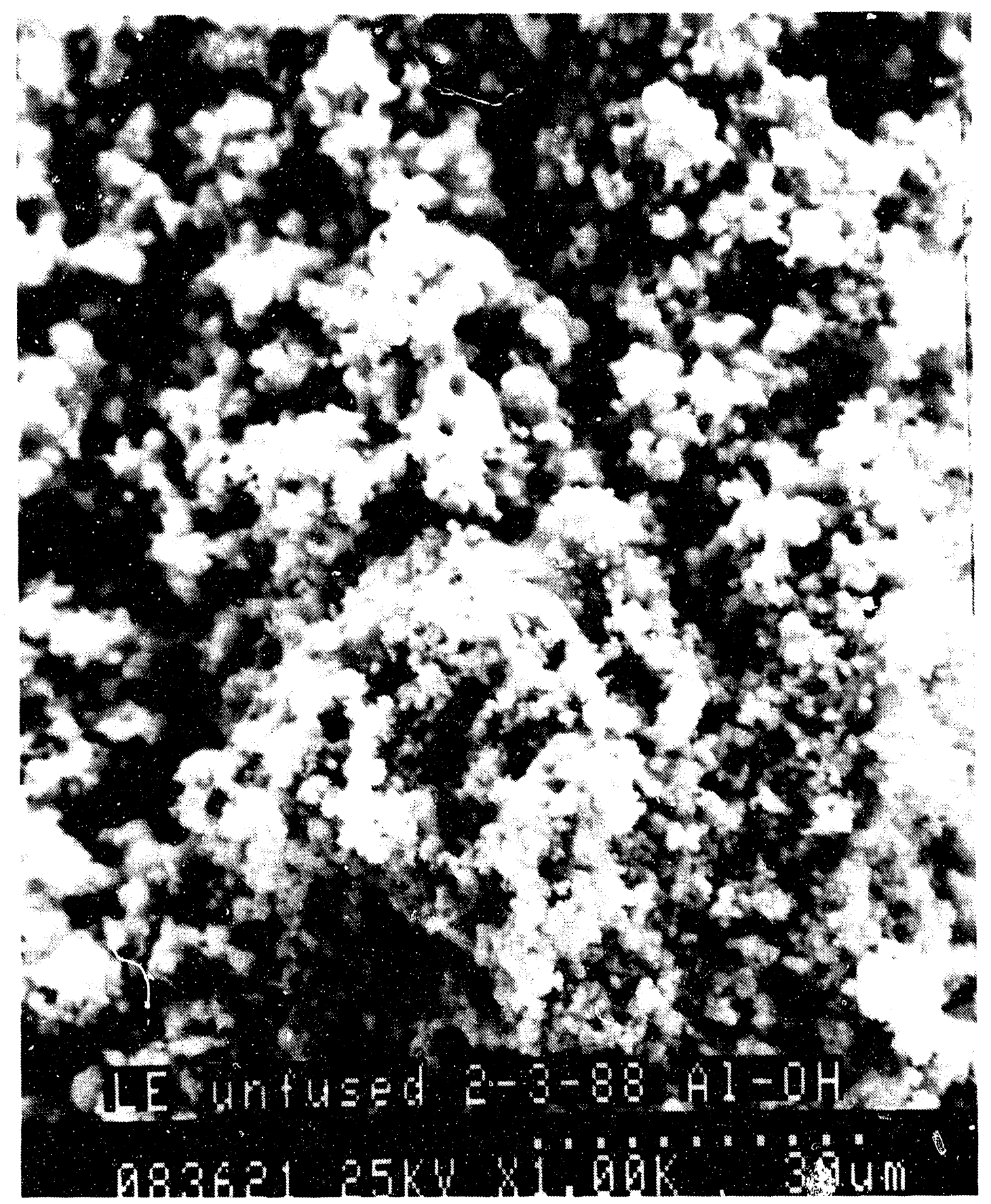

Figure 3.1.4.8 Unfused primary leading edge deposits. 


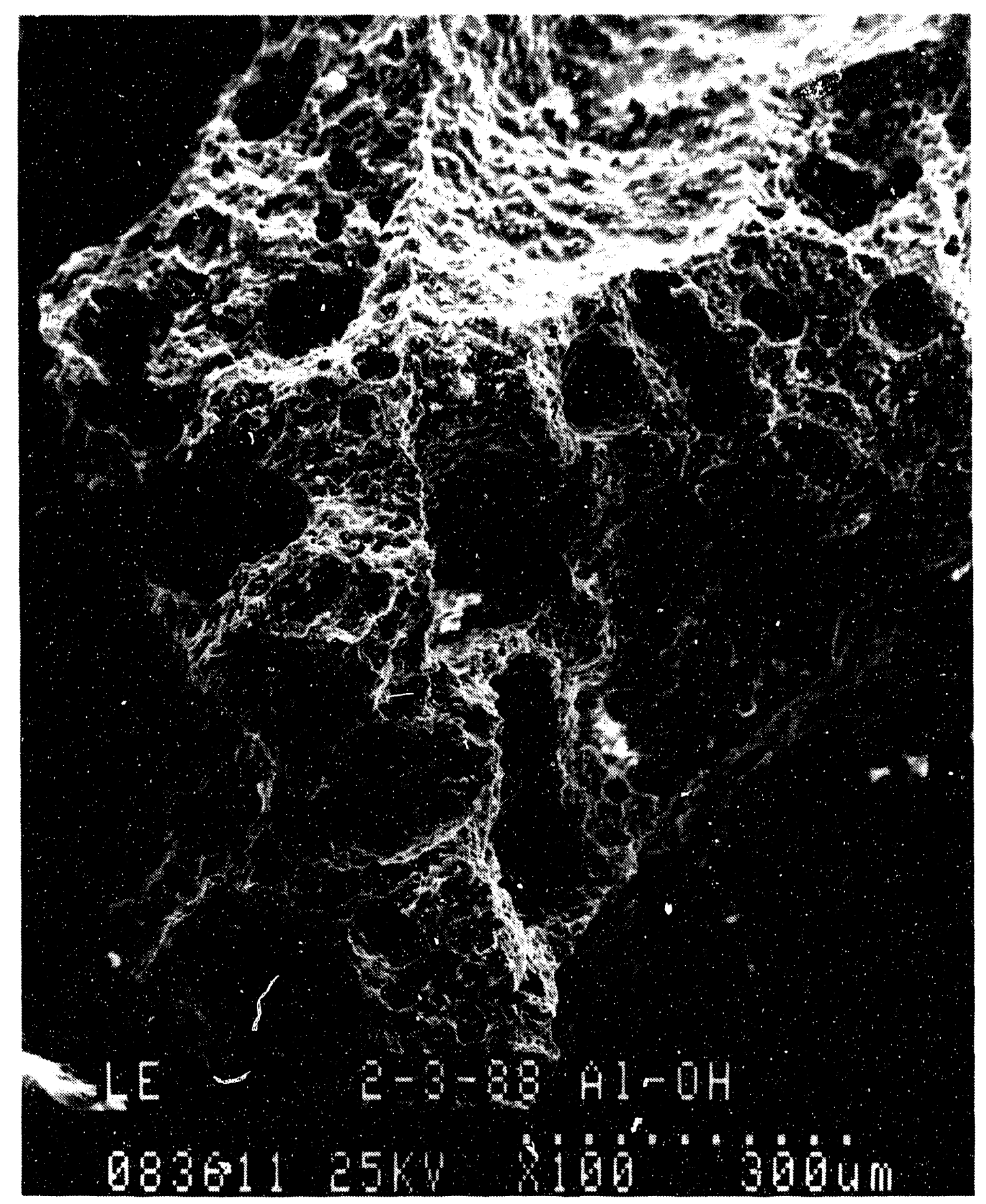

Figure 3.1.4.9 Porous fused deposits from leading edge. 
lined with vuggy corundum as well as unusual needles of anorthite as pseudomorphs after anhydrite, Figure 3.1.4.10. Since the reactions proceeded as planned, why did they not spall as planned?

The answer became clear after examination of the suction side deposits, Figure 3.1.4.11. The $200 \mu \mathrm{m}$ thick plates were largely melted, and contained a great deal of fused sodium sulfate. It is suggested that the reason the deposits were so adherent was the formation of sodium sulfate as an unanticipated byproduct reaction sequence:

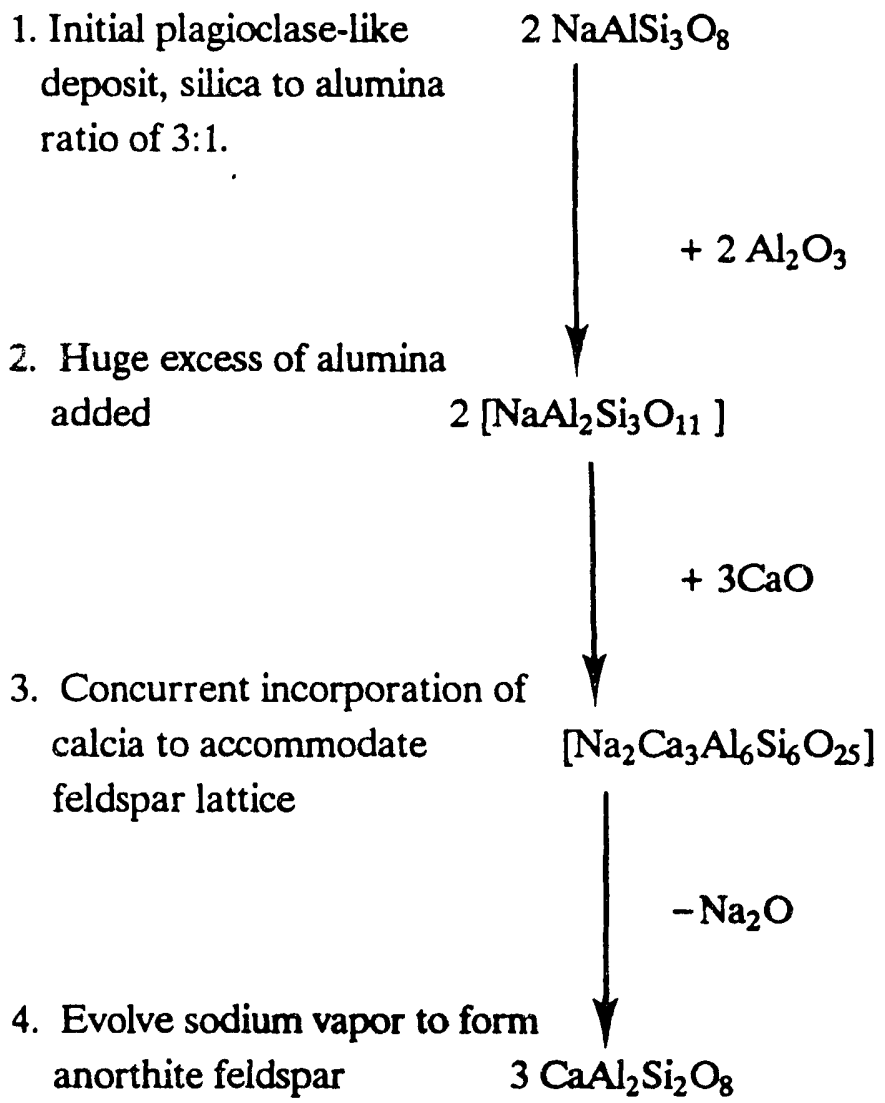

The driving force for these reactions is to incorporate as much of the alumina into the feldspar lattice, which is also benefited by the evolution of alkali. The Si/Al ratio starts at 3/1 and ends at $1 / 1$ as is observed. It is the evolution of alkali which results in alkali sulfate glue formation and deposition. In essence, the alumina reversec' the gettering process.

If this interpretation is correct, the use of alumina as a deposition control additive is fundamentally incorrect; it will exacerbate deposition in all but the most silica-rich deposits. On the other hand, from a deposition control standpoint, it remains that the feldspar lattice can 


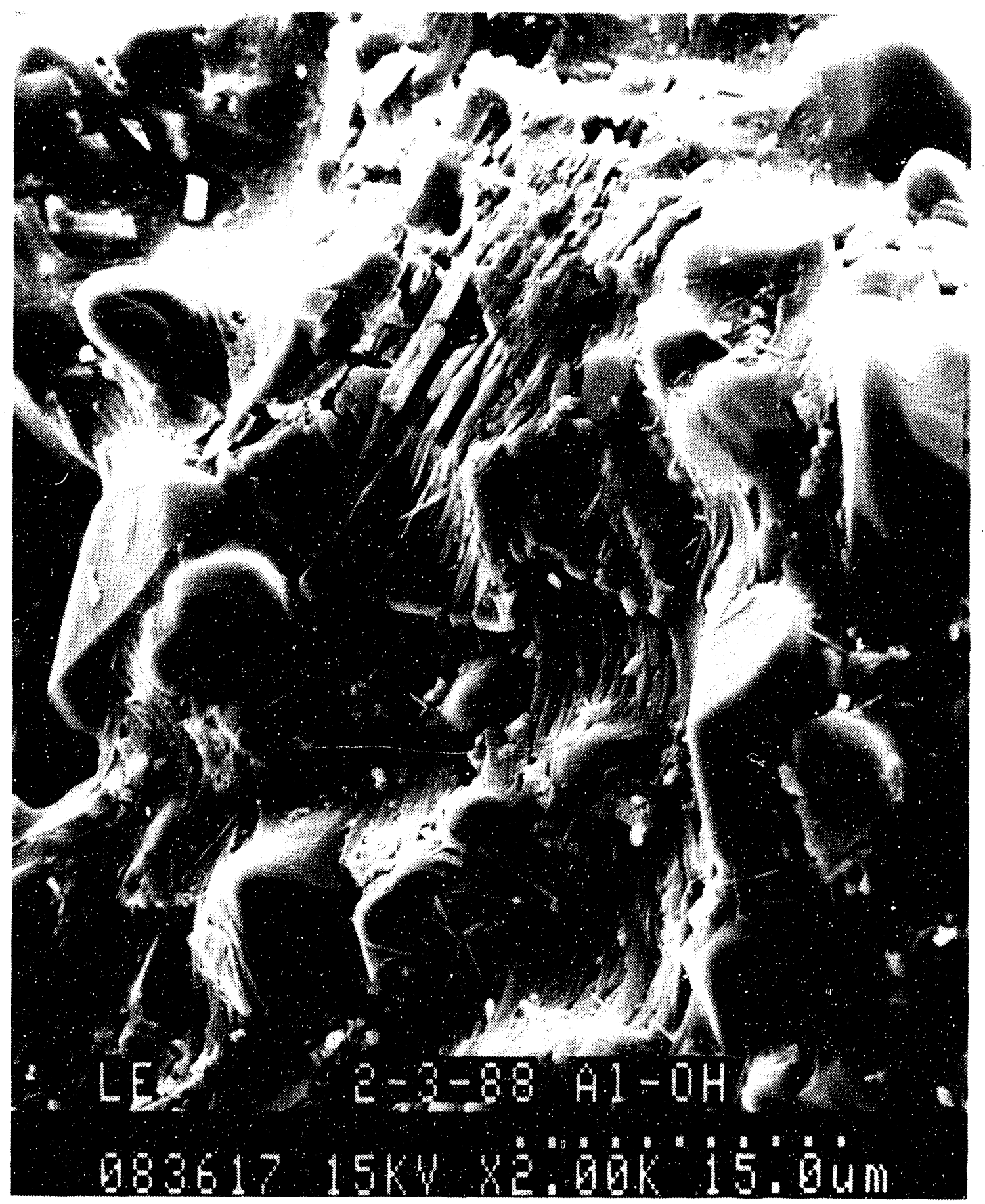

Figure 3.1.4.10. Corundum crystals and anorthite needles lining pores along fused leading edge deposits. 


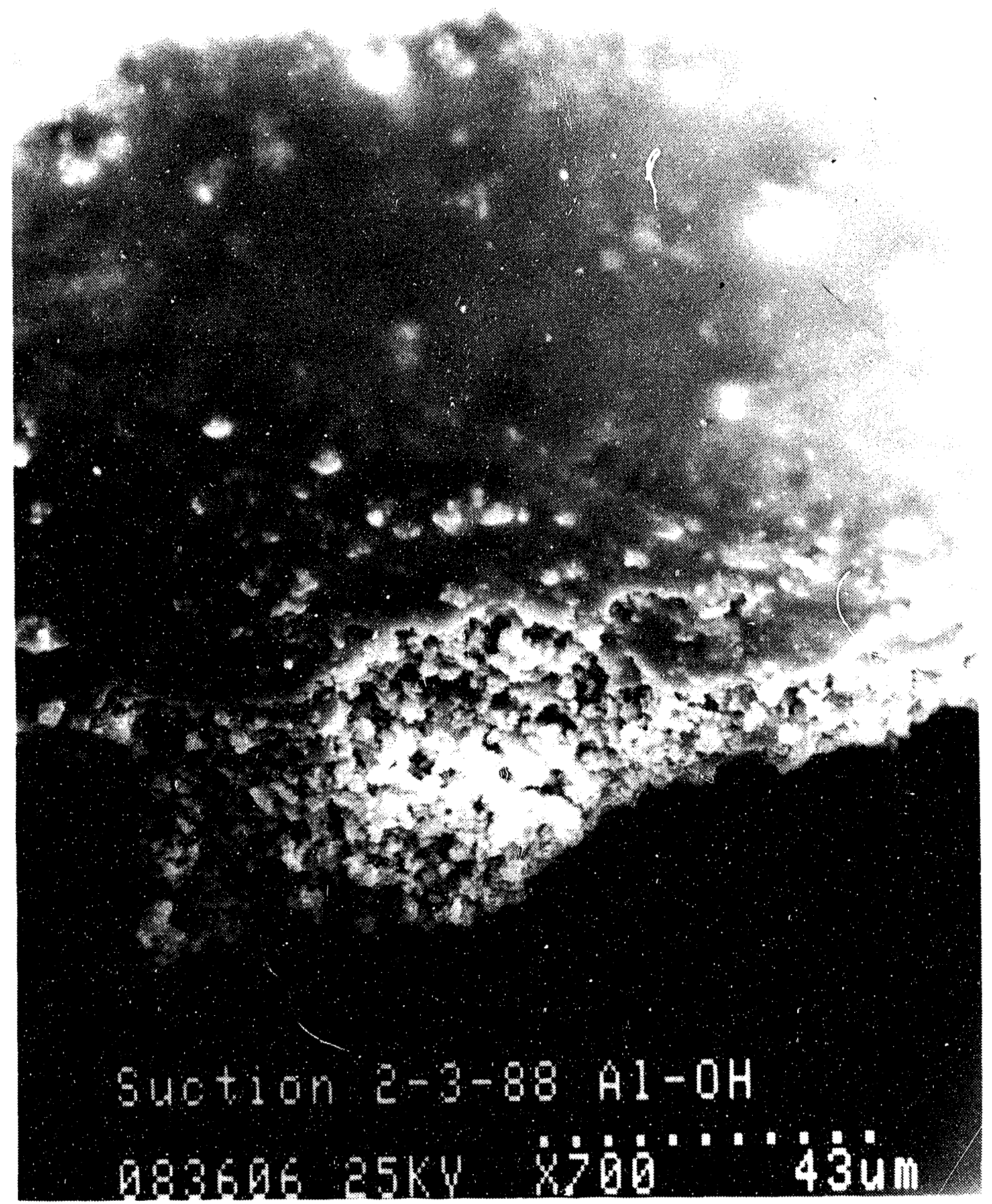

Figure 3.1.4.11. Suction side deposite showing near-complete fusion. 
fully accommcidate kaolin in a solid solution of alkali and calcia feldspars, without evolving alkali. Thus the choice of kaolin was more than adventitious; it was necessary.

\subsubsection{Summary and Conclusions}

The use of boehunite as an additive to control deposition in coal-fired gas turbines was not succesful, though the requisite fusion, viscosity, and pore formation occurred as anticipated. The mitigating factor in deposit control appears to be a side reaction resulting from alumina substitution in the feldspar. The large excess of alumina was sufficient to exceed the available silica in the slag, causing evolution of sodium. The sodium subsequently condensed as the well-known sulfate glue after which deposition was exacerbated.

\section{References}

[1] P.J. Schields, C.L.Spiro,and E. Koch, "Phase Characterization of Coal-Fueled Engine Deposits," in Fly Ash and Coal Conversion Byproducts: Characterization, Utilization, and Disposal $I V$., edited by G.J. McCarthy, F.P. Glaser, and D.M. Roy, Materials Research Society Symposium Series Vol 113, p 133-142, (1988).

[2] S.G. Kimura and C.L. Spiro, Final Report, U.S. Department of Energy, Gas Turbine Components Screening, DOE/MC/21395-2298,(1987). Supplementary volume 4.

[3] C.S. Hurlbut, Jr., and C. Klein, Manual of Minerology, 19th Edition, Wiley and Sons, New York, 1977.

[4] R.N. Shreve and J.A. Brink, Jr., Chemical Process Industries, McGraw Hill Inc., New York, 4th Edition, 1977. 


\subsubsection{Taggart Coal Study}

\subsubsection{Introduction}

Throughout the tenure of this Advanced Coal-Fueled Gas Turbine program, along with the Alkali Species Characterization [1] and Gas Turbine Components Screening programs [2], considerable effort has been expended in the characterization of deposits and products of combustion $[3,4]$. This has led to a phenomenological model of ash behavior and deposition involving sequential in situ deposit decomposition and melt devitrification [5]. Prior to the results described below, all deposition testing had been performed with a Kentucky Blue Gem high volatile A eastern US bituminous coal.

Based on an improved understanding of deposition and how chemistry affects deposition rate and deposit tenacity, we were able to suggest approaches to deposit remediation. One effective means to alter deposition is to change the ash chemistry through additives.

The Blue Gem Otisca source coal has a starting composition which has a high propensity to deposit and adhere. Specifically, it has an unusually high iron and calcia content along with abnormally low silica. This leads to low viscosity slag and high deposition tendencies. The addition of glass network extenders such as aluminosilicates to the highly slagging Blue Gem ash was identified as a promising approach to denosit remediation. In fact, with as little as $0.4 \%$ additive (slurry basis), deposits were substantially 1 ieduced on the pressure side and leading edge surfaces of airfoils in a turbine simulator. A detailed chemical and microstructural analysis of combustion products suggested that the additive reacted in situ with deposits, which raised the liquidus viscosity and caused partial melt devitrification. The exsolution of high density crystallites generated pores which could not collapse due to the augmented viscosity. Void formation at the slag/airfoil interface was sufficient to either spontaneously spall the deposit, or weaken it for subsequent erosion.

Even though effective in deposit amelioration, additives increase the ash content of the fuel, presenting a greater particulate clean-up burden. Additives have small, but nonnegligible direct material costs, and require handling, storage, mixing, and quality assurance. It would be preferable not to require additives.

As an alternative to modification of ash chemistry through additives, it may be possible, through judicious coal selection, to obtain ash chemistries which are inherently non-sticky, or at least require less additive for deposit amelioration. The Taggart coal was selected with these goals in mind.

Taggart seam coal has ash chemistry more typical of US bituminous coals and should have a reduced tendency to deposit compared to Blue Gem coal. In particular, it has low basicity associated with reduced iron and calcia, along with higher acidity associated with increased silica and alumina content. In fact, its starting ash composition is roughly comparable 
to the Blue Gem ash composition after addition of kaolin, the most effective additive for deposit remediation found to date.

The Taggart slurry also has higher heating content, lower viscosity, and increased solids loading, which should be beneficial to combustion. Its main drawbacks are reduced volatility, and higher alkali content than the Blue Gem. The purpose of testing the Taggart was therefore two-fold. First and foremost, it presents a more attractive ash chemistry for deposition minimization, and second, it serves to broaden the range of applicable fuels for the coal-fired turbine. A third, non-technical reason for studying the Taggart coal is that it represents Otisca Industries initial commercial fuel under the Clean Coal II initiative.

What is described below is our first attempt to combust and characterize the deposition tendencies of the Taggart coal.

\subsubsection{Experimental Test Procedure and Combustion}

Coal water mixture was prepared from the Taggart seam coal by Otisca Industries Ltd, using the Otisca-T selective agglomeration method Figure 3.1.5.1. A detailed analysis of the fuel appears in Tables 3.1.5.1 and 3.1.5.2, including ultimate, proximate, particle size and ash analyses. Chemical analyses were performed by Commercial Testing and Engineering Co, Lombard, Ill.

Slurry was burned in the usual fashion, in GE's LM500 gas turbine simulator facility at GE's Corporate Research and Development Laboratory, Schenectady, NY.

\subsubsection{Results}

After the four hours test operation on coal slurry, the cascade was reasonably clean, Figure 3.1.5.2, with very little initially obvious evidence of deposition or fouling. Closer inspection indicated slight depositition in the section just at the beginning of the suction side just past the leading edge, Figure 3.1.5.3. There was a chunk of deposit $\sim 1 / 2^{n}$ diameter in the upper left (looking at the pressure side). This deposit seemed to correspond to the area of the transition piece that had a large amount of deposit. Looking toward the fuel nozzle from the transition piece, there was a large amount of deposit, Figure 3.1.5.4, that had adhered to the wall of the transition piece at the left side wall and part of the upper section on the left. The right side of the transition piece was very clean. The combustor was also very clean, Figure 3.1.5.5, except for the last few rows where there seemed to be some build up in the area noted at $\sim 270^{\circ}$ from TDC looking toward the fuel nozzle. The middle rings of the combustor had some buildup and samples were able to be taken form this area also.

Particulate analysis revealed combustion efficiencies of up to $99.4 \%$; This is somewhat lower than the best achieved for the Blue Gem coal, but is well within the normal range of combustion efficiencies for the micronized coal-water-mixture. 


\section{5- TON PER HOUR \\ T-PROCESS PRODUCTION PLANT}

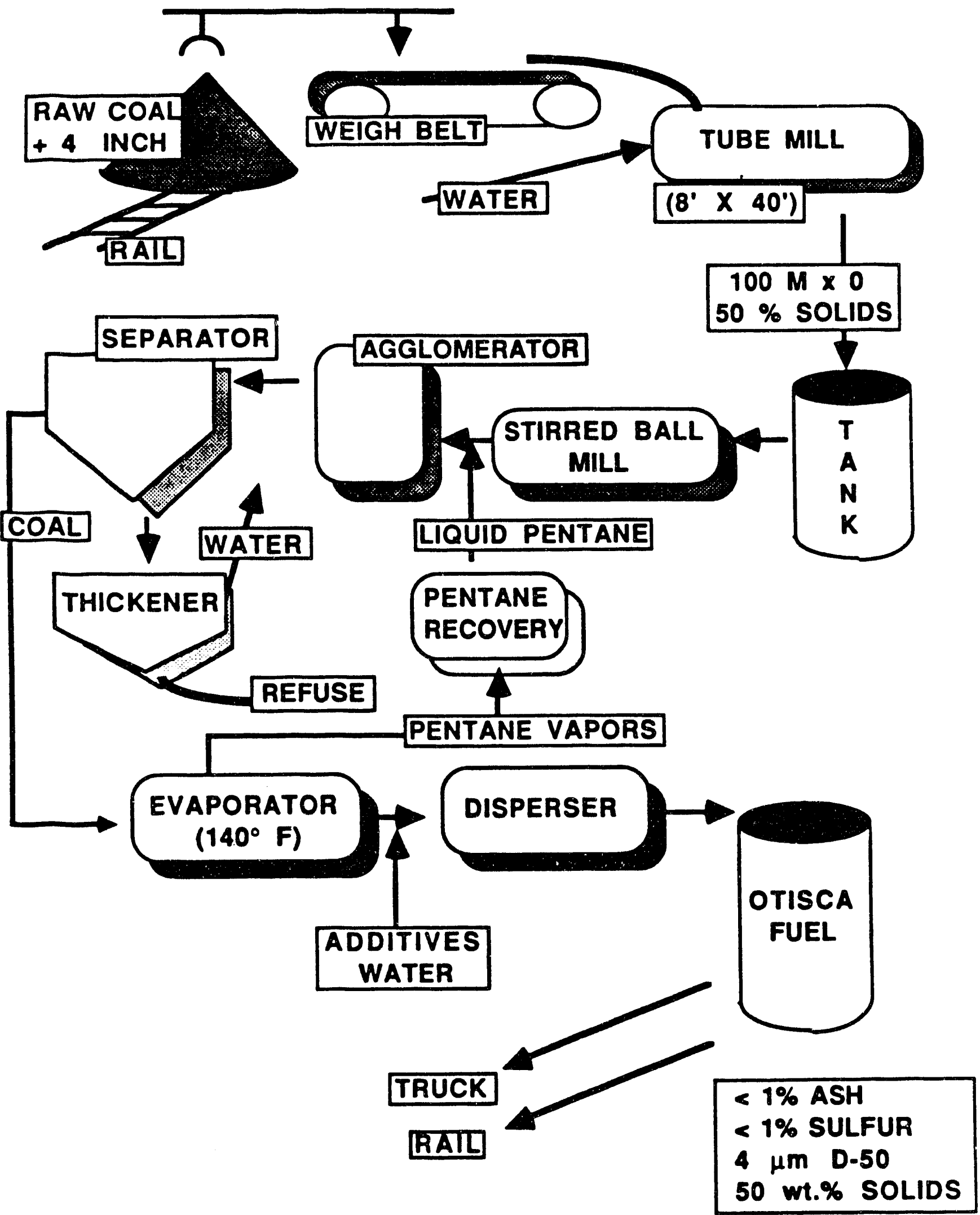

Figure 3.1.5.1 Flow chart, Otisca-T process. 
Table 3.1.5.1

Properties of Otisca Coal-Water Mixture Taggart Steam Coal

\begin{tabular}{lr}
\multicolumn{2}{c}{ Proximate Analysis(Dry Basis) } \\
\hline Ash Content & $0.73 \%$ \\
Total Sulfur & $0.84 \%$ \\
Volatile & $35.74 \%$ \\
Fixed Carbon & $63.53 \%$ \\
Solids & $51.93 \%$ \\
Viscosity cp & 50 \\
(112/sec) & \\
& \\
& \\
Particle Size Distribution \\
\hline Diameter & Mass \% \\
\hline$>9.5$ & 0.0 \\
9.5 & 2.8 \\
8.5 & 0.3 \\
7.5 & 5.2 \\
6.5 & 6.7 \\
5.5 & 5.0 \\
4.5 & 12.7 \\
3.5 & 19.3 \\
2.5 & 22.1 \\
1.5 & 20.8 \\
0.5 & 5.2 \\
& \\
& \\
& \\
& \\
& \\
& \\
& \\
& \\
&
\end{tabular}


Table 3.1.5.2

X-ray Fluorescence Data,

Taggart Steam Coal Ash

\begin{tabular}{|c|c|c|}
\hline \multicolumn{3}{|c|}{ Commercial Testing and Engineering } \\
\hline$\overline{\mathrm{SiO}_{2}}$ & $36.48 \%$ & \\
\hline $\mathrm{Al}_{2} \mathrm{O}_{3}$ & 30.91 & \\
\hline $\mathrm{TiO}_{2}$ & 3.50 & \\
\hline $\mathrm{Fe}_{2} \mathrm{O}_{3}$ & 17.46 & \\
\hline $\mathrm{CaO}$ & 4.64 & \\
\hline $\mathrm{MgO}$ & 1.23 & \\
\hline $\mathrm{K}_{2} \mathrm{O}$ & 1.39 & \\
\hline $\mathrm{Na}_{2} \mathrm{O}$ & 1.16 & \\
\hline $\mathrm{SO}_{3}$ & 1.88 & \\
\hline $\mathrm{P}_{2} \mathrm{O}_{5}$ & 0.38 & \\
\hline SrO & 0.48 & \\
\hline $\mathrm{BaO}$ & 0.43 & \\
\hline $\mathrm{MnO}$ & 0.00 & \\
\hline \multicolumn{3}{|c|}{ Ash Fusion Data } \\
\hline & Reducing & Oxidizing \\
\hline Initial Def & 2160 & 2380 \\
\hline Softening & 2305 & 2465 \\
\hline Hemispherical & 2445 & 2555 \\
\hline Fluid & 2595 & 2635 \\
\hline
\end{tabular}




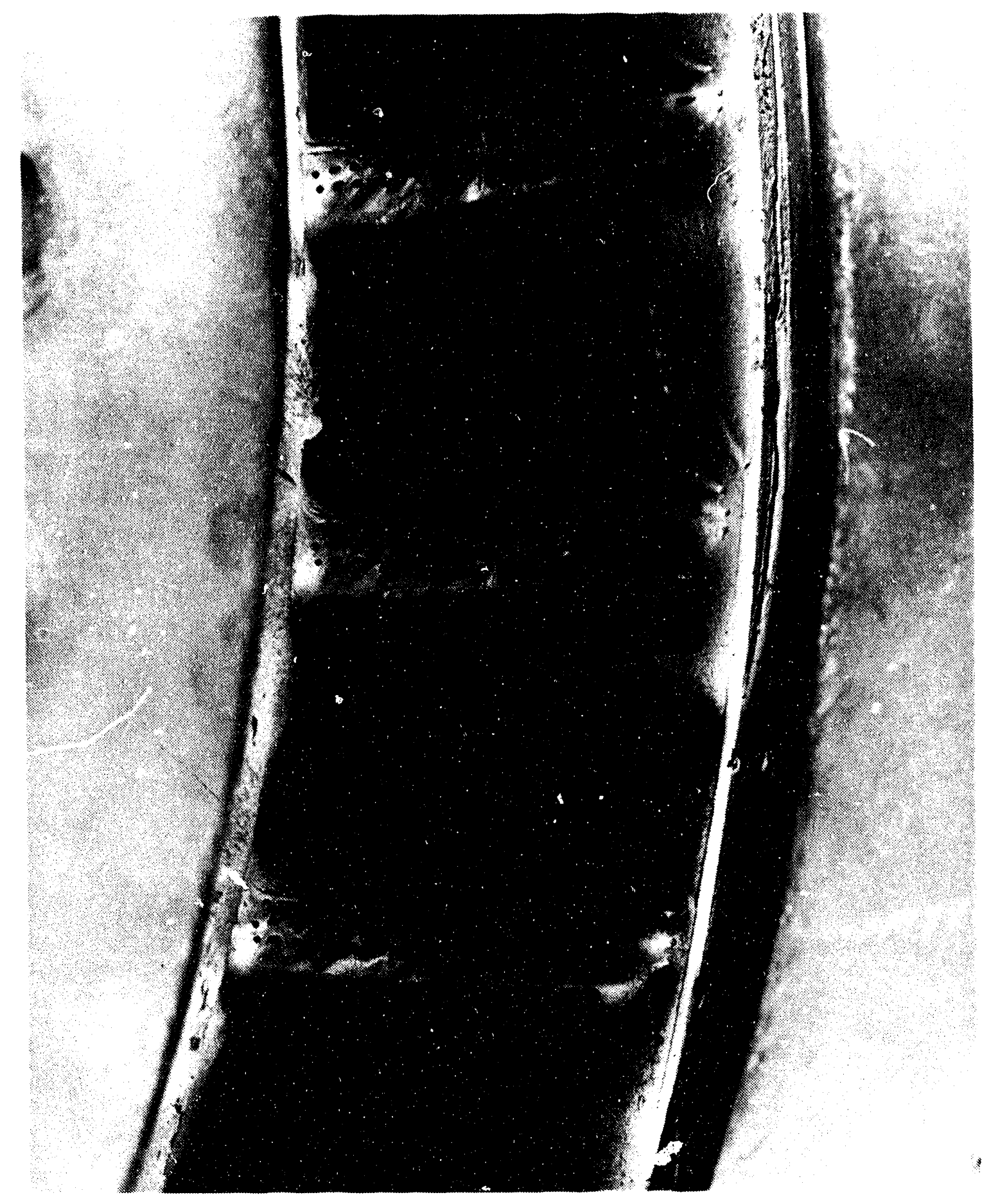

Figure 3.1.5.2 LM500 turbine simulator cassade after 4hr operation on Taggart CWM fuel. 


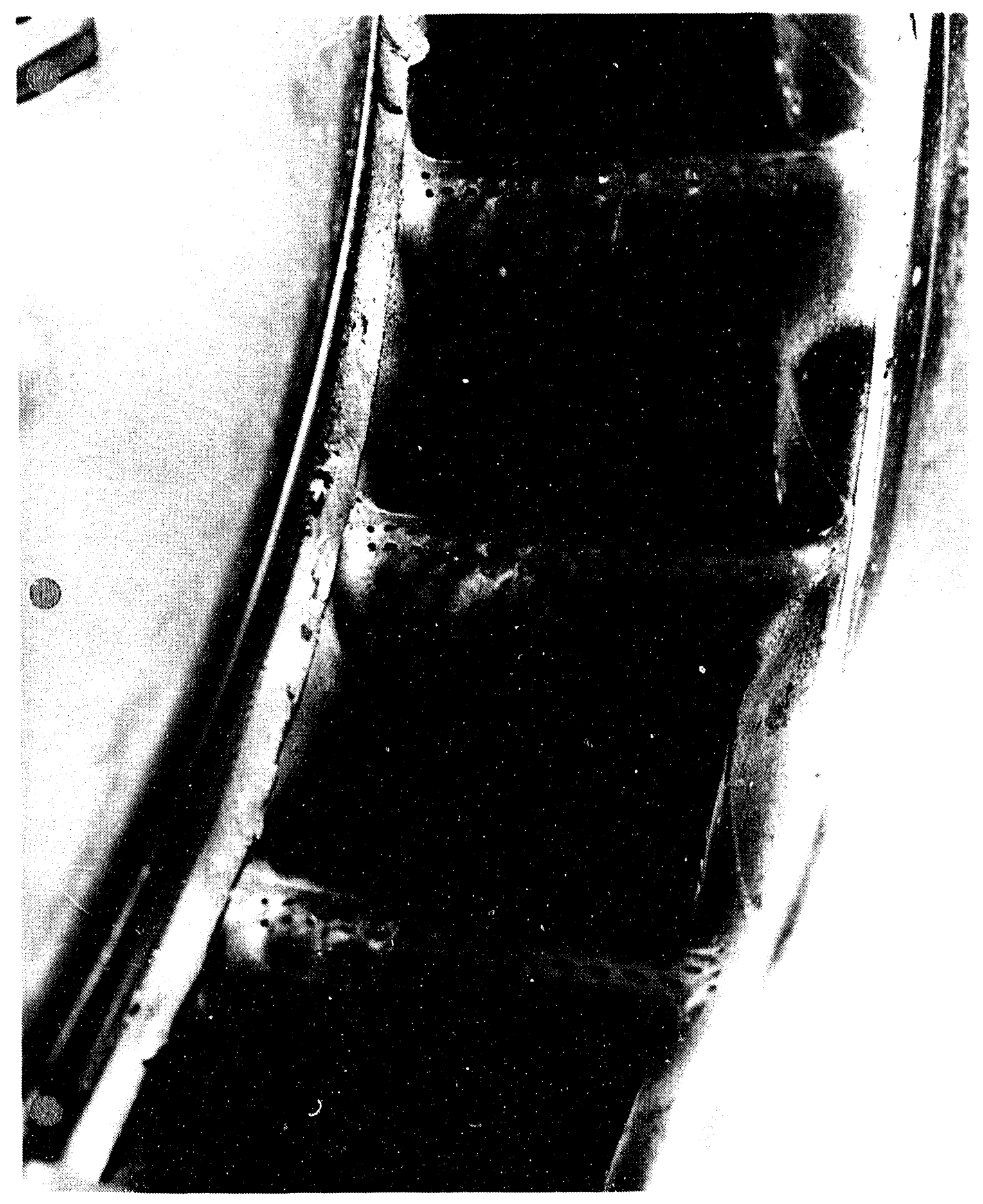

Figure 3.1.5.3 LM500 turbine simulator suction side deposit after 4hr operation on Taggart CWM fuel. 


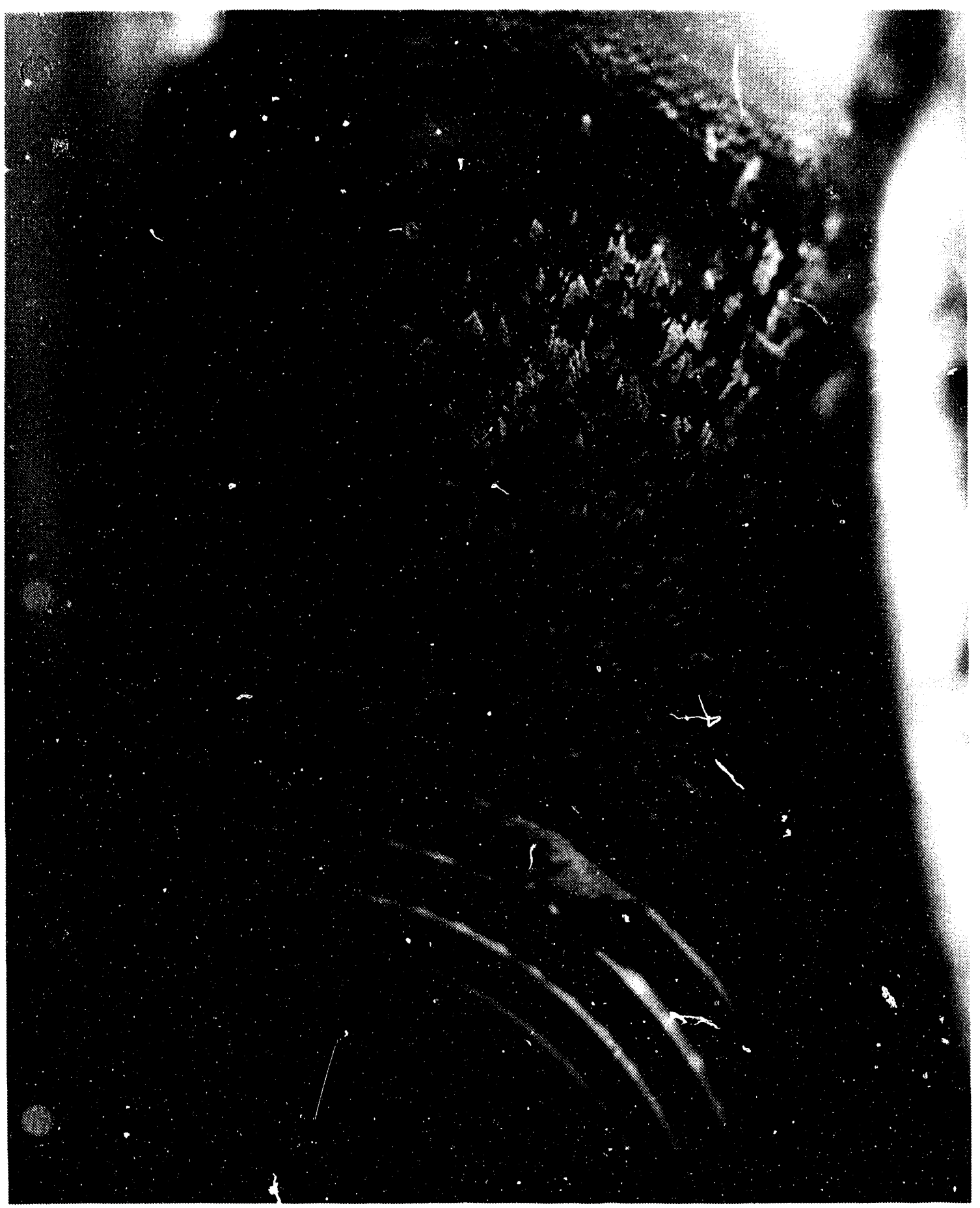

Figure 3.1.5.4 LM500 turbine simulator transition section deposit after 4-hr operation on Taggart CWM fuel. 


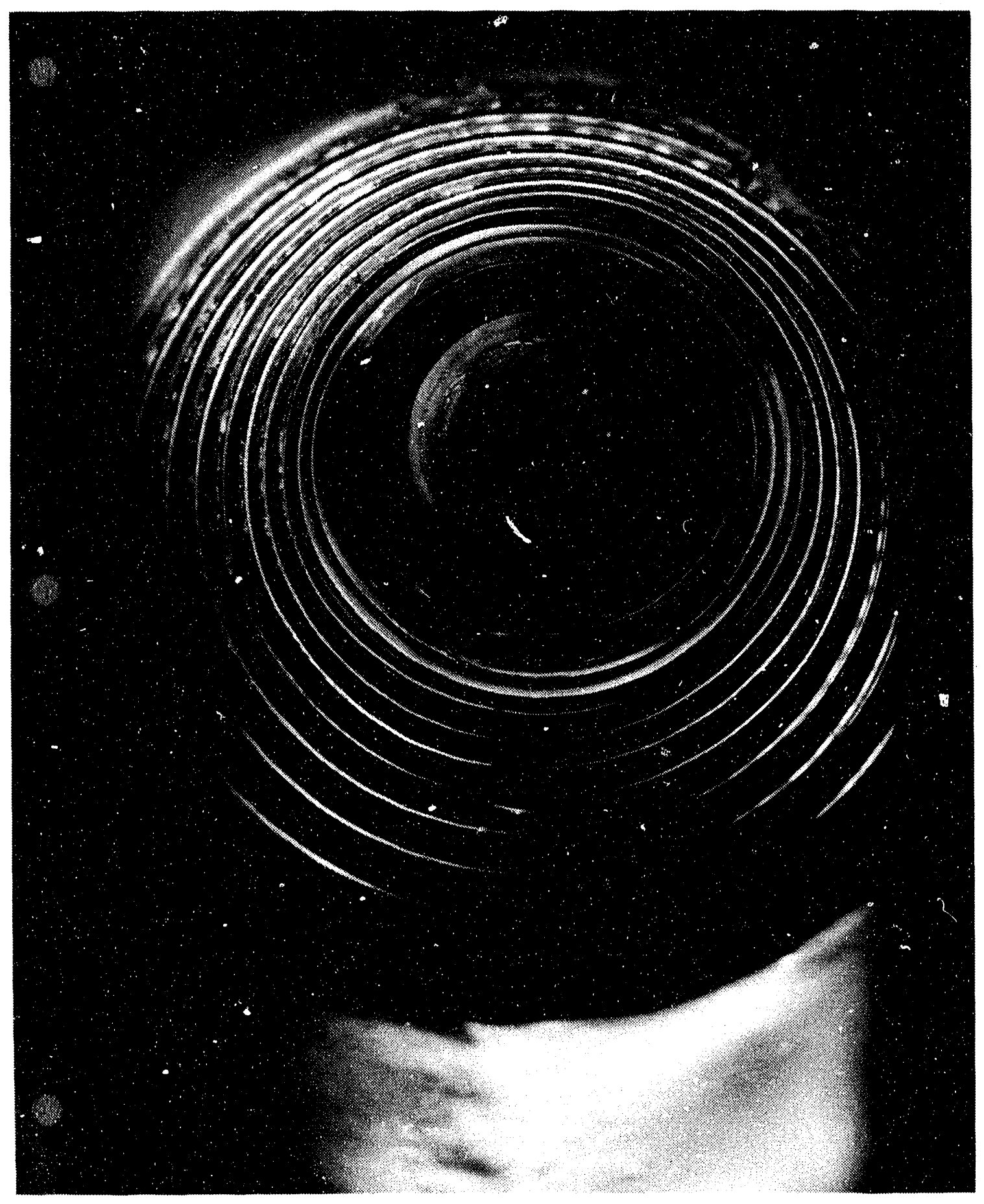

Figure 3.1.5.5 LM500 turbine simulator combustion liner after 4hr operation on Taggart CWM fuel. 


\subsubsection{Discussion}

The commercial viability of a direct coal-fired gas turbine engine depends, in part, on the successful solution to the problem of deposition by coal ash. Frequent shut-down and off-line maintenance are clearly unacceptable. Infrequent on-line abrasive cleaning is tolerable but undesirable. Deposit prevention is preferred.

As described in detail in Section 3.1.1, in order to achieve tolerable deposition, one or more of the key steps in deposition must be interrupted. A prerequisite to the deposition solution is an understanding of deposition phenomenology. Based on data from our and other laboratories, deposition can be considered as a sequence of events consisting of particle arrival and primary deposition by inertial impaction, followed by in situ decomposition, sintering, fusion, and cementation.

In order to minimize ash particle arrival rates, coal has been micronized to comminute mineral matter deposit precursors, and has been beneîiciated to reduce the overall quantity of ash present in the system. Mineral matter occurs in coal as finely disseminated grains that melt during combustion. Obviously, if there is less mineral matter in the coal, there will be less adherence. Complete de-ashing of the coal is not yet economically feasible. By micronizing the coal, mineral grains are also comminuted. Finer ash particles are more likely to follow hot gas path streamlines and avoid impaction on the airfoils. Much of the ash remains weakly adhered to unburned char surfaces which results in larger effective Stokes diameters, and more pronounced inertial impaction. To the extent that good atomization and combustion efficiencies are achieved, this will be minimized.

Once the particles approach the airfoil surfaces, they can undergo elastic or inelastic collisional impact. To adhere, the particle kinetic energy must be discharged to the surface or it will not stick. By cooling the target, the molten slag that comprises the ash will freeze in the boundary layer, greatly reducing its stickiness and tendency for inelastic collision.

Unburned carbon will have a deleterious effect on the deposition tendency of the ash, reducing its melting point and also generating heat even after deposition. Unburned carbon has not been detected in deposits, but samples obtained by quenching combustion products reveal 10 to $40 \%$ of the combustion products consist of unburned carbon, even for combustion efficiencies in excess of $99.5 \%$. Presumably final burnout takes place on the airfoil surface. In addition, carbon shell fragmentation may serve to dissipate particle translational energy. Improved burnout and reduced shell size are desirable, and are ehanced by improved atomization of slurry.

The condition of the target surface will also influence deposition. If it is cool and clean, there will be a limited tendency for inelastic collisions by the ash. If it is covered with a porous and fluffy surface, collisions may collapse the suprastructure and increase deposition. A very weak deposit may be eroded by incoming combustion products. A viscous liquid on the sur- 
face will very efficiently capture particles. In the event of extreme viscosity, the capture may be reduced as the surface may appear to be solid to the POCs.

Once deposited, the particles can be re-entrained by erosion, or may be sintered or even completely fused into a liquid. Kuczynski [6] showed that sintering of glassy particles is governed by viscous flow. Frenkel [7] has developed a sintering model which describes the rate of particle coalescence as the growth of an interfacial radius between two spherical particles. If the ash particles have radii $r$ [8], then values for the radius of the tiny neck bridge between the particles in excess of 0.001 , sintering will commence. For average values of 0.01 , a weakly sintered deposit will develop which is probably amenable to nutshelling. At values of 0.1 , as strongly adhered deposit results and for values of 0.3 , a slag results. For complete fusion, a value of 1 is presumed.

For monodisperse particles, the degree of sintering decreases with the square root of viscosity. Therefore, a priori, a reasonable goal is to maximize the slag viscosity. There are a handful of formulae $[9,10,11]$ in the literature which attempt to fit experimental data for slag viscosity as a function of tenperature and composition, dating back to Reid in the $40 \mathrm{~s}$. In trying to unravel the deposition phenomena, especially in light of the additive effects, the ash composition for the Blue Gem, Taggart, Blue Gem plus kaolin, and Taggart plus kaolin compositions was fitted to Kalmanovitch's model which is a modification to Urbain's treatment of coal ash slagging.

In these models, cations in the liquidus are treated as either network formers that increase viscosity, network modifiers that are responsible for long range order or disorder, and amphoterics. The relative mole fractions of these components are weighted to generate coefficients in a power expansion to yield a pseudo-activation energy for the process whereby a cation jumps from one vacancy site in the melt to another. Resistance to this sort of movement relates directly to viscosity. Thus, unlike simple linear regression analyses of numerous composition/ temperature/viscosity curves, this model has a more phenomenological basis relating cation function to viscosity. The cation mole fractions are also combined to yield a temperature-dependent pre-exponential factor, which represents an overall summary of the melt structure and site vacancy distribution.

Calculated slag viscosities appear in Figure 3.1.5.6, and include data for the Blue Gem coal ash, the Taggart coal ash, the Blue Gem/kaolin combined coal ash, and the Taggart/kaolin combined coal ash. The reader is cautioned that these are calculated values, unverified by experiment, and are generally applicable at temperatures in excess of the gas turbine firing temperatures. Their value lies in the trends indicated by changes in ash composition. Once devitrification of the melt occurs, the liquidus composition will change. Typically we observe exsolution of aluminosilicates such as corundum, mullite, and anorthite along with iron oxides and mixed-metal spinels. To the extent that the melt is depleted of these species, the local 


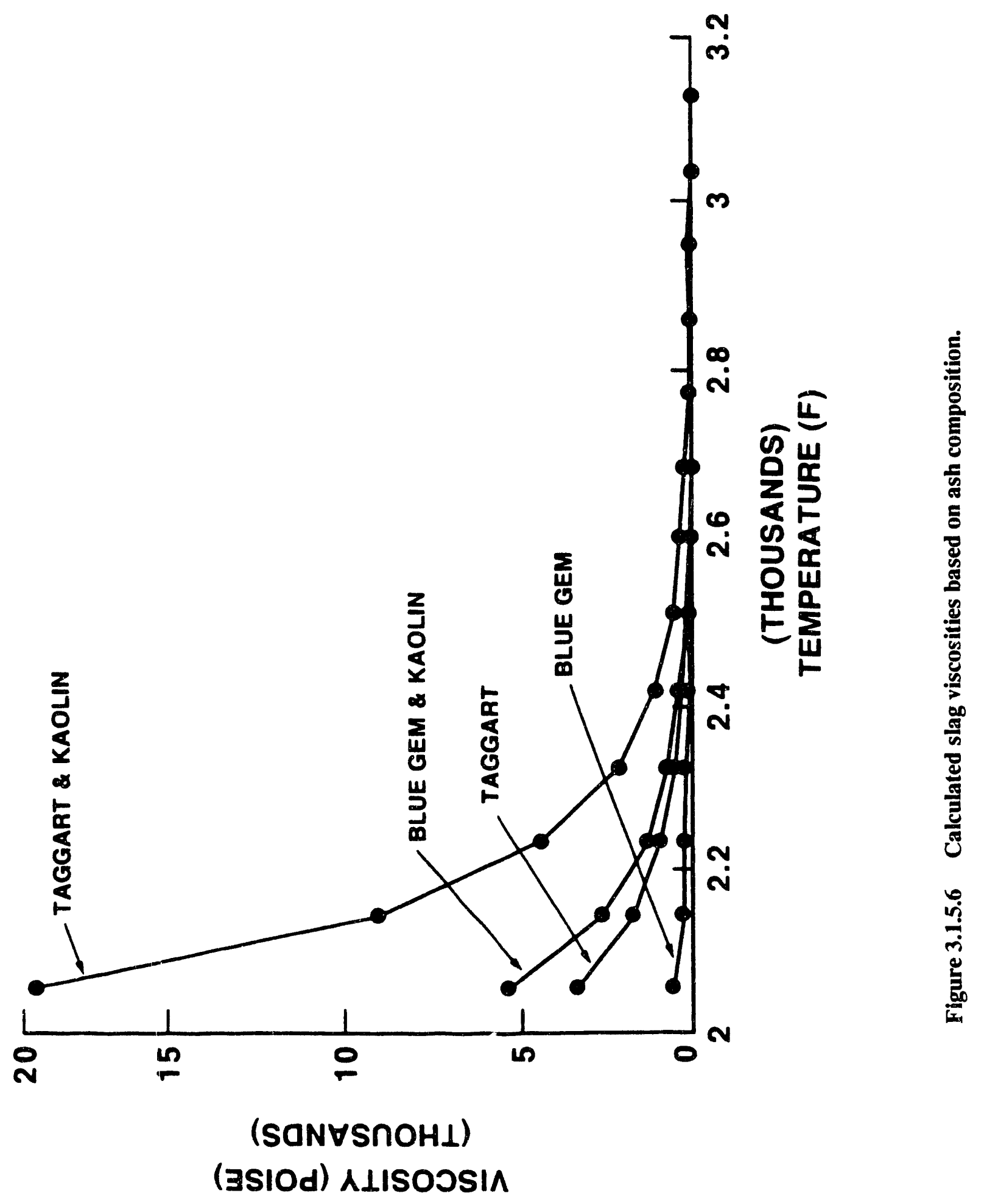


composition and viscosity will also be affected. Also the presence of bubbles and suspended crystalline material will also perturb the bulk slag behavior.

In addition, going through these calculations, it became apparent that the Blue Gem coal yields an unusually fluid ash, all by itself, perhaps several orders of magnitude more fluid than typical US coals [12]. The reasons for this are the high iron content, the low silica content, and the high calcia content. The average iron content of 617 eastern US bituminous coals is $18.6 \%$ compared to Blue Gem's $28.5 \%$; average silica is $44.1 \%$ compared to Blue Gem's $24.1 \%$; average calcia is $2.3 \%$ compared to Blue Gem's $9.9 \%$. Slagging is favored by high iron and calcia as well as low silica.

Raask [8] has characterized the slagging tendency of coals based on both iron content and silica ratios. He found that non-slagging coals have iron contents from 3 to $8 \%$ and silica values from 72 to 80 . Some slagging is observed for coals with iron contents from 8 to $15 \%$ and silica ratios of 65 to 72 . Highly slagging coals have iron contents from 15 to $23 \%$ and silica ratios of 50 to 65 . The Blue Gem is off scale in slagging propensity with iron contents up to $30 \%$ and silica ratios of 35 . By adding kaolin, we just get to a silica value of 65 , on the borderline high-slagging ash. By adding calcia, we get a silica value of 6 , and as reported in Section 3.2, a severely slagging ash was obtained. The Taggart seam coal has iron at $17 \%$, and a silica value of 65 , which gets to roughly the same ash composition as the kaolin-added test, but without adding kaolin, so that the ash content is $0.8 \%$ to begin with. Adding kaolin to this coal should make it even less sticky; results of this study appear in Section 3.1.6.

Indeed, the Taggart coal has a much more representitive ash vis a vis 617 U.S. Coals as in the Table below.

\section{U.S.Average Taggart Blue Gem}

$\begin{array}{lrcr}\text { silica } & 44.1 & 36 & 22.4 \\ \text { alumina } & 24.5 & 30 & 29.1 \\ \text { calcia } & 2.3 & 2.5 & 9.9 \\ \text { iron ox } & 18.6 & 17 & 28.5 \\ \text { alkali } & 2.5 & 2.5 & 0.7\end{array}$

Thus, the Taggart test fuel is important for several reasons. It has an ash very typical of a US average coal; it tests the concept that ash composition determines the deposition character; and it explores the relationship between slag viscosity and sintering/ deposit adhesion behavior; it represents a new coal for combustion testing; it tests the role of slurry rheology and volatile content in combustion; and it represents the first commercial scale fuel to be developed by Otisca Industries under the auspices of the Clean Coal II initiative. 
The results of the test are encouraging; as seen in Figures 3.1.5.2 to 3.1.5.5, deposition was slight compared to the Blue Gem coal which has a much lower calculated slag viscosity. The increased resistance to flow of the Taggart ash is evident in the Mott filtrate quenched probe samples which, for the first time, revealed slag droplets that were not completely spherical, in contrast to all Blue Gem slag droplets that were perfect spheres. The NAIN plot, Figure 3.1.5.7 did, however, show a slight steady decline.

Detailed microstructual, chemical, and $\mathrm{x}$-ray diffraction analyses were performed on deposits taken along the liner, the transition section, at the suction/leading edge interface, and on the suction side. Noteworthy was the enrichment of alkali in the latter two most troublesoma areas, and the appearance of alkali enriched feldspathoids. Thus we see that, despite a particularly desirable ash chemistry, the presence of high levels of alkali at the outset is sufficient to offset the beneficial effect of high ash viscosity. The initial form of the alkali is not completely determined, though trace amounts of illite were present in a low-temperature oxygen plasma treated ash. Most likely the alkali was present as surface adsorbed sodium and potassium chloride which would place it in a highly reactive environment. This was apparently borne out in the deposition on the leading edge/suction interface.

Therefore two alternatives were selected for further exploration. First, an attempt to modify the Taggart ash was made, using the kaolin additive as described earlier. Second, an even more refractory ash from the Elk Creek seam was examined. These are discussed in the following sections.

\subsubsection{References}

[1] S.G. Kimura, C.L. Spiro, C.C. Chen, "Alkali Species Characterization for Coal-Fueled Gas Turbine”, Final Report, DOE/MC/22164-2188, (1987), pp 1-39.

[2] K. Ross, S.G. Kimura and C.L. Spiro,Final Report, U.S. Department of Energy, Gas Turbine Components Screening, DOE/MC/21395-2298,(1987).

[3] C.L. Spiro, S.G. Kimura, and C.C. Chen, "Ash Behavior During Combustion and Deposition in Coal Fueled Gas Turbines", ASME Joumal for Engineering and Power, Vol 109(3), 325-330, 1987. Also presented as paper 87-GT-267 at the Gas Turbine Conference and Exhibition, 5/31/87, Anaheim, CA.

[4] C.L. Spiro, C.C. Chen, J. Wong, S.G. Kimura, and R.B. Greegor, "Characterization of Products from a Direct Coal-Water Mixture Fired Gas Turbine Combustor", Fuel, 66(4), 563-567(1987).

[5] P.J. Schields, C.L. Spiro,and E. Koch, "Phase Characterization of Coal-Fueled Engine Deposits," in Fly Ash and Coal Conversion Byproducts: Characterization, Utilization, and Disposal $I$., edited by G.J. McCarthy, F.P. Glaser, and D.M.Roy, Materials Research Society Symposium Series Vol 113, p 133-142,

[6] G.C. Kuczynski, “The Science of Sintering”, J. Scien Sintering 9, 243, 1977. 


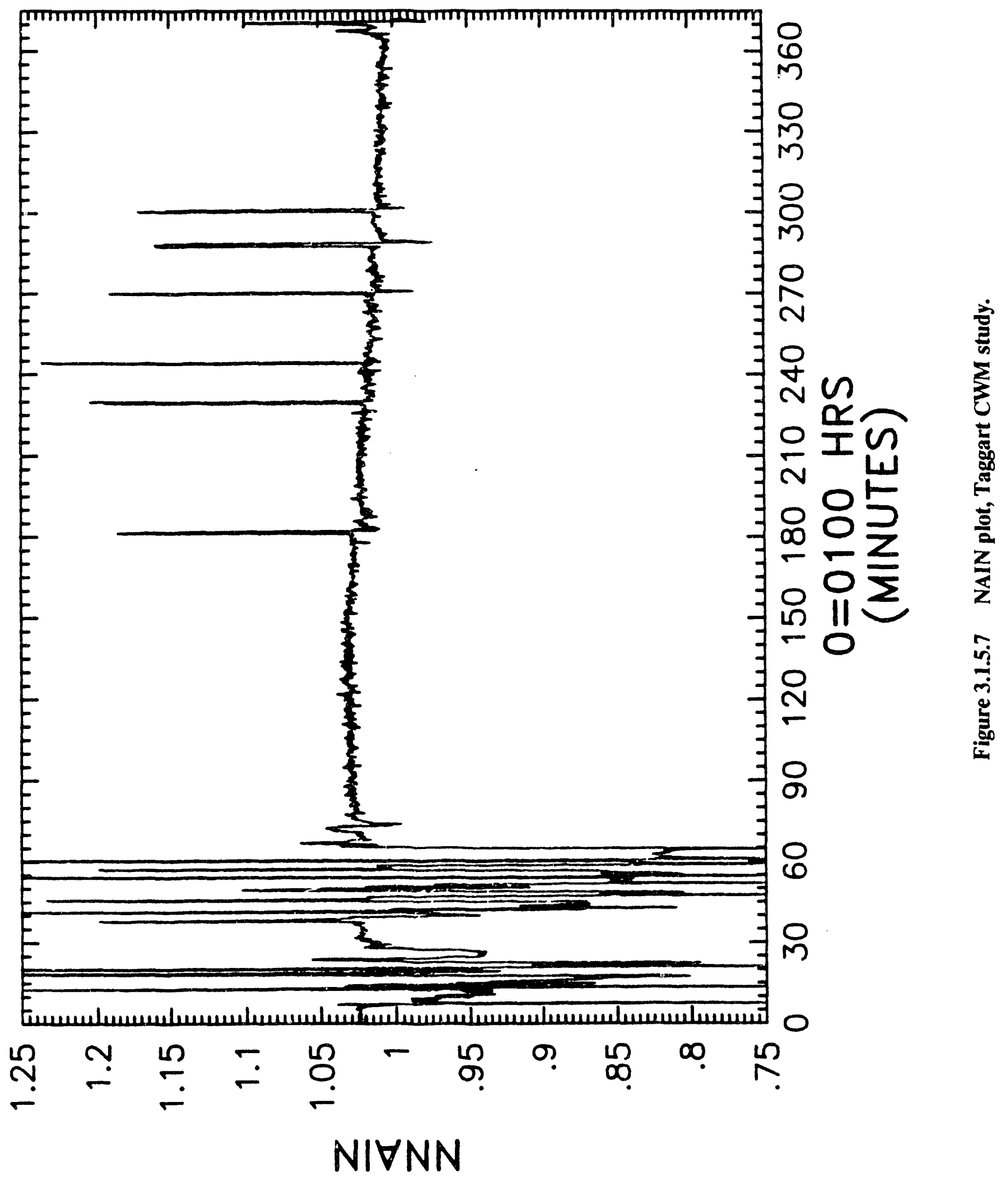


[7] J.J. Frenkel, "Viscous Flow of Crystalline Bodies Under the Action of Surface Tension", J. Phys (Moscow) 9, 385, 1945.

[8] E. Raask, Mineral Impurities in Coal Combustion, Hemisphere Publishing, Washington, 1985.

[9] W.T. Reid and P. Cohen, J. Eng. Power, ASME Trans. Series A 66, 83, 1944.

[10] G. Urbain, F. Cambier, M. Deletter, and M.R. Ansou, "The Viscosity of Silicate Melts", Trans. J. Br. Ceram. Soc., 80, 139, 1980.

[11] D.P. Kalmanovitch and M. Frank, "An Effective Model of Viscosity for Ash Deposition Phenomena", Mineral Matter and Ash Deposition From Coal, Engineering Foundation Conference Proceedings, K. Vorres, ed, 1989, in press.

[12] P. Zubovic, C. Oman, S. Lynn Coleman, L. Bragg, P. Kerr, K. Kozey, F. Simon, J. Rowe, J. Medlin, and F. Walker, US Dept of the Interior Geological Survey, Open File Report 79-665, "Chemical Analysis of 617 Coal Samples From the Eastern United States", 1979. 


\subsubsection{Taggart Coal with Kaolin}

\subsubsection{Introduction}

In previous sections we have seen that ash character plays a major role in deposition. With Blue Gem coal, deposition rates were unacceptaby high; deposits were sintered, fused, and tenacious. Alumina-augmented Blue Gem coal was less adherent, but the additive caused airfoil erosion. Boehmite-augmented Blue Gem showed considerable improvement, but an unanticipated side reaction resulted in the slow, indirect substitution of aluminum for sodium, with concomitant alkali sulfate glue formation. Addition of kaolin to to the Blue Gem coal was effective in deposit remediation, though the Blue Gem coal has an atypical ash composition. The Taggart coal is more representitive of US bituminous coals, but slight deposition due to alkali glues was evident. Described in this section is an attempt to use kaolin to modify the Taggart ash to render it even more viscous and refractory, and to possibly getter alkali glues in the process.

\subsubsection{Experimental, Results and Discussion}

The LM500 turbine simulator was employed as usual, with a $45^{\circ}$ fuel nozzle and a $60^{\circ}$ air swirler. The test fuel was from the Taggart seam, and had properties which appear in Tables 3.1.5.1 and 3.1.5.2, in Section 3.1.5. The fuel had both higher solids content, and reduced viscosity compared to the Blue Gem fuel. Combustion was erratic, presumably due in part to the reduced volatile matter in the fuel.

The test took part in two phases. The first lasted six hours, ending with a flame-out and inspection. This was followed by a $12 \mathrm{hr}$ test.

During the initial test, there was a $1.5 \%$ drop in $i:$ IIN over four hours, followed by a two hour period of negligible NAIN drop. A sudden 10\% drop in NAIN halted the test. This was caused by a now familiar sudden system plugging from a deposit that had apparently formed and spalled from the dome region behind the fuel nozzle. Throughout the deposition testing similar deposits formed in this region of flow instability at the fuel nozzle, which invariably spalled and plugged the airfoils. These deposits were regarded as system artifacts, and efforts were ongoing to eliminate them up until the program was terminated.

Inspection of the airfoils revealed clean, deposit free surfaces, and unlike the untreated Taggart coal, the region at the demarkation between the leading edge and suction surfaces was clean. Also, the NAIN drop for the untreated coal was twice that of the treated coal, Figure 3.1.6.1. The lumps were removed and the system refired for an additional twelve hours.

During the initial stage of the second treated-Taggart test sequence, combustion proceeded relatively smoothly, with occasional flame-outs and small NAIN changes. During this testing, new slurry was mixed with kaolin as needed, and admitted to the slurry tank. After $6 \mathrm{hr}$, the kaolin stock slurry wis depleted, and a new master batch was prepared, but inadvertently 
the wrong surfactant was employed. Normally an ammonium polyacrylate was used, but in this case a sodium polyacrylate was substituted. Though the surfactant constituted an increase of only $15.7 \mathrm{ppm}$ of sodium, this was sufficient to quickly cause the testing to deteriorate. As can be seen in Figure 3.1.6.2, a flameout, chunk deposition, and a drop in NAIN slope followed the alkali addition within minutes.

The test was allowed to proceed for a few hours after the alkali addition as the error was not deternnined until long after the test was completed. The rig was opened and inspected. As before, large chunks had spalled from upstream, Figure 3.1.6.3, but this time, when they were removed, clearly leading edge deposits had formed and adhered, Figure 3.1.6.4. Both the liner and the transition section were reasonably deposit free, Figure 3.1.6.5. Microstructural analysis revealed a highly fused underlayer.

Because of the added sodium, detailed ash analyses were not performed, other than to determine sodium contents. In fact, comparison of sodium in the deposits obtained in the initial test sequence compared to the alkali surfactant sequence showed a $62 \%$ increase of sodium in the latter deposits, and most significantly, a $573 \%$ increase in the soluble sodium in the deposits!

\subsubsection{Summary and Conclusions}

Taggart coal deposition rate and character showed improvement with respect to the more highly slagging Blue Gem coal, but deposition persisted somewhat due to a high inherent alkali content. Addition of kaolin to the slurry was effective in reducing deposition rate. Only on the suction side surfaces were deposits noted, and these were reduced with respect to the untreated Taggart coal.

Inadvertently $15 \mathrm{ppm}$ of soluble sodium was admitted to the fuel midway through the testing. This has a significant deleterious effect on deposition rate and character, yielding massive and tenacious growth on the leading edge surfaces. 


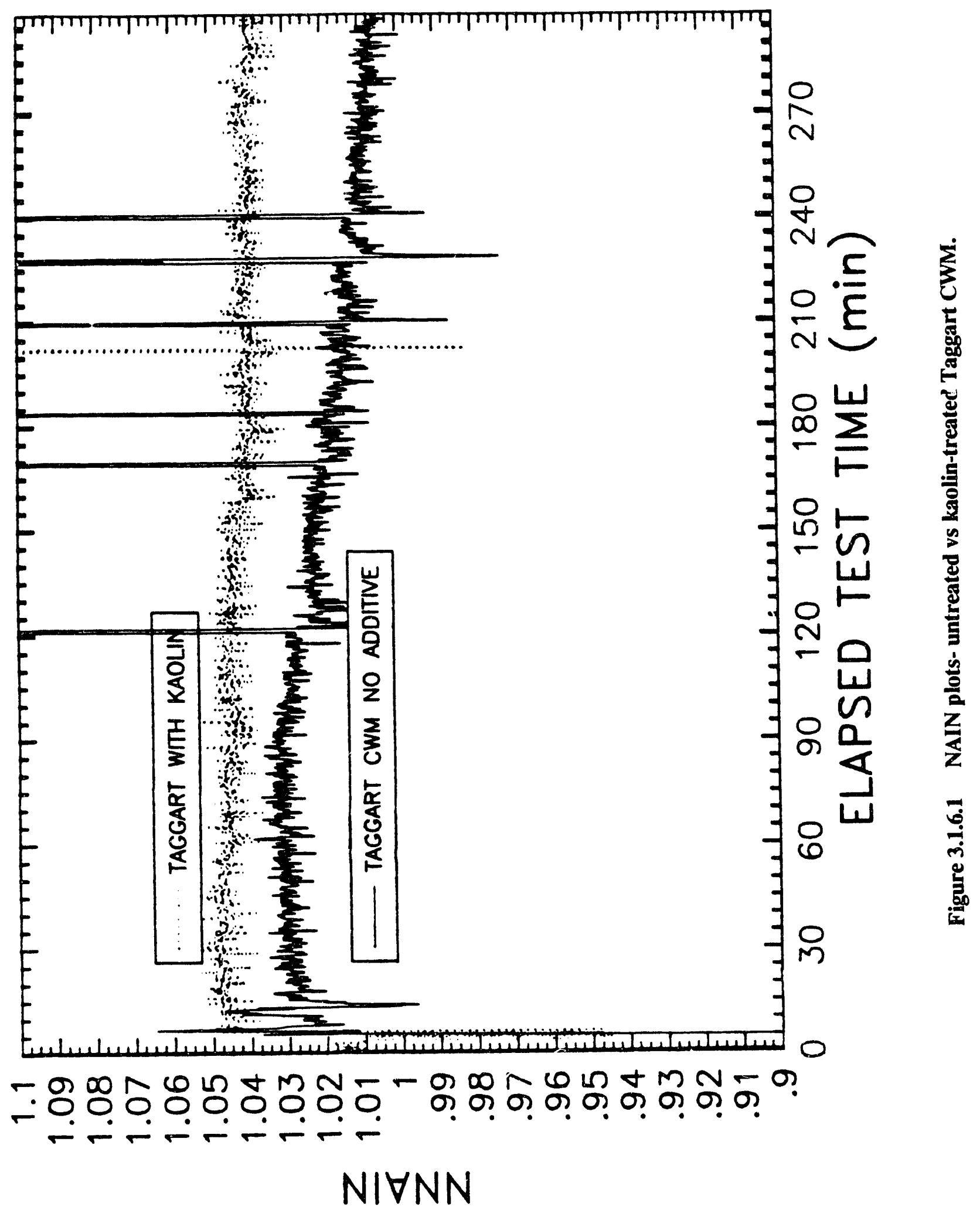




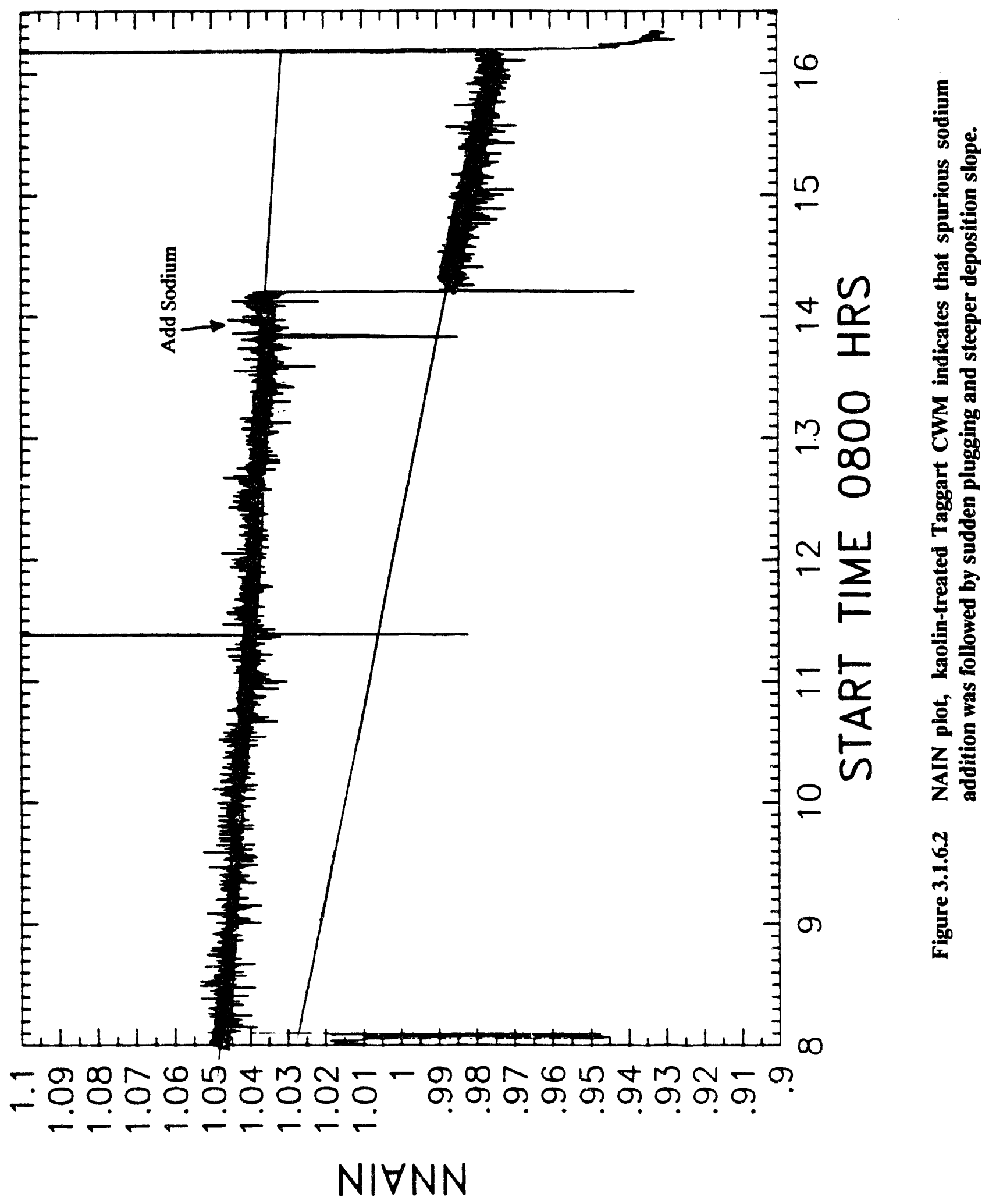




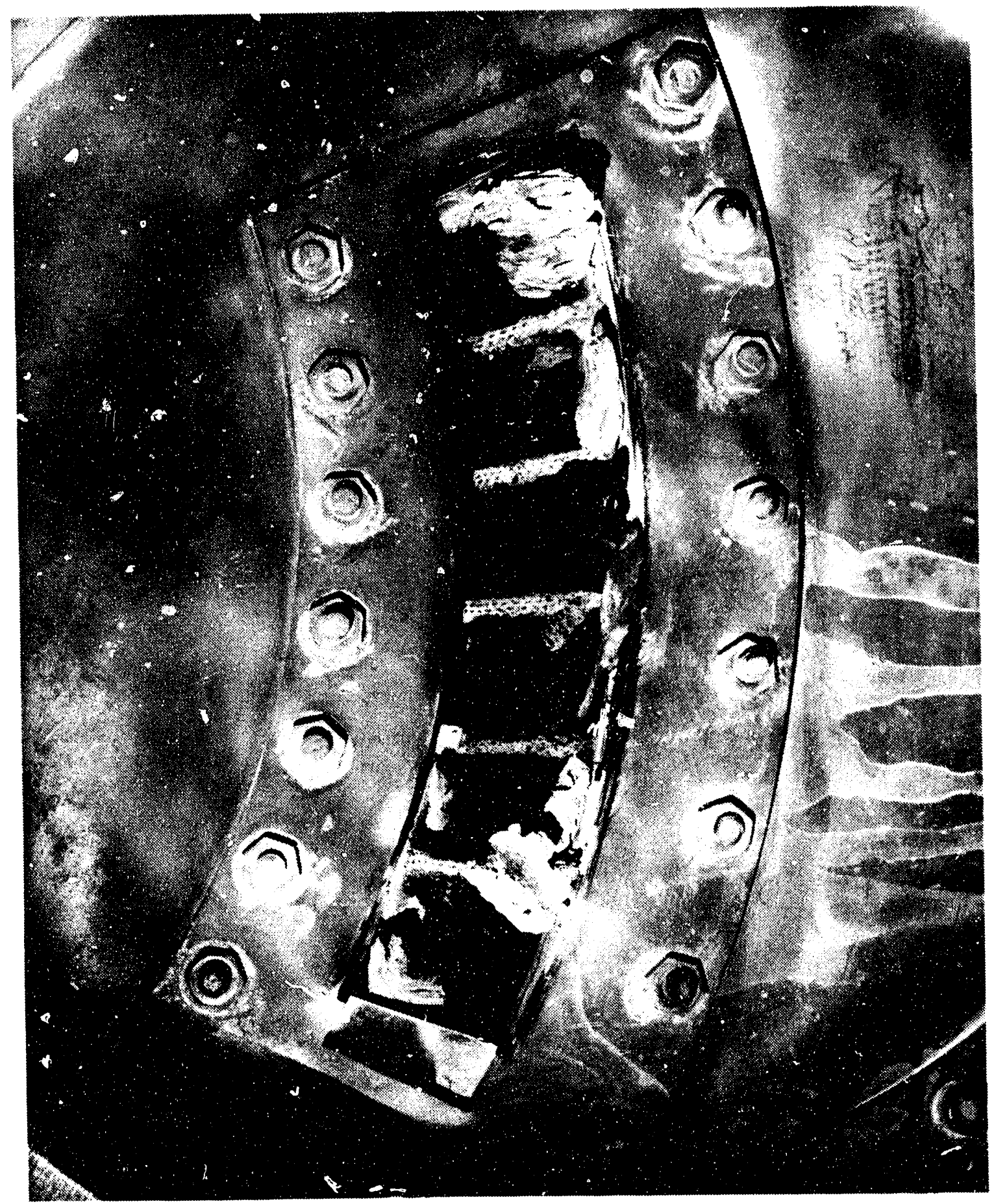

Figure 3.1.6.3 LM500 turbine simulator showing deposits wedged in the cascade from kaolin-doped Taggart CWM test. 


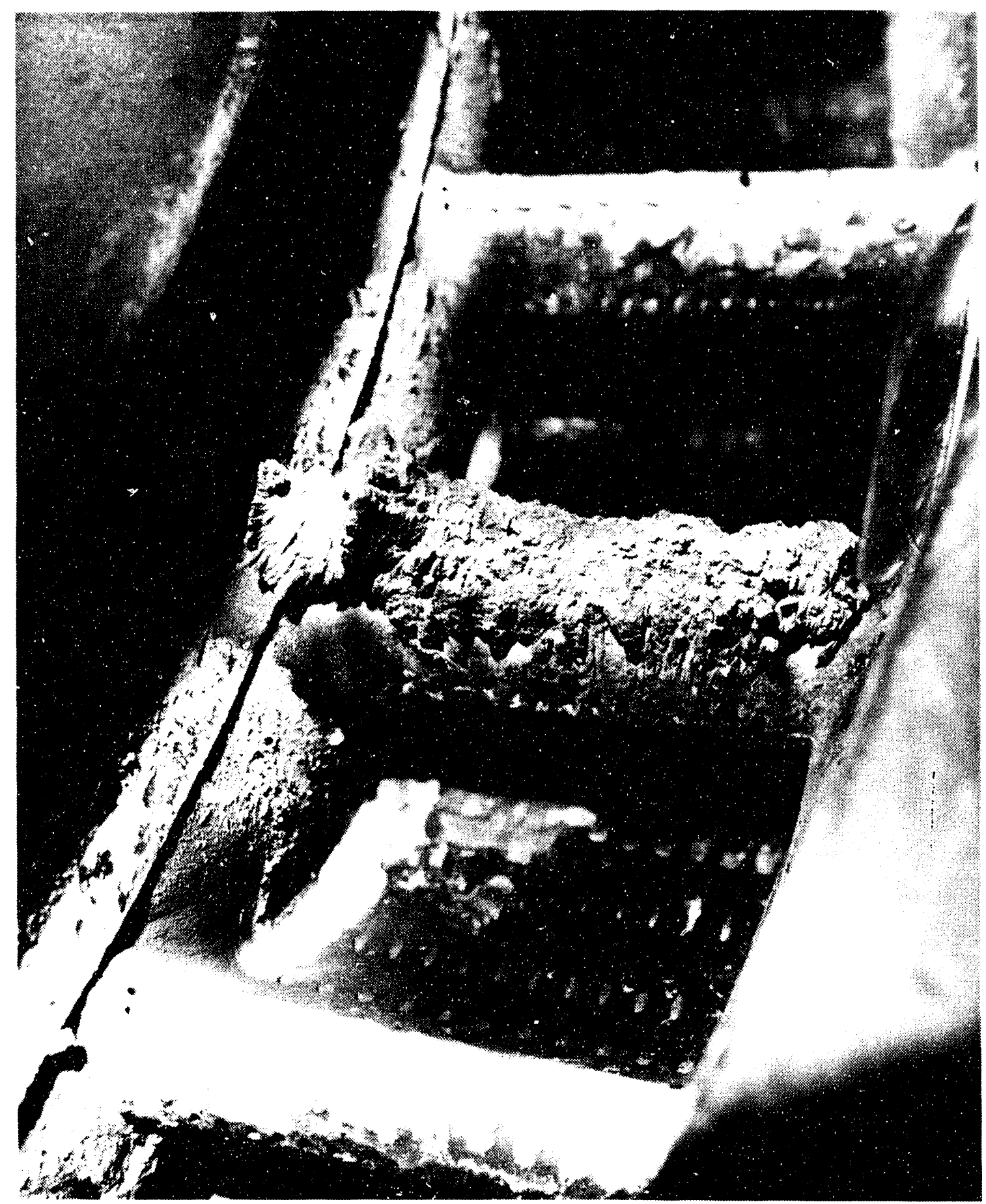

Figure 3.1.6.4 LM500 turbine simulator showing close-up of leading edge deposits from kaolin-doped Taggart CWM test. 


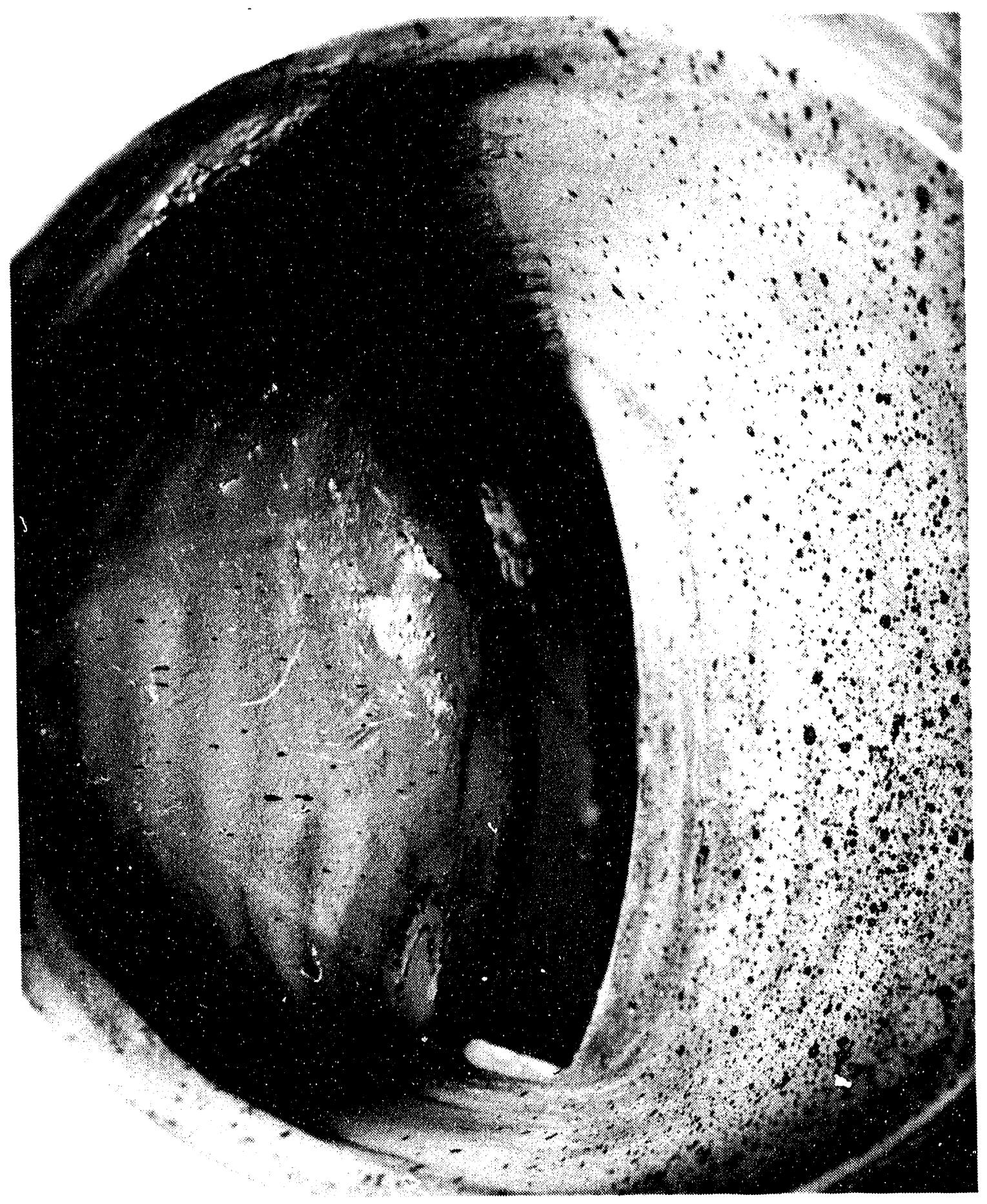

Figure 3.1.6.5 Transition section and liner regions of the LM500 turbine simulator were free of deposits when kaolin-doped Taggart CWM was burned. 


\subsubsection{Elk Creek High Ash Coal}

\subsubsection{Introduction}

In previous sections, we have reported that ash character plays a dominant role in deposition. Addition of small amounts of ash modifiers can have a large effect on deposition rate and character. For example, $0.4 \%$ addition of kaolin to Blue Gem coal slurry converts the highly slagging coal to one in which deposition is essentially eliminated on the airfoils. A switch to a more refractory ash coal - the Taggart - proved effective, though the effects were partially obviated by the presence of alkali metals in high concentration. Addition of kaolin to the Taggart seam further improved on deposition, though an inadvertent addition of just $15 \mathrm{ppm}$ of sodium completely reversed these effects.

Based on these results, it appeared that judicious coal selection might result in deposition free turbine operation for even very high levels of ash. To explore this possibility, a run-ofmine 5.5\% ash Elk Creek seam coal was provided by CXCE fuels, and was burned in the LM500 deposition test rig.

\subsubsection{Experimental}

Combustion testing of this coal was performed as usual in the LM500 turbine simulator. Four combustion trials consisting of almost twelve hours operation on this fuel were performed. No special accommodation for the coarse particle size, high ash, and high solids content were made other than to dilute the slurry to $55 \%$ solids. Fuel analyses appear in Tables 3.1.7.1 and 3.1.7.2.

In general, combustion was not as good as with the micronized coal slurries from OTIS$\mathrm{CA}$. This could be due to a combination of coarse particle size as well as low volatility. Nonetheless, combustion efficiencies in the range of 88 to $90 \%$ were achieved.

\subsubsection{Results}

In each of four tests using the Elk Creek, high-ash coal, qualitatively the same behavior was observed; essentially no drop in NAIN over a period of hours, followed by a sudden drop of 5-15\%. An example of this behavior appears in Figure 3.1.7.1. The simulator was inspected after the tests, and also yielded qualitatively the same observations. The combustor liner was virtually spotless, Figure 3.1.7.2, and the suction side of the airfoils were as clean as had ever been observed in previous tests, Figure 3.1.7.3. Several large, highly fused, porous glassy chunks were caught in the airfoil throats, Figure 3.1.7.4. Inspection of these deposits revealed that they unequivocally formed right in the dome region of the combustor, in the zone just beyond the swirler vanes, Figure 3.1.7.5. Completely non-adherent, when these chunks were removed, they revealed clean airfoils.

Close inspection of the trailing-edge pressure-side surfaces, Figure 3.1.7.6, indicated discoloration probably due to incipient erosion. This is not surprising due to the highly refrac- 
Table 3.1.7.1

Properties of OXCE Elk Creek Coal-Water Mixtere

Proximate Analysis (as received basis)

\begin{tabular}{|c|c|}
\hline Moictu & $650 \%$ \\
\hline Ash content & $4.93 \%$ \\
\hline Total sulfur & $0.67 \%$ \\
\hline Volatile & $32.00 \%$ \\
\hline Fixed carbon & $56.57 \%$ \\
\hline Heat content & $\begin{array}{l}13,350 \mathrm{Btu} / \mathrm{lb} \\
\text { Slurry Properties }\end{array}$ \\
\hline Solids & $63.31 \%$ \\
\hline Density & $1.188 \mathrm{~g} / \mathrm{cc}$ \\
\hline
\end{tabular}

Viscosity shear $\mathrm{rt}$ $3227 / \mathrm{sec}$ $2875 / \mathrm{sec}$ $2539 / \mathrm{sec}$ $1854 / \mathrm{sec}$ $1493 / \mathrm{sec}$

$110 / \mathrm{sec}$

$55 / \mathrm{sec}$

$22 / \mathrm{sec}$

$11 / \mathrm{sec}$

$2.2 / \mathrm{sec}$

$1.1 / \mathrm{sec}$

$1.0 / \mathrm{sec}$

viscosity (cp)

290

285

266

253

236

207

227

246

286

683

1040

1090

Particle Size Distribution

Mass Mean Diameter $10.42 \mu \mathrm{m}$

$97.3 \%$ - mesh

RR Slope 1.0

RR Intercept - 2.59

RR Correlation Coefficient 0.995 
Table 3.1.7.2

Ash Composition Data Elk Creek Coal

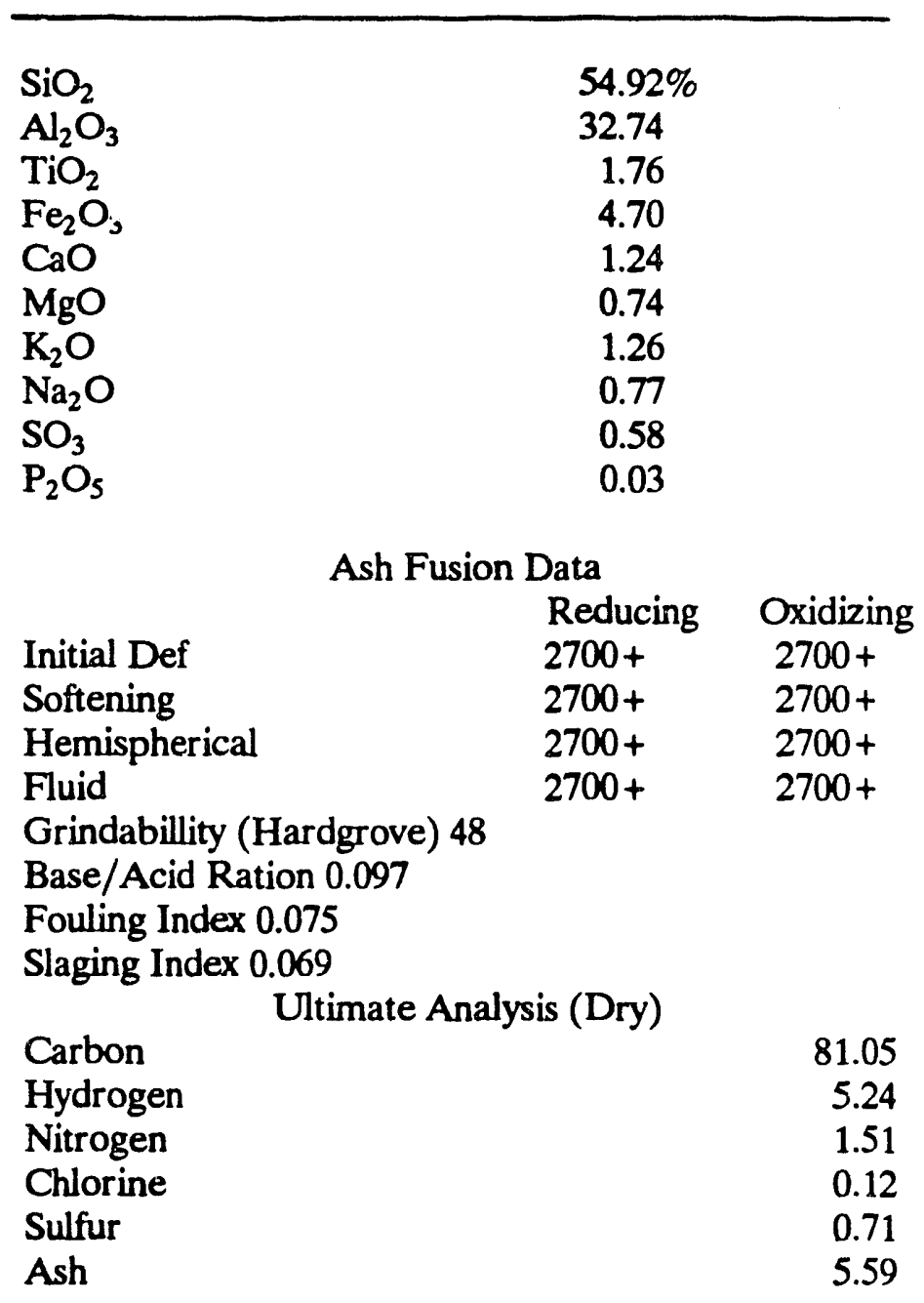




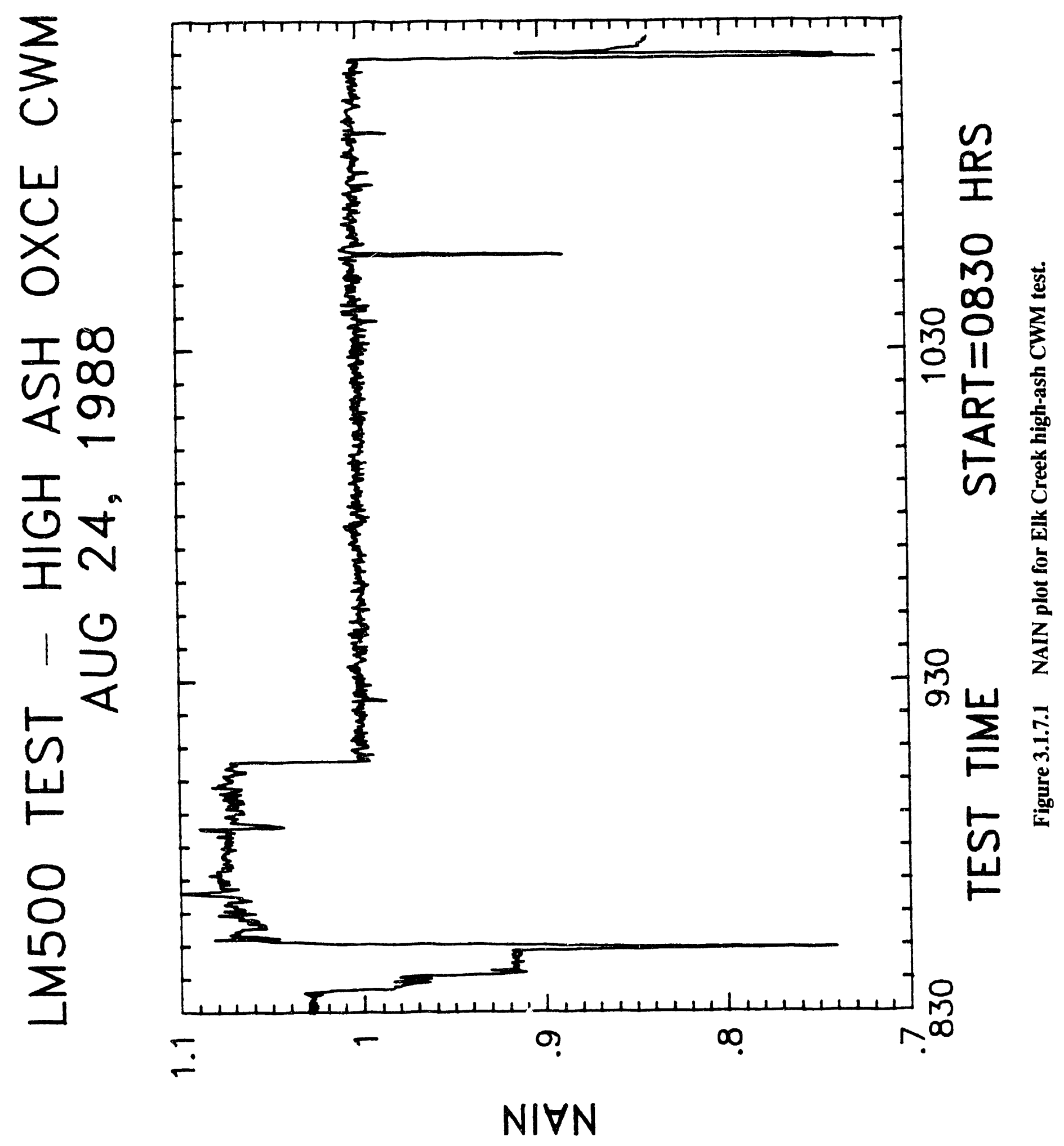




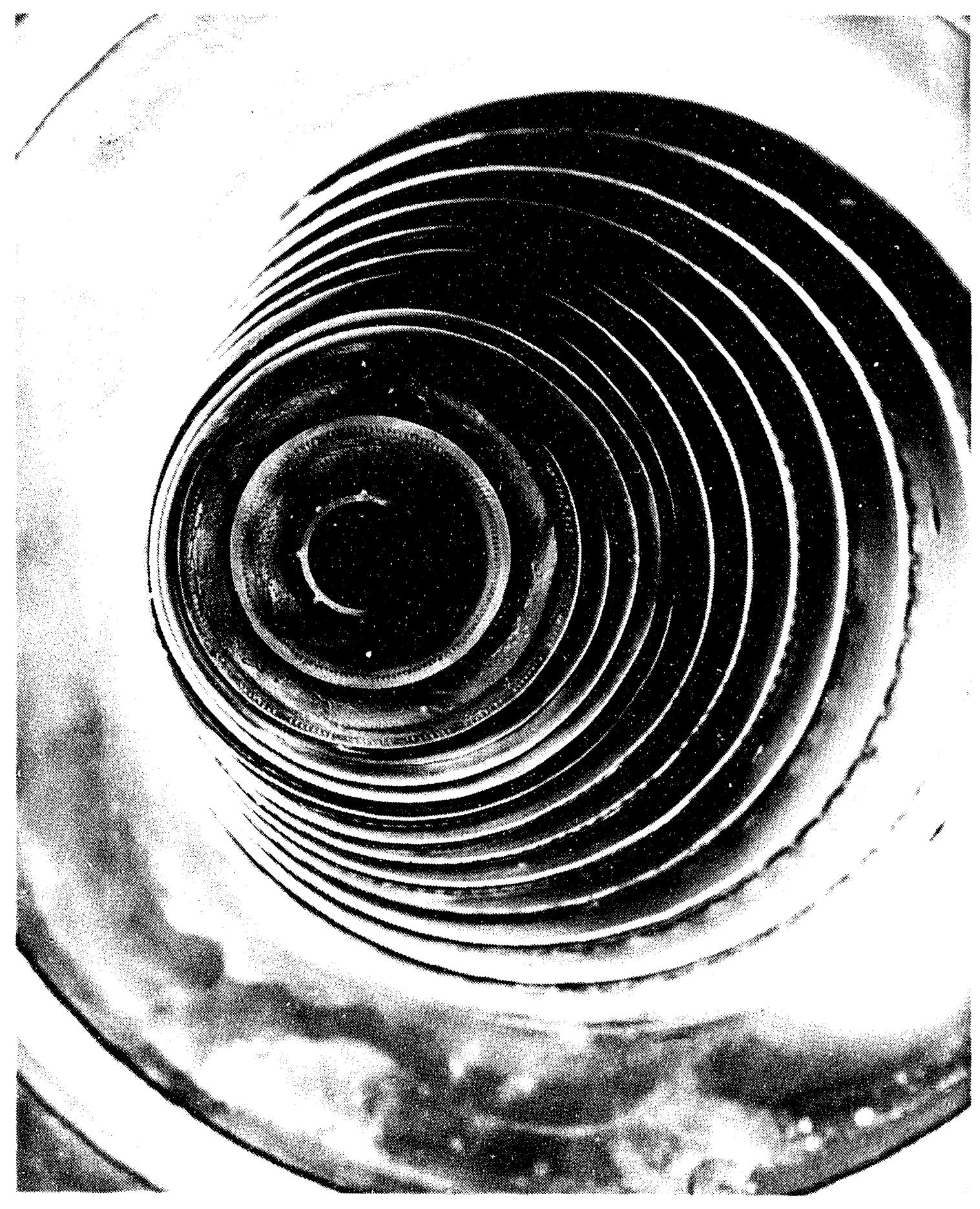

Figure 3.1.7. Liner surfaces are generally clean from the Elk Creek high-ash CWM test. 


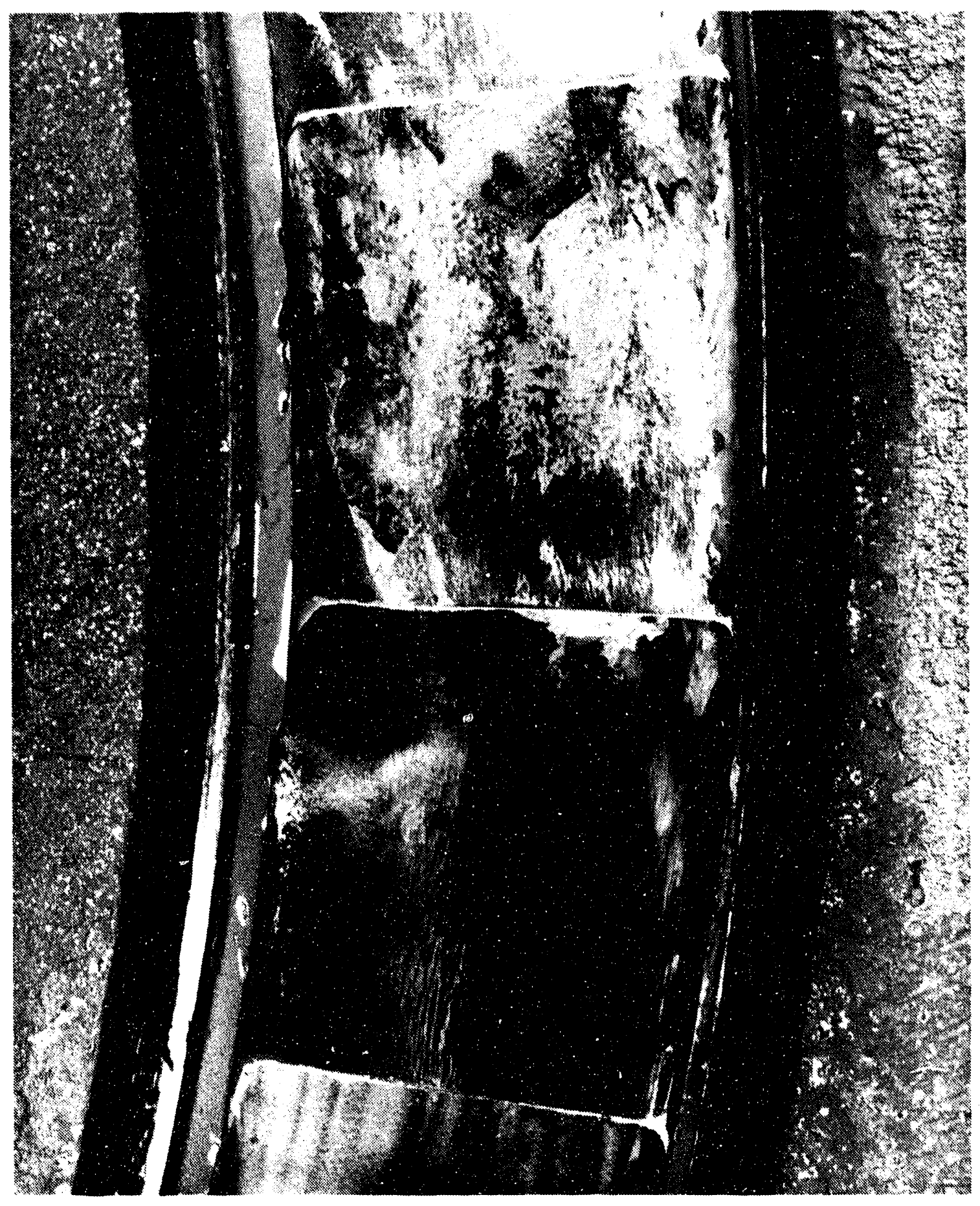

Figure 3.1.73 Suction surfaces are generally clean from the Elk Creek high-ash CWM test. 


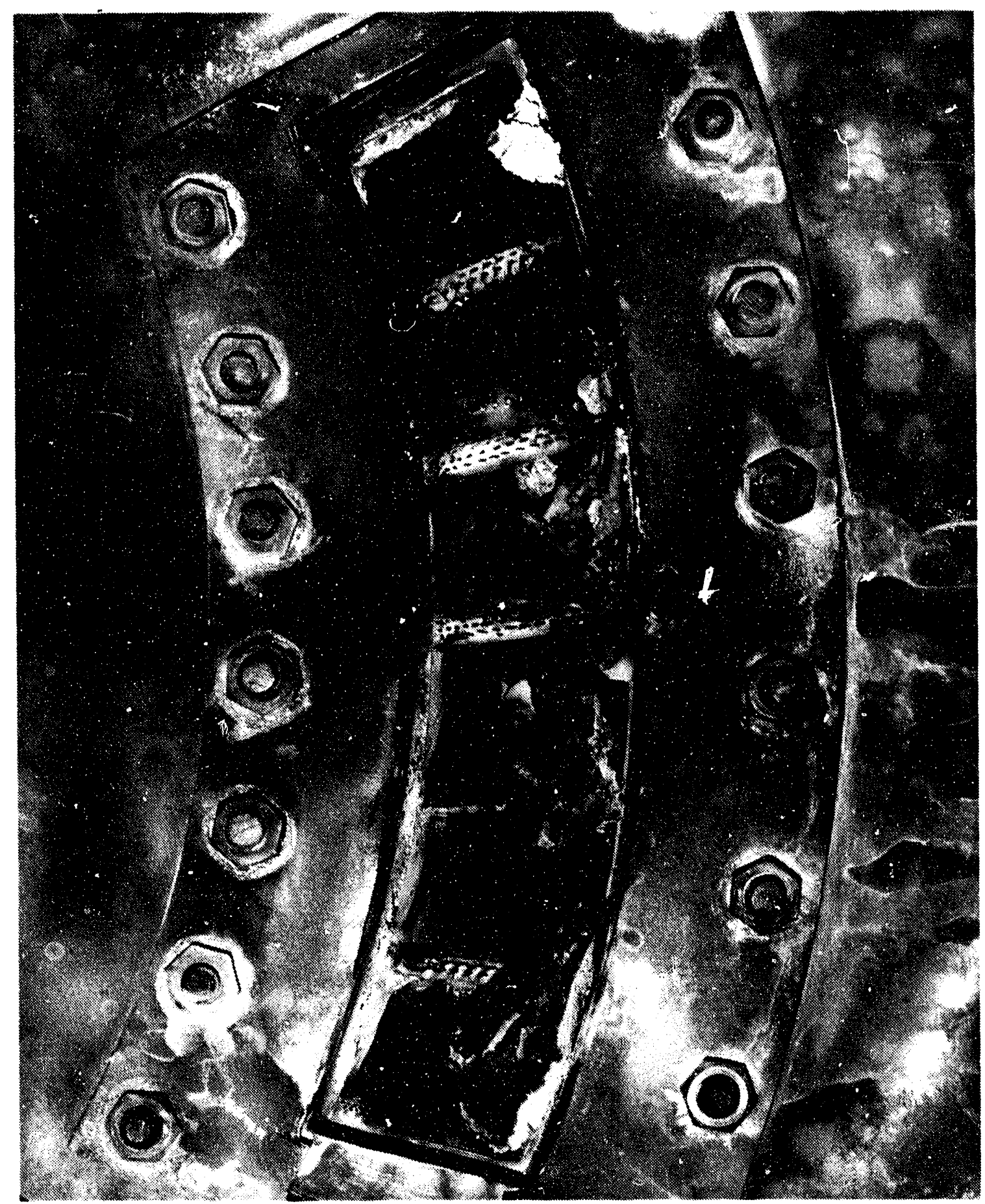

Figure 3.1.7.4 Large chunks which had spalled from the dome region of the fuel nozzle are wedged in an otherwise clean LM500 turbine cascade. 


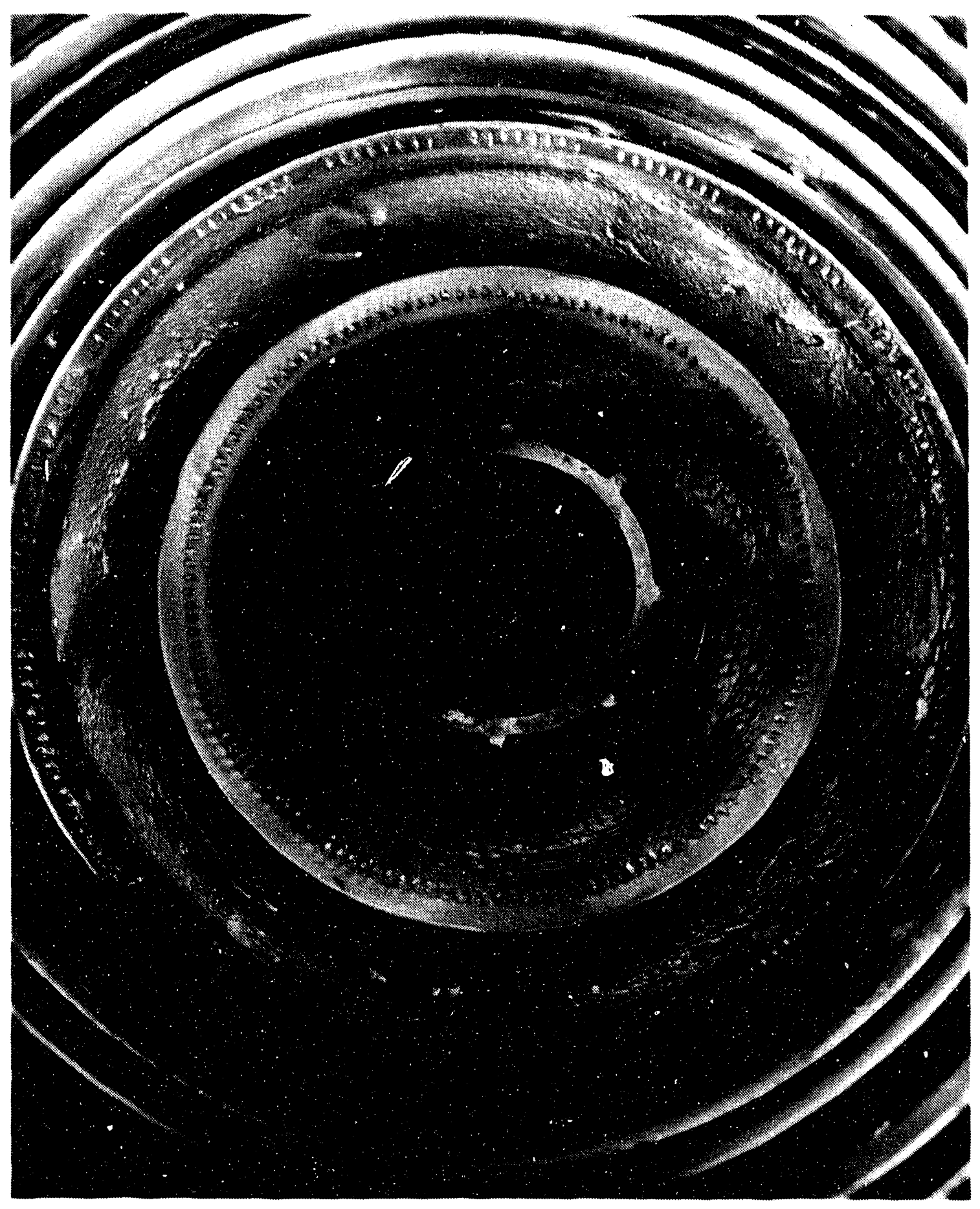

Figure 3.1.7.5 Close-up of the dome region where deposits form. 


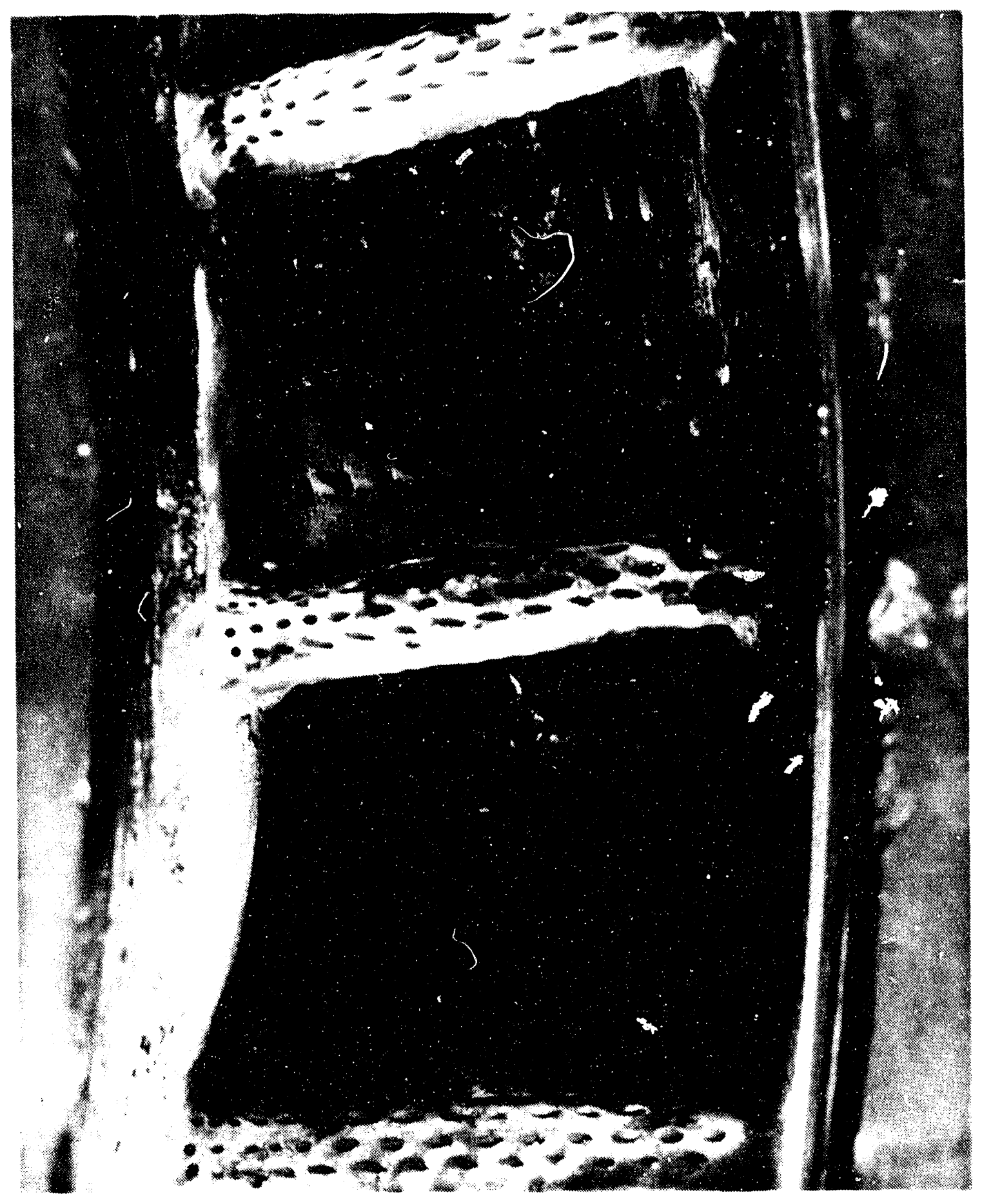

Figure 3.1.7.6 Pressure and leading-edge surfaces are generally clean from the Elk Creek high-ash CWM test. 
tory nature of the ash, and its coarse size. A quenched sample of POCs, Figure 3.1.7.7, shows the size of the POCs, still not much larger than those observed with micronized coal. Salient by its absence is the fume, which previous studies in our laboratories showed that it was iron; this coal is low in iron and therefore low in fume.

\subsubsection{Discussion}

Using a coarse, high-ash coal in the LM500 turbine simulator provided many valuable lessons. First, we learned that coarse, higher ash, lower volatility coal could be successfully burned in our system, but combustion efficiencies well below those typically observed for micronized-coal combustion were obtained. This is most likely due to the large particle sizes which yield a char with lower surface areas. Seconfly, the high ash coal showed little airfoil deposition. This is due, in part, to erosion, but most probably is due to the refractory ash chemistry. Otherwise stagnation points would still show deposition, as was observed when alumina was added to the fuel. Also, the highly clean nature of the suction surface further supports the ash-chemistry influence, rather than erosion.

To help clarify the role of erosion, the fuel was micronized, but was never tested prior to the terminacion of this program.

The nature of the wedged deposits is interesting, having formed up by the dome of the fuel nozzle. Clearly stagnation points anywhere along the hot-gas path must be avoided in the commercial system. To help alleviate this problem, a fumigated fuel nozzle using porous stainless-steel was fabricated, but was not tested due to the termination of the program. 


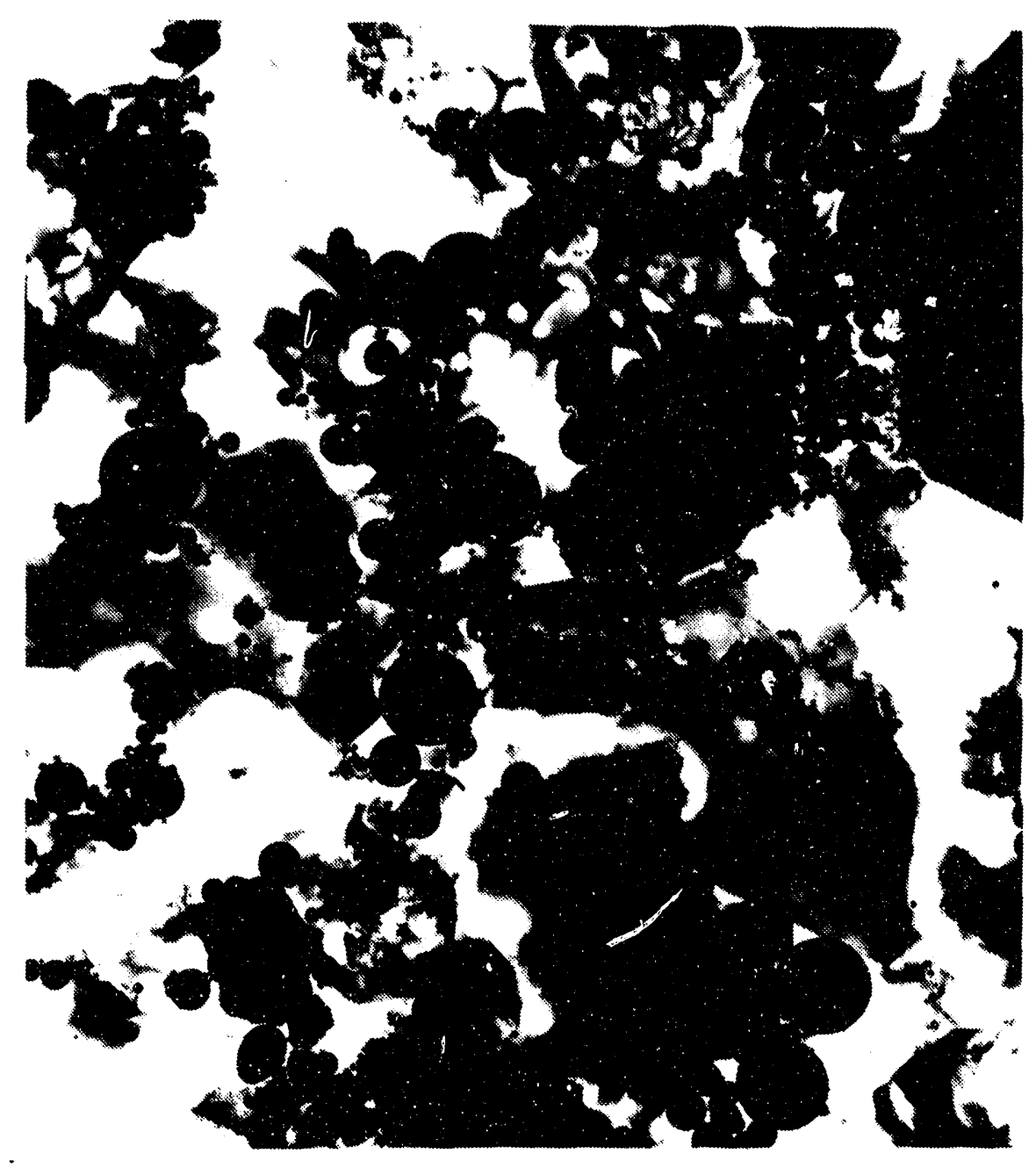

Figure 3.1.7.7 Quench probe samples from the Elk Creek high-ash study. 


\subsubsection{Summary of Deposit Remedintion Strategies and Results}

Several s; ategies for deposit remes iation have been developed, and are summarized in Figure 3.1.8.1. Included are fuel beneficiation and micronization that minimizes the ash present and lowers its tendency to impact. This is accomplished in one step by the Otisca process, Figure 3.1.5.1. High combustion efficiency has been achieved, section 3.4, which reduces particulate mass, and may also eliminate locally reducing conditions or hot spots which are known to exacerbate deposition and sintering on the turbine. The GE airoils are internally and film-cooled to reduce sintering and melting as well. Nutshelling and waterwashing have proved to be partially effective in ash removal. The turbine has been coated, but not yet tested, (Section 3.5), for non-wettability. These collective approaches are moderately effective, but costly or at least undesirable from a down-time or preventative- maintenance view.

The use of ash modification to render deposits non-adherent under turbine conditions represents the most desirable strategy, based on data gathered to date. We do not anticipate major breakthrough in beneficiation technolcgy which would eliminate ash altogether. A phenomenological model of ash chemistry and deposit behavior has been suggested. This consists of in situ devitrification and spontaneous spalling, a result of additive-induced exsolution of high-density crystals. The most effective additive found to date is kaolin clay which is effective at low concentrations $(0.4 \%)$, is inexpensive, and has no apparent deleterious side effects on slurry rheology or combustion. Judicious coal selection may obviate the need for additives, but additives retain their value as a means to broaden coal selection.

The problems of deposition are not completely solved; hot spots and stagnation points must be avoided; extended turbine operation over thousands of hours may reveal new and unanticipated sources of deposition.

Still, based on progress in the GE Advanced Cial-Fueled Gas Turbine program, the outlook for succesful deposition-free operation of a coal-fueled turbine is optimistic. 


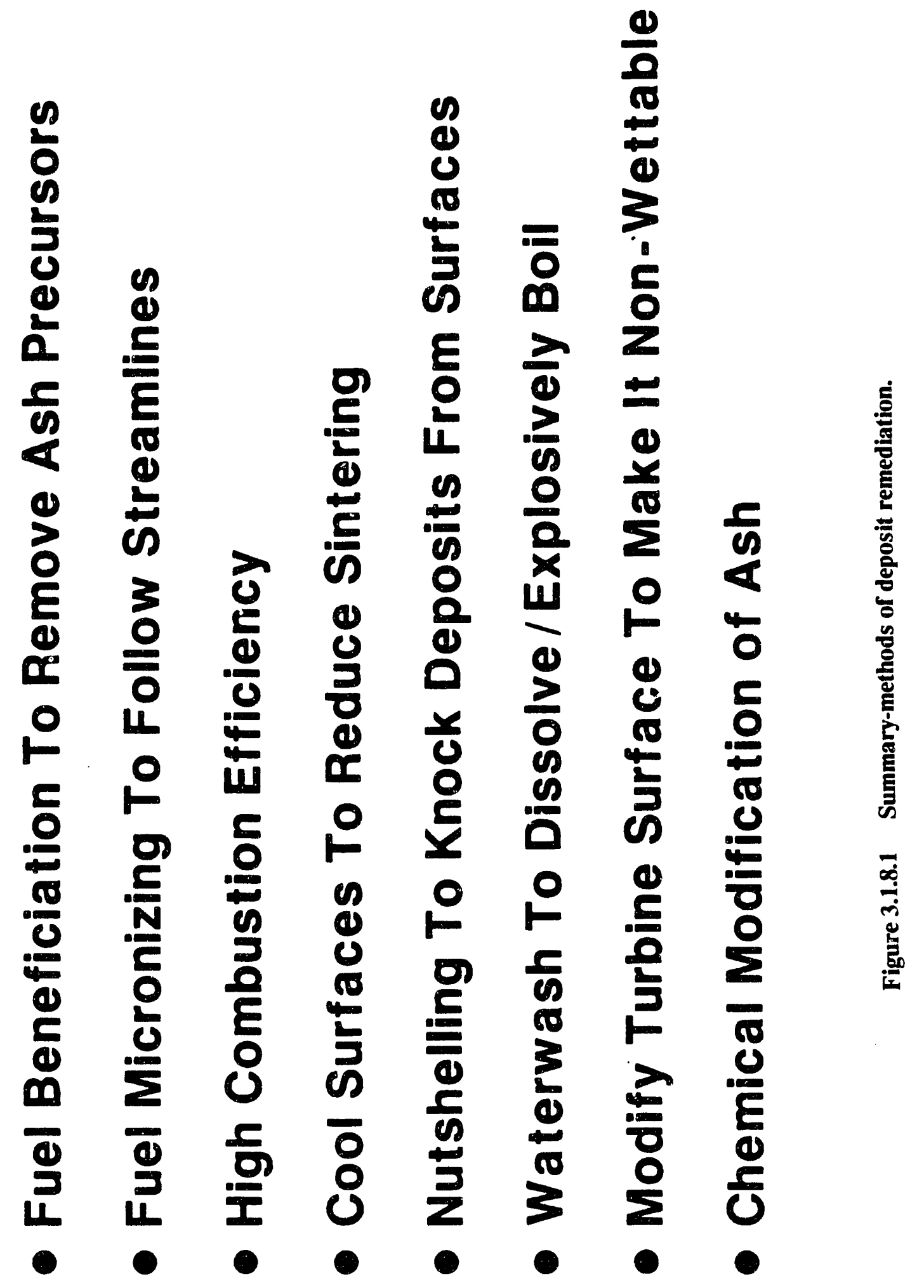




\section{ENVIRONMENTAL SUMMARY}

This report describes research performed in which, methods to control pollutant emissions from burning coal fuel in aero-derivative gas turbines were examined. The activities focused on evaluating new and innovative strategies for reducing $\mathrm{NO}_{2}, \mathrm{SO}_{2}$, and particulates within the turbine. Low-temperature exhaust cleanup technologies were not studied in depth due to their commercial status. However, these options were considered when selecting an effective and compatible emissions control package.

Calcium sorbent injected with the CWM fuel and injected alone in the combustor were investigated for sulfur capture. Results from tests in which sorbent was mixed with the fuel and injected in the LM500 turbine simulator show $60 \%$ sulfur capture at a $\mathrm{Ca} / \mathrm{S}$ (atomic ratio) of 1.5. Results from laboratory drop-tube experiments suggest that $60 \%$ sulfur removal can also be achieved with a slightly higher $\mathrm{Ca} / \mathrm{S}$ ratio if the sorbent is injected separately into the combustor. Unfortunately, deposition of sorbent on the turbine nozzle was extremely rapid, with flow area being reduced by by $10 \%$ within $40 \mathrm{~min}$. The use of additives or dolomitic sorbent did not substantially reduce the deposits. It was concluded that, while calcium-based sorbents can effectively reduce sulfur emissions in the combustor, an integral device for removal of ash and sorbent particulates is needed before this technology can be used.

$\mathrm{NO}_{x}$ levels in the CWM fueled turbine simulator exhaust ranged from 200 to $275 \mathrm{ppm}$, corresponding to 0.6 to $1.0 \mathrm{lb} /$ million $\mathrm{Btu}$. The $\mathrm{NO}_{\mathrm{x}}$ was found to come primarily from oxidation of fuel bound nitrogen. It is expected that axially staged combustion can reduce $\mathrm{NO}_{\mathbf{x}}$ to New Source Performance Standard (NSPS) levels.

A moving granular-bed filter concept was evaluated for the removal of particulates after the combustor and upstream of the turbine. Filtration efficiencies of greater than $99 \%$ were measured in a cold flow test facility using dry fly ash as the entrained particulate. Acceptable pressure drop was obtained. A bench-scale, high-temperature, high-pressure granular bed filter has been designed for possible testing. While preliminary investigations in concept design and process development indicate that the granular bed concept may be feasible, implementation of this technology in a coal-fueled gas turbine system will require considerable development, and the risk is very high. Therefore, further work was suspended.

Based on the results of this emizsions control research program, the recommended emission control system for a coal-fueled aeroderivative gas turbine is exhaust gas cleanup including spray-dry FGD system for sulfur control followed by a baghouse filter for the removal of particulates. Staged combustion should reduce $\mathrm{NO}_{\mathbf{x}}$ to acceptable levels. This emission system has favorable economics as well as a high probability of success. 


\subsection{Emissions Control}

\subsubsection{Program Definition}

\subsubsection{Objectives and Approaches}

The direct combustion of coal produces pollutant emissions due to ash, sulfur, and other contaminant species. The purpose of this program was to develop and evaluate strategies to control, at a minimum, $\mathrm{NO}_{2}$, and particulate emissions from coal-fueled gas turbine systems. Because emissions standards have not been established for coal-fired gas turbines for use in locomotives or stationary power generation systems, New Source Performance Standards (NSPS) for coal-fired boilers were used as guidelines. These include a sliding scale from 0.6 $\mathrm{lb} / \mathrm{MBtu}$ to $1.2 \mathrm{lb} / \mathrm{MBtu} \mathrm{SO}_{2}$ allowable emissions with 70 to $90 \% \mathrm{SO}_{2}$ removal, respectively.

As will be reported in this section, by allowing credit for precombustion sulfur removal through advanced beneficiation processing (i.e., Otisca conglomeration) with in situ sulfur capture, this standard can be achieved for a wide variety of high- and low-sulfur domestic coals.

Innovative devices and strategies evaluated in this program were technologies to reduce the pollutant by processes that occur within the gas turbine system. Exhaust gas cleanup systems were not technically evaluated due to their commercial status and minimal technical risk.

The approach used was to identify these control strategies and to perform laboratory tests where inadequate data were available in order to evaluate their capabilities. Included in the concepts explored in this program were injection of calcium-based sorbents in the turbine combustor for removal of gas-phase sulfur and granular bed filtration for removal of ash and injected sorbent between the combustor and turbine nozzle.

\subsubsection{Report Organization}

This document provides the assessment of the different emissions schemes tested. To effectively transmit the technical results the report was divided into 7 sections:

\subsubsection{Program Definition}

\subsubsection{Sulfur Control}

3.2.3. $\mathrm{NO}_{2}$ Control

3.2.4. Particulate Control Concepts

3.2.5. Economic Evaluation of Pollutant Control Systems

3.2.6. Summary and Conclusions

\subsubsection{References}

Description of selected emissions control concepts, testing, and evaluation are summarized in sections two, three, and four. Section five provides an economic evaluation of the selected pollutant control package. A summary and system recommendation are included in Section 6. 


\subsubsection{Sulfur Emissions Control}

\subsubsection{Emissions Control Alternatives}

Coal contains inorganic and organic sulfur compounds, which, if uncontrolled, will be emitted as $\mathrm{SO}_{2}$. Approaches for control of sulfur emissions include the following:

1. Desulfurization during coal cleaning

2. Control of sulfur emissions in the gas turbine hot gas path

3. Capture of sulfur in the exhaust gas using near-conventional methods

Physical coal cleaning processes such as the OTISCA-T [1] process will remove pyritic sulfur, but will leave behind virtually all of the organic sulfur, which can comprise 30 to $70 \%$ of the total sulfur. Developmental coal beneficiation processes such as microbial desulfurization and molten caustic leaching may also remove organic sulfur. However, it is felt that these processes have high economic and technical risk.

Flue gas cleaning (FGC) methods may be applied to the exhaust gas after cooling to less than about $400^{\circ} \mathrm{F}$ as would occur in systems in which exhaust gas heat recovery is performed. Since FGC methods will incorporate commercial or near-commercial technologies, no experimental investigations were performed on this concept.

The focus of the sulfur control technology development effort has been on sulfur capture in the combustor and hot gas path. Methods evaluated include mixing a calcium-based sorbent with the CWM fuel and injection of the sorbent into other regions of the combustor.

Lowering sulfur emissions by injection of calcium-based sorbents such as limestone, lime, and dolomite (the so called LIMB technology) into the combustion zone has been shown to be effective in coal-fired boilers [2]. Here, $\mathrm{SO}_{2}$ reacts with solid $\mathrm{CaO}$ to form calcium sulfate,

$\mathrm{CaO}+1 / 2 \mathrm{O}_{2}+\mathrm{SO}_{2} \rightarrow \mathrm{CaSO}_{4}$

Typically, at calcium to sulfur ratios of 2 to 3 , over $50 \%$ sulfur capture can be achieved.

However, this technology has been applied only to boilers, where residence times are greater than 1 second as compared with $30 \mathrm{~ms}$ or less for an in-line CWM gas turbine combustor. Additionally, the environment within the combustor is extremely severe, with temperatures greatly exceeding those which are thermodynamically favorable for sulfur capture. Temperatures also exceed that at which sorbent sintering will occur, which may result in reduced sorption capacity. It is possible, however, that the delay in temperature rise of the sorbent due to the presence of water, coupled with the short residence time in the combustor and the rapid quenching of the hot gas, will enable effective sulfur capture. 
Another major issue with sorbent injection into the hot gas path is that of increasing particle loading into the turbine. For a coal containing $1 \%$ sulfur and $1 \%$ ash, at a $\mathrm{Ca} / \mathrm{S}$ of 1.5 the effective ash loading would be increased approximately fourfold. This may result in increased deposition.

\subsubsection{Premixed CWM/Calcium Sorbents}

3.2.2.21 Description of Experimental Methods and Equipment.. Calcium-based sorbents were combined with the fuel and injected and burned in the LM500 turbine simulator [3]. In addition to sulfur capture effectiveness, deposition on the first stage nozzle vanes was evaluated.

The LM500 turbine simulator (Figure 3.2.2.1) consists of a modified J-79 aircraft engine type can combustor, a $45^{\circ}$ sector of the LM500 first-stage nozzle, and a connecting transition piece. The fuel is injected through a dual fuel, air atomized fuel nozzle of GE design. The turbine simulator produces a time, temperature, and pressure environment representative of that found in actual gas turbines. An on-line TMGR [4] data acquisition and analysis system is used to monitor pressures, temperatures, flows, and parameters important to the gas and particulate sample trains. In addition, real-time calculations are performed, which enable rapid analysis of operating conditions such as combustion efficiency and nozzle area index number (NAIN), which is a measure of blockage of the turbine nozzle throat due to deposition.

Samples for $\mathrm{SO}_{2}$ analysis were drawn through a probe, a heated sample line, and a permeation dryer, before entering a Beckman IR $\mathrm{SO}_{2}$ analyzer. Other combustion gases which were monitored continuously include $\mathrm{NO}_{\mathrm{x}}, \mathrm{CO}, \mathrm{CO}_{2}, \mathrm{O}_{2}$, and unburned hydrocarbons.

Particulates in the combustor exhaust were extracted using a near-isokinetic gas-quenched probe, in which the sample was rapidly cooled by mixing nitrogen with the extracted particleladen gas stream near the probe entrance. The particles were then transported through a heated line and collected on a porous stainless steel filter rated $-* 99.99 \%$ retention for particles greater than $0.1 \mu \mathrm{m}$.

Initial sulfur capture experiments were performed with sulfur-doped oil in order to minimize combustion and rheology issues associated with calcium-doped CWM, and to eliminate the possible effects of ash on sulfur capture chemistry. The system for mixing calcium sorbents with fuel oil and transporting the mixture to the combustor is shown in Figure 3.2.2.2. No. 2 fuel oil was doped with a specific quantity of carbon disulfide, $\mathrm{CS}_{2}$, in order to simulate the sulfur present in the CWM fuel. The $C_{2}$ was introduced prior to the gear pump which transports the mixture to the nozzle. Before calcium slurry was added, the flow rate of doped fuel oil was measured by a rotameter and turbine flow meter. A positive displacement diaphragm pump was used to inject the calcium slurry into the stream of doped fuel oil. The resultant stream entered a mixing loop containing a gear pump, in which $10 \%$ of the flow within the 


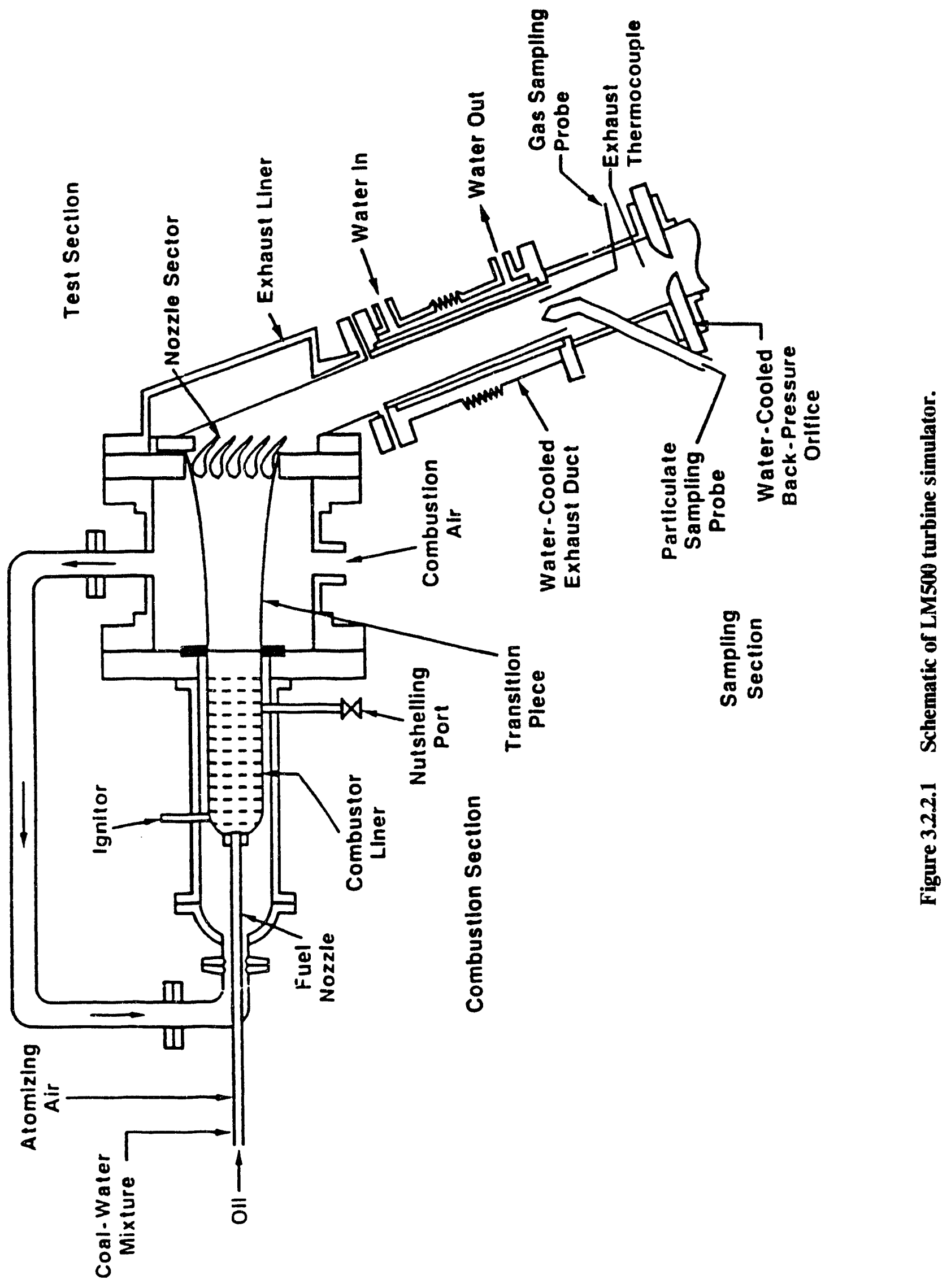




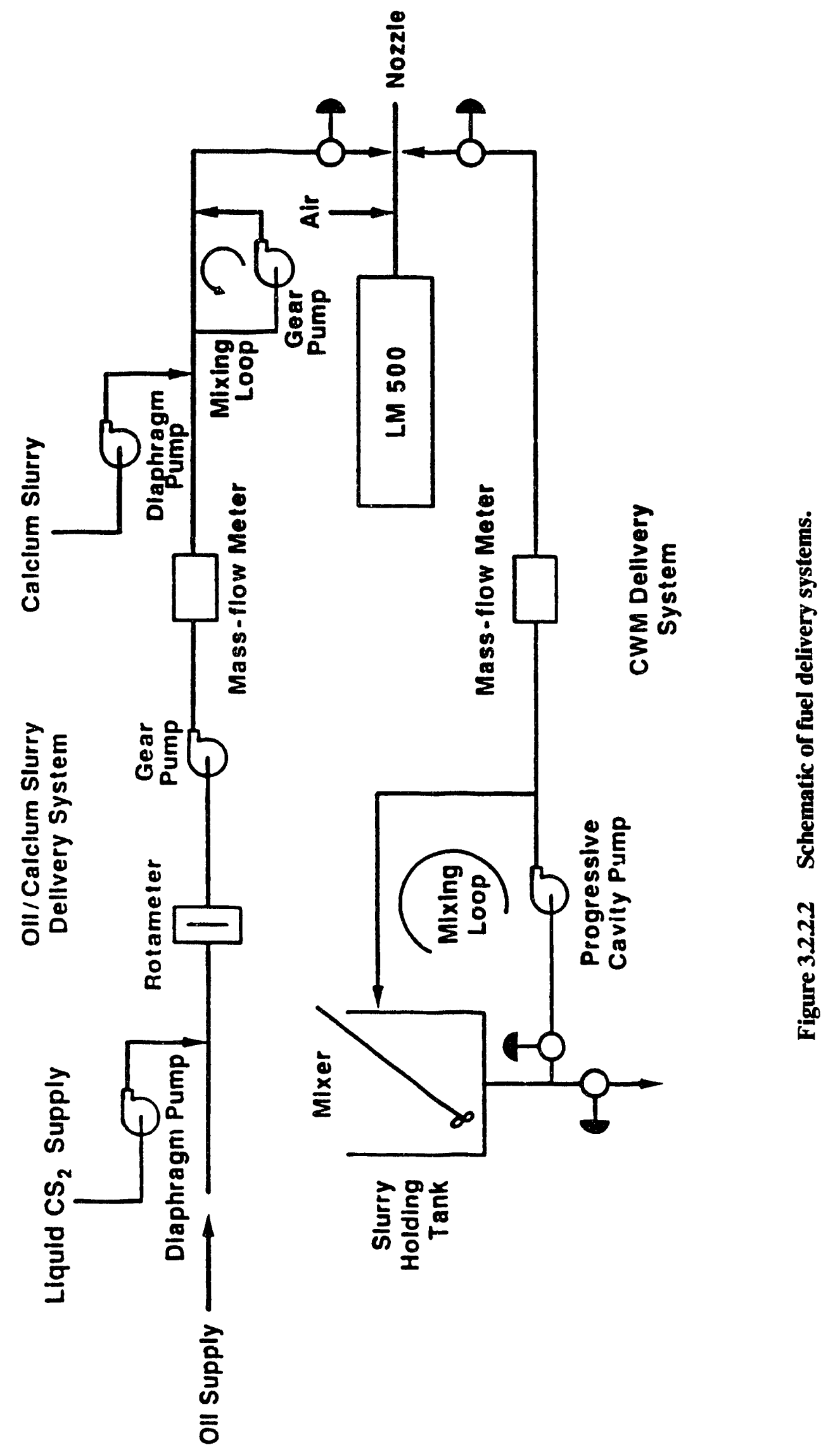


mixing loop was transported to the fuel nozzle.

Sorbent-doped CWM fuels were prepared off-line by mixing the sorbent and surfactants with the CWM in 55-gallon drums. The CWM was then pumped in to a 200-gallon, stirred holding tank from which it was pumped to the test rig. A Moyno progressive cavity pump pressurizes, agitates, and delivers the slurry to the fuel nozzle. The flow of the modified CWM was controlled with a Parajust motor-speed controller, and the flow monitored with a MicroMotion mass flowmeter.

Nominal operating conditions for all sorbent evaluation tests in the turbine simulator are shown in Table 3.2.2.1.

The turbine simulator is typically operated as follows. Combustion is initiated at a lowfiring temperature using distillate oil. As the desired operating conditions are approached, flow of CWM is initiated. The CWM flow rate increased and the distillate oil flow is decreased, while adjusting the combustion and atomizing air flows until the desired CWM to oil ratio, pressure, and firing temperature are obtained.

The CWM fuel used for all tests was supplied by OTISCA Industries. Properties of the CWM are given in Table 3.2.2.2. This fuel, which was prepared by micronization and physical separation of ash by selective agglomeration was selected based on its availability and likelihood that it would be most representative of future gas turbine fuels.

Calcium-based sorbents used in this program were selected based on overall reactivity evaluations as determined in a number of research programs [5]. A sub-micron precipitated $\mathrm{CaCO}_{3}$, a relatively pure calcitic hydrate and a pressure dolomitic hydrate were selected for this study. The precipitated carbonate is reactive toward $\mathrm{SO}_{2}$ capture due to its relatively small particle size of $0.7 \mu \mathrm{m}$. The calcium hydroxide (Linwood) has a mean particle size of $2.2 \mu \mathrm{m}$ and a large number of macro-pores distributed within the particles. $\mathrm{SO}_{2}$ easily diffuses into this particle's interior. The pressure hydrated dolomite (Genstar), like the calcium hydrate, consists of small particles with an open pore structure. In addition, the dolomitic hydrate contains $\mathrm{MgO}(\mathrm{Ca} / \mathrm{Mg}$ atomic ratio of 1$)$ which reduces pore and site blockage. A brief summary of the sorbent properties is provided in Table 3.2.2.3.

\subsubsection{Sulfur Capture-Turbine Simulator Experiments.. Initially, distillate oil, which} was doped with sulfur, was used as the fuel so as to eliminate mineral ash inter? rence which may lead to the reduction of available calcium for reaction with sulfur. Differences in reactivity between the limestone, calcitic and dolomitic hydrates were to be determined to enable selection of sorbents for testing with CWM fuel. In order to prepare sorbent/fuel oil mixtures it was necessary to identify appropriate surfactants and their required quantities to enable the preparation of a semi-stable fuel oil/sorbent/water emulsion. Lomar-D (a sulfonated napthalene condensate) was found to be effective for calcium hydroxide and Trition X-114 (a po- 
Table 3.2.2.1

Nominal Turbine Simulator Operating Conditions

$\begin{array}{lc}\text { Fressure } & 10 \mathrm{~atm} . \\ \begin{array}{c}\text { Comtustor Exit } \\ \text { Temperature }\end{array} & 2000 \mathrm{~F} \\ \text { Air Freheat Temp } & 760 \mathrm{~F} \\ \text { Auniliary Fuel 0il } & 0.10 \\ \text { Etu Fraction } & \end{array}$

Table 3.222

OTISCA Coal-water Mhture Properties

Ash, percent

0.76-0.87

solids, percent

49.6-50.4

Volatiles, percent dry

$38.0-39.0$

Sulfur, percent dry

0.71-0.89

Particle size, $\mu \mathrm{m}$

4.0 mean

$95 \%<15$

Table 32.2 .3

Sorbent Properties

Analysis

Linwwood

Genstar

Calciun Hydrate

Pressure hydrated

Dolomite

Chemical Form

$\mathrm{Ca}(\mathrm{OH})_{2}$

$\underset{(x=1, y=1)}{\mathrm{Ca}_{x} \mathrm{Mg}_{\mathrm{g}}(\mathrm{OH})_{4}}$

BET SA

16.0

20.0

$\left(m^{2} / g\right)$

Density
$\left(\mathrm{g} / \mathrm{cm}^{3}\right)$

2.3

2.3

Mediun size

2.2

1.4

$(\mu \mathrm{m})$ 
lyoxyethene phenol) for calcium carbonate.

Sulfur capture results for the oil/water/sorbent mixtures are provided in Figure 3.2.2.3. The results indicate a significant reduction in gas-phase sulfur with the addition of calciumbased sorbents. The sulfur reduction at $\mathrm{Ca} / \mathrm{S}=1$ was $\sim 10 \%$ for the carbonate, while the hydrate removed $\sim 30 \%$. Sulfur capture appeared to increase with time, especially in the case of the carbonate sorbent. This was attributed to additional sulfur capture on sorbent material which had deposited in the hot gas path.

These results were somewhat unexpected when considering the short time for reaction $(\sim 20 \mathrm{~ms})$ and the severe thermal environment present in the turbine simulator. Solid samples that were collected on the particulate filter and analyzed for sulfur contained only calcium sulfate and calcium oxide for both carbonate and hydrate sorbents. This indicates that complete calcining of the calcium carbonate takes place, and that sulfur capture within the sampling system did not occur.

Upon inspection after completion of the sulfur capture test it was noted that severe deposition had occurred after only 1 to $2 \mathrm{hr}$ of operation (Figure 3.2.2.4). These deposits showed evidence of melting and sintering, but were removed with relative ease. However, it was clear that deposition would be an issue for CWM/sorbent mixtures.

It was not surprising that the calcium hydroxide was more effective than calcium carbonate. Calcium carbonate must first be calcined to $\mathrm{CaO}$ before reacting with $\mathrm{SO}_{2}$, thus decreasing its reactivity at short residence times. Calcium hydroxide slurries contain significant dissolved calcium species, thereby improving distribution of reactive sorbent throughout the $\mathrm{CWM}$ /sorbent mixture. The Linwood calcium oxide sorbent also contains a pore structure which maintains good accessibility to sorption sites during reaction. Unfortunately, calcium hydroxide was found to seriously degrade the rheological properties of the CWM, whereas calcium carbonate was found to be relatively benign. A non-ionic dispersant was identified, which stablizes the mixture and provides similar rheological properties to undoped CWM. Measured viscosity and atomization parameters (i.e., drop-size and distribution, and spray pattern) showed no significant differences between the CWM and the fuel with calcium hydrate.

CWM doped with Linwood $\mathrm{Ca}(\mathrm{OH})_{2}$ was tested in the turbine simulator. At an atomic ratio of $\mathrm{Ca}$ to $\mathrm{S}$ of 1.5 , the $\mathrm{SO}_{2}$ content of the exhaust gas stream was reduced from 150 to $60 \mathrm{ppm}$ indicating a $60 \%$ sulfur reduction as shown in Figure 3.2.2.5. The high degree of sulfur capture results from the intimate contact of the sorbent with the coal, enabling sulfur capture to occur as it is emitted from the devolatilizing and burning coal. Although local temperatures in the high-temperature regions of the combustor are not favorable for sulfur capture, effective sulfur capture is achieved because the sorbent is maintained at a relatively low temperature due to thermal delays in solids heating. This effect has also been reported by 

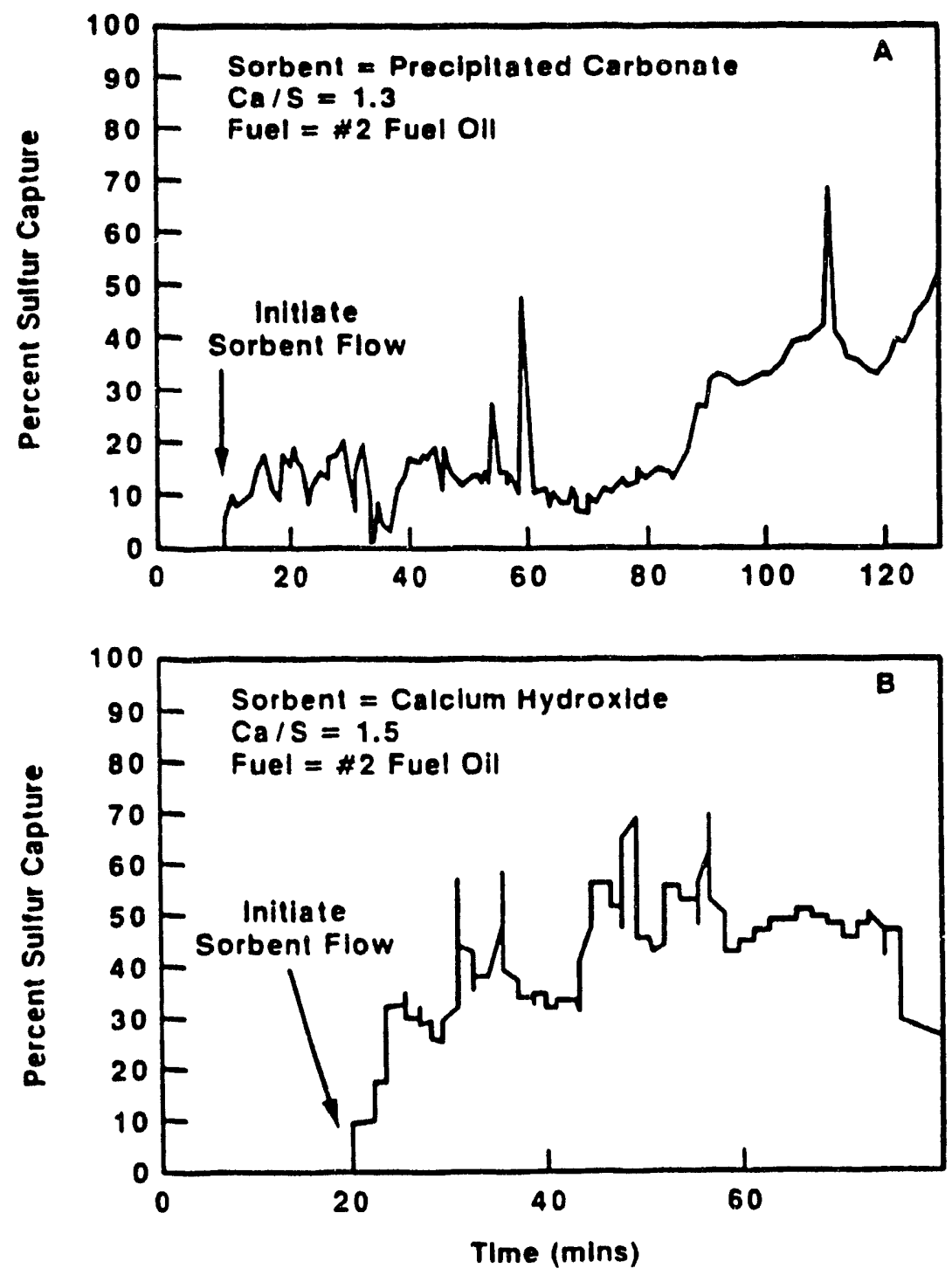

Figure 3.2.2.3 Sulfur capture. (a) Oil doped with calcium carbonate. (b) Oil doped with calcium oxide. 


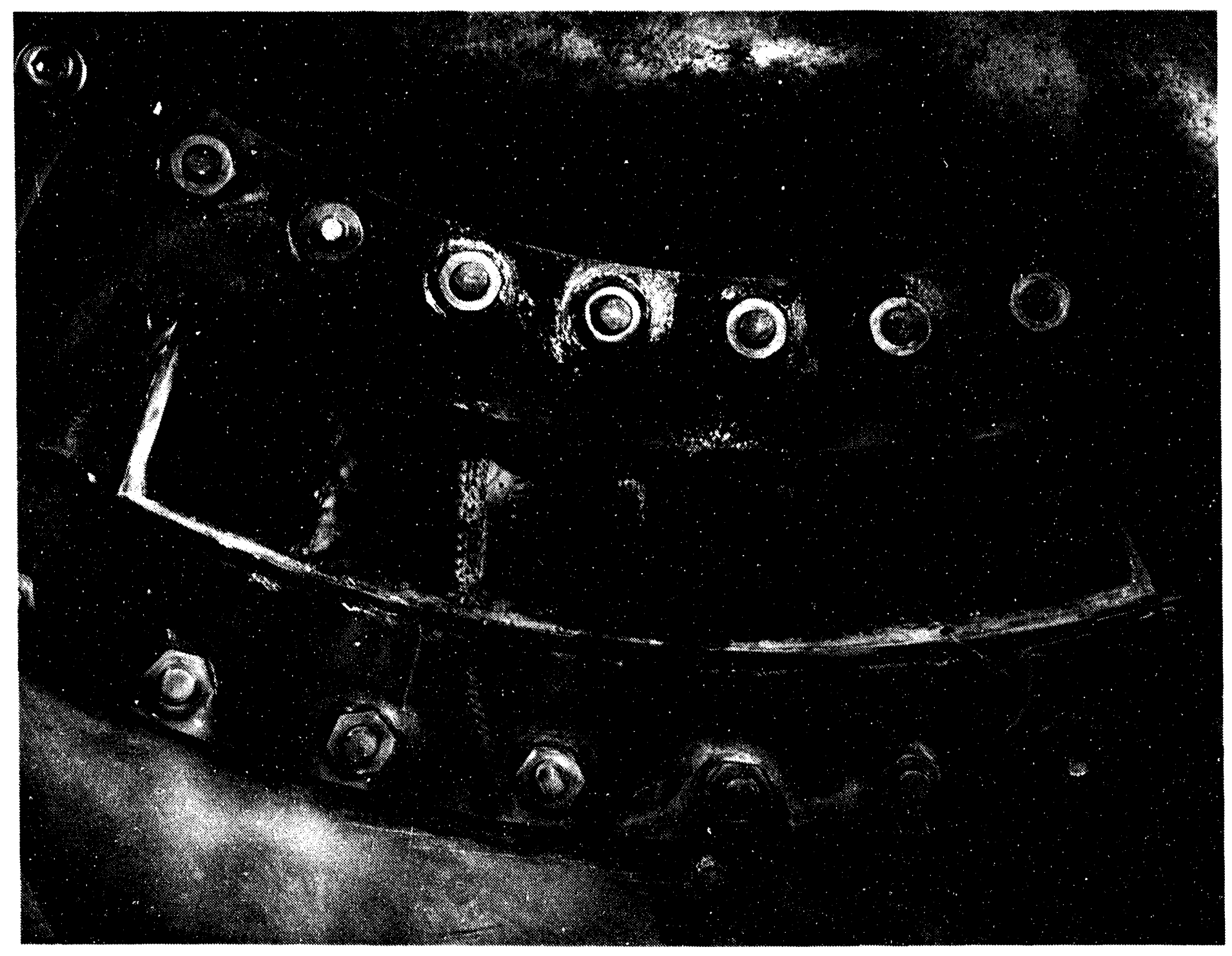

Figure 3.2.4 Photograph of nozzle cascade after oil/CaO test. 


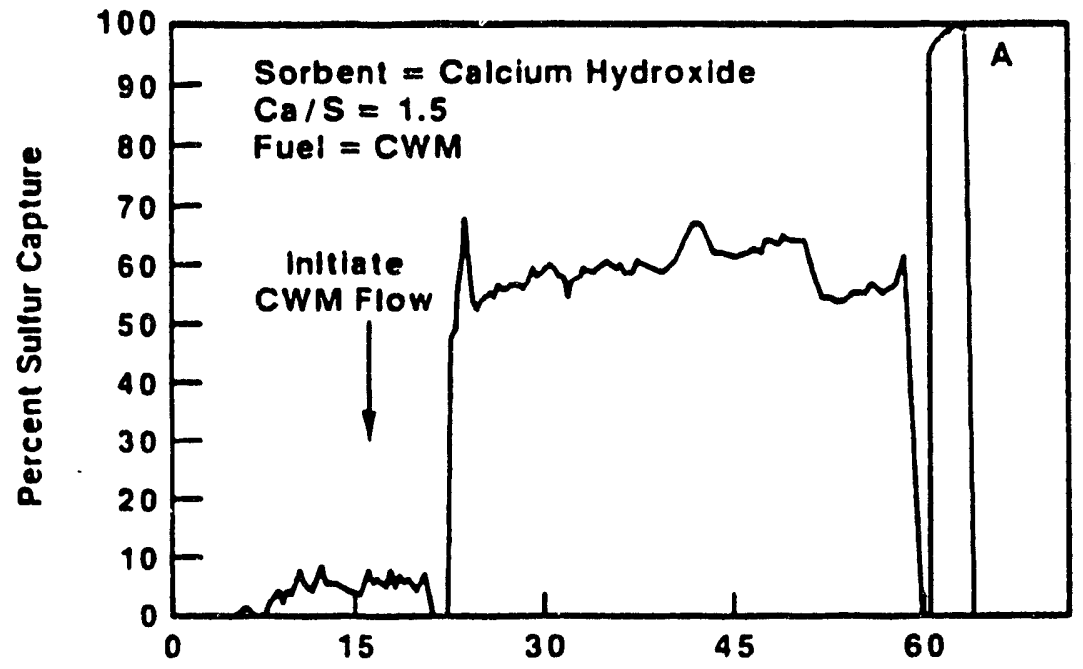

Figure 3.2.2. Sulfur capture for CaO sorbent-doped CWM. 
Abuchandani [6].

It is felt that the initial stage of sorption is relatively fast. Reaction then slows due to sulfate formation on the grain b_undary of the calcium particle. The micropores u'ithin the grain structure are susceptible to thermal sinterir !. The result is the loss of pore volume of the grain. The mezo- and macro-pores (volume between the grains) increase, thus maintaining or increasing the overall pore volume. By maintaining relatively accessible calcium-oxide sites for sulfur absorption, calcium utilization of greater than $40 \%$ was obtained.

During combustion of sorbent-doped CWM, the turbine nozzle cascade area was reduced by approximately $10 \%$ in $40 \mathrm{~min}$ (Figure 3.2.2.6). This can be compared with a reduction of $4 \%$ in ? $4 \mathrm{~h}$ - for undoped CWM [7]. Upon inspection of the turbine simulator after disassembly, large quantities of deposit were found on the combustor wall, the transition piece, and the turbine nozzle cascade. It should be noted that combustor and transition piece deposits are minimal for undoped CWM fuel. A photograph of the cascade shows an $\sim 2$-mill deposit of sorbent and ash which formed during the $40 \mathrm{~min}$ (Figure 3.2.2.7).

The extremely high deposition rate for sorbent-doped CWM could not be attribuied to increased mass of ash alone. Clearly, the calcium interacted with the ash in a manner detrimental to deposition. The morphology of the deposit formed on the cascade was examined with a scanning electron microscope (SEM). SEM micrographs are shown in Figure 3.2.2.8a and b. In general, the deposits contained an extensive macropore structure which was present throughout the deposit. A closer examination of the deposit indicates that particle agglomerates have fused at the particle-particle interfaces. It is this process of reaction and densification of the deposited ash with calcium sorbent which is believed to be responsible for the formation of these tenacious deposits. Diffractograms of the deposits support this conclusion; here, the results show the presence of calcium alumino silicates, calcium iron oxides, and a significant amorphous component.

Research in pulverized coal combustion indicates a sorbent containing $\mathrm{MgO}$ can alter the properties of the deposit [8]. Deposits containing $\mathrm{MgO}$ tend to be more friable and easily removed from boiler tubes. Dolomitic sorbents also tend to better utilize reactive calcium sites because the magnesium oxide helps to maintain sorbent ${ }_{1}$ orosity. The friability of the deposit is believed to be due to the relative difference in the sintering rates of $\mathrm{CaO}$ and $\mathrm{MgO}$ and chemical reactivity of the ash with $\mathrm{MgO}, \mathrm{CaO}$, and $\mathrm{CaSO}_{4}$.

A dolomitic hydrate (Genstar) was used to determine if deposition could be reduced relative to the calcitic hydrate, and to produce deposits that can be readily removed via controlled spalling and nut-shelling techniques. The $1 \mu \mathrm{m}$ sorbent particles contain $\mathrm{Mg}(\mathrm{OH})_{2}$, at $\mathrm{Ca} / \mathrm{Mg}$ atomic ratio of $1 . \mathrm{MgO}$ and $\mathrm{CaO}$ are distributed in patches within the sorbent particle. $\mathrm{MgO}$ does not sulfate under the thermal conditions found in the combustor. However, its presence reduces pore plugging and site blockage of the sorbent particle, thereby increasing calcium 


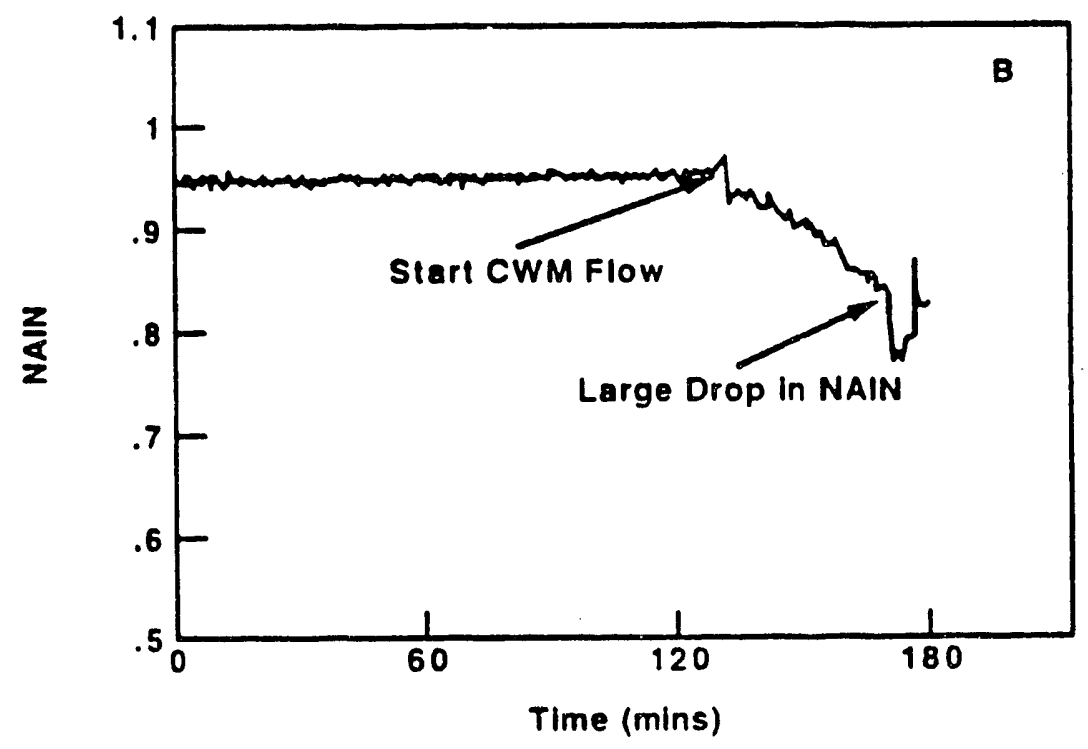

Figure 3.2.2.6 Deposition rate for $\mathrm{CaO}$ sorbent-doped CWM. 


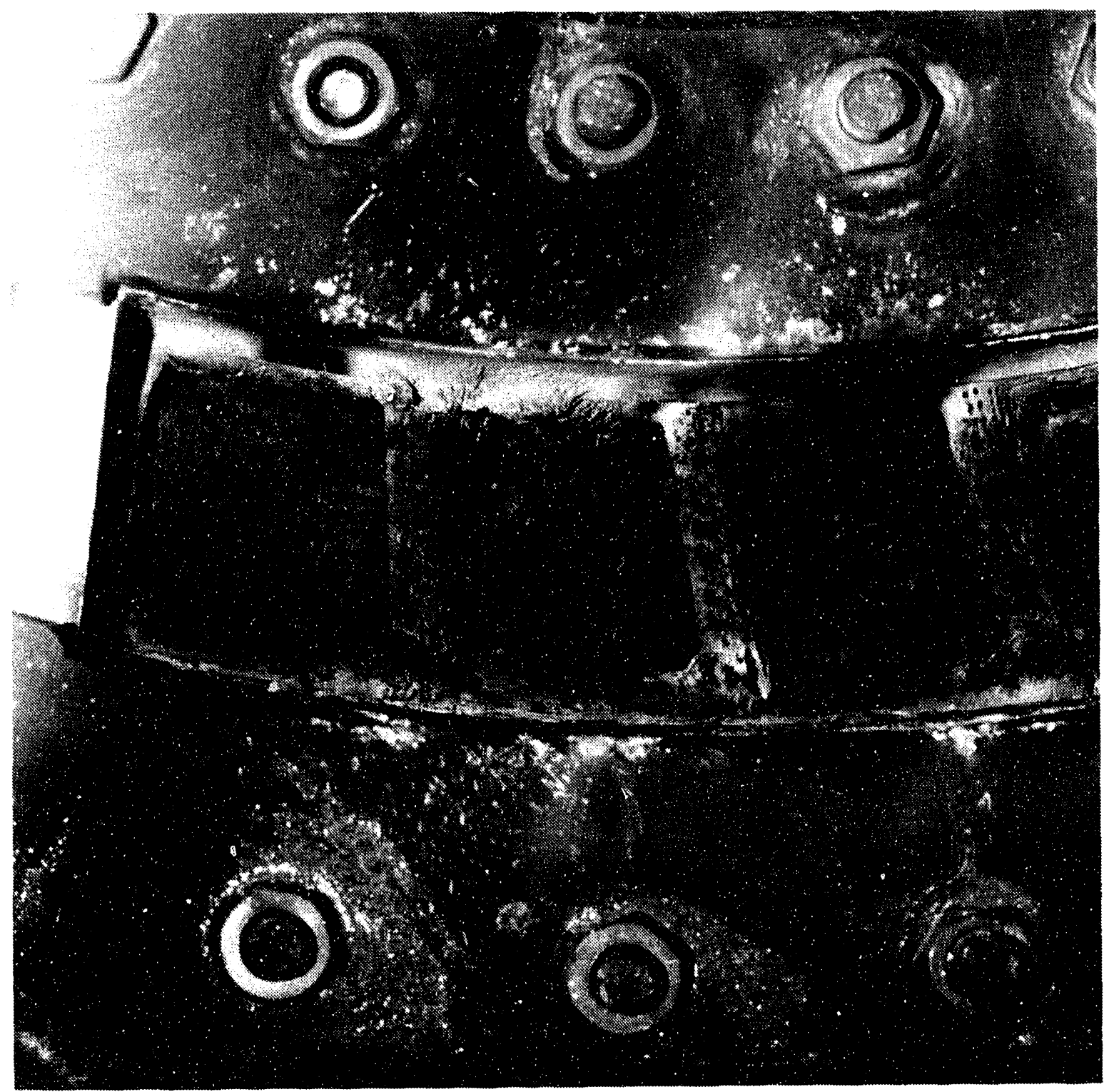

Figure 3.2.2.7 Photograph of nozzle cascade after CWM-calcium hydrate test. 


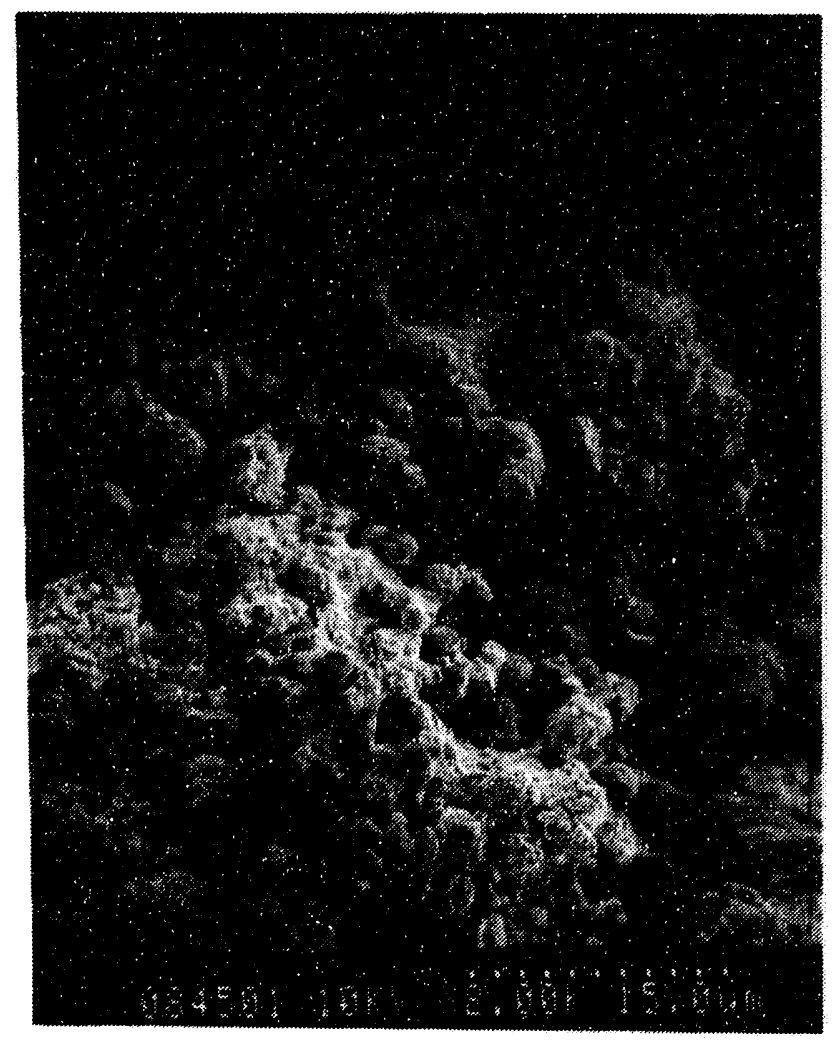

(a)

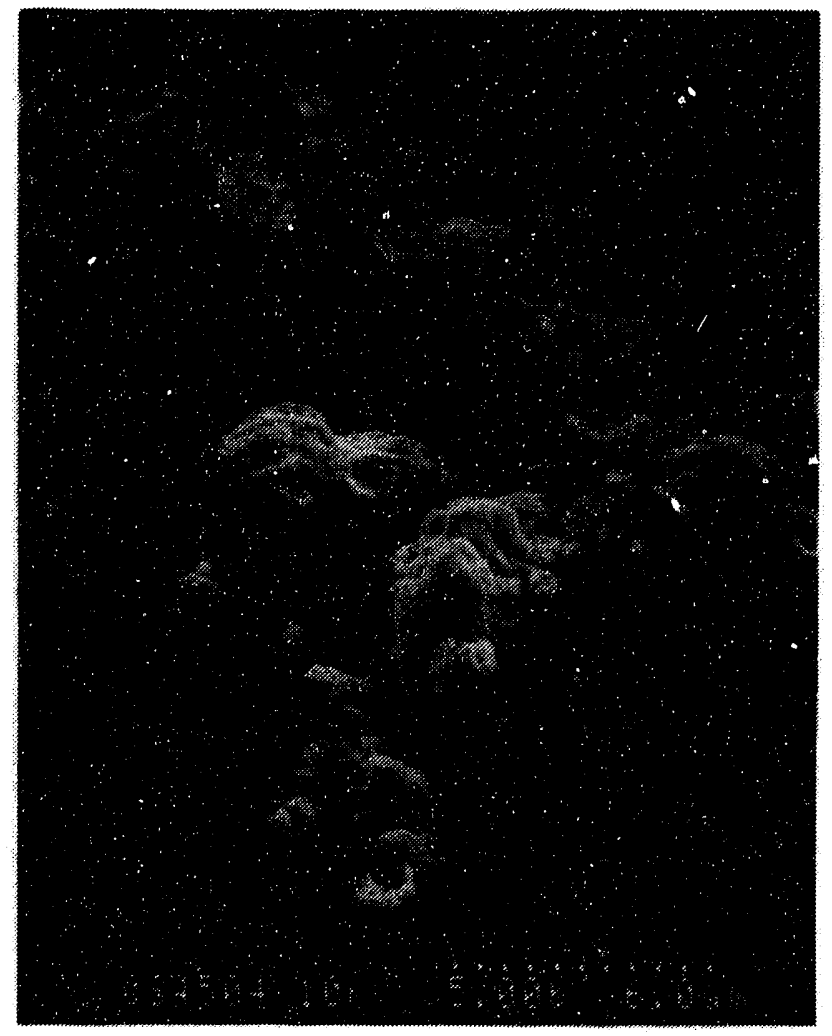

(b)

Figure 32.2.8 Photomicrographs of pressure side deposit from CWM-calcium hydrate test. 
availability for sulfation.

Dolomitic hydrate was added to the CWM along with the non-ionic dispersant. $\mathrm{A} \mathrm{Ca} / \mathrm{S}$ ratio of 0.85 was used to maintain the total sorbent mass loading the same as that used for the CWM containing calcium hydrate. Sulfur capture and deposition rate for dolomitic hydrate are shown in Figure 3.2.2.9a and $\mathrm{b}$. Calcium utilization was similar to that for calcium hydroxide. The deposition rate was somewhat lower than for the calcitic sorbent. In this case, the normalized NAIN decreased $5 \%$ in about $40 \mathrm{~min}$, which is a $50 \%$ improvement over the calcium hydroxide sorbent, but is still unacceptably high. Inspection of the turbine simulator showed a relatively clean combustor with less deposition in the transition piece and nozzle cascade.

Photomicrographs of the deposit formed when dolomtic sorbent was injected with the CWM are provided in Figure 3.2.2.10a and b. Examination of particle and agglomerates provide a sharp contrast to particles from the $\mathrm{Ca}$ /ash formed deposit. In general, particlates in this deposit have not extensively sintered together. It is believed that the presence of $\mathrm{MgO}$ which is less likely to react with the ash to form magnesium silicates inhibits the coalescing of $\mathrm{CaO}$. Comparing the morphologies of deposits, the deposit formed in the presence of $\mathrm{MgO}$ is more friable and suggests that nut-shelling would be effective in its removal.

Recent ash deposition studies performed in our laboratory have determined that alumonosilicate additives such as kaolin added to the CWM results in a significant reduction of deposits on the cascade [9]. Kaolin chemically reacts with mineral ash to form a friable deposit which spontaneously spalls or erodes. This approach was tested for sorbent-doped OTISCA fuel. The CWM was doped with calcium hydrate $(\mathrm{Ca} / \mathrm{S}=1.5)$ and $0.4 \%$ kaolin. The amount of kaolin added was approximately the same as that used for previous testing of undopedCWM fuels. The effectiveness of this approach requires three conditions. First, calcia, alumina, and silica are the major reactive species. This is a good assumption based on previous analyses on turbine nozzle cascade deposits, which shows the only other major constituent, iron oxide, remained unreacted as hematite [10]. Second, the deposition rates for these species were similar. Third, once deposited, a pseudo-equilibrium exists between these oxides.

Sulfur removal was found to be very good. Approximately $30 \%$ sulfur was removed at a $\mathrm{Ca} / \mathrm{S}$ ratio of 0.85 . This is comparable to that which was obtained for calcium hydrate-doped $\mathrm{CWM}$ at $\mathrm{Ca} / \mathrm{S}=1.5$ and without kaolin. However, the deposition rate was not improved. Figure 3.2.2.11 shows loss of flow area for the koalin $/ \mathrm{Ca}(\mathrm{OH})_{2}$-doped test. A decrease of $10 \%$ in the nozzle throat area was obtained in $40 \mathrm{~min}$. In contrast, the deposits were substantially different from those for the calcium-doped CWM without kaolin. There was less material on the cascade (see Figure 3.2.2.12). However, it was relatively difficult to remove, indicating increased ash fusion. X-ray diffraction analyses on the extracted deposits indicated the 

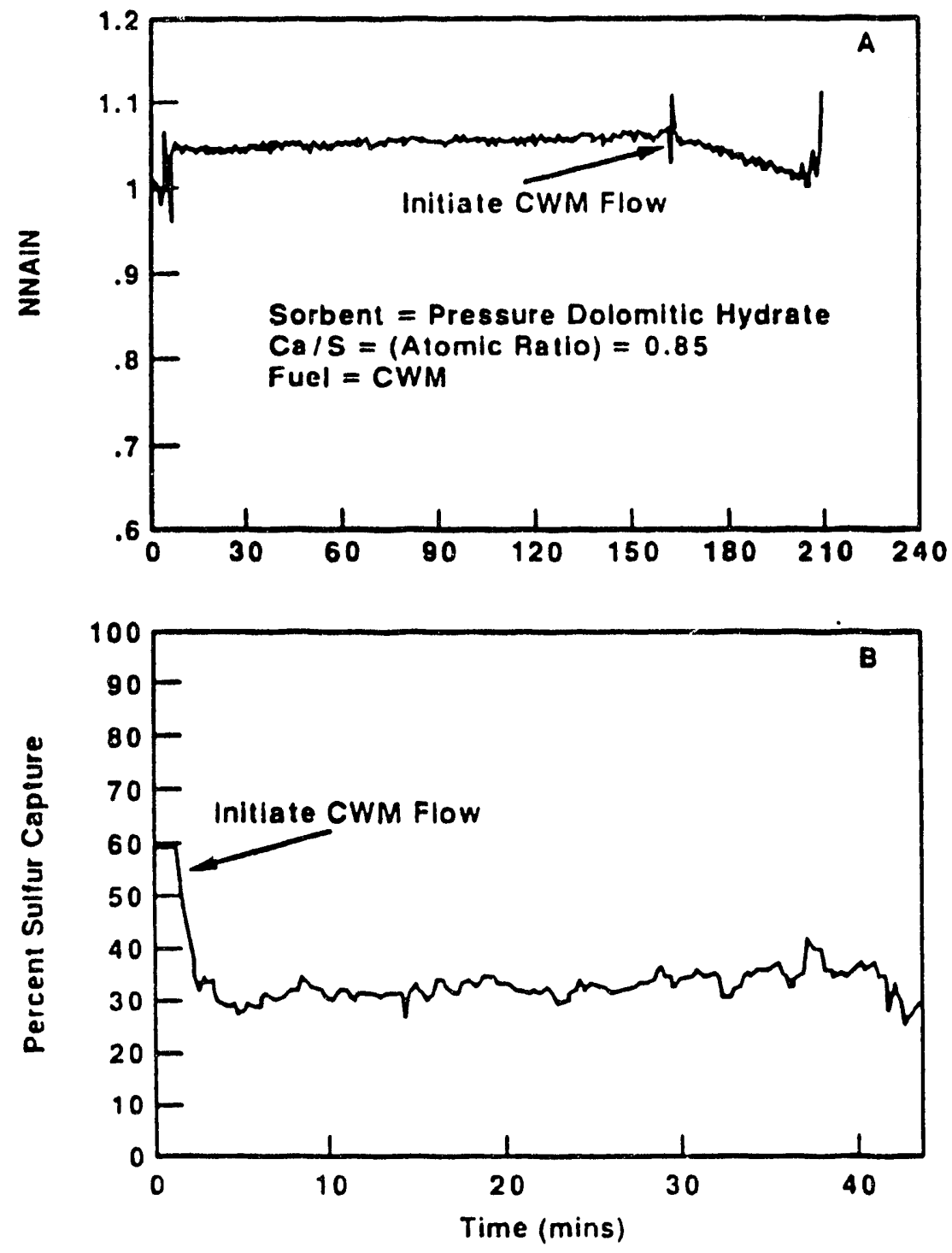

Figure 3.2.2.9 Sulfur capture for dolomitic hydrate-doped CWM. 

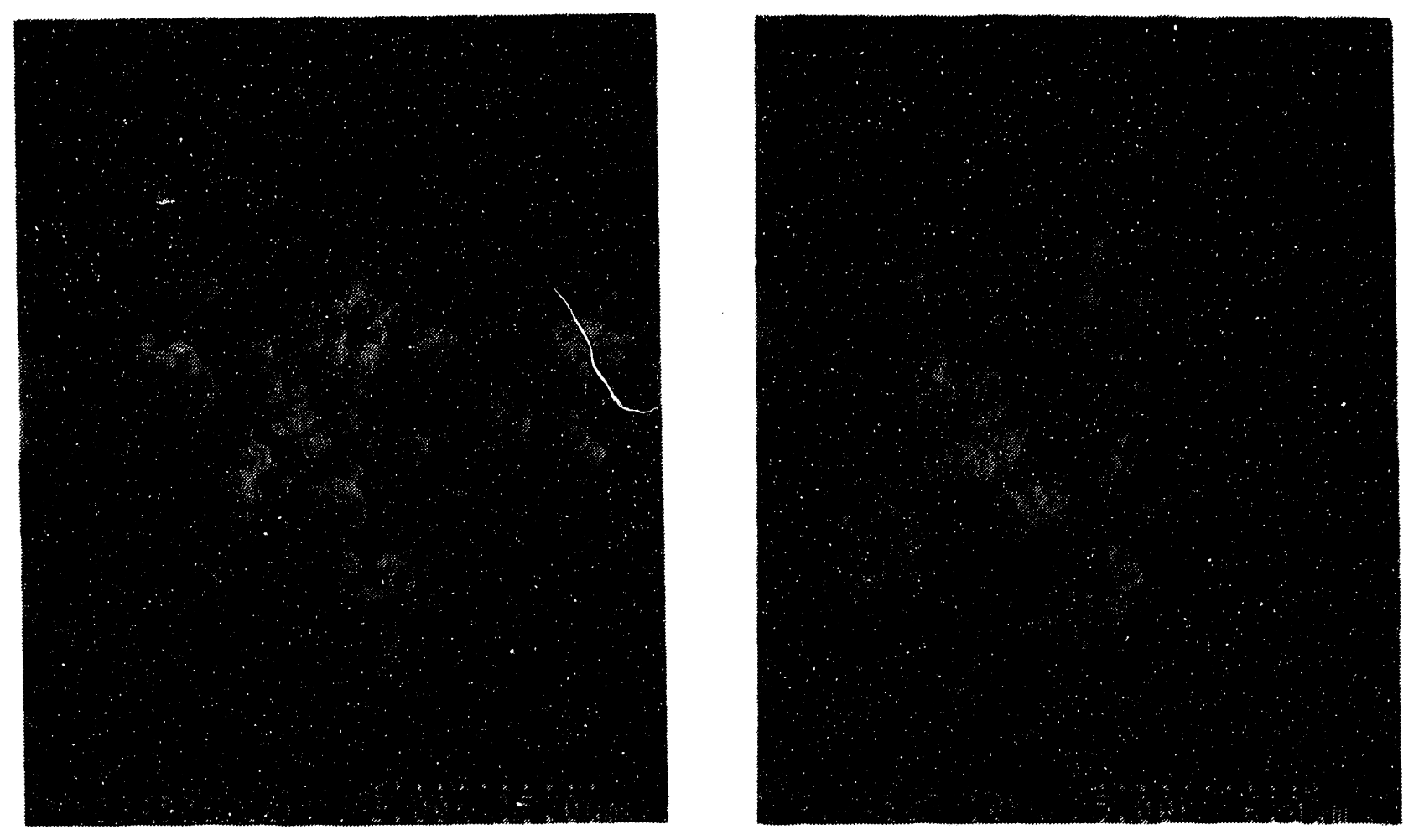

Figure 3.2.2.10 SEM micrographs of cascade deposit extracted from the pressure side: dolomitic deposit. 


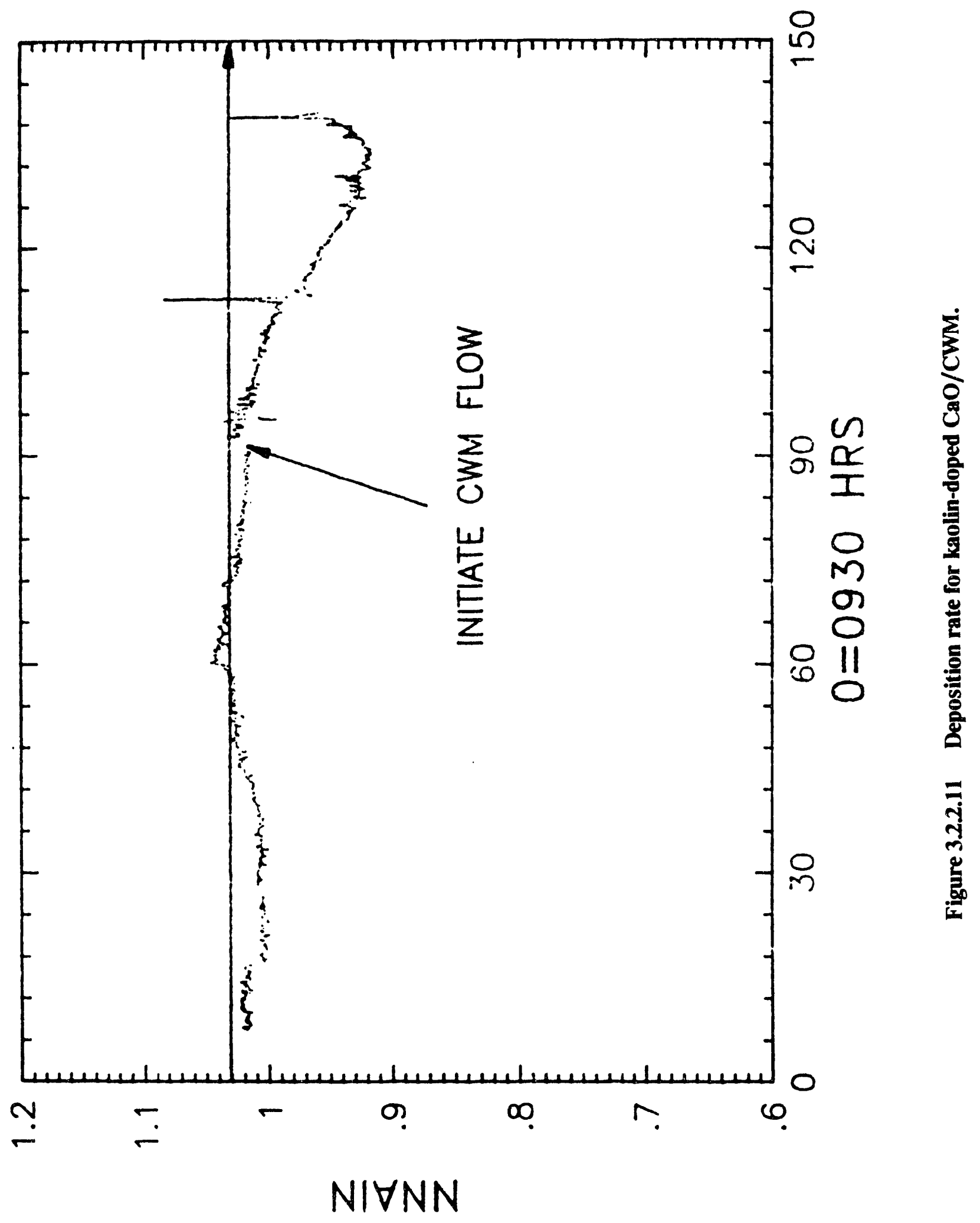




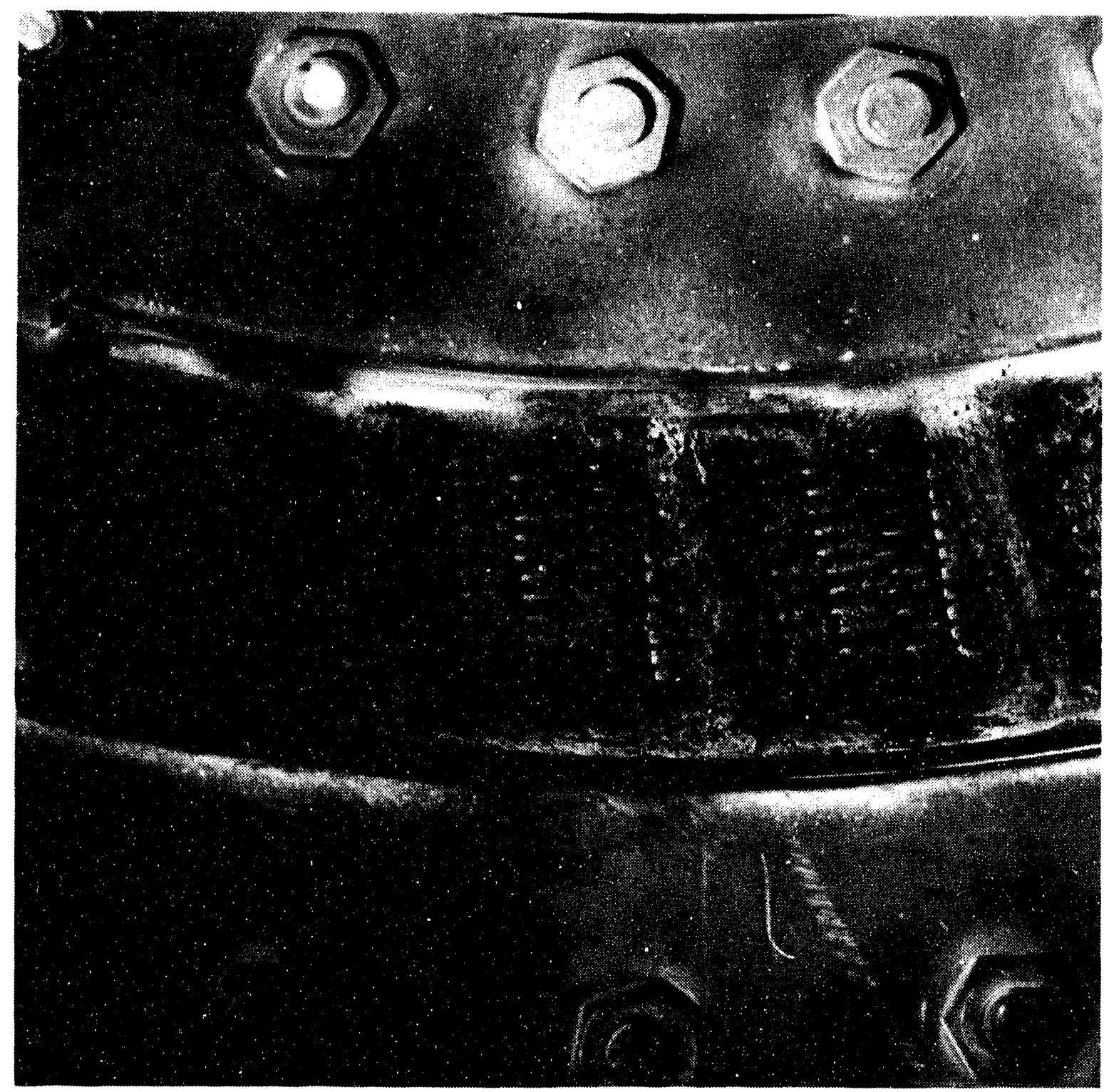

Figure 3.2.2.12 Photograph of nozzle cascade after kaolin-doped $\mathrm{CaO} / \mathrm{CWM}$ test. 
presence of a number of different calcium-silicates.

From these results it has been concluded that although effective sulfur capture can be obtained by mixing a calcium-based sorbent with the CWM fuel, deposition is excessive. Clearly, unless an in-line particulate removal device located between the combustor and the turbine can be developed, this sulfur capture approach is impractical.

\subsubsection{Laboratory Studies of Calcium Sorbent Performance}

Fundamental sulfation kinetic data were obtained for the purpose of evaluating sorbent injection and for inclusion into a sulfation model to predict sulfur removal under a variety of conditions. These results include sulfur capture for an atmospheric calcium hydrate and a pressure dolomitic hydrate as a function of residence time, temperature, and $\mathrm{SO}_{2}$ concentration.

3.223.1 Drop-Tube Furnace Description. Fundamental kinetic data for $\mathrm{SO}_{2}$ absorption for calcium-based sorbents were obtained in the Physical Sciences Technology Company (PSIT) laboratory using a drop tube furnace. Two configurations of the drop tube furnace were used. The straight tube configuration, shown in Figure 3.2.2.13 was used for longer residence time ( 280 to $500 \mathrm{msec}$ ) experiments, while the venturi configuration (Figure 3.2.2.14) was used for residence times in the range of 20 to $60 \mathrm{msec}$.

The straight tube entrained flow reactor is designed to produce well characterized laminar flow conditions, and to simulate the post-flame gases of combustion systems. The reactor is housed in a 3-zone electrically heated furnace to enable the use of any desired temperature profile up to $2372^{\circ} \mathrm{F}\left(1300^{\circ} \mathrm{C}\right)$. The water-cooled sorbent injector can be translated axially to vary residence time of the injected particles. The particle laden gases flow through a 3 to $3 / 8$ in. alumina tube 63 in. long. The collection probe includes radial injection of nitrogen to quench gas-solid reactions. The combustion environment is provided by methane combustion, with $\mathrm{SO}_{2}$ added to the combustion gas.

For short residence time experiments a venturi was inserted into the entrained flow reactor to promote rapid gas/solid mixing. A water-cooled sorbent injector was placed so that sorbent was injected near the venturi throat. The post-reaction sample was then collected using a phase discrimination probe, shown schematically in Figure 3.2.2.15), which was moved axially to vary residence time. In the phase discrimination probe, the solids are effectively separated from the gas stream by forcing the gases to make a $360^{\circ}$-turn before they flow to the analysis equipment. The probe is water jacketed to achieve rapid cooling and quenching of the gas sample. It was determined in later experiments that the reactor incorporating the venturi also improved mixing and, therefore, improved the kinetic rate measurements for long residence time experiments. 


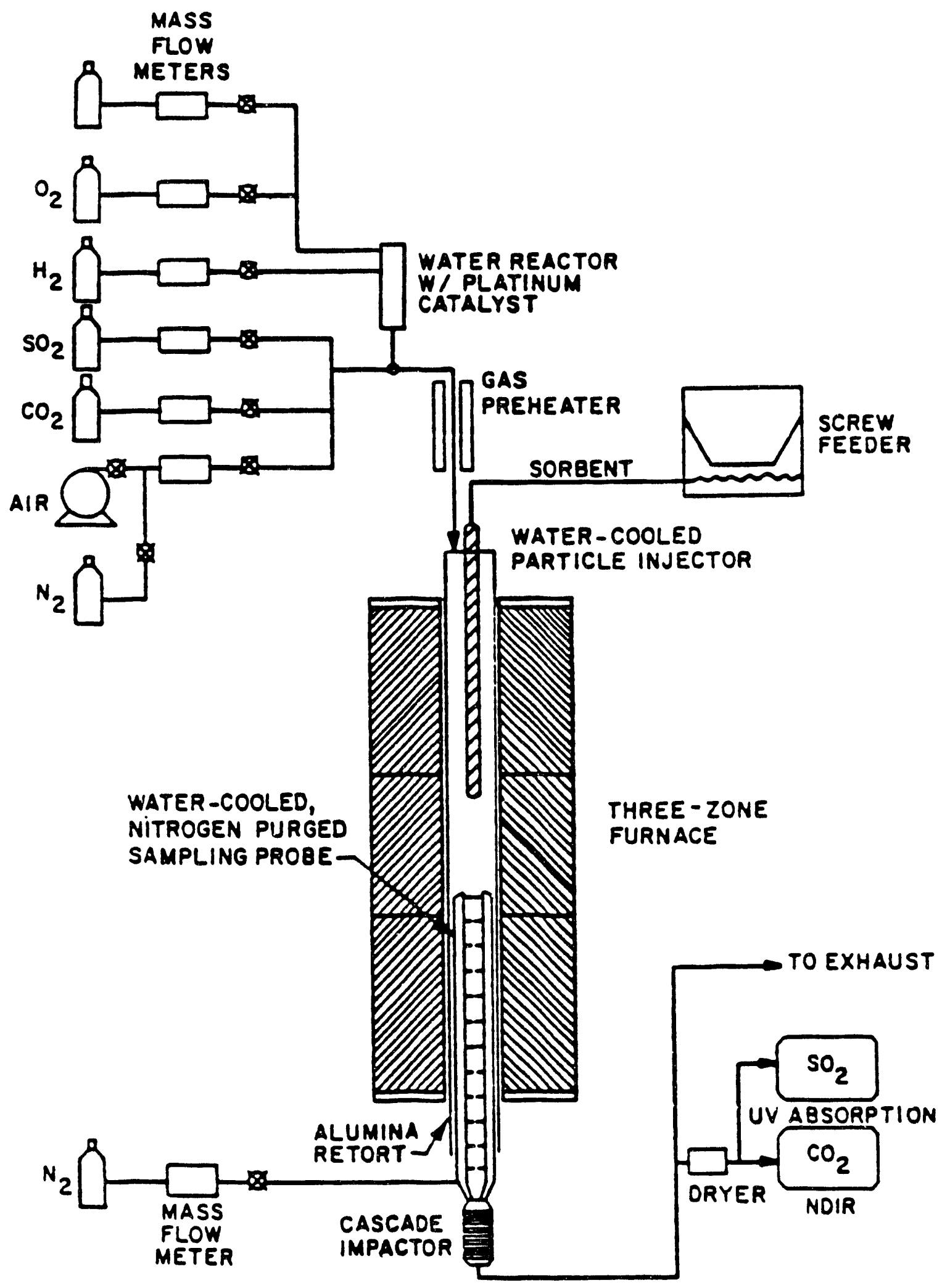

Figure 3.2.2.13 Schematic diagram of PSIT drop tube furnace. 


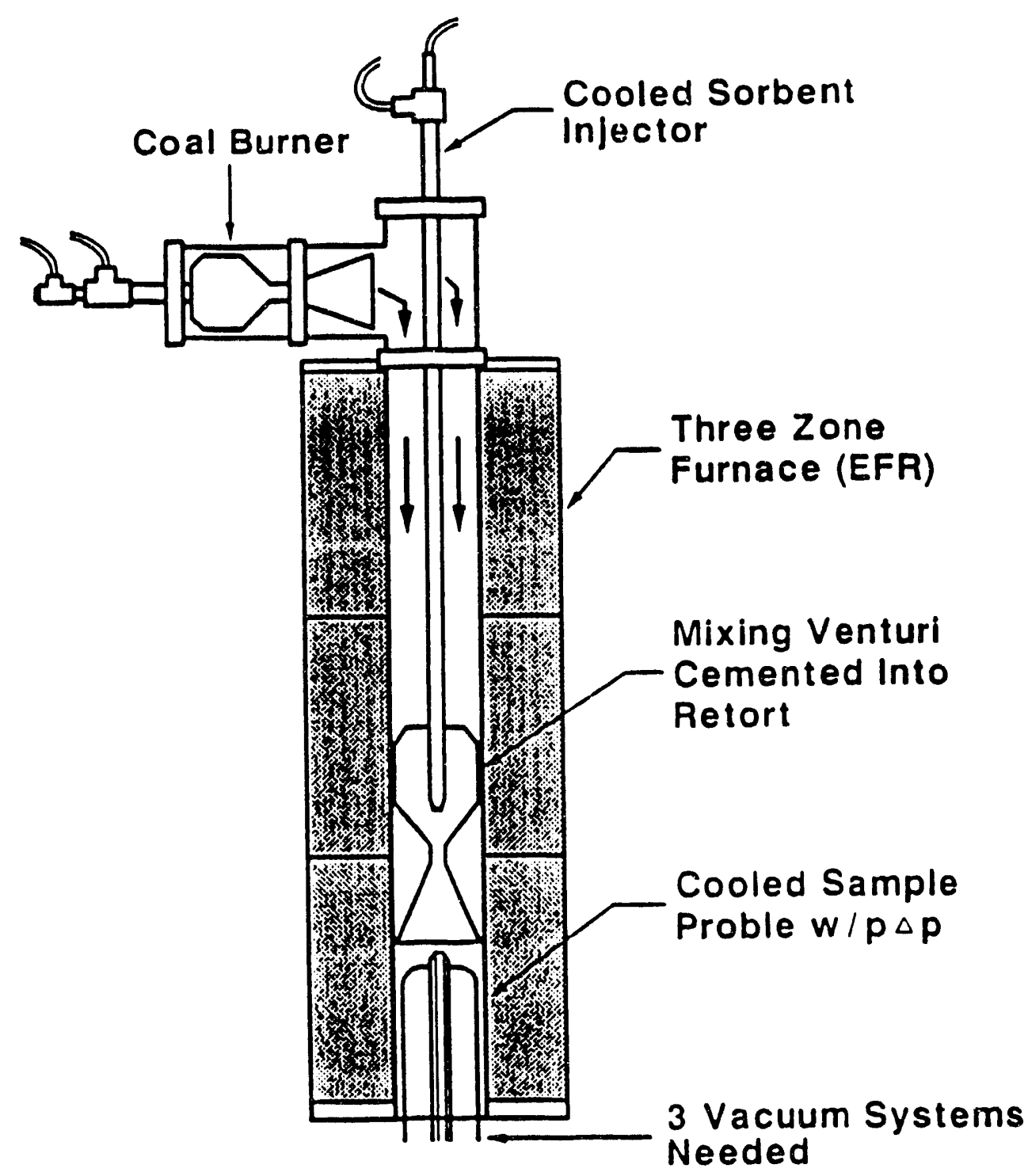

Figure 32.2.14 Schematic diagram of venturi modified drop tube furnace. 


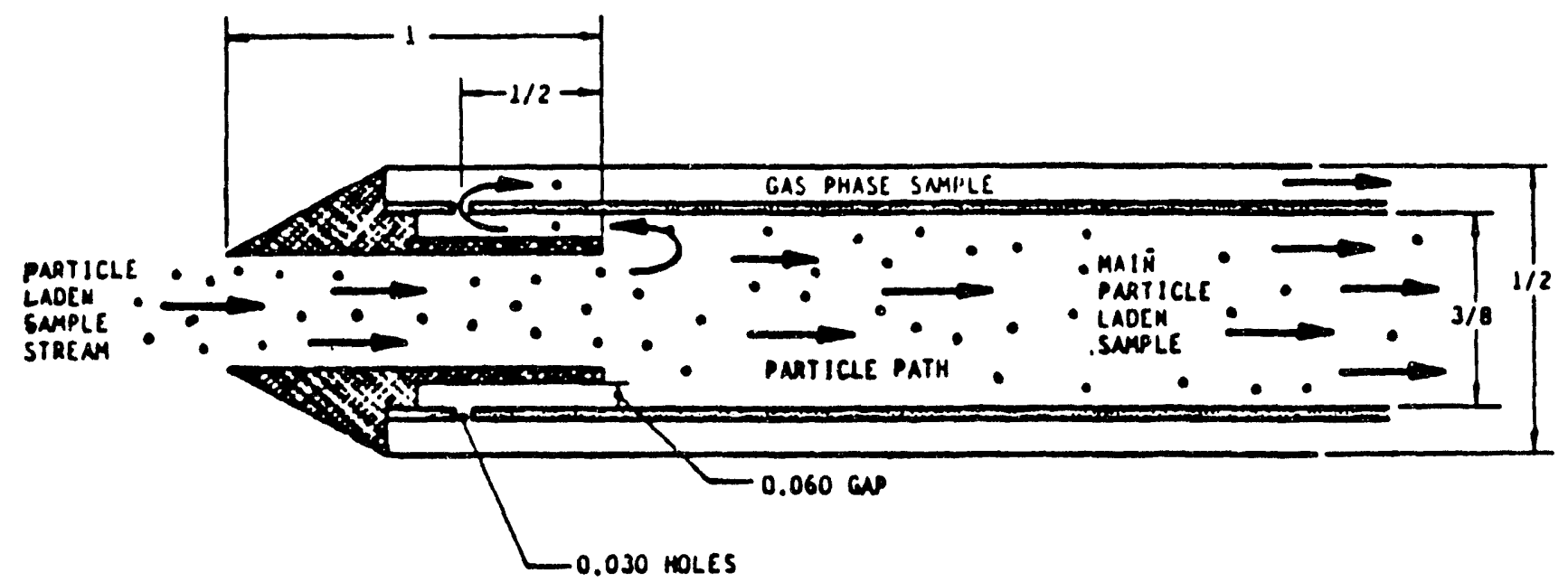

OIMENSIONS: IMCHES

Figure 32.2.15 Diagram of phase discrimination probe.

Table 32.2.4

Measured BET Surface Area

\begin{tabular}{|c|c|c|c|}
\hline \multirow[b]{2}{*}{ Sorbent } & \multirow[b]{2}{*}{ X $\mathrm{CaO}$} & \multicolumn{2}{|c|}{ Surface Area $\left(\mathrm{m}^{2} / 8\right)$} \\
\hline & & As Received & Dehydrated \\
\hline Type S & 50 & 10 & 38 \\
\hline Genstar PHDL & 58 & 17 & 60 \\
\hline Longviev* & 94 & 16 & 37 \\
\hline Type $S^{\star}$ & 50 & 10 & 42 \\
\hline
\end{tabular}


Sorption experiments focused on hydrated lime (Longview) and dolomitic hydrates (Genstar and Type-S). Physical properties of these sorbents as measured in the PSIT laboratories ares shown in Table 3.2.2.4. Precalcination of these sorbents was performed and found to increase surface area in all cases.

Long residence time results are summarized in Table 3.2.2.5 in which the effect of sorbent type, temperature, calcium to sulfur ratio $(\mathrm{Ca} / \mathrm{S})$, and residence time are shown. Type S-38, Genstar-60, and Longview are the dehydrated hydrates.

Precalcining Type $\mathbf{S}$ and Genstar were found to improve sorption somewhat, although improvements are not as high as expected considering the higher surface area obtained by dehydration. Longview actually showed a decrease in $\mathrm{SO}_{2}$ removal.

The effect of temperature on $\mathrm{SO}_{2}$ capture was examined by measuring Type-S performance at $1652^{\circ} \mathrm{F}\left(900^{\circ} \mathrm{C}\right), 1832^{\circ} \mathrm{F}\left(1000^{\circ} \mathrm{C}\right)$, and $2012^{\circ} \mathrm{F}\left(1100^{\circ} \mathrm{C}\right)$. There was a clear increase in sulfur capture effectiveness with increased temperature, indicating that kinetics play an important role for dolomitic sorbents. Interestingly, however, residence time had little effect in the range of 280 to $500 \mathrm{msec}$, supporting the hypothesis that the bulik of the absorption occurs at shorter residence times.

Short residence time sulfur capture was measured for calcitic and dolomitic hydrates. Figure 3.2.2.16 summarizes data for both sorbents. For the pressure hydrated dolomitic lime $(\mathrm{PHDL})$ at $\mathrm{Ca} / \mathrm{S}=2,2012^{\circ} \mathrm{F}, 1000 \mathrm{ppm} \mathrm{SO}_{2}$ and 20 millisecond residence time, $60 \%$ sulfur capture was obtained. It should be noted that this sulfur capture was considerably greater than that previously measured at longer residence time. This indicated that without the venturi section, mixing was poor in the entrained reactor. PHDL sorbent showed no dependence on residence time, which suggests that much of the reaction had occurred before $20 \mathrm{msec}$. $37 \%$ sulfur capture was measured for the calcium hydrate under equivalent conditions. For the calcium hydrate, sulfur capture at $500 \mathrm{ppm} \mathrm{SO}_{2}$ increased from $18 \%$ at $20 \mathrm{msec}$ to $22 \%$ at $60 \mathrm{msec}$, indicating a slight dependence of sulfur capture on residence time.

The differing results suggest that the physical characteristics of the dolomitic and calcitic hydrates effect initial and continuing sulfation rates. The dolomitic sorbent sulfates quickly, but also quickly becomes saturated. The calcitic sorbent, on the other hand, continues to sulfate beyond $100 \mathrm{msec}$. It is known that the presence of unreactive $\mathrm{MgO}$ in the dolomitic material tends to help maintain porosity during sulfation. It can be surmised that sorption in the dolomitic sorbent is kinetically controlled, whereas sulfate plugging of the pores creates a diffusion controlled situation for the calcitic sorbent.

Data on the effect of temperature on $\mathrm{SO}_{2}$ capture is shown in Figure 3.2.2.17. The sorption of sulfur by the calcitic hydrate (Longwood) is relatively independent of temperature, whereas the dolomitic hydrate shows a much stronger temperature effect. This data also sup- 
Table 3.2.2.5

System Conditions and Performance

Percent $\mathrm{SO}_{2}$ Removal at $\tau=\mathbf{2 8 0} \mathrm{ms}$

\begin{tabular}{|c|c|c|c|c|c|c|}
\hline \multirow{2}{*}{ Sorbent } & \multirow{2}{*}{$\begin{array}{l}\text { 'emp } \\
\left({ }^{\circ} \mathrm{c}\right)\end{array}$} & \multirow{2}{*}{$\begin{array}{l}{\left[\mathrm{SO}_{2}\right]} \\
\text { (ppa) }\end{array}$} & \multirow{2}{*}{$\begin{array}{c}{\left[\mathrm{CO}_{2}\right]} \\
(\mathrm{x})\end{array}$} & \multicolumn{3}{|c|}{$\mathrm{Ca} / \mathrm{S}$} \\
\hline & & & & 1 & 2 & 4 \\
\hline Type S & 1100 & 500 & 10 & 10.5 & 17.5 & -25.0 \\
\hline Type S-38 & 1100 & 500 & 10 & 12.5 & 20.0 & 32.0 \\
\hline Genstar & 1100 & 500 & 10 & 12.5 & 22.5 & 29.0 \\
\hline Genstar -60 & 1100 & 500 & 10 & 12.0 & 22.5 & 32.0 \\
\hline
\end{tabular}

Percent $\mathrm{SO}_{2}$ Removal at $r=500 \mathrm{~ms}$

\begin{tabular}{|c|c|c|c|c|c|c|}
\hline \multirow{2}{*}{ Sorbent } & \multirow{2}{*}{$\begin{array}{l}\text { Temp } \\
\left({ }^{\circ} \mathrm{C}\right)\end{array}$} & \multirow{2}{*}{$\begin{array}{l}{\left[\mathrm{SO}_{2}\right]} \\
(\mathrm{pPm})\end{array}$} & \multirow{2}{*}{$\begin{array}{c}{\left[\mathrm{CO}_{2}\right]} \\
(\mathrm{x})\end{array}$} & \multicolumn{3}{|c|}{$\mathrm{Ca} / \mathrm{S}$} \\
\hline & & & & 1 & 2 & 4 \\
\hline Type S & 900 & 500 & 10 & 4.0 & 7.5 & 14.5 \\
\hline Type S & 1000 & 500 & 10 & 6.0 & 11.5 & 17.5 \\
\hline Type S & 1100 & 500 & 10 & 6.5 & 12.0 & 19.5 \\
\hline Type $\mathbf{S - 3 8}$ & 1100 & 500 & 10 & 11.0 & 20.0 & 27.0 \\
\hline Genstar & 1100 & 500 & 10 & 11.0 & 19.0 & 29.0 \\
\hline Genstar-60 & 1100 & 500 & 10 & 17.5 & 24.0 & 29.0 \\
\hline Longrieut & 1000 & 500 & 10 & 12.0 & 22.0 & 35.0 \\
\hline Longriev* & 1100 & 500 & 10 & 6.0 & 10.5 & -18.0 \\
\hline Type $s^{\star}$ & 1100 & 500 & 10 & 5.0 & 11.5 & 19.0 \\
\hline
\end{tabular}




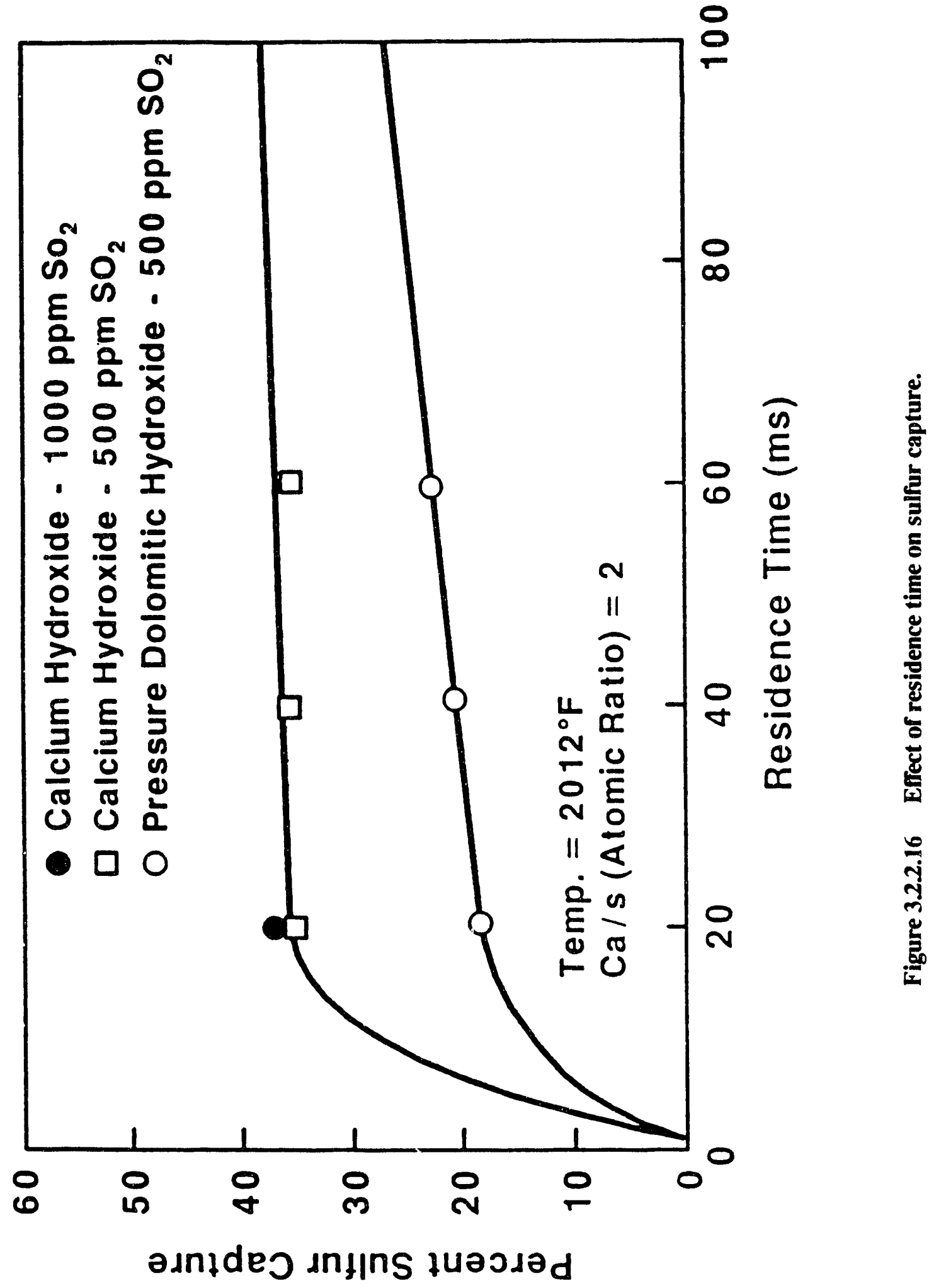




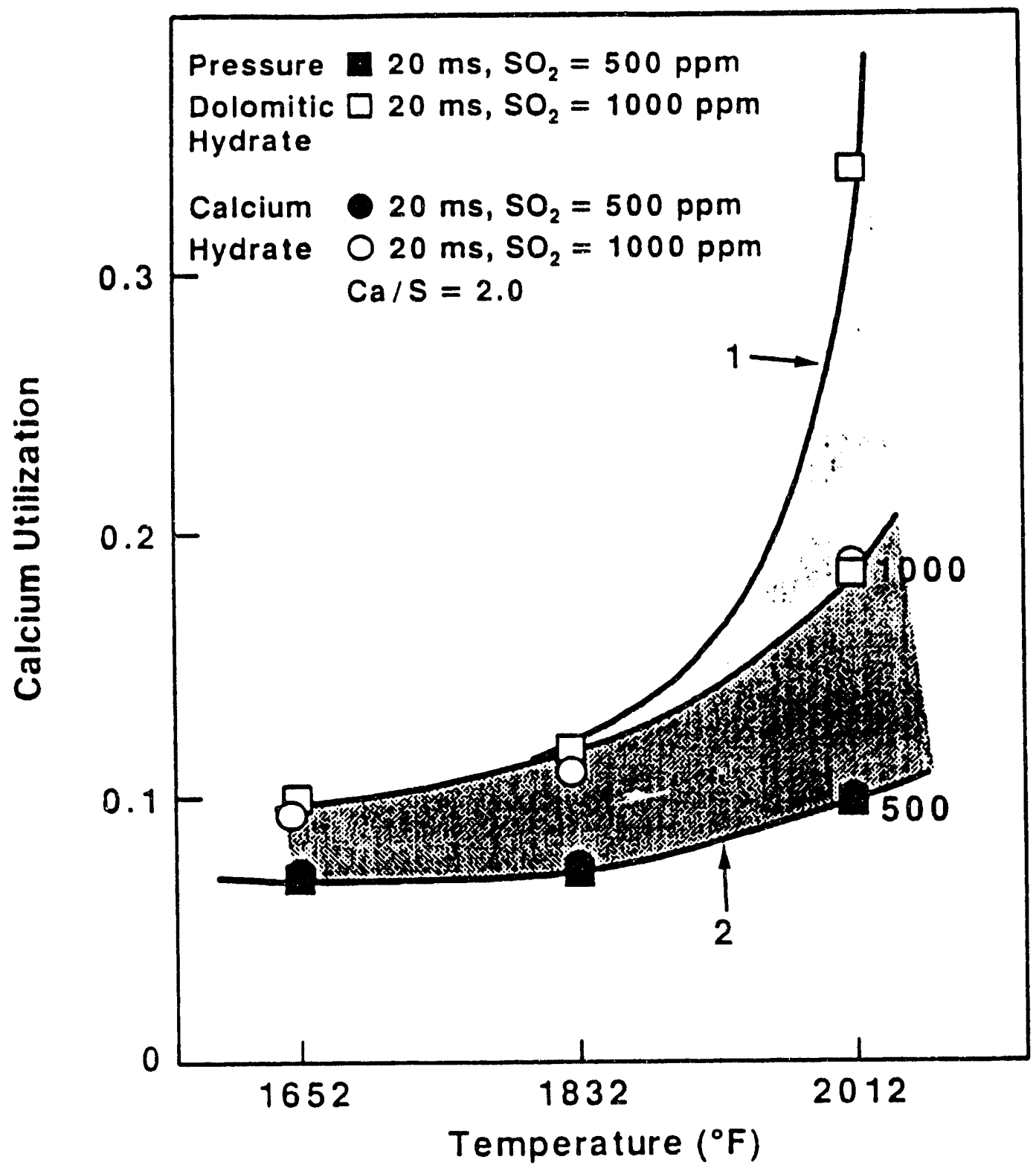

Figure 3.2.2.17 Effect of temperature on sulfur capture for dolomitic and calcitic sorbent. 
ports the idea that the dolomitic sorbent retains higher porosity, thereby reducing differential resistance, and therefore sulfation is kinetically controlled.

Figures 3.2.2.18 and 3.2.2.19 show data for the effect of $\mathrm{SO}_{2}$ partial concentration and $\mathrm{Ca} / \mathrm{S}$ on sulfur capture at $2012^{\circ} \mathrm{F}$ and 20 milliseconds. For the dolomitic sorbent at $\mathrm{Ca} / \mathrm{S}=1$ sulfur capture is proportional to the change in concentration. This dependency is expected for kinetically controlled sorption assuming a first-order in $\mathrm{SO}_{2}$ concentration dependence. In contrast, results for sulfating the calcitic sorbent show a non-linear dependence on initial $\mathrm{SO}_{2}$ concentration, which is believed to be caused by the dominance of diffusional resistance. These results compare favorably with results reported by Milne and Pershing [11]. Also, it is interesting to note that $\mathrm{SO}_{2}$ capture for $\mathrm{Ca} / \mathrm{S}=2$ and $500 \mathrm{ppm} \mathrm{SO}_{2}$ at $20 \mathrm{~ms}$ is $37 \%$, which is virtually identical to that at $300 \mathrm{~ms}$ (35\%) as reported by Muzio, et al.[12] and a previously obtained result of $33 \%$ at $500 \mathrm{~ms}$ of Johnson [13]. This indicates that a major fraction of sulfur removal is accomplished very early.

It should be noted that the LM500 turbine simulator results indicated that approximately $60 \%$ sulfur capture would be obtained for both dolomitic and calcitic sorbents with $\mathrm{Ca} / \mathrm{S}=$ 1.5. This result is consistent with the drop-tube results for dolomitic hydrate for similar $\mathrm{SO}_{2}$ partial pressures, but substantially greater than for the calcitic hydrate. It is possible that use of the sorbents in slurry form in the turbine simulator tests improved their reactivity.

The Grain Model for sulfation [14], was used for predictions of residence time, temperature, and $\mathrm{SO}_{2}$ partial pressure effects, and the predictions compared with experimental results. Figure 3.2.2.20 shows the grain model predictions for sulfur removal compared with experimental sulfation data. In general, the model predicts the trends quite well. Figure 3.2.2.20a shows predicted and experimental change in calcium utilization with time. Results from examination of possible resistances present during sulfation suggest that the initial sorption is kinetically controlled. However, after less than $20 \mathrm{~ms}$ a significant product-layer exits, which is responsible for the shift to diffusional control. It is expected that, at lower temperatures, the shift of the rate controlling step from chemical to diffusional would be more gradual. Increasing the temperature produces faster chemical kinetics and diffusional processes which result in higher sulfur removal. As shown in Figure 3.2.2.20b, the calculated capture from the model predicts this trend with predictions comparing closely to the experimental data. In these calculations, a sintering sub-model to reduce available calcium oxide sites was not used. The predictions suggest available calcium oxide sites are competing favorably for $\mathrm{SO}_{2}$ and not lost to thermal sintering. Again, assuming the kinetic rate is first-order dependent on $\mathrm{SO}_{2}$ concentration, the experimental data for calcium hydroxide did not show a proportional increase with increasing $\mathrm{SO}_{2}$ concentration (see Figure 3.2.2.20c) which would be expected if diffusion is rate limiting. 


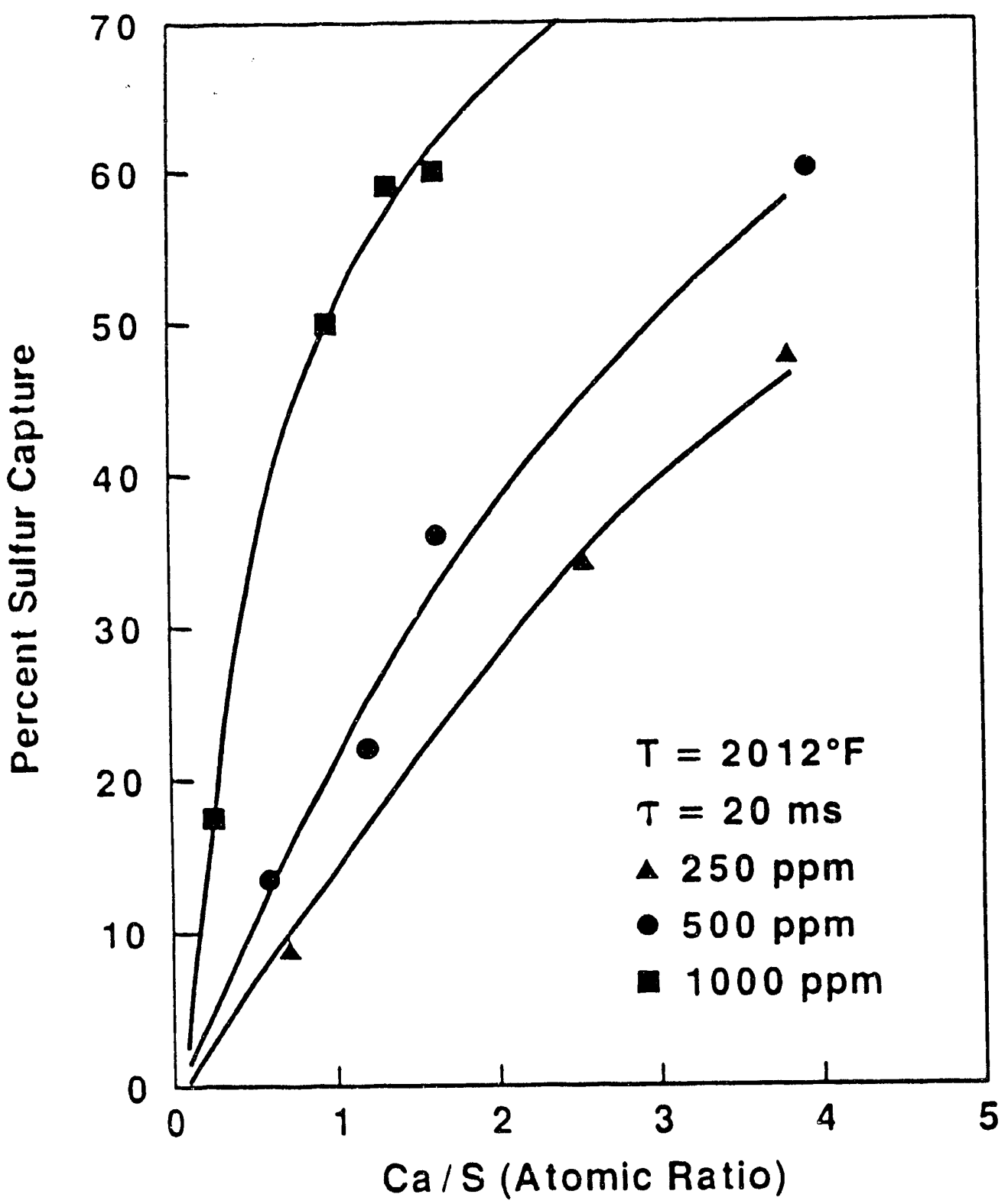

Figure 3.2.2.18 Effect of $\mathrm{SO}_{2}$ concentration on sulfur capture-dolomitic sorbent. 


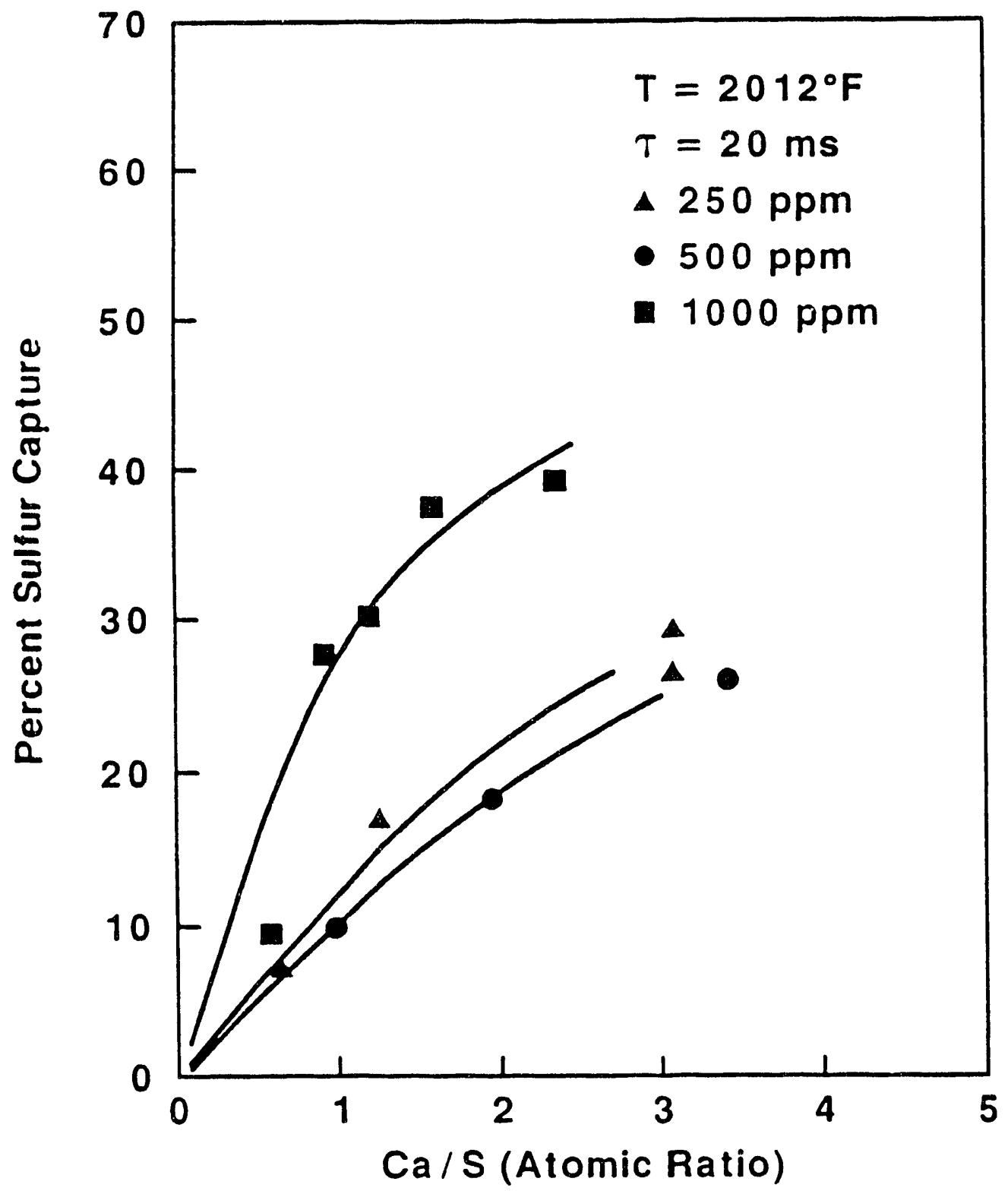

Figure 3.2.2.19 Efiect of $\mathrm{SO}_{2}$ concentration on sulfur capture-calcitic sorbent. 

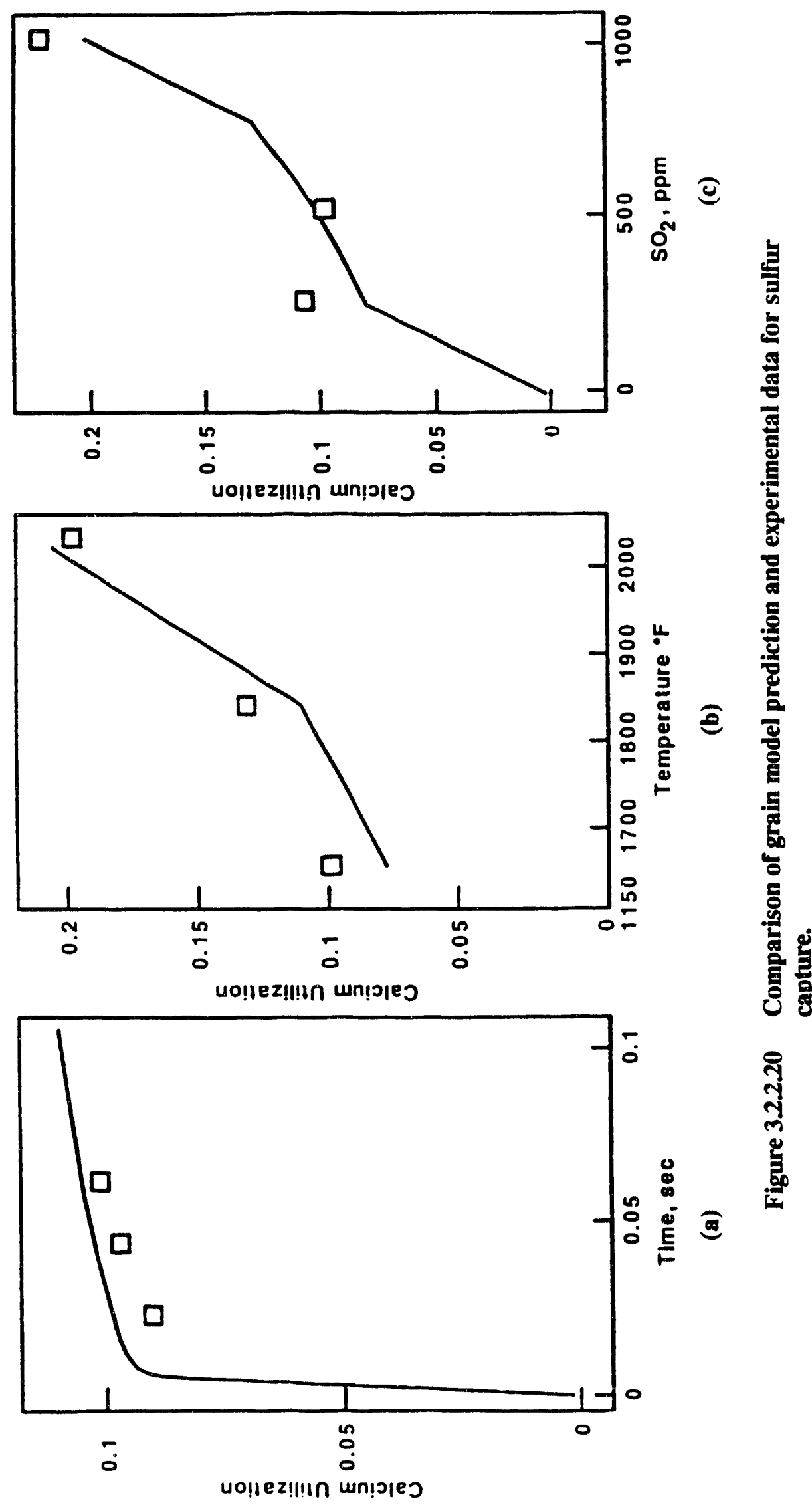
3.2.2.3.2 Injection Location in Turbine.. The venturi drop-tube experiments examined sulfur capture by the injection of sorbents under well mixed conditions. For the dolomitic sorbent results obtained in the drop-tube experiments, reactivity is strongly dependant on temperature and $\mathrm{SO}_{2}$ concentration. Both of these parameters are influenced by the extent of mixing. For example, if sorbent is not uniformly distributed within the gas phase the $\mathrm{Ca} / \mathrm{S}$ required may be high. In addition, inadequate mixing will extend the period of particle heating and dehydration, leaving only a fraction of available time where sulfation is favored. Loss of $\mathrm{CaO}$ sites due to thermal and chemical induced sintering at temperatures which are below that for effective sulfation is also a concern.

A Teach-type fluid dynamic code, Fluent (licensed from Creare), was used to provide an estimate of the flow fields in an annular combustor to determine the best location for injection of sorbent other than with the fuel. Three possible injection locations were examined: with atomizing air, with swirl air, and with secondary dilution air.

Examination of the mixing in the combustor suggests that the best location for injection of dry sorbent is with the atomizing air. With the presence of recirculating zones located between the CWM nozzle and primary air inlet and in close proximity to the sulfur emitter, mixing and subsequent reaction with sulfur is expected to be within a few milliseconds. The total residence time in the combustor is estimated to be $\sim 20 \mathrm{~ms}$ for $10 \mu \mathrm{m}$ particles.

Injection with the swirl-air produces similar residence time as calculated for injection in the nozzle. While this time is significant, a large portion of the particles tends to follow the wall where the gas is expected to be cooler and contain a relatively low concentration of $\mathrm{SO}_{2}$. Reduced temperature and $\mathrm{SO}_{2}$ concentration will slow diffusional and kinetic rates.

The final location examined for dry sorbent injection was introducing powdered sorbent in the secondary dilution air holes in the combustor. While sulfation has been shown to be rapid under ideal mixing, calculations predict that mixing will be incomplete at the nozzle inlet, where a rapid reduction of temperature takes place.

In general, the best alternative to injsction with the CWM slurry is with the atomizing air where rapid mixing along with sufficient temperatures and $\mathrm{SO}_{2}$ concentration allow sulfation to be competitive with sintering processes. It is possible that introduction of the sorbent in one of these alternate locations will reduce the excessively high-deposition rate associated with the sorbent-doped CWM fuel.

\subsubsection{Conclusions}

Sulfur capture in the combustor using calcium-based sorbents mixed with the CWM fuel were found to be very effective even for the very short residence times and severe thermal environments in the combustor. $60 \%$ sulfur capture was obtained at $\mathrm{Ca} / \mathrm{S}=1.5$ using calcium hydroxide sorbent. However, severe deposition was experienced. Use of dolomitic sorbents, 
which have been found to reduce deposition on boiler tubes, and kaolin additive, which greatly reduced CWM fuel-deposition rates in turbine simulator tests, were not effective in reducing deposition rates to acceptable levels.

In laboratory experiments it was determined that sulfation can be extremely rapid. For dolomitic sorbents, the bulk of the sorption occurs within $20 \mathrm{~ms}$. For calcitic hydrates, sorption rates are slower due to increased diffusional resistances. These results support the sulfur capture results from turbine simulator experiments.

Although excellent sulfur capture can be achieved through sorbent injection into the turbine, this technique will not be practical unless an in-line particulate system is used to clean combustor exit gas prior to entering the turbine. We believe that such a device is impractical for an in-line combustion system. 


\subsection{3 $\mathrm{NO}_{\mathrm{x}}$ Control}

\subsubsection{NO Emissions}

Nitrogen oxides are formed during the combustion of CWM fuel primarily from oxidation of fuel-bound nitrogen (FBN). The oxidation of FBN is dependent upon the local stoichiometry and is a weak function of temperature. The production of $\mathrm{NO}_{x}$ by thermal fixation of atmospheric nitrogen during CWM combustion is limited by the lower flame temperature due to the presence of water. Rosfjord [16] estimates that the thermal $\mathrm{NO}_{\mathrm{x}}$ contribution for CWM fuels is $\sim 20 \mathrm{ppm}$.

During initial phases of sorbent injection studies several turbine simulator combustion tests were run in which water/oil emulsions were combusted. Although results are somewhat scattered, Figure 3.2.3.1 shows the effect of this water on $\mathrm{NO}_{\mathrm{x}}$ formation. Clearly at ratios of water to oil approaching 1 , thermal $\mathrm{NO}_{x}$ formation was considerably suppressed. It is thus reasonable to surmise that $\mathrm{NO}_{\mathrm{x}}$ formation from CWM fuel combustion is primarily from FBN.

In the turbine simulator testing $\mathrm{NO}_{\mathrm{x}}$ levels have ranged from 200 to $300 \mathrm{ppm}$ for CWM combustion. Table 3.2.3.1 lists the range of $\mathrm{NO}_{\mathrm{x}}$ levels for three CWM fuels which we have tested, along with their nitrogen contents.

\subsubsection{2 $\mathrm{NO}_{\mathrm{x}}$ Emission Control Methods}

$\mathrm{NO}_{x}$ emission levels correspond to a conversion of $\mathrm{FBN}$ to $\mathrm{NO}_{x}$ of approximately $1 / 3$, or 1 lb NO $\mathrm{N}_{\mathrm{x}}$ / million Btu for coal containing $2 \%$ nitrogen. To meet NSPS, $40 \%$ reduction of $\mathrm{NO}_{\mathrm{x}}$ emissions will be required. It is felt that staged combustion through air staging will be able to reach this objective.

For systems in which $\mathrm{SO}_{2}$ capture is performed in the exhaust duct, $\mathrm{NO}_{x}$ removal by methods such as selective catalytic reduction (SCR) and approaches for coupled $\mathrm{SO}_{2} / \mathrm{NO}_{x}$ control can be considered.

For high temperature exhaust gas cleanup for simple cycle systems or where cleanup upstream of the heat recovery system is desirable, a candidate combined $\mathrm{SO}_{2} / \mathrm{NO}_{\mathbf{x}}$ cleanup approach is the copper oxide process under development by UOP Inc. [17]. It is reported that over $90 \% \mathrm{SO}_{2}$ removal along with $90 \% \mathrm{NO}_{\mathbf{x}}$ removal can be achieved at temperatures in the range of 700 to $800^{\circ} \mathrm{F}$.

At lower temperatures such as at those at the exit of the heat recovery steam generator, methods such as the $\mathrm{NO}_{\mathrm{x}}$ SO process [18], in which NO reacts with a sodium-based sorbent can be applied. Calcium and sodium based sorbent injection methods such as in-duct scrubbing may also be effective in the simultaneous removal of $\mathrm{SO}_{2}$ and $\mathrm{NO}_{x}$ [19]. 


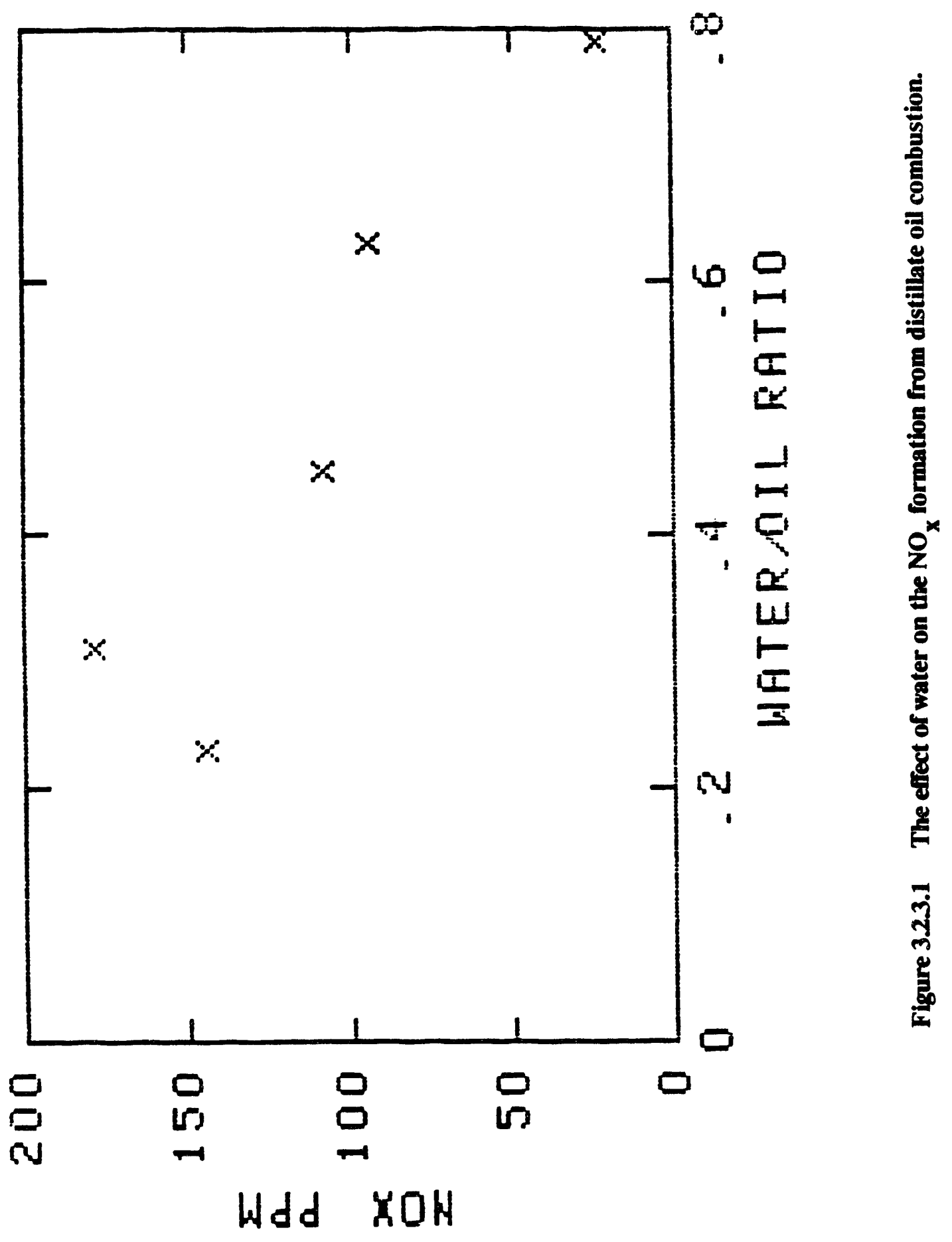


Table 3.2.3.1

$\mathrm{NO}_{x}$ Production from CWM Fuels

\begin{tabular}{ccc}
\hline Fuel & $\begin{array}{c}\text { Fuel Nitrogen } \\
\%, \text { dry }\end{array}$ & $\begin{array}{c}\mathrm{NO}_{x} \\
\mathrm{ppm}\end{array}$ \\
\hline Blue Gem & 2.1 & $260-300$ \\
Taggart & 1.9 & $200-250$ \\
OXCE & 1.5 & $210-230$ \\
$\begin{array}{c}\text { Blue Gem in } \\
\text { Single Cup Can }\end{array}$ & 2.1 & $200-250$ \\
\end{tabular}

\subsubsection{Conclusions}

The primary approach for $\mathrm{NO}_{\mathrm{x}}$ combustion will be staged combustion. Where exhaust stream cleanup is used for particulate and sulfur control, SCR or methods which simultaneously remove $\mathrm{SO}_{2}$ and $\mathrm{NO}_{x}$ can be considered. 


\subsubsection{PARTICULATE CONTROL}

\subsubsection{Particulate Emissions}

The design condition for the combustor exit gas for the coal-fueled LM500 turbine is 208 psia and $2212^{\circ} \mathrm{F}$. The total flow of combustor exit gas is $97000 \mathrm{lb} / \mathrm{hr}$ containing $57 \mathrm{lb} / \mathrm{hr}$ of ash for a typical CWM fuel cleaned by physical beneficiation. This corresponds to a particulate loading of $0.6 \mathrm{lb} / \mathrm{million}$ Btu, or 20 times that allowable by NSPS. The high temperature of the gas limits the filtration options to devices constructed of ceramic materials such as ceramic bag filters or to granular bed filters containing ceramic media. Inertial devices such as cyclones are felt to have inadequate performance for these small particles, many of which are submicron in size. Because of the sticky nature of the ash, which has been shown to cause deposition on the first stage turbine nozzle, it is felt that barrier filters such as ceramic bags, candles, or cross-flow filters will quickly become plugged. Thus, our efforts have focused on granular bed filters.

This section describes an investigation of the feasibility of operating a Fixed/Moving Granular Bed Filter (FMGBF) system under the harsh conditions that exist in the exhaust of a gas turbine combustor. To be successful, the filter must reduce particulate matter to a level which meets New Source Performance Standard (NSPS) for coal-fired power plants and provide adequate protection for the turbine. The particulate matter removed by the filter contains ash, unburned coal and, possibly, calcium-based sulfur sorbents. The filtration media may also contain sorbents for sulfur capture.

Particulate emissions primarily consist of residual coal ash with minor amounts of carbon not consumed during combustion. The quantity of particulates is, thus, a direct function of the degree to which coal is cleaned. In our turbine simulator combustion tests, the particulates contained 10 to $30 \%$ carbon, which corresponds to a combustion efficiency of $>99.5 \%$.

High resolution photomicrographs, Figure 3.2.4.1, of extracted ash show that ash particles were primarily in the 1 to $5 \mu \mathrm{m}$-size range, which is within the acceptable range for efficient granular bed operation. Particles exist as refractory-oxides and metal-oxide spheres, carbonaceous cenospheres, and agglomerated aerosols. X-ray diffraction studies on extracted ash indicate the presence of alumina, silicon oxide, silicates, calcium sulfate, and hemitite. In addition, a significant amount of amorphous materials is also present. Microscopic analyses indicate that sub-micron aerosols are enriched with iron.

Characterization of the organic material was determined by thermal gravimetric analysis (TGA) and gas chromatography mass spectroscopy (GC-MS). Results from TGA (Figure 3.2.4.2) indicate that two distinct temperature ranges in which significant weight-loss occur, exist. The first, between 212 to $750^{\circ} \mathrm{F}$, is caused by the loss of absorbed $\mathrm{SO}_{2}$ and $\mathrm{CO}_{2}$, and low-molecular weight hydrocarbons and carbon-oxides. This was substantiated by results from GC-MS which was used to analyze evolved gases from the ash-sample heated to $570^{\circ} \mathrm{F}$. 


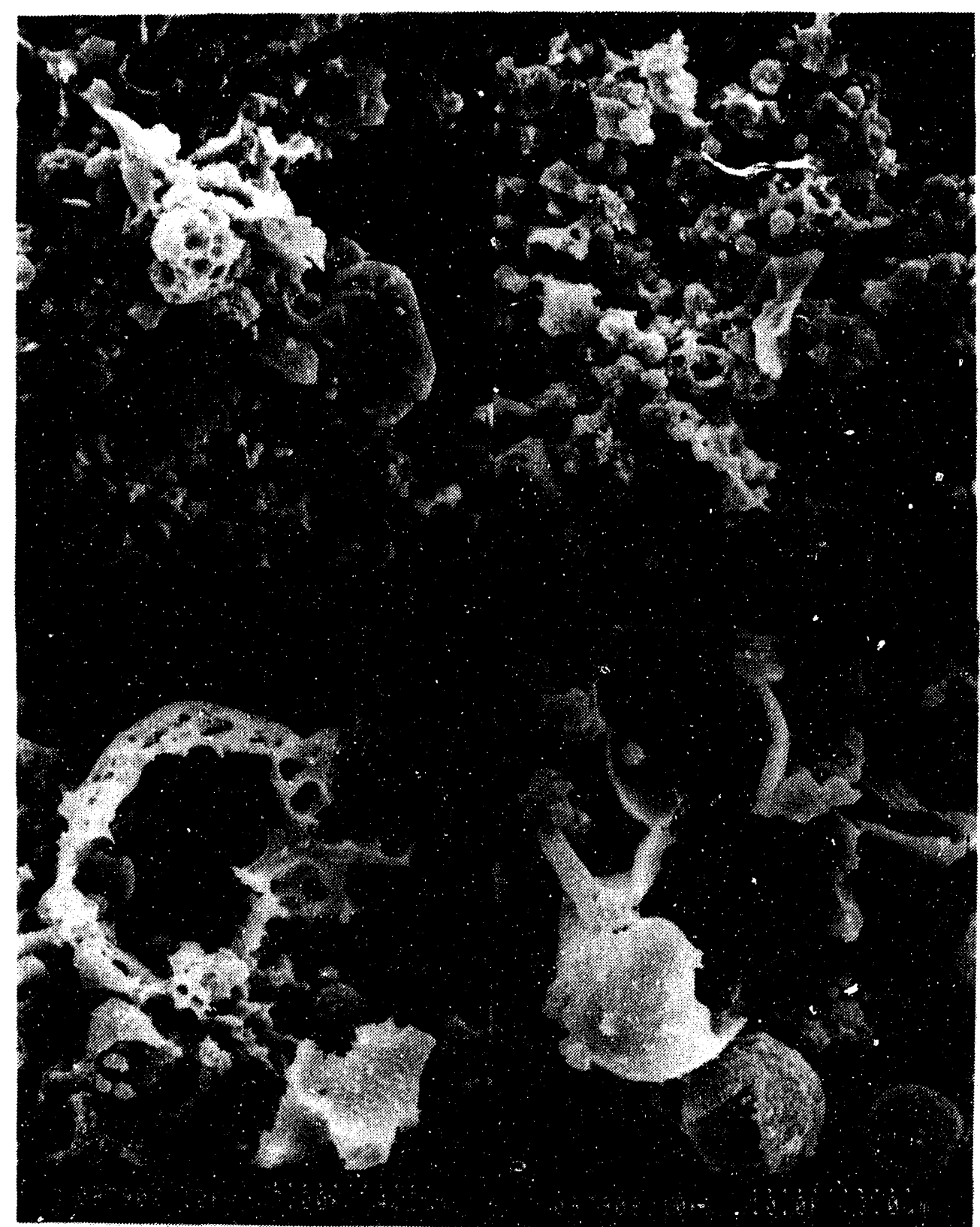

Figure 3.2.4.1 SEM photographs of ash samples from the turbine simulator. 


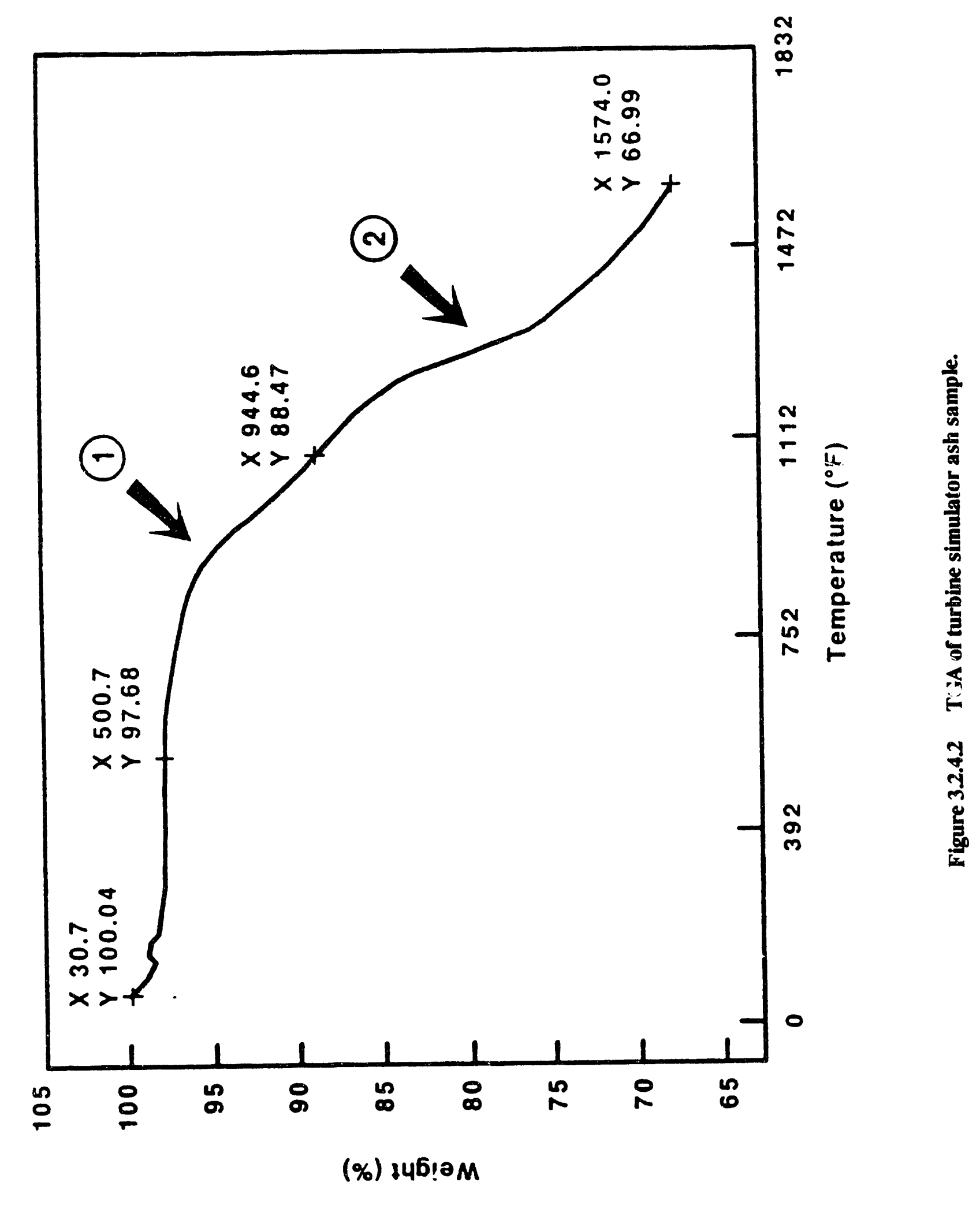


At temperatures above $750^{\circ} \mathrm{F}$, a second region of weight loss results from the evolution of higher molecular organic compounds. These higher weight compounds were identified by extracting organic fragments with toluene and then analyzing the extract by GC-MS. Eliminating the spectral-lines associated with the toluene, it was found that the organic constituents comprised of highly condensed aromatic compounds which include anthracene, phenanthrene, pyrene, fluoranthene, phthalic acid diester, naphthalene, fluorene, and acenapthene. A cumulative mass spectrograph (without specural-lines associated with toluene) is provided in Figure 3.2.4.3. Also detected were relatively stable aliphatic hydrocarbons. Some spectral-lines could not be identified.

\subsubsection{Granvlar Bed Filter}

In granular bed filtration particles in the gas enter the void space of the bed, where they collide with the larger filtration media. Particle collection is by adhesion to the surface of the media rather than actual filtration by bed structure. The particles remain in the bed while the clean gas discharges from the system. Collision between the bed material and the dust particles is due to a combination of inertial impaction, diffusion, gravitational settling, and electrostatic forces. Adhesion of the particles to the media is necessary to achieve good particulate removal efficiency. Collection is enhanced by sticky particles of the type which exist in the combustor exhaust gas. The dust-laden filtration media are continuously or semicontinuously regenerated through separation, of the collected dust and media. Thus, it is important that the particle/media adhesion not be excessive. Additionally, the particles must not adhere to such a degree that granular bed movement is inhibited.

Filtration efficiency increases with increasing function of the Stokes number. Higher efficiency is obtained in granular bed filters for large, high density particles. High filtration efficiency can also be achieved for micron and submicron dust particles when high velocity gas, in the range of 1 to $10 \mathrm{ft} / \mathrm{s}$, flows through a granular bed filter comprised of small size bed material in the range of 0.5 to $2.0 \mathrm{~mm}$.

Currently, DOE is supporting the development of screenless moving bed granular bed filter designed by Combustion Power Corporation (CPC) [19] for high-pressure hightemperature applications. High-filtration efficiency has been demonstrated by the CPC filter over many hours of operation. The CPC filter has no bed support, and as a result the gas velocity is limited to substantially below the fluidization velocity of the bed material. Since, in order to achieve high filtration efficiency, small granules ( $2 \mathrm{~mm}$ alumina spheres) are used, the gas velocity is limited to about $2 \mathrm{ft} / \mathrm{s}$. Upset conditions in the CPC system may cause a higher than design gas flow rate which may result in bed material carryover downstream of the filter and into the turbine.

The GE Fixed/Moving Granular Bed Filter concept, shown in Figure 2.2.2.1, is a combination of a moving bed of 1 to $2 \mathrm{~mm}$ spherical alumina media supported by a fixed bed of 


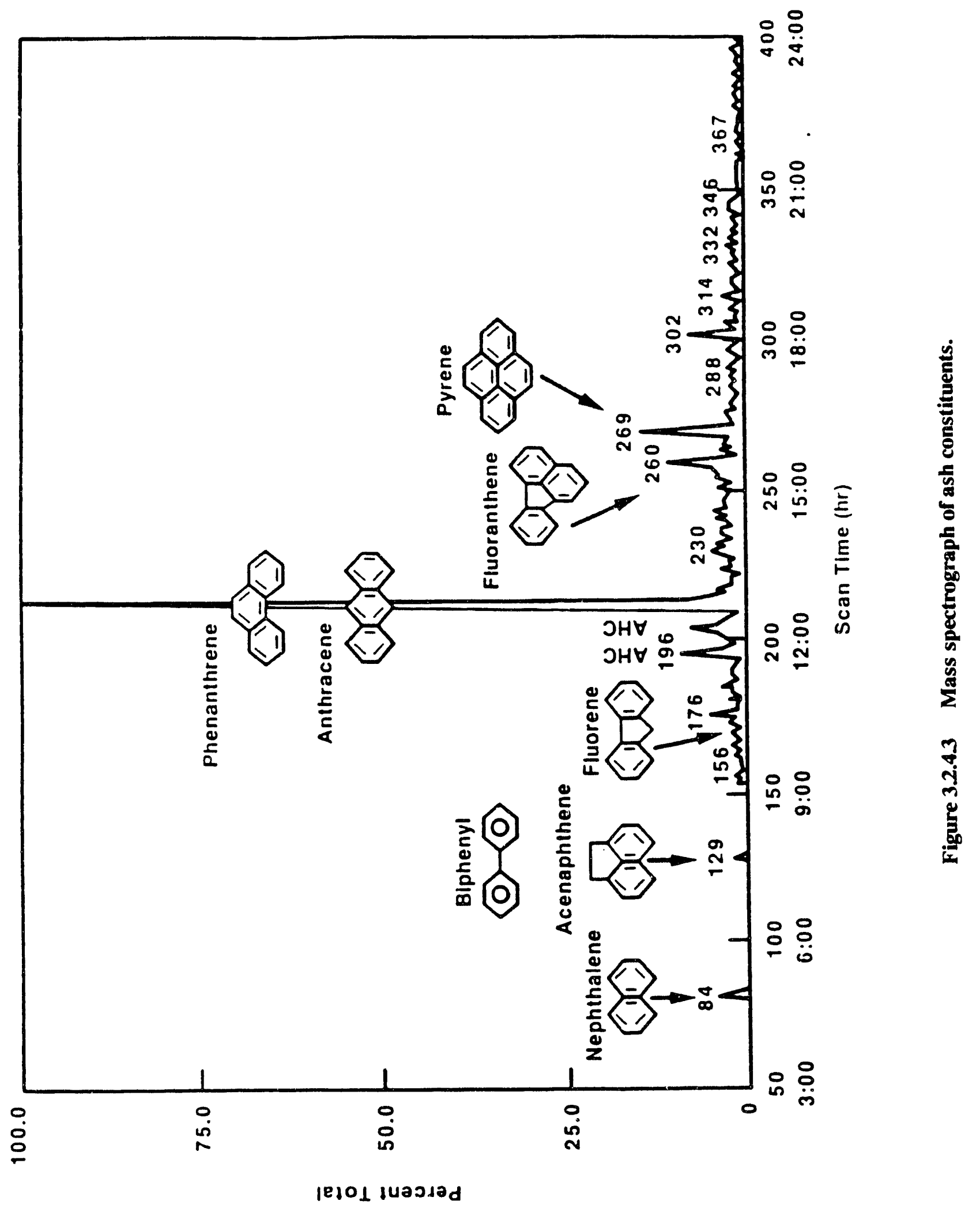


larger size granular alumina bed media. The supporting fixed bed is comprised of a few layers of increasingly larger granules in the outflow direction. The size of the channels in each layer is smaller than the size of the granules which it is supporting so that penetration of the small size granules through the channels is avoided. The outermost layer may be comprised of granules as large as $1 \mathrm{in}$. in diameter so that even at a very high velocity, entrainment of the bed will not occur. The use of small size bed material in the moving bed zone results in a high filtration efficiency. At the same time high gas velocity can be achieved.

The filter vessel contains two concentric internal pipes open at the bottom. The length and diameter of these pipes determine the boundaries of the moving bed, the velocity of the particle laden gas and its injection location into the moving bed. The innermost pipe is an extension of the gas turbine combustor. The gas flows inside the pipe at a velocity comparable to the gas velocity in the combustor. The clean, small size alumina spheres, are fed to the annular space between the two internal pipes and move downward by gravity into the bottom of the conical hopper. The stationary support bed, comprised of a few layers of increasingly larger size granules in the gas outer flow direction, is located in the annular space between the vessel refractory wall and the outer of the two internal pipes. The stationary bed is supported from the bottom. The fixed/moving bed interface is determined by both the size of the stationary bed support and the diameter of the internal pipe.

Particle filtration is accomplished in the cross-flow zone of the moving bed where the bed moves down by gravity and the gas flows radially outward. As a result, the drag force on the moving bed material is mainly in the horizontal direction and it has a rather small impact on the moving bed gravitational flow.

\subsubsection{Cold Flow Experiments. A cold flow model, shown schematically in Figure} 3.2.4.4, was constructed to investigate the performance of the FMGBF. The filter is a cylindrical vessel with a conical hopper. Both vessel and hopper are split along the axis of symmetry, and the center face is constructed of transparent plexiglass to allow observation of bed material flow. The two inner pipes form an annular space in which the moving bed material, comprised of 1 to $2 \mathrm{~mm}$ alumina spheres, flows downward by gravity and discharges at the bottom of the hopper. A stationary bed of coarser material fills the annular space between the external inner pipe and the vessel wall and is used as a support for the moving bed. The stationary bed is layered with large granules layered in the outer flow direction. Dusty gas flows through the internal pipe and penetrates through the moving bed at high velocity. The gas then further penetrates the stationary bed and discharges from the bed in an upward flow direction. The dust is collected in the moving bed and discharges with the moving bed material. A separate, small stream of lift air, pneumatically transports the granules and the dust up to the de-entrainment vessel where the granules settle and flow back into the filter, and the dust entrains in the air stream. The dusty gas stream is cleaned in a small baghouse (not shown). 


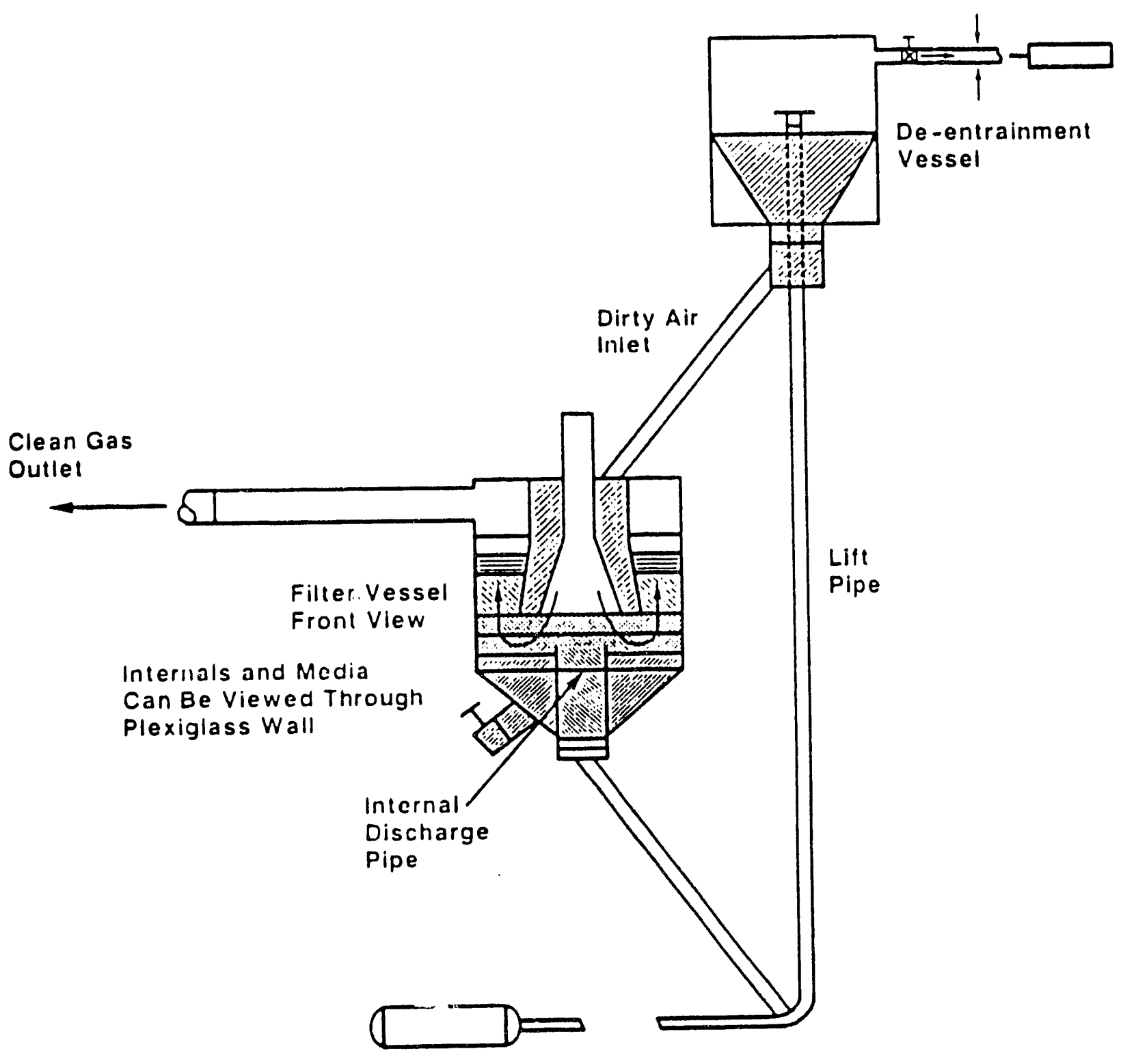

Figure 32.4.4 Cold flow model of the granular bed filter. 
The filter was sized to accommodate gas-flow rates in excess of the flow rates expected in the one-nozzle segment combustor. All the designs that were tested showed a high removal efficiency. It was found that interface between the stationary and the moving bed tended to plug after a few hours of operation due to accumulation of ash in that layer. Modifications to the design which included increasing the moving bed depth from 5 to 7.5 in. and improvement of the bed material discharge arrangement solved the plugging problem.

The test results are encouraging. Pressure drop through the bed was as expected from theoretical calculations and low overall due to the fact that most of the bed was comprised of a large material. The difference in pressure drop through a clean bed and contaminated bed was rather small and bed plugging did not occur. Pressure drop through a clean bed is shown as a function of gas flow rate in Figure 3.3.4.5. The pressure drop as a function of time during $5 \mathrm{hr}$ of filtration at an inlet dust concentration of $2 \mathrm{gr} / \mathrm{acf}$ is shown in Figure 3.3.4.6. Overall average gas velocity is defined as gas flow rate divided by the overall cross sectional area of the vessel. The $600 \mathrm{cfm}$ represents an overall average gas velocity of $4.08 \mathrm{ft} / \mathrm{s}$, which is far higher than the velocities in the CPC screenless granular bed filter. It is felt that still higher gas flow rates can be achieved in the current filter. However, it should be noted that cold flow tests were run with dry particulates. Ash from CWM combustion may be sticky, resulting in higher particle agglomeration with resulting higher pressure drop.

Filtration efficiency of the granular bed filter using a $7.5 \mathrm{in}$. thick bed is shown in Figure 3.3.4.7. From an inlet concentration of $2 \mathrm{gr} / \mathrm{acf}$, emission was reduced to 0.006 to 0.007 $\mathrm{gr} /$ acf representing filtration efficiency in excess of $99.6 \%$. Penetration of dust occurs along the plexiglass wall and the actual filtration efficiency, through the bed, is believed to be even highe: . It is expected that the commercial size filter with a 12 inch thick bed will be extremely efficient.

\subsection{Bench-Scale High Pressure High-Temperature Granular Bed Filter. The} bench scale system for the one-nozzle segment combustor test rig [20] located at the GE CRD laboratory is similar in size to the cold flow model described above. It is designed to operate at $2200^{\circ} \mathrm{F}$ and 200 psi and to filter combustion gas particulate matter which includes coal ash, unreacted lime and calcium sulfate. The vessel is shown in Figure 2.2.2.7. The vessel is refractory lined. The combustor is installed on top of the vessel and the hot gases are fired downward through a ceramic pipe into the filter media. The outer internal pipe that forms the annular void for moving bed flow will either be made of ceramic or fabricated of high alloy metal such as Hastelloy with a thermal barrier coating (TBC). If a metal is used, a cool stream of high pressure steam or air will be injected in the annular space between the internal pipes to maintain low metal temperature. No recycle of granules is designed for this bench system. Instead, the bed material will move down from a pressurized inlet lockhopper to an outlet lockhopper at the bottom until the top lockhopper is empty and the bottom one is full. There will be enough bed material in the bed for $8 \mathrm{hr}$ of continuous operation. The arrange- 


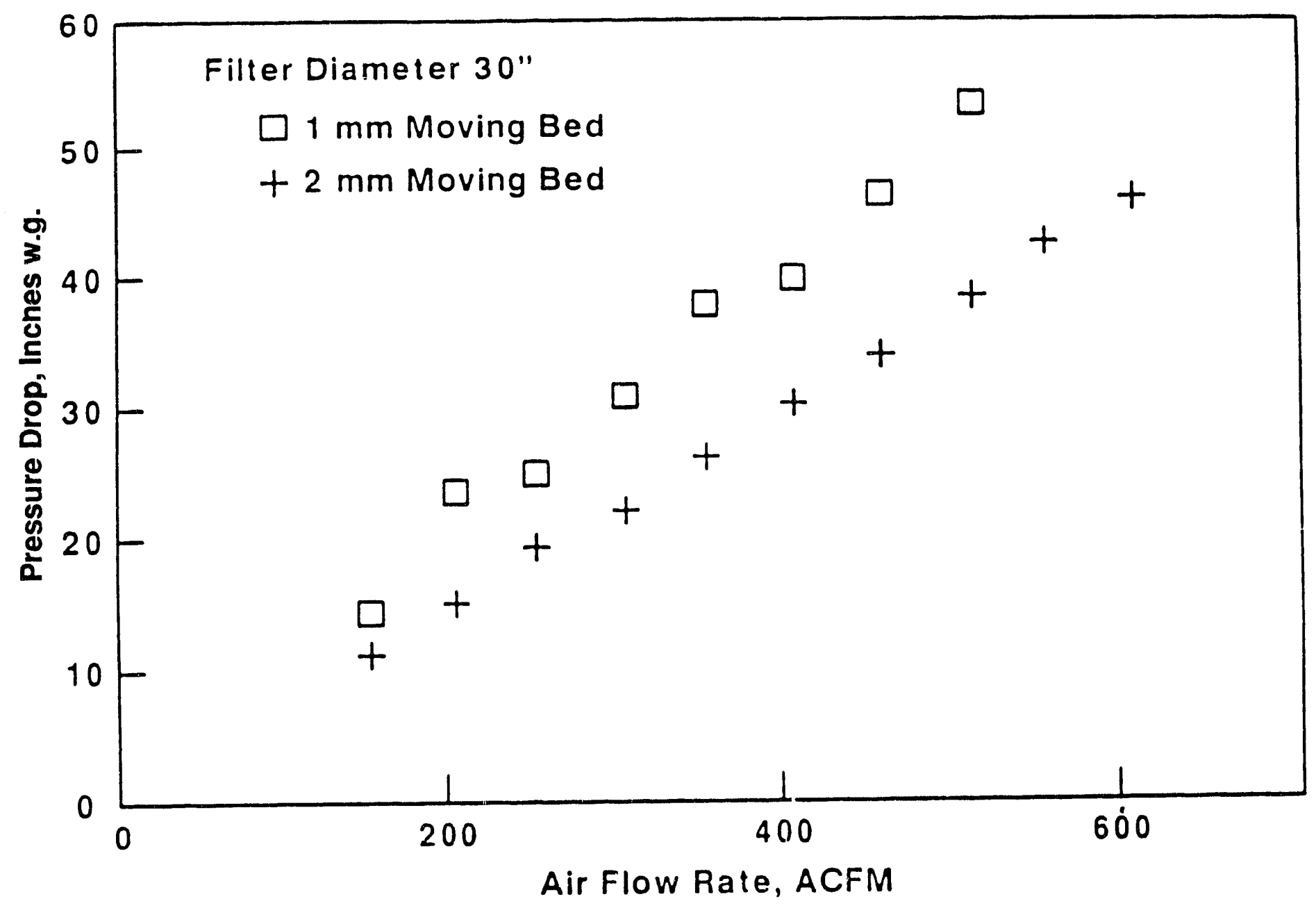

Figure 32.4.5 GBF pressure drop - cold now model. 


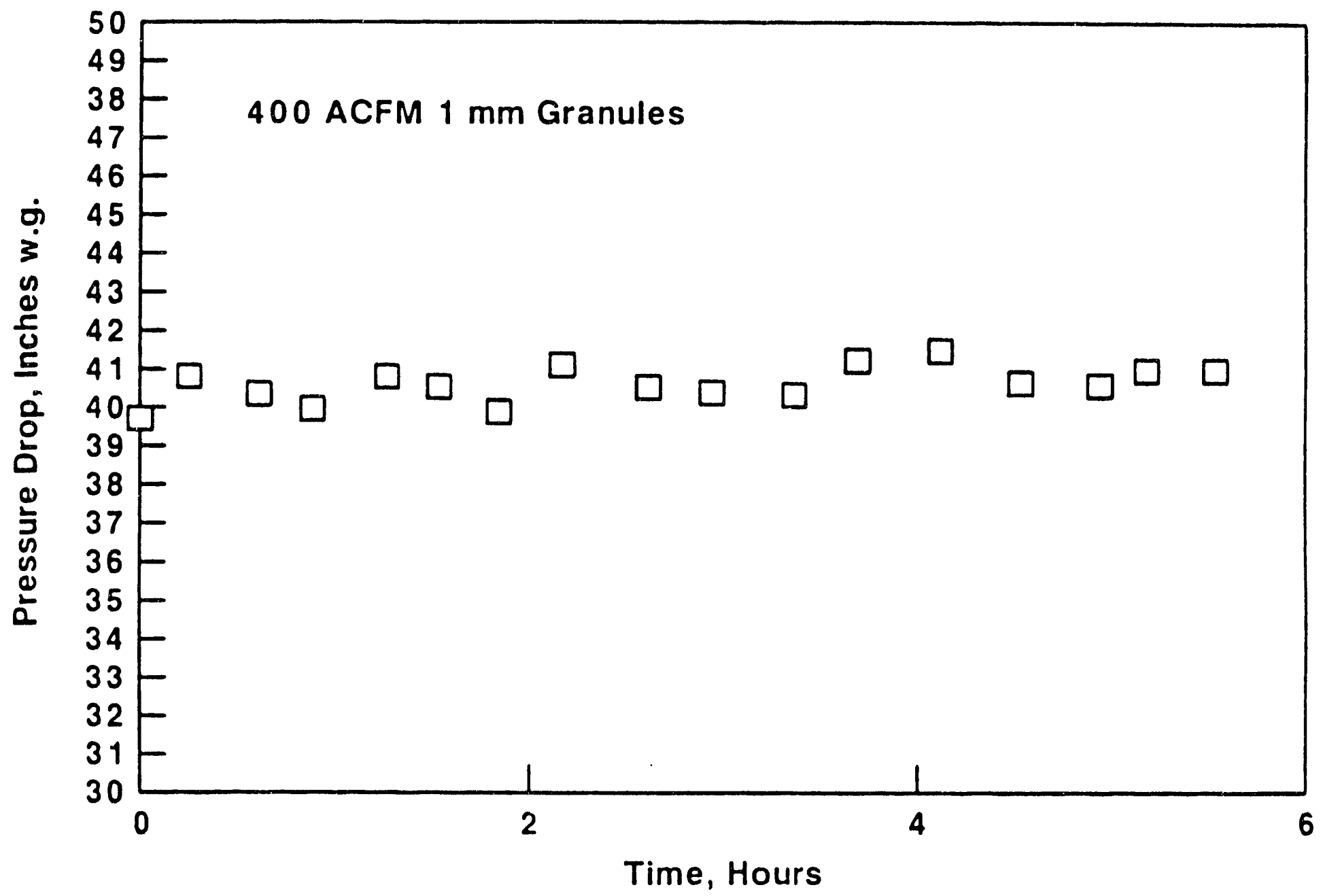

Figure 3.4.6 GBF pressure drop with time - cold Flow Model. 


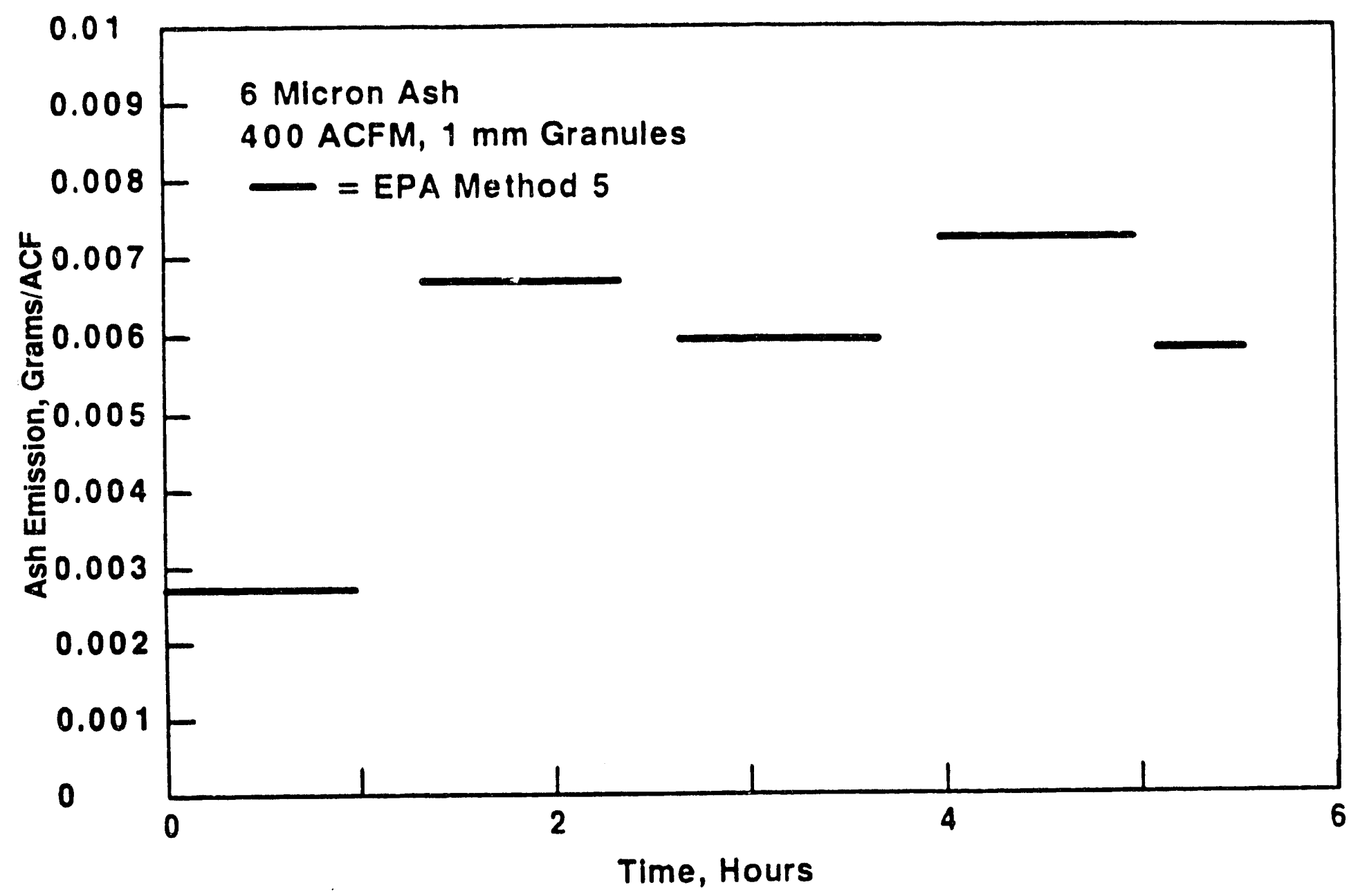

Figure 32.4.7 Dust emission from the FMGBM - Inlet concentration is $2 \mathrm{gr} / \mathrm{acf}$. 
ment of the high-temperature granular bed filter in the CRD combustion lab is shown in Figure 2.2.2.8. The structure's total height is $18 \mathrm{ft}$. The high-temperature laboratory granular bed filter was not fabricated, as it has been concluded that the granular bed filter is not an attractive approach for a gas turbine with an in-line combustion system.

3.2.4.2.3 Granular Bed Filter Conceptual Design. A conceptual design of a CWM-fired LM500 gas turbine with an integral granular bed filter was performed. A process flow diagram including all the main streams of the granular bed filter system is shown in Figure 2.2.2.9. The fuel feed to the combustor, stream 1, is a CWM containing $26.6 \mathrm{lbs} / \mathrm{hr}$ ash, $26.6 \mathrm{lbs} / \mathrm{hr}$ sulfur and $92.4 \mathrm{lbs} / \mathrm{hr}$ hydrated lime representing $1.1 \mathrm{Ca} / \mathrm{S}$ ratio. Stream 3 is the hot, clean, combustion gas containing $50 \%$ of the inlet sulfur and less than $1 \%$ of the total solids input. The captured sulfur in calcium sulfate form, as well as excess lime and coal ash are captured by the granular bed material and discharge from the filter vessel by means of a bottom discharge pipe, Stream 5 . The particle laden bed material discharging from the filter vessel contains about $5 \%$ captured particulate by weight. It is elevated to the de-entrainment vessel by a stream of lift air, Stream 6 . In the de-entrainment vessel the bed granules settle and flow back into the filter vessel through a small media reservoir vessel. The particles are entrained in the lift air, Stream 8, which is cooled in the heat exchanger, Stream 9, and filtered in a small low temperature, high pressure baghouse. The particles discharge from the system through a lockhopper system, Stream 11, while the clean air, Stream 10, is compressed in a boost compressor and recycled into the pneumatic lift system. The heat lost by the bed material during transportation is recovered by the heat exchanger and generates $700 \mathrm{lbs} / \mathrm{hr}$ of high-pressure steam. The $400^{\circ} \mathrm{F}, 250 \mathrm{psi}$ steam is used to cool the internal pipes. The steam, Stream 13, can be injected through the media reservoir or directly into the top of the annular space between the internal pipes. Steam injection increases the mass flow through the filter and the turbine by less than $1 \%$.

A schematic of the system layout, drawn to scale, is shown in Figure 2.2.2.10. The total height of the structure is about $70 \mathrm{ft}$. The height is driven by the need to allow access to the combustor and room for removing the top of the vessel.

The $9.5 \mathrm{ft}$ diameter granular bed filter shown in Figure 2.2.2.11 is a carbon steel vessel with 1 foot thick refractory lining which reduces the internal diameter of the vessel to $7.5 \mathrm{ft}$. A manhole on top of the vessel provides access to the vessel for stationary bed loading and for maintenance. The vessel is conservatively designed for an overall average velocity of about $3 \mathrm{ft} / \mathrm{s}$. Based on projection from current cold flow modeling, it is believed that the overall average velocity can be doubled. As a result the vessel size can be significantiy reduced or the flow can be significantly increased. The can combustor is located inside the vessel suspended from the top of the small dome. There is an inner and outer pipe arrangement similar to that in the cold-flow model for introduction of gases and media in the bed. The inner pipe ( $2 \mathrm{ft}$ diameter) penetrates deep into the granular bed vessel and directs the hot combustion gas into 
the bed. A moving bed of 1 to $2 \mathrm{~mm}$ alumina spheres is formed in the void between this inner pipe and the $4 \mathrm{ft}$ diameter outer pipe. The bed is 12 in. thick. It flows by gravity downward to the conical hopper at the bottom of the vessel and discharges through a 6 in. discharge pipe. The outer boundary of the moving bed is formed by the $4 \mathrm{ft}$ in diameter alloy pipe hanging from the top of the vessel. The fixed bed is located in the annular void between the $4 \mathrm{ft}$ internal pipe and the vessel refractory lined wall. The stationary bed comprises of layers of increasingly larger, in the outer and upper direction, alumina spheres. Without considerations to sticky or partially molten particles, the efficiency of the moving bed is expected to exceed 99\%.

Moving bed material is fed to the vessel from the top through three feeding pipes. The bed material then flow by gravity downward as described above. Steam at $400^{\circ} \mathrm{F}$ and $250 \mathrm{psi}$ is injected in the moving bed and is a sink for the heat conducted from the hot combustion gases. Heat transfer calculations shows that it takes about $500 \mathrm{lb} / \mathrm{hr}$ of $400^{\circ} \mathrm{F}$ steam to reduce the metal temperature to below $1800^{\circ} \mathrm{F}$ when the combustor gas is at $2200^{\circ} \mathrm{F}$. A higher-flow rate of steam results in an even lower temperature.

The small dome on top of the vessel is maintained at a temperature level of 500 to $800^{\circ} \mathrm{F}$ by the flow of compressor discharge air about $750^{\circ} \mathrm{F}$, the flow of steam at about $400^{\circ} \mathrm{F}$, and the flow of granular material at $1400^{\circ} \mathrm{F}$. All the flows are in the downward direction and hot gases from the combustor are not expected to penetrate into the dome space.

Additional work and detailed design of granular bed turbine interface as well as detailed design of the granular bed vessel are still required.

\subsubsection{Conclusions}

The GE granular bed filter has the advantages of using fine granules to achieve high filtration efficiency, yet it operates at high gas throughput per unit area typical of lowefficiency large bed material granular bed filters. Cold flow modeling tests have shown that the concept is feasible. Filtration efficiency should be high enough to meet NSPS requirements. Gas throughput is high, and pressure drop is reasonable (with dry particulates). However, experiments with actual products of coal combustion at relevant temperatures are required before feasibility can be demonstrated. Additional work should include investigation of the impact of various types of dusts on filtration efficiency and bed plugging. The impact of dust stickiness on filtration efficiency, bed plugging, and bed material cleaning is critical and requires further study. Optimization of internal piping arrangement to achieve higher gas throughputs, and erosion issues also need to be investigated further before feasibility can be fully assessed. 


\subsubsection{Economic Evaluation of Exhaust Gas Cleanup}

Sulfur removal with sorbent injection in the turbine combustor introduced aither with the CWM fuel or alone, has been experimentally evaluated. While sulfur capture was significant with sorbent injected in the combustor, heavy sorbent/ash deposits were formed on the first stage nozzle. Thus, this concept would require the use of a in-line particulate cleanup device such as a granular bed filter located between the combustor and the turbine. Unfortunately, the relative risk, cost and time required for the development of this concept were substantial. With the successful development of a method for control of coal-ash deposition, a particlecontrol device within the turbine is not needed. Thus, near conventional flue gas cleanup processes may be applied to the turbine exhaust gas.

Baghouse filters and electrostatic precipitators are two traditional particulate removal technologies considered for the exhaust gas. In general, resistivity of the sorbent/ash is considered moderate with sorbent/ash removal possible with existing electrostatic precipitators with or without small modifications to the inlet-gas stream. The presence of water increases particle resistivity. While dry FGD for sulfur removal and electrostatic precipitators for particulate control are compatible technologies, their use when paired provide no added advantages. However, an advantage exists with the use of a filter-baghouse system. Fabric filters are not only effective in removing sorbent and ash particles in the size range of interest, but also in capturing additional gas-phase sulfur with available unreacted calcium sorbent in the filter cake.

Thus, an effective emissions system which may be integrated with the coal-fueled turbine with minimal risk and good compatibility with the gas turbine is the dry FGD system coupled with a fabric filter for $\mathrm{SO}_{2}$ and particulate control.

This section presents the performance estimates, and economic analysis for exhaust gas cleanup downstream of a coal-fired gas turbine comprised of a spray absorber for $\mathrm{SO}_{2}$ and a fabric filter for particulate removal. This system is a direct transfer of proven technology from existing dry-flue gas desulfurization installations for utility pulverized coal-fired boiler applications as illustrated in Figure 3.2.5.1. As shown in this Figure, $\mathrm{SO}_{2}$ and flyash-laden gas from the boiler enters the top of the spray absorber. There it is contacted by a lime slurry atomized into fine droplets by a single rotary atomizer. Cyclonic gas flow within the absorber provides sufficient residence time for the gas inside the unit to evaporate the slurry water and to allow the lime to react with, and remove, the $\mathrm{SO}_{2}$ from the gas stream. Particulates which are not removed in the spray dryer are carried over to the fabric filter for removal. Additional $\mathrm{SO}_{2}$ removal occurs in the dust cake on the filter bags.

Deviating from the conventional dry flue gas desulfurization system for utility power generation, hydrated lime, rather than lower cost lime, can be specified in an effort to reduce the overall capital cost of this small system by the elimination of lime slaker. A waste heat 


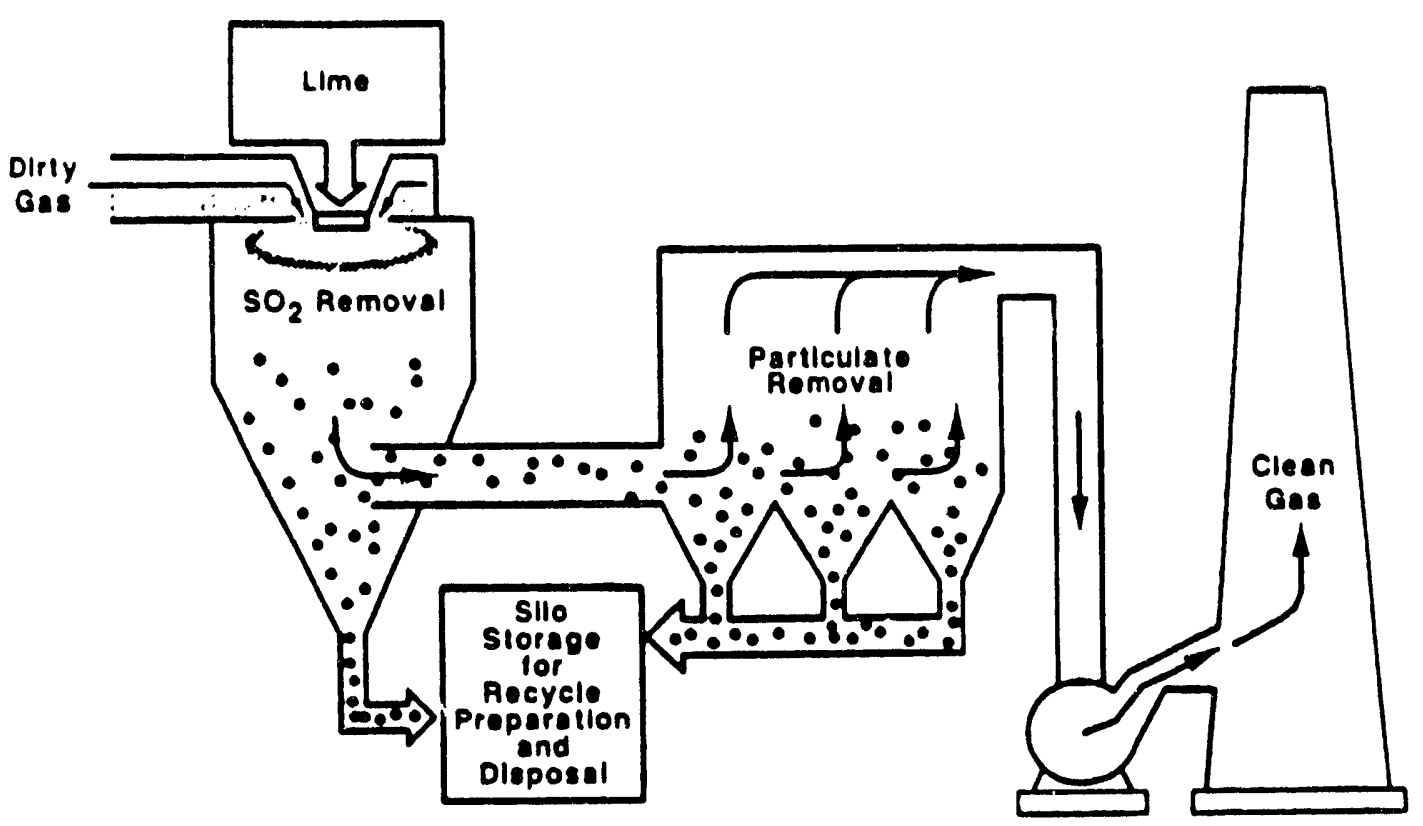

Figure 3.2.5.1 Dry-flue gas desulfurization process for coal-fired boilers. 
recovery boiler is, however, required ahead of the spray absorber to reduce the flue-gas temperature to the appropriate value for the absorber and the baghouse. A simplified process flow diagram is shown in Figure 3.2.5.2. Table 3.2.5.1 summarizes system conditions and performance. Table 3.2.5.2 describes the design and operating conditions of the pulse jet baghouse. The spray absorber and the baghouse are sized to operate at and up to about $50 \%$ in excess of the expected gas flow rate. A preliminary arrangement of this exhaust gas cleanup system is presented in Figure 3.2.5.3.

The cost estimates for the annular system with downstream flue-gas desulfurization were supplied by GE Environmental Systems (GEES). Where necessary, the data were adjusted to fit into the format necessary for the TAG methodology used in the economic model calculations [21].

The principal economic assumptions are listed in Tables 3.2.5.3 and 3.2.5.4. These values wera used as inputs to the economic model. Table 3.2.5.4 lists the economic parameters which were taken directly from the EPRI TAG publication, and Table 3.2.5.4 shows additional economic and performance assumptions with all dollar values being adjusted to January 1988 values using the assumed inflation rate of $6.0 \%$. Table 3.2.5.5 shows the general economic and performance parameters estimated for the CWM-fueled turbine with an annular combustor. The gas turbine heat rate, power exhaust flow, and process steam production were determined from cycle deck calculations. Table 3.2.5.6 summarizes the capital cost estimates used for the plant equipment.

A cost estimate for this system has been made based on a commercial sulfur and particulate control system consisting of a dry, flue-gas desulfurization and baghouse filter system installed downstream of the turbine exhaust as illustrated in Figure 3.2.5.3. All pertinent assumptions used in arriving at the cost estimate for this system are summarized in Table 3.2.5.7. In this table, a capacity factor of 0.7 is assumed for base-load operation in estimating the variable operating and maintenance costs, and long-term inflation rate of $6 \%$ per year is used. Hydrated lime was chosen as the sulfur-capture sorbent instead of conventional pebble lime, which would require additional on-site treatment. This saves $\$ 113,000$ in capital cost or about $13 \%$ of the total capital cost for this cleanup system. The use of a two-fluid nozzle system would further reduce the total process capital requirement, but is not included because GEES does not offer a commercial two-fluid nozzle system.

The cost estimate for this commercial sulfur and particulate control system is presented in Table 3.2.5.8. The total and itemized direct cost estimates are shown, as well as the first-year operating and maintenance costs. These estimates are consistent with EPRI TAG formats and procedures, although to establish this reference cost in as general a manner as possible, cost items which are site and system specific have been neglected. These neglected items include: 


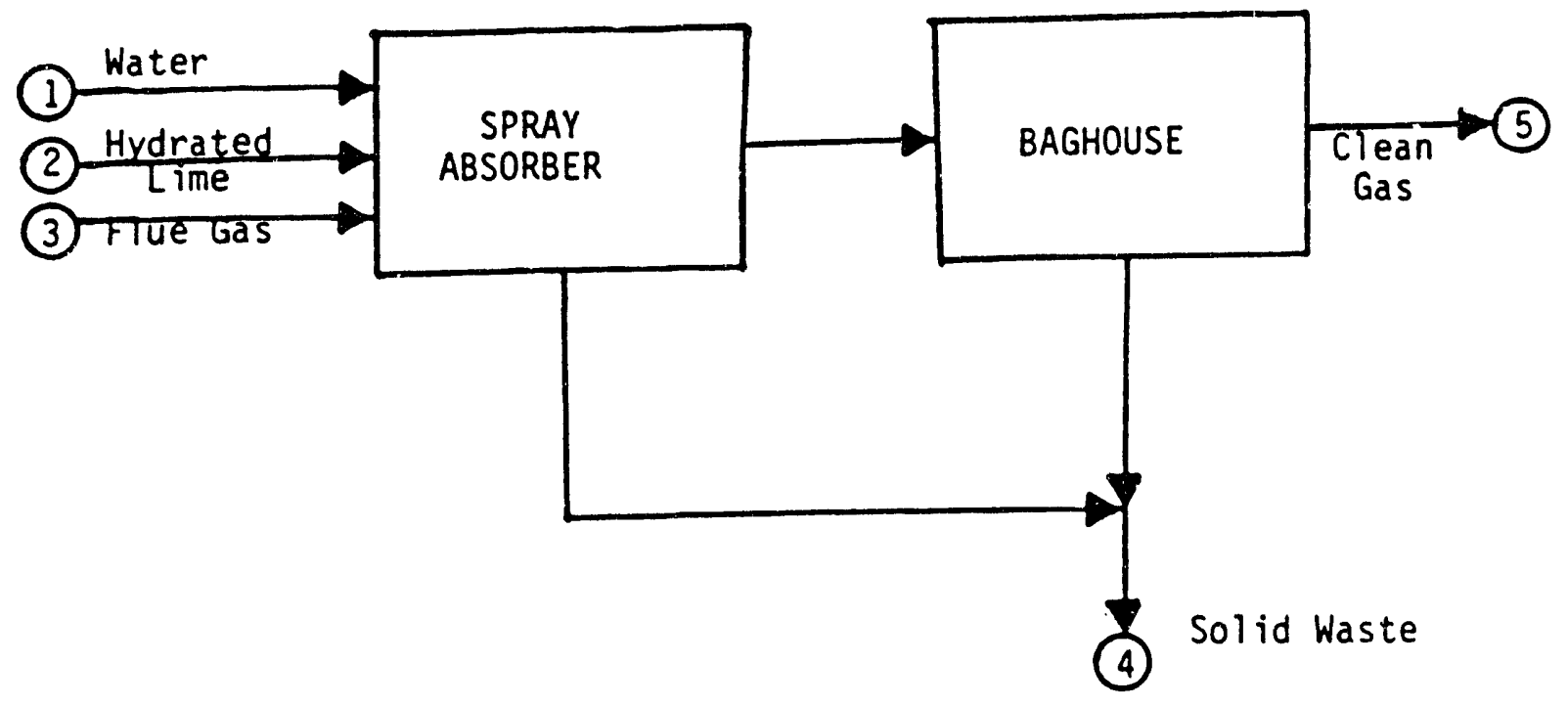

(1) Water $5340 \mathrm{lbs} / \mathrm{hr}$

(2) Hydrated Line $80 \mathrm{lbs} / \mathrm{hr}$
(3) Flue Gas $97,000 \mathrm{lbs} / \mathrm{hr}$
Particulate $40 \mathrm{lbs} / \mathrm{hr}$ $\mathrm{SO}_{2} \quad 40 \mathrm{lbs} / \mathrm{hr}$

(4) Solid Waste $150 \mathrm{lbs} / \mathrm{hr}$

(5) Clean Gas $102,302 \mathrm{lbs} / \mathrm{hr}$

Particulate $0.7 \mathrm{lbs} / \mathrm{hr}$

$\mathrm{SO}_{2} \quad 8 \mathrm{ibs} / \mathrm{hr}$

Figure 3.2.5. Simplified process flow diagram. 
Table 32.5.1

System Conditions and Performance

Inlet Conditions to Dry FGD

Flow rate

35,000 ACFM

Pressure

$14.7 \mathrm{psi}$

Temperature $370^{\circ} \mathrm{F}$

Particulate loading (with kaolin)

Sulfur dioxide

$40 \mathrm{lb} / \mathrm{hr}$

$40 \mathrm{lb} / \mathrm{hr}$

187 PPMV

Outlet Conditions from Fabric Filter

Flow rate

Pressure

Temperature

Particulate loading

Sulfur dioxide

27,000 ACFM

$14.7 \mathrm{psi}$

$165 \%$

$0.7 \mathrm{lb} / \mathrm{hr}$

$8 \mathrm{lb} / \mathrm{hr}$

35 PPMV

Table 32.52

Pulse Jet Baghouse

Design and Operatiug Conditions

Design Conditions

Maximum volume

Temperature $175^{\circ} \mathrm{F}$

Dust loading

Assumed part. size rist.
44,000 ACFM

$1.0 \mathrm{GR} / \mathrm{ACF}$

$6 \mu \mathrm{m} M M D$

Expected Pulse Jet Offering

Pulse jet model no.

Air-to-cloth ratio

Gross

Net-1

Expected pressure drop

Expected outlet emission level
4-154-6-14

$3.26: 1$

4.35:1

6.0 in. W.C.

$0.02-0.03 \mathrm{lb} / \mathrm{mm}$ Btus 


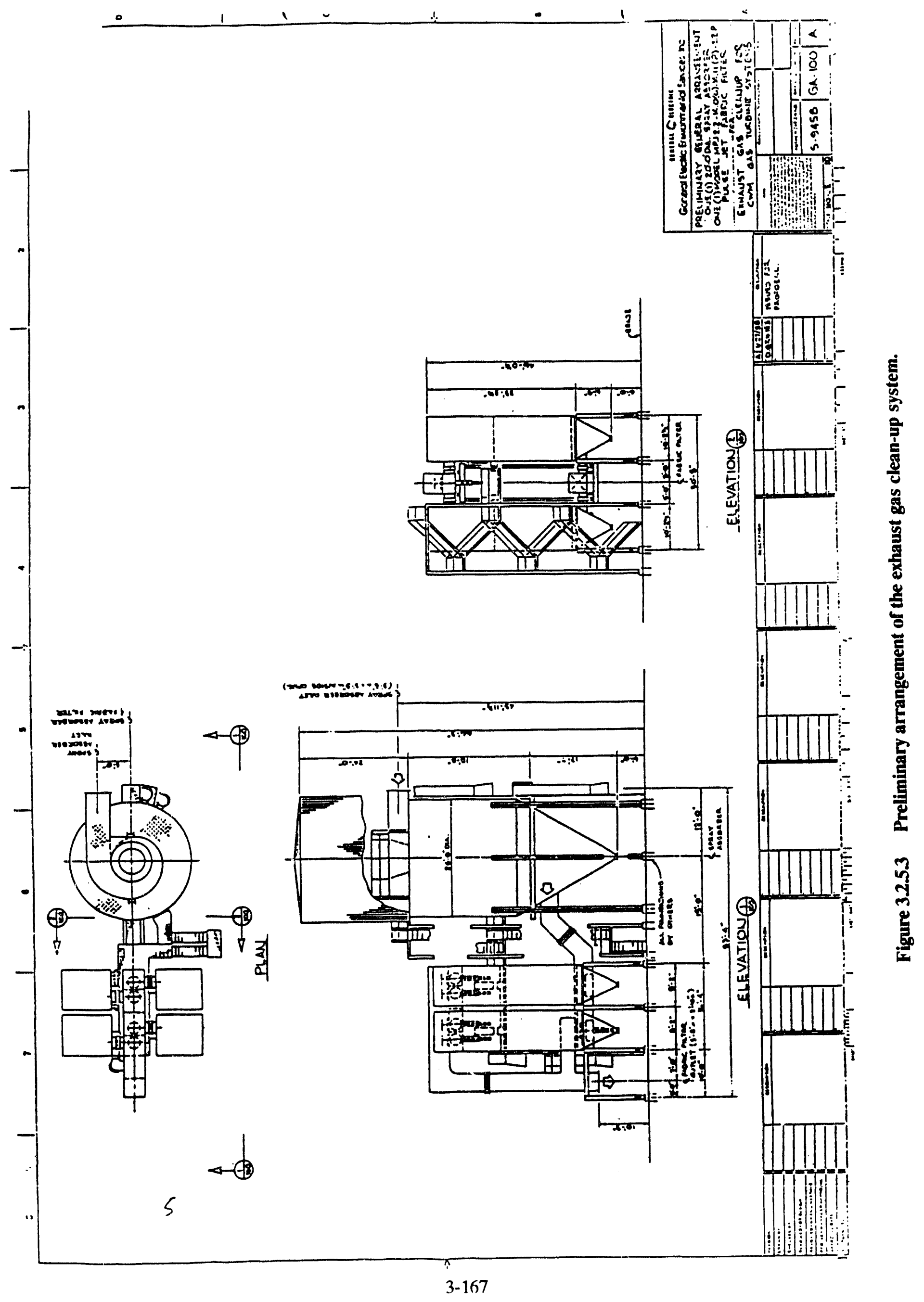


Table 3.2 .5 .3

Economic Parameter Used

Consistent with 1986 EPRI TAG

(All Costs Adjusted to January 1988 \$)

\begin{tabular}{lr}
\hline Parameter & Value \\
\hline Interest Rate for Financing, \% & 12.5 \\
Discount Rate for Net Present Value, \% & 12.5 \\
Inflation Rate, \% & 6.0 \\
Fuel Escalation Rate, \% & 6.8 \\
Electricity Escalation Rate, \% & 6.3 \\
Steam Credit Escalation Rate, \% & 6.3 \\
Net Tax Rate, \% & 38.0 \\
Property Taxes \& Insurance, \% & 2.0 \\
Depreciation Method & $150 \% . c o m b i n a t i o n$ \\
Tax Lifetime, years & 20 \\
Field Index for Indirect Costs, \% & 90 \\
O\&M Labor Fraction of Total O\&M, \% & 40 \\
Overhead Rate for O\&M Labor, \% & 30 \\
Labor Wage, \$/hr & 23.46 \\
Preproduction period, months & 1 \\
Preproduction Capaciry, \% & 25 \\
Other Preproduction Costs, \% of TPI & 2 \\
Inventory Period, days & 80 \\
Land Cost, \$ & 7742 \\
Water Acquisition Cost, \$/1000-gal & 0.71 \\
Steam Credit, \$/1000-lbm & 4 \\
Electricity Credit, \$/kWh & 0.06 \\
\hline
\end{tabular}


Table 3.2.5.4

Economic Parameters Used

Based on Best Estimates

(January 1988 \$)

\begin{tabular}{lr}
\hline Parameter & Value \\
\hline Construction Period, years & 2 \\
Plant Lifetime, years & 20 \\
Debt, \% & 75 \\
Term of Loan, years & 16 \\
Sales Tax, \% & 5 \\
General Facilities, \% of Total Process Capital & 10 \\
Jobs, persons per shift & 1 \\
Solid Waste Disposal Costs, \$/ton & 22.72 \\
Plant Capacity Factor, \% & 75 \\
\hline
\end{tabular}

Table 3.2 .55

Base-Case Economic and Performance Parameters

\begin{tabular}{lrrr}
\hline & Petroleum-Fired & Annular & Off-Board \\
\hline Project Contingency, \% & 10 & 15 & 15 \\
Engineering/Home Office Fees, \% & 5 & 5 & 10 \\
Land Requirements, acres & 0.5 & 1 & 1 \\
Gas Turbine Heat Rate, HHV Btu/kWh & 11,970 & 12,548 & 12,692 \\
Gas Turbine Power, KW & 3803 & 3737 & 3538 \\
Gas Turbine Exhaust Flow, lb/hr & 120,240 & 123,120 & 118,116 \\
Process Steam Production, Ibm/hr & 21,300 & 21,500 & 20,700 \\
Fuel HHV, Btu/lbm & 19,504 & 7050 & 7050 \\
Fuel Ash Content, \% & 0.0 & 0.4 & 0.4 \\
Fuel Sulfur Content, \% & 0.0 & 0.5 & 0.5 \\
Fuel Water Content, \% & 0.0 & 50.0 & 50.0 \\
Sorbent/Fuel Molar Ratio & 0.0 & 0.0 & 1.254 \\
Sorbent Molecular Weight & $\mathrm{N} / \mathrm{A}$ & $\mathrm{N} / \mathrm{A}$ & 74 \\
Sorbent Cost, \$/ton & $\mathrm{N} / \mathrm{A}$ & $\mathrm{N} / \mathrm{A}$ & 70 \\
Chemicals/Exhaust Ratio & 0.0 & 0.00065 & 0.000024 \\
Chemicals Cost, \$/ton & $\mathrm{N} / \mathrm{A}$ & 70 & 2000 \\
Excess Water Usage, \% of process & 1.0 & 25.0 & 5.0 \\
\hline
\end{tabular}


Table 32.5.6

Capital Cost Estimates

\begin{tabular}{|c|c|c|}
\hline & Petroleum-Fired & Annular \\
\hline \multicolumn{3}{|l|}{ Gas Turbine } \\
\hline $\begin{array}{l}\text { Factory Material, } \$ 000 \text { 's } \\
\text { Field Installation, } \$ 000 \text { 's } \\
\text { Process Contingency, \% } \\
\text { Maintenance Factor, \% }\end{array}$ & $\begin{array}{r}1300 \\
0 \\
0 \\
2\end{array}$ & $\begin{array}{r}1300 \\
0 \\
5 \\
6\end{array}$ \\
\hline \multicolumn{3}{|l|}{ HRSG } \\
\hline $\begin{array}{l}\text { Factory Material, } \$ 000 \text { 's } \\
\text { Field Material, \$000's } \\
\text { Field Labor, \$000's } \\
\text { Process Contingency, \% } \\
\text { Maintenance Factor, \% } \\
\text { Power Requirements, kW }\end{array}$ & $\begin{array}{r}324 \\
0 \\
40 \\
0 \\
2 \\
25\end{array}$ & $\begin{array}{r}324 \\
0 \\
40 \\
0 \\
2 \\
25\end{array}$ \\
\hline \multicolumn{3}{|c|}{ Coai-Water Slurry Receiving/Transfer } \\
\hline $\begin{array}{l}\text { Size of Unit Costed, lb/s } \\
\text { Factory Material, \$000's } \\
\text { Field Material, \$000's } \\
\text { Field Labor, \$000's } \\
\text { Process Contingency, \% } \\
\text { Maintenance Factor, \% } \\
\text { Power Requirements, kW }\end{array}$ & & $\begin{array}{r}117.3 \\
0 \\
908 \\
485 \\
15 \\
3 \\
25\end{array}$ \\
\hline \multicolumn{3}{|l|}{ Annular System } \\
\hline $\begin{array}{l}\text { Faciory Material, \$000's } \\
\text { Field Material, \$000's } \\
\text { Field Labor, \$000's } \\
\text { Process Contingency, \% } \\
\text { Maintenarce Factor, \% } \\
\text { Power Requirements, kW }\end{array}$ & & $\begin{array}{r}561 \\
118 \\
92 \\
5 \\
4 \\
80\end{array}$ \\
\hline
\end{tabular}


Table 3.2.5.7

Exhaust Gas Cleanup

Cost Assumptions

CAPACITY FACTOR

PARTICULATE REMOVAL

$\mathrm{SO}_{2}$ REMOVAL

SORBENT CONSUMFTION

WATER CONSUMPTION

POWER CONSUMPTION

SOLID WASTE PRODUCTION

INFLATION RATE

CONSTRUCTION PERIOD

BASE YEAR OF COST ESTIMATE

HYDRATED LIME COST

WATER COST

POWER COST

DISPOSAL COST, OFF SITE

LABOR COST (O\&M)

BAG $\operatorname{COST}\left(6^{\prime \prime}\right.$ DIA $\left.\times 14^{\circ}, 160 Z\right)$
BASE LOAD, 70\%

$0.7(8760 \mathrm{HRS} / \mathrm{YR})=6132 \mathrm{HRS} / \mathrm{YF}$

GEESI INOUSTRIAL PULSE JET BAGHOUSE

(1) MODEL MPJ2.2-14.0(6)-14.11(P)-2.2P

GEESI SPRAY ABSORBER

(1) 20 FT-O IN. DIA VESSE:

HYDRATED LIME $\odot 80$ LBS/HR

$641 \mathrm{GAL} / \mathrm{HR}$

$80 \mathrm{KW}$

$150 \mathrm{LBS} / \mathrm{HR}$

$6 \% / Y R$

$1 Y R$

JANUARY 1988

$\$ 70 / T O N F .0 . B$. CHICAGO

$\$ 0.50 / 1000 \mathrm{GAL}$

$\$ 0.035 / K W$ HR

\$22.71/TON 1 HR HAUL DISTANCE AND BASED ON 50 LBS/FT ${ }^{3}$ DENSITY

$\$ 24.50 / H R$

$\$ 20.34 / B A G$ 


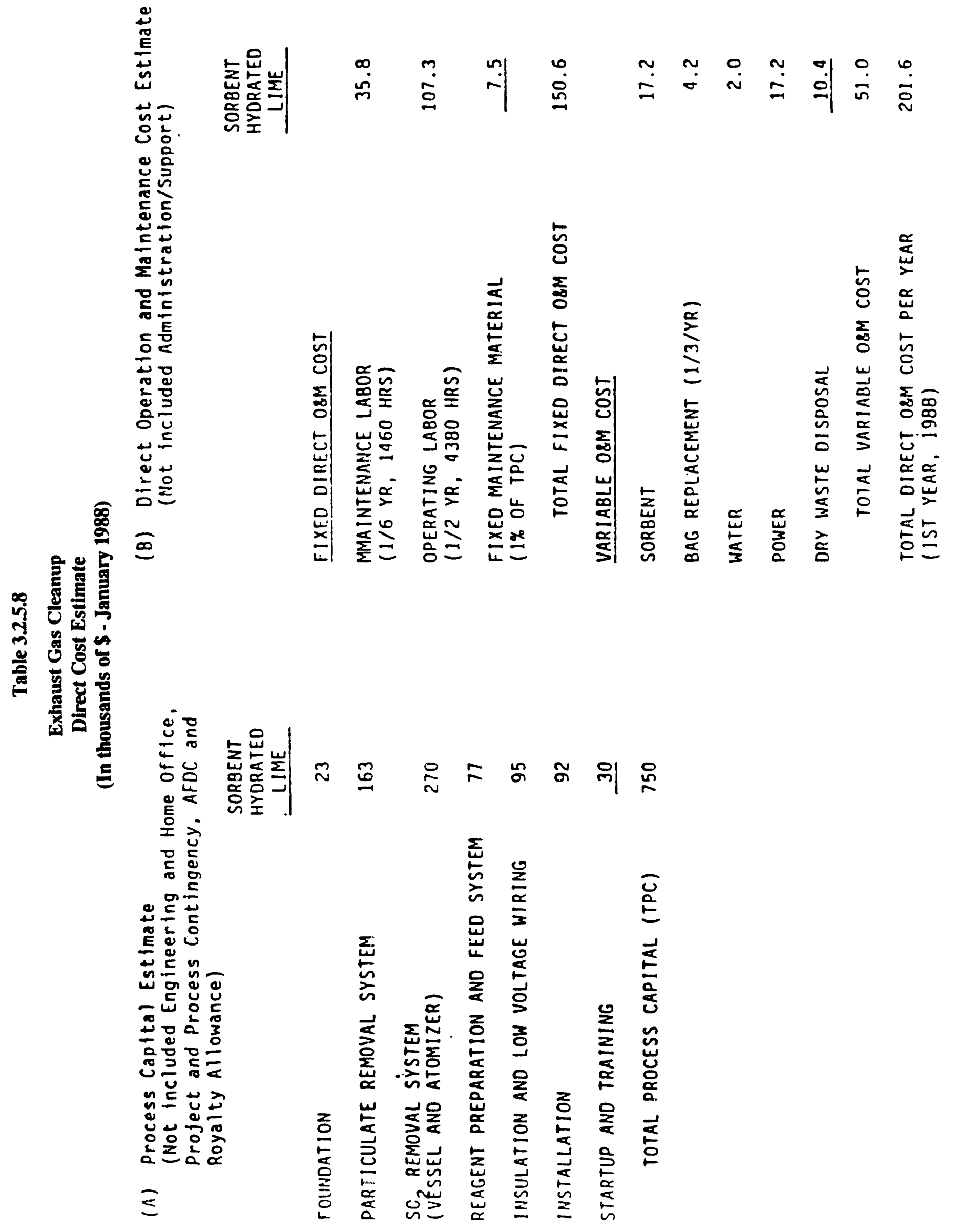


- Seismic zone

- Soil conditions

- Altitude

- Climate

- Regional cost factors

- Site accessibility

- Connecting ductwork

The annular system is based on commercially proven technologies; therefore, a process contingency of 5\% is consistent with EPRI TAG recommendations and is used in the economic model for this plant section.

It is expected that gas turbine maintenance costs will increase when the turbine is fired by a coal-water mixture. Table 3.2.5.9 shows the effect of increased maintenance costs on the system economics for the annular combustor system with downstream cleanup and with the higher-performance $(130 \%)$ gas turbine engines. With a maintenance factor of $6 \%$, which is significantly higher than a normal maintenance factor of 2 to $3 \%$ for a petroleum-fired system, the calculated internal rate of return is $60.2 \%$. If the maintenance factor were increased to $24 \%$, which would represent a yearly maintenance cost of over $\$ 400,000$ (enough for yearly turbine reblading), the internal rate of return would decrease to $50.9 \%$. Maintenance costs are thus shown to be significant, but even with extreme maintenance assumptions, the economics of the annular system with downstream cleanup remain attractive.

Table 3.2.5.9

Effect of Gas Turbine Maintenance Costs

Maintenance Factor

(\%)

6

12

18

24 Yearly Maintenance Charge
(January 1988 \$)

102,000

205,000

307,000

$410,000^{\star}$
IRR

(Current \$, \%)

60.2

57.1

54.7

50.9

* Full Reblading Every Year 


\subsubsection{Summary and Conclusions}

Methods for the control of emissions from coal-fueled gas turbines have been evaluated. Table 3.2.6.1 summarizes approaches which were considered.

The emissions control systems selected for technical evaluation under this program were:

\begin{tabular}{ccc} 
Sulfur & $\mathrm{NO}_{x}$ & Particulates \\
\hline $\begin{array}{c}\text { Sorbent Injection } \\
\text { in Combustor } \\
\text { Sorbent injection }\end{array}$ & Staged Combustion & Exhaust Gas Cleanup \\
& Staged Combustion & $\begin{array}{c}\text { In-Line Granular Bed } \\
\text { Filter }\end{array}$
\end{tabular}

Selection of these systems was made for their integration potential with gas turbine systems and their potential effectiveness. It should also be noted that, although not directly evaluated under this program, exhaust gas cleanup has been addressed through the work performed on ash deposition control, as the use of downstream cleanup requires that the turbine be tolerant to the coal ash.

Mixing calcium sorbents with the CWM fuel was found to be surprisingly effective for sulfur capture. At $\mathrm{Ca} / \mathrm{S}=1.5,60 \%$ sulfur capture was obtained despite the unfavorable thermal environment of the combustor. However, severe deposition on the first-stage nozzle occurred. Methods for deposit control which were developed for CWM without sulfur sorbent were found to be inadequate. Laboratory studies indicated that injection of sorbent into the combustor in other locations, such as with the swirl air, would be slightly less effective in capturing sulfur. However, it is expected that severe deposition would also accompany this approach.

It was concluded that sorbent injection into the combustor would require an in-line particulate capture device for turbine protection. The granular bed filter (GBF) was selected for evaluation because of its potential tolerance to sticky-ash particles which are present in the combustor exit gas. It was felt that barrier filters would quickly become irreversibly fouled and that inertial devices such as cyclones would have inadequate performance for small particles.

In order to use a GBF, a concept in which granular media are not constrained by screens, was required as restraining devices such as screens and louvers would quickly become plugged. A fixed-moving granular bed concept in which large granular media are used to constrain smaller media, which perform the filtration function, was identified and cold-flow 
Table 3.2.6.1

Candidate Emissions Control Technologies

\begin{tabular}{|c|c|c|c|}
\hline Pollutant & Approach & Technical Status & Technical Issues \\
\hline \multirow[t]{7}{*}{ Sulfur } & Coal beneficiation & $\begin{array}{l}\text { Physical cleaning- } \\
\text { near commercial }\end{array}$ & $\begin{array}{c}\text { Removes only pyritic } \\
\text { sulfur }\end{array}$ \\
\hline & & $\begin{array}{l}\text { Molten Caustic- } \\
\text { pilot }\end{array}$ & $\begin{array}{l}\text { Probable high cost } \\
\text { Residual alkali }\end{array}$ \\
\hline & & $\begin{array}{l}\text { Microbial Desulf- } \\
\text { laboratory }\end{array}$ & Slow rate \\
\hline & $\begin{array}{l}\text { Sorbent injection } \\
\text { in combustor }\end{array}$ & $\begin{array}{l}\text { Lab scale testing } \\
\text { under this program }\end{array}$ & $\begin{array}{l}\text { Deposition in hot } \\
\text { gas path }\end{array}$ \\
\hline & $\begin{array}{l}\text { Granular bed filter } \\
\text { with sorbent }\end{array}$ & Not tested & $\begin{array}{l}\text { GBF integration with } \\
\text { gas turbine }\end{array}$ \\
\hline & Exhaust gas cleanup & $\begin{array}{l}\text { High temperature- } \\
\text { lab and pilot }\end{array}$ & $\begin{array}{c}\text { Effective } 1000^{\circ} \mathrm{F} \\
\text { sorbent }\end{array}$ \\
\hline & & $\begin{array}{l}\text { Low temperature- } \\
\text { commercial }\end{array}$ & Cost \\
\hline \multirow[t]{3}{*}{$\begin{array}{l}\text { Nitrogen } \\
\text { oxides }\end{array}$} & Staged combustion & Applied to furnaces & $\begin{array}{l}\text { Effective staging } \\
\text { in g.t. type system }\end{array}$ \\
\hline & Exhaust gas cleanup & $\underset{\text { laboratory }}{\text { Simultaneous } \mathrm{SO}_{2} \mathrm{NO}_{x}}$ & Cost \\
\hline & & $\begin{array}{l}\text { Selective cataiytic } \\
\text { reduction (SCR)- } \\
\text { commercial }\end{array}$ & Cost \\
\hline \multirow[t]{3}{*}{$\begin{array}{l}\text { Partic- } \\
\text { ulates }\end{array}$} & $\begin{array}{l}\text { High temperature } \\
\text { granular bed filter }\end{array}$ & $\begin{array}{l}\text { Pilot scale testing } \\
\text { on PFB }\end{array}$ & $\begin{array}{l}\text { Integration with } \\
\text { gas turbine }\end{array}$ \\
\hline & $\begin{array}{l}\text { High temperature } \\
\text { barrier filters }\end{array}$ & $\begin{array}{l}\text { Pilot scale tests } \\
\text { on PFB }\end{array}$ & $\begin{array}{c}\text { Operation at }>2000^{\circ} \mathrm{F} \\
\text { Filter plugging }\end{array}$ \\
\hline & Exhaust gas cleanup & Commercial & Cost - high flows \\
\hline
\end{tabular}


evaluations performed. After several conceptual designs were developed, it was determined that the inherent advantages of the in-line metal wall combustion system would be substantially compromised if a GBF were incorporated into the gas turbine system.

The primary approach for $\mathrm{NO}_{x}$ control is staged combustion, which was not experimentally evaluated under this program.

As a result of these studies along with the promising results for the use of additives for control of coal-ash deposition, it was determined that the most feasible emissions control is cleaning of the exhaust gas. Exhaust gas cleanup technology for sulfur, $\mathrm{NO}_{\mathbf{x}}$, and particulate control are commercially available. Modifications may be required in order to optimize these systems for the coal-fueled gas turbine.

\subsubsection{References}

[1] D.V. Keller, Fifth Symposium on Coal Slurry for Combustion Tech., April 1983, U.S. DOE, Pittsburgh, $\mathrm{Pa}$.

[2] T.E. Emmel, and B.A. Laseke, "Analysis Of Utility Control Strategies Using the LIMB Technology," Radian Corporation, EPA Final Report, NTIS: PB87100574

[3] S.G. Kimura, C.L. Spiro, and C.C. Chen, "Alkali Species Characterization for CoalFueled Gas Turbines", Proceedings of the Third Annual Heat Engines Contractors Meeting, U.S.DOE, May 1986.

[4] D.P. Smith, "TMGR, A Computer-Aided Test System," General Electric publication, 1985.

[5] G.D. Silcox, et al., "Status And Evaluation of Calcitic $\mathrm{SO}_{2}$ Capture: Analysis of Facilities Performance," Final Report, EPA Contract 68-02-4208, 1986.

[6] J.S. Abichandani, "Super Equilibrium Sulfur Removal From High-Temperature Gases", presented at the Advanced Coal Fuel Heat Engines and Gas Stream Cleanup Systems Contractors Review Meeting, U.S. DOE, June 1988

[7] S.G. Kimura, C.L. Spiro, and C.C. Chen, "Combustion and Deposition in Coal-Fired Turbines," ASME Transactions, J.Engineering for Gas Turbines and Power Vol 109, July 1987.

[8] D..M. Slaughter, "Formation and Control of Nitrogen and Sulfur Oxides in Suspension Coal Combustion," Ph.D. Dissertation, Department of Chemical Engineering, University of Utah, 1986.

[9] C.L. Spiro, "GE Gas Turbine Environmental and Deposition Control", Annual Coal Fuel Heat Engines and Gas Stream Cleanup Systems Contractors Review Meeting, June 1988.

[10] C.L. Spiro, S.G. Kimura, and C.C. Chen, "Ash Behavior During Combustion and Deposition in Coal-Fueled Gas Turbines", Trans ASME J. Engineering for Gas Turbines and Power Vol 109, July 1987. 
[11] C.R. Milne, D.W. Pershing, "Time resolved Rate Measurements for Sized Sorbents," Presented at the Pittsburgh Coal Conference, September 1987.

[12] L.J. Muzio, et al., "Dry Sorbent $\mathrm{SO}_{2}$ Control for New Power Plants Burning Low Sulfur Western Coals," Proceedings 1986 Symposium on Dry $\mathrm{SO}_{2}$ and Simultaneous $\mathrm{SO}_{x} / \mathrm{NO}_{x}$ Control Technologies Vol 1, December 1986.

[13] S.A. Johnson, Private Communication, November 1987.

[14] D.M. Slaughter, "Enhanced Sulfur Capture by Calcium-Based Sorbents", Proceedings of the 1986 Symposium on $\mathrm{Dr} y \mathrm{SO}_{2}$ and Simultaneous $\mathrm{SO}_{x} / \mathrm{NO}_{x}$ Control Technologies, Vol 1, December 1986

[15] T.J. Rosfjord, "Coal Water Mixture Combustion Technology Development", Third Annual Heat Engines Contractors Meeting, U.S. DOE, May 1986.

[16] J.C. McArdle, D.G. Leshock, and B.R. Williamson, "Sorbent Life Cycle Testing Fluidized-Bed Copper Oxide Process", Third Annual Coal Utilization and Environmental Control Contractors Conference, U.S. DOE, July 1987.

[17] H.P. Tseng, J.L. Haslbeck, and L.G. Heal, "Evaluation of the NO $\mathrm{NO}_{x}$ Combined $\mathrm{NO}_{x} / \mathrm{SO}_{2}$ Flue Gas Treatment Process, DOE/FE/60148-T2, Sept. 1983.

[18] S.G. Kimura, "Method for Scrubbing Sulfur Oxides and Nitrogen Oxides in a Flue Gas Duct”, U.S. Patent 4,645,653, Feb. 1987.

[19] K.B. Wilson, K.B., "Granular Bed Filter Evaluation in a Pressurized Fluidized Bed System", Fifth Annual Contractors Meeting on Contaminant Control in Coal Derived Gas Streams, May 1985.

[20] M.W. Horner, P.E. Sabla, and S.G. Kimura, "Coal-Fueled Aero-Derivative Gas Turbine: Design Approach", Gas Turbine and Aeroengine Congress, June 1988.

[21] TAG-Technical Assessment Guide, EPRI RP-4463-SR, V.1, Electric Power Research Institute, Palo Alto, Ca 1980. 


\subsection{Fuel Atomization}

\subsubsection{Introduction}

Prior research and development programs have shown that fuel atomization and combustion zone mixing are very important to successful combustion of coal-water slurries, References [15, 25, and 26]. In these testing programs, natural gas or fuel oil was used to establish a stable flame and to avoid ignition delay of the slurry fuel droplets. The first attempts at burning coal-water slurries in a $27.9 \mathrm{~cm}$ diameter cylindrical can combustor, as reported in Reference [25], resulted in severe combustion instabilities when slurry flow exceeded $80 \%$ on a heat input basis. These tests indicated that improved fuel atomization and enhanced recirculation would be needed to reduce the use of auxiliary fuel. The approach taken here for successful combustion of coal-water slurries in gas turbines involves the use of in-line, short residence time combustors typical of present day gas turbines. Use of near-conventional technology for fuel atomization, fuel-air mixing, liner cooling, air dilution and overall fabrication techniques improves the reliability of analytical predictions as well as hardware producibility. Benefit is also taken of significant on-going research and development activities toward improvements in the technical performance of these combustion systems for aircraft applications.

This section describes the results of studies to characterize CWS fuel nozzle performance and to establish predictive combustor performance criteria for coal-water fuels. The nozzle characterization studies employed an optical particle sizer and measured velocity profiles to obtain the spatial and temporal drop size distributions. The combustor performance criteria were developed using a 3D code to predict the fuel drop residence time and combustor velocity field. The performance criteria and model results have been compared with actual combustion performance.

\subsubsection{Fuel Nozzle Characterization}

To achieve carbon burnout in gas turbine combustors using micronizea coal-water slurries, minimum atomized drop size is required since the short available residence times, typically 20 to $30 \mathrm{msec}$, are of the same magnitude as the time needed for complete carbon utilization. This is especially the case if the micronized slurry droplets burn in the agglomerated manner shown for larger coal particles by Beer [1]. Standard pulverized coal slurries were not considered in vievv of the need for maximum ash removal from the coal and the fact that the large particle fraction of such coals is too large for the required residence time. To determine whether air atomized nozzles can achieve the needed drop size, a spray tunnel was employed to obtain the spatial and temporal drop size distribution of several candidate nozzle designs. An axisymmetric flow model of the spray tunnel was employed with measured velocity profiles to verify the calculation method employed to yield the temporal drop size distribution. The characterization technique, nozzle performance results and their verification are given below. 


\subsubsection{Characterization Technique}

A schematic of the spray tunnel employed to measure the spray drop size distribution is shown in Figure 3.3.1 and described further in Reference [2]. The $25 \mathrm{~cm}$ diameter tunnel allows a uniform axial velocity environment to $30 \mathrm{~m} / \mathrm{s}$ at 1 atn and can be operated at pressures to $10 \mathrm{~atm}$, temperatures to $150^{\circ} \mathrm{C}$ and at controlled relative humidities between $10 \%$ and $90 \%$. Tile spray can be traversed over the tunnel diameter and over an axial distance from a 2 meters nozzle. The opposed windows are optically flat and parallel. A Malvern Mod 2600 HSD optical particle sizer is mounted on the traversing bench shown in Figure 3.3.1. Suitable slurry flushing and separation is provided. The tunnel is operated at a velocity large enough to prevent any recirculation of drops from the spray envelope.

In a prior investigation, Reference [3], GE Corporate Research and Development (CRD), designed LT nozzle, Figure 3.3.2, was selected for the $15 \mathrm{~cm}$ diameter combustor employed here since it provided the desired spray diameter and small drop size. A comparison with a Parker Hannefin nozzle is given subsequently.

The atomized spray structure can be roughly divided into three regions that more or less overlap. These consist of the initial drop formation region, discussed by Simpkins and Bates [4] and Chigier [5], the relative deceleration region where the spatial size distribution is a strong function of axial distance, Lefevbre [6], and the developed spray region where droplet behavior is dictated by the ambient flow field. Since the tunnel provides a well defined ambient field, the axial distance selected for the traversing measurements reported here was just beyond the relative deceleration region. The latter was calculated to be about $8 \mathrm{~cm}$ at a $1 \mathrm{~atm}$ tunnel pressure using a drop tracking model, Reference [2]. Selected spatial measurements are reviewed below, followed by a brief discussion of the calculation method for the temporal distribution and the verification of this simplified characterization technique.

As a first step to determine the temporal drop size distribution generated by each nozzle, the multiple chordal scans of both the drop size distribution and their concentration, obtained at $9 \mathrm{~cm}$ axial distance, were first transformed to radial distributions, see Chigier et al. [7] and Cormack [8]. The large beam obscuration encountered near the spray centerline required correction due to multiple scattering effects. The correction relations given by Felton [9] were employed. When those of Dodge [10] were used, excessive correction at high obscuration was obtained as evidenced by the fact that the corrected drop sizes were maximum at about half the spray radius while both the measurements and the drop flow analysis showed that the maximum drops are located at the outer radius of the spray.

The second step used to determine the temporal size distribution generated by each nozzle was to measure the axial air velocity distributions of the same measurement location and the same nozzle operating point but without fuel flcw. As will be observed subsequently, the assumption of equal axial air and drop velocities over the spray diameter is reasonably 
$180^{\circ}$ OPPOSED WINDOWS, VARIABLE AXIAL LOCATION

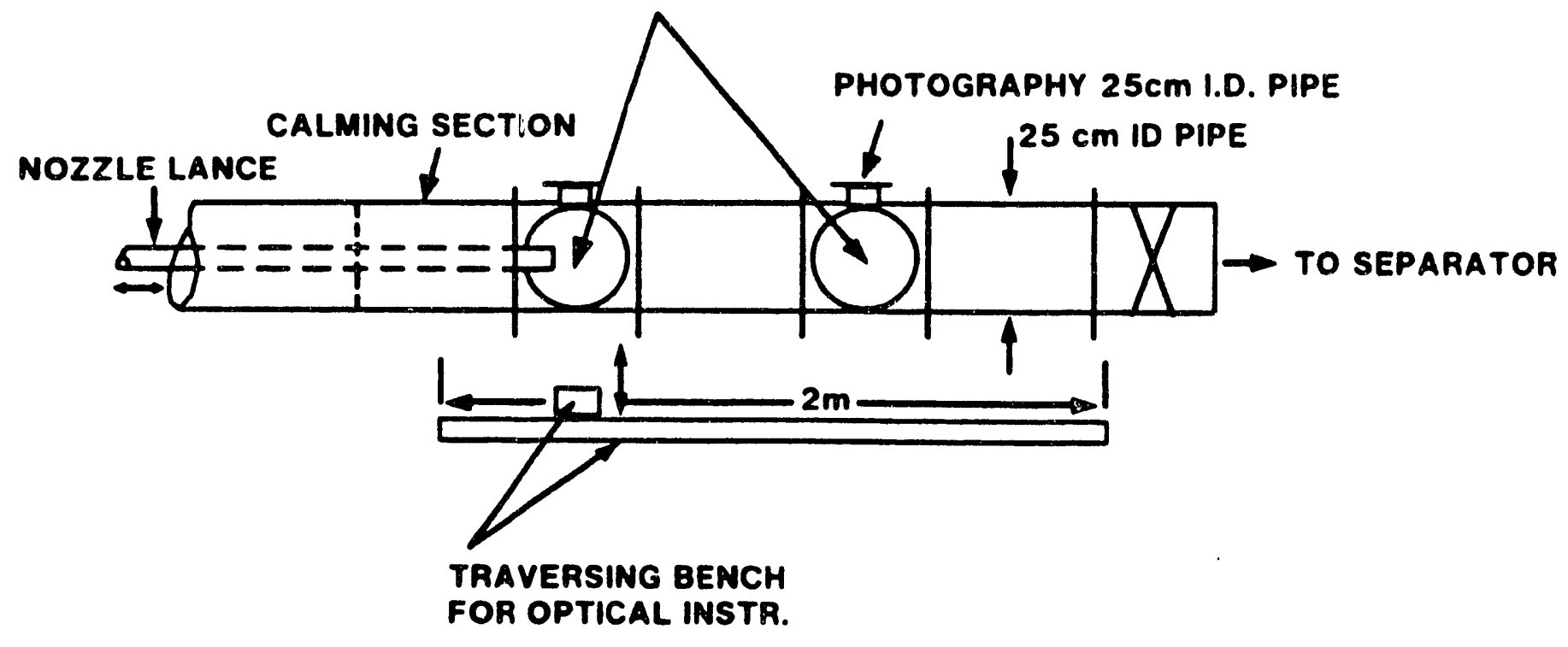

Figure 3.3.1 CRD spray tunnel schematic.

\section{Dimensions in Inches}

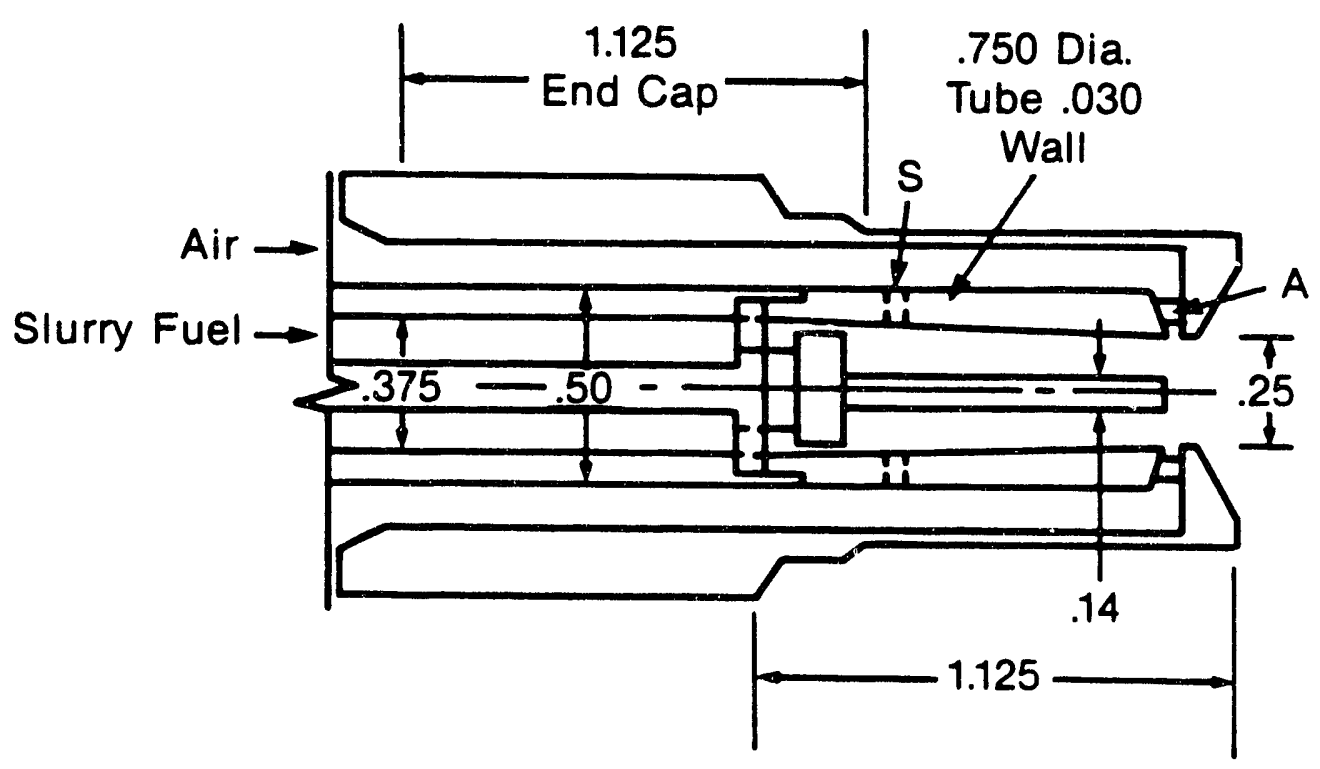

Figure 3.3.2 Schematic of LT nozzle geometry. Center 0.14 in. passage for auxiliary fuel. Holes at ' $S$ ' premix air with slurry. Vanes at 'A' provide swirl. 
justified, within about $15 \%$, for these nozzle operating conditions and the selected measurement location. The meas!ured radial velocity distribution, RR drop size distribution and concentration distribution for each nozzle were used to calculate the temporal (flowing) drop size distribution at the measurement location over the spray radius.

\subsubsection{Slurry Properties}

Both water and micronized coal-water slurry provided by Otisca were used with the slurry properties given below.

Coal Water Slurry Properties

\begin{tabular}{lcc}
$\begin{array}{l}\text { Particle Size } \\
\text { Distribution }\end{array}$ & \multicolumn{2}{c}{ Viscosity } \\
& Shear Rate $(\mathrm{l} / \mathrm{s})$ & Viscosity $(\mathrm{Pa} \cdot \mathrm{s})$ \\
& & 0.8 \\
$1.8 \%>14.5 \mu \mathrm{m}$ & $10^{3}$ & 0.55 \\
$50 \%>4.26 \mu \mathrm{m}$ & $10^{4}$ & 0.20 \\
$5 \%<1.5 \mu \mathrm{m}$ & $10^{5}$ &
\end{tabular}

$\begin{array}{ll}\text { Average Percent Solids }-50 & \text { Percent } \text { Ash }=.78 \\ \text { Density }-1.1 \text { s.g. } & \text { Percent Sulfur }=.87 \\ \text { Htg. Valve }=3800 \mathrm{cal} / \mathrm{gr} \text { of slurry } & \end{array}$

A capillary tube viscometer was employed by MIT, Reference [22] to measure the viscosity of the Otisca slurry at two values of the solids loading and at slurry temperatures from 25 to $100^{\circ} \mathrm{C}$. The measured viscosities are shown in Figures 3.3.3 and 3.3.4 up to shear rates of $1.5 \times$ $10^{6} \mathrm{~s}^{-1}$, values that are commensurate with those present in the tested fuel nozzles. The viscosity decreases with temperature at high-shear rates and increases with temperature at low-shear rate. The implication of these results is discussed later.

\subsubsection{Results}

The original LT nozzle and three added nozzles, the MS, HS and HH nozzles, were characterized using the above technique. The MS and HH nozzles in Figure 3.3.6 each, had successively increased atomizing air swirl at the same $(.039 \mathrm{~kg} / \mathrm{s})$ atomizing air flow as the LT nozzle, while the HS nozzle had the same swirl as the HH nozzle but employed an atomizing air flow of $.035 \mathrm{~kg} / \mathrm{s}$. The maximum swirl velocity was increased by $50 \%$ between the LT and MS nozzles and about $90 \%$ between the LT and HH nozzles. 


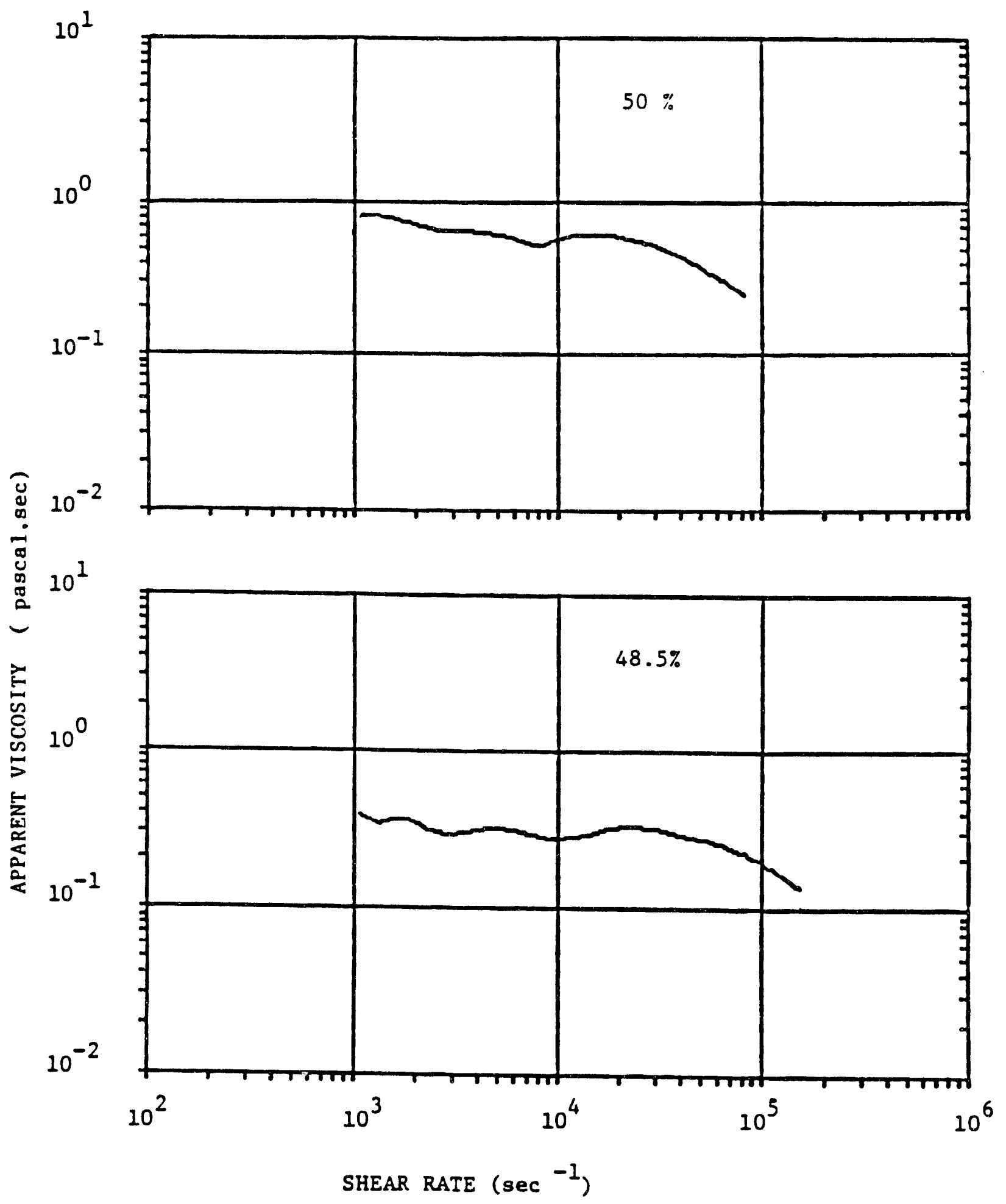

Figure 3.3.3 Efiect of solids loading on high shear rate viscosity of Otisca CWF at room temperature $\left(25^{\circ} \mathrm{C}\right)$. 


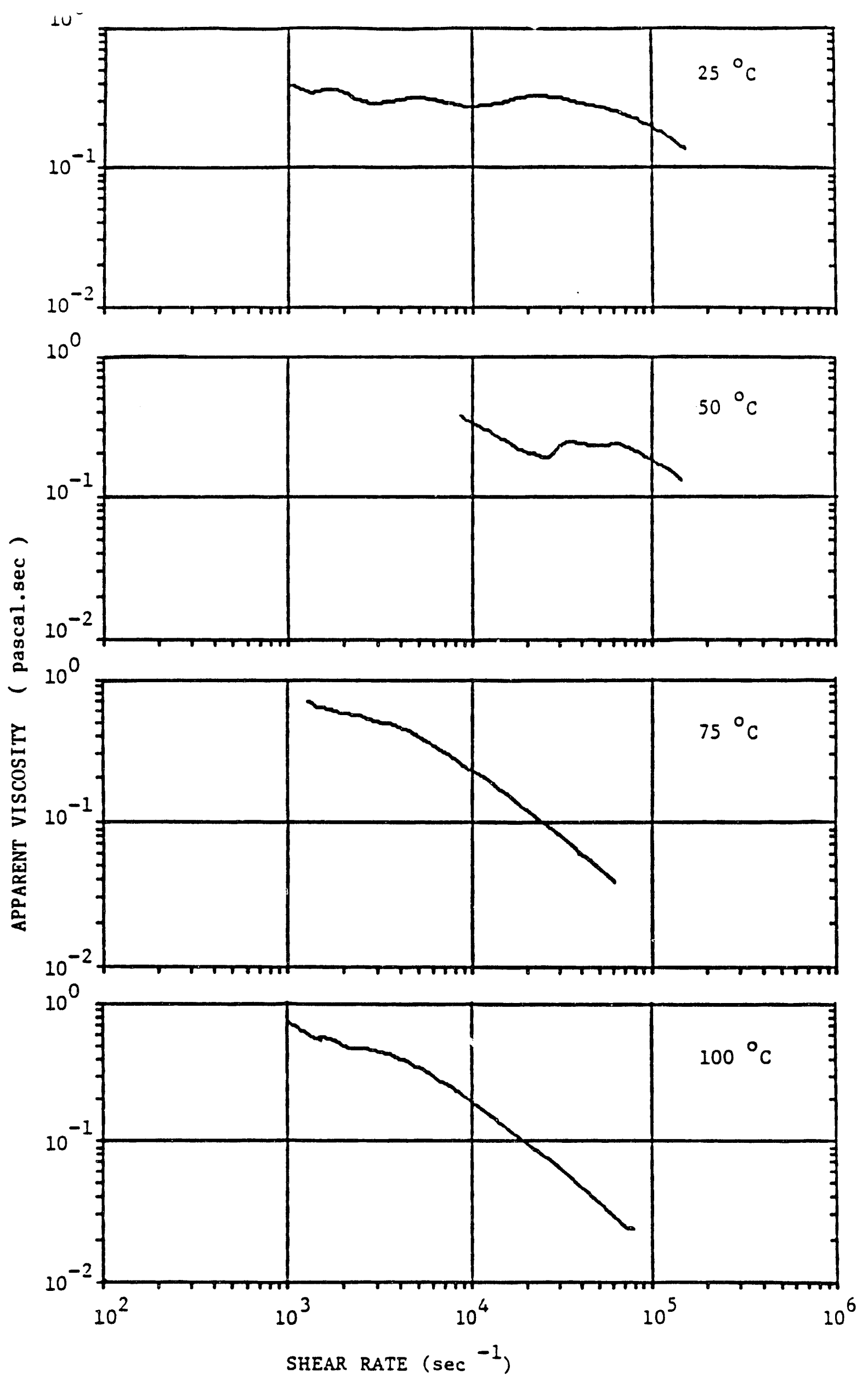

Figure 3.3.4 Effect of fuel temperature on high shear rate viscosity of Otisca CWF at solids loading of $\mathbf{4 8 . 5 \%}$. 
The chordal average Rosin Rammler (RR) drop diameter measured at the spray centerline using the Malvern Sizer with the LT nozzle is shown in Figure 3.3.5 as a function of the axial distance from the nozzle. The water data are shown to demonstrate that water cannot be employed to model a coal-water slurry. Note the much larger increase in mean size with ambient air density with water, compared to that with the slurry. The faster rate of size decrease with decreasing axial distance below $8 \mathrm{~cm}$ is primarily due to the influence of the relative deceleration region indicated above. The RR mean size measured $9 \mathrm{~cm}$ from the LT nozzle, as well as that measured for the three design changes discussed subsequently, was proportional to the slurry flow rate raised to the 0.51 to .65 power and was inversely proportional to the atomizing air flow rate. For coal-water slurry, this dropsize was proportional to the tunnel air density raised to the 0.4 power. Recent data on air atomized nozzles, Reference [23] has shown a similar increase in dropsize with increasing ambient air pressure and a subsequent decrease of dropsize with air pressures above about five atmospheres. Different nozzle designs show maximum drop sizes at different ambient pressures. The maximum pressure of $3 \mathrm{~atm}$ tested here is relevant to this application since it matches the combustor gas design point density in the drop formation zone.

A set of the radial RR size distributions for each of the indicated nozzles tested is shown in Figure 3.3.6, obtained as shown above from the chordal data, at $.023 \mathrm{~kg} / \mathrm{s}$ fuel and $3 \mathrm{~atm}$ tunnel operating pressure. Three selected profiles of the temporal drop size distribution are shown for the LT and HS nozzles in Figure 3.3.7. The size fraction above $20 \mu \mathrm{m}$ shows a peak at roughly one-half the spray radius. The larger drop size at the higher tunnel pressure is clearly evident in Figure 3.3.7. The integration over the radius yielded the RR drop diameter and exponent for the drop size generated by each nozzle as given in Figure 3.3.8. The distributions shown in Figure 3.3.8 are those employed in a combustor model at an axial distance from the nozzle large enough to be past the expected drop formation length, typically $2.5 \mathrm{~cm}$ Chigier [11].

The effect of nozzle scale on the drop size distribution was measured for the LT nozzle by characterizing a scaled-up version of the nozzle shown in Figure 3.3.2. This nozzle involved a critical flow passage area increase of about $50 \%$. The mean RR drop size measured $9 \mathrm{~cm}$ from each for these two nozzles at a tunnel pressure of $1 \mathrm{~atm}$ are shown in Table 3.3.1 below. For this nozzle configuration, the effect of a 50\% scale-up on the measured CWS drop size was thus felt to be too small to warrant further characterization.

In view of the effectiveness of thermally assisted secondary CWS atomization on combustor performance, Reference [24], MIT carried out nozzle characterization tests with the LT nozzle and, subsequently, combustor evaluation using thermally assisted CWS atomization. The LT nozzle characterization tests were carried out at $1 \mathrm{~atm}$ using the same Otisca CWS that MIT employed in the high shear viscosity measurements summarized here. A slightly diluted (48.5\% solids content) Otisca slurry was also tested. The slurry was heated up to a max- 

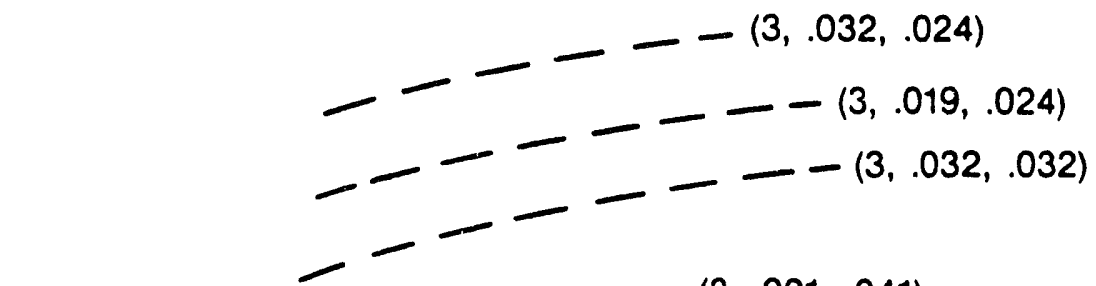

$(3, .021, .041)$

$(1, .021, .038)-$

$(1, .01, .038)$

- - - - - $(1, .032, .024)$

三三 二- - - $(1, .019, .024)$

Figure 3.3.5

Average RR mean drop diameters measured at the centerline for the LT nozzle at the indicated conditions. 


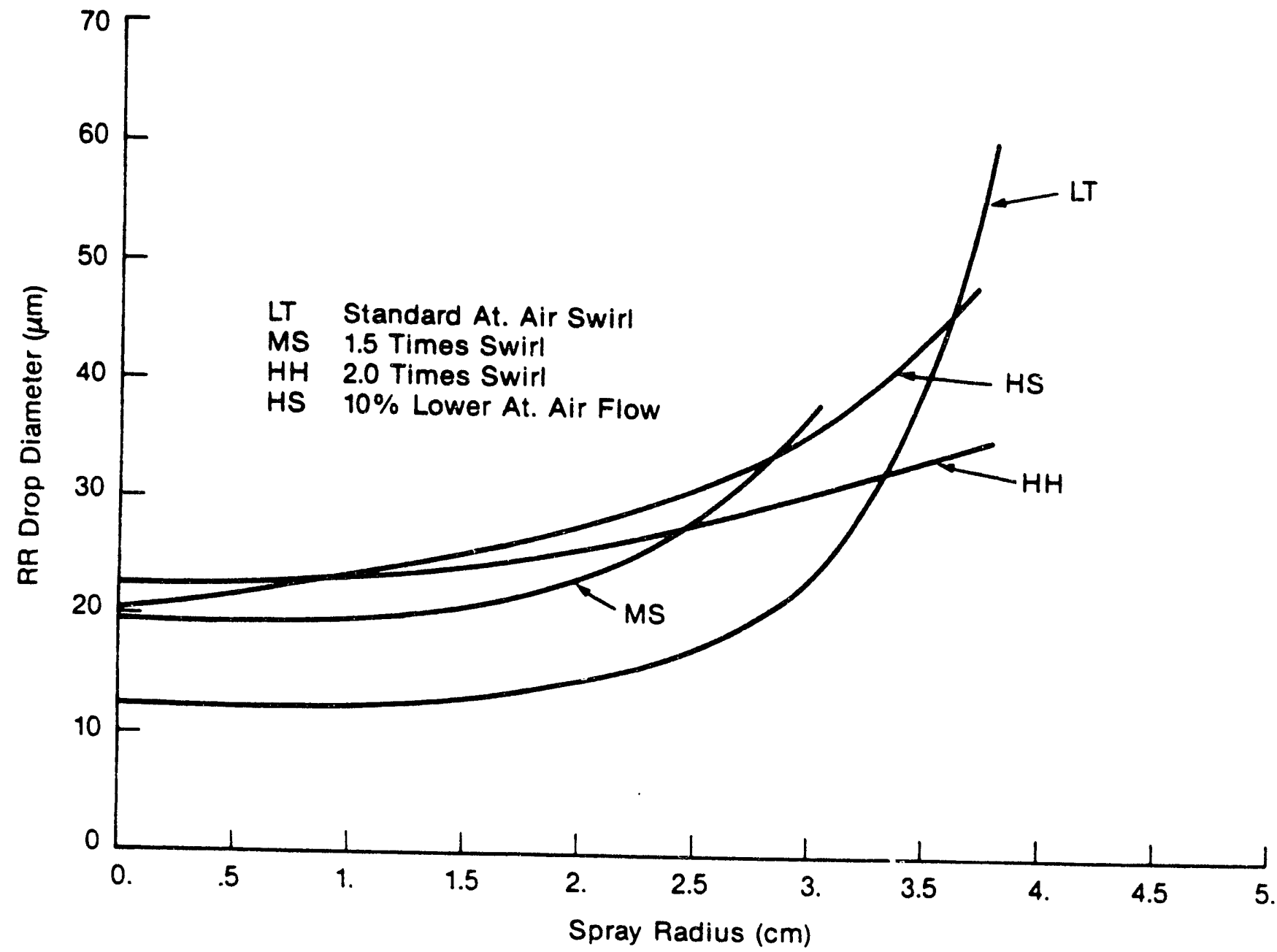

Figure 33.6 Radial distribution of Rosin Rammler drop size as obtained from chordal traverse data with slurry at $0.021 \mathrm{~kg} / \mathrm{s}$, atomizing air at $0.041 \mathrm{~kg} / \mathrm{s}, 3 \mathrm{~atm}$ ambient pressure, $9 \mathrm{~cm}$ from nozzle. See text for nozzle description. 


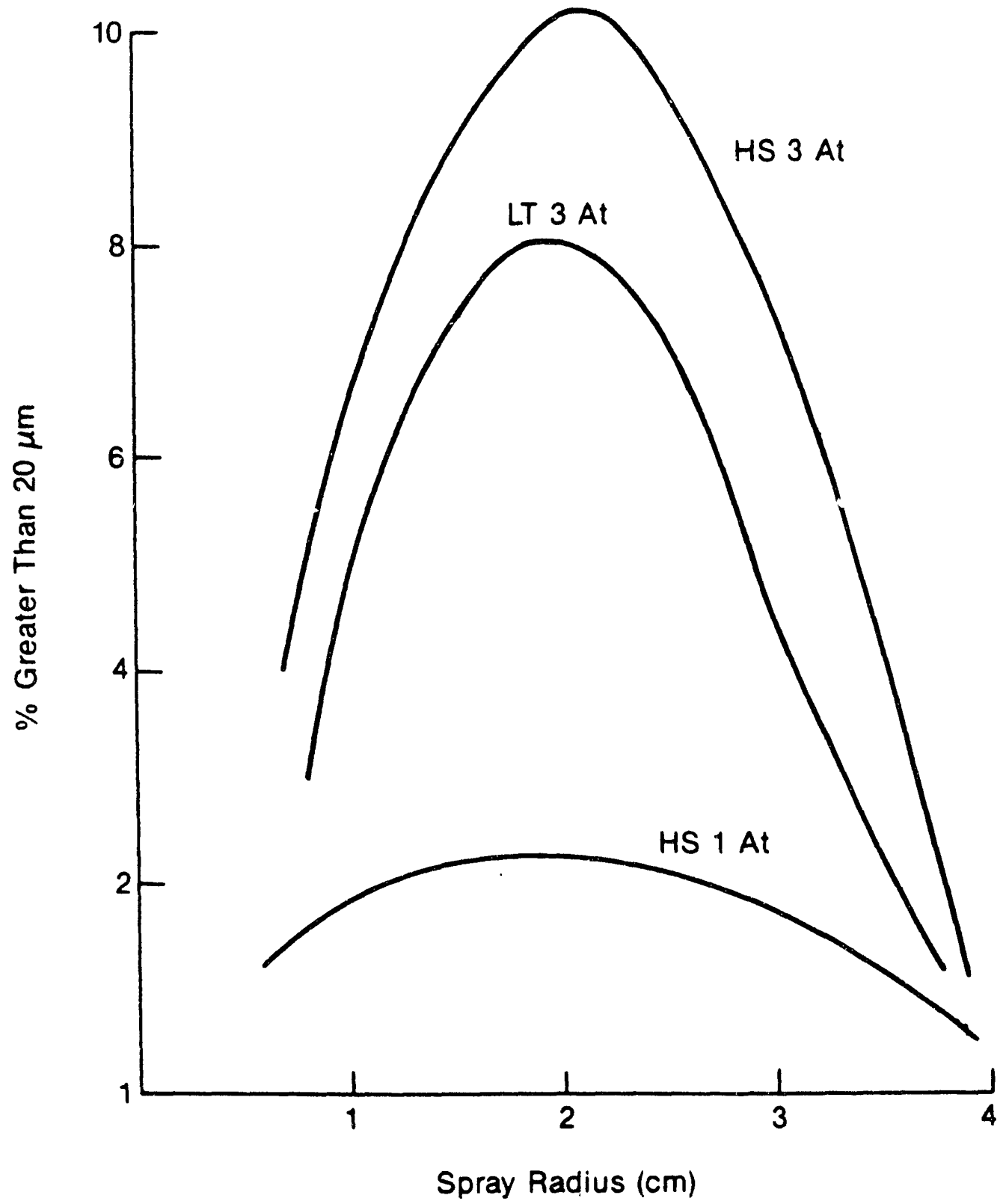

Figure 3.3.7 Temporal distribution of drop size larger than $20 \mu \mathrm{m}$ in fowing fuel. Slurry at $0.021 \mathrm{~kg} / \mathrm{s}$, atomizing air at $0.041 \mathrm{~kg} / \mathrm{s}, 9 \mathrm{~cm}$ from nozzle. 


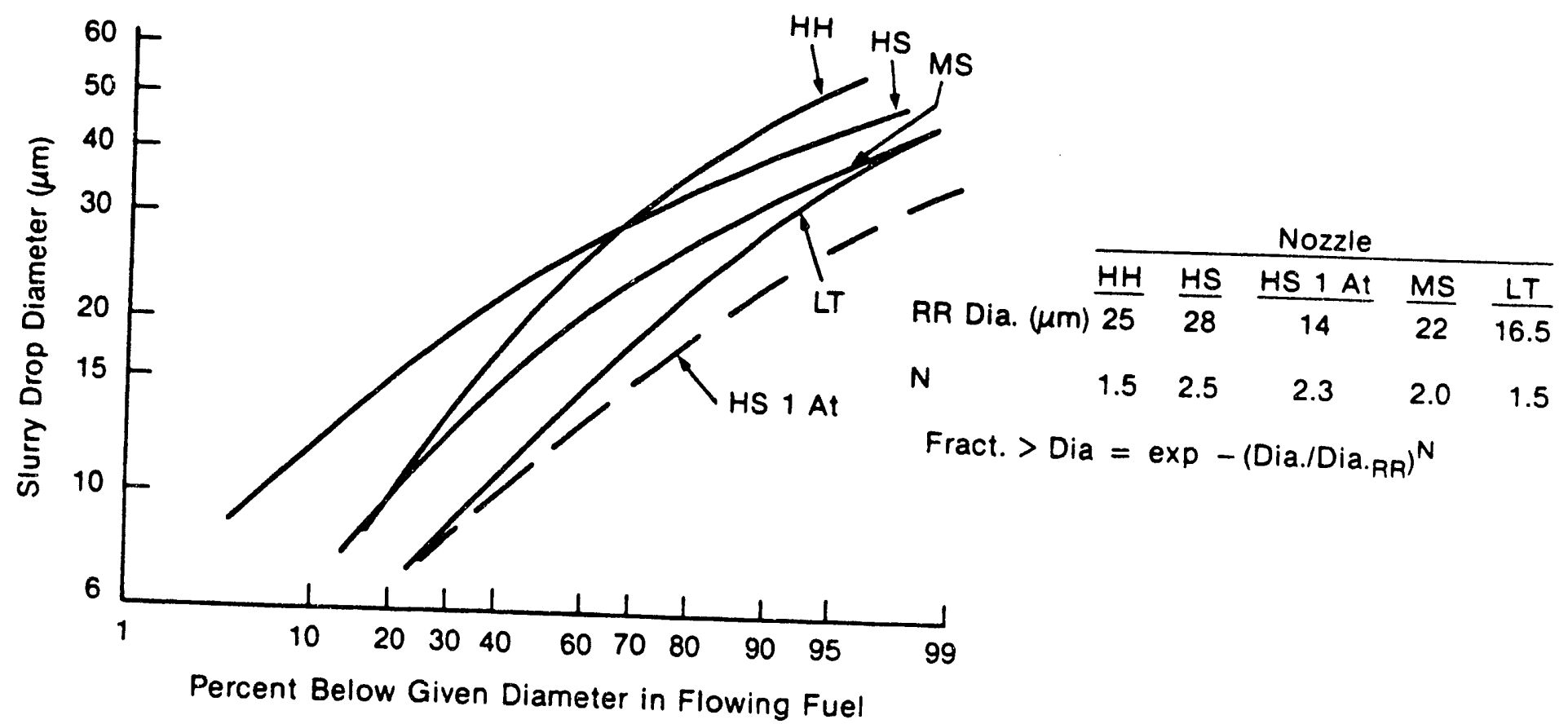

Figure 3.3.8 Temporal drop size distributions generated by CWS nozzles at $0.021 \mathrm{~kg} / \mathrm{s}$, air/fuel ratio1.7. Ambient pressure $3 \mathrm{~atm}$ unless otherwise noted.

Table 3.3.1

Effect of LT Nozzle Size on CWS Drop Size

\begin{tabular}{lcccc}
\hline Nozzle & $\begin{array}{c}\text { Atomizing Air } \\
\text { Pressure } \\
(\mathrm{atm})\end{array}$ & $\begin{array}{c}\text { Air } \\
\text { Flow } \\
\mathrm{kg} / \mathrm{s}\end{array}$ & $\begin{array}{c}\text { OTISCA CWS } \\
\text { Flow } \\
\mathrm{kg} / \mathrm{s}\end{array}$ & RR Drop Lia \\
\hline Large & 6.5 & .027 & .024 & $(\boldsymbol{\mu m})$ \\
Large & 7.1 & .031 & .045 & 19.7 \\
Small & 6.5 & .017 & .015 & 22.5 \\
Small & 7.1 & .020 & .030 & 19.2 \\
& & & & 25.9
\end{tabular}


imum temperature of $125^{\circ} \mathrm{C}$ prior to atomization at $.024 \mathrm{~kg} / \mathrm{s}$ slurry flow, $.04 \mathrm{~kg} / \mathrm{s}$ air flow similar to the nozzle operating conditions employed in Figure 3.3.5. The chordal average Sauter mean drop diameter (SMD) measured by MIT as a function of spray radius is shown in Figure 3.3.9 at $22^{\circ} \mathrm{C}$ and $115^{\circ} \mathrm{C}$ respectively. The centerline chordal average SMD is shown in Figure3.3.10 as a function of slurry temperature. The effect of CWS heating to reduce the drop size is clear. The gradual decrease of drop size up to $100^{\circ} \mathrm{C}$ in Figure 3.3 .10 is due to the decrease in the high shear viscosity. The larger rate of decrease above $100^{\circ} \mathrm{C}$ is clearly due to flashing. These results led to a subsequent evaluation of thermally induced secondary CWS atomization in the MIT combustor. These experiments are summarized in the Appendix. The results illustrated the increased combustion efficiency resulting from thermally enhanced CWS atomization between 1 and 3 meters from the nozzle as determined from residual carbon. While the residence time in the large MIT combustor was larger than that available in a gas turbine combustor, the drop size range was also larger, so that the conclusion from: the MIT experiments can be qualitatively applied to the combustors of interest here.

An alternative fuel nozzle, consisting of a two-fuel Parker-Hannefin air atomized CWS nozzle, designed for the same fuel flow rate was characterized for a comparison to the LT nozzle. The Parker-Hannefin nozzle was equipped with a \#6881038 swirl insert. It was operated at the same air and fuel flow rates as the LT nozzle. The temporal drop size distribution generated by these two nozzles was found to be essentially the same. The atomizing air velocity profiles of the Parker-Hannefin nozzle produced in a simulated gas turbine liner was, however, different from that of the LT nozzle. The effect of these differen 'es in the atomizing air velocity profiles is further discussed under Flow Model Verificatior.

\subsubsection{Verificecion}

The assumptions of equal drop and air axial velocities and the absence of drop agglomeration inherent in this simplified nozzle characterization method require at least first order verification. Using the measured radial distribution of the axial air velocity and the radial concentration distribution derived from the chordal measurements, the calculated volumetric slurry flow rate was within $\pm 15 \%$ of the measured flow rate. To obtain an approximate check on the assumption of equal axial air and drop velocities as well as the radial concentration distribution generated by the derived temporal drop size distribution, the FLIJENT* flow code was employed to model the tunnel and nozzle flow conditions.

In the absence of fuel flow, the measured and calculated axial velocity profiles are shown in Figure 3.3.11 with the LT nozzle at the indicated operating conditions. The angular momen-

- CREARE Inc., Hanover, NH. 


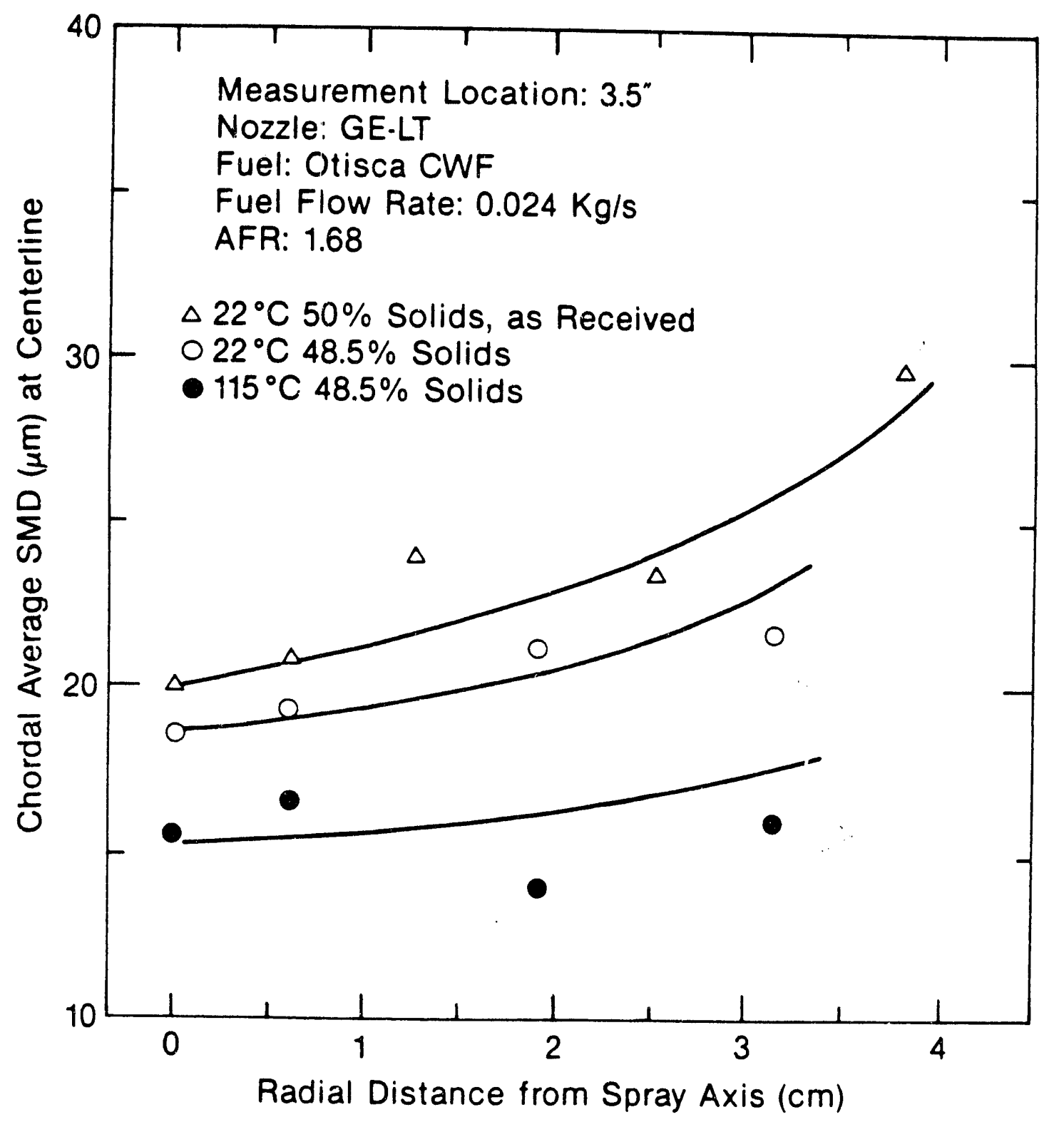

Figure 3.3.9 Chordal average Sauter mean diameter of Otisca CWF sprays at various radial bcations. 


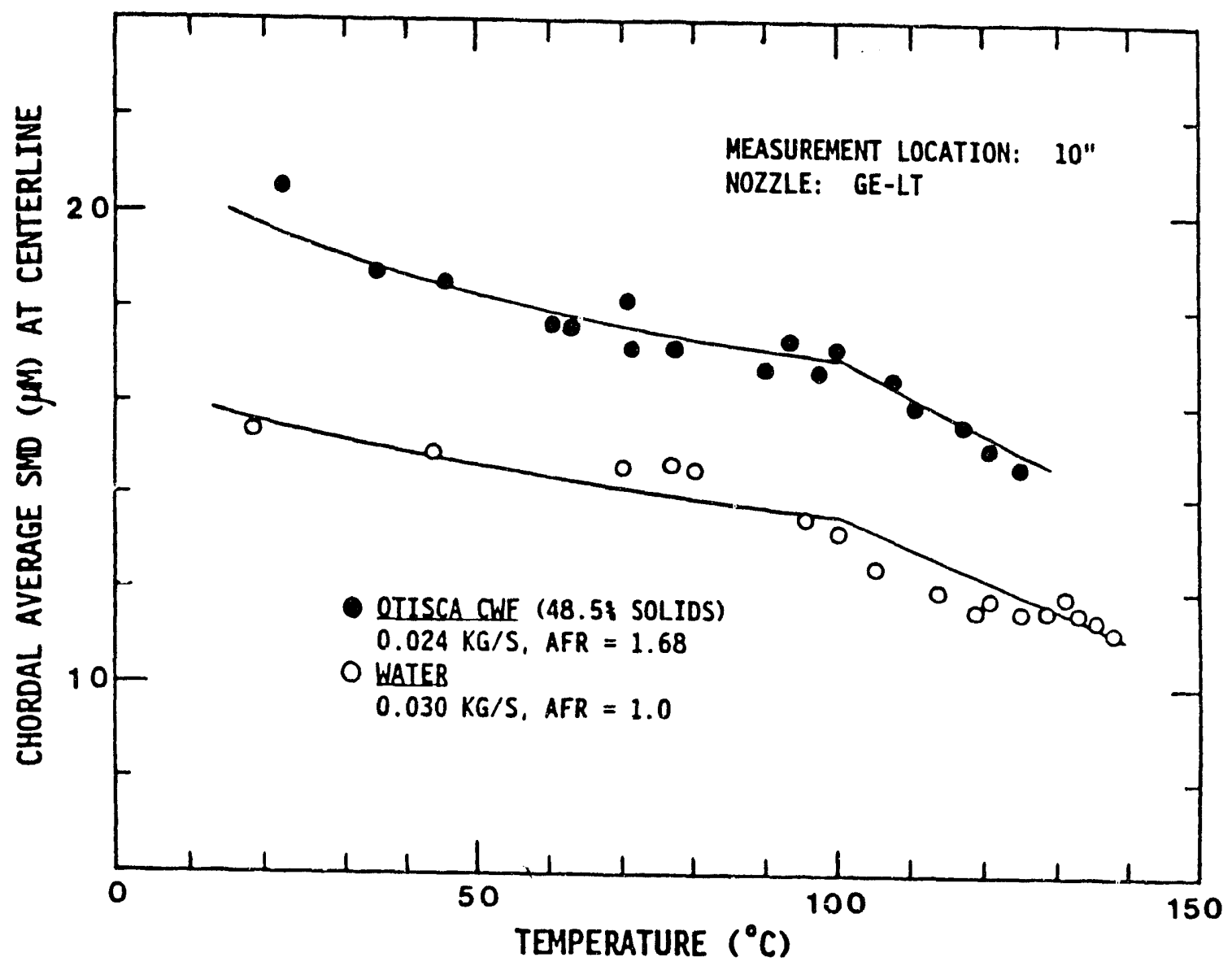

Figure 3.3.10 Effect of fuel temperature on Sauter mean diameters of Otisca CWF and water sprays. 


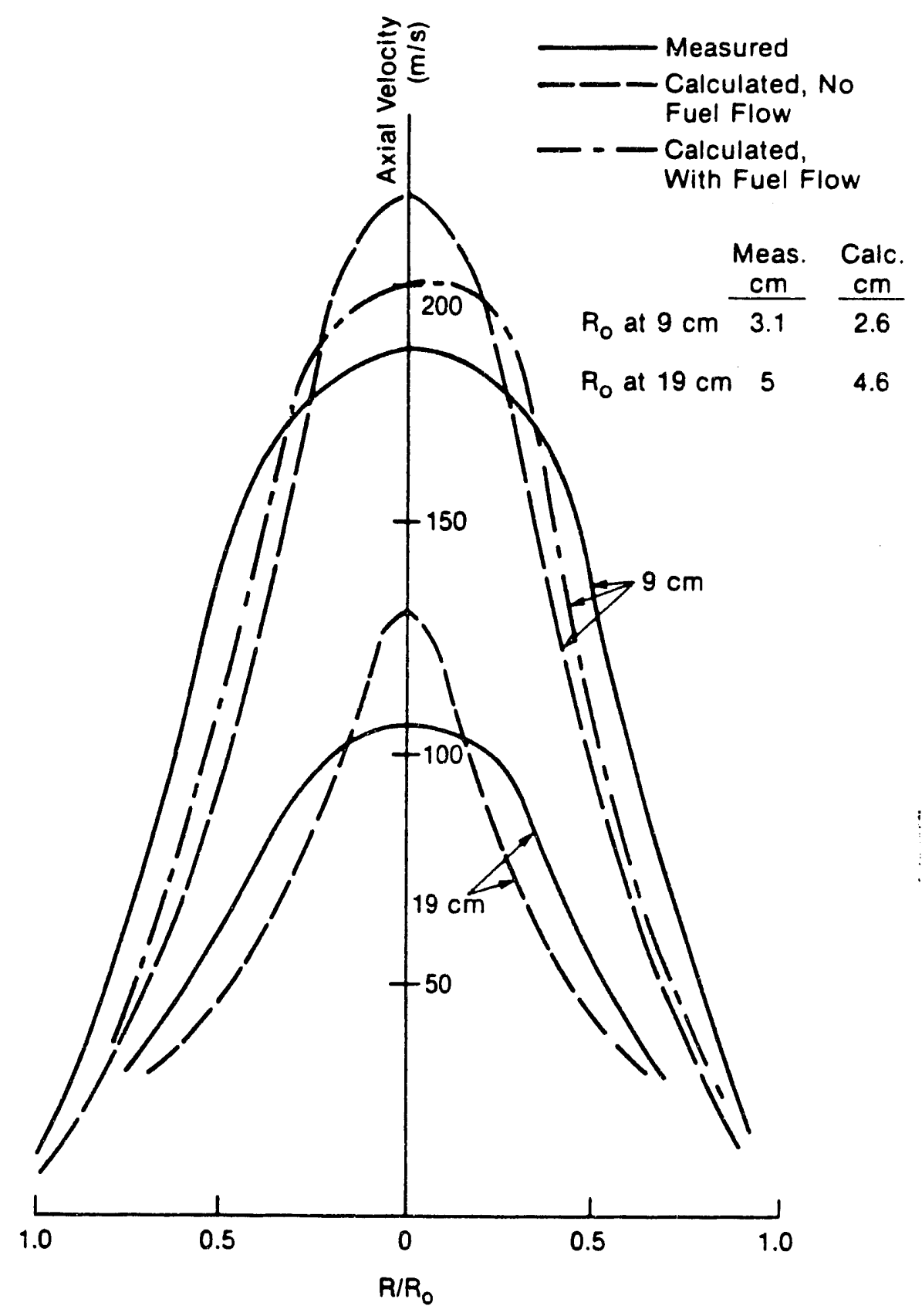

Figure 3.3.11 Comparison of calculated and measured axial air velocity profiles in spray tunnel for LT nozzle at $0.041 \mathrm{~kg} / \mathrm{s}$ atomizing air, $1 \mathrm{~atm}$ ambient pressure, $9 \mathrm{~cm}$ and $19 \mathrm{~cm}$ from nozzle. Calculated efiect of slurry flow at $0.021 \mathrm{~kg} / \mathrm{s}$.
$R$-spray radius, $R_{0}$-spray outer radius. 
tum measured for this nozzle at the $9 \mathrm{~cm}$ location was taken to be conserved for the atomizing air flow leaving the nozzle. While the agreement between the measured and calculated axial profiles in Figure 3.3.11 is not exact, it is satisfactory considering the limitations of the $k-\varepsilon$ turbulence model for swirling flows. The calculated effect of fuel flow on the axial air velocity profile at the $9 \mathrm{~cm}$ location is also shown in Figure 3.3.11 and indicates the relatively small effect of fuel-air momentum exchange for this nozzle. The RR parameters for this operating condition were taken at the nozzle discharge with an injected drop size range from $2 \mu \mathrm{m}$ to 30 $\mu \mathrm{m}$ using FLUENT. A comparison of the maximum drop velocities calculated for each drop size at the $9 \mathrm{~cm}$ location with the axial air velocity at the same location yielded the following results:

$\begin{array}{ccc}\text { Drop Dia. } \mu \mathrm{m} & \text { Drop Velocity }(\mathrm{m} / \mathrm{s}) & \text { Air Velocity }(\mathrm{m} / \mathrm{s}) \\ 2 & 190 & 170 \\ 9 & 140 & 120 \\ 23 & 79 & 70 \\ 30 & 20 & 20\end{array}$

The equal velocity assumption thus seems to hold within about $15 \%$ for this nozzle. As a further check on the temporal drop size distribution, the radial distribution of the drop concentration calculated for this nozzle at the $9 \mathrm{~cm}$ location using FLUENT is compared in Figure 3.3.12 with the concentration profile measured by the Malvern Sizer. Again, the agreement is satisfactory within the accuracy of both the model and the experimental measurement. The change in drop velocity distribution for each drop size with axial distance from the nozzle is calculated by the model to cause an increase in the spatial RR drop size of $35 \%$ between the $9 \mathrm{~cm}$ and $19 \mathrm{~cm}$ position at the above operating point. The measured spatial RR drop size increased by $40 \%$ between these locations. This expected behavior, also pointed out by Chigier [12], is predicted by this flow modeling technique. It implies negligible agglnmeration past the $9 \mathrm{~cm}$ location.

The above use of a flow model to verify measured information is still an indirect technique that is recommended only for well defined and controlled flow fields. Direct temporal measurements are preferred. Unfortunately, optical drop velocity measurement methods must be employed with great care to obtain valid data, Dodge [13], Chigier [12], and cannot be employed in sprays as dense as those investigated here.

\subsubsection{Predictive Combustor Performance Criteria}

In recent years the modeling of gas turbine combustor performance has advanced rapidly with increased computational speed. Three dimensional combustor models have successfully predicted measured performance for standard fuels where rapid fuel evaporation and 


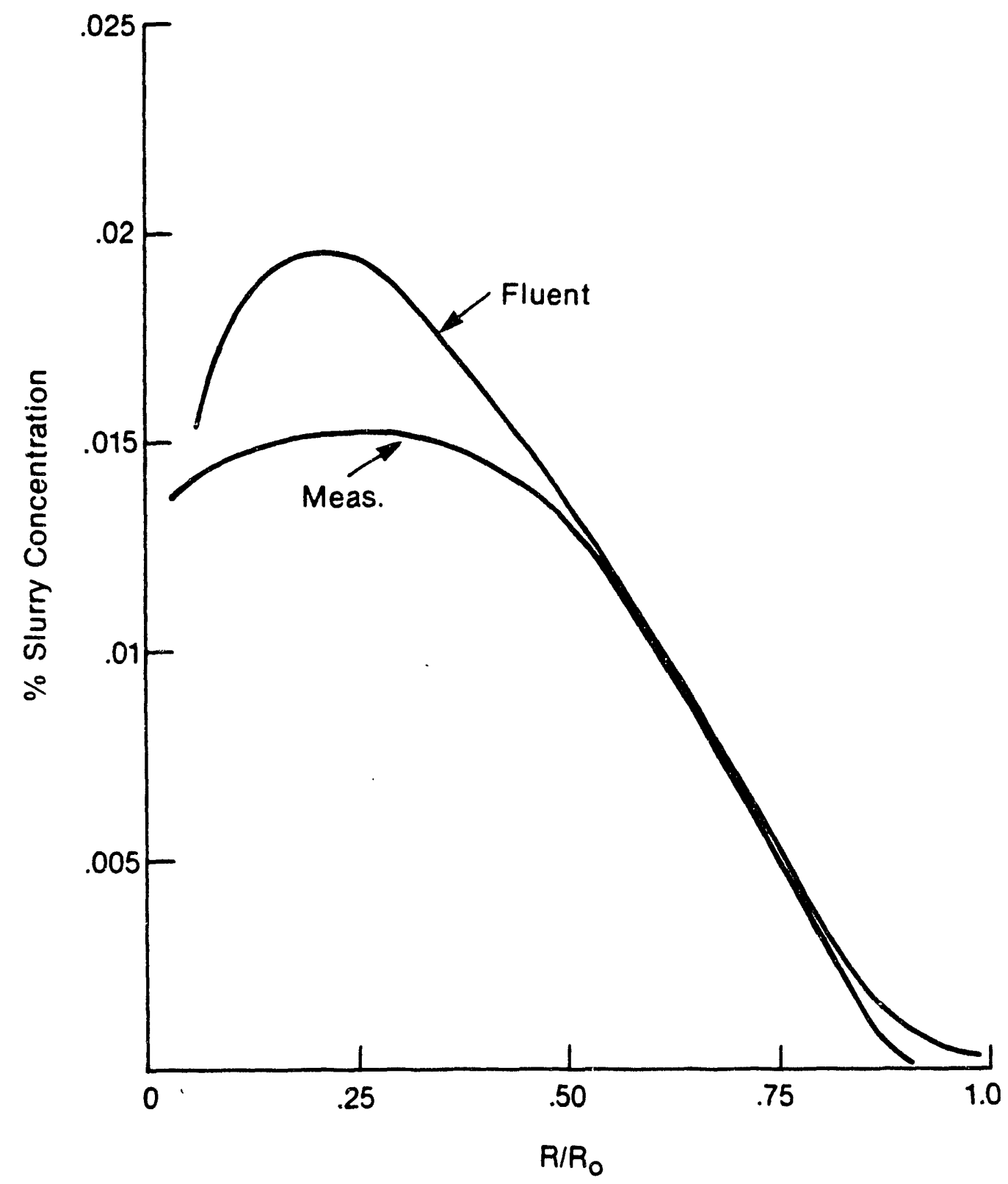

Figure 3.3.12 Comparison of calculated (FLUENT) and measured slurry concentration profiles for LT nozzle with slurry at $0.041 \mathrm{~kg} / \mathrm{s}$, atomizing air at $0.021 \mathrm{~kg} / \mathrm{s}$, $1 \mathrm{~atm}$ ambient pressure, $9 \mathrm{~cm}$ from nozzle. 
combustion was obtained. Even where fuel evaporation was not sufficiently rapid, drop tracking models have been employed, Swithenbank [14], to obtain improved agreement with measurements. For coal water slurry combustion, however, the required burning time is over an order of magnitude longer than that of standard fuels. Even the most recent combustion models require several rate constants for each coal and are dependent on whether or not the slurry drop break-up takes place. For these reasons, it was decided to first exercise an isothermal model of the combustor of interest. The isothermal model outlined below was employed to determine the drop residence time and location as well as the gas flow distribution in two combustors. The former is compared to the expected residence time requirement and the latter was used to evaluate a flame stabilization criterion. The flow stabilization criterion was developed using the LM500, $16 \mathrm{~cm}$ diameter combustor. The $12 \mathrm{~cm}$ diameter sector can combustor configuration was employed to verify the predicted velocity distribution and the performance of this combustor was compared with that predicted by the model.

A brief description of the combustion conditions is given for each combustor prior to the discussion of the respective flow modeling.

\subsubsection{LM500 Combustor}

3.3.3.1.1 Combustion Conditions. Coal-water mixture combustion was first tested on the LM500 turbine simulator Reference [15]. Three modified LT-type dual fuel nozzles, which had previously been characterized for atomization performance, and five combustion air swirlers were tested for their effect on combustion efficiency and stability.

The LM500 turbine simulator is a pressurized combustion/deposition test facility in which the combustion exhaust gases pass through a LM500 gas turbine first stage nozzle cascade. This facility has been used to study disposition with coal-water mixture fuel, Reference [15]. Previous testing had all been performed using a single swirler and dual fuel nozzle. Typically, 20 to $25 \%$ of the fuel input was fuel oil on a heating value basis. Combustion efficiencies, which are based on $\mathrm{CO}$ and unburned hydrocarbons in the exhaust gas and residual carbon in collected particulates, were always in excess of $99.5 \%$.

The effect of fuel nozzle characteristics and air swirler on combustor stability and efficiency were evaluated for a fuel nozzle/swirler combination by measuring combustion efficiencies over a range of fuel oil flows. The minimum fuel oil flow required to maintain stable combustion was then determined. Nominal operating conditions are shown in Table 3.3.2. Otisca-T coal-water mixture was used in all tests.

Combustion tests were performed as follows. Combustion was initiated on distillate oil, and air and fuel flows were increased until the test point was approached. CWM fuel flow was then initiated and increased while decreasing oil flow. When an oil/CWM heating value ratio reached approximately $25 \%$ and test point conditions achieved, conditions were main- 
Table 3.3 .2

Operating Conditions for Combustion Tests

Pressure

$10 \mathrm{~atm}$

Combustor exit temperature Air preheat temperature

$1090-1200^{\circ} \mathrm{C}$

Fuel input (oil + CWM)

$400^{\circ} \mathrm{C}$
$3.7 \times 10^{9} \mathrm{~J} / \mathrm{hr}$ 
tained at steady state. Particulate samples were collected using a quenched, isothermal probe, Reference [16], and were analyzed for residual carbon content. The oil/CWM ratio was reduced in approximately $5 \%$ increments, with gas analysis and particulate sampling at each operating point. When significant reduction in efficiency or an indication of the onset of combustion instabilities was noted, it was judged that the minimum ratio for stable combustion was reached. The atomizing air-to-fuel flow ratio was maintained at about 1.8 for these experiments. These results are summarized in Table 3.3.3.

It should be noted that under no circumstances in which stable combustion was maintained did the combustion efficiency drop below $99 \%$. There was sufficient variability in CO content in the exhaust gas and residual carbon content in the particulates during the runs to prevent derivation of a clear trend of these variables with auxiliary fuel use.

\subsection{LM500 Flow Model. A three dimensional, 90\% sector symmetry FLUENT model} of the combustor shown in Figure 3.3.13 was generated. The design point air mass flow rates (see Table 3.3.4) were injected through the nozzle swirler, primary hole and cooling slots. The design fuel flow rate was injected at the nozzle using the characterized RR distribution for the selected nozzle.

The injected nozzle flow rates are at $50^{\circ} \mathrm{C}$ while the remaining injected flows are at $350^{\circ} \mathrm{C}$. The resign pressure level is $10 \mathrm{~atm}$. An average gas temperature of $750^{\circ} \mathrm{C}$ is a compromise between a higher temperature that would more closely approach a mean gas density and a lower temperature that would allow a minimum change in the liner flow areas. Since both the injected air mass flow rates and their total momentum define the flow field, both were matched in the model. This requires a change in the cross-sectional injected flow areas since the injected flow rates are at a lower temperature than the local combustor gas flow. The selection of $750^{\circ} \mathrm{C}$ required an increase of $26 \%$ in both these areas and the injection velocities to achieve the desired match. Clearly, the use of an isothermal model provides mostly qualitative information, with quantitative results that should be interpreted with caution.

\subsection{LM500 Slurry Residence Time. The slurry evaporation model given in Refer-} ence [17] and the slurry devolatization and char combustion model of Beer [18,1] were employed to estimate the required residence times for this bituminous coal in the test combustor. This model assumes that the drops stay agglomerated as a porous matrix after evaporation. In the primary zone $\left(1400^{\circ} \mathrm{C}\right)$ drops larger than $20 \mu \mathrm{m}$ have diffusion controlled char burnout while downstream of the primary zone $\left(1250^{\circ} \mathrm{C}\right)$ those larger than $30 \mu \mathrm{m}$ are diffusion controlled. The calculated residence time distributions shown in Table 3.3.5 were obtained with these assumptions.

These required residence times imply that the slurry drop in this combustor should not exceed $40 \mu \mathrm{m}$ in diameter if no drop recirculation takes place. 
Table 3.3 .3

Summary of Combustion Tests

\begin{tabular}{|c|c|c|}
\hline $\begin{array}{c}\text { Fuel } \\
\text { Nozzle }\end{array}$ & Swirler & $\begin{array}{l}\text { Minimum Oil } \\
\text { For Stable } \\
\text { Combustion, } \%\end{array}$ \\
\hline
\end{tabular}

$\begin{array}{llr}\text { LT } & 45^{*} & 22 \\ \text { MS } & 45^{*} & 8 \\ \text { HS } & 45^{*} & 8 \\ \text { LT } & 30 & 20 \\ \text { LT } & 38 & 15 \\ \text { LT } & 45 & 10 \\ \text { LT } & 60 & 11 \\ \text { HS } & 30 & 4 \\ \text { MS } & 45 & >30 \\ \text { LT } & 60 \text { LF } & 2\end{array}$

*45 swirler refers to the original swirler, which has considerable bypass.

Table 3.3.4

Design Point Combustor Flow Rates

\begin{tabular}{lr}
\hline Nozzle Air & $7.5 \%$ \\
Swirl Air & $21.0 \%$ \\
Primary Air & $15.0 \%$ \\
Dilution Air & $9.0 \%$ \\
Cooling Air & $47.5 \%$
\end{tabular}

Total Air Flow $1.0 \mathrm{~kg} / \mathrm{s}$ 


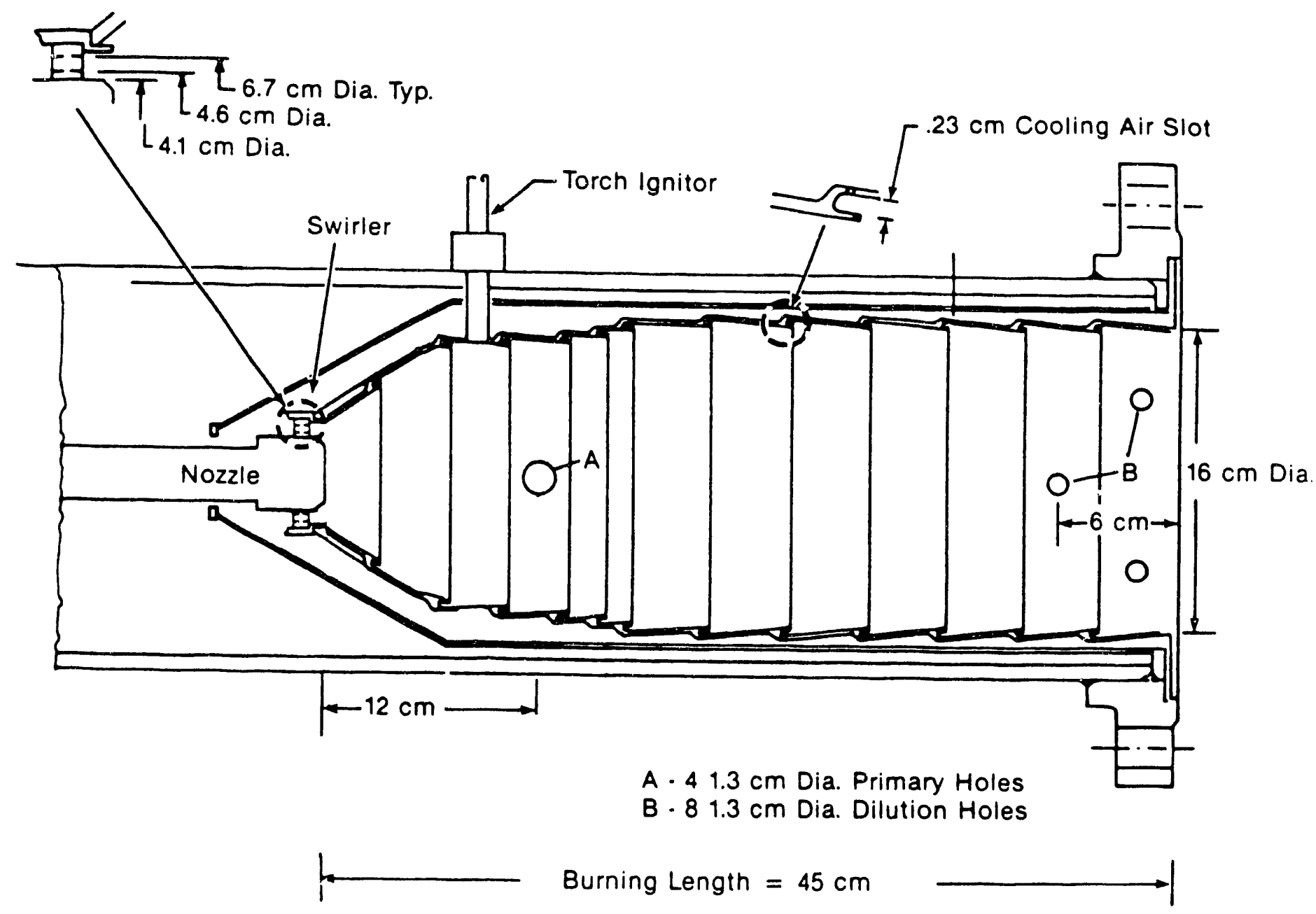

Figure 3.3.13 Schematic of LM500 combustor.

Table 3.3 .5

\section{Calculated Coal-Water Slurry Drop Residence Times Required in Combustor}

$\begin{array}{ccccc}\begin{array}{c}\text { Slurry Diameter } \\ (\boldsymbol{\mu m})\end{array} & \begin{array}{c}\text { Evaporation } \\ (\mathrm{ms})\end{array} & \begin{array}{c}\text { Devol. } \\ (\mathrm{ms})\end{array} & \begin{array}{c}\text { Char Burnout } \\ (\mathrm{ms})\end{array} & \begin{array}{c}\text { Total } \\ (\mathrm{ms})\end{array} \\ 10 & 0.7 & 7.0 & & \\ 20 & 2.0 & & 1.0 & 8.7 \\ 30 & 2.7 & & 1.7 & 10.7 \\ 50 & 7.0 & & 3.6 & 13.3 \\ & & & 10.0 & 24.0\end{array}$


The combustor flow model was employed to calculate the drop residence times to a point $5 \mathrm{~cm}$ downstream of the primary holes where the model no longer predicted gas recirculation. Drop sizes from $5 \mu \mathrm{m}$ to $60 \mu \mathrm{m}$ were evaluated using each of the nozzles characterized at the design point.

The calculated effect of nozale atomizing air swirl and of redistribution of the primary and swirler air flows is shown in Figures 3.3.14 and 15. To obtain the total calculated residence time, 13 msec must be added to the values in Figure 3.3.14 to account for the remaining combustor length. Changing the LT nozzle to the high swirl HS nozzle more than doubles the gas backflow and increases the $30 \mu \mathrm{m}$ drop residence time by $50 \%$ as shown in Figure 3.3.14 at $15 \%$ primary air flow. The anticipated benefit of this increased residence time was es. timated to be greater than the effect of the small increase in maximum drop size produced by the HS nozzle. The calculated $30 \mu \mathrm{m}$ drop tracks, shown in Figu re 3.3.15, also indicate that the increased residence time with the HS nozele is due to greater circulation in the primary zone near the nozzle. Increasing the primary flow to $30 \%$, with a corresponding flow reduction through the swirler, has a weaker effect on gas backflow and residence time (see Figure 3.3.14). Nevertheless, Figure 3.3.14 indicates that the maximum gas backflow for different nozzle air swirl values will take place at different primary/swirler air flow splits so that a change in nozzle swirl may need a change in this flow split to maximize gas backflow.

Although the residence times calculated for the combustor all exceeded the required values, the use of the isothermal model and the lack of combustion rate-constant data on this coal limit the quantitative significance of this comparison.

3.3.3.1.4 Flame Stabilization Criterion. The use of air swirl to improve combustor stability and efficiency is well documented, (Beer $[19,20]$ et al.). As swirl is increased, the decreased static pressure near the nozzle yields increased gas backflow in that region. Excessive swirl has also been shown by [19] and Driscol [21] to reduce combustor efficiency or even cause flame blow-off. For this reason, the calculated backflow percentage half way between the nozzle and the primary hole location $(6 \mathrm{~cm})$, was selected as a criterion for combustor performance.

The tested combustor configuration corresponds to the $15 \%$ primary air flow case in Figure 3.3.14 for all cases except one noted below. The design of the original air swirler, which had reduced swirl due to by-pass, was changed to a replaceable configuration to allow four swirlers with increasing swirl angle to be evaluated with several nozzles as described in Table 3.3.3. The six cases from Table 3.3.3 are shown in Figure 3.3.16 where the minimum auxiliary fuel flow is compared with the calculated air backflow. The correlation between increased backflow and decreased need for auxiliary fuel is clear up to about 33\% backflow. The swirler air swirl numbers, as defined by the ratio of angular-to-axial momentum flux in the swirler flow, Beer [19], range from 0.9 for the $30^{\circ}$ swirler to 2.5 for the $60^{\circ}$ swirler in Figure 3.3.16. 


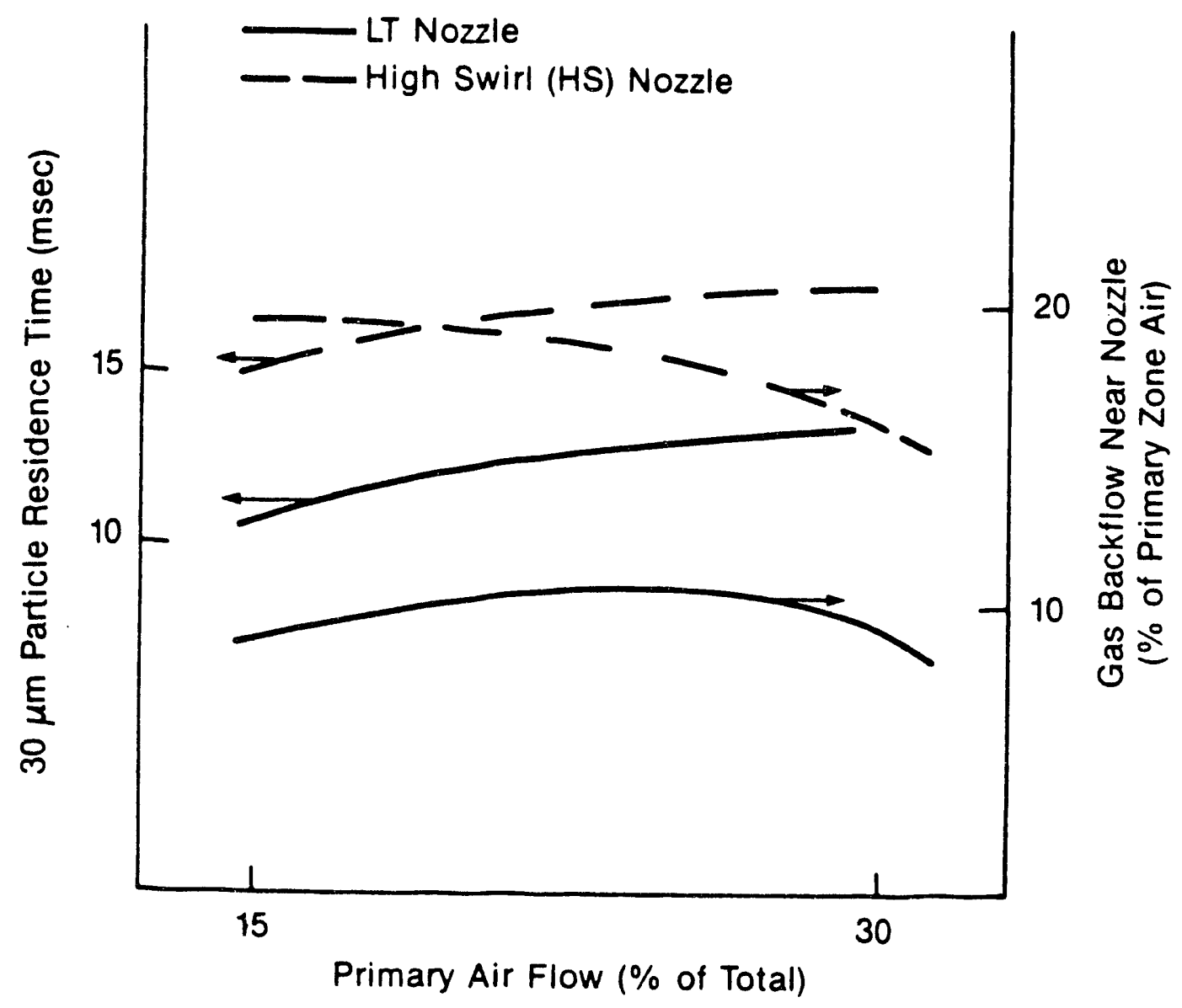

Figure 3.3.14 Calculated 30 $\mu \mathrm{m}$ drop residence time $5 \mathrm{~cm}$ downstream of primary holes and gas backflow $6 \mathrm{~cm}$ from LT and HS nozzles as function of primary air now. Primary plus swirler air flow held constant. 


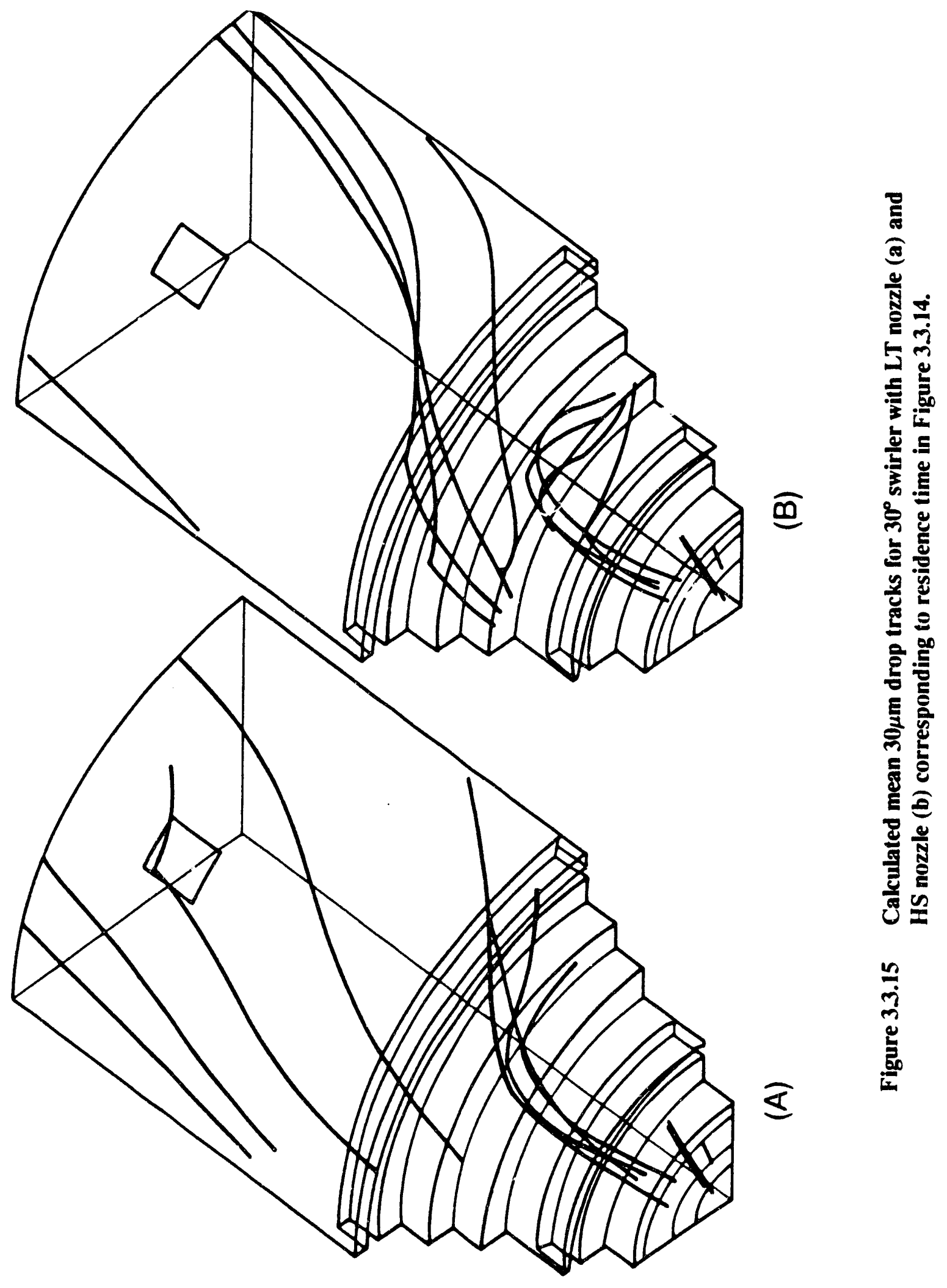




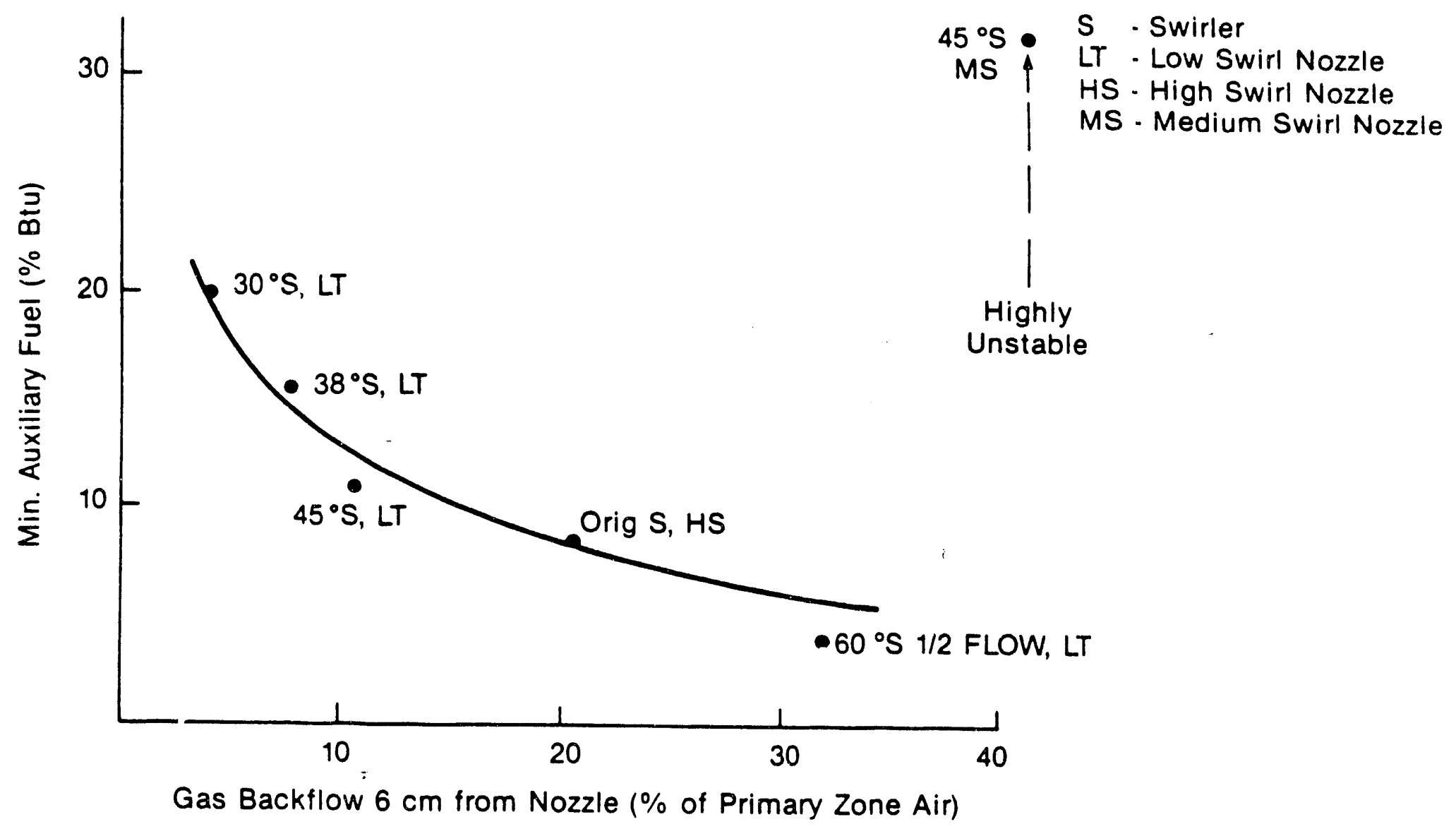

Figure 3.16 Comparison of calculated gas backflow with minimum auxiliary fuel combustor operation at $10 \mathrm{~atm} 1100^{\circ} \mathrm{C}$ design point (see text). 
The latter does not include the additional angular momentum of the atomizing air between the LT and HS nozzles. The minimum auxiliary fuel test in Figure 3.3.12 was obtained with the LT nozzle and a $60^{\circ}$ swirler whose flow rate was about one-half uf the design point swirler flow. The primary air flow wai increased for this test to yield approxin ately constant swirlerplus-primary air flow. The calculated magnitude and distribution of the gas backflow for this test case is compared in Figure 3.3.17 to that obtained at full $45^{\circ}$ swirler flow ( $45^{\circ} \mathrm{S}$, LT case in Figure 3.3.16). It is clear from Figure 3.3.17 that a larger fraction of the primary zone is in backflow with the $60^{\circ}$ swirler.

With a $45^{\circ}$ swirler and the MS nozzle, highly unstable comburtion ensued that required shut-down. The ratio of angular air momentum to axial fuel momentum exceeds the maximum value above which combustor instability is expected [21] only for the $42 \%$ backflow case in Figure 3.3.16.

The effect of moving the primary holes downstream was analyzed. For a $30 \%$ increase in the primary zone length the increase in drop residence time was about the same as the best achieved by a combination of higher-swirler swirl arid lower-swirler flow. The gas backflow remained about the same for the lengthened primary zone. In addition a somewhat smaller increase in gas backflow took place for the longer primary zone as swirler flow was decreased and swirl increased. Since it was also easier to make swirler and primary flow changes, than to change to a longer primary zone, no significant combustion trials were carried out with a lengthened primary zone.

At this point, the emphasis of combustor design shifted to the sector can. For this reason the verification of the computed isothermal velocity field was carried out using the sector can geometry described below prior to further application of the above combustor performance criteria.

\subsubsection{Sector Can Combustor}

3.3.3.21 Combustion Conditions. The sector can CWS combustor, shown in Figure 3.3.18, was designed in part based on the results of the LM500 CWS combustor results obtained previously. This sector can was representative of the anticipated sector combustor design. The design point operating conditions for this combustor are given in Table 3.3.6 and the representative flow splits are given in Table 3.3.7. The flow modeling technique developed using the LM500 combustor was applied to the sector can combustor to evaluate and select design changes that would increase residence time and gas backflow in the primary zone.

Prior to the sector can modeling activity, a simulated cold flow experiment was installed to allow a comparison between the calculated and measured velocity profiles in the primary zone. 


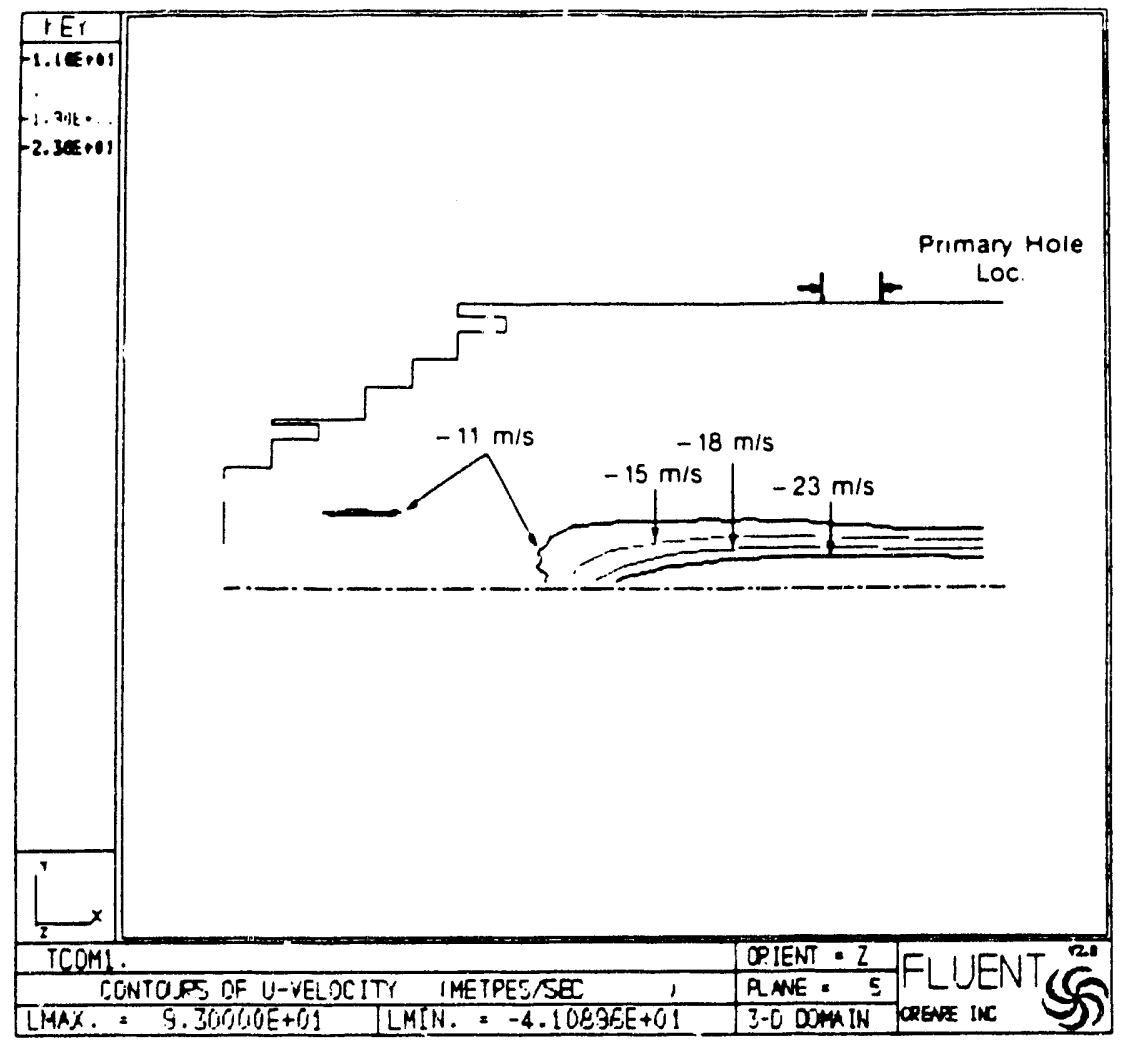

(A) $60^{\circ} \mathrm{S}, 1 / 2$ Flow, LT

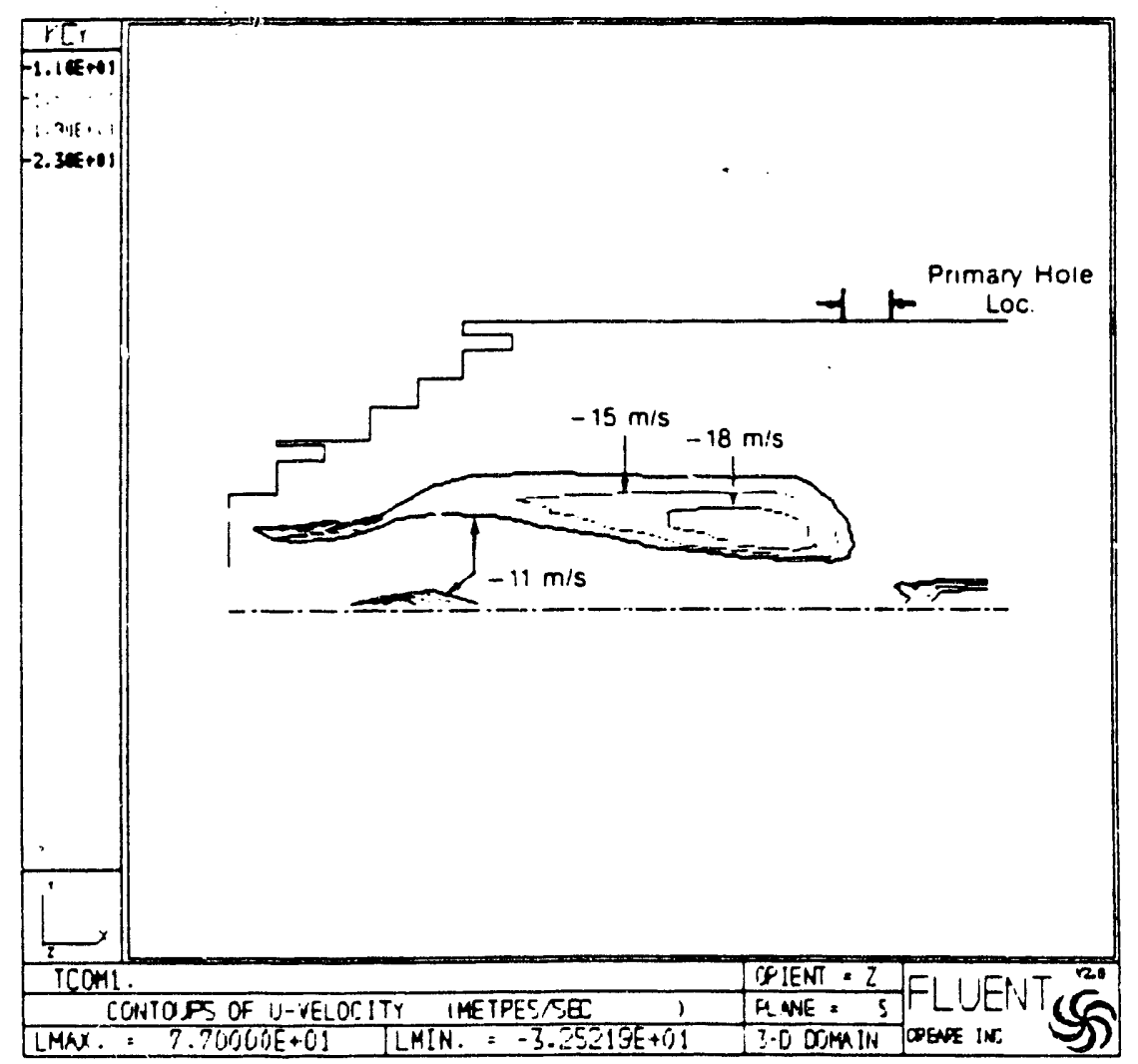

\section{(B) $45^{\circ} \mathrm{S}, \mathrm{LT}$}

Figure 3.3.17 Calculated gas backflow velocity contours in primary zone of LM500 combustor - comparison of high backflow (a) and low backflow (b) cases (see figure 3.3.16). 


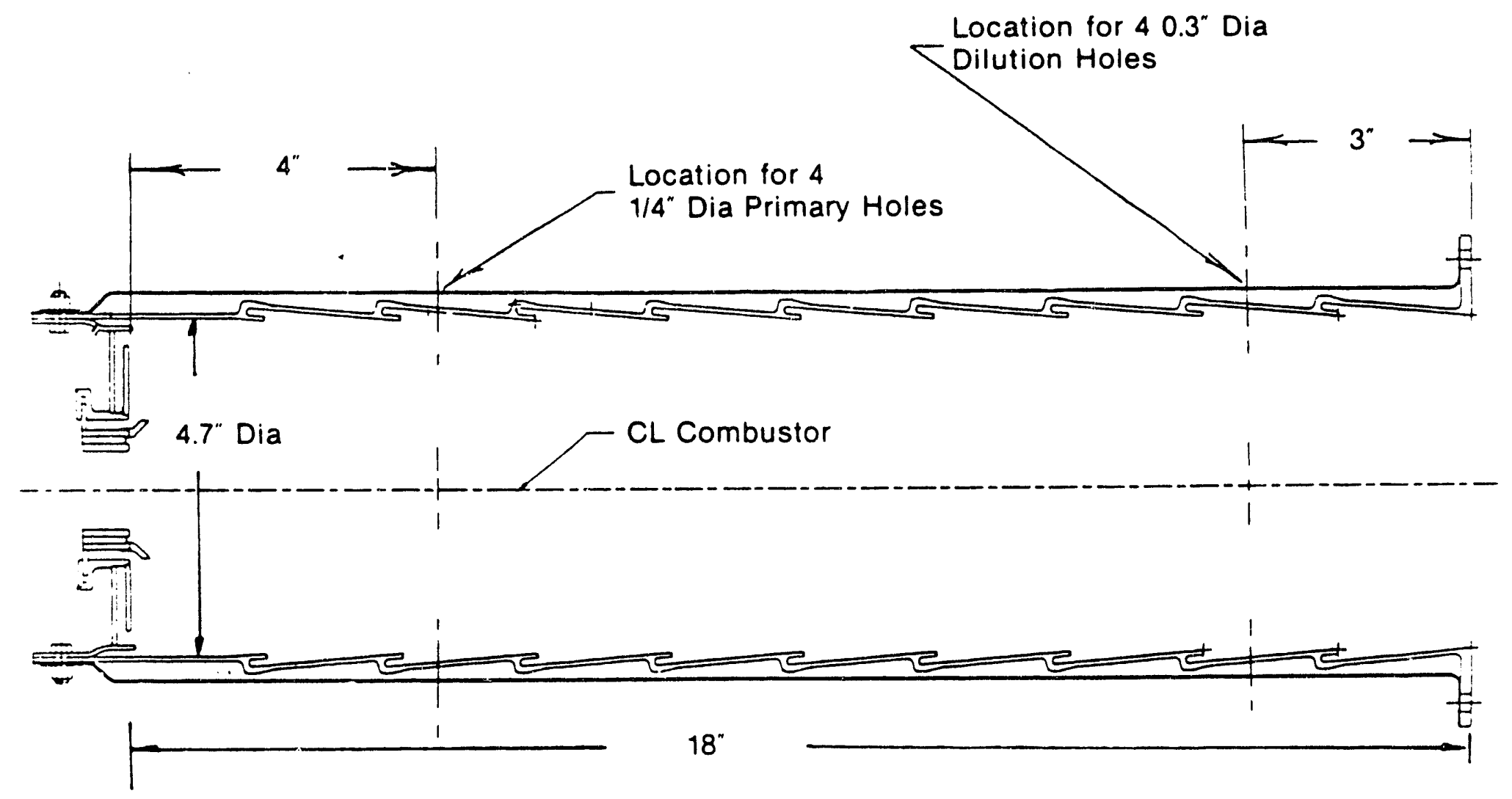

Figure 3.3.18 Schematic of sector can combustor. 
Table 3.3.6

Operating Conditions for Sector Can

Pressure

$14 \mathrm{At}$

Combustor Exit Temperature

$1100-1200^{\circ} \mathrm{C}$

Air Preheat Temperature

Fuel Input (oil + CWM)

$400^{\circ} \mathrm{C}$

$2.5 \times 10^{9} \mathrm{~J} / \mathrm{hr}$

Table 3.3.7

Design Point Sector Can

Combustor Flow Rates

\begin{tabular}{lc}
\hline Nozzle Air & $10 \%$ \\
Swirl Air & $6.9 \%$ \\
Dome Cooling & $9 \%$ \\
Primary Air & $13.6 \%$ \\
Dilution Air & $20.8 \%$ \\
Cooling Air & $39.7 \%$
\end{tabular}

Total Air Flow at $14 \mathrm{At}=0.7 \mathrm{Kg} / \mathrm{s}$ 
3.3.3.22 Flow Model Verification. A dome and swirler assembly for the combustor shown in Figuree 3.3.18 was fitted to a $12 \mathrm{~cm}$ I.D. transparent tube $30 \mathrm{~cm}$ long with four primary air holes having the same diameter and located at the same distance from the dome as those in the combustor. The cooling air for the liner was not modeled, nor was the secondary dilution air. This model was designed to operate up to $2 \mathrm{~atm}$ absolute pressure and to accommodate either the LT or Parker-Hannefin nozzles. The nozzle atomizing air could be varied to model the correct flow split in the liner. Three measurement ports were provided in the primary zone in line with one of the primary cooling holes and three were centered circumferentially between two primary holes at the same axial positions. Three sets of ports were also provided downstream of the primary holes. Two five-hole United Sensor directional velccity probes, $.30 \mathrm{~cm}$ in diameter, were obtained, calibrated and mounted with a micrometer traverse mechanism and angle dial indicator to allow complete radial traverse of the simulated primary zone. A Scannivalve was employed to read the pressure differences required for the computerized data reduction system. The axial and swirl velocity components were measured with the greater accuracy while the measurement of the radial velocity component was limited to pitch angles of about $\pm 40^{\circ}$.

Initial comparison between the measured velocity profiles and those calculated by the FLUENT model was not satisfactory. A check of the inlet velocity profile generated by the nozzle atomizing air, when only nozzle air was admitted to the simulator, showed that unlike the velocity profile measured with the same nozzle in the $25 \mathrm{~cm}$ diameter spray tunnel, that generated in the $12 \mathrm{~cm}$ simulated combustor developed a larger cone angle with a negligible centerline velocity. This corrected inlet profile was subsequently employed in the data comparison given below.

The design pressure drop ratio across the liner holes and swirler was held constant to yield the same inlet velocity to the liner. At one atmosphere liner pressure this implies a total liner flow of $.051 \mathrm{~kg} / \mathrm{s}$ including the nozzle atomizing air flow of $.013 \mathrm{~kg} / \mathrm{s}$. Although the total flow is reduced due to the absence of liner cooling and secondary dilution air, the correct ratios of the remaining flow additions were thus maintained. In addition to the above test conditions, one test was carried out at three-quarter of the design condition flow rate and both flow rates were repeated at $1.56 \mathrm{~atm}$ liner pressure. The latter involved an increase of $56 \%$ in the respective mass flow rates to hold the superficial velocities constant, i.e., similar to turndown in a gas turbine combustor. The comparison between measured and calculated velocity profiles shown in Figures 3.3.19 and 3.3.20 is representative of the remaining measurements in the primary zone. Only the axial and swirl velocity components are compared since the measurement accuracy of the radial component was insufficient for a meaningful evaluation.

The comparison between the calculated and measured axial velocity component is shown in Figures 3.3.19a, b and $\mathrm{c}$ and that for the swirl component in Figures 3.3.20a, b and c. The axial locations indicated were close to the maximum backflow locations in both the calculated 


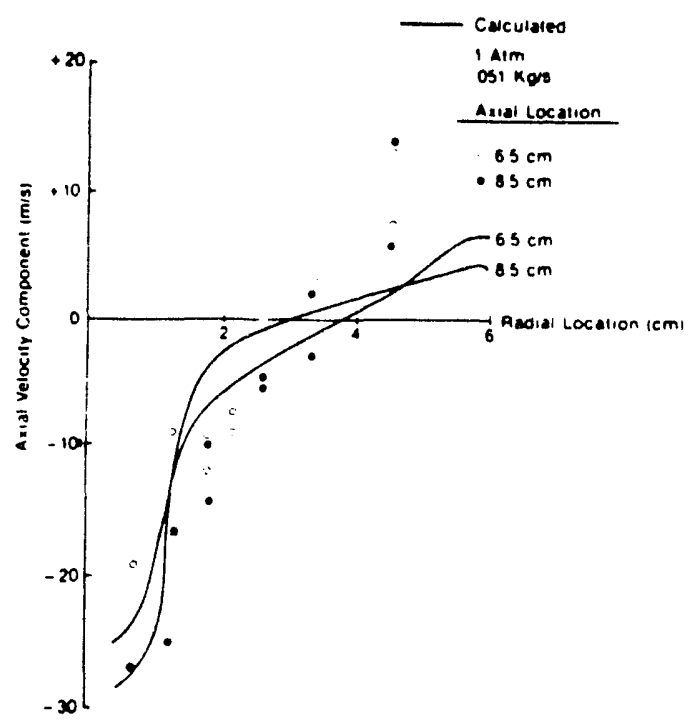

(A) Circumferential Location In-Line With Primary Holes

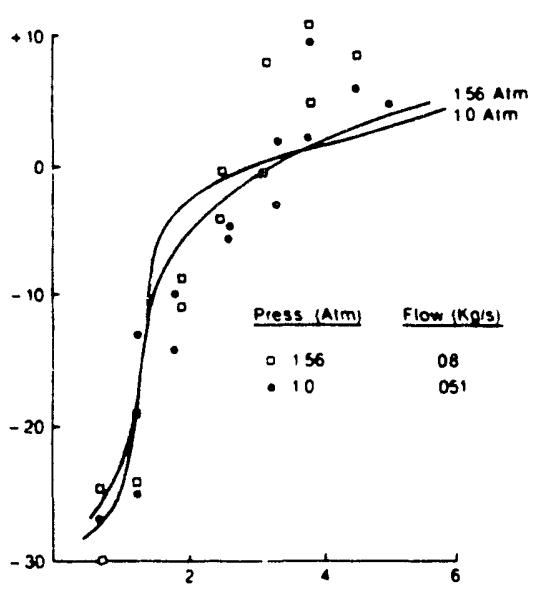

(B) Axial Location $8.5 \mathrm{~cm}$ From Nozzle. Circumferential Location In-line With Primary Holes.

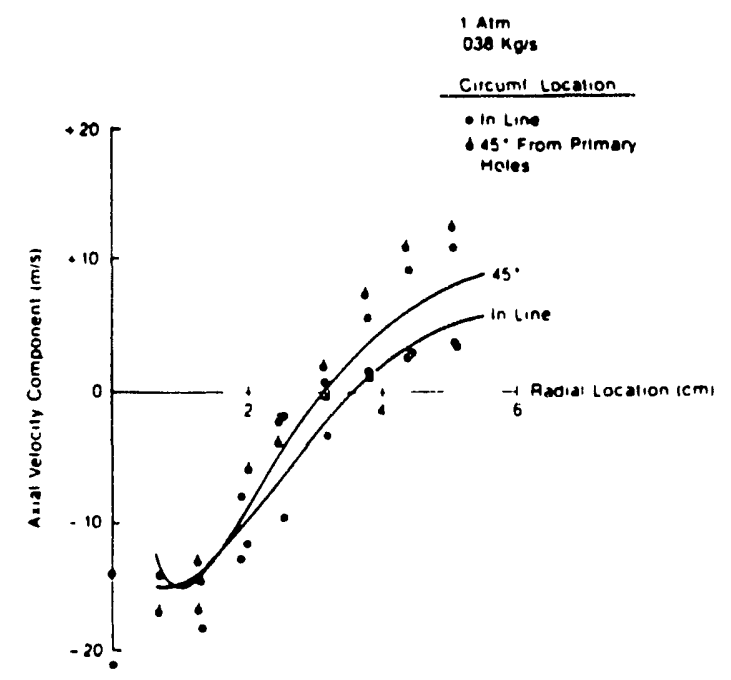

(C) Axial Location $8.5 \mathrm{~cm}$ From Nozzle

Figure 3.3.19 Comparison of measured and calculated axial velocity component in simulated sector can at indicated locations, flow rates and pressures. Data points at each location show degree of asymmetry about centerline. 


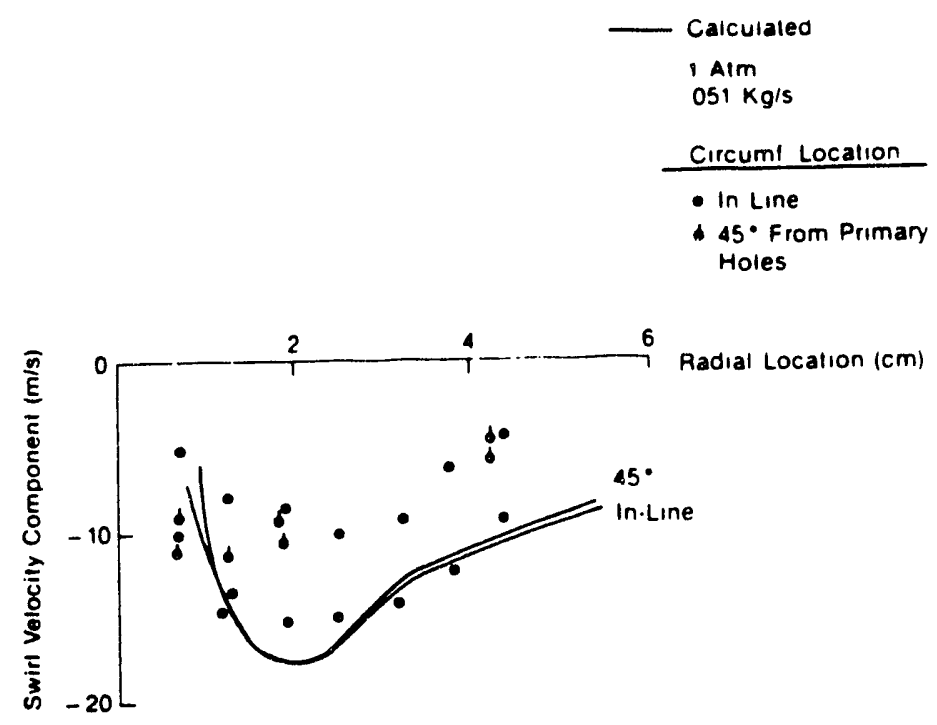

\section{(A) Axial Location $8.5 \mathrm{~cm}$ From Nozzle}

\begin{tabular}{ll} 
Press. (Atm) & Flow (Ko/s) \\
\hline 01.56 & .08 \\
-1.0 & .051
\end{tabular}

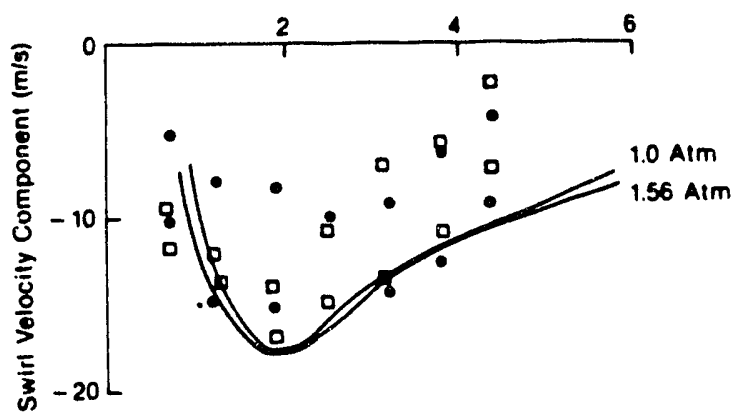

(B) Axial Location $8.5 \mathrm{~cm}$ From Nozzle. Circumferential Location In-line With Primary Holes.

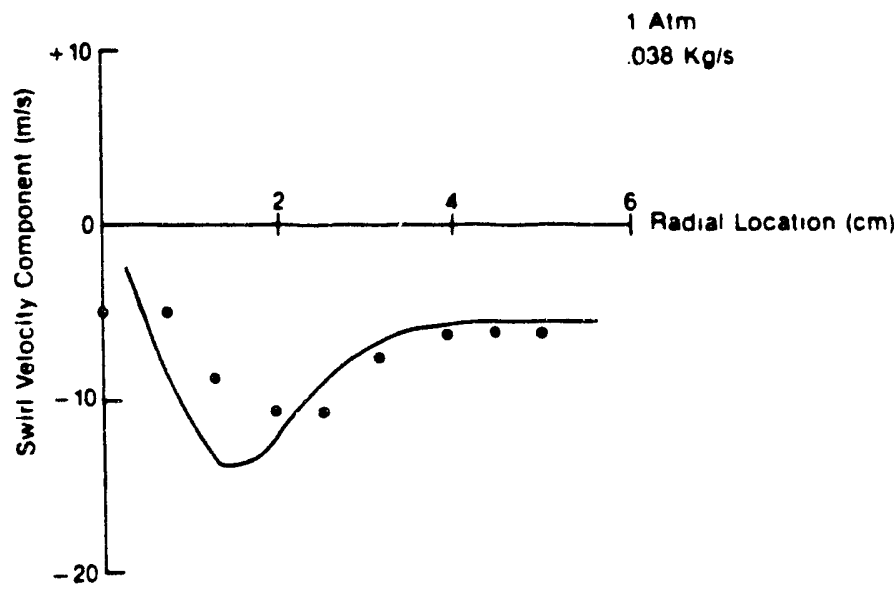

(C) Location Same as (B) Above. Average Velocity About Centerline.

Figure 3.3.20 Comparison of measured and calculated swirl velocity component in simulated sector can at indicated locations, flow rates and pressures. Data points at each location show degree of asymmetry about centerline. 
and measured results. The traverse locations and operating conditions are given in Figures 3.3.19 and 3.3.20. In general, the analysis predicts the degree of axial backflow and its location correctly and predicts the swirl component within about $25 \%$. A lack of measured symmetry on each side of the centerline of roughly $\pm 25 \%$ is indicated that is not predicted in Figure 3.3.20a and underpredicted in Figure 3.3.19c. One possible cause of such asymmetry is any non-symmetry in the nozzle air jet or any axial or swirl component in the primary air inlet velocities. Such possible asymmetries were not included in the analysis. The negligible effect of air density on the velocity profiles is indicated in Figures $3.3 .19 \mathrm{~b}$ and $3.3 .20 \mathrm{~b}$ in both the measurements and the analysis. The lower velocity components at the reduced flow rate are also close to those predicted in Figures 3.3.19c and 3.3.20c. Considering the complexity of this highly sivirled, non axisymmetric flow, the agreement between measured and calculated velocity profiles is reasonable. It also underscores the validity of predicted changes in the velocity profiles due to changes in the operating condition. The latter is of more significance in this isothermal model of the combustor velocity field.

The simulated sector can was also employed to characterize the nozzle air velocity profiles, when only nozzle air was injected, for two nozzle geometries. The axial and swirl components for the LT and Parker Hannefin (\#6881038 swirler) are shown in Figure 3.3.21 measured $4 \mathrm{~cm}$ from the nozzles. The LT nozzle provides larger swirl and a hollow cone type of profile while the PH nozzle yields a narrow cone with less swirl. The swirl direction of these nozzles are in opposite directions. On the basis of this test the LT nozzle would yield more wall deposition, but is expected to provide a larger gas backflow in the primary zone. To determine the effect of counter-current versus co-current swirler flow, between nozzle swirl and swirler swirl, these two nozzles were operated at the design flow conditions. As shown in Figure 3.3.22 counter-current swirl caused very low gas backflow and severe lack of circumferential symmetry compared to co-current swirl operation. For this combustor configuration, co-current swirl is thus recommended.

3.3.3.2.3 Predicted Sector Can Performance. Subsequent to the above verification of the predicted sector can velocity profiles, the design point condition shown in Table 3.3.7 was modeled to determine the relative gas backflow and drop residence times in the primary zone. The design point involved a change from a preliminary can design which had slightly less dome cooling and swirler air flow and about one-half of the liner pressure drop. The preliminary design had about the same calculated gas backflow and $20 \%$ lower residence time of 30 $\mu \mathrm{m}$ drops in the primary zone. The design point yielded a gas backflow of $36 \%$ of the primary zone air and a $30 \mu \mathrm{m}$ drop residence time of $24 \mathrm{msec}$ in the primary zone. This backflow is equivalent to that requiring the lowest auxiliary fuel flow in the LM500 combustor while, as expected, the drop residence time is almost twice as large as that calculated at the best LM500 operating point. The further improvement in the expected sector can combustor performance, over that achieved with the LM500 combustor, was verified by the ability to operate 


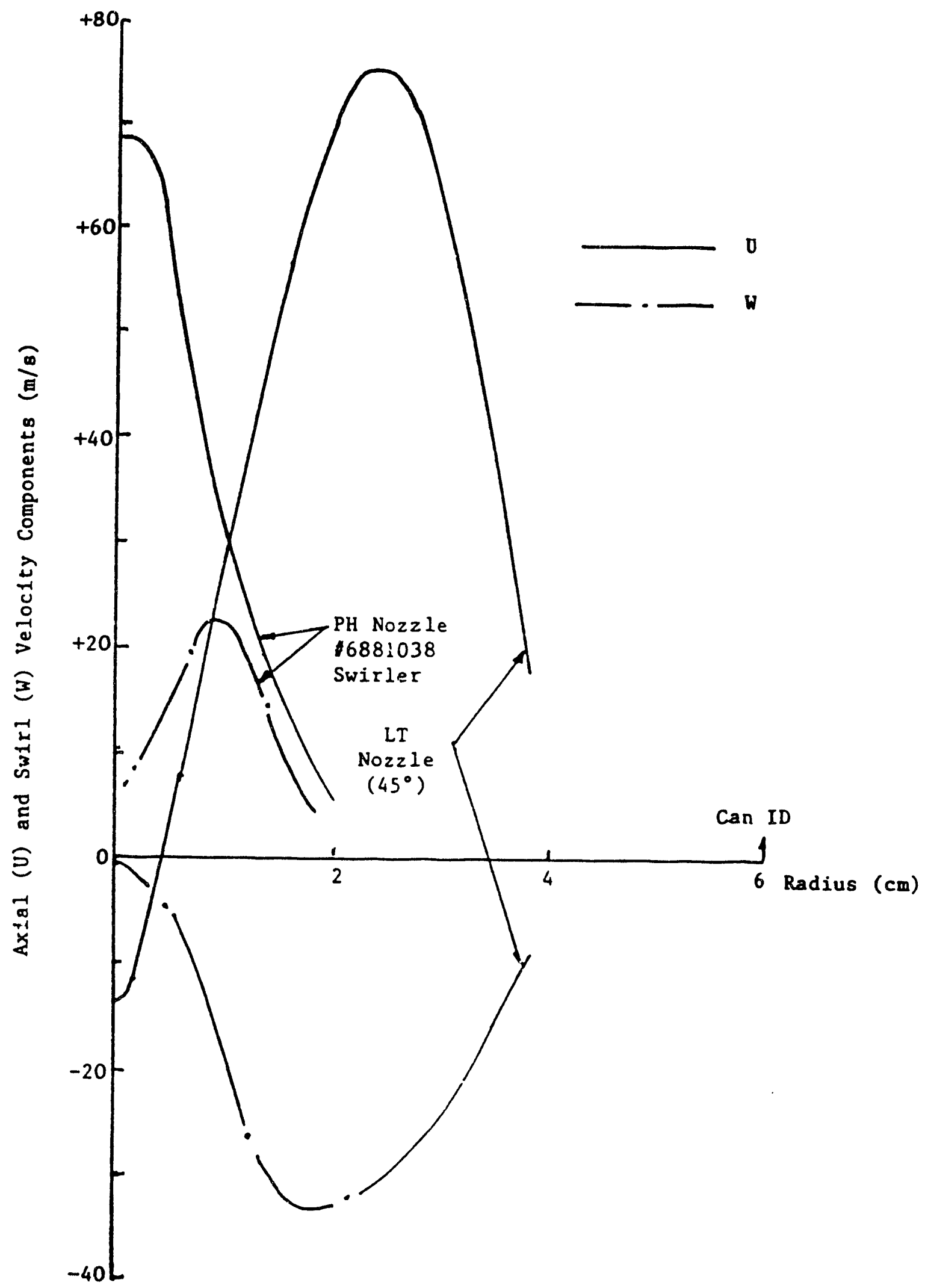

Figure 3.3.21 Measured velocity components in simulated sector can $4 \mathrm{~cm}$ from the nozzle when only nozzle flow is injected into can. Profiles were close to symmetric about centerline. 


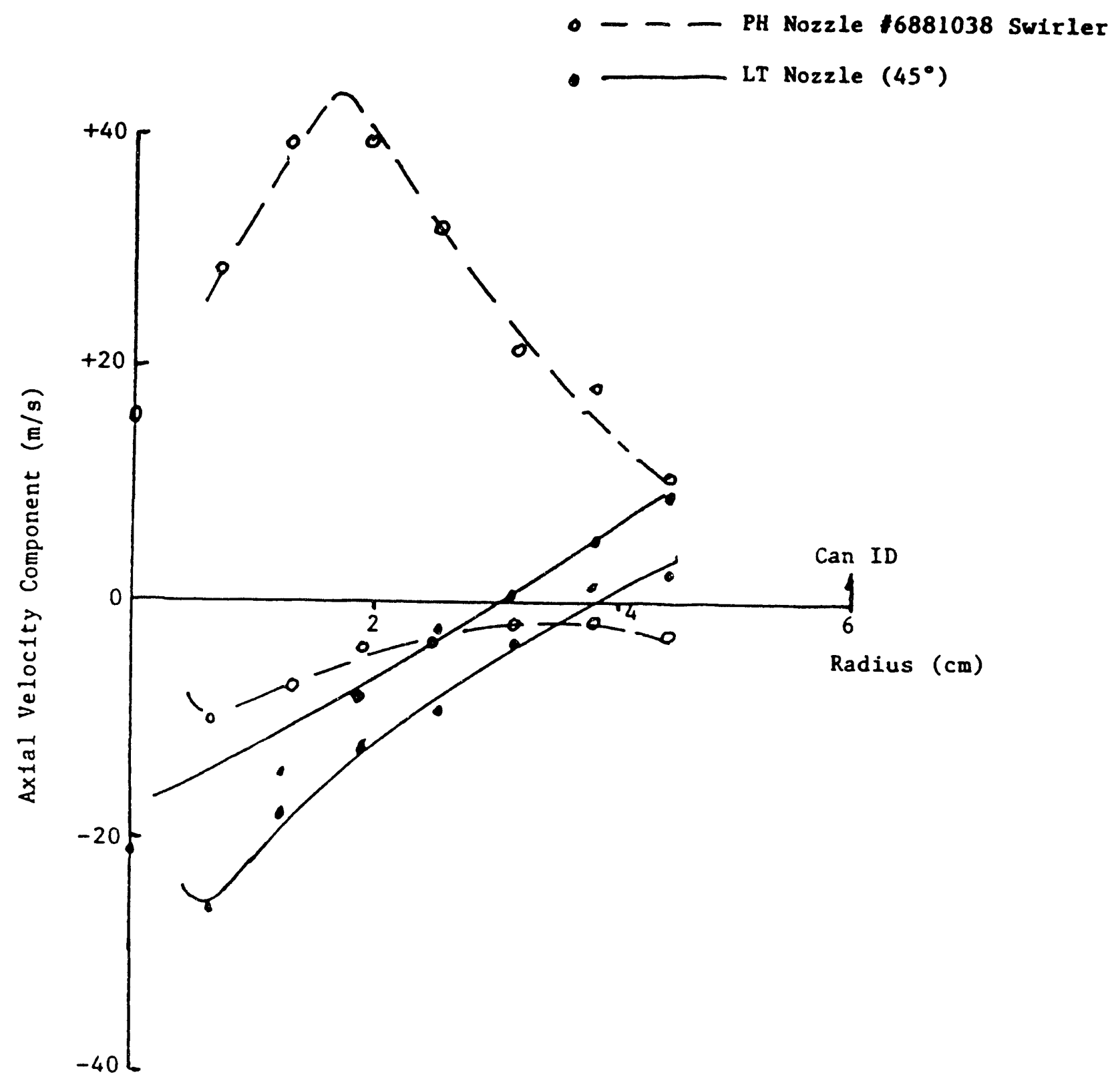

Figure 3.322 Measured axial velocities on each side of centerline in simulated sector can $8.4 \mathrm{~cm}$ from nozzle at circumferential location in-line with primary hole. 
the sector combustor without use of auxiliary fuel.

The only adverse change in the calculated sector can flow behavior was the marked increase in liner wall impingement by the slurry drops in the primary zone. For this reason, the effect of moving the primary holes downstream, with different combinations of swirler swirl and nozzle atomizing air swirl, was analyzed to determine the trade-off between decreased impingement and changes in gas backflow or residence time. The effect of a $40 \%$ increase in the length of the primary zone with the LT, MS and HS nozzles is shown in Table 3.3.8, in addition to the effect of increasing the swirler swirl from 45 to $60^{\circ}$. While liner impingement was significantly reduced in all cases, only the MS nozzle case avoided a sharp decrease in $30 \mu \mathrm{m}$ residence time in spite of the fact that the maximum gas backflow increased somewhat in all cases. This result suggests that, if excessive liner impingement takes place in the present design, an increase in the primary zone length should yield less impingement and no reduction in performance provided the higher swirl MS nozzle is employed. Again, it is emphasized that this isothermal flow model can be used to reduce combustor development time by identifying the optimum selection of design changes.

\subsubsection{Conclusions}

A simplified nozzle characterization technique that allows a reasonable definition of the temporal drop size distribution has been developed and verified. The use of this distribution in an isothermal flow model of the combustor related the drop sizes to their residence time. By comparing this residence time to that required for carbon burnout, satisfactory nozzle geometries were selected for the LM500 and sector can combustors.

Measurement of the shear viscosity of Otisca slurry showed that, at shear rates typical in piping, the shear viscosity increases with heating while at the high shear rates typical in atomizing nozzles, the shear viscosity decreases with heating. As a result, the atomized drop size decreased with slurry heating. On further heating to permit flashing, the atomized drop size was reduced at a more rapid rate. In an atmospheric pressure combustor test the decreased atomized drop size due to slurry heating yielded significantly higher carbon utilization. This benefit should be evaluated at gas turbine combustor operating conditions.

The isothermal flow model of the combustor provided guidance to the selection of the swirler-primary air flow split, the desired angular momentum in the injected air and the best axial location for the primary air. The best correlating parameter between the calculated flow distribution and the measured combustor performance, as determined by the minimum use of auxiliary fuel, was found to be the percent of gas backflow near the nozzle based on the total air addition to the primary zone.

A simulated can combustor liner flow experiment was employed to compare the measured velocity field to that calculated by the isothermal model. Both the axial and swirl velocity distributions compared satisfactorily with those calculated and verified the model. 
Table 3.3.8

Calculated Design Point Performance of Sector Can

Combustor With Longer Primary Zone

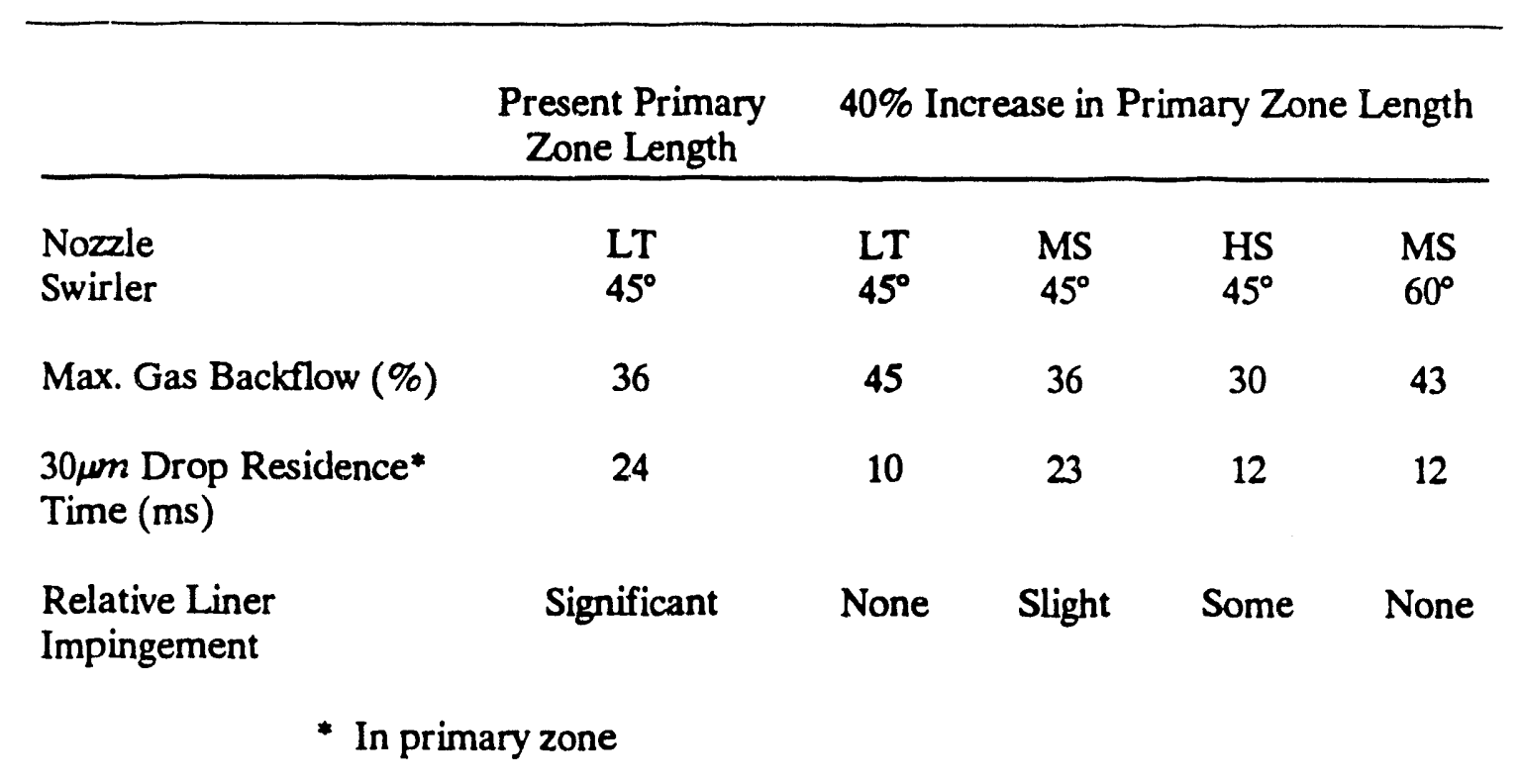


The nozzle characterization and flow model significantly shortened the combustor development time and enhanced the ability to achieve high combustion efficiency without the use of auxiliary fuel.

\subsubsection{References}

[1] J.M. Beer, et al., "A Mechanistic Model of Coal Water Fuel Combustion", 21st Int. Symp. on Combustion, August 1986, Munich, W. Germany.

[2] F.W. Staub, "Spray Characterization and CW Slurry Atomization", GE TIS Report No. 86CRD123, July 1986.

[3] F.W. Staub, "Air Atomized Coal-Water Slurry Nozzle Performance", GE TIS Report No. 86CRD169, October 1986.

[4] P.G. Simpkins, E.L Bates, "Water Drop Response to Sudden Accelerations", J. Fl. Mech., Vol. 55, Pt 4, p. 629, 1972.

[5] N. Chigier, et al., "Drop Size Distribution in Air Assist Swirl Atomizer Sprays", The Combustion Institute Joint Technical Meeting, San Antonio, Texas, April 1985.

[6] A.H. Lefebvre, N.K. Risk, "Influence of Downstream Distance on Simplex Atomizer Spray Characteristics", 1984 ASME Annual Winter Meeting, New Orleans, LA, December 1984.

[7] N.A. Chigier, et al., "Laser Tomographic Investigation of Liquid Fuel Sprays", 18th Symposium (Int.) on Combustion, The Combustion Institute, p. 1501, 1981.

[8] A.M. Cormack, "Representation of a Function by Its Line Integrals with Radiological Applications", Joumal of Applied Physics Vol. 34, No. 9, September 1963.

[9] P.G. Felton, et al., "Measurement of Drop Size Distribution in Dense Sprays by Laser Diffraction", Proceedings of ICCASS-85, 3rd Int. Conference on Liquid Atomization and Spray Systems, Inst. of Energy, London, pg IVA1411 (1985).

[10] Dodge, L.G., "Change of Calib. of Diffraction Based Particle Sizers in Dense Sprays", Optical Eng., Sept.-Oct. 1984, Vol. 23, No. 5, Pg. 626.

[11] N. Chigier, P.C. Meyer, "Atomization of Coal Water Slurries"” Proc. 6th Int. Symp. on Coal Slurry Comb. and Technology, Orlando, FL, June 1984.

[12] N. Chigier, et al., "The Structure and Characterization of Air-Assisted Swirl Atomizer Sprays", ASME Paper 85-WA/HT-45, ASME Winter Annual Meeting, Nov. 1985.

[13] LG. Dodge, "Comparison of Drop Size Measurement in Fuel Sprays: Malvern Diffraction and Aerometrics Phase/Doppler", 1986 Meeting of Central States Section/The Combustion Institute, NASA Lewis Res. Center, May 1986.

[14] J. Swithenbank, et al., "Spray Combustion Modeling" ASME Publication H00350, p. 259.

[15] S.G. Kimura, C.L. Spiro, and C.C. Chen, "Combustion and Deposition in Coal Fired 
Turbines", Trans. ASME, J. of Eng. for Gas Turbines and Power 109, 319-324, July 1987.

[16] S.G. Kimura, C.L. Spiro, and C.C. Chen, "Alkali Species Characterization in CoalFired Turbines", Proceedings of the Third Annual Heat Engines Contractors Meeting, F.W. Crouse, ed., May 1986.

[17] N. Abuaf, and F.W. Staub, "Drying of Liquid-Solid Slurry Droplets", GE TIS Report No. 85CRD225, December 1985.

[18] J.M. Beer, G.Vermes, "Gas Turbine Combustion for Coal Water Mixtures", Eng. Found. Conf., Santa Barbara, CA, November 1982.

[19] J.M. Beer, K.B. Lee, "The Effect of Residence Time Dist. on the Performance and Efficiency of Combustors", Tenth Int. Symp. on Combustion, The Combustion Institute, pg. 1187.

[20] J.M. Beer, H. Chigier, "Stability and Comb. Intensity of Pulverized Coal Flames Effect of Swirl and Impingement", Journal of the Institute of Fuel, p. 443, December 1969.

[21] J.F. Driscoll, "Scattering Measurements to Study Blow-off of Swirling Flames", AIAA Paper 86-0593, AIAA 24th Aerospace Sciences Mtg., January 1986.

[22] J.M. Beer, et al., "Measurement of Viscosity of Coal-Water Fuels at High Shear Rate", 8th International Symposium on Coal Slurry Preparation and Utilization, Orlando, Florida, May 1986.

[23] A.H. Lefebvre, X.F. Wang, "Influence of Ambient Air Pressure on Pressure-Swirl Atomization", Atomization and Spray Technology, Vol. 3, No. 3, p. $209,1987$.

[24] J.M. Beer, et al. "Secondary Atomization of Coal-Water Slurries", Seventh International Symposium on Coal Slurry Combustion and Technology, New Orleans, LA, May 1985.

[25] M.W. Horner, "Combustion of a Coal-Water Mixture in Gas Turbine Combustor", Joint ASME/IEEE Power Generation Conference, October 1985.

[26] K.J. Ross, "Gas Turbine Component Screening Program", Vol. I, DOE/MC213952298, Final Report, March 1987. 


\subsection{Combustor Development}

\subsubsection{Introduction}

The economical and environmentally acceptable use of beneficiated coal-water slurry as a primary fuel source for gas turbine combustors has been the subject of a number of recent studies. In attempts to burn coal-water slurries in gas turbine can combustors, Horner (1985) found that whenever slurry flows exceeded $80 \%$ of the total heat input value, combustion became unstable and problems were created by the formation of ash deposits on the combustor liner walls and on downstream turbine components. Kimura et al. (1987) and Ross (1987) found that, because of the short residence times of present-day gas combustors, fuel atomization and combustion zone recirculation are key determinants of efficiency of coal-water mixture (CWM) slurry combustion. Those findings suggest that improving fuel atomization and enhancing recirculation in the primary zone of the combustor would be important steps in reducing the amount of auxiliary fuel needed.

An LM500 turbine simulator previously installed at CRD (Kimura et al., 1987) was selected as the test system to be used for a series of investigatory programs on CWM combustion, including an exploration of the effects of additives on reducing deposits on combustor and turbine components and reducing environmental emissions. Before the research on additives could be done, however, it was necessary to determine the optimal configuration of fuel nozzle and air swirler for combustor stability with minimal heat input value from an auxiliary fuel. The methods used to determine that configuration are the subject of this report.

Using CWM as primary fuel and \#2 fuel oil as pilot and auxiliary fuel, nine sets of fired tests were performed to study the effect that varying (1) the amount of combustion air swirl and (2) the fuel nozzle spray angle would have on combustion performance.

The first three sets of tests (Table 3.4.5, A-C) were carried out with the combustor liner in the configuration used for previous testing as described by Kimura et al, (1987). The original air swirler, an integral part of the combustor liner that could not be modified, was tested with three new fuel nozzles that were based on the original design. One nozzle ( $\left.45^{\circ} \mathrm{LF}\right)$ had a $45^{\circ}$ spray angle and an atomizing air flow rate lower than the original. A second nozzle $\left(65^{\circ} \mathrm{HF}\right)$ had a $65^{\circ}$ spray angle and an atomizing air flow rate higher than the original. A third nozzle $\left(55^{\circ} \mathrm{MF}\right)$ had a $55^{\circ}$ spray angle and an atomizing air mass flow rate between the original and the flow rate of the $45^{\circ} \mathrm{LF}$ nozzle.

The remaining tests were carried out with a modified air swirler design. Swirlers with vane angles of $30^{\circ}, 38^{\circ}, 45^{\circ}$, and $60^{\circ}$ were run with the the original fuel nozzle (Table 3.4.5, D$\mathrm{G}, \mathrm{I}$ ); a swirler with a $30^{\circ}$ vane angle was run with a $65^{\circ}$ nozzle (Table $3.4 .5, \mathrm{H}$ ).

An important function of these tests was to provide empirical data that could be used to develop and verify a predictive model for a combustor burning CWM fuel. 


\subsubsection{LM500 Turbine Simulator Test Facility}

The turbine simulator test facility is a pressurized combustion/deposition facility in which combustion eshaust gases pass chrough an LM500 aeroderivative gas turbine first-stage nozzle cascade. The combustor is a modified J-79 can type combustor. The combustor liner walls are slot-cooled segments with an outer in, ingement shield. Figure 3.4.1 is a schematic diagram of the test hardware. Preheated compressed air is delivered to the test rig by means of a centrifugal compressor and a nonvitiated gas-fired air heater. Exhaust gas samples are taken from the test rig and transported via electrically heat traced sample lines to the analysis instrumentation. Particulate samples are extracted from the exhaust stream by means of a nitrogen-quenched isokinetic sample probe and collected on a sintered metal filter with a pore size of $0.5 \mu \mathrm{m}$. Operating conditions for the combustion system are shown in Table 3.4.1.

\subsubsection{Coal -Water Mixture Fuel}

The beneficiated CWM fuel used was supplied by the Otisca Corporation. The Otisca T-Process involves wet-stirred ball-mill grinding and mixing followed by selective agglomeration with pentane. Properties of a typical batch of Otisca CWM fuel are shown in Table 3.4.2. The solid content of the CWM fuel is $\sim 50 \%$ by weight and the heating value is $\sim 7000 \mathrm{Btu} / \mathrm{lb}$. Immediately before use, each barrel of CWM fuel was thoroughly mixed to insure homogeneous coal dispersion. The fuel was transferred from the $55 \mathrm{gal}$ barrels to a $200 \mathrm{gal}$ stainless steel storage tank by an air-actuated pump and was delivered to the combustor test stand by a $\mathrm{Moyno}^{\circ}$ progressive cavity pump. To ensure good mixing, the CWM fuel was continuously recirculated to the storage tank during testing by means of a bypass line.

\subsubsection{Fuel Nozzle}

Air-atomizing, dual-fuel nozzles were used because they satisfy the need to atomize (1) distillate fuel used for startup and (2) both distillate and CWM fuel used during the combustion tests. The fuel nozzle used for the initial CWM tests was invented by Lee Tomlinson (GE-CRD patent applied for) and is therefore referred to as the LT nozzle. Results

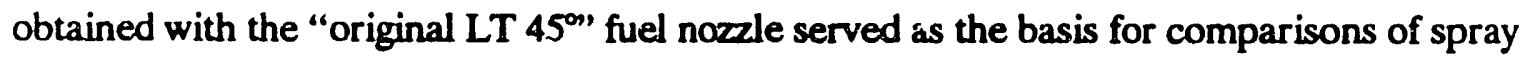
angle and atomizing air flow.

A series of dual-fuel nozales were designed to provide a range of spray angles and atomizing air flows. Figure 3.4.2 shows the atmospheric air flow test results for the fuel nozzles tested. Figure 3.4.3 shows the nozzle spray angle. The nozzle spray angle was varied to a maximum of $65^{\circ}$ because there was some concern that a spray angle of that magnitude might deposit CWM particles on the combustor liner walls. That possibility was predicted by Staub (1988) in studies he performed using the results of fuel nozzle spray characterization tests in conjunction with an isothermal combustor flow model.

The atomizing air flow was adjusted by modifying the vane height at the tip of the nozzle. The vanes were machined to the prescribed angle and width, and the height was adjusted to 


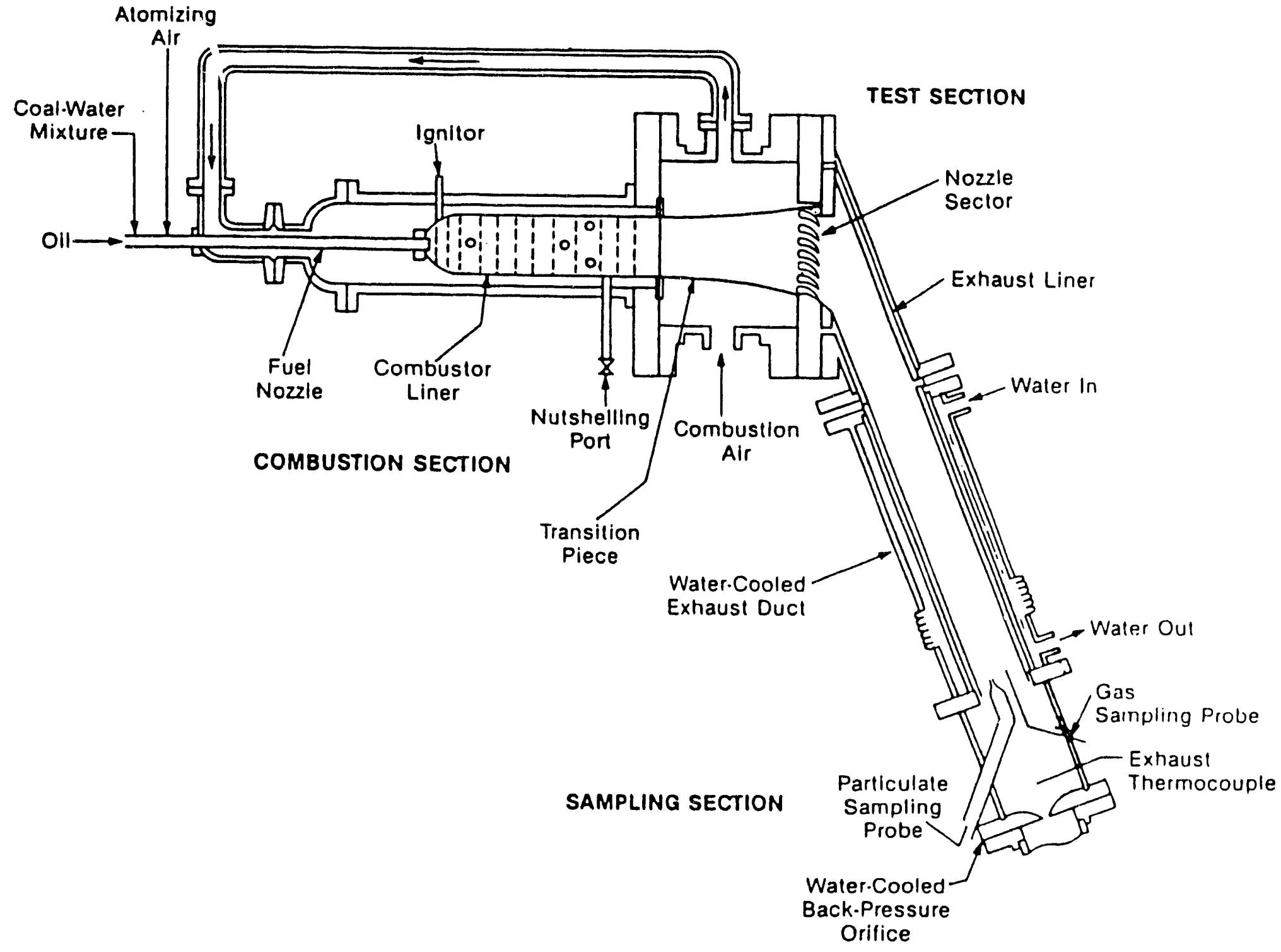

Figure 3.4.1 Schemat:ic diagram of LM500 turbine simulator. 
Table 3.4.1

\section{Operating Conditions for LM500 Combustion Tests}

$\begin{array}{ll}\text { Pressure } & 10 \mathrm{~atm} \\ \text { Combustor Exit Temperature } & 2000-2200 \mathrm{~F} \\ \text { Air Preheat Temperature } & 760 \mathrm{~F} \\ \text { Total Mass Flow } & 3.2 \mathrm{lbm} / \mathrm{s} \\ \text { Total Heat Input (Oil + CWM) } & 3.5 \mathrm{MBtu} / \mathrm{hr}\end{array}$

Table 3.42

Properties of OTISCA Coal Water Mixture

PROXIMATE ANALYSIS (Dry Basis)

Ash Content \%

0.90

Total Sulfur \%

0.80

Volatile \%

37.12

Fixed Carbon \% 61.18

$\overline{100.00}$

\% Solids in Slurry

49.87

Slurry Viscosity cp

270

PARTICLE SIZE DISTRIBUTION

$\begin{array}{rr}\text { Diameter } & \text { Mass \% } \\ >11.5 & 7.0 \\ 11.5 & 0.5 \\ 10.5 & 0.0 \\ 9.5 & 4.0 \\ 8.5 & 4.4 \\ 7.5 & 3.2 \\ 6.5 & 6.2 \\ 5.5 & 7.6 \\ 4.5 & 10.8 \\ 3.5 & 14.0 \\ 2.5 & 18.4 \\ 1.5 & 18.5 \\ 0.5 & 5.4\end{array}$




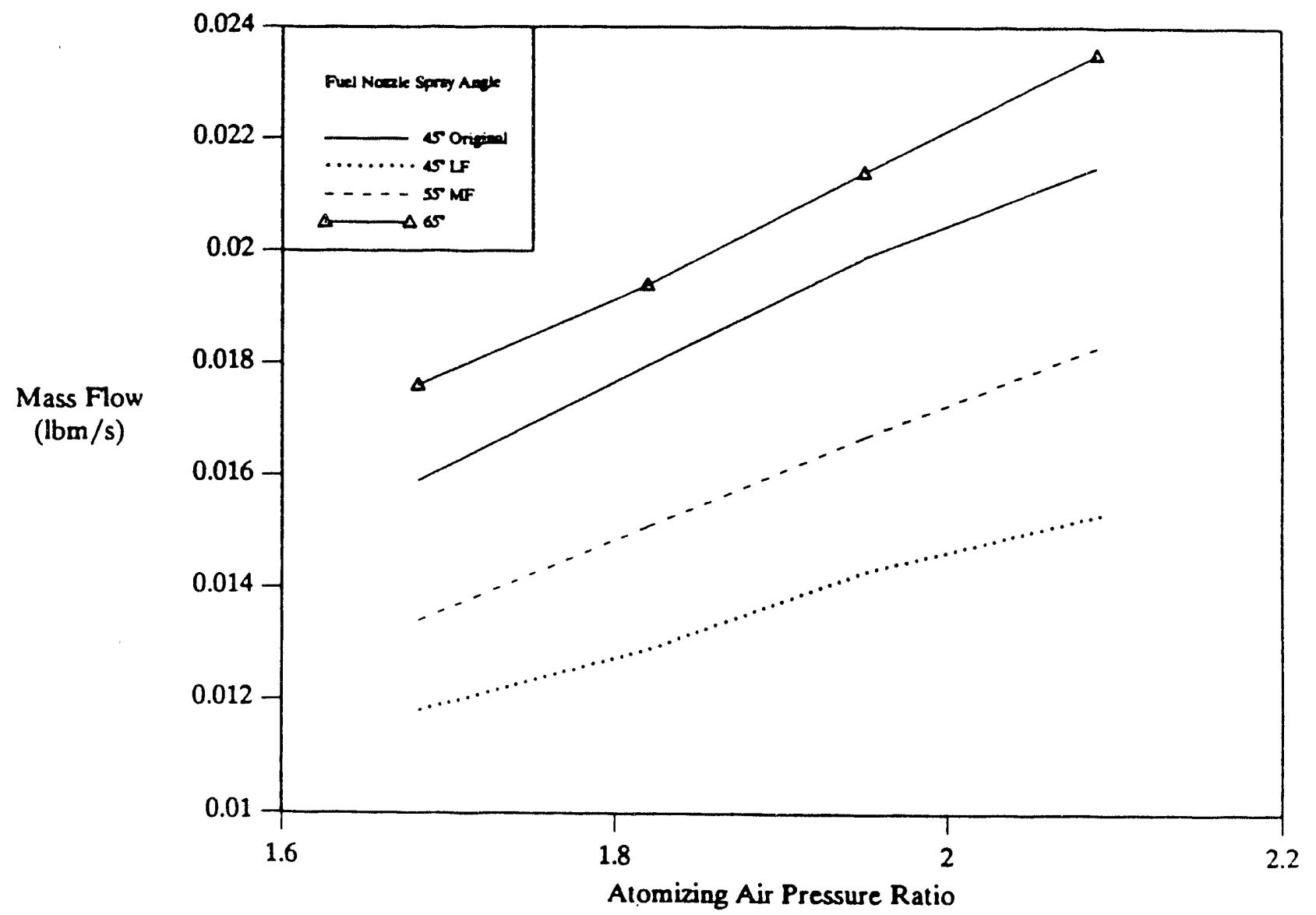

Figure 3.4.2 Flow rate through fuel nozzle measured at atmospheric pressure. Atomizing air pressure ratio $=$ nozzle pressure/discharge pressure. 


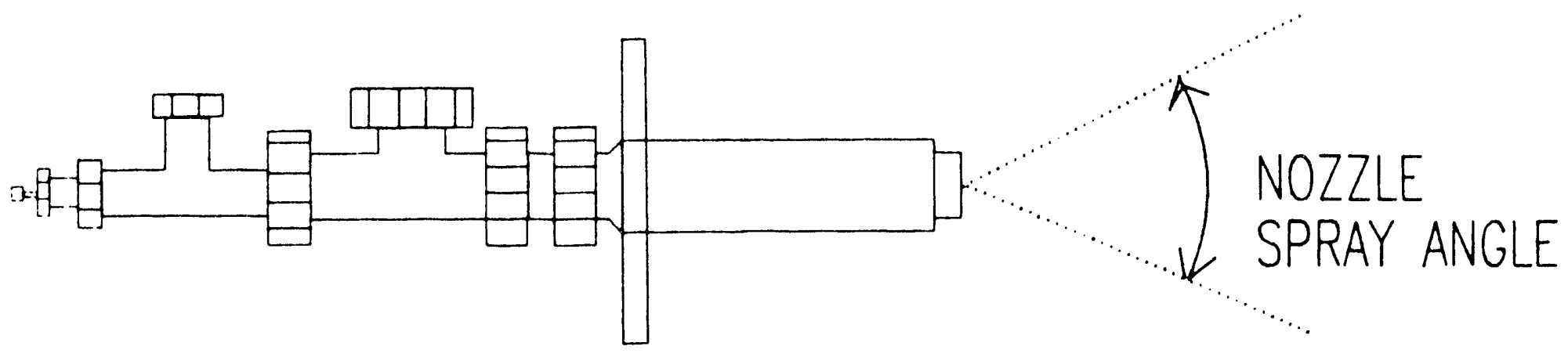

FUEL NOZZLE

Figure 3.4.3 Schematic of fuel nozzle spray angle. 
provide the amount of atomizing air flow determined by test specifications. The atomizing air flow associated with the original LT fuel nozzle is the standard to which the fuel nozzles were rated. A nozzle is designated as "low flow" (LF) if the mass flow of atomizing air at a given pressure ratio is lower than the mass flow through the original LT nozzle at the same pressure ratio, "medium flow" (MF) if the flow is the same, and "high flow" (HF) if it is higher.

\subsubsection{Main Air Swirler}

The air swirler at the head end of the combustor was designed to take advantage of the total combustor pressure drop. The original air swirler design, as shown in Figure 3.4.4, was a series of flat vanes welded to the inner surface of the combustor liner. After the first three sets of tests (Table 3.4.5, A-C), the combustor liner was modified to allow for the installation and removal of various swirler assemblies. The holder and the assemblies were all fabricated of stainless steel. Figure 3.4.5 shows the new swirler holder welded to the combustor liner with one of the swirler assemblies inserted.

The fuel nozzle was inserted through the center of the air swirler, as shown in Figure 3.3.13, in both the original and modified configurations.

The smallest vane angle was $30^{\circ}$, the largest $65^{\circ}$, referenced from the axial centerline. By varying the vane height, we could change the open area through which the swirler air would flow. As a result, we could control the swirler air mass flowrate and the swirl number.

The swirl number $\left(S_{n}\right)$ was varied by changing the vane height with respect to the hub diameter. Lefebvre (1983) calculates the swirl number for annular vanes with a constant vane angle by using the following relationship:

$$
S_{n}=\frac{2}{3} \frac{1-\left(D_{h u b} / D_{s w}\right)^{3}}{1-\left(D_{h u b} / D_{s w}\right)^{2}} \tan \theta
$$

where $D_{h u b}$ is the diameter of the hub of the swirler, $D_{s w}$ is the diameter of the swirler at the tip of the vanes, and $\theta$ is the angle of the vanes with respect to the axial direction of airflow.

Lefebvre shows that for swirl numbers smaller than .04, there is no flow recirculation and the swirl is weak. Most swirlers of practical interest operate under conditions of strong swirl, that is, $S_{n} \gg .6$. The air swirlers designed for use in this series of tests were all straight vaned swirlers. The calculated $S_{n}$ for each swirler tested in the LM500 turbine simulator is shown in Table 3.4.3.

Each air swirler was flow-tested at atmospheric pressure to determine relative air mass flow rate. Figure 3.4.6 shows the results of the atmospheric air flow tests performed for each air swirler. Because of the poor fit between the fuel nozzle cap and the inner radius of the swirler vanes of the original air swirler, 5 to $10 \%$ of the air bypassed the air swirler. After the 


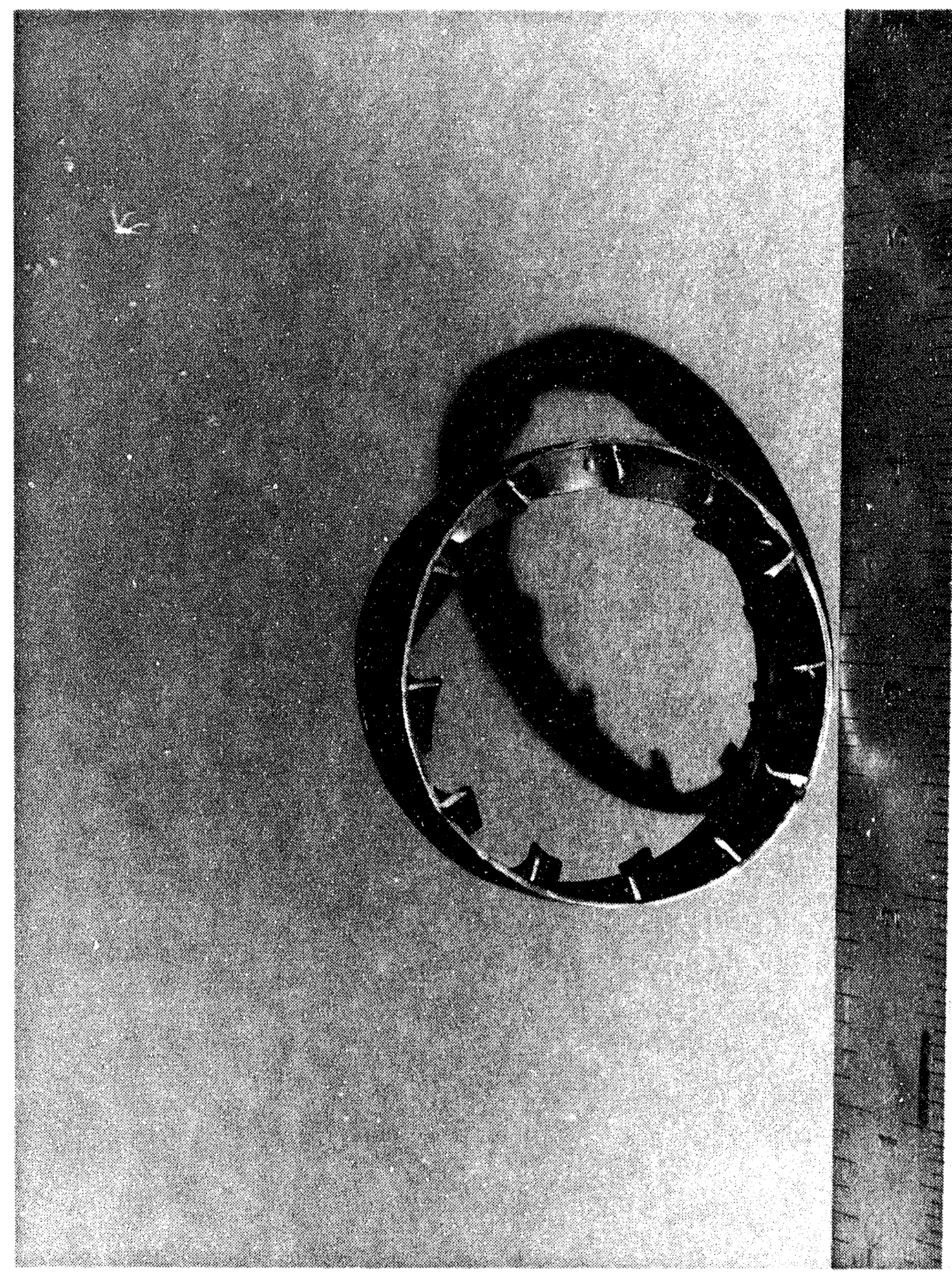

竞 


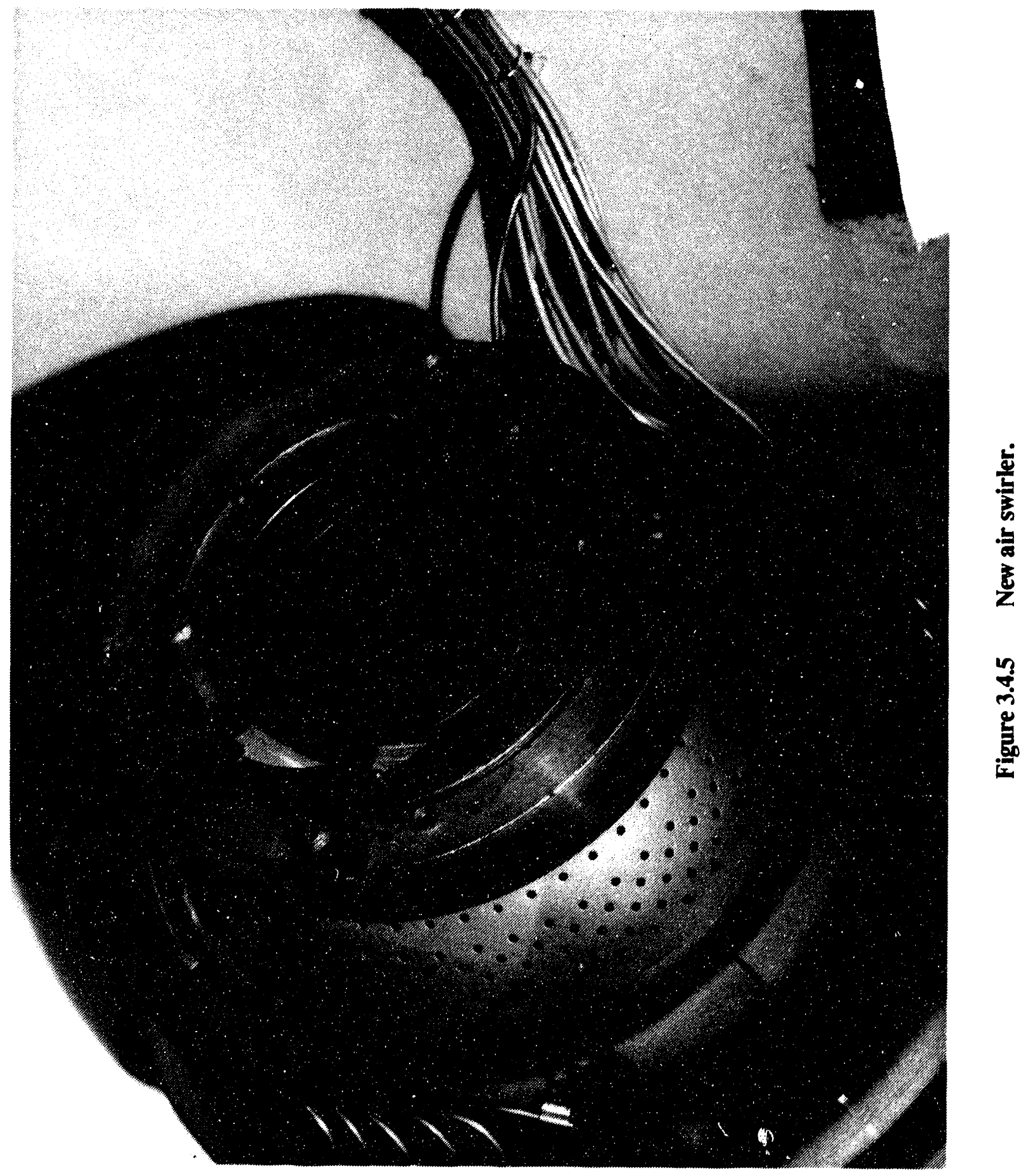




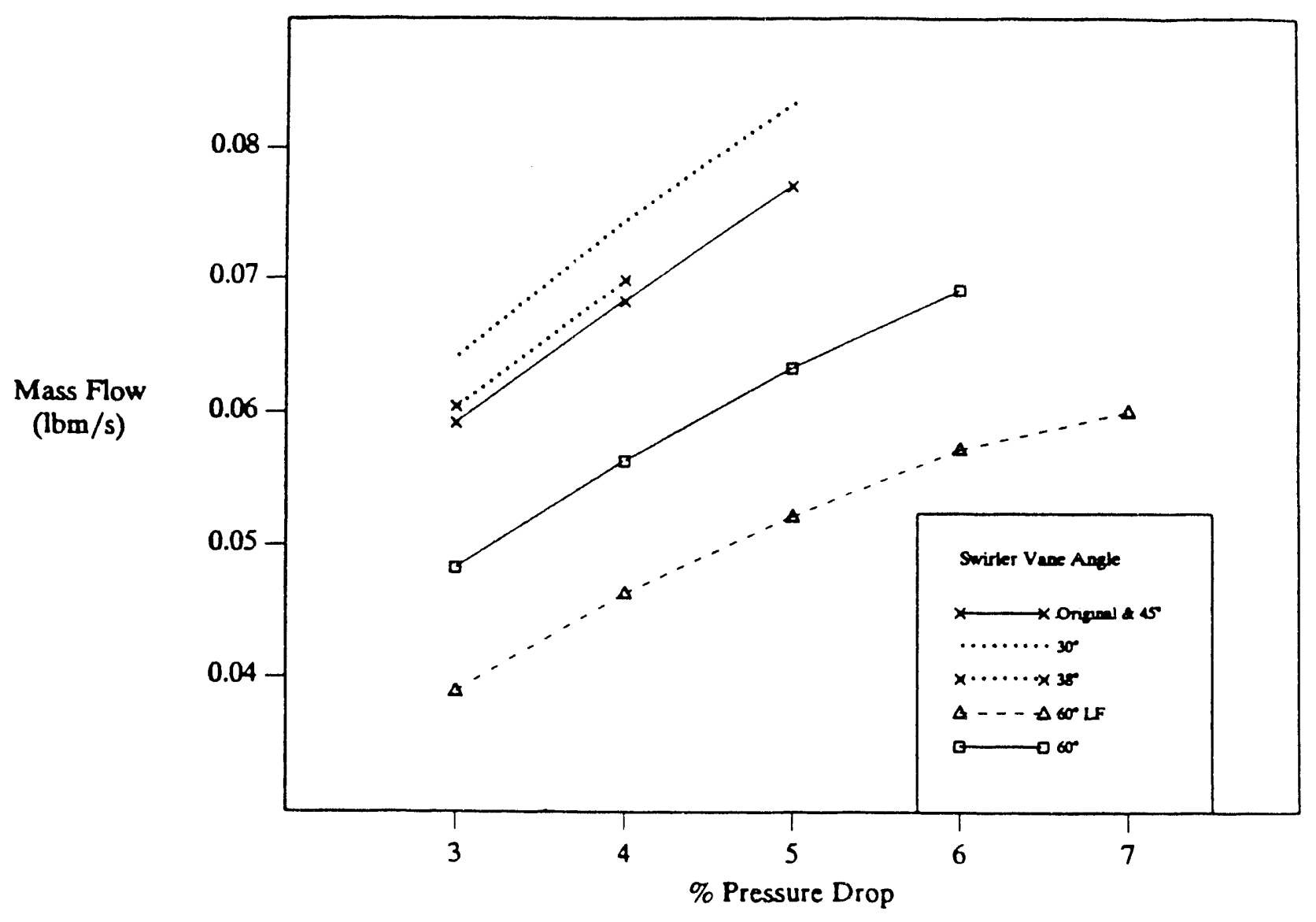

Figure 3.4.6 Flow rate through air swirler measured at atmospheric pressure.

Table 3.4.3

Air Swirler Design Parameters

\begin{tabular}{|lclll|}
\hline Vane Angle & \# Vanes & $D_{\text {hub }}$ & $D_{\text {sw }}$ & $S_{\mathrm{n}}$ \\
\hline Original $\left(45^{\circ}\right)$ & 12 & 1.665 & 1.989 & .92 \\
$30^{\circ}$ & 15 & 1.94 & 2.25 & .54 \\
$38^{\circ}$ & 13 & 1.92 & 2.24 & .72 \\
$45^{\circ}$ & 12 & 1.875 & 2.25 & .92 \\
$60^{\circ}$ & 8 & 1.835 & 2.33 & 1.55 \\
$60^{\circ}$ Low Flow & 8 & 1.89 & 2.25 & 1.59 \\
\hline
\end{tabular}


original swirler was cut from the combustor liner, it was flow-checked at atmospheric discharge pressure using the actual fuel nozzle cap as the center plug. All of the new air swirlers were flow-checked the same way, with the fuel noezle cap in place. The $30^{\circ}$ and $38^{\circ}$ air swirlers had a slightly greater mass flow than the original air swirler. The fabricated $45^{\circ}$ swirler had the same mass flow as the original, and the $60^{\circ} \mathrm{LF}$ and $60^{\circ}$ swirlers had lower mass flows than the original. The percentage of total combustor air flow for each swirler at design combustor conditions is shown in Table 3.4.4. That percentage of swirler flow is based on a total combustion air flow of $2.4 \mathrm{lbm} / \mathrm{s}$ and a swirler pressure drop of $5 \%$ at $10 \mathrm{~atm}$ chamber pressure. The flow through the air swirlers ranged from a maximum of $34 \%$ (for the $30^{\circ}$ swirler) down to $21 \%$ (for the $60^{\circ} \mathrm{LF}$ swirler) of the total combustor air flow.

\subsubsection{Test Procedure}

After suitable combustor and test component hardware preheat, combustion was initiated on fuel oil. Combustion air and fuel oil were increased until the operating conditions were approached. CWM fuel flow was then initiated. As the CWM fuel flow was increased, the fuel oil flow was decreased while the firing temperature was kept constant. The heat input for each fuel was calculated as a percentage of the total heat input. The \% oil heat input was calculated as:

$$
\% \text { oil heat input }=\frac{\text { fuel oil Btu input }}{C W M \text { Btu input }+ \text { fuel oil Btu input }} \times 100
$$

When the oil heat input was reduced to $25 \%$, the air and fuel flows were trimmed to maintain a steady test point, and exhaust gas stream sampling for products of combustion (POC) and particulates was initiated. The exhaust gas was analyzed for the following gases: $\mathrm{CO}$, $\mathrm{CO}_{2}, \mathrm{NO}_{x}, \mathrm{O}_{2}, \mathrm{SO}_{2}$, and unburned hydrocarbons (UHC). Particulate samples collected were analyzed for $\mathrm{C}, \mathrm{H}$, and $\mathrm{N}$. The analysis of the particulate samples provided the information necessary to calculate the carbon burnout fraction, which is an indication of combustion efficiency. The carbon burnout fraction was calculated using the formula given by Wenglarz (1986), which relates the weight fraction of ash in the particulate sample, $W_{x}$, to the weight fraction of ash in the CWM fuel, $W_{a}$ :

$$
\text { Carbon Burnout Fraction }=\frac{1-W_{a} / W_{x}}{1-W_{a}}
$$

Sampling was continued at steady-state combustor conditions for $\sim 1 \mathrm{hr}$, which was determined to be sufficient time to collect a representative particulate sample. The $\%$ oil heat input was reduced in increments of 5\%, and gas and particulate samples were taken at each 
test point until combustion became unstable or a combustor flame-out occurred. When flame-out did occur, the combustor was relit by increasing the fuel oil flow and test conditions were again established. The \% oil heat input was again reduced slowly to determine the point of flame-out in order to establish the smallest percentage that would sustain combustion.

Table 3.4.4

\section{Percentage of Total Combustor Air Flow Supplied by Each Air Swirler}

\begin{tabular}{|lc|}
\hline Swirler Vane Angle & \% Total Flow \\
\hline \hline Original $\left(45^{\circ}\right)$ & 32 \\
$30^{\circ}$ & 34 \\
$38^{\circ}$ & 32 \\
$45^{\circ}$ & 31 \\
$60^{\circ}$ & 26 \\
$60^{\circ}$ Low Flow & 21 \\
\hline
\end{tabular}

\subsubsection{Test Results}

Table 3.4 .5 is a summary of test results - including the lowest \% oil heat input that would sustain combustion - for each of the various fuel nozzle and air swirler combinations. Test Sets $A, B$, and $C$ were performed using the original air swirler with fuel nozzles having spray angles of $45^{\circ}, 55^{\circ}$, and $65^{\circ}$. The fuel nozzles with the larger spray angles performed more stably. The $55^{\circ}$ fuel nozzle (Test Set B) and the $65^{\circ}$ fuel nozzle (Test Set C) were operated at a minimum oil heat input of $8 \%$. Similar results were obtained with a smaller angle swirler and a large spray angle fuel nozzle. The $30^{\circ}$ air swirler and the $65^{\circ}$ fuel nozzle (Test Set $\mathrm{H}$ ) were operated at a minimum oil heat input of $4 \%$. The most stable combination with the lowest $\%$ oil heat input, $2 \%$, was the $45^{\circ}$ original LT fuel nozzle and the $60^{\circ} \mathrm{LF}$ air swirler (Test Set I).

For the intermediate ranges of air swirler and fuel nozzle combinations, the combustor could be operated in the range of 20 to $10 \%$ oil heat input, but the combustion was less stable (Test Sets D-G).

The combination of a fuel nozzle with a large spray angle and an air swirler with a small vane angle, low $S_{n}$, was very stable and able to operate at $4 \%$ oil heat input (Test Set $H$ ). Those results were very encouraging since there had been some concern that deposit formation on the liner walls could be a major problem. The combustor model developed by Staub (1988) predicted that the combination of high-swirl air swirler and large fuel nozzle spray angle might place a substantial percentage of CWM slurry at the outer radial areas of the primary zone, thus increasing the possibility of increased deposit on the liner walls. Within the 
range of values tested, however, no combination of air swirler and fuel nozzle increased liner wall deposits. Some deposits were found around the primary dilution holes and at the interface of the fuel nozzle and at the head end of the combustor in all of the tests, but most of the deposits were formed in the nozzle cascade sector and the transition piece. The tests were of too short duration to allow us to measure the deposition rate.

Carbon conversion, as determined from the carbon analysis in the particulate samples, indicated a very high level of carbon utilization. In all of the tests where combustion was stable, the percentage of carbon in the particulate sample was low, indicating a very high percentage of carbon utilization. A high percentage of carbon utilization means high combustion efficiency. At CWM flows representing $>80$ to $90 \%$ of the total heat input, the degree of atomization and primary zone air flow distribution were very good. At CWM flows in excess of $90 \%$, combustion became unstable, as evidenced by combustor pressure fluctuations and flame outs. Combustion efficiency was decreased, as evidenced by the increase in carbon monoxide in the exhaust gas.

The firing temperature (TFire) shown on Table 3.4.5 is the theoretical adiabatic flame temperature calculated from the fuel-to-air ratio. In Test Sets A and B the firing temperature was increased to $>2100$ to $2220^{\circ} \mathrm{F}$ to evaluate the effect of elevated firing temperature on combustor performance. It was quickly evident that the major effect of elevated firing temperature was much faster formation of ash deposits on the combustor and cascade surfaces. The higher firing temperatures resulted in higher metal temperatures that accelerated deposit formation, preventing steady-state operation of the combustor. In the remaining tests, we tried to maintain the firing temperature between 2000 to $2050^{\circ} \mathrm{F}$.

\subsubsection{Conclusions}

From the experiments described here, it was possible to identify the air swirler and fuel nozzle combination that would provide a stable, efficient, and reliable combustion system with which to perform the next series of CWM tests - evaluation of deposition and environmental control systems. Combustion efficiencies of $>99.5 \%$ were observed for most of the tests performed. In addition to determining the most stable combustor configuration, the data supplied from these tests were useful in helping to develop and verify Staub's CWM combustion model (Staub, 1988). The overall testing required was greatly reduced by the application of his model. As that model is developed further, it will be possible to get a greater return on the test time and other resources invested in exploring CWM combustion.

The results of these experiments prove that efficient combustion of CWM can be performed in gas turbine type can combustors. Residence times of 10 to 20 milliseconds typical of gas turbine combustors are within the capability of CWM combustion systems. In order to achieve rapid combustion, combustion delay and char burnout time must be minimized through effective fuel atomization. Combustors can be designed to operate with enhanced recirculation to promote rapid evaporation of slurry water and devolitalization of coal particles. 
Table 3.4 .5

LM500 Combustor Test Results

\begin{tabular}{|c|c|c|c|c|c|c|c|c|c|c|c|}
\hline $\begin{array}{l}\text { Test } \\
\text { Series }\end{array}$ & Air Swirler & Fuel Noade & $\begin{array}{l}\text { Lowest \% Oil } \\
\text { Heat Input }\end{array}$ & $\begin{array}{l}\text { Atomizing Air } \\
\text { Pressure Ratio }\end{array}$ & $\begin{array}{c}\text { \% Oil } \\
\text { Heat Input }\end{array}$ & $\begin{array}{c}\text { TFire } \\
\mathbf{F}\end{array}$ & $\% \mathrm{C}$ & $\begin{array}{c}\text { C Conv. } \\
\%\end{array}$ & $\begin{array}{c}\mathrm{CO}_{2} \\
\%\end{array}$ & $\begin{array}{c}\mathrm{CO} \\
\mathrm{ppm}\end{array}$ & $\begin{array}{l}\mathrm{O}_{2} \\
\%\end{array}$ \\
\hline $\mathbf{A}$ & Original & $45^{\circ} \mathrm{LP}$ & 20 & $\begin{array}{l}1.88 \\
1.87 \\
1.88\end{array}$ & $\begin{array}{l}27 \\
20 \\
22\end{array}$ & $\begin{array}{l}2130 \\
2140 \\
2220\end{array}$ & $\begin{array}{l}27.8 \\
35.7 \\
40.5\end{array}$ & $\begin{array}{l}99.6 \\
99.4 \\
99.2\end{array}$ & $\begin{array}{l}5.5 \\
5.25 \\
5.60\end{array}$ & $\begin{array}{l}106 \\
165\end{array}$ & $\begin{array}{l}14.8 \\
13.67 \\
14.25\end{array}$ \\
\hline B & Original & $\mathbf{S 5} \cdot \mathrm{MF}$ & 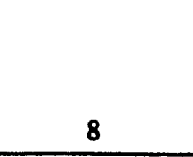 & $\begin{array}{l}1.96 \\
1.96 \\
1.96\end{array}$ & $\begin{array}{l}25 \\
25 \\
10\end{array}$ & $\begin{array}{l}2090 \\
2130 \\
20075\end{array}$ & $\begin{array}{l}15.34 \\
25.62 \\
23.8\end{array}$ & $\begin{array}{l}99.8 \\
99.6 \\
99.7\end{array}$ & $\begin{array}{l}5.06 \\
5.43 \\
5.25\end{array}$ & $\begin{array}{r}55 \\
110 \\
187\end{array}$ & $\begin{array}{l}14.99 \\
14.9 \\
14.84\end{array}$ \\
\hline C & Original & $65^{\circ}$ & 8 & $\begin{array}{l}1.93 \\
1.93 \\
1.94 \\
2.16\end{array}$ & $\begin{array}{l}25 \\
20 \\
15 \\
15\end{array}$ & $\begin{array}{l}2075 \\
2085 \\
2065 \\
2026\end{array}$ & $\begin{array}{l}12.96 \\
16.23 \\
25.09 \\
21.65\end{array}$ & $\begin{array}{l}99.82 \\
99.76 \\
99.58 \\
99.65\end{array}$ & $\begin{array}{l}5.18 \\
5.31 \\
5.18 \\
5.00\end{array}$ & $\begin{array}{c}43.7 \\
71.8 \\
178 \\
129\end{array}$ & $\begin{array}{l}15.0 \\
14.9 \\
15.0 \\
14.88\end{array}$ \\
\hline $\mathrm{D}$ & $30^{\circ}$ & $45^{\circ}$ original & 20 & 1.97 & 25 & 2075 & 17.24 & 99.74 & 4.87 & 128 & 15.39 \\
\hline $\mathbf{E}$ & 38 & $45^{\circ}$ original & 15 & $\begin{array}{l}2.0 \\
1.85 \\
1.86\end{array}$ & $\begin{array}{l}25 \\
20 \\
20\end{array}$ & $\begin{array}{l}2060 \\
2075 \\
2187\end{array}$ & $\begin{array}{l}25.29 \\
27.39 \\
37.34\end{array}$ & $\begin{array}{l}99.78 \\
99.52 \\
98.99\end{array}$ & $\begin{array}{l}5.0 \\
5.12 \\
5.50\end{array}$ & $\begin{array}{r}75 \\
175 \\
60\end{array}$ & $\begin{array}{l}15 \\
15 \\
145\end{array}$ \\
\hline $\mathbf{F}$ & $45^{\circ}$ & $45^{\circ}$ original & 10 & $\begin{array}{l}1.93 \\
1.93 \\
1.93\end{array}$ & $\begin{array}{l}25 \\
20 \\
15\end{array}$ & $\begin{array}{l}2000 \\
2000 \\
2031\end{array}$ & $\begin{array}{l}18.86 \\
19.93 \\
27.63\end{array}$ & $\begin{array}{l}99.75 \\
99.69 \\
99.51\end{array}$ & $\begin{array}{l}4.81 \\
5.00 \\
5.25\end{array}$ & $\begin{array}{l}100 \\
150 \\
450\end{array}$ & $\begin{array}{l}16.01 \\
15.80 \\
15.62\end{array}$ \\
\hline G & $60^{\circ}$ & $45^{\circ}$ original & 10 & $\begin{array}{l}1.82 \\
1.80 \\
1.75\end{array}$ & $\begin{array}{l}25 \\
20 \\
10\end{array}$ & $\begin{array}{l}2048 \\
2062 \\
2062\end{array}$ & $\begin{array}{l}1250 \\
17.9 \\
31.98\end{array}$ & $\begin{array}{l}99.82 \\
99.73 \\
99.39\end{array}$ & $\begin{array}{l}4.35 \\
4.40 \\
4.6\end{array}$ & $\begin{array}{l}39.3 \\
71.0 \\
128\end{array}$ & $\begin{array}{l}15.9 \\
15.8 \\
15.68\end{array}$ \\
\hline $\mathrm{H}$ & $30^{\circ}$ & $65^{\circ}$ & 4 & $\begin{array}{l}1.89 \\
1.90 \\
1.94\end{array}$ & $\begin{array}{l}20 \\
15 \\
10\end{array}$ & $\begin{array}{l}2029 \\
2046 \\
2034\end{array}$ & $\begin{array}{l}14.45 \\
37.04 \\
44.99\end{array}$ & $\begin{array}{l}99.86 \\
99.54 \\
99.33\end{array}$ & $\begin{array}{l}4.71 \\
4.8 \\
4.93\end{array}$ & $\begin{array}{c}93.3 \\
>500 \\
187\end{array}$ & $\begin{array}{l}15.67 \\
15.5 \\
15.07\end{array}$ \\
\hline I & $60^{\circ} \mathrm{LF}$ & $45^{\circ}$ Original & 2 & $\begin{array}{l}1.80 \\
1.79\end{array}$ & $\begin{array}{l}20 \\
15\end{array}$ & $\begin{array}{l}2023 \\
2036\end{array}$ & & & $\begin{array}{l}4.74 \\
4.83\end{array}$ & $\begin{array}{c}39.3 \\
107\end{array}$ & $\begin{array}{l}15.6 \\
15.2\end{array}$ \\
\hline
\end{tabular}




\subsection{Materials Research for the GE Coal-Fired Turbine}

Abstract In a coal-water slurry fueled gas turbine, vanes may be environmentally artacked due to deposits and ash combustion products. In this study a variety of candidate coatings were evaluated. Several promising coating compositions were identified for use in this application. A series of seven vanes were coated and assembled into a vane cascade for test on the CRD turbine simulator test rig.

\subsubsection{Introduction}

Early in the coal-fired turbine program it was observed that ash build-up occurred on the vane segment of the turbine simulator test rig. There was concern that the ash deposit could lead to a hot corrosion attack on the X-40 blades or that an ash removal technique could result in undesirable damage to the blades.

The objective of this study was to evaluate a variety of coatings for the X-40 blades to be used in coal-fired turbines to identify preferred compositions that would: a) minimize corrosive or erosive attack due to interactions with ash particles; and, b) minimize the build-up of ash and/or ease ash removal.

A group of coating compositions was selected for evaluation based on our coating experience and after consultation with several turbine coating/corrosion experts. A literature search also was made to identify possible coating alloys and laboratory corrosion/erosion testing techniques to be considered.

The selected coatings were deposited onto $X-40$ pin test specimens. The primary evaluation of the coatings was to expose the coated pins to the turbine simulator environment. Then, the ash/coating interactions were determined by metallographic examination of cross sections cut from the pins.

In addition, the possibility of developing a simple laboratory simulative hot corrosion test was considered. Four such tests were explored as follows:

a. Diffusion couple test.

b. Crucible test in air.

c. Crucible test in a $\mathrm{O}_{2} / \mathrm{N}_{2} / \mathrm{SO}_{4}$ atmosphere.

d. Coal slurry spray and burn test.

None of these tests was considered reliable for coatings selection, therefore, only the turbine simulator was used to evaluate coatings.

The culmination of this study was to coat seven X-40 blades which were used to fabricate a nozzle section for the expected 24-hour deposition test. A masking technique was developed 
So that two different coating compositions could be applied to each blade.

\subsubsection{Experimental}

Test specimens used in this study were machined from cast ingots of X-40 ( Co-10.5 Ni25.0 Cr-7.5 W-0.5C). The pins specimens were 0.1 in diameter $X 1.5$ in. long.

Many of the coatings were applied by LPPD (low pressure plasma deposition) processing. In this process the pin specimens were mounted on a rotating and reciprocating work holder in a water-coated (hamber. The chamber was pumped to less the 0.5 torr before the EPI gun was activated and the pumping system was throttled so that a steady-state pressure of 60 torr was maintained during deposition. The powders used for deposition typically were argon atomized and screened to -400 mesh $(-37 \mu \mathrm{m})$.

Other coatings were applied by pack cementation (Al), sputtering (C, Pt), slurry (Sermalloy $\mathrm{J}$ to deposit Al-Si) electroplating (Cr) and APS (atmospheric plasma spraying). These deposition techniques were used following standarized processing procedures.

The coated pins were welded onto a holding rod that was inserted in the turbine simulator rig. They were exposed to the combustion environment downstream of the vane segment.

After simulator exposure, the pins were evaluated as follows:

a. The pin-set was photographed.

b. The end of each pin was epoxy coated and cut for metallographic examination. (The purpose of the epoxy was to retain the ash deposition layer.)

c. Peel-test samples were obtained using replicating tape to remove the "loosely bonded" ash deposits for analyses.

d. The remainder of the pin was retained for studies such as further thermal exposures and hot corrosion and erosion studies.

The X-40 LM500 vanes were obtained from GEAE as pairs. The pairs were separated using the wire EDM process; then each vane was coated. Where required, a foil "mask" was attached to half of the blade; then the masked blade was coated. The mask was removed, another mask was applied to the "coated half" and the blade was coated. That second mask was removed and the coated vane was ready for assembly into the vane cascade for the turbine simulator rig.

\subsubsection{Results and Discussion}

\subsubsection{Turbir \& Simulator Tests}

Coatings about 0.005 in. thick were applied to $\mathrm{X}-40$ pins for the first simulator test as follows: 


\author{
4 each with CONiCrAlY by LPPD \\ 4 each with $\mathrm{CoNiCrAlY} / \mathrm{Al}_{2} \mathrm{O}_{3}$ by LPPD \\ 4 each with NiCrAlY by LPPD \\ 4 each with $\mathrm{NiCrAlY} / \mathrm{Al}_{2} \mathrm{O}_{3}$ by LPPD \\ 4 each with COCrAlY by LPPD \\ 4 each with $\mathrm{CoCrAlY} / \mathrm{Al}_{2} \mathrm{O}_{3}$ by LPPD \\ 4 each aluminide by pack alumunization.
}

These MCrAlY compositions were previously developed for providing environmental resistance for superalloys. Generally, the Ni-based coatings are preferred for oxidation resistance and co-based coatings are preferred for hot corrosion resistance. The $\mathrm{Al}_{2} \mathrm{O}_{3}$ added to a coating is expected to improve the erosion resistance of the coating. Seven pins, one of each coating above plus an uncoated X-40 pin, were welded to the pin holder as shown in Figure 3.5.1. One pin of each coating was sectioned for metallographic examination - all coatings appeared to be dense and well bonded to the substrates. The other coated pins were in reserve for further testing as needed.

The turbine simulator test consisted of about $15 \mathrm{hr}$ at $1500^{\circ}$ to $1600^{\circ} \mathrm{F}$. The pins and holder after test are shown in Figure 3.5.2. Metallographic analysis of these pins indicated that there was a tenaciously bonded ash deposition around the circumference of all of the pins including the uncoated pin. In addition, the "downstream" side of the pins had a thick, porousappearing deposit.

Even during this relatively short time of exposure, there was evidence of an apparent hot corrosion attack on the uncoated S-40 as is shown in Figure 3.5.3. This indicates that coatings must be considered for the coal-fired gas turbine.

The MCrAlY and MCrAlY/ $\mathrm{Al}_{2} \mathrm{O}$ coatings all showed evidence of an apparent hot corrosion attack also. Examples of this are shown in Figure 3.5.4. The aluminized coating showed very little attack as can be seen in Figure 3.5.5. Based on these very limited data, the aluminized coating may be a good candidate coating for this application.

It was decided to expose 16 specimens on the second turbine simulator test. Pins were coated as follows:

- Low pressure plasma sprayed:

- FeCrAlY

- WC-Co over CoNiCrAlY

- CoSi

- $\mathrm{COCr}$

- $\mathrm{Al}_{2} \mathrm{O}_{3}$ graded with CoNiCrAlY

- $\mathrm{Cr}_{2} \mathrm{O}_{3}$ graded with CoNiCrAlY 


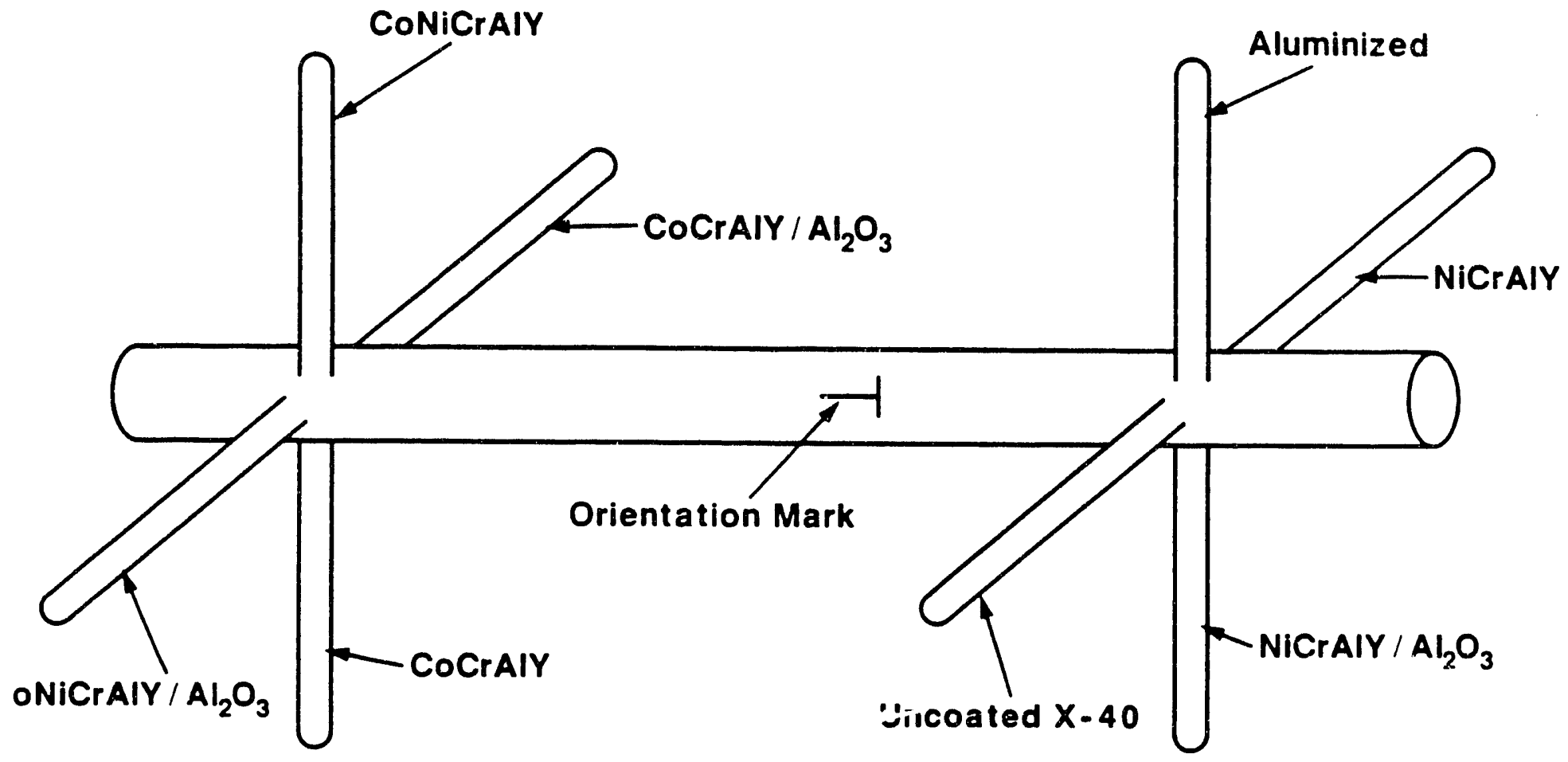

Figure 3.5.1 Coated $X-40$ pins mounted on a rod holder for the first simulator test. 


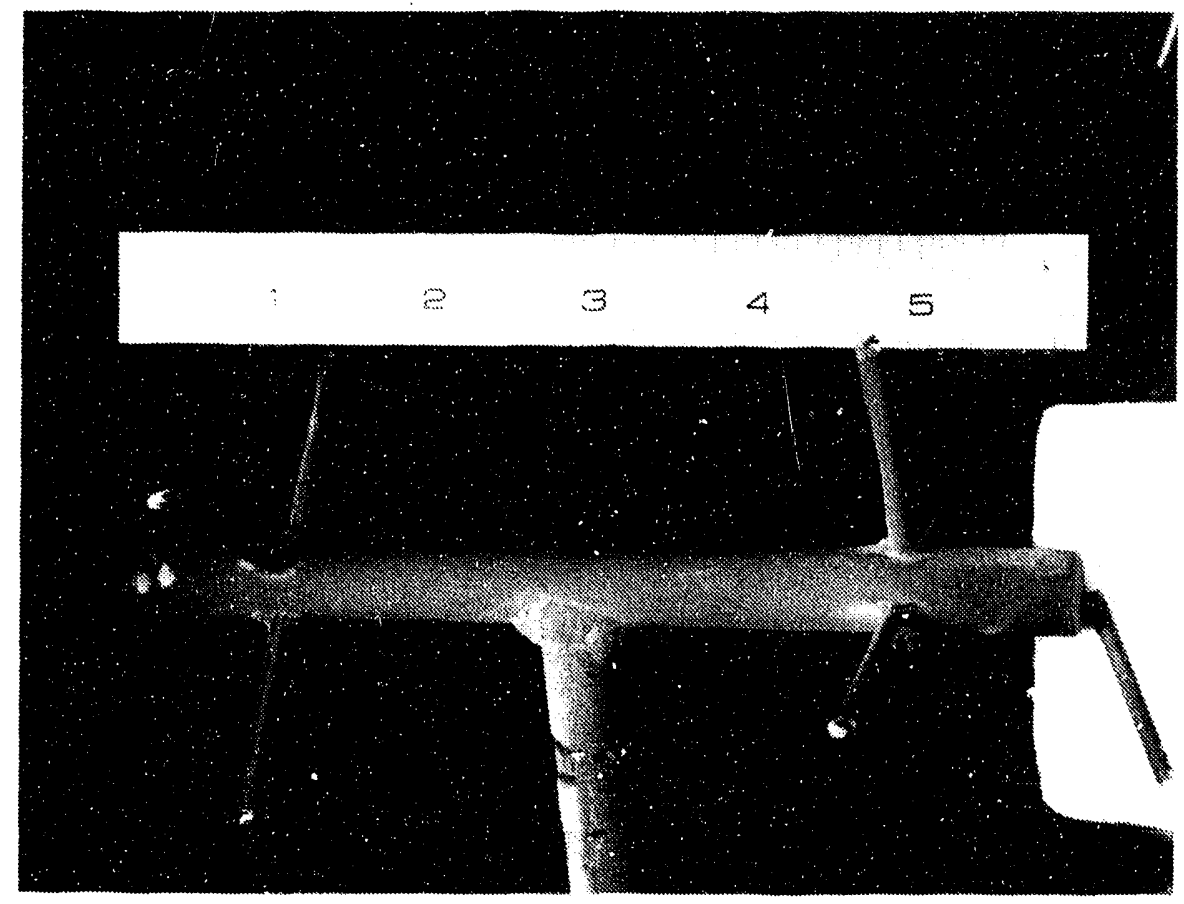

Figure 3.5.2 Pins and holder after first simulator test (one pin broke-off during disassembly after the test).

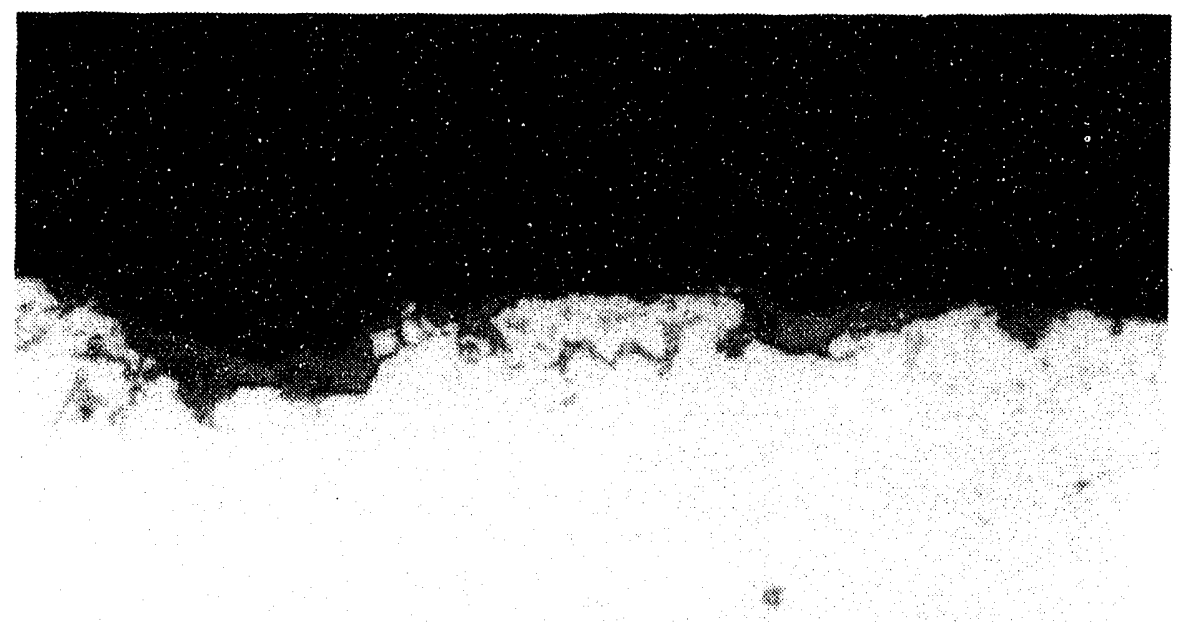

Figure 3.5.3 Uncoated $\mathrm{X}-\mathbf{4 0}$ after the first simulator test $(800 \mathrm{X})$. 


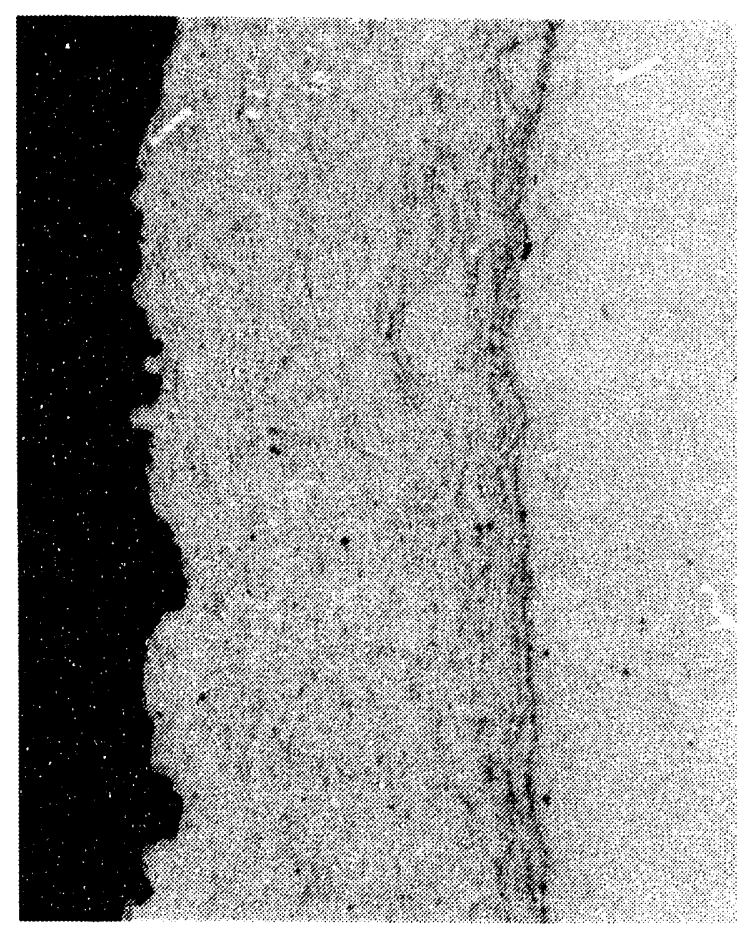

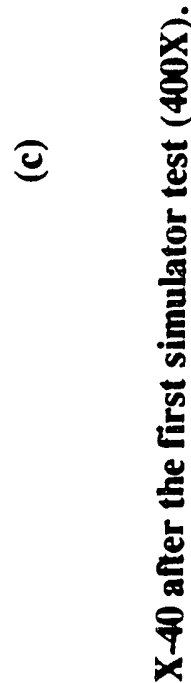

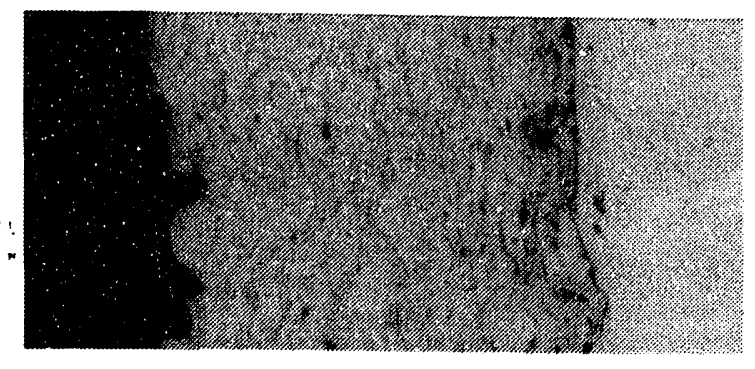

อ

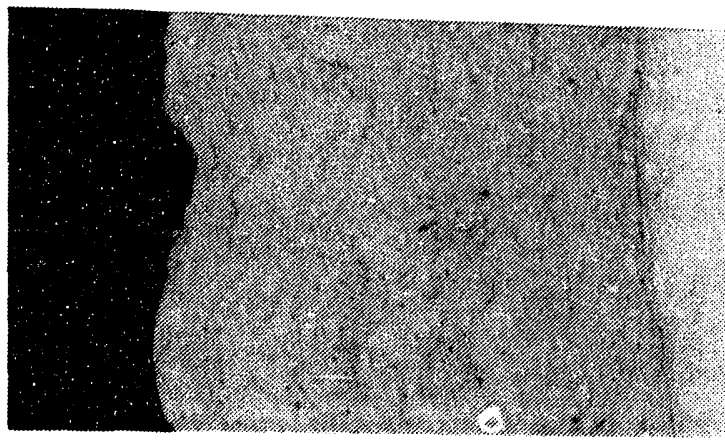

葛

买 


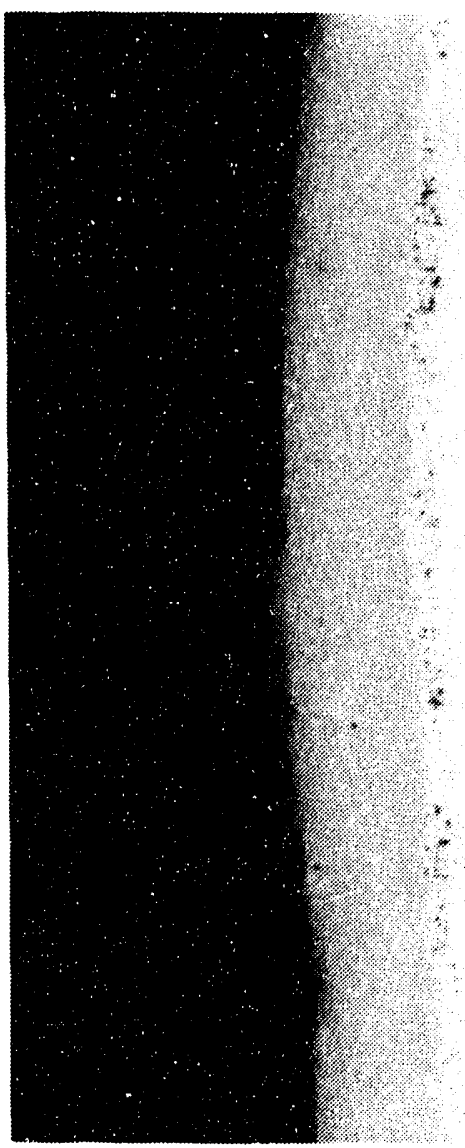

Figure 3.5.5 Aluminized coating on $\mathrm{X}-\mathbf{4 0}$ after the first simulator test (400X). 
$-\mathrm{Cr}_{3} \mathrm{C}_{2}+\mathrm{NiCr}$

- $\mathrm{Cr}_{2} \mathrm{C}_{2}+\mathrm{NiCR} / \mathrm{CoNiCrAlY} \sim \mathrm{M}^{3}$ using two guns

- $\mathrm{Al}_{2} \mathrm{O}_{3} / \mathrm{CoNiCrAlY} \sim \mathrm{M}^{3}$ using two guns

- Air plasma sprayed:

- $\mathrm{Al}_{2} \mathrm{O}_{3}$ over LPPD CoNiCrAlY

- $\mathrm{Cr}_{2} \mathrm{O}_{3}$ over LPPD CoNiCrAlY

- $\mathrm{SiO}_{2}$ over LPPD CoNiCrAlY

- Sputtered and/or electroplated

- Pt sputtered about 0.2-mil thick. Half of these pins will be electroplated to form a total Pt coating thickness of 1 mil; the other half of these pins will be aluminized to form a Pt-Al-type coating.

- Au sputtered about 0.2-mil thick; then electroplated to form a total Au coating thickness of $1 \mathrm{mil}$.

- Cr electroplated to form a 1-mil thick coating.

- C sputtered to form a 0.2 -mil thick coating.

The specimens that were selected for the second simulator test included one uncoated pin and the following coated pins:

- Aluminized by pack cementation.

- Sermaloy J aluminized/chromized.

- NiCrAlY by LPPD. Two specimens to check the effects of mounting position and to compare with the previous simulator test.

- FeCrAlY by LPPD.

- Composite $50 \mathrm{v} / \mathrm{o} \mathrm{CoNiCrAlY} / 50 \mathrm{v} / 0 \mathrm{Cr}_{3} \mathrm{C}_{2}$ - NiCr by LPPD.

- WC-Co over CoNiCrAlY by LPPD

- $\mathrm{Cr}_{3} \mathrm{C}_{2}-\mathrm{NiCr}$ by LPPD

- CoNiCrAlY by LPPD + (CoNiCrAlY $\left./ \mathrm{Al}_{2} \mathrm{O}_{3}+\mathrm{Al}_{2} \mathrm{O}_{3}\right)$ by APS (air plasma spray).

- C by sputtering.

- CoSi by LPPD

- CoNiCrAlY by LPPD + (CoNiCrAlY/ $\left./ \mathrm{Cr}_{2} \mathrm{O}_{3}+\mathrm{Cr}_{2} \mathrm{O}_{3}\right)$ by APS.

- Pt by sputtering. 
The pins were welded to the rod holder to form two sets of radially mounted specimens spaced about one-half inch apart as is shown in the photograph in Figure 3.5.6 after the test. The two sets were offset mounted so that none of the pins would be "shadowed" by any other pin.

The second simulator test was conducted during the time period of May 1987 to March 1988. The pins were exposed for about 20 hours to a variety of conditions during several combustion experiments.

Metallographic examination of samples cut from the pins again showed evidence of environmental attack. Table 3.5.1 is a summary of the microscopic observations.

In order to evaluate a maximum number of coatings on the cascade test, two coatings were applied to each vane. The coatings selected for the seven LM500 vanes were:

\author{
Vane No. 1: Aluminize (Standard Codep) \\ LPPD NiCrAlY \\ Vane No. 2: LPPD CoNiCrAlY \\ LPPD NiCrAlY \\ Vane No. 3: Aluminize (Standard Codep) \\ Uncoated (Codep stripped) \\ Vane No. 4: LPPD Composite CoNiCrAlY $/ \mathrm{Al}_{2} \mathrm{O}_{3}$ \\ LPPD Composite CoNiCrAlY $/ \mathrm{Al}_{2} \mathrm{O}_{3}$ \\ $+\operatorname{APS~} \mathrm{Al}_{2} \mathrm{O}_{3}$
}

Vane No. 5: $\quad \mathrm{CoCr}$ (GE Gas Turbine GT-43)

LPPD René 80

Vane No. 6: LPPD CoSi

LPPD FeCrAlY

Vane No. 7: $\quad$ Sputtered Pt

Sputtered C

The uncoated, the Rene 80-coated and the CoSi-coated vane halves were expected to show the most corrosion and those results would be compared with those of the other, more 


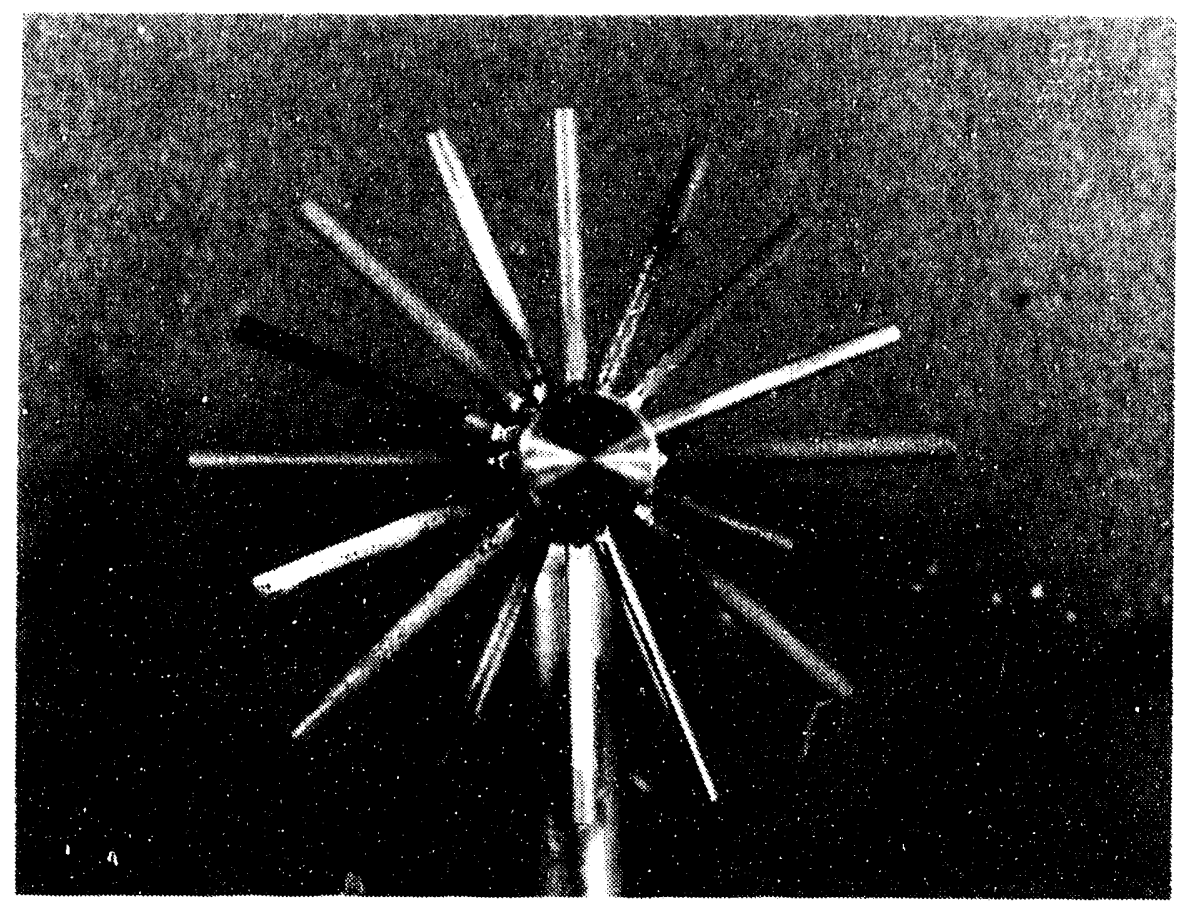

Figure 3.5.6 Photograph of the 16 pins mounted on the holder after the second simulator test.

Table 3.5.1

Environmental Attack Observations for the X-40 Pin Specimens from the Second Turbine Simulator Test

Coating Composition

Uncoated

NiCrAlY

$\mathrm{Pt}$

$\mathrm{CoNiCrAlY} / \mathrm{Cr}_{2} \mathrm{O}_{3}$

$\mathrm{CoSi}$

$\mathrm{C}$

$\mathrm{CoNiCrAlY} / \mathrm{Al}_{2} \mathrm{O}_{3}$

$\mathrm{Cr}_{3} \mathrm{C}_{2} / \mathrm{NiCr}$

CoNiCrAlY/WC-Co

Composite CoNiCrAlY / $\mathrm{Al}_{2} \mathrm{O}_{3}$

$\mathrm{CoNiCrAlY}+\mathrm{Al}_{2} \mathrm{O}_{3}$

Composite $\mathrm{NiCrAlY} / \mathrm{Al}_{2} \mathrm{O}_{3}$

FeCrAlY

Sermaloy J

Aluminized
Microscopic Observations of Environmental Attack

Similar to that shown in Figure 3.5.3

Minor amounts

In a few localized regions

Significant in localized regions

Severe

Similar to uncoated, but ash accumulation was very small Some

Some, coating debonded from the substrate

WC-Co shows some distress

Very minor

Some

Very minor

General

Severe

Minor 
corrosion-resistant coatings.

The assemble cascade with the seven coated vanes is shown in Figure 3.5.7. This contract was halted before the cascade test could be run.

\subsubsection{Laboratory Hot Corrosion Test Exploration}

The goal of this GE funded effort was to identify a simple test that would yield preliminary rankings of candidate coatings. The most promising coatings could then be evaluated on the turbine simulator rig. The information described here was included in the 1988 IR\&D Report.

Four laboratory hot corrosion tests were explored as follows:

1. The Diffusion Couple Test

A cup and cap were machined out of $\mathrm{X}-40$ and the reactive species sandwiched between them. Two reactive species were used: sodium sulfate $\left(\mathrm{Na}_{2} \mathrm{SO}_{4}\right)$ and coal ash obtained from the simulator. These samples were subjected to two thermal exposures in air: $24 \mathrm{hr}$ at $825^{\circ} \mathrm{C}$ and $48 \mathrm{hr}$ at $850^{\circ} \mathrm{C}$.

This test did not corrode the $\mathrm{X}-40$. Neither the coal ash nor the sodium sulfate significantly reacted. A small amount of oxide was detected, but somewhat less than that on the outside of the cup.

2. The Crucible Test in Air

Coal ash from the simulator was ground and separated into two fractions; black ash (hard) and red ash (fluffy).

Each type of ash was placed in a platinum crucible so as to surround an X-40 pin; these were heated in air for $168 \mathrm{hr}$ at $850^{\circ} \mathrm{C}$. A separate crucible with a bare X-40 pin was used as a control. Sections of the pins were taken prior to treatment, after $48 \mathrm{hr}$, after $96 \mathrm{hr}$ and after $168 \mathrm{hr}$. The pins were weighed before and after each step to determine the extent of weight loss or gain.

This test in air did not give encouraging results. One small spot on the pin in the black ash with carbon showed some possible corrosion. The other pins did not show any accelerated reaction.

3. The crucible test in an atmosphere that consisted of $23.9 \mathrm{v} / \mathrm{o}$ nitrogen and $0.1 \mathrm{v} / \mathrm{o} \mathrm{SO}$ with the balance being axygen.

A platinum gauze was placed in the furnace to create an $\mathrm{SO}_{3}$ equilibrium. In addition, two weight percent carbon was added, in the form of coal, to the red ash crucible and one black ash crucible in an attempt to form locally reducing conditions that might 


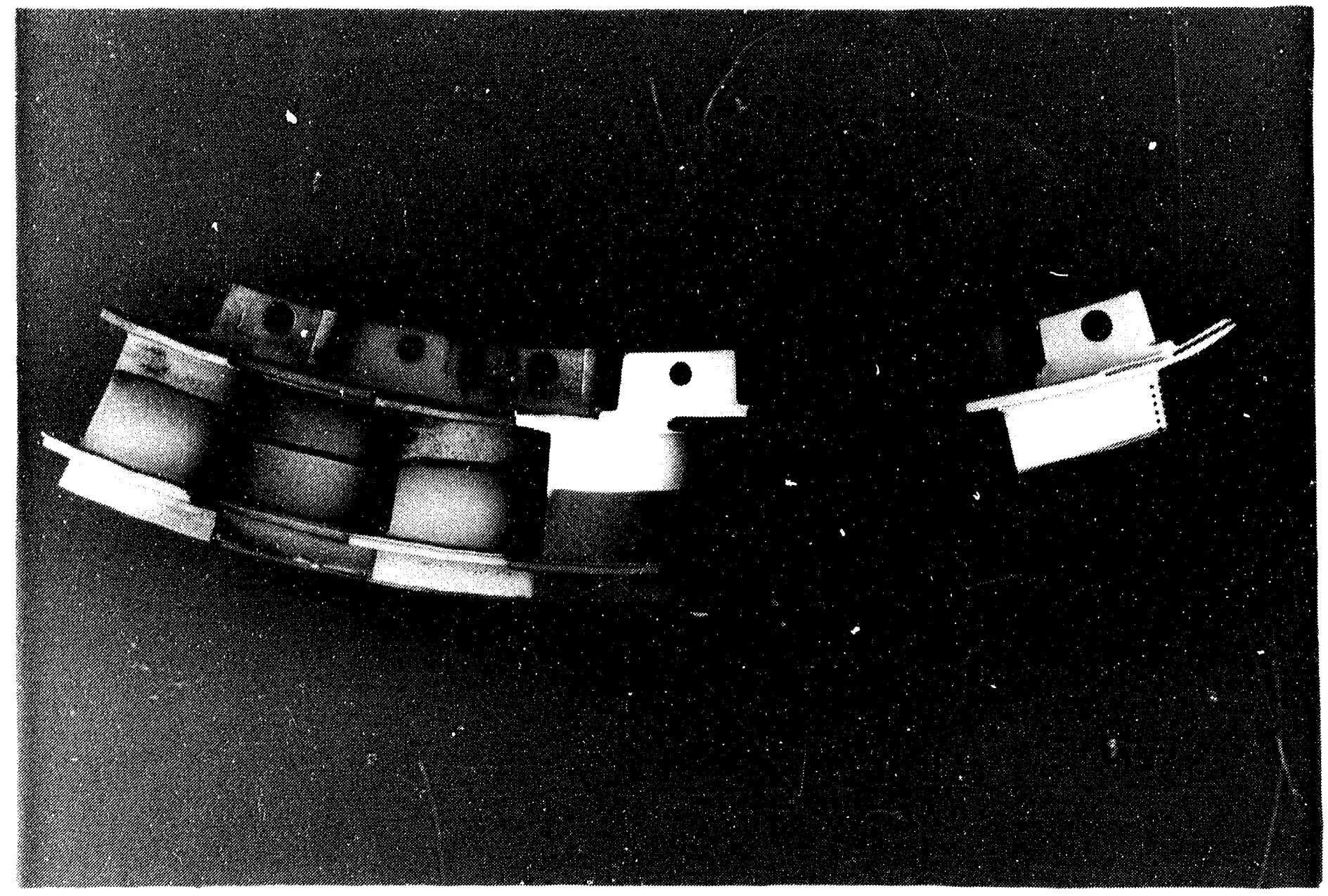

Figure 3.5.7 Coated blades assembled into a vane cascade ready for test on the CRD turbine simulator rig. 
promote corrosion. Two other crucibles were used: one contained black ash with no carbon and the other contained a bare $\mathrm{X}-40$ pin as a control. These samples were heated for $168 \mathrm{hr}$ at $850^{\circ} \mathrm{C}$ as previously described.

The X-40 pins showed considerable corrosion in the red ash with carbon additions. After $48 \mathrm{hr}$ of exposure, considerable pitting was evident. After $96 \mathrm{hr}$ and $168 \mathrm{hr}$, the corrosion products grew considerably.

The other pins showed unexpected results. The black ash with carbon shows some corrosion for the $\mathrm{X}-\mathbf{4 0}$, but only in selected areas. The black coal ash with no carbon showed little corrosion for 48 and $96 \mathrm{hr}$, but showed extensive corrosion after $168 \mathrm{hr}$.

\section{The Coal Slumy Spray and Bum Test}

An ash deposit was formed on the surface of a rotating X-40 pin by using a simple aspirator to spray the slurry directly on the pin; then it was burned off in an oxygenacetylene flame. The pin was sprayed for about 4 seconds and then heated for 6 to 8 seconds. This cycle was repeated for 10 minutes. This test led to areas of significant corrosion on the X-40. They then were subjected to a thermal exposure for $48 \mathrm{hr}$. at $859^{\circ} \mathrm{C}$ in the simulated turbine environment and for $72 \mathrm{hr}$ at $850^{\circ} \mathrm{C}$ in air. This thermal exposure did not appear to accelerate corrosion.

It was decided that diffusion couple test and the crucible test in air did not simulate the conditions in the turbine. This was evident from the lack of corrosion of X-40 by these two methods.

The crucible test in the simulative turbine environment gave appreciable corrosion on the X-40 pins when exposed to red ash. This was evident from the weight changes and light microscopy. It is not known if the corrosion products are the same as those for the turbine. Also, it was not conclusively determined if the presence of the carbon in the ash makes a difierence for the corrosion.

The spray and burn method for hot corrosion is effective and quick, but hard to control or reproduce. At present, the procedure is not automated and requires two people to operate. One must operate the torch while the other controls the slurry feed.

Therefore, it was decided that the testing of coatings should be done in the simulated turbine. Although that test procedure takes longer to get results, it is a combustion environment that will be similar to the turbine conditions. Any judgments made regarding materials selections should be based on tests made in environmental conditions of an actual turbine.

\subsubsection{Erosion Test Development}

The goal of this GE funded effort was to identify a simple laboratory test that would rank candidate coatings for applications such as the coal-fired gas turbine. Early results obtained 
during the operations of the turbine simulator rig indicated that particle erosion was a potential problem, particularly if particulates were to be added to the gas stream for emissions control. The information described here was included in the 1988 IR\&D Report. An erosion test facility was established at CRD. An S.S. White Model 6500 Airbrasive System was used as the basic unit. Similar equipment (larger capacity, same manufacturer) has been used by J.S. Hansen* of the Albany Metallurgy Research Center Federal Bureau of Mines, Albany, Oregon to conduct erosion tests both at room temperature and at $700^{\circ} \mathrm{C}$. Fixtures to allow room temperature tests of pins were designed and fabricated.

Calibration tests of the unit were made. It was found that the built-in powder feeder was not satisfactory because of intermittent operation, so a Plasmatron powder feeder was used. At $20 \mathrm{psi}$, particle velocities of $80 \mathrm{~m} / \mathrm{sec}$. were measured by the two disc method. This is considered satisfactory for evaluating corrosion pins. Apart from actually testing a rotating pin, the erosion apparatus is ready for use. It was used to evaluate the erosion resistance of $\mathrm{CF}$ diesel engine nozzle materials under DOE sponsored work; the reproducibility between duplicate samples was excellent.

\subsubsection{Conclusions}

The results of this study strongly indicate that environmentally resistant coatings will be required for components such as blades and vanes in an uncooled coal-fired gas turbine. The ash products that result from coal-water slurry combustion, if allowed to deposit, can lead to an apparent hot corrosion attack the $X-40$ vane alloy.

A number of candidate coating compositions were screened in this study. Several compositions were identified which hold promise of providing resistance to environmental attack during turbine operation.

It is possible that particle erosion resistance will be required for a suitable coating also for this application.

It was demonstrated that vanes can be coated for this application using low-pressure plasma deposition, pack cementation or sputter processing.

\footnotetext{
" J.S. Hansen, "Relative Erosion Resistance of Several Materials", ASTM STP 664, 1979, pp. 148-162.
} 


\subsection{LM500 Turbine Simulator Test Facility}

All of the deposition, environmental and combustion performance tests described in this section were performed using the LM500 turbine simulator test facility. The LM500 test facility can be divided into three main components: (1) The combustion section which incorporates the fuel nozzle and combustor hardware, (2) the test secticn whirh houses the first stage nozzle cascade, and (3) the sampling section which encompasses the gas analysis, sampling probes and test samples used for materials evaluation. Figure 3.4.1 is a schematic diagram of the LM500 turbine simulator combustion/deposition test facility. Each of these components will be described in detail in the following sections:

\subsubsection{Combustion Section}

The LM500 Turbine Simulator combustor system incorporates a modified J-79 can combustor, and an air-atomized dual fuel fuel nozzle to accommodate coal slurry and/or \#2 petroleum distillate. The combustor liner is comprised of a commercial jet engine J-79 dome along with its first three rings, but modified for this program by the addition of 7 rings to extend its length. This modification was made to provide greater combustion time and ensure improved burnout of the solid fuel. The combustor liner is constructed of Hastelloy-X, with the panels joined by high temperature oven brazing. The modified J-79 can combustor has a diameter of $6.5 \mathrm{in}$. and is $17.75 \mathrm{in.} \mathrm{long.}$

The combustor liner is housed in an impingement sleeve which provides uniform pressure drop for cooling and combustion air. The impingment sleeve is sized to provide $50 \%$ of the total pressure drop.

The original combustor configuration was fabricated with the air swirler vanes permanently welded to the dome end of the combustor. These vanes were 0.030 in. thick, having a vane height of $0.165 \mathrm{in}$. and hub diameter of $1.65 \mathrm{in}$.. The vanes were welded to the inner hub with a $45^{\circ}$ angle from the axial centerline. The fuel nozzle was positioned in the center of the air swirler and the inner edges of the swirler vanes were used to support the end cap of the fuel nozzle. Figure 3.3.13 is a schematic of the combustor, impingement liner, as assembled with the fuel nozzle in the test facility.

A later modification of the combustor liner was made to allow for the easy removal and replacement of the air swirler. The combustion performance could then be evaluated while varying parameters such as vane angle, swirler air mass flcw rate and swirl number. These tests are described in section 3.4 .

The combustor liner is slot cooled in each ring section. Primary combustion air is introduced 4.75 in. downstream of the air swirler by means of four holes 0.5 in. diameter. Secondary dilution is provided by four holes $0.5 \mathrm{in}$. diameter and $2.4 \mathrm{in}$. from the aft flange of the combustor. Cooling air flow distribution was adjusted to maintain skin temperatures below $1400^{\circ} \mathrm{F}$. Table 3.6.1 shows the typical air flow split for the LM500 combustor: 
Table 3.6.1

LM500 Air Flow Split

\begin{tabular}{ll}
\multicolumn{2}{c}{ Atomizing Air } \\
Swirler Air & $15 \%$ \\
Primary Air & $16 \%$ \\
Secondary Dilution & $12 \%$ \\
Cooling & $51 \%$
\end{tabular}

Table 3.62

LM500 Typical Operating Conditions

LM500 Typical Operating Conditions

Chamber Pressure psig

130

Air Preheat, of

760

Atomizing Air Pressure Ratio

2.0

Atomizing Air Flow \#/sec

.18

Main Air Flow */sec

2.4

CWM Slurry Flow */sec

.11

Distillate Fuel Flow \#/sec

.052 
The design operating conditions for the LM500 turbine simulator are shown in Table 3.6.2.

The ratio of the heat input supplied by the oil/CWM fuel was maintained at 0.20 to 0.25 for the initial tests; during subsequent tests the heat input ratio was varied to determine the over all combustor performance at lower oil levels, and to determine the lowest ratio of oil to CWM on a Btu basis that would sustain stable combustor performance.

The combustor liner and impingement sleeve were instrumented with thermcouples circumferentially and axially to provide skin temperature data. Pressure taps provided overall $\Delta P$ and the $\Delta P$ between the impingement sleeve and the combustor liner.

The fuel nozzle used for all of the tests performed in this program was a GE design. Figure 3.6.1 is a schematic of the GE-designed fuel nozzle used for CWM atomization. This fuel nozzle is an air atomization type, which employs separate passages for CWM and distillate fuels. The two fuels are segregated prior to being introduced into the combustor. The fuel oil is transported by means of an inner $1 / 8$ in. diameter tube; the CWM fuel flows in the annulus surrounding the fuel oil supply tube. The atomizing air flows in the annulus around the CWM supply tube. Each flow rate is independently controlled, and thus it is easy to vary the firing temperature, ratio of heat supplied by CWM and oil, and the atomizing- air-to-fuel-flow ratio. The atomizing air swirl is co-current with the main air swirler. The atomizing-air-tochamber-pressure ratio was maintained between 1.9 to 2.0. Maximum atomization efficiency was achieved by maintaining the impingement velocity of the atomizing air as close to sonic conditions as possible. The spray angle of the fuel exiting the nozzle was nominally $45^{\circ}$, but this was later varied to evaluate the effect of fuel nozzle spray angle on combustion performance. These tests are described in section 3.4.

The fuel handling and delivery system is illustrated in Figure 3.6.2. The CWM fuel is supplied from the vendor in 55 gallon plastic drums. Prior to a fired test, the slurry was mixed in the drums for approximately 1 to $2 \mathrm{hr}$. After mixing, the slurry was pumped to a 250 gallon stainless steel storage tank which was equipped with a mixer. During fired operations the level of CWM in the stainless steel tank was maintained at $\sim 100$ gallon by the addition of CWM slurry at reqular intervals.

The CWM fuel was pumped to the test rig by means of a Moyno ${ }^{\bullet}$ pogressive cavity pump. As shown in Figure 3.6.2, fluid flow splits were adjusted through the use of a by-pass loop. The by-pass line pressure was adjusted by changing the pump speed and/or the by-pass valve position. During fired operations the fuel valve to the turbine simulator was open and the CWM flow ' $\supset$ the combustor was adjusted by increasing or decreasing the pump speed, thus increasing or decreasing the by-pass loop pressure. The supply piping to the Moyno pump from the stainless steel tank is 2 in. diameter flexible tose, and the pump discharge is $1 / 2$ in. stainless steel tubing. Measurement of the CWM flow was made by a Micro-Motion flow me- 


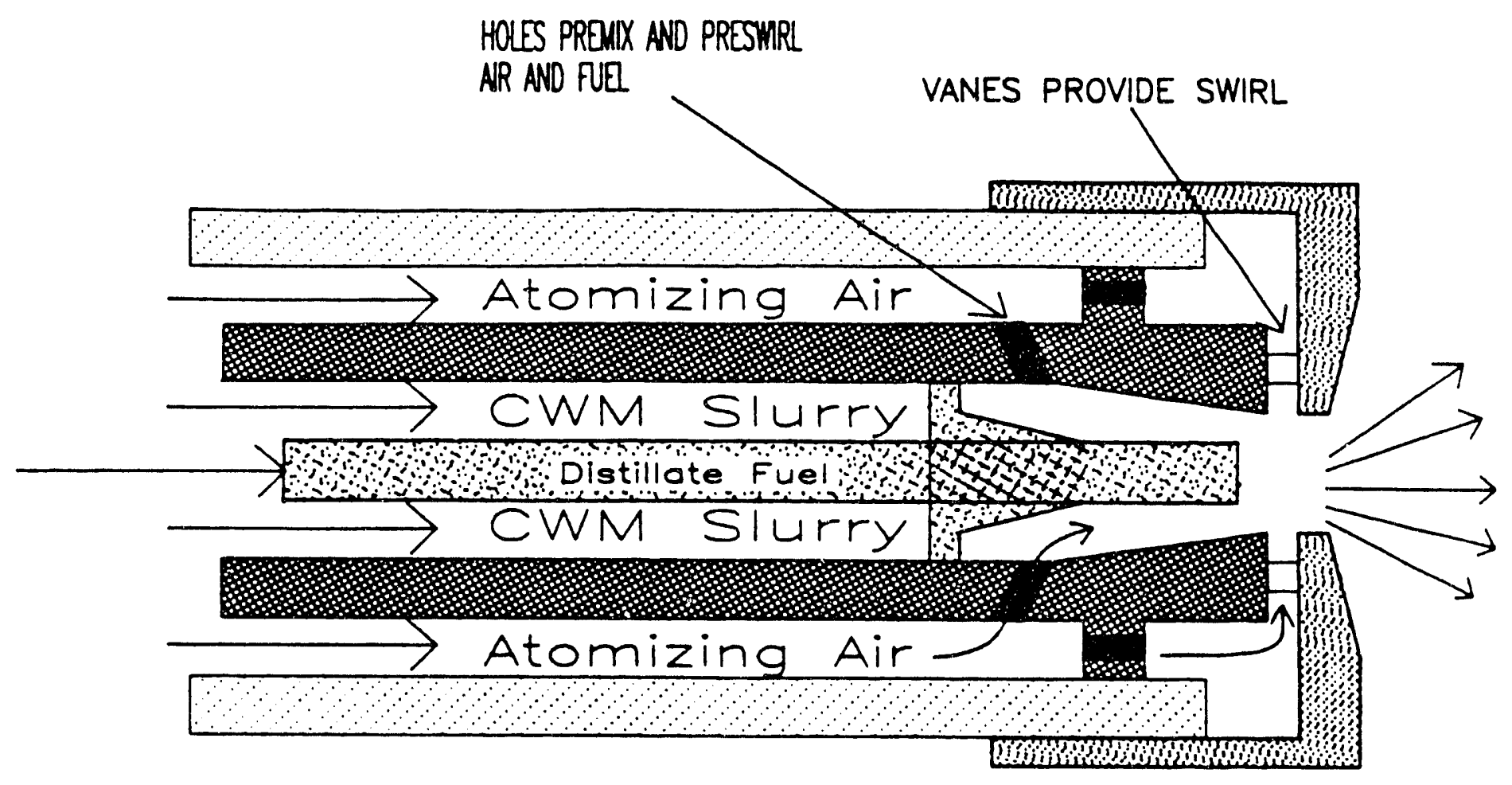

Figure 3.6.1 GE-LT fuel nozzle schematic.

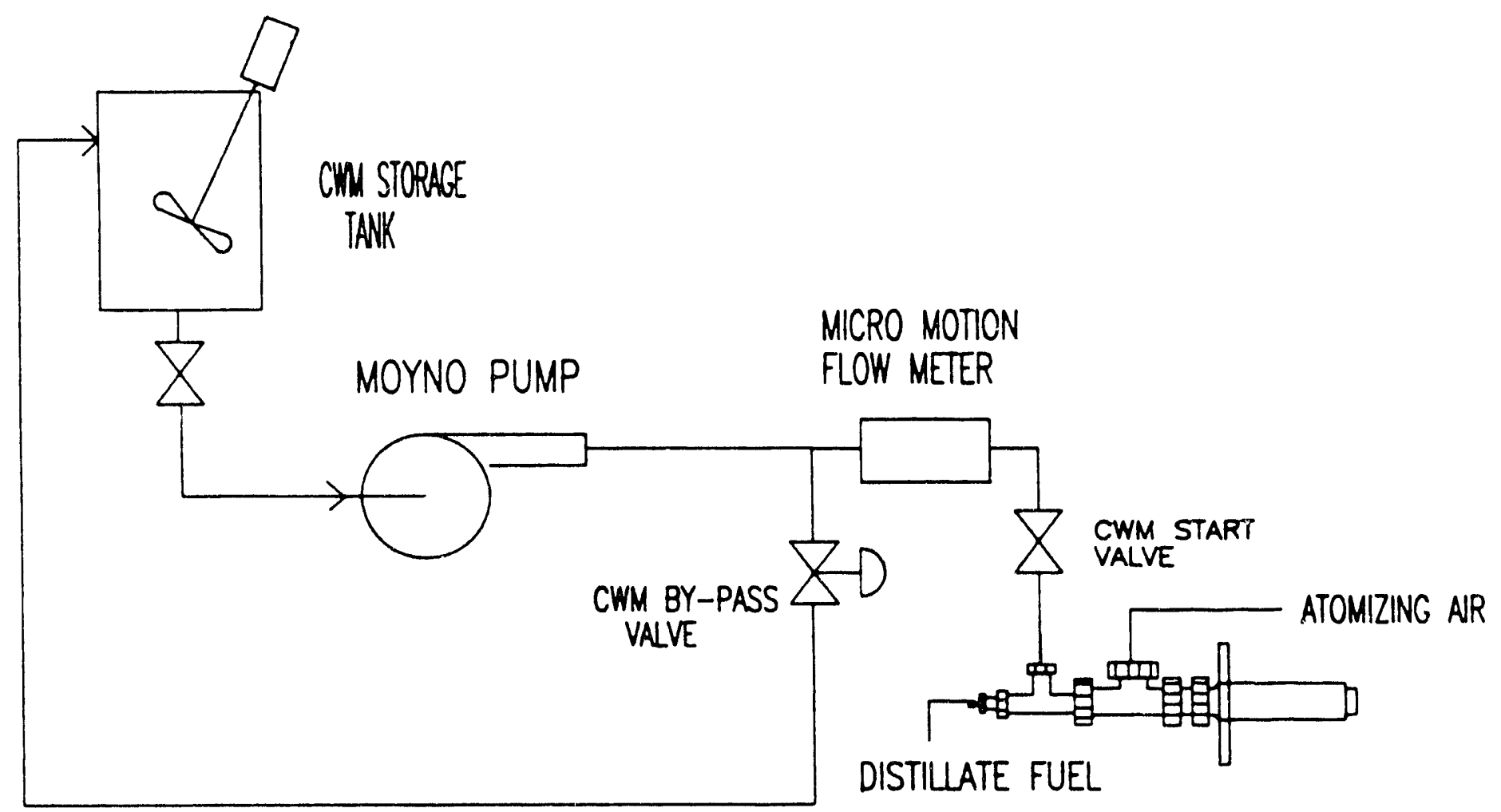

Figure 3.6.2 CWM fuel delivery system schematic. 
ter; fuel oil flow rate was separately measured using a turbine flow meter.

Ignition of the combustor was performed at low chamber pressure (10 psig) using a hydrogen/air mixture detonated by an electrically generated spark. Once the combustor was firing on oil in a stable manner, the spark and $\mathrm{H}_{2}$ supply were shut off, the igniter air valve was closed, and the air and fuel flow were increased to the desired operating conditions. After a suitable period of time to insure that all instrumentation, controls and data acquisition equipment is online and operating properly, the CWM fuel start valve is open and the CWM fuel flow inscreased to the desired operating condition. At the same time the oil flow rate is decreased on a proportional Btu basis.

Incoming combustion air cools the outside surface of the transition section. In the actual turbine, this would represent compressor discharge air. This serves to pre-heat the combustion air slightly.

Initially, hot spots were observed on the transition section, especially at the exit flange. These hot spots were found to be areas of increased ash deposit formation. To alleviate this problem, impingement cooling manifolds were installed so that $\sim 10 \%$ of the cooling air was directed at the hot spots. This enhanced impingement cooling decreased the average skin temperature by $\sim 200^{\circ} \mathrm{F}$, and reduced deposit formation at the exit of the transition section.

The transition from a round geometric shape of 6.5 in. in diameter to a $45^{\circ}$ sector of an annulus was accomplished in an axial length of 12 in.. All inner surfaces of the transition duct were ground as smooth as possible, but the complex shape of the transition duct resulted in some areas of sharp side wall corners, which were by nature difficult to properly cool. A full annular combustor does not have a transition section, and a full size can type combustor has a more geometrically smooth transition section, so the problems with cocling and deposit formation would most likely not occur in hot spots.

\subsubsection{Test Section}

The test section of the LM500 Turbine Simulator consists of a $45^{\circ}$ cascade sector fabricated from actual production first stage turbine airfoils that were welded together and mounted in a stainless steel flange. Figure 3.6.3 is a photograph of the inlet side of the cascade.

Cooling air to the cascade sector is introduced through a plenum machined into the mounting flange. The cooling air is preheated to the same temperature as the combustion air, but is independently controlled. The cooling flow to the cascade was maintained at 12 to $14 \%$ of the total airflow passing through the cascade.

The cascade was instrumented with thermocouples that were spot-welded on to the inner surface of the cooling passages. Internal skin temperatures were typically 1000 to $1100^{\circ} \mathrm{F}$ when the cooling flow rate was maintained at $12 \%$ of total flow and the cooling air supply temperature was maintained a $760^{\circ} \mathrm{F}$. Flow was choked in the throat of the cascade, so the 


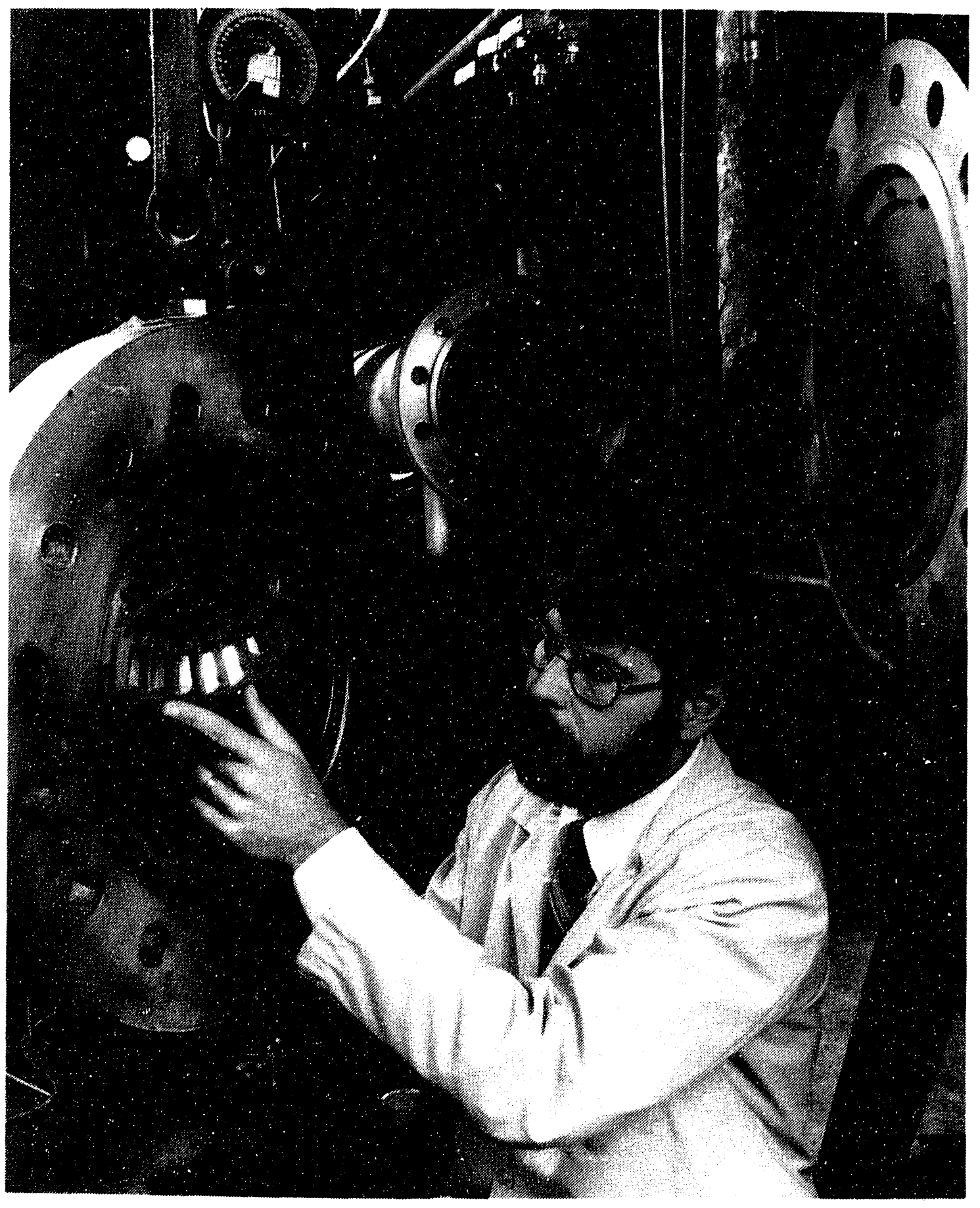

Figure 3.6.3 LM500 turbine simulator cascade. 
resultant exit velocity was sonic. The exhaust gas is turned $\sim 90^{\circ}$ as it passes through the cascade and is then directed to the exhaust section which contains the gas analysis and sampling probes. The temperature of the gas entering the cascade is $2000^{\circ} \mathrm{F}$, the designated firing temperature. The temperature of the gas exiting the cascade is between 1500 to $1700^{\circ} \mathrm{F}$, depending on the vane cooling air flow rate. The pressure in the exhaust section adjusted to $\sim 45 \mathrm{psig}$ by means of a water cooled orifice plate. The exhaust pressure downstream of the cascade is necessary to provide for sufficient pressure drop across the valves for gas sampling and particulate collection systems described. in the next section.

\subsubsection{Instrumentation Section}

The instrumentation section is located in the exhaust piping downstream of the cascade section. The physical location of the instrumentation section is $\sim 6$ feet downstream of the cascade, with sufficient intermediate piping sections to insure adaquate mixing of the products of combustion (POC). The instrumentation section consists of gas sampling probes, a quenched particulate sampling probe, and a series of control thermocouples. Additionally in this instrumentation section material samples for corrosion and erosion evaluation have been located.

The gas sampling probes transport exhaust gases via a heat-traced pressurized sample line to a gas-conditioning system. The gas conditioning system consists pressurize ceramic filters, for particulate removal and ice bath traps for water removal. The conditioned gas is then distributed to the various analytical instruments used to measure $\mathrm{CO}, \mathrm{CO}_{2}, \mathrm{O}_{2}$, unburned hydrocarbons, $\mathrm{SC}_{2}$ and $\mathrm{NO}_{\mathbf{x}}$. Analyses are displayed in real time by means of an online-dataacquisition system.

The particulate sampling probe is designed to operate at near isokinetic conditions. The sampled gas is immediately quenched by the addition of high-pressure nitrogen as the sample enters the particulate probe. Figure 3.6.4 is a schematic of the particulate probe design. The particulate sample is transported at pressure via a heat- traced sample line to a hot pressurized stainless-steel filter. This Mott filter is sized to operate with a particle retention of $.5 \mu$ and greater. The sampling times are typically 1 hour at normal operating conditions. The particuiate samples are removed from the filter and analyzed for carbon, hydrogen and nitrogen. As a result of this analysis the combustion efficiency can be evaluated based on the carbon reminaing in exhaust gas stream. All of the respective flow rates, for both the sample collected and the quench $\mathrm{N}_{2}$, are monitored by the data acquisition system. Total system mass flow is determined, and real-time calculations are made to determine appropriate sample and $\mathrm{N}_{2}$ flow rates to maintain isokinetic conditions.

\subsubsection{Auxilliary Systems}

An A900 Hewlett Packard Computer system with disk and magnetic-tape storage are used to collect, and archive data. A high-speed scanning digital voltmeter (DVM) examines all 


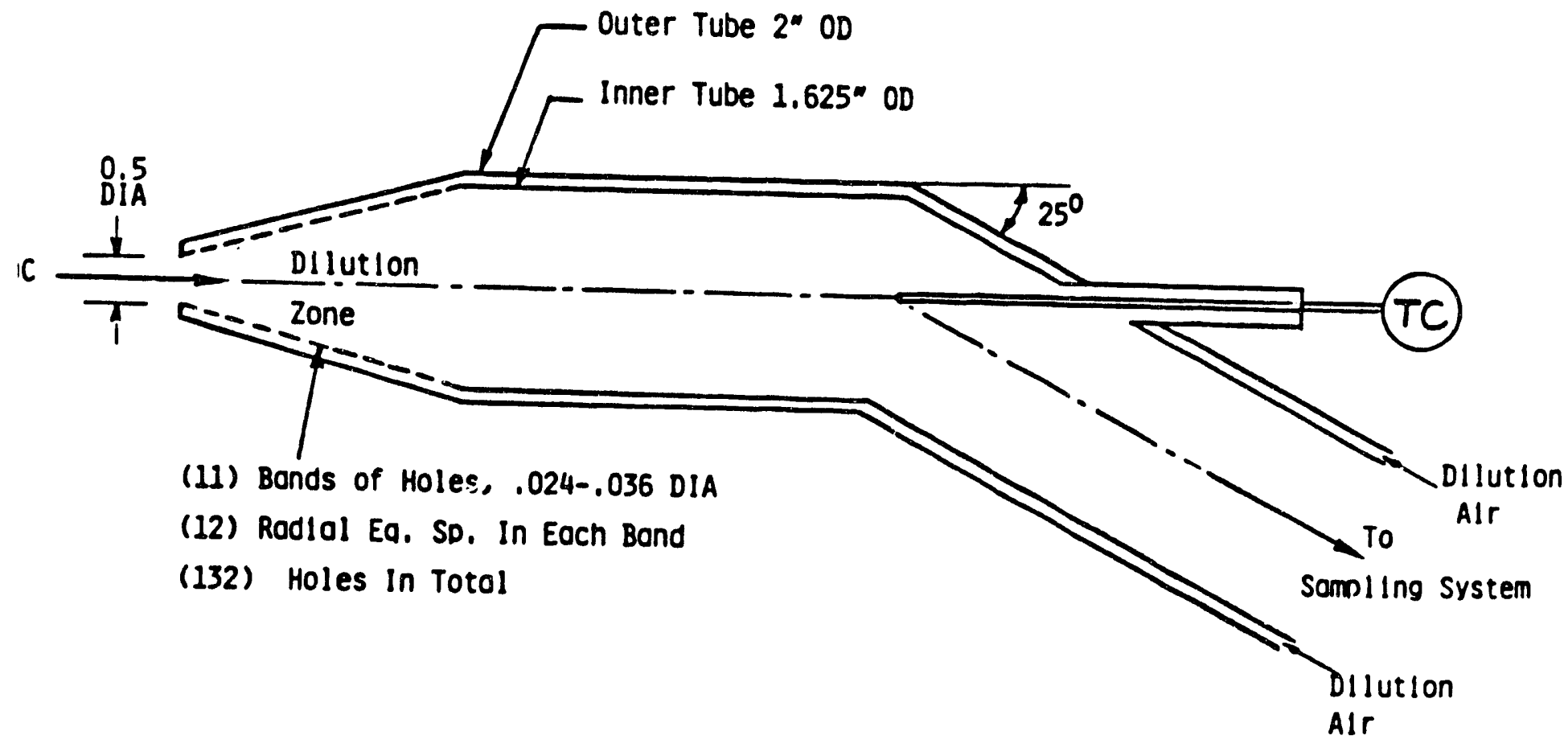

Figure 3.6.4 Air-quenched particulate sampling probe.

$(400+)$ data channels every 5 to 15 seconds. All of the raw test data are converted to engineering units in real time by Fortran computer programs. Engineering data are available to the operator and the test engineer within 1 scan duration. At the conclusion of a test all of the collected data can be plotted for further analysis.

High-pressure air is supplied to the test rig by means of a centrifigual compressor capable of generating $10 \mathrm{lb} \mathrm{m} / \mathrm{s}$ of air flow at $500 \mathrm{psi}$. A gas fired nonvitiating air heater is used to preheat process air to up to $1000^{\circ} \mathrm{F}$. 
CONTENTS

1. TEST DATE: 4-1-87 BLUE GEM $\quad$ • . . . . . . . . . . . . . . . . . . . . . . . 1

2. TEST DATE: 4-2-87 BLUE GEM

3. TEST DATE: 4-7-87 BLUE GEM

4. TEST DATE: 5-11-87 BLUE GEM

5. TEST DATE: 5-19-87 BLUE GEM

6. TEST DATE: 5-21-87 BLUE GEM

7. TEST DATE: 5-28-87 BLUE GEM

8. TEST DATE: 6-3-87 BLUE GEM

9. TEST DATE: 6-8-87 BLUE GEM .

10. TEST DATE: 6-10-87 BLUE GEM

11. TEST DATE: 6-17-87 BLUE GEM

12. TEST DATE: 6-19-87 Environmental-Fuel Oil

13. TEST DATE: 6-24-87 Environmental-Fuel Oil

14. TEST DATE: 8-19-87 Environmental-Fuel Oil/ $\mathrm{CaCO}_{3}$

15. TEST DATE: 8-27-87 Environmental-Fuel Oil/ $\mathrm{CaCO}_{3}$

16. TEST DATE: 8-31-87 Environmental-Fuel Oil/ $\mathrm{CaCO}_{3}$

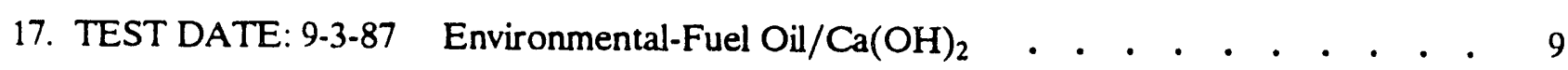

18. TEST DATE: 10-6-87 BLUE GEM . . . . . . . . . . . . . . . . . . . . . 10

19. TEST DATE: $10-7-87$ Environmental-Blue $\mathrm{Gem} / \mathrm{Ca}(\mathrm{OH})_{2} \quad$ • . . . . . . . . . $\quad$. 10

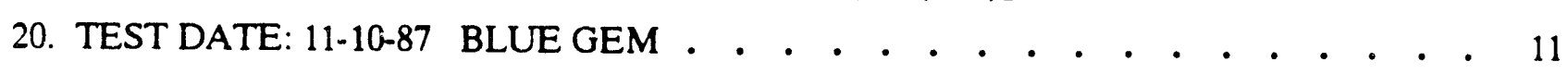

21. TEST DATE: 11-17-87 Deposition BLUE GEM/KAOLIN • • • • • • • . . . 11

22. TEST DATE: 11-24-87 Environmental-Blue Gem/Dolomite . • . • • • . . . 11

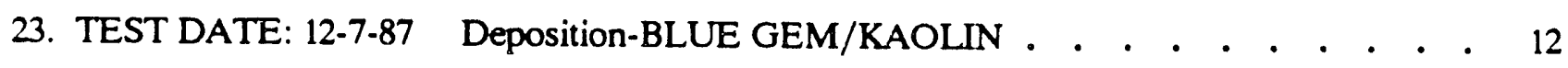

24. TEST DATE: $12-10-87$ Environmental BLUE GEM/KAOLIN/Ca(OH) $)_{2}$ • . . . . 13

25. TEST DATE: 2-2-88 Deposition- BLUE GEM/KAOLIN . . . . . . . . . . 13

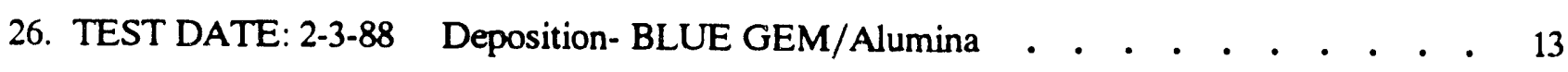

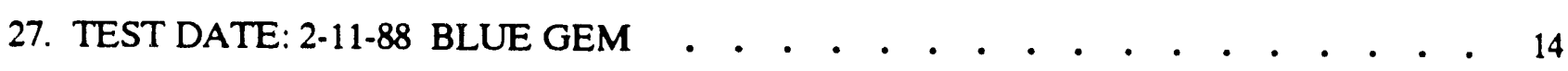

28. TEST DATE: $3-8-88$ BLUE GEM/KAOLIN

29. TEST DATE: $3-9-88$ Deposition TAGGART

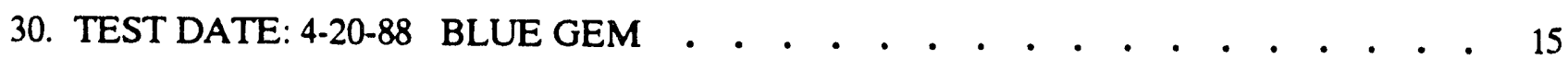

31. TEST DATE: 6-8-88 BLUE GEM • • • • • • • • • • • • • • • • . . . . 16

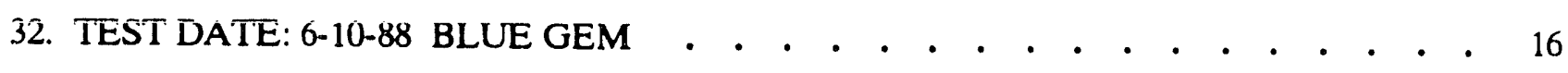




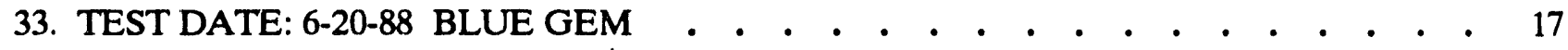

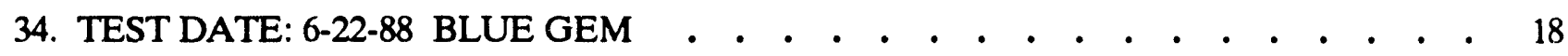

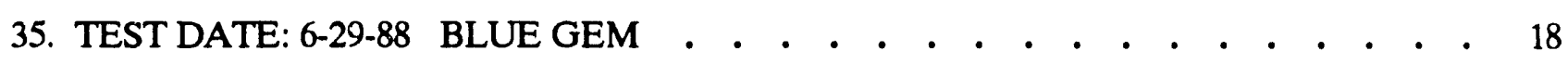

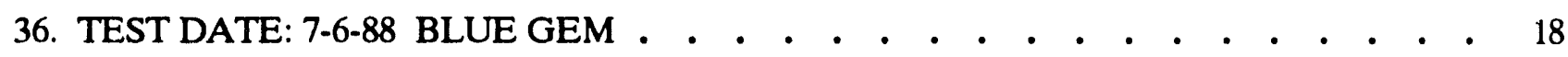

37. TEST DATE: 7-13/14-87 TAGGART/KAOLIN • . • . . . . . . . . . . . 19

38. TEST DATE: 7-28-88 ELK CREEK . . . . . . . . . . . . . . . . . 20

39. TEST DATE: 8-2-88 ELK CREEK $\quad$ • . . . . . . . . . . . . . . . . 20

40. TEST DATE: 8-8-88 ELK CREEK $\quad$ • . . . . . . . . . . . . . . . . . 21

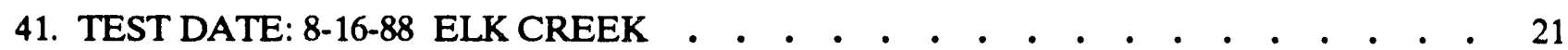

42. TEST DATE: 8-18-88 ELK CREEK . . . . . . • . . . . . . . . . . 22

43. TEST DATE: 8-24-88 OXCE-ELK CREEK . . . . . . . . . . . . . . . . 22 


\section{LM500 TURBINE SIMULATOR FIRED TEST SUMMARY}

\section{TEST DATE: 4-1-87 BLUE GEM}

Test Objectives: Combustion performance-Fuel Nozzle evaluation

Test Fuel: Otisca Blue Gem CWM

Combustor Configuration: Orignial Air Swirler $45^{\circ}$ Fuel Nozzle

Test Conditions:

TFire $=2000^{\circ} \mathrm{F}$

Oil BTU $=.25 / .20$

TFire $=2200^{\circ} \mathrm{F}$

Oil Btu: .20

Exhaust $\mathrm{CO}$ emissions increased as the oil Btu ratio was decreased. At the lower oil Btu ratios the combustor became unstable, the chamber pressure experienced pulsing just before a flame-out occurred.

Test Hours: 4.5

CWM Hours : 4.0

\section{TEST DATE: $4-2-87$ BLUE GEM}

Test Objectives: Combustor performance-Fuel nozzle

Test Fuel: Otisca Blue Gem CWM

Combustor Configuration: Original Air swirler $55^{\circ}$ Fuel Nozzle

TFire $2000^{\circ} \mathrm{F}$

Oil Btu: $25 \mathrm{CO}=-55 \mathrm{ppm}$

Oil Btu: $.20 \quad \mathrm{CO}=55 \mathrm{ppm}$

$.15 \mathrm{CO}=100 \mathrm{ppm}-250 \mathrm{ppm}$ \{Calibration Problems

$.10 \mathrm{CO}=190 \mathrm{ppm}$

Lowest oil BTU $=7 \% *$ CWM flow may have physically stopped due to pump probiems 


\section{NO FLAME-OUTS}

After CO instrument calibration --Stable operation

There was a large amount of deposit on leading edge, Type B TC's and the transition piece. Combustor liner was clean.

Test Time: $4.5 \mathrm{hrs}$

CWM Time $4.0 \mathrm{hrs}$

\section{TEST DATE: 4-7-87 BLUE GEM}

Test Óbjectives: Combustion performance-fuel nozzle evaluation

Test Fuel: Otisca-Blue Gem CWM

Combustor Configuration: Original Air swirler $65^{\circ}$ Fuel Nozzle

*First time this new fuel nozzle cap was used. The change was prompted by a shut down during which the fuel nozzle cap originally installed was found to be lose.

TFire $=2000^{\circ} \mathrm{CO}=85 \mathrm{ppm}$

Oil Btu $=.25$

TFire $2000^{\circ}$

Oil Btu $=.2 \quad \mathrm{CO}=69 \mathrm{ppm}$

TFire $=2000^{\circ}$

Oil $\mathrm{Btu}=.15 \quad \mathrm{CO}=175 \mathrm{ppm}$

Lowest oil BTU $=.08$

*NO FLAME-OUT prior to lowest test point or during the operation of the test.

No deposit formation on the combustor.

Test Time: $6.5 \mathrm{hrs}$

CWM Time : $6 \mathrm{hrs}$

Modifications to the combustor liner were made that would make it possible for the air swirler to be removed, and replaced, without necessitating a complete teardown to the test rig. New air swirlers with varying swir! vane angle and mass fow were fabricated to be used in subsequent tests. 


\section{TEST DATE: 5-11-87 BLUE GEM}

Test Objectives: Combustion performance-Fuel nozzle/Air swirler

Test Fuel: Otisca Blue Gem CWM

Combustor Configuration: $45^{\circ}$ Air swirler

$45^{\circ}$ Fuel Nozzle Original LT nozzle

TFire $2000^{\circ}$

Oil Btu $=.25 \quad$ Exhaust $\mathrm{CO}=75 \mathrm{ppm}$

TFire $2000^{\circ}$

Oil Btu $=.15 \quad \mathrm{CO}=178 \mathrm{ppm}$

Problems with exhaust gas instruments. Questionable readings especially during the second phase of the test.

While removing the fuel nozzle, the air swirler assembly became disloged and the rig had to be dissassembled for repairs. The head-end of the combustor liner was coated with a black soot-like substance.

Total Test Time: $3.5 \mathrm{hrs}$

\section{TEST DATE: 5-19-87 BLUE GEM}

Test Objectives: Combustion performance-Fuel nozzle/Air swirler

Test Fuel: Otisca Blue Gem CWM

Combustor Configuration: $30^{\circ} \mathrm{Air}$ swirler $45^{\circ}$ Original LT fuel nozzle

TFire $=2000^{\circ}$

Oil Btu $=.25 \mathrm{CO}=65 \mathrm{ppm}$

Flame-outs /quick re-ignition

TFIre $2000^{\circ}$

Oil BTU $=.20 \mathrm{CO}=165$ Unsteady operation

Numerous flame-outs and re-lights. This configuration basically unstable at OIL Btu $<.20$ 
Test Time: $3 \mathrm{hrs}$

CWM Time : $2.5 \mathrm{hrs}$

\section{TEST DATE: 5-21-87 BLUE GEM}

Test Objectives: Cornbustion performance-Fuel nozzle/Airswirler

Combustor Configuration: $38^{\circ}$ Air Swirler $45^{\circ}$ Fuel Nozzle

TFire $2000^{\circ}$

Oil Btu $=.25 \quad \mathrm{CO}=75 \mathrm{ppm}$

TFire $2000^{\circ}$

Oil Btu $=.20 \quad \mathrm{CO}=160 \mathrm{ppm}$

Flame out at .16

TFire $2200^{\circ}$

$\mathrm{Oil} \mathrm{Btu}=.20 \quad \mathrm{CO}=53 \mathrm{ppm}$

Flame-outs and combustion instability were the main cause for the test to be terminated.

Test Time: $5 \mathrm{hrs}$

CWM Time : $4.5 \mathrm{hrs}$

\section{TEST DATE: 5-28-87 BLUE GEM}

Test Objectives: Combustion performance-fuel nozzle/air swirler

Test Fuel: Otisca Blue Gem CWM

Combustor Configuration: $45^{\circ}$ origina' LT Fuel Nozzle

$45^{\circ}$ Air Switler \{originally tested on $5 / 11 / 87$ \}

TFire $=2000^{\circ}$

Oil BTU $=.23 \quad \mathrm{CO}=\sim 100 \mathrm{ppm}$

Stable No flame-outs

TFire $=2000^{\circ}$

Oil Btu $=.20 \quad \mathrm{CO}=150-175$

No Flame-outs

TFire $=2000^{\circ}$ 
Oil Btu $=.15 \quad C O=300-400 \mathrm{ppm}$

No Flame-outs

Lowest oil Btu ratio $=.109$ Flame-out occured

Deposits on Type B TCs and on the ourer side wall of the transition section. The cascade was clean as was the combustor.

Test Time: $5.5 \mathrm{hrs}$

CWM Time : $4 \mathrm{hrs}$

\section{TEST DATE: 6-3-87 BLUE GEM}

Test Objective: Combustor performance-fuel nozzle/air swirler

Test Fuel: Otisca Blue Gem CWM

Combustor Configuration: $45^{\circ}$ Air swirier

$55^{\circ}$ Fuel nozzle

No stable combustion attained. Numerous flame-outs and problems with this system of fuel nozzle and air swirler combination. The flame-outs occurred at oil Btu values $<.35$ but greater than .25 consistently. The fuel nozzle was found to be quite dirty and plugged up, but overall the system was clean considering the numerous flame-outs and relights.

\section{TEST DATE: $6-8-87$ BLUE GEM}

Test Objectives: Combustor performance-fuel Nozzle/air swirler

Test Fuel: Otisca Blue Gem CWM

Combustor Configuration: $45^{\circ}$ Original LT Fuel nozzle $60^{\circ}$ Air Swirler

TFire $=2000^{\circ}$

Oil Btu $=.25 \quad \mathrm{CO}=54 \mathrm{ppm}$

TFire $=2000^{\circ}$

Oil Btu $=.20 \quad \mathrm{CO}=75 \mathrm{ppm}$

Flame-out for an unexplained reason, easy re-light.

TFire $2000^{\circ}$

Oil Btu $=.10 \quad \mathrm{CO}=150-175 \mathrm{ppm}$ 
Numerous flame-outs especially at the lower oil flow. The CO readings were not stable, and there was not stable operation at the lower oil BTU ratios.

The cascade was clean and free of any buildup. Transition and type B TCs were very clean and free of deposit. The combustor head end was blackened with evidence of some deposit.

Test Time: $5.5 \mathrm{hrs}$

CWM Time : $4 \mathrm{hrs}$

10. TEST DATE: 6-10-87 BLUE GEM

Test Objectives: Combustor performance-Fuel nozzle/air swirler

Test Fuel: Otisca Blue Gem CWM

Combustor Configuration: $30^{\circ}$ Air swirler $65^{\circ}$ Fuel Nozzle

TFire $2000^{\circ}$

Oil $\mathrm{Btu}=.20 \quad \mathrm{CO}=75-100 \mathrm{ppm}$

TFire $2000^{\circ}$

Oil Btu $=>200 \mathrm{ppm}$

* No flame-outs but extremely high $\mathrm{CO}$ in exhaust. Adjusting the AA Pr and flow had no positive effect at controling the high $\mathrm{CO}$.

TFire 2000

Oil Btu $=.1$ i)

$\mathrm{CO}=>500 \mathrm{ppm}$ initially, but somthing let loose in the fuel nozzle and suddenly the combustion became much smoother.

$\mathrm{CO}=53 \mathrm{ppm}$ but then continued to rise at a steady rate.

Minimum Oil Btu attained .04 , due to the fast change in conditions it wa. impossible to obtain steady $\mathrm{CO}$ readings.

The fuel nozzle was definitely fouling and there was an obvious build-up on the end cap. There was considerable deposit on the leading edges as well as the transition piece.

Test Time: $5.5 \mathrm{hrs}$

CWM Time : $5.0 \mathrm{hrs}$ 


\section{TEST DATE: 6-17-87 BLUE GEM}

Test Objectives: Combustor performance: fuel nozzle/air swirler

Test Fuel: Otisca Blue Gem CWM

Combustor Configuration: $60^{\circ}$ Low Flow Air swirler

TFire $=2000^{\circ}$ $45^{\circ}$ Original LT Fuel nozzle

Oil $\mathrm{BTU}=.20 \quad \mathrm{CO}=30-50 \mathrm{ppm}$

TFire $2000^{\circ}$

Oil Btu $=.15 \quad \mathrm{CO}=150 \mathrm{ppm}$ (fluctuating)

Flame-outs followed high $\mathrm{CO}$ concentrations in the exhaust.

Lowest recorded Oil Btu was $<.01$ but the problems with oil and slurry flow control make this value less credible. The exhaust $\mathrm{CO}$ was varying through a large range, but there was a definite correlation between the $\mathrm{CO}$ and the time of the flame-out.

The fuel nozzle was found to have considerable build-up on the outer face and the dome end the combustor also had evidence of deposit formation. The cascade was heavily deposited on the leading edge.

Test Time: $5.5 \mathrm{hrs}$

CWM Time : $5.0 \mathrm{hrs}$

\section{TEST DATE: 6-19-87 Environmental-Fuel Oil}

Test Objectives: Evaluate combustor tolerance for water addition, in preparation for tests using sorbent/water slurry.

Test Fuel: Distiliate \#2 fuel oil

Combustor configuration: $45^{\circ}$ Original LT Fuel Nozzle $60^{\circ}$ LF Air Swirler

Calibration run to determine the residence time and the controllability of the $\mathrm{CS}_{2}$ doping additive. Additionally an evaluation of how much water coulc be added to the combustor before a flame-out was caused by excessive flame quenching.

Water flow through the CWM side of the fuel nozzle and oil flow through the normal $1 / 8^{n}$ tube.

Total Run Time $=5.5 \mathrm{hrs}$ 


\section{TEST DATE: 6-24-87 Environmental-Fuel Oil}

Test Objectives: Evaluate combustor tolerance for water addition, in preparation for tests using sorbent/water slurry.

Test Fuel: Distiallate \#2 fuel oil

Combustor configuration: $45^{\circ}$ original LT Fuel Nozzle

$60^{\circ}$ LF Air swirler

Water flow through the $1 / 8^{n}$ tube and the fuel oil through the CWM side of the fuel nozzle

Calibration of the $\mathrm{CS}_{2}$ doping system and closing the sulfur balance in the system

Total run time $=5.0 \mathrm{hrs}$

\section{TEST DATE: 8-19-87 Environmental-Fuel Oil $/ \mathrm{CaCO}_{3}$}

Test Objectives: Evaluate $\mathrm{CaCO}_{3}$ slurry mixed with fuel oil as sorbent for sulfur capture.

Test Fuel: Distillate \#2 fuel oil

Combustor configuration: $45^{\circ}$ Original LT Fuel Nozzle

$60^{\circ} \mathrm{LF}$ air swirler

Sorbent doping using $\mathrm{CaCO}_{3}$ slurry added via the Moyno pump system. Numerous problems encountered using the Moyno pump to add $\mathrm{CaCO}_{3}$ slurry to the combustor.

*oil only no CWM fuel for this test

Total test time: $7 \mathrm{hrs}$

15. TEST DATE: 8-27-87 Environmental-Fuel Oil/ $\mathrm{CaCO}_{3}$

Test Objectives: Evaluate $\mathrm{CaCO}_{3}$ slurry mixed with fuel oil as sorbent for sulfur capture.

Test Fuel: Distillate \#2 fuel oil

Combustor configuration: $60^{\circ} \mathrm{LF}$ Air Swirler

$45^{\circ}$ Original LT fuel nozzle

The fuel delivery system was modified to provide for the Vickers pump to mix fuel oil, $\mathrm{CaCO}_{3}$ slurry and surfactant. The $\mathrm{CaCO}_{3}$ slurry was fed by the moyno pump, surfactant fed by a pulsafeeder pump.

Problems were encountered holding a steady oil fire, the test rig was shut down for inspection. 
Total test time: $8 \mathrm{hrs}$

\section{TEST DATE: 8-31-87 Environmental-Fuel Oil/ $\mathrm{CaCO}_{3}$}

Test Objectives: Evaluate $\mathrm{CaCO}_{3}$ slurry mixed with fuel oil as sorbent for sulfur capture.

Test Fuel: Distillate \#2 fuel oil

Combustor configuration: $45^{\circ}$ Original LT fuel nozzle

$60^{\circ} \mathrm{LF}$ Air Swirler

$10 \% \mathrm{CaCO}_{3}$ slurry added through Vickers pump. $\mathrm{CS}_{2}$ added to oil supply and surfactant through the pulsafeeder pump.

The test was carried out with some control difficulty. There was some sulfur capture and it was considered sucessful.

Considerable plugging of the transition section was experienced, especially in the area of the type B TC's that are protruding into the transition piece at the inlet of the cascade.

Firing temperature was questionable due to loss of TC's and calculated values.

There were a few flame-outs and subsequent relights.

Total test hours: $6.5 \mathrm{hrs}$

\section{TEST DATE: 9-3-87 Environmental-Fuel Oil/Ca(OH)}

Test Objectives: Evaluate $\mathrm{Ca}(\mathrm{OH})_{2}$ slurry mixed with fuel oil as sorbent for sulfur capture.

Test Fuel: Distillate \#2 fuel oil

Combustor configuration: $45^{\circ}$ Original LT Fuel Nozzle

$60^{\circ}$ LF Air Swirler

Slurry for Sulfur capture $\mathrm{Ca}(\mathrm{OH})_{2}$ with Lomar D surfactant. The Ca slurry was added via the Moyno pump and mixed with the fuel oil via the zenith pump. $C S_{2}$ was added to the fuel oil line in the conventional manner at the pump house.

Again there was significant reduction in the $\mathrm{SO}_{2}$ in the exhaust, but the combustor system quickly payed the price and was completely plugged with a white deposit.

The type B TC's and the exit surface of the transition piece were the prime location of deposit formation. 
Total test Time: $5 \mathrm{hrs}$

\section{TEST DATE: 10-6-87 BLUE GEM}

Test Objectives: Evalute new TC arrangement, transition piece and combustor liner.

Test Fuel: Otisca Blue Gem CWM

Combustor configuration: $45^{\circ}$ Original LT fuel Nozzle $60^{\circ} \mathrm{LF}$ air swirler

New TC's in cascade, transition piece and combustor liner.

Purpose of this test run was to chek-out the new cascade installation,. and instrumentation calibration. The combustor ran very smooth with no flame-outs or out of control activity. CO levels in the exhaust were very low throughout the test. Lowest oil Biu ratio was somewhere between 1-5\%. The test was aborted when the CWM slurry tank was emptied and were had no more fuel available.

Total test Time $4 \mathrm{hrs}$ CWM test time $3.5 \mathrm{hrs}$

\section{TEST DATE: 10-7-87 Environmental-Blue Gem/Ca(OH $)_{2}$}

Test objectives: Evaluation of $\mathrm{Ca}(\mathrm{OH})_{2}$ as a sorbent for sulfur capture. The $\mathrm{Ca}(\mathrm{OH})_{2}$ was mixed with the CWM fuel.

Test fuel: Otisca Blue Gem CWM

Combustor configuration: $45^{\circ}$ Original LT fuel nozzle $60^{\circ} \mathrm{LF}$ air swirler

CWM fuel used with $\mathrm{Ca}(\mathrm{OH})_{2}$ added to the CWM fuel supply. There was initial difficulty establishing the sulfur baseline in the exhaust gas stream, due possibly to the presence of residual $\mathrm{CS}_{2}$ in the fuel oil line.

When slurry flow was initiated and the combustor operated at design point: TFire $=2000^{\circ}$ and Oil $\mathrm{Btu}=.10$ the combustor ran smooth for $\sim 50$ minutes when there was a sudden jump in the chamber pressure ciue to deposit plugging.

The main area of plugging occurred in the transition section but there was considerable plugging of the cascade, especially in the area of the leading edge. 


\section{TEST DATE: 11-10-87 BLUE GEM}

Test Objectives: Operation of the turbine simulator totally on CWM fuel, and no auxillary distillate fuel.

Test fuel: Otisca Blue Gem CWM

Combustor Configuration: $60^{\circ} \mathrm{LF}$ Air swirler $45^{\circ}$ Original Lt fuel Nozzle

Numerous problems maintaining the fire in the combustor. Totally erratic control and response. The fuel nozzle was pulled and replaced by the $55^{\circ}$ fuel nozzle for the 2 nd half of the test. Again repeated attempts to get to "zero oil" were thwarted by flame-outs. The lowest recorded oil Btu ratio was $\sim 1$ $2 \%$.

Total test time: 8.5

CWM test hrs : 8

\section{TEST DATE: 11-17-87 Deposition BLUE GEM/KAOLIN}

Test Objectives: Evaluate Kaolin as an additive for deposit prevention.

Test fuel: Otisca Blue Gem CWM doped with Kaolin

Combustor configuration: $45^{\circ}$ Original LT Fuel Nozzle $60^{\circ}$ LF Air Swirler

Initial test operations were aborted after $\sim 2 \mathrm{hrs}$ to change the fuel nozzle.

$55^{\circ}$ Fuel nozzle installed.

Numerous flameouts occurred as well as combustion instabilities for the next $\sim 10 \mathrm{hrs}$. The final flame-out was accompanied by a large reduction in NAIN due to what appeared to be chunks that spalled off of the combustor liner/dome and were too large to pass through the cascade throat.

The cascade was cleaned and the test continued. The fired operations on CWM continued for an additional 2 hrs when again the NAIN suddenly dropped the test was aboorted. The cascade had a few large chunks lodged in the throat, and it was not clear where the chunks came from.

Total Test Time on CWM $12.5 \mathrm{hrs.}$

\section{TEST DATE: 11-24-87 Environmental-Blue Gem/Dolomite}

Test objectives: Evaluate Dolomite as a sorbernt for sulfur capture.

Test fuel: Otisca Blue Gem CWM 
Combustor configuration: $60^{\circ} \mathrm{LF}$ Air swirler

$45^{\circ}$ Original LT fuel Nozzle

All Type B TC's removed from the transition piece.

CWM slurry doped with Dolomitic Hydride and the test operated to determine the reduction in $\mathrm{SO}_{2}$ in the exhaust. Operation on CWM was for $\sim 45$ minutes when there was a large drop in NAIN and the test was aborted.

The cascade and transition piece were covered with deposit.

Total Test hrs $=3.0$

\section{TEST DATE: $12-7-87$ Deposition-BLUE GEM/KAOLIN}

Test objectives: Evaluate Kaolin as an additive for deposit control.

Test fuel: Otisca Blue Gern CWM doped with Kaolin

Combustor configuration: $60^{\circ} \mathrm{LF}$ Air swirler

$45^{\circ}$ Original LT Fuel nozzle

All transition type B TCs removed

The first phase of the test was just Kaolin. The test was run to evaluate the effect of no TCs in the transition. The test ran for $\sim 4 \mathrm{hrs}$ after which a shut down was necessitiated due to a severe flameout and unable to restart the rig. Prior to the final flame-out there were numerous flame-outs that were able to be recovered from.

Phase I test hours: 4.0

Phase II was a continuation of the first part of the test. Again there was numerous flame-outs and the combustion was unstable. The NAIN value slowly degraded $\sim 3 \%$, when there was another sudden large reduction in NAIN and the test was aborted.

Phase II test hours: $5.5 \mathrm{hrs}$

Phase III of the test was performed after the nozzle cascade and the transition piece cleaned. The test was again aborted after $\sim 4$ hrs and it was unsucessfully attempted to nutshell ( 3 time) the deposit from the cascade.

The transition exit and the cascade were loaded with deposit.

Total Test Time: 13.5 hrs 
24. TEST DATE: $12-10-87$ Environmental BLUE GEM/KAOLIN/Ca(OH $)_{2}$

Test Objectives: Evaluate Kaolin $/ \mathrm{Ca}(\mathrm{OH})_{2}$ as additives to the CWM Fuel for deposit control as well as sulfur removal.

Test fuel: Otisca Blue Gem CWM doped with Kaolin and $\mathrm{Ca}(\mathrm{OH})_{2}$.

Combustor configuration: $60^{\circ} \mathrm{LF}$ air swirler

$45^{\circ}$ Original LT fuel Nozzle

This test lasted for $<1 \mathrm{hr}$ after firing on slurry, due to severe plugging of the cascade. The was evidence of sulfur capture, as recorded in the reduction in exhaust $\mathrm{SO}_{2}$ concentrations, but a steady state value was not obtained.

Total test time $=3 \mathrm{hrs}$

CWM Test time $=1 \mathrm{hr}$

\section{TEST DATE: 2-2-88 Deposition-BLUE GEM/KAOLIN}

Test Objectives: Evaluate CWM doped with Kaolin for deposit control.

Test fuel: Otisca BLue Gem doped with Kaolin

Combustor configuration: $60^{\circ} \mathrm{LF}$ air swirler $45^{\circ}$ Original LT fuel Nozzle

This test was also plagued by flame-outs and combustion instabilities. Fired operations on CWM lasted for $\sim 5.5$ hrs when a sudden drop in NAIN caused a shut down. 3 attempts to nutshell the system were not sucessful.

Again the cascade was found to have large chunks of ash blocking the throat.

Total test time: $6.5 \mathrm{hrs} \mathrm{CWM} \mathrm{time:} 5.5 \mathrm{hrs}$

\section{TEST DATE: 2-3-88 Deposition-BLUE GEM/Alumina}

Test Objectives: Evaluate CMW fuel doped with alumina for deposition control.

Test fuel: Otisca Blue Gem CWM doped with Alumina

Combustor configuration: $60^{\circ} \mathrm{LF}$ air swirler $45^{\circ}$ Original LT fuel Nozzle

The cascade was cleaned post the 2-2-88 test and operated using CWM doped with alumina. The results were basically the same as for the previous tests. The shut down was preceeded by a sudden large reduction in the NAIN and recovery was impossible via nutshelling. 
Inspection yielded the same form of cascade plugging and the transition section indicating that this was the area of most of the build-up.

Total test time: $7 \mathrm{hrs}$ CWM test time:6 hrs

\section{TEST DATE: 2-11-88 BLUE GEM}

Test objectives: Evaluate combustor performance with new fuel nozzle hardware.

Test fuel: Otisca Blue Gem CWM

Combustor configuration: $60^{\circ} \mathrm{LF}$ Air swirler $45 w$ fuel nozzle $45-I$

The purpose of this test was to evaluate the new fuel nozzle and compare it to the old fuel nozzle.

Test operations occurred with little problems, there were a few flame-out problems at oil BTU ratios $\sim .10$ and in general the exhaust gases were within the average values seem in the previous tests.

Test Time: 4 hrs

CWM time: $3.0 \mathrm{hrs}$

Impingement cooling installed in the LM500 TS, for 1 he purpose of preventing the build up of deposits in this area.

\section{TEST DATE: 3-8-88 BLUE GEM/KAOLIN}

Test objectives: Evaluate impingement cooling added to the transition piece with CMW fuel doped with kaolin for deposit control.

Test fuel: Otisca BLue Gem CWM

Combustor configuration: 45-I Fuel Nozzle

$60^{\circ}$ LF Air swirler

CWM doped with Kaolin

Deposition test to evaluate improved cooling to the transition section. Test operations were plagued with flame-outs and problems with the slurry line plugging and causing a fuel flow disruption. 
Test time: $8 \mathrm{hrs}$

CWM Time : $4 \mathrm{hrs}$

\section{TEST DATE: 3-9-88 Deposition TAGGART}

Test objectives: Evaluate the combustion performance, depsoit formation and overall system performance using Taggart seam CWM

Test fuel: Otisca Taggart Seam CWM

Combustor configuration: 45 -I fuel nozzle

$60^{\circ}$ LF fuel nozale

Pintle and $1 / 8^{n}$ tube modified from previous test

The operation of the LM500 TS was much smoother using the Taggart CWM fuel. There was a few flame-outs, and it is unclear as to why the flame-outs occurred. It was attempted to hold the oil btu ratio at .15 and the firing temperature at $\sim 2000^{\circ}$.

The test was terminated after $5 \mathrm{hrs}$ of operation trouble free and the combustor brought off line in a controlled manner.

Most of the components of the test rig were found to be quite clean and especially the transition piece was clean in the area of the walls and the exit area of the throat.

Test time: 6 hrs

CWM time: 5 hrs

\section{TEST DATE: 4-20-88 BLUE GEM}

Test objectives: Evaluate baseline conditions with new fuel nozzle, transition cooling and standard Blue Gem CWM.

Test fuel: Otisca Blue Gem CWM

Combustor configuration: 45-I fuel nozzle $60^{\circ}$ LF Fuel nozzle

This test was performed to evaluate the baseline conditions with the new fuel nozzle and Blue Gem CWM. The transition piece was completely smooth, and the test fuel was filtered at the exit of the transfer pump and just before the fuel nozzle.

The test in general was not entirely sucessful. At lower oil Btu ratios the exhaust $\mathrm{CO}$ was too high $>150 \mathrm{ppm}$. There was a few flame-outs and the combustion was not stable. There is a strong indication that there was build-up in the area of the fuel nozale cap. 
Test time: 5 hrs

CWM time : $4.5 \mathrm{hrs}$

LM500 Turbine Simulator modified to seal the impingement sleeve around the outer flange of the air swirler.

\section{TEST DATE: 6-8-88 BLUE GEM}

Test objectives: Evaluate the changes made to the combustor liner [sealing the impingement sleeve to the airswirler flange].

Test fuel: Otisca Blue Gem CWM

Combustor configuration: 45-I fuel nozzle

$60^{\circ}$ LF Fuel nozzle

In General the test went wel' At an oil btu ratio of $\sim .11$ the exhaust CO values were $\sim 125 \mathrm{ppm}$. There was an flame-out but the general feeling was that the Moyno pump may have had a problem.

The overall delta pressure between the impingemnt sleeve and the combustor liner was greater and more uniform. The combustion stability did not seem to be adversly affected by the change made to the air swirler.

All test hardware was clean and free of excessive deposits at the conclusion of the test run.

Test time: $4 \mathrm{hrs}$

CWM Time : $3.5 \mathrm{hrs}$

\section{TEST DATE: 6-10-88 BLUE GEM}

Test objectives: Evaluate the combustor performance with the modification made to the air swirler to provide for purge air at the end cap of the fuel nozzle.

Test fuel: Otisca Blue Gem CWM

Combustor configuration: 45-I fuel nozzle

$60^{\circ}$ LF Fuel nozzle 
The main air swirler was machined out to provide some purge air around the fuel nozzle end cap outer annulus and the inner radius of the air swirler ring.

Test operations were plagued with flame-outs which followed the cyclic variation of the exhaust gas CO. The viscosity of the CWM was adjusted to be at $\sim 50 \mathrm{cps}$ as tested on our Brookfield.

There were cyclic pressure rises in the Moyno pump exit pressure and the CWM flow seem very erratic.

The CO was higher than normai for no explained reason.

Test Time: $7 \mathrm{hrs}$

CWM Time : 6.5 hrs

Fuel nozzle cap drilled with holes to provide an air purge

\section{TEST DATE: 6-20-88 BLUE GEM}

Test Objectives: Determine if lowering the CWM viscosity, by the addition of water has a positive effect on reducing the deposit formation occurring at the end cap area of the fuel nozzle.

Test fuel: Otisca Blue Gem CWM

Combustor configuration: $45-1$ fuel nozzle drilled end cap $w / 12$ holes $.018^{n}$

Air Swirler: $60^{\circ} \mathrm{LF}$

Blue Gem CWM viscosity adjusted by the addition of water.

There were again, flame-outs and poor combustion control. It is important to note that the past few runs performed with the LM500 turbine simulator were completed with enchanced fuel flow and measurement control. There is strong question as tc how accurate the flow measurements were for previous test runs.

Definite cyclic CO fluctuation, at the high $\mathrm{CO}$ values the combustor was most suceptable to flame-out problems.

Operating oil Btu ratio - $15-.17$, firing temperature at $2000^{\circ}$.

NO real change in the NAIN value during this iest.

Test Time: 6 hrs

CWM Time : $5.5 \mathrm{hrs}$ 


\section{TEST DATE: 6-22-88 BLUE GEM}

Test objectives: Evaluate combustion performance improvments, using CWM fuel with water added, and a fuel nozzle cap that ad purge air hole drilled for deposit control.

\section{Test fuel: Otisca Blue Gem CWM}

Combustor configuration: Fuel Nozzle 45-I with end cap with drilled holes $60^{\circ} \mathrm{LF}$ air swirler

CWM viscosity adjusted by the addition of water.

Test operations were as for the previous test. The oil BTU ratio was held at .15 and the exhaust CO fluctuated between $125-175$ ppm. There were flame-outs and the combustor experienced periods of unstable operation.

Post the test there was evidence of some deposit formation at the headend of the combustor and there was some indication of deposits forming at the exit of the fuel nozzle cap.

Test Time: $6 \mathrm{hrs}$

CWM time : $5.5 \mathrm{hrs}$

\section{TEST DATE: 6-29-88 BLUE GEM}

Test objectives: Evaluate combustor performance.

Test fuel: Otisca Blue Gem CWM

Combustor configuration: Fuel nozzle 45-I (end cap without holes) $60^{\circ} \mathrm{LF}$ air swirtler

Flame-outs did occur but overall the $\mathrm{CO}$ levels in the exhaust were lower at a given oil Btu ratio than for previous tests. Operating Oil Btu ratio was around .10-.13

CO levels were just below 75 and held around $50 \mathrm{ppm}$

Flame-out to ET the test due to burning all of the slurry in the tank. Controlled shutdown on \#2.

Test time: $4.5 \mathrm{hr}$

CWM Time : $4.0 \mathrm{hrs}$

\section{TEST DATE: 7-6-88 BLUE GEM}

Test objective: Evaluate combustor performance using a fuel nozzle cap that was tested prveviously but modified by the drilling of air purge holes to prevent the formation of deposits on the cap. 
Test fuel: Otisca Blue Gem CWM

Combustor configuration: 45-I fuel nozzle w/drilled end cap $60^{\circ} \mathrm{LF}$ air swirler Vibrator on fuel nozzle

CWM Viscosity adjusted by the addition of water.

Cyclic $\mathrm{CO}$ values, flame-outs corresponding to the higher $\mathrm{CO}$ in the exhaust system.

Problems with the Moyno pump and fuel delivery system.

Lots of deposit on the leading edge and in the transition piece. Even the combustor liner had deposits formed

Test Time: 4.5 hrs

CWM Time : $4.0 \mathrm{hrs}$

\section{TEST DATE: 7-13/14-87 TAGGART/KAOLIN}

Tesi objectives: Operate the LM500 turbine simulator with Taggart seam CWM. The combustor performance, depposit formation and overall combustion efficiency will be monitored. If there was a noticable reduction in NAIN, nutshelling would be performed to determine if the deposits were removable by this technique.

Test fuel: Otisca Taggart Seam CWM

Combustor configuration: $45-I$ fuel nozzle (holes is end cap)

Air Swirler: $60^{\circ} \mathrm{LF}$

Phase I

Enchanced fuel flow control.

Unexplained flame-outs that occured at unusually low $\mathrm{CO}$ values.

Some indications were that the fuel nozzle seemed to be the root of the problem when deposit builtup in this area.

The test was shut down after a large sudden increase in iJAIN and the chamber pressure started to get above 150 psig.

Phase I Total test time: $6.5 \mathrm{hrs}$

Phase I CWM Time : $6.0 \mathrm{hrs}$

Phase II 
14. TEST DATE: FEB 17, 1988

SINGLE CUP CAN COMBUSTOR FIRED TEST

Test Date: Feb 17, 1988

Hardware Configuration: Combustor configuration Mod-III with thermal barrier coating (TBC) as delivered from GE-AE. Primary holes in panel \#3, .0285" diam and secondary thimbles .022" diam. The dome splash plate outer ring was sealed and the outer film cooling holes all sized at $.027^{\mathrm{n}}$ diam. Half of the swirller holes were plugged. The igniter was in a thimble as for previous tests. The dome was rigidly bolted to the combustor, and the impingent sleeve was slotted 1" wide in the area of the bolt heads.

The CRD fuel nozzle was installed with an additional spacer added to provide for more clearence between the outer swirller ring and the end of the fuel nozzle.

Test Operations: Air flow was initiated to the test rig in the usual mmaner at $0800 \mathrm{hrs}$ for heatup. All combustor TC's were functioning at the start of the test. Light off was initiated at 1000 hrs on oil and the combustor was operating as designed. All combustor temperatures were very low, with no hot spots noted. At $1001 \mathrm{hrs}$ the combustor flamed out, apparently due to the higher than normal AA flow. After a smooth re-light the chamber pressure was attempted to be increased. There were a few attempts at getting the combustor up in pressure and operating stable. CWM slurry was initiated at $1208 \mathrm{hrs}$ and the combustor operated in a more unstable fashion. The chamber pressure was raised to $190 \mathrm{psig}$ in an attempt to gain more control. All during this period the combustor skin temperatures were quite low, at the higher system pressures the combustor temperature was vary close to $T 3$ temperature rather than firing temperature. The Atomizing air flow was quite high and way out of specification for this particular fuel nozzle design.

At $1245 \mathrm{hrs}$ the system was shut down to inspect the fuel nozzle. After pulling the fuel nozzle, it was discovered that the wrong air swirrler button was installed by mistake in the fuel nozzle body. The correct fuel nozzle swirller button was installed and bench flow checked prior to installation in the test rig. AT $1353 \mathrm{hrs}$ the fuel nozzle was installed in the test rig and heat up of test components resumed. The combustor was ignited on oil at $1411 \mathrm{hrs}$ and the chamber pressure brought up smoothly. The combustor experienced a hot spot axially in all panels. Temperatures as high as $1700^{\circ} \mathrm{F}$ were noted. The test was aborted after $\sim 25$ minutes of operation, and the test rig was cooled down for inspection. In the final few minutes of firc] operation and during the cool down the combustor $\Delta \mathrm{P}$ was quite high and there was some concern that there was a problem with the liner.

Post Test Inspection: The combustor exibited no signs of over temperature exposure. There was a split in the braze joints in rings \#1,2,3. The separation was not all the way around the ring but rather appeared to be isolated in areas where the braze material was non-existent or minimal. There was some evidence of cooling hole plugging in the first 2 rings, especially in the lower quadrant of the combustor liner.

The combustor will be TIG welded in trre ring area after re-positioning the rings to the correct locations. 
15. TEST DATE: FEB19, 1988

SINGLE CUP CAN COMBUSTOR FIRED TEST

Fired Test Date: February 19, 1988

Hardware Configuration: Combustor Combustor configuration Mod-III with Thermal barrier coating TBC as delivered from GE-AE. Primary holes in panel \#3,.0285" diam and secondary thimbles $.022^{n}$ diam. The dome splash plate outer ring was sealed and the outer film cooling holes all sized at $.027^{n}$ diam. Half of the swirrler holes were plugged. The igniter was in a thimble as for previous tests. The dome was rigidly bolted to the combustor, and the impingent sleeve was slotted $1^{n}$ wide in the area of the bolt heads.

The fuel nozzle was the CRD, with an additional spacer installed to provide for more clearence between the outer swirrler ring and the end of the fuel nozzle.

The combustor liner was repaired by pushing rings \#1,2,3 back in place an TIG welding a few spots around the circumference of the ring, in the area of the braze joint.

Test Operations: At $0630 \mathrm{hrs}$ the compressor, air preheater and cooling water systems were started to initiate the test hardware heat-up. The air preheater control tubing were frozen and there was a slight delay in the firing of the air heater. At 0715 hrs the airheater was operating and the main air temperature was increasing in the system. At $0934 \mathrm{hrs}$ the $\mathrm{N}_{2}$ and fuel oil systems were valved in AT $0937 \mathrm{hrs}$ the combustor was fired on oil and the chamber pressure was increased. At $0953 \mathrm{hrs}$ the chamber pressure was $180 \mathrm{psig}$ and the DPRef was $3.6 \%$. Slurry flow was initiated at $1004 \mathrm{hrs}$ and at $1021 \mathrm{hrs}$ the oil BTU ratio was <1\%. A flame-out occured at $1024 \mathrm{hrs}$ for no apparent reason. The combustor was re-lighted and again the oil flow reduced to the point that there was no oil flow to the combustor, but the solenoid isolation valve had not been shut yet. Again there occured a flame-out at $1033 \mathrm{hrs}$ and the combustor was easily re-lighted and brought to a zero oil condition. AT 1055 hrs the power supply to the panel meters and field transducers failed and started to smoke. The test was aborted immediatly, with out this power supply there was no indication of flow, pressure or overall system condition. The test was evendually aborted for the remainder of the day due to the fact that a new power supply could not be secured until late in the afternoon.

Post Test: The fuel nozzle end-flange was removed and the combustor inspected with a boroscope. There was evidence in the primary zone area of the liner of some melted blobs of what appeared to be ash. There was no significant build up of deposits, but there was some evidence of something forming in this area. The short duration of the actual fired operation on slurry was not long enough to cause any significant deposition. The cooling holes were unable to be seen with this boroscope at this time. The fuel nozzle was cleaned, flow checked and re-installed in the test rig for the next planned test on Monday Feb 22, 1988. 
16. TEST DATE: FEB 22, 1988 Zero oil $10.5 \mathrm{hrs}$

\section{SINGLE CUP CAN COMBUSTOR FIRED TEST}

Test Date: Feb 22, 1988

Hardware Configuration: The Single Cup Can Combustor was configured as described in Mod III, with the addition of thermal barrier coating (TBC) applied at GE-AE. The primary holes were sized $.0285^{\prime \prime}$ diam (no thimbles), the secondary holes were thimbles sized $.022^{\prime \prime}$ diam. The skin TC locations were as follows:

\section{Panel 1-4 three TC's each spaced $120^{\circ}$ apart}

\section{Panel 5-10 one TC located TDC}

The outer ring in the dome splash plate was sealed, and the outer ring of film cooling holes were all sized $.027^{\prime \prime}$ diam. Half of the swirler vanes were plugged. The dome was rigidly bolted to the combustor liner and the impingment sleeve was slotted $1^{n}$ wide in the area of the bolts.

The CRD fuel nozzle was installed with a $1 / 4^{n}$ shim to provide for more clearance between the fuel nozzle outer tube and the swirler face. After the final fit up is is estimated that the combustor has $\sim .41^{\prime \prime}$ of clearance for expansion.

The back pressure for the system was provided by the blast gate valve. Only one particulate probe was in place just up stream of the blast gate valve.

Test Operations: Air flow was initiated to the test rig at $0700 \mathrm{hrs}$, the air preheater control line to the high pressure side of the Barton gauge was frozen and needed to be thawed prior to the start of the preheater. At $0800 \mathrm{hrs}$ the main air inlet temperature was $500^{\circ} \mathrm{F}$ and climbing steadily. The DPRef value at this point was indicating $>3.71 \%$. The combustor airflow was within the design values.

Light-off on oil was initiated at 0848 hrs and was very smooth, the chamber pressure was slowly increased with the main air flow. The chamber pressure was brought to $190 \mathrm{psig}$ and held constant while the firing temperature was stabilized by adjusting the fuel oil flow. Slurry flow was initiated at $0910 \mathrm{hrs}$ and the oil BTU ratio was quickly reduced to $<.5$, the firing temperature was maintained at $2100^{\circ} \mathrm{F}$ and the chamber pressure held at 190 pisg. A flame-out occured at $0918 \mathrm{hrs}$ but a quick recovery was effected and the chamber pressure dropped only momentarily. The oil BTU ratio had been reduced to $\sim .10$ when the flame-out occured. The combustor was quickly relighted by increasing the oil flow to the combustor. The total elapsed time for the flame-out was less than 30 seconds. The AA was reduced to .13 \#/sec and again the oil btu ratio was lowered, and again there was a flame-out at an oil BTU ratio of .18. The combustor was re-ignited as before and the system was stabilized. After a third flame-out at similar conditions it was decided to allow the atomizing air temperature to increase by closing the cooling water supply to the aftercooler at the Joy compressor exit. The oil BTU ratio was held at AA temperature was $48^{\circ} \mathrm{F}$ and by closing the aftercooler the temperature would eventually come up to the exit temperature of the compressor, after all of the supply piping and insulation also came up in temperature. The aftercooler valve was shut at $0928 \mathrm{hrs}$, at $1030 \mathrm{hrs}$ the AA temperature was $74^{\circ} \mathrm{F}$ and coming up very slowly. The oil BTU ratio was lowered to .10 at this point to evaluate the stability of the system. At 1032 hrs the coarse control valve was completely off and the combustor was firing 
completely on the fine valve for oil and the CWM slurry. The estimate of oil BTU ratio at this point is $<2 \%$. At $1043 \mathrm{hrs}$ there occured another flame-out with a quick recovery. The combustor was again stabilized on only the fine valve and eventually weaned from oil at $1050 \mathrm{hrs}$. A flame-out occured at 1053 hrs with the usual quick recovery. The combustor was at zero again at $1055 \mathrm{hrs}$. The system seemed more stable at this point and the airflows were adjusted very slowly to the design conditions. At 1109 hrs another flame-out with quick recovery occured, the combustor was back at zero oil by $1112 \mathrm{hrs}$ and again was running very smooth. The atomizing air temperature at this point was $93^{\circ} \mathrm{F}$ and the main air temperature was $730^{\circ} \mathrm{F}$. The CO levels in the exhaust were $36 \mathrm{ppm}$ and were holding steady

The combustor ran very steady while system parameters were slowly adjusted to maintain stable operation. At $1151 \mathrm{hrs}$ there again occured a flame-out that was unexplained. The combustor was back at zero oil by $1153 \mathrm{hrs}$ and was again operating smonth. At $1217 \mathrm{hrs}$ the following set of readings were taken:

$\begin{array}{ll}\text { Pchamb } & 191 \mathrm{psig} \\ \text { Comb DP } & 6.2 \mathrm{psi} \\ \text { FAR } & 2300^{\circ} \mathrm{F} \\ \text { AApr } & 1.94 \\ \text { Main Air } & 1.34 \# / \mathrm{sec} \\ \text { Main Air Temp } & 735^{\circ} \mathrm{F} \\ \text { AA Flow } & 0.17 \# / \mathrm{sec} \\ \text { AA Temp } & 105^{\circ} \mathrm{F} \\ \text { CO } & 18 \mathrm{ppm} \\ \mathrm{O}_{2} & 12.3 \% \\ \mathrm{CO}_{2} & 6.8 \% \\ \mathrm{NO}_{x} & 47 \mathrm{ppm}\end{array}$

The test continued in a smooth manner over the next period of 9 hours. There were NO additional flame-outs experienced, and for the most part the combustor was stable at just about any operating condition that was attempted. The test conditions were held faily constant until 1534 hrs when the slurry flow was reduced to lower the firing temperature TFire FAR to $2000^{\circ} \mathrm{F}$. The Chamber pressure was held constant at $\sim 190-195$ psig. The CO concentration in the exhaust gas stream rose slightly to a maximum of $80 \mathrm{ppm}$ but then dropped back to the range of $35 \mathrm{ppm}$. The first particulate sample was taken from $1430-1515 \mathrm{hrs}$. The second particulate sample at the 2000 of firing temperture was taken starting at $1544 \mathrm{hrs}$ to $1630 \mathrm{hrs}$.

AT $1640 \mathrm{hrs}$ the firing temperature Tfire FAR was increased to $2000^{\circ} \mathrm{F}$. A particulate sample was started at $1654 \mathrm{hrs}$ and ended at $1737 \mathrm{hrs}$. During this period of time the combustor pressure and flows were held constant, again the $\mathrm{CO}$ levels in the exhaust remained very steady, but were at $\sim 16-18 \mathrm{ppm}$. The $\mathrm{NO}_{\mathrm{x}}$ levels were in the range of $85 \mathrm{ppm}$ with very little change. The DPRef was averaging $3.2 \%$ but was varing between 2.9 and $3.3 \%$. The third particulate sample was started at $1654 \mathrm{hrs}$ and run until $1734 \mathrm{hrs}$. The firing temperature was held at $\sim 2200^{\circ} \mathrm{F}$ for this test point. The CO levels in the exhaust stream were 13-16 ppm and holding constant. The BP valve was adjusted during this time period to account for a slow increase in chamber pressure, it was also noticed that the combustor skin temperatures were slowly decreasing over a long period of time. This effect could possibly be due to the buildup of deposit on the liner walls.

At 1916 hrs the gas sampling lines became plugged and had to be blown out with HP $\mathrm{N}_{2}$. During 
the period of time the sample lines were plugged the firing temperature was held at $2200^{\circ} \mathrm{F}$ and the flows were stable.

At 1953 hrs the main air flow was decreased to 1.238 \#/sec, while using the BP valve to maintain the system pressure the firing temeperature was held constant by adjusting the CWM flow.

At $2010 \mathrm{hrs}$ the main air flow was increased to 1.51 \#/sec, again the BP valve was used to control a constant system pressure and the slurry flow adjusted to keep TFire FAR constant. The CO levels in the exhaust were changing as the air flow was varied.

At $2021 \mathrm{hrs}$ the main air flow was decreased to $1.14 \# / \mathrm{sec}$ and the firing temperature and chamber pressure held constant.

At $2042 \mathrm{hrs}$ preparations were made to bring the test down in a controlled manner. The main air flow, and fuel flow were slowly reduced and the AAPr held constant to allow for all combustor inputs to be reduced essentially in proportion. At $2055 \mathrm{hrs}$ the chamber pressure was 128 psig and a set of printouts made for this test point. All flows were continued to be reduced until the chamber pressure was $111 \mathrm{psig}$, when control of the slurry pressure was no longer possible. The CWM by-pass line had plugged and it was impossible to lower the pump speed any further to drop the slurry pressure. Rather than over temperature the combustor it was decided to simply shut the slurry valve and allow the combustor to flame-out. At $2115 \mathrm{hrs}$ the slurry valve was shut and the system flamed out. Total test time was $10 \mathrm{hrs} 25$ minutes at $100 \% \mathrm{CWM}$ fuel.

The test hardware was allowed to cool with main airflow in the usual manner.

Post Test: The fuel nozzle was removed within $1 \mathrm{hr}$ of the test shut down and examined. The fuel nozzle was extremely clean with no signs of buildup or plugging. The combustor was removed after $2 \mathrm{hrs}$ of cooling and found to have extensive build up of deposits in all areas of the liner. The primary zone area ring 1,2,3,4 was the most severe, the deposits in this area appeared darker, and more melted. Down stream, the deposits did not appear to be as thick. All of the deposits were very hard and difficult to remove. There was evidence that the ceramic TBC may have provided sites for the deposit to form, as the previous tests with this combustor had little evidence of this type of deposit. The dome splash plate had a large piece spall off and was laying inside the liner. There was some build up around the primary holes, but the holes were not pligged completely.

Down stream in the exhaust piping there was a significant build up of reddish deposit. This deposit was very soft and later found to be very easy to remove. Scraping and water washing was all that was required to clean this section of the piping. 
17. TEST DATE: FEB 25, 1988

SINGLE CUP CAN COMBUSTOR FIRED TEST

Fired Test Date: February 25, 1988

Hardware Configuration: After the 10 hour zero oil test on 2-22-88 the combustor was inspected by removai from the test rig. The combustor was photographed and only the large loose chunks were removed from the combustor. The combustor liner was not removed from the impingement sleeve for inspection. At the specific instructions of GE-AE engineering personnel the combustor was re-installed in the test rig for another round of testing. The CRD fuel nozzle was cleaned and flow checked prior to installation in the test rig.

Test Objectives: The main objectives of this phase of the test were to finish the low pressure test points (4 atm), at a zero oil condition. The second objective was to evaluate the effect of continued operation on the already very thick deposition on the combustor liner.

Test Operations: At 0700 hrs the air compressor, preheater, and cooling system were started to begin the test rig warm-up. The compressor aftercooler was shut down to efect a faster than normal warm-up of the AA. During the warm up period the combustor DPRef was calculated to be $4.31 \%$, this is considerably higher than when the rig was shut down on $2-22-88$. There was some concern that cooling holes or possibly some of the dillution holes were plugged with deposit material. At $0959 \mathrm{hrs}$ the combustor was fired on oil. The AA temperature had risen to $\sim 65^{\circ} \mathrm{F}$ and it was decided to fire the system at this time. The temperatures in the combustor were as follows:

\begin{tabular}{cccc} 
Panel \# & TDC & $120^{\circ}$ & $240^{\circ}$ \\
\hline \hline 1 & 1552 & 1390 & 1458 \\
2 & 1498 & 1211 & 1359 \\
3 & 1284 & 882 & 1098 \\
4 & 954 & 792 & 949 \\
5 & 1156 & & \\
6 & 1061 & & \\
7 & 1030 & & \\
8 & 993 & & \\
9 & 996 & & \\
10 & 1011 & &
\end{tabular}

Slurry livw was initiated at $1024 \mathrm{hrs}$ and immediately there were problems with the system. A high slurry by-pass pressure was noted, a high combustor pressure was also noted. The blast gate valve was responding very poorly and the the test system in general seemed to be operating in an unstable manner. At $1038 \mathrm{hrs}$ the combustor was brought off line to evaluate the situation. The air flow was kept going through the combustor and the blast gate valve was cycled to the full open position a few times. It was concluded that something had lodged in the blast gate valve and caused the poor control, the combustor DPRef had dropped to $\sim 3 \%$ and it was concluced that the deposit on the combustor liner had spalled off and possibly lodged in the blast gate valve area. 
It was decided to continue with the test in the hope that the combustor had cleaned itself out.

The combustor was ingnited on oil at $1113 \mathrm{hrs}$ and the system temperature and pressures were brought up slowly. Slurry flow was initiated at $1117 \mathrm{hrs}$ and the oil BTU ratio was brought to 22 very smoothly. At this point it was noted the the $C O$ reading in the exhaust stream were $>100$ ppm which was indicative of somewhat poorer combustor than in the previous tests. A flame-out occured at $1234 \mathrm{hrs}$, the combustor was at $10 \mathrm{~atm}$ chamber pressure and a firing temperature of $\sim 2000^{\circ} \mathrm{F}$. The combustor was re-iginited very quicky and conditions were re-established within 5 minutes. At $1245 \mathrm{hrs}$ the coarse fuel valve was closed and the cobustor was operating at $<2 \%$ oil momentarily. Another flame-out occured at $1302 \mathrm{hrs}$, and subsequently every time the oil flow was reduced to the fine valve the fire went out and the combustor had to be re-ignited on oil.

At $1313 \mathrm{hrs}$ it was decided to increase the chamber pressure to try and get to zero oil at the higher chamber pressure. There was difficulty encountered again trying to adjust the blast gate valve. At $1328 \mathrm{hrs}$ it was decided to drop the chamber pressure to $4 \mathrm{~atm}$ and evaluate the combustor performance at this chamber pressure. Attempts to get to zero oil at chamber pressures of 57 psig, 75 psig and various air flow were fruitless. It was decided that the test was to be shut down at $1403 \mathrm{hrs}$. The instability of the blast gate valve and the obvious problems with the combustor airflow distribution were justification for aborting the test at this point. The combustor flamed out at $1356 \mathrm{hrs}$, and the auxillary systems were shut down to allow the combustor to cool down. The DPRef value at this point was $2.63 \%$, it appeared that the combustor had opened up.

Post Test: The fuel nozzle was quite blackened, and there was evidence of CWS that had lodged and dried in the end of the tip.

The combustor was suprisingly clean, with most of the deposits no longer on the walls. The area of the primary zone was covered with deposit material, but the downstream rings were clean. The combustor liner was removed from the impingemnet shield. There was evidence of cooling hole plugging in rings $7,8,9,10$. The material that was plugging the cooling holes was hard, grey and appeared to be braze material. The rings in this area were not warped or discolored to to over temperature. It was suspected that there may have been some local burning in this area due to the numerous shutdowns and problems. The braze joints in ring 1,2,3 were separated much farther that what was observed during the previous inspection. All of the TIG welds that were made were split apart or at a minimum cracked. There was obvious "daylight" seen in the area of the braze joints due to the extent of the separation. It is unclear as to when these problems occured. The dome was undamaged, it was discolored but there were no obvious problems noted. 
Test Date: May 12, 1988

Hardware Configuration: New Single-cup can combustor, with the same cooling, primary and secondary hole sizes as for the previous test.

\section{Fuel Nozzzle: CRD}

Test Fuel: Distillate, CWM

Test Operations: The initial oil firing, resulted in very uneven temperature distributions in the combustor liner. The test was temporarily shut down to inspect the fuel nozzle installation and the spray pattern. The fuel nozzle spray pattern appreared symetrical and the atomization was as was observed in previous tests. The fuel nozzle was re-inserted and the test restarted. Numerous flame-outs occurred before it was possible to operate the combustor stable enough to introduce CWM fuel. Firing on CWM fuel was smooth once the chamber pressure was held steady at 14 atmospheres and the cooling flows were adjusted. Each attempt to fire exclusively on CWM was met with a flame-out shortly after the fuel oil valve was closed. The combustor liner temperature reached $1900^{\circ} \mathrm{F}$ at one point in the test and there was strong concern that the combustor had split in one of the ring joints. All attempts at operating at different residence times, by changing the back pressure position were unsucessful. The test rig was shut down for inspection

Post Test: The fuel nozzle was very clean, and there were no obvious chunks of material or plugging that was apparent. The fuel nozzle was flow checked on the bench at atmospherice pressure with water and the spray pattern and the atomization rate appeared normal. The combustor liner was not removed from the impingement shield for instpection, but is was observed that the interior of the liner was clean and free of deposits. There was a noticable dimple in the liner wall opposite the igniter area, ard it was impossible to determine if the braze joints had separated. 


\title{
SINGLE-CUP CAN COMBUSTOR FIRED TEST
}

\author{
Test Date: May 17, 1988
}

Liner History: A fired test performed on May 12 was terminated when it became impossible to sustain stable operation at a zero-oil condition for more than a few minutes. The test was aborted after operating for over three hours with numerous flame-outs. The combustor and impingement liner were removed from the test rig for inspection and cleaning. The combustor liner was not separated from the impingement liner. The interior of the combustor liner was cleaned by wire brushing, and loose particles were removed by blowing house air through an air blast nozzle. The fuel nozzle was cleaned and flow-checked. The spray angle, atomizing air mass flow, and spray distribution all appeared to be within specification.

Hardware Configuration: The combustor hardware used for the May 17 test was configured exactly the same as the liner used for the $10 \mathrm{hr}$ zero-oil test, except that there was no thermal barrier coating at the inner surface of the liner.

Test Operations: The compressor and air preheater were started at $0600 \mathrm{hrs}$ for test rig warmup. CWM slurry barrels \#933 and \#960 were put on mixers for final mix preparation. Initial values for combustor/chamber $\Delta \mathrm{P}$ were slightly higher than typical, but the high $\Delta \mathrm{P}$ reading slowly dropped to typical values. The slow response was attributed to a possible plugging of the $1 / 16^{\prime \prime}$-tubing used for monitoring the $\Delta \mathrm{P}$. The test rig warm-up continued until $0845 \mathrm{hrs}$, when the rig was prepared for a light-off on oil. Combustion was initiated on fuel oil at $0856 \mathrm{hrs}$, and the light-off was smooth and trouble free. The pressure level on the compressor was slowly increased to the operating design point, and the fuel flow was increased to maintain firing temperature. The firing temperature was held at $<1800^{\circ} \mathrm{F}$.

CWM flow was initiated at $0907 \mathrm{hrs}$ at a chamber pressure of $\sim 140 \mathrm{psig}$. The initial total $\Delta \mathrm{P}$ was $\sim 10 \mathrm{psi}$, but was slowly decreasing. The liner temperatures were reasonably uniform, with a maximum temperature of $1350^{\circ} \mathrm{F}$ in panels 1,2 , and 3 . The chamber pressure was increased to $185 \mathrm{psig}$, and the main air and atomizing air flows were trimmed to maintain the combustor flow function at .230 and the atomizing air pressure ratio at 2.0. The fuel oil and slurry flowrates were slowly adjusted until the combustor was firing only on CWM. The fuel oil valve was closed and the delivery pump shut down. The firing temperature was maintained at $\sim 2000-2050^{\circ} \mathrm{F}$ average Type B TCs. At $1135 \mathrm{hrs}$ the combustor flamed out for no apparent reason. The total time at zero-oil was $1 \mathrm{hr} 40 \mathrm{~min}$. After the chamber pressure was brought to initial light-off conditions, the combustor was restarted usirig fuel oil and CWM.

The combustor relit easily, but the $\Delta \mathrm{P}$ was lower than it had been before the flame-out. Slurry flow was initiated without water-washing the fuel nozzle in order to prevent the removal of any deposits that might have formed. The chamber pressure and main air flow were increased to the same operating point as just before the flame-out. All attempts to get to a zero-oil condition were unsuccessful. The combustor would flame-out as soon as the oil valve was completely closed. The combustor reference $\Delta \mathrm{P}$ was calculated at $\sim 3.2-3.3 \%$, which was the same as for the May 12 test. The combustor was now performing the same way it had performed during the May 12 test.

At $1309 \mathrm{hrs}$ a decision was made to bring the test down and inspect the combustor liner. The 
CWM valve was closed, and the combustor was fired on fuel oil. The fuel oil was reduced until a controlled flame-out occurred. The fuel nozzle was not water washed.

Post Test Inspection: The fuel nozzle was found to have some buildup in the area just after the CWM pintle, which is not unusual. Spray tests on the bench with water revealed no obvious problem with the spray angle, atomization, or flow control.

Viewed through the boroscope, the liner at the head-end area appeared damaged but the extent of the damage was not clear. The only evidence of deposit was at the upstream side of the igniter thimble. The decision was made to pull the combustor from the test rig and inspect it further on the bench. It was immediately observed that the liner was severely warped in the area of panels 1 , 2 , and 3. The extent of the damage was not fully realized until the impingement liner was removed. Holes had been burned in panels 1 and 3 of the liner. All cooling holes appeared to be open, but the inner film cooling lip of panels 1 and 3 was distorted. There was no evidence of significant deposit formation anywhere other than in the area upstream of the igniter thimble. 
20. TEST DATE: $M A Y 19,1988$

SINGLE-CUP CAN COMBUSTOR FIRED TEST

Test Date: May 19, 1988

Hardware Configuration: The combustor liner was repaired by spot welding nichrome patches over the holes that were discovered after the May 17 test. The CRD fuel nozzle was thoroughly cleaned and air flow tested on the bench before being installed in the test rig. The thermocouples in panels 7,8 and 9 were removed and installed in panel, 2 equally spaced between the existing thermocouples. The combustor liner was cleaned by wire brushing.

Test Operations: The compressor and air preheater were started at $0630 \mathrm{hrs}$ for test rig warmup. Initial air flow through the combustor indicated that the nichrome patches spot welded over the holes were in place and there were no obvious air leaks determined at that time. The combustor reference $\Delta \mathrm{P}$ was calculated to be 3.35 , this value was consistent with the calculated reference $\Delta \mathrm{P}$ that was observed before the combustor was tested on May 17. The combustor was ignited on fuel oil at $0900 \mathrm{hrs}$, and the light off was smmoth and contrulled. At $0922 \mathrm{hrs}$ CWM flow was attempted to be initiated, but there was no indication of CWM flow. The test was shut down and the CWM inlet fuel filter screen inspected. The fine screen was found to be completely plugged with very fine coal particles. The fine screen was removed, but the course screen was left in the filter.

Combustion was re-initiated on fuel oil at $0948 \mathrm{hrs}$, and CWM flow was initiated at $1000 \mathrm{hrs}$. The transition to CWM was very smooth. AT $1008 \mathrm{hrs}$ the fuel oil flow con :ol valve was completely closed, and when the fuel oil solenoid valve was shut the combustor fla $\mathrm{n}$ : $2 \mathrm{~d}$ out. The combsutor was easily relit by opening the fuel oil fine control valve and increasing the fuel oil delivery pressure. The chamber pressure was held at $185 \mathrm{psig}$, and the firing temperature maintained at $2000 \mathrm{~F}$ using the type B average TC readings. Zero oil firing was attained at $1029 \mathrm{hrs}$, and the fuel oil solenoid valve was completly shut. The combustor operated in a zero oil mode until $1114 \mathrm{hrs}$ when there was an unexpected and sudden flame-out. Attempts to re-establish zero oil operation were unsuccessful. Each time the combustor was hrought to the point of zero oil operation a flame-out occurred. Relighting the combustor was very easy, but operation at zero oil was impossible. Throughout the remainder of the test, zero oil operation was attempted by varying the combustor residence time, atomizing air flow or firing temperature. The operation of the combustor was unstable, and operation without oil assist for any period of time was not accomplished.

Before finally terminating the test, operation at lower chamber pressures was attempted. The main air flow and fuel flows were gradually decreased to effect a drop in chamber pressure. Operation of the combustor at chamber pressures less than 100 psig was very unstable and accompanied with frequent flame-outs. The test was terminated at $1446 \mathrm{hrs}$ and the test rig was allowed to cool.

Post Test Inspection: The fuel nozzle (CRD) was removed and found to be plugged. The plugging of the fuel nozzle was determined to be a result of shut down. The fuel nozzle was not water washed after final the combustor flame-out in order to preserve the condition of the inner surface 
of the combustor liner.

The combustor was clean and free from any observed deposits. The combustor liner and impingement sleeve were not removed from the test rig. Inspection was carried out through the air swirler by means of a boroscope. There was evidence of additinal warping, but it was difficult to determine the severity of the warpage using the boroscope. 


\section{TEST DATE: MAY 20, 1988 Parker nozzle \\ SINGLE-CUP CAN COMBUSTOR FIRED TEST}

Test Date: May 20, 1988

Hardware Configuration: The combustor liner was not removed from the test rig after the May 19 test. The Parker-Hannifin fuel nozzle with the new swirler hardware was installed in the test rig. The Parker-Hannifin fuel nozzle was air flow tested before being install in the test rig. The atomizing air flow rate from the Parker-Hannifin nozzle was found to be $\sim 18 \%$ greater than the CRD nozzle. The spray angle was much more narrow than the previous Parker nozzle, and the atomization using water through the CWM port, appeared to be very good.

Test Operations: Airflow to the test rig was initiated at $1130 \mathrm{hrs}$ to provide for test rig warm-up. Ignition on fuel oil was accomplished at $1256 \mathrm{hrs}$ in a very smooth and controlled manner. CWM flow was initiated at 1302 hrs and the main air flow and firing temperature adjusted. The combustor flamed-out at $1311 \mathrm{hrs}$, the oil Btu ratio at this point was .40. The combustor was relit and again the CWM flow increased. The combustor again flamed-out at an oil Btu ratio again of .45 . The combustor was again relit and the chamber pressure increased to $\sim 185-190 \mathrm{psig}$. Again the combustor flamed-out when the CWM flow was increased and the oil Btu was between . 30-.40. Attempts at varying the residence time were tried, with no real success. The combustor did on a few attempts get to the point that the fuel oil fluw control valves were almost shut, but there always was a flame-out out before operation at zero oil could be accomplished. At $1359 \mathrm{hrs}$, the test using the Parker-Hannifin fuel nozzle was terminated.

Post Test Inspection: The combustor was inspected Monday May 23. The fuel nozzle (ParkerHannifin) was not fouled as viewed before disassembly. The end cap was black, but there was not any obvious blockage of any of the flow paths.

The combustor liner was removed from the impingement sleeve and inspected. The interior of the combustor was reasonably clean, with no evidence of deposit formation. There was areas of black powdery layers that wiped off very easily. Panel 2 and 3 were warped much more than was observed after the May 17 test. There were 2 new holes burned in the area of the film cooling holes in panel 2 and there was a hole burned in the nichrome patch over the previously burned holes. All of the holes in the liner were all located in the same general area. 


\title{
APPENDIX \\ COMBUSTION OF COAL WATER SLURRY FOR GAS TURBINE APPLICATION*
}

\author{
J.M. Beer, T.U. Yu, M.A. Toqan \\ Massachusetts Institute of Technology
}

\section{INTRODUCTION}

One of the principal problems of coal-burning gas turbine technology is the prevention of turbine blade erosion by fly ash particles. Coal-water fuels are carefully prepared with minimal ash content and ultrafine coal particle size distribution to reduce the number of large particles that would not follow streamlines around blades but impact on them. Early studies at MIT have shown that the particle size distribution (p.s.d.) within a coal water fuel (CWF) flame correlates more closely with the size distribution of the atomized fuel spray than with the initial p.s.d. of the coal particles in the slurry. This is because there is a tendency for the coal particles to agglomerate within individual droplets while the water is evaporating and agglomerates undergo thermal decomposition in the flame. Large particles formed through agglomeration take longer to burn out and produce large fly ash particles which accelerate turbine blade erosion. One route to finer p.s.d. of the spray droplets and of the fly ash is secondary atomization by fuel treatments. In view of the dropsize reduction achieved by fuel heating, as discussed in the text, a measurement of the effect of fuel heating on combustor performance was carried out in a one atmosphere research combustor.

\section{EXPERIMENTAL APPARATUS AND PROCEDURES}

\section{Facility and Burner Descriptions}

The MIT Combustion Research Facility (CRF) was used in this experimental study. The facility is a $1.2 \mathrm{~m} \times 1.2 \mathrm{~m}$ cross-section, $10 \mathrm{~m}$ long combustion tunnel equipped with a single burner capable of up to $3 \mathrm{MW}$ firing rate. The combustion tunnel, shown in Figure A-1, is comprised of a number of $0.3 \mathrm{~m}$ wide, watercooled, refractory lined or bare metal interchangeable sections. The sections can be arranged to control heat extraction along the length of the llame, and thus to sinulate the thermal environment of a wide range of industrial and utility flames. The facility is extensively instrumented to permit accurate control of flame conditions and detailed characterization of internal flame structures. For this study the combustion tunnel was arranged to have twelve watercooled refractory lined
sections.

The burner used in this study was a new multi annular burner developed by Massachusetts Institute of Technology and Combustion Engineering, Inc. under the sponsorship of the Pittsburgh Energy - The measurement of the effect of fuel heating on the dropsize distribution and the measurernent of the shear viscosity of
OTISCA fuel carried out by MIT is summarized in the text. 
Technology Center (PETC-DOE). The burner was attached to the front end of the combustion tunnel of the CRF. The burner is equipped with a CWF gun surrounded by primary and secondary air supplies. The fuel gun and atomizer are moveable along the axis of the burner, permitting variation in the position of fuel injection relative to the nozzle throat. The primary air is introduced through a fixed vane swirler, while the secondary air is introduced first through a variable swirler and then passes through three concentric air annuli (rings A,B, and C) before entering the combustion chamber. These annuli can be moved separately, allowing the aerodynamic variation of the size of fuel-rich and -lean flame zones necessary for $\mathrm{NO}_{\mathbf{x}}$ reduction. A schematic of two modes of operation using this burner is shown in Fig. A-2.

\section{Combustion Conditions}

CWF flames investigated using the GE-LT (air-blast type) nozzle proved to be highly unstable in this furnace and, thus, required large feeding rates of natural gas to sustain the flame. This instability is from very high axial momentum of the fuel sprays generated by high atomizing air flow rate, which is required to produce sprays with good atomization quality. In order to relax the axial momentum, the GE-LT nozzle was replaced by a C.E. swirl nozzle (air-assisted type) which produces a sufficiently fine spray for the combustion conditions of this experiment. The $26 \mu \mathrm{m}$ SMD dropsize is roughly twice that obtained without fuel heating at the gas turbine combustor design point. Although natural gas was still required to stabilize the flames using the latter nozzle, the quantity of natural gas required dropped by $\sim 20 \%$.

Six flames of OTISCA CWF sprays were tested; three flames without heating $\left(22^{\circ} \mathrm{C}\right)$ and three flames with heating $\left(\sim 110^{\circ} \mathrm{C}\right)$. The combustion conditions maintained in the flames studied and the flue gas analysis for these flames are iisted in Table A-1.

\section{Measurements}

The gas-sampling system consisted of a water-cooled probe through which the combustion gases were transported to a dryer, and then to a set of continuous on-line gas analyzers for detection of $\mathrm{O}_{2}, \mathrm{CO}_{2}, \mathrm{CO}, \mathrm{NO}_{\mathbf{x}}$, and $\mathrm{SO}_{\mathbf{x}}$.

To determine if the secondary atomization had any effect upon carbon burnout and flyash particle size distribution, in-flame solids were collected from the two flames of No. ? (without fuel heating) and No. 6 (with fuel heating) at three axial locations. Solids sampling was carried out with a probe in which the sampling line was steam-cooled. The probe was connected to a cyclone where particulates could be separated aerodynamically. Size distributions of the in-flame particulates collected were determined by using the laser diffraction size analyzer which was arranged to accommodate particulates suspended in an optical cell and stirred by a magnetic stirrer. The volatile and ash contents in the solid samples were measured using a thermogravimetric analyzer. In this analysis, $5 \mathrm{mg}$ of sample was heated to $120^{\circ} \mathrm{C}$ to dry out, and then to $950^{\circ} \mathrm{C}$ at a heating rate of $160^{\circ} \mathrm{C} / \mathrm{min}$ in an inert environment (nitrogen surroundings). The sample was kept at this temperature for five minutes, and oxygen was then introduced to burn the remaining char. Throughout the whole procedure the sample weight was continuously monitored as a function of time, and the weight loss in each step wa determined. For this, the ash content and the proximate volatile matter content in the sample were obtained.

\section{EXPERIMENTAL RESULTS AND DISCUSSION}

One of the primary purposes of the combustion experiments was to determine if secondary atomization by fuel heating enhanced flame stability and carbon burnout. However, even without fuel heaiing, ignition and flame stability constituted a major problem. Natural gas flow around the CWF spray had to be maintained to insure flame stability. In fact, in some of the cases studied, the thermal input 
ratio of N.G./CWF was around 0.40 to insure a non-lifted stable flame front. As a result, the effect of secondary atomization upon flame stability and carbon burnout had to be examined carefully together with the effect of natural gas injection.

The particulates concentrations measured along the centerline of the two flames with and without heating (No. 3 and No. 6 flames) are given in Table A-2, together with the carbon conversion efficiencies calculated based on the ash contents of the particulate samples collected. The carbon conversion efficiencies and the particulates concentration are also plotted in Fig. A-3. The results show that CWF heating to $110^{\circ} \mathrm{C}$ has significant improvement in carbon-burnout and particle loading oer the unheated case. The carbon conversion efficiency was also significantly enhanced by the heating of the ClVF to $110^{\circ} \mathrm{C}(92 \%$ to $99.6 \%)$. It is expected that heating of the fuel to $110^{\circ} \mathrm{C}$ produces finer CWF sprays, resulting in the improvement of the CWF droplets ignition process and flame stability and, thus, resulting in the reduction of the combustion times of CWF droplets. The difference of carbon conversion efficiencies at the axial distance of $3.12 \mathrm{~m}$ between the heated and unheated fuel flame cases is a reflection of the importance of fuel heating in achieving high carbon burnouts ( $99 \%$ for $T_{f}=110^{\circ} \mathrm{C}$ vs $\eta-92 \%$ for $T_{f}=22^{\circ} \mathrm{C}$ ). The particle size distributions of the in-flame solids samples shown in Fig. A-4 further demonstrate that the particle size distribution of the flame with fuel heating was finer than that of the base case $\left(T_{f}-22^{\circ} \mathrm{C}\right)$.

It is roteworthy that, although the results obtained were for the C.E. swirl jet nozzle, similar conclusions could be extended to other types of nozzles. However, to quantitatively extend the above conclusions to other nozzles, the problems of ignition and flame stability have to be resolved first. This can be done by determining the proper aerodynamic flow field near the burner needed to decelerate the CWF droplets for a particular nozzle, thus insuring ignition and the subsequent combustion of the CWF droplets.

\section{SUMMARY AND CONCLUSIONS}

Combustion tests of OTISCA coal-water slurry were carried out in the MIT-CRF. Six flames of OTISCA CWF sprays were tested. Three flames were without fuel heating $\left(22^{\circ} \mathrm{C}\right)$ and the remaining flames were with fuel heating $\left(-110^{\circ} \mathrm{C}\right)$. Samples of solids particulates were taken rom the two flames of unheated and heated cases at three axial locations along the flames. The samples were analyzed for chemical and physical properties. The result of analyses showed that CWF heating to $110^{\circ} \mathrm{C}$ has significant improvement in carbon-burnout and particle loading over the unheated case. The carbon conversion efficiency was also significantly enhanced from $92 \%$ to $99 \%$ by the heating of the CWF to $110^{\circ} \mathrm{C}$. Furthermore, the particle size distribution of the flame with fuel heating was finer than that without fuel heating. Consequently, it can be concluded that the secondary atomization by fuel heating is an effective technique in enhancing carbon burnout and in producing finer fly ash particle size distribution. 


$$
\begin{aligned}
& 8 \text { E }
\end{aligned}
$$

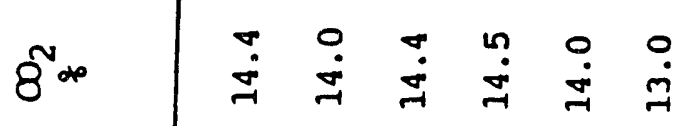

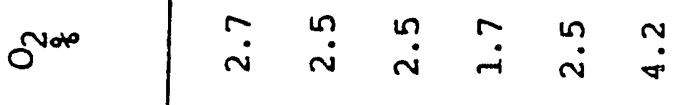

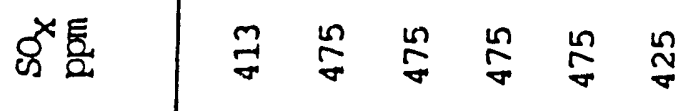

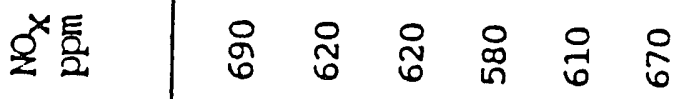

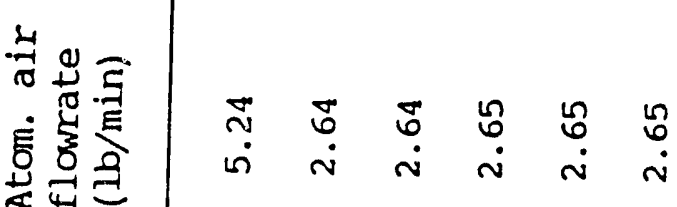

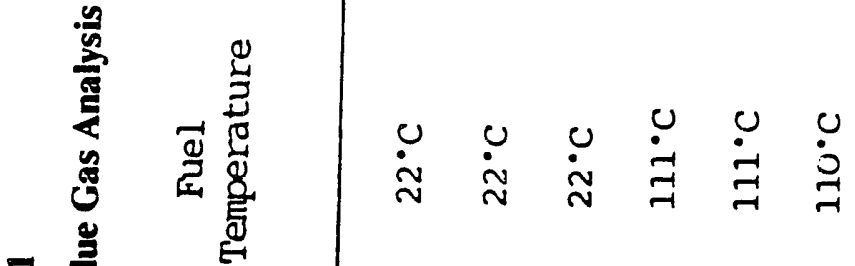

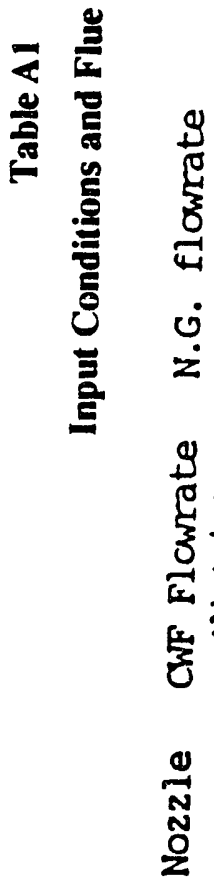

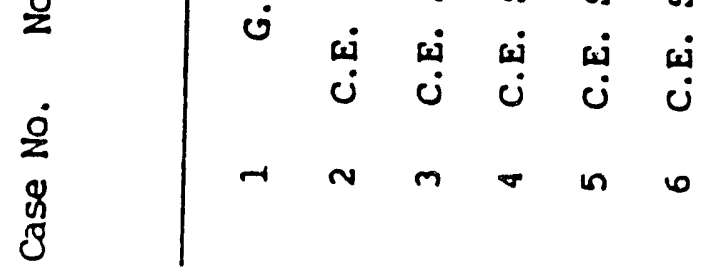

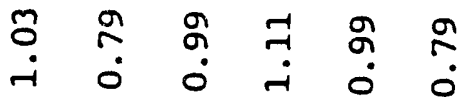

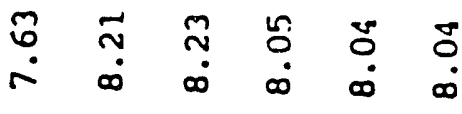

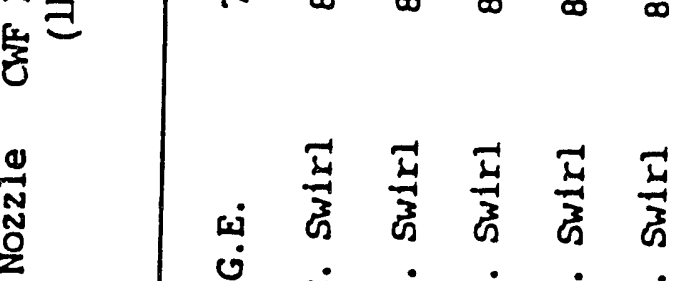




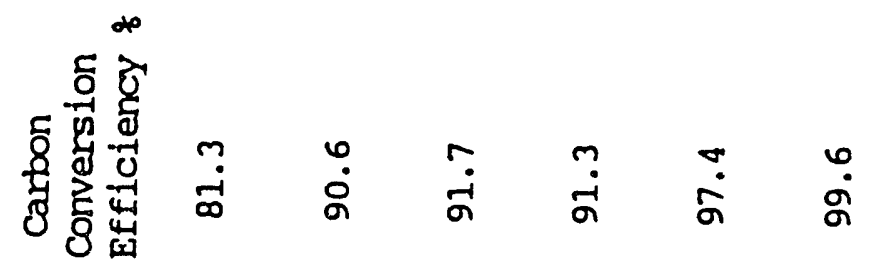

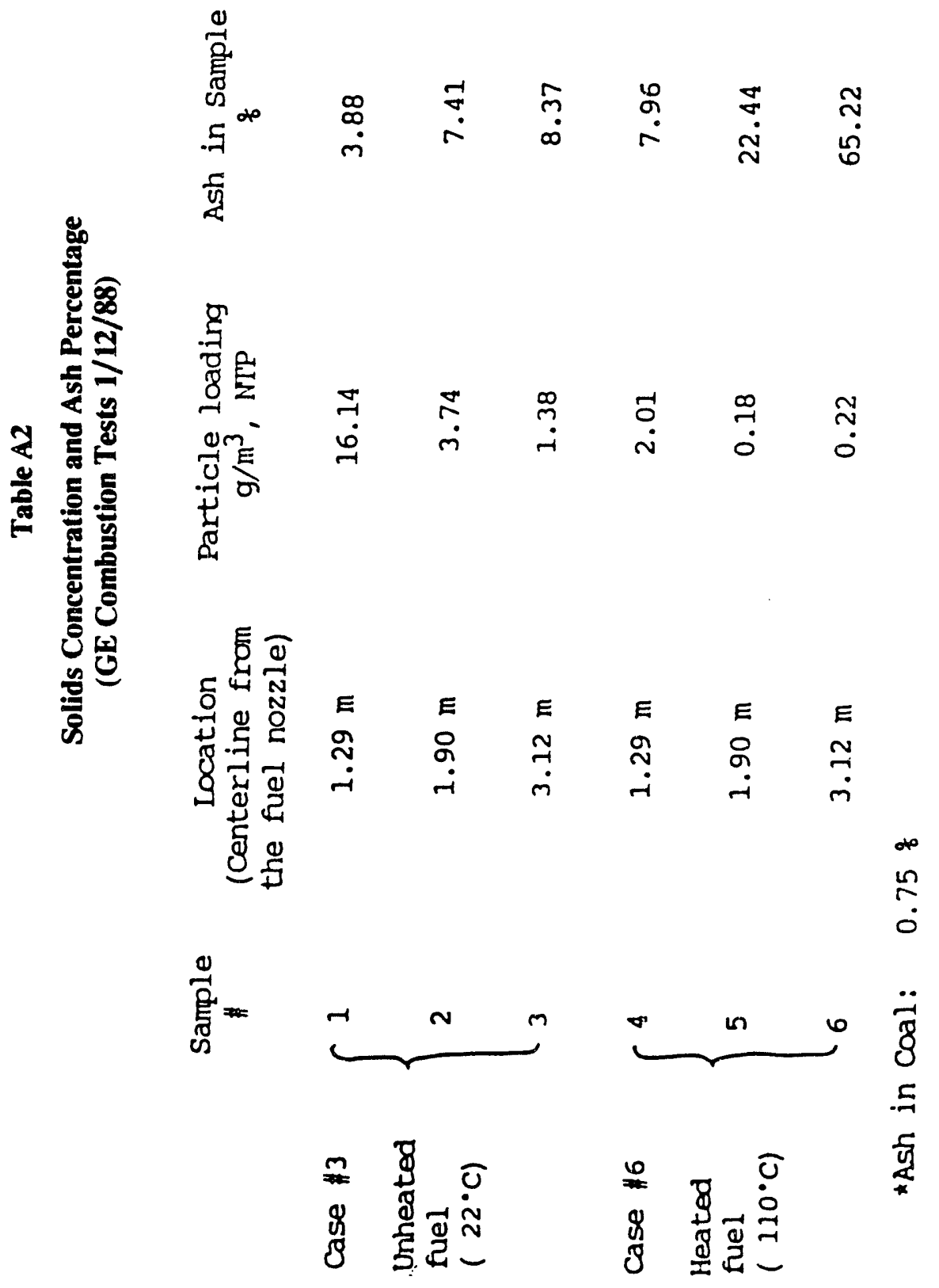

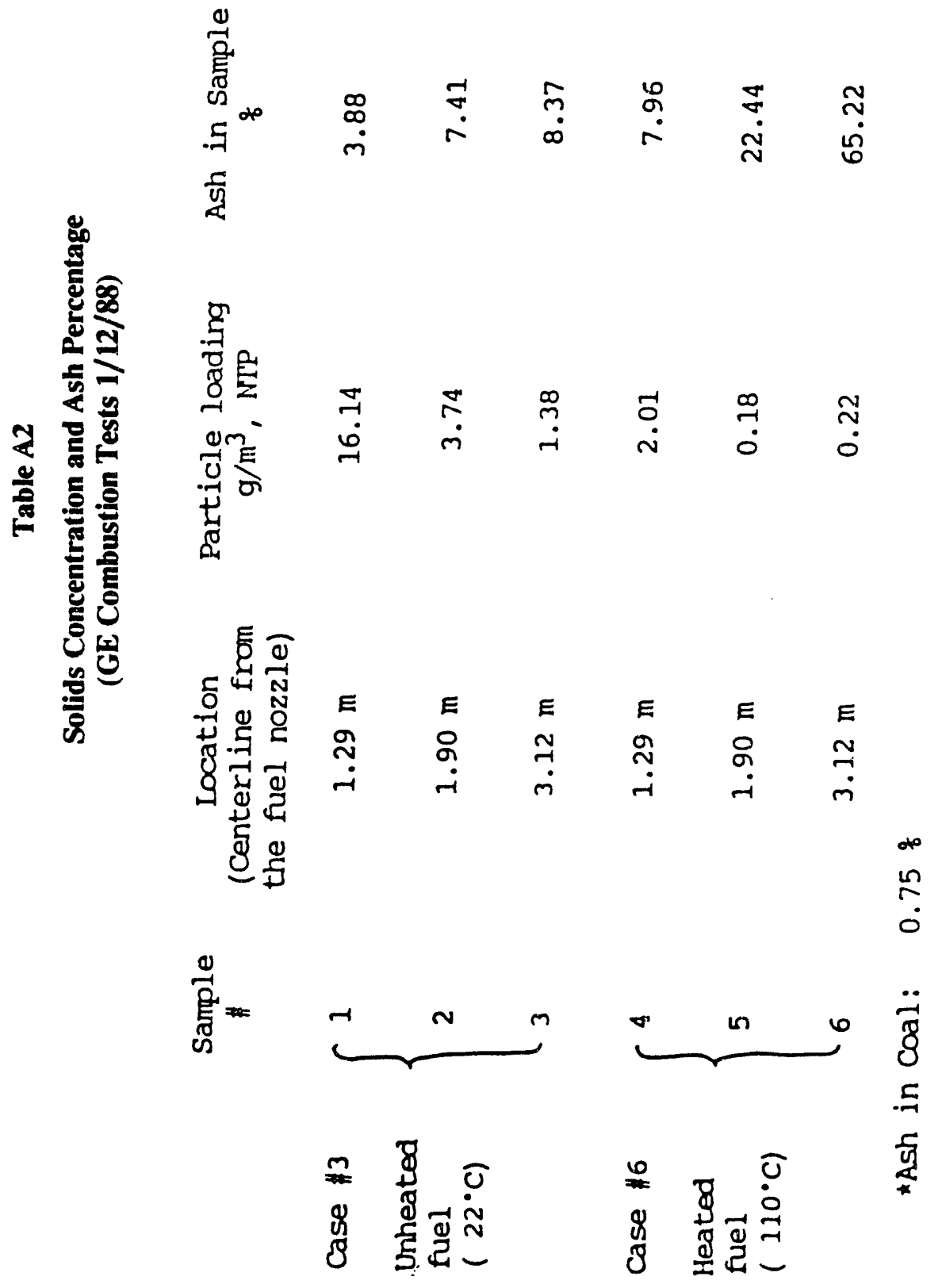




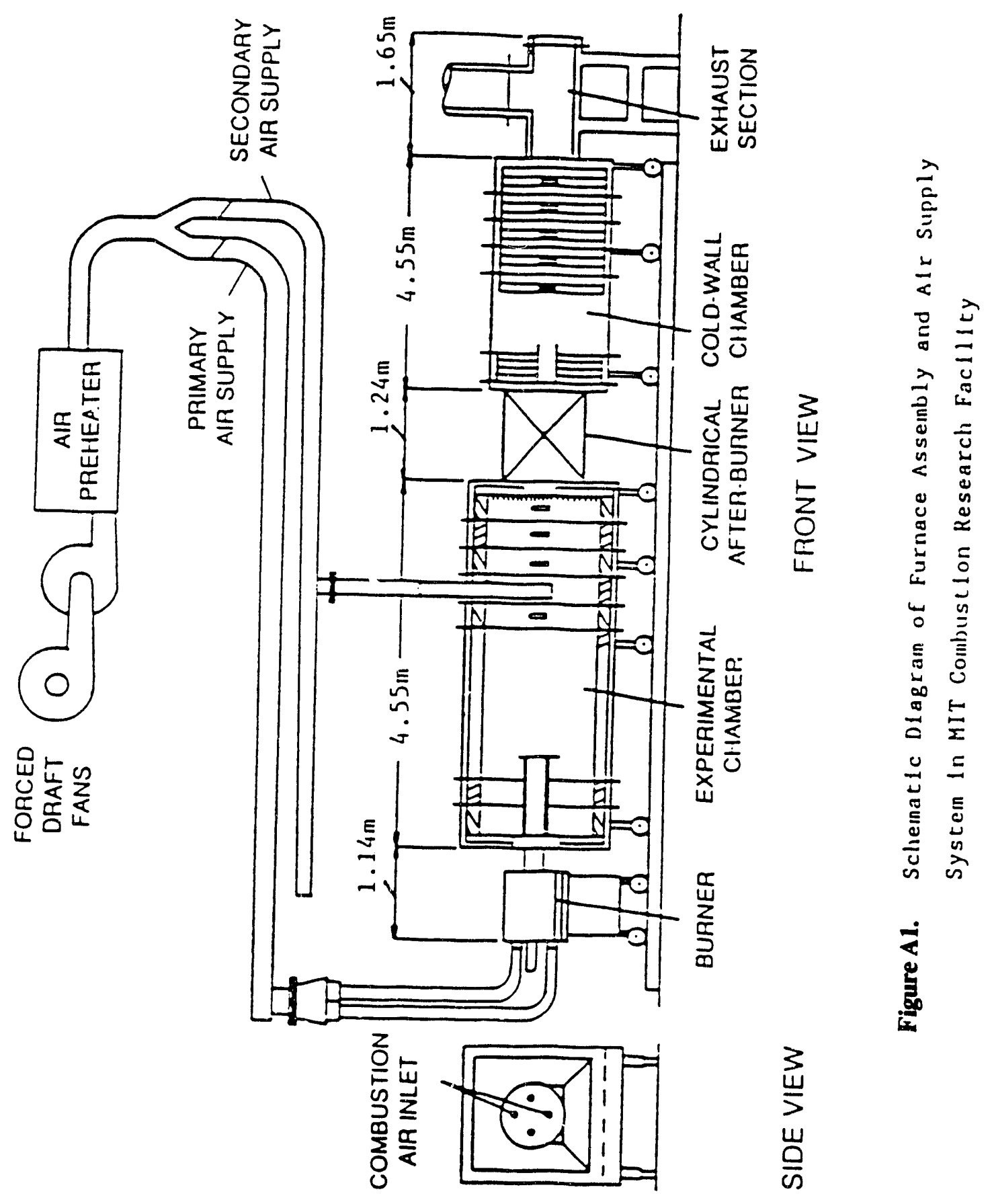



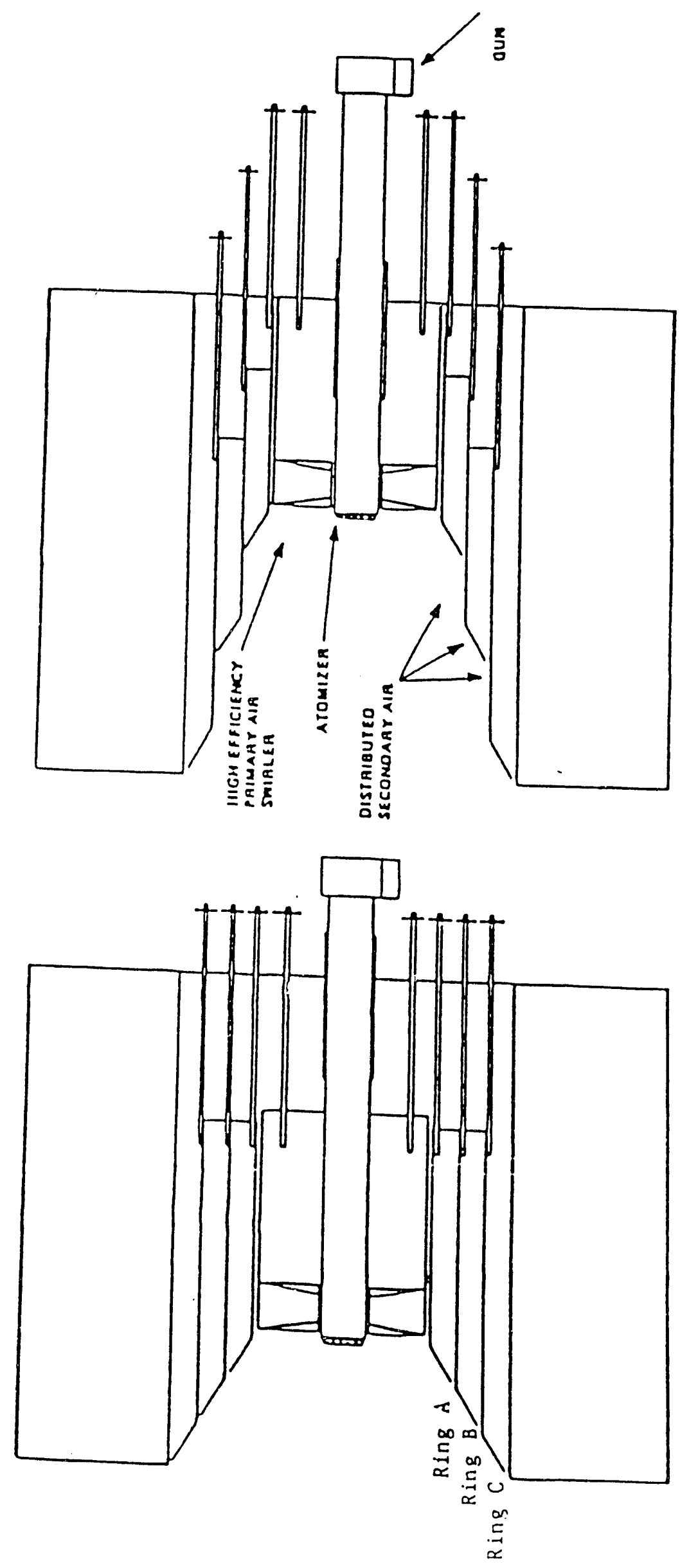

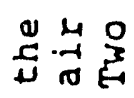

w

n

c ง के

开 3 至

טn

.

0 म

索告

पै

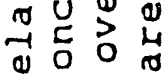

$\triangle 0$

व

.

崖

E i $^{>}$

ว

$\stackrel{5}{5}^{\infty}$ c

먼

- 3 .

o ज出

-

苾

n.t

-

万ั

这 


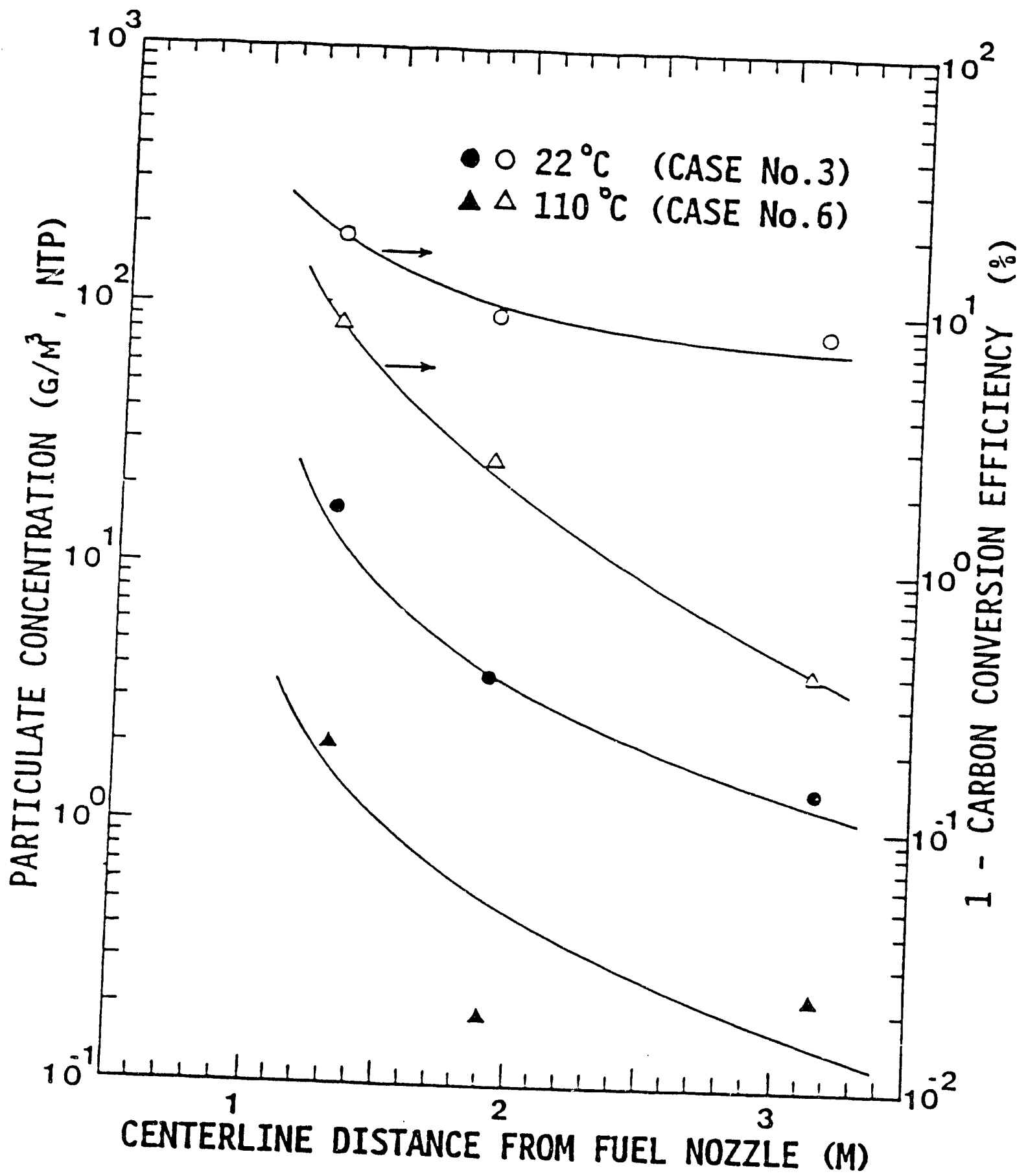
Figure A3. Particulate Concentration and Carbon Conversion Efficiency on the
Cencerline of OTISCA CHF Flames with and without Fuel Heating. 

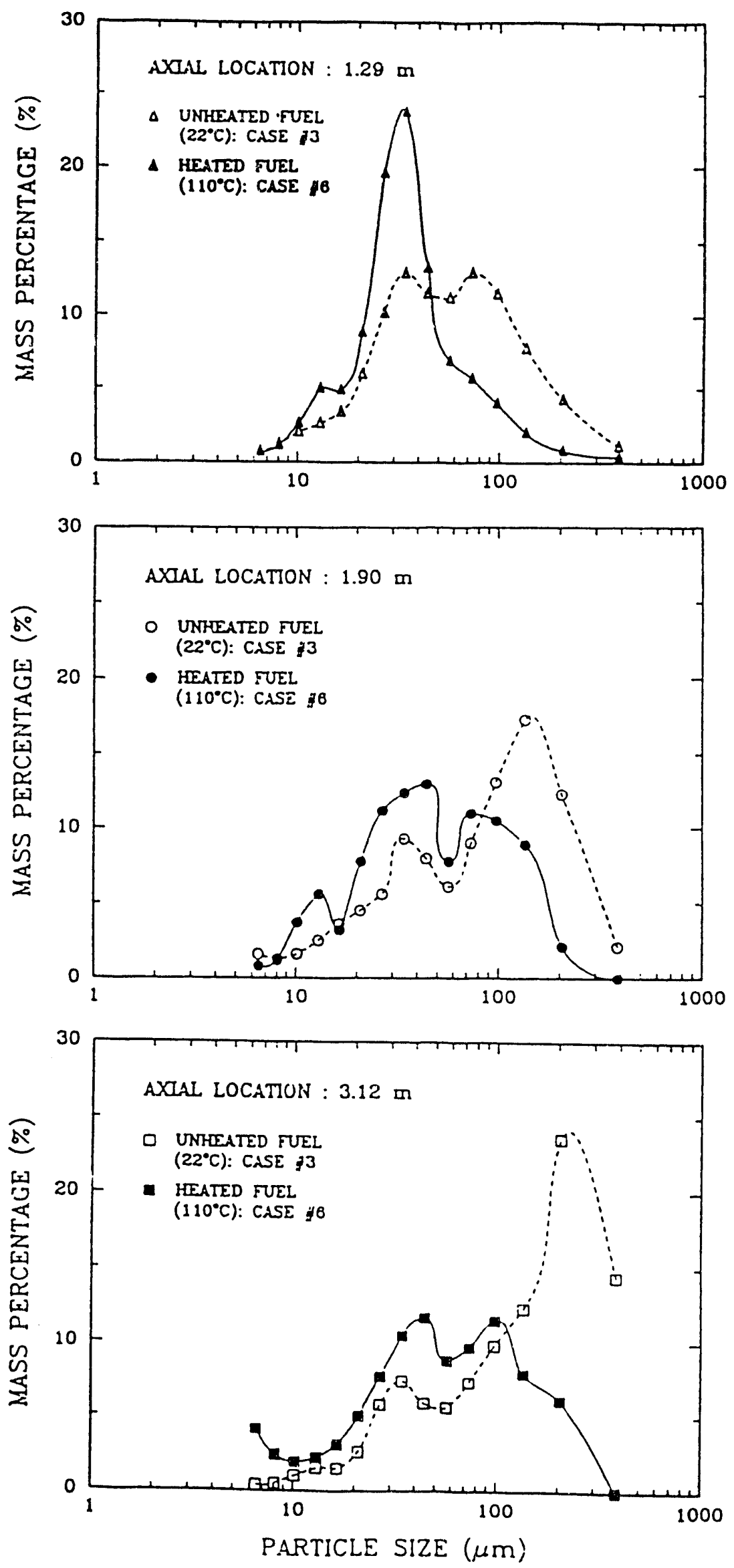

Figure A4. Size Distribution of Solid Samples Collected at Three Axial Stations from OTISCA CWF Flames with and without Fuel Heating. 


\section{APPENDIX-3.0 - GRAIN MODEL DESCRIPTION}

While a number of models are being developed to predict $\mathrm{SO}_{2}$ removal with calcium oxide, the models can be classified as either "pore" or "grain" models. Grain models view the porous lime particle as conglomerates of spherical $\mathrm{CaO}$ grains that may change in size as the reaction proceeds. Pore models, on the other hand, consider mono-pore or distributed-pore sizes that may be randomly oriented and interconnected throughout a spherical particle. Both model types address intra-particle processes:

- Diffusion to the particle surface,

- Diffusion through the porous lime,

- Diffusion of the reactant sulfur species through the product-layer, and

- Heterogeneous reaction at the $\mathrm{CaO}-\mathrm{CaSO}_{4}$ interface.

The grain model [1] used in this program is a modification of an earlier model formulated by Hartman and Coughlin [2]. This model contains the following assumptions:

- Particles are fully calcined.

- Bulk diffusion of reactant to the particle is nut rate limiting.

- Calcium oxide reaction with $\mathrm{SO}_{2}$ to form calcium sulfate is irreversible.

- $\mathrm{CaSO}_{4}$ is the sole sulfation product.

- Particles are spherical and isothermal.

- $\mathrm{CaO}$ and $\mathrm{MgO}$ grains are the same average size.

- Surface Area is from $\mathrm{CaO}$ and $\mathrm{MgO}$ grains.

The governing equations are obtained from material balances on the particle and constituent grains. If a steady-state approximation [3] is assumed, a $\mathrm{SO}_{2}$ mass balance in a spherical shell yields,

$$
\frac{d^{2} C}{d R^{2}}+\left(\frac{2}{R}+\frac{1}{D e f f} \frac{d D e f f}{d R}\right) \frac{d C}{d R}-\frac{N}{D e f f}=0
$$

Where $\mathrm{C}$ is the $\mathrm{SO}_{2}$ concentration, $\mathrm{R}$ is the radial coordinate, Deff is the effective diffusion for porous $\mathrm{CaO}$ and $\mathrm{N}$ is the rate at which $\mathrm{SO}_{2}$ is consumed per unit volume of the solid. The boundary conditions, 


$$
\begin{aligned}
& \text { at } R=0, \frac{d C}{d R}=0 \text { for all time, and } \\
& \text { at } R=R_{p}, C=C_{o} \text { for all time, }
\end{aligned}
$$

are applied at the center and the outer edge of the particle, respectively. To determine the $\mathrm{SO}_{2}$ consumed within the particle a sulfur balance is applied on individual "grains" of unreacted $\mathrm{CaO}$.

Important parameters include the rate constant, effective pore diffusivity, and the product-layer diffusivity. To determine the intrinsic rate constant, two as"'Imptions are made. First, $\mathrm{SO}_{2}$ concentration is uniform throughout the porous lime particle and is equal to the bulk gas concentration. Second, product-layer formed is small producing a low diffusional resistance. Implementing these assumptions, a relationship between the kinetic rate constant and the time rate of change of conversion, $\frac{d X}{d t}$ is obtained,

$$
K=\frac{\rho \mathrm{CaO} \frac{d X}{d t} r_{g}}{3 M_{\mathrm{CaO}} z C_{\mathrm{SO}_{2}}} .
$$

The derivative in the above equation is determined from time-resolved experimental conversion data An Arrhenius expression is obtained by extrapolating their rate data and computing $\frac{d X}{d t}$ at time equal to zero;

$$
K=1.5 E+11 e^{\frac{-16,000}{T}}, \frac{\mathrm{cm}}{\mathrm{s}} .
$$

The effective pore diffusivity is calculated by

$$
D e f f=D e_{x}^{2}
$$

Here, $\mathrm{D}$ and $\mathrm{e}_{x}$ are the combined diffusivity coefficient and porosity of the sulfated lime, respectively. The combined diffusivity includes bulk and pore diffusional contributions. Bulk diffusion is calculated by the Chapman-Enskog theory for the binary pair $\mathrm{SO}_{2}$-air while pore diffusion is determined by the knudsen equation. 
The solid product layer diffusion coefficient, $\mathrm{D}_{s}$ is calculated by fitting experimental data obtained by Borgwardt [4] to an Arrhenius form,

$$
D_{s}=0.0124 e^{\frac{-12200}{T}}, \frac{\mathrm{cm}^{2}}{s}
$$

Equation (1) and its boundary conditions are solved by converting them into finite difierence equations. The particle is divided into $n+1$ nodes where the first node is at the center and the $n+1$ at the outer radius of the particle. The linear system of equations is solved for $\mathrm{SO}_{2}$ concentration using Gaussian elimination. Because a tridiagonal matrix is formed, the Thomas alogorithm is used. Once the interfacial concentration is found, the decrease in grain radius is then calculated. With a new radius of the unreacted grains determined, the sequence is repeated until the assigned time is reached. At each time step the calculated overall conversion is used to decrease the $\mathrm{SO}_{2}$ partial pressure.

\section{NOMENCLATURE}

C

Concentration of $\mathrm{SO}_{2}$ at radius $\mathrm{R}, \frac{\mathrm{gmol}}{\mathrm{cm}^{3}}$

D

Combined diffusivity coefficient, $\frac{\mathrm{cm}^{2}}{\mathrm{~s}}$

Deff

$$
\text { Effective diffusivity of } \mathrm{SO}_{2}, \frac{\mathrm{cm}^{2}}{\mathrm{~s}}
$$

$\mathrm{D}_{x} \quad$ Product-layer diffusion coefficient, $\frac{\mathrm{cm}^{2}}{\mathrm{~s}}$

e $\quad$ Porosity of sulfated lime

K Rate constant, $\frac{c m}{s}$

$\mathrm{M}_{d} \mathrm{CaO} \quad$ Molecular wt. $\mathrm{CaO}$ 


$\begin{array}{cc}\mathrm{N} & \text { Rate of reactant consumed, } \frac{\mathrm{gmol}}{\mathrm{cm}^{3} \mathrm{~s}} \\ \mathrm{R} & \text { Radius, } \mathrm{C} \mathrm{n} \\ \mathrm{R}_{p} & \text { Particle radius, } \mathrm{cm} \\ \mathrm{r}_{\mathrm{g}} & \text { Grain radius, } \mathrm{cm} \\ \mathrm{T} & \text { Temperature, } \mathrm{K} \\ \mathrm{X} & \text { Conversion, gmol } \\ \mathrm{z} & \text { Fraction of grains which are } \mathrm{CaO} \\ \rho_{\mathrm{CaO}} & \end{array}$

\section{REFERENCES}

[1] M.S. Peters, and K.D. Timmerhaus, Plant Design and Economics for chemical Engineers, McGraw-Hill Book Comparı, New York, 1980.

[2] G.D. Silcox, "Analysis of the $\mathrm{SO}_{2}$-Lime Reaction: Mathematical Modeling and Experimental Studies with Emphasis on Stoker Applications." Ph.D. Dissertation, Department of Chemical Engineering, University of Utah, 1985.

[3] M. Hartman, R.W. Coughlin, ""Reaction of Sulfur Dioxide with Limestone and the Grain Model." AIChE J. 22, 3, 490, 1976.

[4] D. Luss, "On the Pseudo Steady State Approximation for Gas-Solid Reactions," The Canadian J. of ChE. 46, 154, 1968.

[5] R.H. Borgwardt, "Kinetics of the Reaction of $\mathrm{SO}_{2}$ with Calcined Limestone," Envr. Sci. Tech. 4, 59, 1970. 

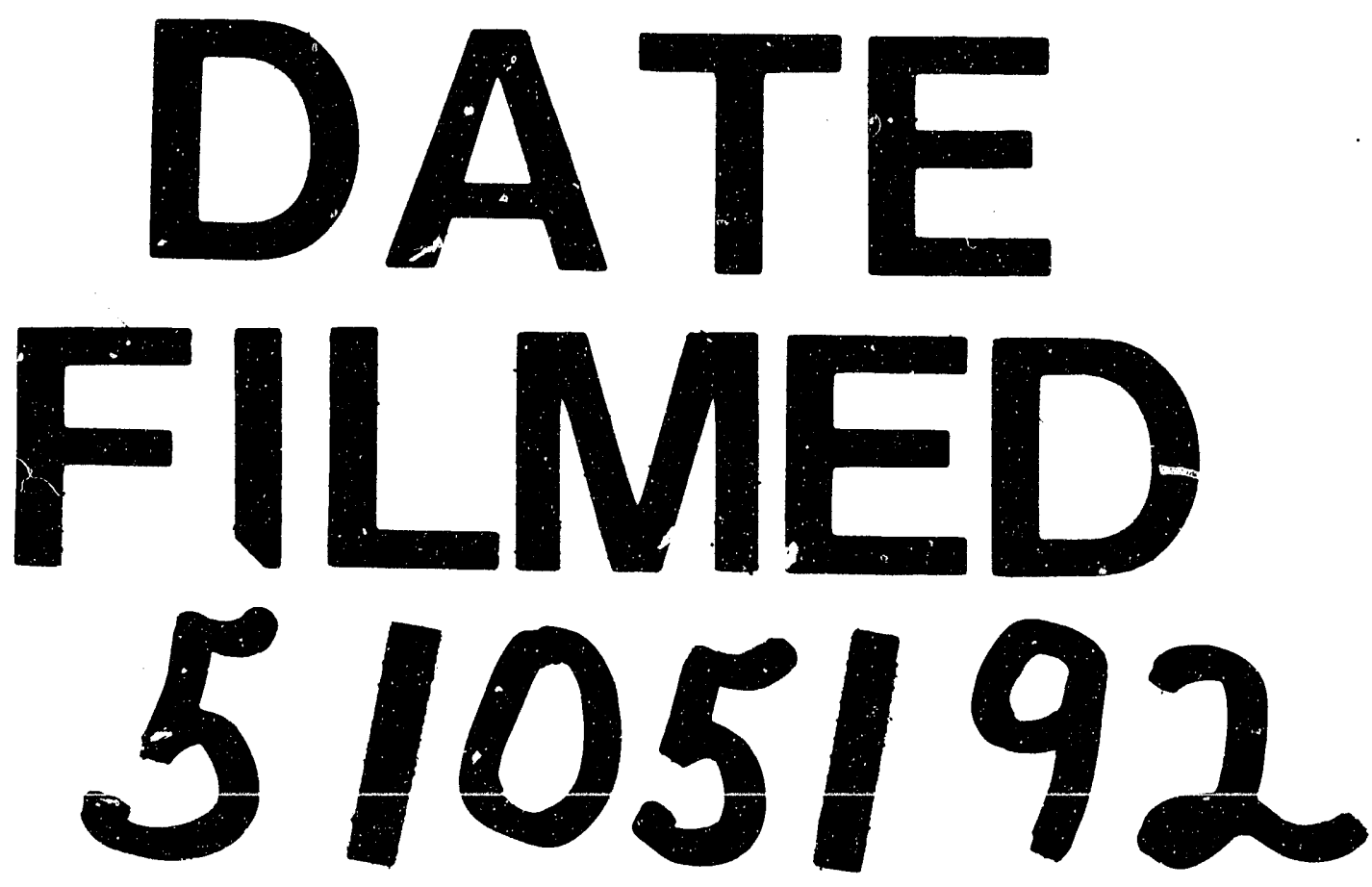

. 4 
